Walter Hahn

Steuerpolitische

Willensbildungs-

prozesse in der

Europäischen

Gemeinschaft

Das Beispiel der Umsatzsteuer-Harmonisierung 


\section{Walter Hahn}

\section{Steuerpolitische Willensbildungsprozesse in der Europäischen Gemeinschaft}

Eine über das bereits erreichte Maß hinausgehende Harmonisierung der europäischen Umsatzsteuersysteme ist Voraussetzung für die Abschaffung der Grenzkontrollen innerhalb der Europäischen Gemeinschaft; sie bildet damit ein Kernstück der für 1992 anvisierten Vollendung des europäischen Binnenmarktes.

Die Darstellung des mit Gründung der EG im Jahre 1958 begonnenen Prozesses der Umsatzsteuerharmonisierung macht u.a. deutlich, daß Stuerharmonisierung keinesfalls einseitig als Opfer nationaler Steuerpolitik an das übergeordnete Ziel der europäischen Integration interpretiert werden darf. Steuerharmonisierung kann im Gegenteil mit dazu beitragen, in jedem einzelnen Mitgliedsstaat der EG rationale Steuerpolitik gegen festgefahrene innenpolitische Strukturen durchzusetzen.

Walter Hahn wurde 1959 in Lollar geboren. 1979-1983 Studium der Volkswirtschaftslehre an der Justus-Liebig-Universität Gießen, 1983 Dipl.-Volksw.. 1983/84 Postgraduiertenstudium an der London School of Economics and Political Science. 1984-1986 Promotionsstipendium der Studienstiftung des Deutschen Volkes, 1987 Promotion an der Universität des Saarlandes. Der Autor ist z. Zt. als Unternehmensberater bei der Firma McKinsey \& Company, Inc. tätig. 
Steuerpolitische Willensbildungsprozesse in der Europäischen Gemeinschaft 


\section{FINANZWISSENSCHAFTLICHE SCHRIFTEN}

Herausgegeben von den Professoren

Albers, Krause-Junk, Littmann, Oberhauser, Pohmer, Schmidt

Band 37

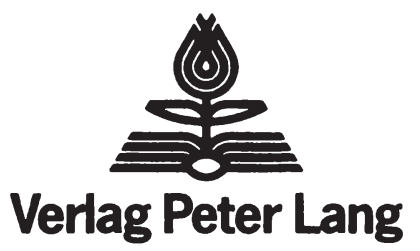

Frankfurt am Main - Bern · New York · Paris 


\title{
Walter Hahn
}

\section{Steuerpolitische Willensbildungsprozesse in der Europäischen Gemeinschaft}

\author{
Das Beispiel der \\ Umsatzsteuer-Harmonisierung
}

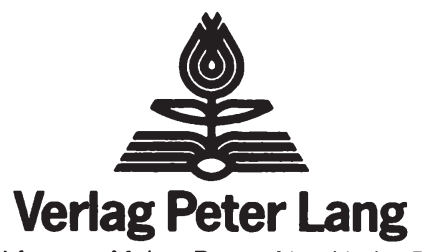

Frankfurt am Main · Bern · New York · Paris 
CIP-Titelaufnahme der Deutschen Bibliothek

Hahn, Walter:

Steuerpolitische Willensbildungsprozesse in der Europäischen Gemeinschaft : d. Beispiel d. Umsatzsteuer-Harmonisierung / Walter Hahn. - Frankfurt am Main ; Bern ; New York ; Paris : Lang, 1988

(Finanzwissenschaftliche Schriften ; Bd. 37)

Zugl.: Saarbrücken, Univ., Diss., 1988 ISBN 3-631-40446-8

NE: GT

Open Access: The online version of this publication is published on www.peterlang.com and www.econstor.eu under the international Creative Commons License CC-BY 4.0. Learn more on how you can use and share this work: http://creativecommons. org/licenses/by/4.0.

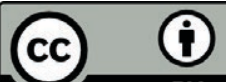

BY

This book is available Open Access thanks to the kind support of ZBW - Leibniz-Informationszentrum Wirtschaft.

\author{
D 291 \\ ISSN 0170-8252 \\ ISBN 3-631-40446-8 \\ ISBN 978-3-631-75235-7 (eBook) \\ (c) Verlag Peter Lang GmbH, Frankfurt am Main 1988 \\ Alle Rechte vorbehalten.
}

Das Werk einschließlich aller seiner Teile ist urheberrechtlich geschützt. Jede Verwertung außerhalb der engen Grenzen des Urheberrechtsgesetzes ist ohne Zustimmung des Verlages unzulässig und strafbar. Das gilt insbesondere für Vervielfältigungen, Übersetzungen, Mikroverfilmungen und die Einspeicherung und Verarbeitung in elektronischen Systemen.

Printed in Germany 


\section{Gewidmet}

in Dankbarkeit und Freundschaft

meinen Eltern 
Walter Hahn - 978-3-631-75235-7 Downloaded from PubFactory at 01/11/2019 06:49:14AM via free access 


\section{Inhaltsverzeichnis}

o. Vorwort

A. Einleitung 4

B. Hintergrundinformationen 7

1. Okonomische Grundlagen $\quad T$

1.1. Alternative Formen der indirekten Besteuerung 7

1.2. Beurteilung der indirekten Besteuerung aus der Sicht

1.2.1. Das fiskalische Ziel 12

1.2.2. Das Allokations-, Verteilungs- und Stabilitätsziel 16

1.3. Beurteilung der indirekten Besteuerung aus der Sicht
einer Zollunion

1.3.1. Das Ziel der Wettbewerbsneutralität 18

1.3.2. Anforderungen an die Steuersysteme 21

1.3.3. Anforderungen an die Steuersätze 25

2. Historische Entwicklung 30

2.1. Enttäuschung der Benelux-Union 30

2.2. Streit in der Montan-Union 34

2.3. Verhandlungen zum EWG-Vertrag 41

3. Rechtliche Regelungen 48

3.1. Der Inhalt der Art.95-99 EWG-Vertrag 48

3.2. Die Unzulänglichkeiten des Diskriminierungsverbotes

3.3. Die Auswirkungen auf das Harmonierungsgebot
nach Art.99 EWG-Vertrag

C. Die Einführung der MWSt in der EG: der große Erfolg der
60er Jahre 
1. Die Zlele und Strateglen der wichtigsten Akteure 60

1.1. Die Gemeinschaftsperspektive:

die Harmonisierungsziele der Kommission 60

1.1.1. Kurzfristiges Ziel: Wettbewerbsneutralität 60

1.1.2. Langfristiges Zlel: Abschaffung der Steuergrenzen 64

$\begin{array}{ll}\text { 1.1.3. Strategie: Entwicklung eines Stufenprogrammes } & 69\end{array}$

1.2. Die nationale Perspektive:
die steuerpolitischen Ziele der Mitgliedstaaten

1.2.1. Binnenpolitische Ziele: Dominanz des fiskalischen Ziels 72

1.2.2. Außenpolitische Zlele: Beurtellung der Zlele der Kommission 79

$\begin{array}{lll}\text { 1.2.3. Strategien: Jeder will etwas anderes } & 81\end{array}$

2. Der Willensbildungsproze $\beta \quad 84$

2.1. Die Gemeinschaftsperspektive:
die Einfürung der MWSt in der EG

2.1.1. Erste Uberlegungen und vorentscheidungen: 1958-1960 84

2.1.2. Die erfolgreiche Erarbeitung eines Harmonisierungsprogrammes
auf der technischen Ebene: $1960-1962$

2.1.2.1. Der Steuer- und Finanzausschuß 90

2.1.2.2. Die Arbeitsgruppe I 93

2.1.3. Die vergeblichen Bemühungen um eine Ubergangslösung auf
der politischen Ebene: $1960-1963$, eine Parallelentwicklung

2.1.3.1. Das Scheitern einer Stillhaltevereinbarung 96

2.1.3.2. Das Scheltern einer gemeinsamen Berechnungsmethode 102

2.1.4. Die Harmonisierung der USt als einziger Ausweg: 1962-1967 105

2.1.4.1. Der erste Harmonislerungsvorschlag der Kommission 105

2.1.4.2. Die Diskussion der 1. USt-Richtlinie 108

2.1.4.3. Die Diskussion der 2. USt-Richtlinie 114

$\begin{array}{ll}\text { 2.1.4.4. Von der Krise bis zur Annahme } & 118 \\ & \text { der beiden Richtlinien }\end{array}$

2.1.5. Die schleppende Implementierung der USt-Richtlinien:
$1967-1973$

2.2. Die nationale Perspektive:
die USt-Reformdebatte in den Mitgliedstaaten

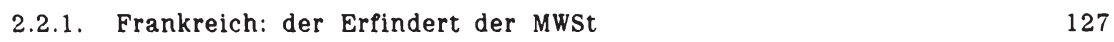

2.2.2. Deutschland: die treibende Kraft 135

2.2.3. Belgien: ein Mitläufer 150

2.2.4. Niederlande: der Bremser 160

2.2.5. Großbritannien: die Insel bereitet sich auf Europa vor 172 
D. Die Harmonisierung der MWSt-Bemessungsgrundlage:

der ungeplante $\mathrm{Zwischenschritt} \mathrm{der} \mathrm{70er} \mathrm{Jahre}$

1. Die Ziele der wichtigsten Akteure

185

1.1. Das alte Ziel: Wettbewerbsneutralität

185

1.2. Das Endziel: Abschaffung der Steuergrenzen

188

1.3. Das neue Ziel: Schaffung von MWSt-Eigenmitteln

2. Der Willensbildungsproze $\beta$

2.1. Die hart erkämpfte 6.USt-Richtlinie: 1970-1977

2.1.1. Ausarbeltung des Kommissionsvorschlages

2.1.2. Toter Punkt in den Verhandlungen

2.1.3. Verabschledung durch den Rat

209

2.1.4. Implementierung in den Mitgliedstaaten

215

2.2. Zahlrelche Aktivitäten ohne grelfbare Erfolge: 1977-1985

220

2.2.1. Verwaltung der 6.USt-Richtlinie

220

2.2.2. Vervollständigung der gemelnsamen Bemessungsgrundlage

2.2.3. Vereinfachung der Grenzformalitäten

2.2.4. Gesamtschau der Entwicklung

2.3. Das perfektionistische Binnenmarktprogramm:

der aktuelle Stand der Dinge

E. Die Harmonisierung der MWSt-Sătze und der MWSt-Verwaltung: noch vor der Jahrhundertwende?

1. Das Ziel Abschaffung der Steuergrenzen

2. Der Willensbildungsproze $\beta$

2.1. Zur Abschaffung der Steuergrenzen fur nicht-steuerpflichtige Letztverbraucher

2.1.1. Rückblick auf eine erfolgreiche $\mathrm{Zwischenlösung:}$ die Reiseverkehrsrichtlinien

2.1.2. Ausblick auf das Endziel: die Angleichung der nationalen Steuersätze

2.2. Zur Abschaffung der Steuergrenzen für steuerpllichtige Unternehmer

2.2.1. Rückblick auf eine gescheiterte Zwischenlösung: der Vorschlag für eine 14.USt-Richtlinie 
2.2.2. Ausblick auf das Endziel:

die Vernetzung der nationalen Finanzverwaltungen 285

2.3. Zukunftsperspektiven: ein Europa der vier Geschwindigkeiten? 287

$\begin{array}{ll}\text { F. Abschließende Bemerkungen } & 291\end{array}$

Anlage I: Verzeichnis der wichtigsten Abkürzungen 294

Anlage II: Verzeichnis der vom Verfasser gefuhrten Intervlews 296

Anlage III: Verzeichnis der USt-Richtlinien der EG 302

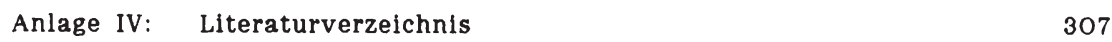




\section{Vorwort}

Die Untersuchung über den umsatzsteuerpolitischen Willensbildungsproze $\beta$ in der Europäischen Gemeinschaft geht auf eine Anregung meines Lehrers, Herrn Prof. Dr. Norbert Andel, zurück. Für seine Unterstützung und das mir entgegengebrachte Vertrauen möchte ich ihm herzlichen Dank sagen. Ein Wort des Dankes gebührt ebenfalls dem inzwischen verstorbenen Prof. Alan R. Prest, der mich während meines einjăhrigen Forschungsaufenthaltes an der London School of Economics and Political Sclence betreute. Er wird mir fachlich wie auch menschlich immer ein Vorbild bleiben. Und bedanken möchte ich mich schließlich bei der Studienstiftung des Deutschen Volkes für die mir zwischen 1978 und 1986 in großzügiger und unbürokratischer Weise gewährte finanzielle Unterstützung.

Das zentrale Problem der Arbeit lag, wie von Anfang an klar war, in der unsicheren Quellenlage begründet. Die wissenschaftlichen Veröpfentlichungen, die sich mit der Steuerharmonisierung in der EG beschäftigen, berühren, von ganz wenigen Ausnahmefallen abgesehen, Fragen der politischen wlllensbildung nur ganz am Rande. Dle ökonomische und juristische Literatur, zusammen mit den amtlichen Veröpfentlichungen der EG, konnten daher lediglich als eln Ausgangspunkt für die vorliegende Untersuchung dienen. Sie wurden in einem ersten Schritt ergänzt durch die Berichterstattung der Tagespresse. Bedauerlicherwelse verfügen nur elne kleine Minderheit von Zeitungen und Zeitschriten (z.B. die Londoner Times) über detalllierte Indices. Unschätzbare Dienste erweisen dem Forscher daher die umfangreichen Presseauswertungen, whe sie seit Jahrzehnten beispielsweise von der Bibliothek des Deutschen Bundestages (Bonn), vom Royal Institute of International Affairs (London) und von der Fondation Nationale des Sciences Politiques (Paris) erstellt werden. ${ }^{1}$

Am Rande sei vermerkt, daß die genannten Presseauswertungen bei den von innen archivierten Artikeln zwar jeweils den Namen der Zeitung sowie deren Erscheinungstag vermerken, auf eine Angabe der entsprechenden Seitenzahlen jedoch verzichten. Soweit die vorliegende Arbeit auf Zeitungsartikel Bezug nimmt, wird dieser zugegebenermaßen ungewöhnlichen Zitierweise gefolgt. 
Auf der Basis der genannten Quellen war es dem Verfasser möglich, sich einen ersten Eindruck von dem Hergang der Umsatzsteuer-Harmonisierung zu verschapfen. Das Blld hätte jedoch unvollständig bleiben müssen, wenn es nicht gelungen wäre, auch Informationen aus erster Hand zu erhalten. Unverzichtbar für die erfolgrelche Durchfuhrung des Forschungsvorhabens war daher der Kontakt zu Personen, die an den Brüsseler HarmonisierungsVerhandlungen unmittelbar betelligt waren oder die den Fortgang der Meinungsbildung in der einen oder anderen Weise mittelbar zu beeinflussen vermochten.

Als ich die Arbeit an der Dissertation aufnahm, war keinesfalls klar, ob eln solcher Kontakt hergestellt werden könnte. Unsicher war auch, inwleweit die jeweils interviewten Personen bereit sein würden, Auskunft über vertrauliches Material zu geben. Alle anfänglichen Befürchtungen erwiesen sich jedoch, dank der großzügigen Hilpsbereitschaft von insgesamt über 60 Gesprăchspartnern, als völlig unbegründet. Es würde den Rahmen eines Vorwortes sprengen, Jedem einzeln meinen Dank auszusprechen, und ich möchte daher um Verständnis bitten, daß ich die Namen nur in einem Anhang aupführen konnte. An dieser Stelle erwähnen möchte ich lediglich zwel Personen, ohne deren Unterstützung die Arbelt in der vorliegenden Form niemals hătte zustandekommen können. $\mathrm{Zu}$ nennen ist zum einen Herr Dr. h.c. Hans von der Groeben, über viele Jahre hinweg Kommissar bel der EG und damals unter anderem für die Steuerharmonisierung verantwortlich. In mehreren Gesprächen, dle Herr Dr. h.c. von der Groeben nicht zuletzt auf der Grundlage elnes umfangreichen Archivs führen konnte, gab er dem Verfasser einen tiefen Einblick in die steuerpolitischen Diskussionen, die wăhrend der 50er und 60er Jahre auf europäischer Ebene stattfanden. Zu nennen ist zum zwelten Herr Ministerialrat Richard Kohler, Leiter des Grundsatzreferates Umsatzsteuer im Bundesministerium der Finanzen und in dieser Position für alle Fragen der USt-Harmonisierung, sowelt die deutsche Seite betroffen ist, verantwortlich. Herr Ministerialrat Kohler stand mir nicht nur, wann immer ich ihn darum bat, mit wertvollen Hinweisen zur Seite, sondern knüpfte für mich auch Kontakte zu seinen Kollegen in den anderen Hauptstädten der EG.

Allen meinen Gesprächspartnern darf ich vielmals für ihre Hilfe danken. Jeder beschrieb den Proze $\beta$ der Umsatzsteuer-Harmonisierung aus einer anderen Perspektive, und es war nicht immer einfach, die sehr unterschiedlichen und zum Teil sich auch gegenseitig widersprechenden Informationen zu einem Gesamtbild zusammenzufügen. Die auf den folgenden Seiten versuchte Darstellung der europäischen Umsatzsteuer-Harmonisierung bleibt damit notwendigerweise die rein subjektive Sichtweise des Verfassers. Sle ist, wie wahrschelnlich kaum $\mathrm{zu}$ vermeiden war, unvollständig und in elnigen Punkten wohl auch falsch. Alle diejenigen Leser, die über ein besseres Wissen verfügen, möchte ich auffordern und darum bitten, sich an 
mich zu wenden. Eine permanente Postadresse findet sich am Ende des Vorwortes.

Die dem Verfasser in persönlichen Gesprächen oder Briefen gegebenen Informationen waren fast durchweg vertraullcher Natur. Es ist daher unmöglich, die entsprechenden Angaben, sofern sie in die vorliegende Arbelt Eingang landen, in der üblichen Weise zu zitleren. Für wortliche Zitate des einen oder anderen Interviewpartners kann daher in der entsprechenden Fußnote nur Persönliches Interview als Quelle genannt werden. Der Rückschluß von elnem Zitat auf den vermeintlichen Informanten ist auch für Insider unmöglich, da die in Anlage I zu findende Liste der interviewten Personen unvollständig ist: Eine nicht genannte Zahl von Gesprächspartnern hat ausdrücklich darum gebeten, in einer Veröffentlichung nicht namentlich erwähnt $\mathrm{zu}$ werden. Von besonders senslblen Informationen, die dem Verfasser hin und wleder $\mathrm{zu}$ Ohr kamen, wurde in der vorllegenden Untersuchung an keiner Stelle Gebrauch gemacht.

Düsseldorf, Im Oktober 1986

Walter Hahn

Am Faltergarten 16

6304 Lollar

B.R. Deutschland 


\title{
A. Einleitung
}

\author{
"Harmonizing La Bohème with \\ Götterdämmerung would be \\ easier than harmonizing EEC \\ taxes"1
}

Dle in der Europäischen Gemeinschaft aus integrationspolitischen Gründen unbedingt notwendige Harmonisierung der nationalen Steuersysteme ist, da kann man der Aupfassung des Economist nur beipflichten, keln leichtes Unterfangen. Mehr noch als in der Musik spiegeln sich in den unterschiedllchen Steuersystemen die nationalen Besonderheiten der elnzelnen EGStaaten wider. Denn wăhrend Opern schon immer fur ein internationales Publikum komponiert wurden, orientierte sich die Ausgestaltung von Steuern, da ihre Erhebung an der jewelligen Staatsgrenze haltmacht, von alters her an den Bedürfnissen eines elnzelnen Landes.

Die Steuersysteme, die in den Mitglledstaaten der EG heute verwandt werden, sind das Ergebnis langer Entwlcklungsprozesse, die sich uber Jahrzehnte und teils sogar uber Jahrhunderte hinweg in den verschiedenen Ländern weitgehend unabhängig voneinander vollzogen. Sie sind Ausdruck eines politischen Gleichgewichts, das sich im widerstreit der jeweiligen wirtschaftlichen Interessen nach und nach herausgebildet hat. Der Versuch, innerhalb der EG die unterschiedlichen Abgabensysteme einander anzuglelchen bzw., wie man auch sagt, sle zu harmonisieren, muß zwangsläufig auf zahllose Widerstände treffen, greift er doch in das Verhältnis $z$ wischen den Mitgliedstaaten und deren Bürgern unmittelbar ein. Die europäische Steuerharmonisierung kam denn bislang auch nur im Schneckentempo voran. Spektakuläre Erfolge in Sachen Steuerharmonisierung konnte die EG, obwohl ihre Grundung nun schon fast 30 Jahre zurückliegt, nur bei der Umsatzsteuer erzielen. $\mathrm{Zu}$ keinen nennenswerten Fortschritten kam es demgegenuber bel den speziellen Verbrauchsteuern und bel den direkten Abgaben. Und auch bel der Umsatzsteuer nahm in letzter Zelt die Zahl der von der Kommission der EG ausgearbeiteten Richtlinienentwürfe zu, die nun schon seit Jahren vergeblich auf eine Verabschledung durch den Ministerrat warten.

$1 \quad$ Economist 23.8 .75 . 
Weder fehlt es an gutgemeinten Harmonisierungsinitiativen der Kommission noch besteht ein Mangel an wissenschaftlicher Literatur über die Steuerharmonislerung. Allen voran beschäftigen sich die Juristen mit der Steuerpolitik der EG. Sle kommentierten in einer unüberblickbaren Zahl von Arbeiten die steuerlich relevanten Vertragsartikel, die vom Rat bereits in Kraft gesetzten Richtlinien sowle die darauf basierenden Urtelle des Europäischen Gerichtshofes. Die Okonomen gingen über den deskriptiv ausgerichteten Ansatz der Rechtswissenschaftler hinaus. Sie stellten die Frage, bis $\mathrm{zu}$ welchem Grade die Steuern in der Gemeinschaft angeglichen werden müssen, damit die Ziele der europäischen Integration (insbesondere die Errichtung eines Gemeinsamen Marktes) erreicht werden können.

Zwischen dem von den Juristen beschriebenen Ist-Zustand auf der einen und dem von einer Mehrheit der Okonomen abgeleiteten Soll-Zustand auf der anderen Seite klafft eine weite Lücke in Form eines ganz erheblichen Harmonisierungsdefizits. Es wäre zu einfach, dieses Defizit alleine mit dem Hinweis darauf erklären zu wollen, daß es den Mitglledstaaten an dem für eine Steuerharmonisierung notwendigen politischen Willen mangele. Zugegebenermaßen sind es die nationalen Reglerungen, an deren Nein die von der Kommission ausgehenden Harmonisierungsinitiativen so oft scheitern. Der Begriff politischer wille jedoch ist elne Leerformel, solange nicht en détall herausgearbeitet wird, welche Motlve und Uberlegungen sich dahinter konkret verbergen.

Die Antwort aup die Frage, wie Steuerpolltik gemacht werden sollte, wird bereits in der Theorie rationaler Wirtschaftspolitk behandelt und ist daher allseits bekannt. Noch weitgehend im Dunkeln liegt demgegenüber das Problem, wie Pinanzpolitische Willensbildungsprozesse in der Praxis tatsächlich ablaufen. Das gilt für den Bereich nationaler Steuerpolitik, und es gilt, in noch welt größerem Maße, für das überaus komplexe Zusammensplel unterschiedlicher Steuerpolitiken aup europäischer Ebene.

Ziel der vorliegenden Arbeit ist es, steuerpolitische willensbildungsprozesse in der EG anhand eines Beisplels zu analysleren und damit einen Beitrag zur Entwicklung einer Theorie konkreter Wirtschaftspolitik zu leisten. Für die Entscheidung, die Umsatzsteuer - kurz USt genannt - zum Gegenstand der Untersuchung $\mathrm{zu}$ machen, waren zwel Gründe ausschlaggebend. Zum einen ist die USt die bislang einzige Abgabe, bei der die Gemeinschaft neben zahlreichen Pehlgeschlagenen Harmonisierungsversuchen auch durchaus beachtliche Erfolge vorzuweisen hat. Insbesondere aus der Gegenuberstellung von verabschiedeten mit bis dato blocklerten Richtlinienentwürfen lassen sich interessante Schlußfolgerungen zlehen. Zum anderen ist die USt-Harmonisierung, als eine zentraler Bestandtell des Gemeinschaftsprogrammes zur Vollendung des Binnenmarktes ${ }^{2}$, in den letzten Jahren in den Mittelpunkt des Ringens um die Zukunft der EG geruckt. Die bisherige

Vgl. Kommission (1985). 
Entwicklung der USt-Harmonisierung erlaubt Aussagen daruber, inwleweit weitergehenden Harmonislerungsmaßnahmen sinnvoll wären und inwleweit sie in năchster Zelt möglich erscheinen.

Besonderer Wert soll darauf gelegt werden, die wechselselte Beeinflussung zwischen nationaler Steuerpolitik auf der einen und europäischer Steuerharmonisierung auf der anderen Selte herauszuarbeiten. Zurückhaltung wird gewahrt bel der Frage, inwlewelt die mit der USt-Harmonisierung gemachten Erfahrungen auf andere Bereiche europäischer und/oder nationaler Wirtschaftspolitik übertragen werden können. $\mathrm{Zu}$ glauben, aus der Analyse elnes elnzigen Fallbeisplels Aussagen allgemeiner Art ableiten zu können, wäre vermessen und zugleich wissenschaftlich unseriös. Bevor der Schritt der Verallgemeinerung getan werden kann, müssen noch eine größere Anzahl vergleichbarer Fallstudien vorgelegt werden. Ergänzt sel, daß dle Harmonisierung der USt und die der speziellen Verbrauchsteuern zum Tell ähnlich gelagerte Probleme aufwerfen. Hierauf soll an den entsprechenden Stellen der Arbelt jewells gesondert hingewlesen werden.

Die Struktur der vorllegenden Arbeit stellt sich wie folgt dar. Ein erstes Kapitel glbt dem Leser elnen Kurzuberblick uber die wichtigsten Hintergrundinformationen okonomischer, historischer und juristischer Art, deren Kenntnis fur das Verstandnis des USt-politischen Harmonislerungsprozesses in der EG unabdingbar sind. Drel weitere Kapitel beschaftigen sich nacheinander (a) mit der Einfürung der Mehrwertsteuer - kurz MwSt genannt - in der EG, (b) mit der Harmonisierung der MWSt-Bemessungsgrundlage und (c) mit der Harmonisierung der MwSt-Sătze und der MwSt-Verwaltung.

Dle an sachlichen Erwägungen ausgerichtete Untergliederung deckt sich weitgehend mit der zeitlichen Abfolge der einzelnen Harmonisierungsschritte. Wahrend in den 60er Jahren die Einfuhrung der MwSt im Vordergrund der europäischen USt-Harmonislerung stand, nahm die Angleichung der MWSt-Bemessungsgrundlage die gesamten 70er Jahre in Anspruch und ist bis heute noch nicht ganz abgeschlossen. Die Harmonisierung der MWStSătze und der MWSt-Verwaltung rückte, obwohl sich erste Gespräche darüber bis in die Aufbaujahre der EG zurückverfolgen lassen, erst in den Jahren 1985/86 in den Mittelpunkt der Brüsseler Harmonisierungsverhandlungen.

Jedes der drel Hauptkapitel ist in zwel Abschnitte unterteilt. Der jeweils erste Abschnitt analysiert die wichtigsten Ziele, die für den entsprechenden Harmonisierungsschritt von Bedeutung waren bzw. sind. Der jewells zweite Abschnitt ist chronologisch angelegt. Er zeichnet den Verlauf des bisherigen Willensbildungsprozesses nach und gibt, sofern der entsprechende Harmonisierungsschritt noch nicht abgeschlossen ist, einen Ausblick auf das in den kommenden Jahren Notwendige und Mögliche. 


\section{B. Hintergrundinformationen}

Das erste Kapitel verfolgt den Zweck, den Leser mit einem Paket von Hintergrundinformationen $\mathrm{zu}$ versehen, die zum Verständnis und zur Beurtellung des umsatzsteuerpolitischen willensbildungsprozesses in der EG unabdingbar sind. Der erste Abschnitt gibt elnen Uberblick uber die wirtschaptstheoretischen Grundlagen der USt-Politik in elnem Gemeinsamen Markt. Der zweite Abschnitt ist den historischen Entwicklungen gewidmet, die zur Aufnahme steuerlicher Vorschriften in den 1957 unterzelchneten EWG-Vertrag gefuhrt haben. Die PUr uns relevanten Artikel 95-99 EWGV werden schlleßlich in einem dritten und letzten Abschnitt im elnzelnen erläutert. Dabei wird insbesondere versucht herauszuarbeiten, daß es letztendlich dle Unzulänglichkeiten der Art. 95-97 waren, die elne Harmonisierung der indirekten Steuern nach Art. 99 notwendig gemacht und vorangetrieben haben.

1. Okonomische Grundlegen

1.1. Alternatlve Formen der Indirekten Besteuerung

Die Unterscheldung zwischen direkten Steuern aup der einen und indirekten Steuern auf der anderen Selte beruht nicht aup der Anwendung elnes ökonomisch exakt definlerbaren Kriteriums. Trotzdem hat die angesprochene Klassifikation Im Rahmen steuerpolitischer Diskussionen im allgemeinen und bel der EG-Steuerharmonisierung im besonderen eine zentrale Bedeutung erlangt. ${ }^{1}$

Die elnzelnen Autoren ziehen die Trennungslinle zwischen direkt und indirekt an ganz unterschiedlichen Stellen. Ohne auf die zahlreichen Definitionsmöglichkeiten und deren jewellige Problematlk năher eingehen zu wollen, wird der vorliegenden Arbelt die folgende Begriffsfassung zugrundege-

1 Vgl. hlerzu z.B. Kap.B.2.3. 
legt: Während direkte Steuern das Einkommen des Steuerzahlers unmittelbar belasten sollen, verbindet der Gesetzgeber mit indirekten Steuern die Absicht, daß der Steuerzahler die Abgabe über erhöhte Produktpreise an den Konsumenten überwälzt und damit dessen Verbrauch bzw. Einkommensverwendung belastet. Es ist offensichtlich, daß die vorgestellte Definition kelneswegs in der Lage ist, alle denkbaren Steuerarten in die eine oder die andere schublade elnzuordnen. Als Problemfall seien nur die Kapitalverkehrsteuern genannnt, die von der EG als indirekte Steuern auf Kapital bezeichnet werden. Solche Grenzfalle sollen uns aber nicht weiter beschartigen: Unter dem Begrifp indirekte Steuern werden im folgenden vereinfachend die aup Güter und Dienstleistungen erhoben Abgaben verstanden.

Im Bereich der Verbrauchsbesteuerung gibt es als grundlegende Alternat1ven zunächst die auf einzelne oder wenige Produkte erhobenen speziellen Verbrauchsteuern - auch Akzisen genannt - sowie die eine breite Produktpalette umfassenden allgemeinen Verbrauchsteuern. Die aufkommensstarken Akzisen - Mineralöl-, Tabak- und Alkoholsteuern - werden typischerweise als spezlfische Steuern auf elner frühen Stufe des Produktionsprozesses von einer relativ kleinen Anzahl Steuerpflichtiger - Raffinerien, Zigarettenhersteller, Brennerelen, etc. - erhoben. Allgemeine Verbrauchsteuern sind demgegenuber als ad valorem Abgaben ausgestaltet und werden daher oft als UStn bezeichnet. Bei ihnen lassen sich, je nachdem, wieviel Stufen besteuert werden und wie die Bemessungsgrundlage definiert ist, eine Vielzahl unterschiedlicher Varianten beobachten. ${ }^{2}$

\section{Alternative Formen einer einphasigen USt}

Nach dem Kriterium, wieviele Stufen des Produktions- und Verteilungsprozesses der Steuerpflicht unterliegen, kann man zwischen Ein-, Mehr- und Allphasensteuern unterscheiden. Bei den einphasigen Abgaben ist es grundsätzlich denkbar, zwischen der Urproduktion auf der einen und der Einzelhandelsstufe auf der anderen Seite eln bellebiges Glied der Produktionskette herauszugrelfen und der Besteuerung $\mathrm{zu}$ unterwerfen. Trotzdem konnten sich in der Praxis die aup pruhe Stufen des Produktionsprozesses erhobenen allgemeinen Verbrauchsteuern nicht durchsetzen, da unterschiedliche Guter sehr verschiedenartige Produktionswege durchlaufen, was wlederum die eindeutige Abgrenzung elner für die Besteuerung aller Produkte maßgeblichen Stufe de facto unmöglich macht. Daher haben in der Besteuerungspraxis lediglich solche Abgaben elne Bedeutung erlangt, die sich auf eine relativ späte Stufe des Herstellungszyklusses stützen: auf die letzte Produktions-, die Großhandels- oder die Einzelhandelsstufe.

2 Eine ausfuhrliche Darstellung alternativer USt-Systeme findet sich bel Pohmer (1980), S.650ff., ein Kurzüberblick z.B. bel Cnossen (1977), S.15fe. 
Alternative Formen einer allphasigen USt

Das andere Extrem allgemeiner Verbrauchsteuern bilden die Allphasensteuern, die sämtliche Produktions- und Handelsstufen der Steuerpflicht unterwerfen. Während bel einer einphasigen Abgabe grundsätzlich immer der Bruttoumsatz als steuerliche Bemessungsgrundlage herangezogen wird, lassen sich Allphasensteuern nach dem Kriterium unterscheiden, ob der Brutto- oder aber der Nettoumsatz belastet wird. Bemessungsgrundlage elner Bruttoust ist die Summe der Verkaufserlöse. Demgegenüber gibt es bel der Ausgestaltung einer Nettoust mehrere technische Varianten, die sich in ihren steuerlichen Auswirkungen zum Tell voneinander unterscheiden.

Die erste und einfachste Variante ist der Vorumsatzabzug, kurz VUA genannt. Zur Ermittlung des steuerpflichtigen Nettoumsatzes werden von dem Bruttoumsatz dle Ausgaben der Unternehmung für Vorprodukte subtrahlert. Eine zweite Variante ist die additive Ermittlung und Besteuerung des in einer Unternehmung erwirtschafteten Mehrwertes, der sich als Summe aus Lohnkosten, Zinskosten und Bruttogewinn ergibt. Der additiv ermittelte Mehrwert unterscheidet sich von dem subtraktiv errechneten Nettoumsatz lediglich in der Höhe der in elner Perlode getätigten Nettolnvestitionen. ${ }^{3}$ wăhrend also eine Mehrwertbesteuerung, aus der volkswirtschaftlichen Perspektive betrachtet und ein wenig idealisiert, das gesamte Volkseinkommen der Besteuerung unterwirft - sie wird daher auch als NettouSt vom Einkommenstyp bezelchnet -, läßt elne aup dem VUA-Prinzip beruhende USt die Nettoinvestitionen steuerfrel bzw. besteuert lediglich den gesamtwirtschaftlichen Konsum - man spricht daher auch von einer Nettoust vom Konsumtyp. Es bleibt zu ergänzen, daß es durchaus möglich 1st, durch kleinere Korrekturen an den jeweiligen Berechnungsmodi den Steuertypus zu verändern:

- Zieht man vom additiv ermittelten Mehrwert die Nettolnvestition nachträglich ab, so erhält man eine NettoUSt vom Konsumtyp.

- Lăßt man belm VUA-Verfahren die für Investitionsgüter getătigten Ausgaben nicht sofort, sondern nur entsprechend der Jährlichen Abschreibungsbetrăge - pro-rata-temporis - zum Abzug zu, dann erhalt man umgekehrt eine NettoUSt vom Einkommenstyp.

Als Ergebnis bleibt festzuhalten, daß die Entscheidung zwischen VUA- und Mehrwert-Methode weniger von steuerpolitischen Uberlegungen grundsătzlicher Art denn von technischen Erwägungen dominlert wird. Dabel wird der VUA 1.d.R. als das einfachere Verfahren betrachtet.

Der Vorsteuerabzug - kurz VSA genannt - stellt eine dritte Variante der Nettoust dar. Dabei wird zunächst auf der Basis des Bruttoumsatzes die zu zahlende Steuer ermittelt, von der, in einem zweiten Schritt, die aup den Vorumsätzen lastende Vorsteuer abgezogen wird. Wle der VUA, so ist auch

$3 \quad$ Anm.: Nettoumsatz + Nettoinvestitionen $=$ Mehrwert. 
der VSA der Grundidee nach eine NettoUSt vom Konsumtyp. Er unterscheidet slch aber vom VUA durch den sogenannten Nachholeffekt, der wegen seiner grundlegenden Bedeutung fur die späteren Erörterungen kurz an einem Beisplel verdeutlicht werden soll. Betrachtet wird die Produktion und der Vertrleb elnes Gutes über Insgesamt 3 Stufen:

\section{Schaubild B-1: VUA und VSA}

\begin{tabular}{|c|c|c|c|c|c|c|c|c|}
\hline & \multirow{2}{*}{ Bruttoumsatz } & \multirow{2}{*}{$\begin{array}{l}\text { Nettoumsatz } \\
1 \\
=\text { Mehrwert }\end{array}$} & \multicolumn{3}{|c|}{$\begin{array}{l}\text { Steuerzahlung bei } \\
\text { einem Satz von } 20 \% \\
\text { auf alle Stufen }\end{array}$} & \multicolumn{3}{|c|}{$\begin{array}{l}\text { Steuerzahlung bei } \\
\text { einem Satz von } 20 \% \\
\text { auf } 1.4 .3 \text {. Stufe, } \\
10 \% \text { auf } 2 . \text { Stufe }\end{array}$} \\
\hline & & & VUA & & VSA & VUA & i & VSA \\
\hline $\begin{array}{l}\text { 1.Stufe } \\
\text { (z.8. Produktion) }\end{array}$ & 50 & 50 & 10 & & 10 & 10 & $\begin{array}{l}T \\
1 \\
1\end{array}$ & 10 \\
\hline $\begin{array}{l}\text { 2.Stufe } \\
\text { (z.B. Großhandel) }\end{array}$ & 80 & $\begin{array}{l}1 \\
1\end{array}$ & 6 & & 6 & 3 & i & -2 \\
\hline $\begin{array}{l}\text { 3.Stufe } \\
\text { (z.B. Einzelhandel) }\end{array}$ & 100 & $\begin{array}{l}1 \\
1\end{array}$ & 4 & 1 & 4 & 4 & $\begin{array}{l}1 \\
1 \\
\end{array}$ & 12 \\
\hline Steuer total & & & 20 & 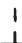 & 20 & 17 & & 20 \\
\hline
\end{tabular}

Aus dem Belspiel wird klar ersichtlich, daß VSA und VUA genau dann zu identischen Ergebnissen fuhren, wenn auf allen stufen eln elnheltlicher Steuersatz angewandt wird. Kommt Jedoch eine einzelne Stufe in den Genuß eines reduzierten Satzes, dann unterscheiden sich die Resultate. Während die Steuerreduktion beim VUA - für die additive Mehrwert-Methode gilt dasselbe - zu einer endgültigen Entlastung des Endproduktes Puhrt, wird die Belastung beim VSA nachgeholt, da die geringere Steuerzahlung auf der 2.Stufe automatisch den auf der 3.Stufe zulässigen VSA um den gleichen Betrag kürzt.

Als vierte und letzte Variante blelbt noch das Suspensionsverfahren zu erwăhnen, bel dem zunăchst alle von Unternehmern getătigten Umsätze der Steuerpilicht unterliegen. In elnem zwelten Schritt werden jedoch solche Lleferungen von der Pflicht zur Steuerzahlung befreit - die Zahlung wird suspendiert -, die ein (steuerpflichtiger) Betrieb an einen anderen (steuerpflichtigen) Betrieb lelstet. Das Suspensionsverfahren unterscheidet sich vom VSA nur insolern, als in allen Fallen, in denen der Steuerpflicht des Lleferanten ein VSA-Recht des Belleferten gegenubersteht, von den entsprechenden Zahlungsvorgängen abgesehen wird. Das Suspensionsverfahren ruckt die Nettoust in elne auffallige Năhe zur elnphasigen EinzelhandelsUSt. Hier wle dort lösen nur solche Lleferungen eine Steuerzahlung aus, die eln (steuerpllichtiger) Betrieb an einen (nicht-steuerpflichtigen) Konsumen- 
ten leistet. Im Gegensatz $z u$ der hier gewählten Einordnung beschreibt daher Pohmer vollkommen zu Recht das Suspensionsverfahren als eine Methode zur Implementierung einer einphasigen USt. ${ }^{4}$

\section{Zusammenfassung}

Festzuhalten blelbt, da $\beta$ durch die Verwendung zweier Kriterien dle unterschiedlichen Typen einer allgemeinen Verbrauchsteuer klassifiziert und beschrieben werden können:

- Nach dem Kriterium der Zahl der steuerpflichtigen Stufen wird zwischen ein-, mehr- und allphasigen Abgaben unterschleden.

- Nach dem Kriterium der steuerpflichtigen Bemessungsgrundlage konnten bel den allphasigen Abgaben die beiden Extremtypen Brutto- und NettouSt herausgearbeitet werden, während sich die einphasigen UStn in EinzelhandelsUSt, GroßhandelsuSt etc. untertellen ließen.

Die belden genannten Kriterien sollen nun dazu dienen, eine Fläche aupzuspannen, auf der neben den bereits erwăhnten Grundtypen alle möglichen Mischformen, die ebenfalls als Alternativen für die Ausgestaltung einer allgemeinen Verbrauchsteuer in Frage kommen, lokalisiert werden können.

Schaubild B-2: Alternative Formen indirekter Besteverung

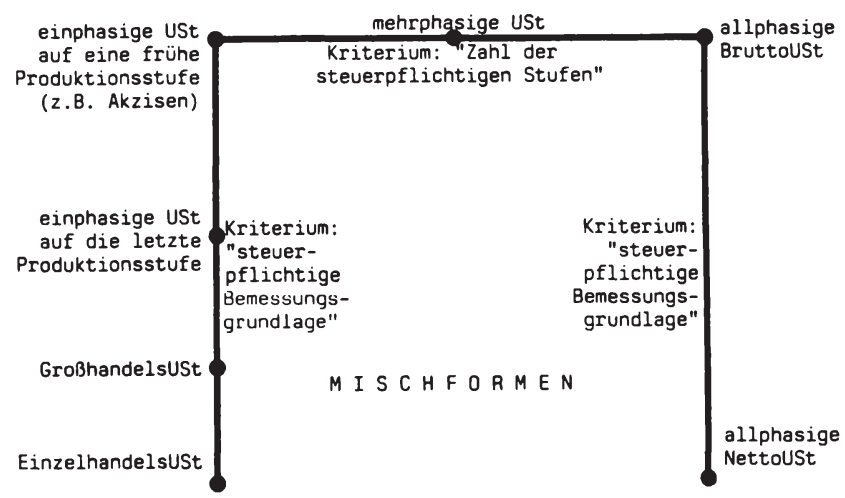

- Vgl. Pohmer (1980), S.674ff. 


\subsection{Beurtellung der indirekten Besteuerung aus der Sicht eines souveränen Staates}

\subsubsection{Das Plskalische Zlel}

Aus der Sicht einer elnzelnen Volkswirtschaft heraus wird in der uberwiegenden Zahl der Fälle dle Erhebung indirekter Steuern vom fiskalischen Zlel dominiert: Indirekte Steuern sollen in erster Linie dazu dienen, den Finanzbedarf der öffentlichen Hand zu decken. Dle relative Unmerklichkelt, mit der die Verbrauchsteuern den letztendlich belasteten Konsumenten zur Kasse bitten, laßat sle, zumindest in den Augen der entscheidungsbefugten Politiker, fur die Erledigung dieser Aufgabe als besonders geelgnet erschelnen.

Die Fählgkeit einer konkreten USt, ein hohes Aufkommen belzutreiben, hängt davon $a b$, in welchem Maße ihre jewellige Ausgestaltung elne politische Opposition gegen weitere Steuersatzerhöhungen provoziert. In der reinen Wirtschaftstheorie kann es kelne Rechtfertigung geben für die Vermutung, daß die verschledenen, oben vorgestellten USt-Typen ein unterschiedlich hohes Aufkommenspotential haben könnten. Ein Theoretlker würde im Gegentell bei allen USt-Typen ein ungefähr gleich hohes Aufkommenspotential unterstellen und dabel etwa wle folgt argumentieren: Der Grad der politischen Opposition gegen eine USt ist eine Funktion der epfektiven Steuerlastverteilung; jeder der bisher diskutierten Steuertypen ist bel entsprechenden Modiflkationen gleichermaßen in der Lage, ein politisch jewells gewünschstes - bzw. mehrheitsfähiges - Belastungsprofll zu erzeugen. Gegen diese, zugegebenermaßen extrem formulierte Sichtwelse lassen sich zwel Einwände ins Feld führen:

1. Die Bedeutung des Konzeptes der effektiven Steuerlastvertellung ist in der Wirtschaftstheorie unbestritten. Wenn es aber darum geht, die Inzldenz einer konkreten USt in der Praxis zu ermitteln, so mulssen sich die Theoretiker oft genug mit Tendenzaussagen begnügen. Hinzu kommt, daß dle meisten Polltiker und wahler sich schon unter dem Inzidenz-Begriff nichts Sinnvolles mehr vorstellen können. Es braucht daher nicht zu verwundern, daß in steuerpolitischen Diskussionen die effektive Lastvertellung einer USt eine weit geringere Rolle splelt als etwa dle Vertellung der Steuerzahllast und die Höhe des Steuersatzes. Beide zuletzt genannten Größen varileren sehr stark in Abhängigkelt von der jeweils gewăhlten USt und beelnflussen damit deren Aufkommenspotential.

2. Es ist eine Sache, aup dem Papler ein gewünschtes Belastungsprofil für eine gegebene USt zu entwerfen. Es ist aber eine ganz andere Sache, das theoretische Konzept in ein System allgemein anwendbarer und verbindlicher Rechtsregeln zu gießen. Um übersichtlich und handhabbar zu bleiben, 
läßt die jewellige USt nur elne sehr begrenzte Anzahl von Modiflkationen bzw. Ausnahmeregelungen zu. Es kann daher in der Praxis nicht vermieden werden, daß die verschiedenen Steuertypen spezlfische Allokationsverzerrungen nach sich ziehen, deren Bedeutung mit steigendem Steuersatz zunimmt. Da solche Verzerrungen weder wirtschaftspolitisch erwunscht sind noch von den jewells Belasteten ohne widerstand hingenommen werden, vermindern sie das Aufkommenspotential der betreffenden USt.

Das Aufkommenspotential einphaslger Verbrauchsteuern

Wir müssen polglich in der Realităt davon ausgehen, daß verschledene Verbrauchsteuer-Typen in ganz unterschledlichem Maße in der Lage sind, zur Erreichung des fiskalischen Zieles belzutragen.' Was ein System von Akzisen angeht, so muß ihnen ein vergleichsweise geringes Aupkommenspotential zugeschrleben werden: $\mathrm{Da}$ die Bemessungsgrundlage sehr schmal ist, mussen die Steuersätze entsprechend hoch seln; weltere Satzanhebungen bergen die Gefahr in sich, daß die Nachprage nach den belasteten Gutern absolut zurückgeht; dies wiederum bedroht nicht nur das Steueraufkommen, sondern provoziert daruberhinaus auch den Protest der betroffenen Produzenten und Konsumenten.

Demgegenuber ist das Aufkommenspotential einphasiger, allgemeiner Verbrauchsteuern wesentlich höher, was zum einen daraup zurackzufuhren ist, da $\beta$ Verzerrungen $z$ wischen besteuerten und nicht-besteuerten Gutern von vornhereln ausgeschlossen sind. Die verbrelterte Bemessungsgrundlage gestattet daruberhinaus fur alle Guter niedrigere Steuersatze. Dabel ist die Bemessungsgrundlage umso größer, je mehr der Steuerzugriff von der Produktionssphäre zum Einzelhandel hin verschoben wird. Aber auch bel elner breit angelegten, einphasigen USt können Verzerrungen meist nicht ganz verhindert werden. 6

Zum einen stellt sich das Problem der exakten Abgrenzung der Stufe, auf der Im Laufe des Wirtschaftszyklusses der Steuerzugriff erfolgen soll. Im Idealfall müte die steuerpflichtige Stufe so definlert werden, daß das Verhältnis der Wertschöpfung, die bis zum Zeltpunkt des Steuerzugriffs errelcht 1st, zum späteren Einzelhandelsprels bel allen Gütern identisch ist.? Da dieses Ideal jedoch in der Besteuerungspraxis nicht realislerbar ist, sind Diskriminierungen $\mathrm{zwischen}$ verschiedenen Produktions- und Absatzkanälen die unausweichliche Folge. Dle Verzerrungseffekte werden umso kleiner, je

- Zu den folgenden Ausfuhrungen vgl. Insbes. die umfassende Arbeit von Pohmer (1980). Vgl. \&. Due (1957), S.353ff.

- Vgl. z.B. Bohley (1970), S.420pP.

7 Nur wenn das Verhältnis zwischen der (besteuerten) Wertschøpfung und dem späteren Elnzelhandelspreis bel allen Gutern Identisch 1st, kann gewăhrleistet werden, daß gleiche nominale Steuersătze elne glelche effektive Belastung der an die Endverbraucher ausgelleferten Endprodukte nach sich ziehen. 
näher dle steuerpflichtige Stufe an den Letztverbraucher heranrückt. Lediglich in dem Grenzfall, daß der Einzelhandel selbst der Besteuerung unterworfen wird, verschwinden sie gänzlich. Solange dies nicht der Fall ist, verbleibt als elnzige Möglichkeit der Versuch, die mangelhafte Abgrenzung der steuerpllichtigen Stufe durch eine nachträgliche Korrektur des steuerpflichtigen Umsatzes - Verfahren der britischen Purchase Tax - oder des darauf erhobenen Satzes - Verfahren der schweizerischen WarenUSt - notdürftig zu kompensieren.

Das zweite zentrale Problem einer einphasigen USt ist die Abgrenzung $\mathrm{zwi}$ schen (steuerpflichtigen) Konsum- und (steuerbefreiten) Investitionsgüter. Oft ist die Abgrenzung nicht exakt möglich, da ein- und dasselbe Gut (z.B. ein PKW) sowohl Konsum- als auch Investitionszwecken zugeführt werden kann. Abhilfe ist, wie im ersten Fall auch, nur von elner Verschiebung des Steuerzugriffs hin zum Einzelhandel zu erwarten, da mit zunehmender Verbrauchernähe der Antell der Investitionsgüter am Gesamtumsatz elner Stufe abnehmen dürfte: Während Konsumgüter in aller Regel über den Elnzelhandel vertrieben werden, beziehen Unternehmen die von ihnen nachgefragten Investitionsgüter vom Großhandel oder gar direkt vom Produzenten.

Das Aufkommenspotential allphasiger Verbrauchsteuern

Im Vergleich zu einem System von Akzisen kommt auch einer allphasig erhobenen USt ein weitaus höheres Aufkommenspotential zu. So kann belspielswelse die Bruttoust schon bei einem sehr niedrigen Steuersatz ein beachtliches Aufkommen erzielen. Aber auch die Bruttoust geht mit Verzerrungen einher: Da ein Gut beim Durchlaufen des Produktions- und Vertellungsprozesses anläßlich jeder Lieferung erneut besteuert wird - man spricht daher von einer Steuerkumulation -, werden vertikal integrierte Unternehmen nledriger belastet als nicht-integrierte. Auch hier nimmt der Grad der Diskriminierung mit wachsendem Steuersatz zu.

Es gibt zahlreiche Möglichkeiten, die mit einer Bruttoust verbundene Kumulationswirkung abzuschwächen und damit ihr Aufkommenspotential weiter zu erhöhen. Die wichtigsten Varianten seien in einem kurzen uberblick dargestellt: ${ }^{8}$

- Integrierte Unternehmen werden den nicht-integrierten steuerlich gleichgestellt: Dies kann beispielsweise durch die Erhebung von Zusatzsteuern errelcht werden, die von vertikal integrierten Betrieben fur bestimmte interne Umsätze zu zahlen sind.

- Nicht-integrierte Unternehmen werden den integrierten steuerlich gleichgestellt: Die umsatzsteuerliche Organschaft wirkt in eine solche Richtung, da sie beim Vorllegen einer engen wirtschaftlichen Verflechtung die zwischen zwel rechtlich selbständigen Unternehmen getätigten Umsätze von der Steuerpplicht freistellt.

8 Vgl. z.B. Pohmer (1980), S.671ff. Vgl. a. Due (1957), S.357. 
- Entwicklung hín zu einer Mehrphasensteuer: Einzelne Produktions- und/ oder Verteilerstufen kommen in den Genuß eines reduzierten Steuersatzes oder werden ganz steuerbefreit.

- Entwicklung hin zu einer Einphasensteuer: Bel einzelnen Produkten wird von der Allphasenbesteuerung abgesehen; sie werden stattdessen an einer im Einzelfall festzulegenden Stelle des Wirtschaftszyklusses einer einmaligen Steuerzahlung unterworfen - Prinzip der Phasenpauschalierung.

Keine der genannten Varianten ist auch nur annähernd in der Lage, Verzerrungseffekte gänzlich zu vermeiden. Man muß vielmehr im Regelfall davon ausgehen, daß mit der Lösung eines Poblemes an anderer Stelle zwei neue aufgeworfen werden. Mit jeder Modiflkation handelt man sich darüberhinaus eine zunehmende Komplizierung des Systems ein. Soll das Prinzip der Allphasenbesteuerung beibehalten werden, so gibt es nur eine Möglichkeit, der Diskriminierungen Herr zu werden: der vollständige Ubergang von einer Brutto- zu einer Nettoust. Obwohl man auch von der Nettoust keine vollständige Beseitigung aller Verzerrungen erwarten darf,9 ist der Fortschritt gegenüber einer Bruttoust doch unverkennbar. Das Belastungsprofil der auf sämtlichen Stufen erhobenen Nettoust - System der fraktionierten Zahlungen - entspricht genau dem einer einphasigen EinzelhandelsuSt.

\section{Gegenuberstellung von NettoUSt und EinzelhandelsUSt}

Es drängt sich damit die Frage auf, ob die beiden genannten Steuern, vom Blickwinkel ihres Aufkommenspotentiales her gesehen, als gleichwertig einzustufen sind. Die Frage wird gewöhnlich mit der folgenden Argumentation verneint: Der Steuerpilicht einer EinzelhandelsuSt unterliegen ein große Zahl kleiner und nur schwer kontrollierbarer Einzelhändler, Handwerker, Freiberufler, etc.; sie werden bei stelgenden Sätzen zunehmend der versuchung erliegen, die Steuer zu hinterziehen; ${ }^{10}$ eine Nettoust schränkt das Ausma $\beta$ möglicher Steuerhinterzlehungen insofern ein, als zumindest die aup den Vorumsätzen der Einzelhandelsstufe ruhende Belastung nicht mehr oder nur noch sehr schwer hinterzogen werden kann; das Aufkommenspotential einer NettouSt, so lautet die Schlußfolgerung, ist daher größer als das einer EinzelhandelsuSt. Die vorgetragene Argumentation hat durchaus ihre

9 Einen umfassenden Überblick über die von einer Nettoust verursachten Verzerrungen gibt Forte (1966). Krautwald spricht insbesondere die diskriminierende Belastung langlebiger Konsumgüter an, die einen zumindest partiellen Ubergang zu sogenannten "user taxes" nahelegt; vgl. Krautwald (1982), S.184pp.

10 Ab welchem Satz das Hinterziehungsproblem so gravlerend wird, daß es ein Abgehen von der EinzelhandelsuSt nahelegt, dürfte, in Abhängigkeit von der Handelsstrukter, der Steuermoral und der Epfizienz der Finanzverwaltung von Land $\mathrm{zu}$ Land sehr unterschledlich sein. In bezug aup Kanada hălt die Royal Commission on Taxation belispielsweise einen Satz von 14\% für die Obergrenze; vgl. Schiff (1973), S.46. 
Berechtigung. Es sel jedoch im Vorgriff auf spätere Erörterungen schon jetzt darauf hingewiesen, daß bei einer konkreten Entscheldung zwischen den beiden Steuertypen oft andere Erwägungen elne ausschlaggebende Rolle splelen, die der Okonom eher als irrational bezeichnen würde. ${ }^{11}$

\section{Zusammenfassung}

Aus dem bisher Gesagten läßt sich schlußpolgern, daß bel elner Bewegung von einem System spezleller Verbrauchsteuern aup der einen hin zu einer NettoUSt aup der anderen Selte das Aufkommenspotential der betreffenden Abgabe tendenziell zunimmt. Aber gleichzeitig steigen auch die für die Steuererhebung anfallenden Verwaltungskosten, da immer mehr Unternehmer zu einer immer komplizlerteren Buchhaltung gezwungen werden. Eine Erhöhung des Aufkommenspotentiales der indirekten Steuern hat damit einen Preis, der zu zahlen sich nur lohnt, wenn eln erhöhter staatlicher Finanzbedarf dies zu rechtfertigen vermag.

Schaubild 8-3: Aufkommenspotential unterschiedlicher UStn

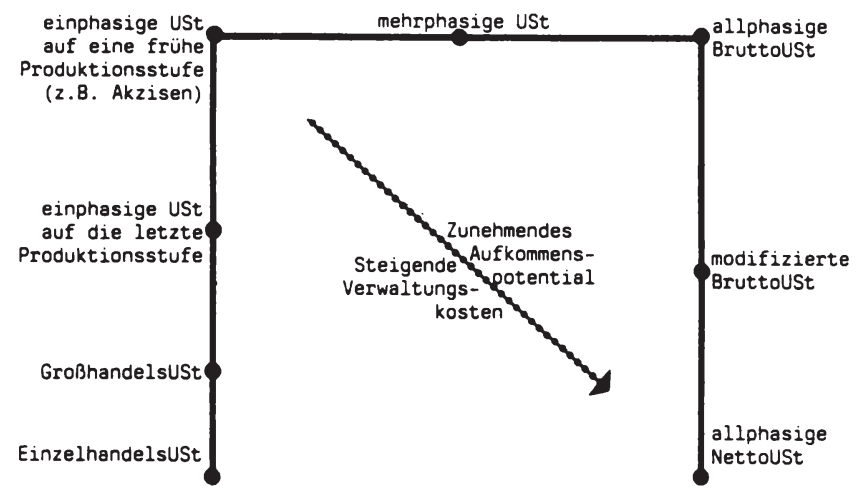

\subsubsection{Das Allokations-, Vertellungs - und Stabilitätsziel}

Bisher haben wir lediglich gepruft, inwieweit unterschledliche Formen der indirekten Besteuerung in der Lage sind, zur Erreichung des fiskalischen Zleles beizutragen. Da der Besteuerung neben der reinen Aufkommenserzielung aber auch allokations-, vertellungs- und stabilitatspolitische Aup- 
gaben zufallen können, soll aup die drel letztgenannten Ziele kurz eingegangen werden.

Was die allokatlve Zlelsetzung anbelangt, so sind zwei grundsätzlich voneinander verschledene Polltlkansätze denkbar. Zuerst ist der Ansatz zu nennen, der auf die Făhigkeit der Marktkräfte vertraut, eine optimale Allokation sicherzustellen. Für dle Besteuerung wird Polgerichtig die Forderung der Neutralitát - man spricht auch von Wettbewerbsneutralitat - erhoben: Die Steuern sollen dle Unternehmer bel der Suche nach der optimalen Allokation nicht behindern. Nehmen wir an, Neutralität könne mit paretianischer Allokationseffizienz gleichgesetzt werden, so dürfte nach der ausfuhrlichen Erörterung der verschledensten Verzerrungen klar geworden sein, daß eine mit einem einheltlichen Satz erhobene Nettoust diesem Ideal am Năchsten kommt.

Von dem marktwirtschaftlichen ist der interventionistische Ansatz zu unterschelden, der die Fählgkeiten staatllcher Planung höher einschătzt als die marktlicher spontaneität. Fur die Steuerpolitik folgt daraus, daß sie durch gezlelte Eingriffe in den Wirtschaftsablauf sogenanntes Marktversagen zu kompensieren versucht. Natürlich muß auch einer interventionistischen Politik daran gelegen seln, unbeabsichtigte Diskriminierungen zu vermeiden. Von daher spricht elniges für die Nettoust. Auf der anderen Seite gilt es Jedoch $z u$ bedenken, daß kelne USt schlechter für eine Differenzlerung des Steuersatzes geeignet ist als gerade die NettouSt: Bei einer allphasigen NettoUSt ist die Differenzierung des Satzes zwischen verschiedenen Produkten mit wesentlich mehr Schwierigkeiten verbunden als bel einer einphasigen USt, da der durch dle Satzdlfferenzlerung bedingte höhere Verwaltungsaupwand eine erheblich größere Zahl von Steuerpilichtigen trippt.

Mit Bllck auf das Vertellungsziel wird oft darauf hingewiesen, daß indirekte Steuern grundsätzlich regressiv wirken, da die relative Bedeutung des (besteuerten) Konsums beí steigendem Einkommen 1.d.R. zurückgeht. Diesem Regressionseffekt kann entgegengewirkt werden, indem man den aup Güter des GrundbedarPs erhobenen Steuersatz senkt und/oder den Luxuskonsum höher belastet. Nach den vorhergehenden Erörterungen ist bereits deutlich geworden, daß eine solche Satzdifferenzierung bel einer einphasigen USt wesentlich einfacher zu implementieren ist als bel einer Allphasensteuer.

Es bleibt das stabilitätspolitische Zlel. Zum elnen muß, wenn man aup den automatischen Stabilisierungsepfekt abstellt, eine ad valorem steuer einer spezifischen Abgabe als eindeutig überlegen angesehen werden. Zum anderen ist, und das gilt sowohl für den automatischen Aspekt als auch Pür diskretionäre Eingriffe, die Elgnung einer Indirekten Steuer fur stabilisierende Aufgaben umso Größer, je höher ihr Aufkommenspotential ist. Jedoch werden in der Praxis selbst aupkommensstarke Verbrauchsteuern nur ungern stabilitätspolitlsch elngesetzt, da z.B. elne im Boom vorgenommene 
Steuererhöhung nicht nur überschüssige Kaufkraft abschöpft, sondern gleichzeitig, wie man allgemein befürchtet, den Inflationsproze $\beta$ weiter anheizt.12 Festzuhalten bleibt daher, daß, sehen wir von den aupkommensschwachen und in aller Regel als spezlfische Abgaben ausgestalteten Akzisen einmal ab, stabilitätspolitische Erwägungen für die Beurteilung unterschiedlicher USt-Systeme eine nur untergeordnete Rolle spielen.

Bisher haben wir die unterschiedlichen Formen der USt aus der Perspektive eines einzelnen Staates betrachtet. Dabei haben wir davon abgesehen zu untersuchen, inwieweit die Erhebung indirekter Steuern elnen Einfluß aup die Außenhandelsströme der betreffenden Volkswirtschaft hat. Diese Vorgehensweise ist solange plausibel, als der jeweilige Staat in souveräner Weise durch Einsatz von Zöllen, quantitativen Importrestriktionen, Exportsubventionen, etc. seine grenzüberschreitenden Handelsströme zu kontrollieren vermag. Von der Besteuerung auf den internationalen Handel ausgehende Wirkungen lassen sich damit, zumindest annäherungsweise, jederzeit neutralisieren. Die genannte Annahme kann entsprechend dann nicht mehr auprechterhalten werden, wenn einzelne Länder durch einen Beitritt in eine Zollunion auf eine national eigenständige, protektionistische Außenhandelspolitik verzichten. In dem nun folgenden Kapitel gilt es daher, die bisherige Untersuchung auszuweiten und die Wirkung der Verbrauchsbesteuerung aup die internationalen Warenströme zu analysieren. Darauf aupbauend soll gefragt werden, welche Anforderungen aus der Sicht einer Zollunion an die indirekten Steuern gestellt werden müssen.

\subsection{Beurteilung der indirekten Besteuerung aus der Sicht einer Zollunion}

\subsubsection{Das Ziel der Wettbewerbsneutralltăt}

Das Ziel einer Zollunion ist es zunächst, durch den Abbau von Handelsschranken den Warenaustausch zwischen den Mitgliedstaaten zum gegenseitigen Nutzen auszuweiten. Die von der Unions-Gründung erhoffte Effizienzsteigerung der Wirtschaft kann jedoch nur dann in vollem Ausmaß realisiert werden, wenn nach opfnung der Grenzen die internationalen Handelsströme nicht durch private und/oder staatliche Eingriffe kunstlich verzerrt werden. Da insbesondere steuerlíche Regelungen die Wettbewerbsfähigkeit einzelner Branchen nachhaltig zu beeinflussen vermögen, müssen auch die nationalen Steuerpolitiken unter das Primat der Wettbewerbsneutralität gestellt werden: Es gllt zu verhindern, daß von den nationalen Steuersystemen wettbe-

12 Vgl. ausführlicher dle Darstellung in Kap.E.2.1.2. 
werbsverzerrende oder -hemmende Wirkungen auf den grenzüberschreitenden Handel ausgehen.

Was hat man sich aber unter dem schillernden Begriff der Wettbewerbsneutralitat konkret vorzustellen? Bereits hier gehen, wie kaum anders zu erwarten, die Meinungen auseinander. Die einen behaupten, Wettbewerbsneutralität sel dann gegeben, wenn die internationalen Handelsströme durch die Indirekte Besteuerung, im Vergleich zu einer Situation ohne Steuern, nicht verändert würden. ${ }^{13}$ Dieser Ansatz korrespondiert mit einem zweiten Konzept, das Wettbewerbsneutralltăt für den Fall einer geschlossenen Volkswirtschaft definlert als: unveränderte Produktions- und Konsumstrukturen relativ zu einer Situation ohne Besteuerung. Die beiden Konzepte sind ebenso populär wie unzweckmäßig:

- Wettbewerbsneutrale Verbrauchsteuern in dem hier definierten Sinne sind zwar theoretisch vorstellbar, praktisch aber niemals zu verwirklichen, da die auf elnzelne Güter zu legenden Steuersätze entsprechend den jewelligen Angebots- und NachPrageelastizitäten differenziert werden müßten, der hierfür nötige Infomationsbedarf aber nicht gedeckt werden kann.

- Es ist äußerst zweifelhaft, warum die Situation ohne Besteuerung wirtschaftspolitisch überhaupt erstrebenswert sein sollte. Die Wirtschaftssubjekte reagieren auf den durch die Besteuerung bewirkten Einkommensentzug mit einer Anpassung ihres Nachprage- und Angebotsverhaltens. Es ist nun schwierig einzusehen, was daran neutral sein soll, wenn man durch eine Differenzierung der Steuersätze diese Anpassung zu verhindern versucht.

Gerade der letzte Aspekt dient als Ausgangspunkt für eine zweite Definition, die man heute mit Recht als herrschende Lehrmeinung ansehen kann: Eine Steuer wird als neutral bezeichnet, sofern sie mit dem Konzept der allokativen Effizienz vereinbar ist. ${ }^{14}$ Eine in diesem Sinne neutrale Steuer liegt z.B. vor, wenn alle Konsumgüter mit einem einheitlichen Steuersatz belastet werden.15 Die Steuer ist effizient, da sie zwar Einkommens-, aber

13 Zu diesem Konzept u. seiner Kritik vgl. z.B. Peffekoven (1983), S.225p .

14 Vgl. z.B. Sievert (1964), S.10P. Sievert zerlegt das Konzept der allokativen Effizienz darüberhinaus in die beiden Aspekte Handels- und Produktionsoptimum; vgl. Sievert (1964), S.181. Da der theoretische Vorspann dieser Arbeit auf das für das Verständnis der nachfolgenden Kapitel unbedingt Notwendige beschränkt bleiben soll, wird die genannte Differenzlerung hier nicht welter diskutlert. Vermerkt sel lediglich, daß die von Sievert abgeleiteten Ergebnisse mit den am Ende dieses Kapitels gezogenen Schlußfolgerungen übereinstimmen. Auch sei ausdrücklich daraup hingewiesen, daß der im folgenden verwendete Begriff der Effizlenz bzw. der Neutralităt sowohl den Aspekt des Handels - als auch den des Produktionsoptimums umpaßt.

15 In diesem Zusammenhang wird von Verzerrungen abgesehen, die bel der Wahl zwischen Arbeltszeit und Freizeit auftreten können. Es sel da- 
keine Substitutionseffekte auslöst. Sowelt zur Neutralität in einer geschlossenen Volkswirtschaft. Welche Steuerformen können aber nun als neutral im Hinblick aup den grenzüberschreitenden Handel angesehen werden?

Dle Besteuerung des internationalen Handels hängt zunächst davon $a b$, ob das Exportland - das Ursprungsland - oder aber das Importland - das Bestimmungsland - ein die Grenze uberschreitendes Gut belastet. Je nachdem, welche Konstellation vorliegt, lassen slch insgesamt vier mögliche Fälle voneinander unterscheiden:16

Schaubild B-4: Besteuerung grenzüberschreitender Warenströme

\begin{tabular}{|c|c|c|c|}
\hline $\begin{array}{l}\text { Bestimmungs- } \\
\text { Ursprungs- land. } \\
\text { land. . }\end{array}$ & $\begin{array}{l}\text {.bestevert } \\
\text { Importe }\end{array}$ & $\begin{array}{l}1 \\
1 \\
1\end{array}$ & $\begin{array}{l}\text {. bestevert } \\
\text { Importe nicht }\end{array}$ \\
\hline $\begin{array}{l}\text {.bestevert } \\
\text { Exporte } \\
------- \\
\text {.bestevert } \\
\text { Exporte nicht }\end{array}$ & $\begin{array}{c}\text { Doppelbesteuerung } \\
\begin{array}{c}\text { Bestimmungslandprinzip } \\
\text { - BLP - }\end{array}\end{array}$ & $\begin{array}{l}1 \\
1 \\
1 \\
1 \\
1 \\
1\end{array}$ & $\begin{array}{l}\text { Ursprungslandprinzip } \\
\qquad \begin{array}{l}- \text { ULP - } \\
-----\end{array} \\
\text { Steuerfreiheit }\end{array}$ \\
\hline
\end{tabular}

Es ist offensichtlich, daß es sich weder bel der Doppelbesteuerung noch bel der Steuerfreiheit um eine effizlente Situation handelt. Im ersten Fall werden die Importe gegenüber elnheimischen Waren benachtelligt, im zweiten Fall bevortellt. Als neutral in Bezug aup den grenzüberschreltenden Handel können also lediglich das BLP und das ULP elngestuft werden. Und auch dlese Aussage gilt nur unter ganz bestimmten Bedingungen.

Soweit ein Kurzuberblick. Dle Frage, welche Voraussetzungen Im einzelnen erfullt sein mulssen, damit eine Verbrauchsbesteuerung die internationalen Warenströme nicht verzerrt, soll im nun folgenden Kapitel en détail analyslert werden. ${ }^{17}$ Dabel ist in einem ersten Schritt zunăchst zu zelgen, daß

rüberhinaus vermerkt, daß zwischen den beiden hler erwähnten Definitionswelsen auch durchaus Mischformen denkbar sind. So legt z.B. Whalley selner Analyse ein Modell zugrunde, daß bestimmte Einkommenseffekte als "verzerrend" definiert, wahrend andere als "neutral" hingenommen werden; vgl. Whalley (1979).

16 Die folgende Darstellung ist ubernommen von Peffekoven (1983), S.221.

17 Wir betrachten hier die Frage der Neutralitat lediglich in bezug aup die Handelsströme. Es ist durchaus möglich, daß die Erhebung indirekter Steuern neben den Guter- auch die internationalen Faktorbewegungen beelnflußt. Da jedoch der letztere Aspekt bel der Diskussion der USt-Harmonisierung in der EG kelne erwähnenswerte Rolle gespielt hat, soll im Rahmen der vorllegenden Arbelt darauf nicht eingegangen 
die eindeutig ineffizienten Situationen der Doppelbesteuerung und der Steuerfrelheit immer dann nicht auftreten können, wenn die Steuersysteme der miteinander Handel treibenden Länder bestimmten Anforderungen genügen. In diesem Fall haben wir es also alleine mit dem BLP und/oder mit dem ULP zu tun. Anschlleßend bleibt in elnem zweiten Schritt nachzuwelsen, daß die Anwendung des BLP bzw. des ULP genau dann zu neutralen Ergebnissen fürt, wenn die in den verschledenen Ländern erhobenen Steuersätze bestimmte Voraussetzungen erfüllen.

\subsubsection{Anforderungen an die Steuersysteme ${ }^{18}$}

\section{Modelle mit steuerlichem Grenzausgleich}

Dle Verwendung des BLP und/oder des ULP eröffnet, wie gerade festgestellt wurde, die Möglichkeit, den $z$ wischenstaatlichen Handel in neutraler Weise zu besteuern. Widmen wir uns zunächst dem erstgenannten Besteuerungsprinzip und Pragen uns, wie das BLP rein steuertechnisch implementiert werden kann. Dle Antwort lautet: "Es kommt daraup an". Genauer gesagt hängt es davon $a b$, welche Formen der Verbrauchsbesteuerung in den belden mitelnander Handel trelbenden Ländern angewandt werden. Am elnfachsten ist es bei einer ElnzelhandelsuSt. Da der weltaus größte Tell des internationalen Handels aup einer dem Einzelhandel vorgelagerten Stufe abgewickelt wird, gelangen die meisten Exportprodukte unversteuert an die Grenze. Im Importland wiederum durchlaufen sle auf ihrem Weg zum Konsumenten Irgendwann elnmal die Einzelhandelsstufe, wo sle automatisch der gleichen Besteuerung unterworfen werden wie Im Inland erstellte Guter.

Problematisch wird diese Regelung aber berelts dann, wenn private Reisende Im Ausland gekaufte Waren ins Heimatland importieren. Die Schwlerigkeiten nehmen welter zu, sobald dem Elnzelhandel vorgelagerte Stufen besteuert werden: Je weiter der Steuerzugriff vom Einzelhandel entfernt llegt, desto größer wird die Wahrscheinlichkeit, daß eln Gut zum Zeltpunkt seines Exportes bereits ein- oder mehrmals im Inland besteuert worden ist. Es ergibt sich daher die Notwendigkeit, Exportgüter belm Grenzübertritt durch eine Steuerrückerstattung von der inländischen Steuerlast wieder zu bepreien. Genau umgekehrt liegt der Fall im Importland, wo, nun aup der anderen Selte der Grenze, Importguter mit der Steuer nachbelastet werden müssen, die gleichartige, im Inland produzlerte Waren bereits tragen. Das hier beschriebene Verfahren - es wird gemeinhin als steuerlicher Grenz-

werden. Der interessierte Leser sel z.B. verwiesen auf Dosser (1967), S.121ff. Vgl. a. Slevert (1964), S.75ff. sowle S.89ff.

$18 \mathrm{Zu}$ den folgenden Ausfuhrung vgl. die ausfuhrlichen Analysen in Dosser (1967), Musgrave (1969), S.270fP., Peffekoven (1983), Sullivan (1967a). Eln Kurzuberblick findet sich z.B. bel Andel/Grasmann/Rehm/ Schnelder (1976), S.85pp. 
ausgleich bezeichnet - stellt sicher, daß alle die Grenze passierenden Waren entsprechend dem BLP besteuert werden. Die korrekte Anwendung des Grenzausgleiches setzt voraus, da $\beta$

- im Exportland die steuerliche Belastung der Exportwaren exakt ermittelt werden kann und daß

- Im Importland die steuerliche Belastung gleichartiger, im Inland hergestellter Güter einheltlich und der Höhe nach bekannt ist.

Nicht jedes Steuersystem läßt die Ermittlung der beiden genannten Informationen zu. Bel einphasigen Verbrauchsteuern gestalten sich die Berechnungen umso schwieriger, je Prüher der Steuerzugriff in der Produktionsund Vertellungskette erfolgt. Die in der Praxis vorherrschende GroßhandelsuSt sowle die auf der letzten Produktionsstufe erhobene USt dürften jedoch im Regelfall eine korrekte Durchführung des Grenzausgleiches zulassen. Demgegenüber sind die bei einer allphasigen Bruttoust auftretenden Probleme unüberwindlich: Die Kosten für die Berechnung der auf einem einzelnen Gut lastenden inländischen Steuer sind prohibitiv hoch. Ein steuerlicher Grenzausgleich kann daher nur über mehr oder weniger ungenaue Pauschalsätze erfolgen. Bei der allphasigen Nettoust ergibt sich ein differenziertes Bild. Keinerlei Probleme bereltet die Nettoust mit VSA: Die Steuerlast 1st bel jedem Gut und jederzeit bekannt, da sie wegen des Nachholeffektes der auf der jeweils letzten Stufe gezahlten Steuer genau entspricht. Für elne auf dem VUA- oder dem Mehrwertverfahren beruhende NettouSt gilt nur dann dasselbe, wenn für alle Umsätze eln einheitlicher Steuersatz angewandt wird. Andernfalls kann auch hier nur mit Pauschalsätzen gearbeitet werden.

Abschlleßend läßt sich sagen, daß Immer dann, wenn der steuerliche Grenzausgleich exakt durchgeführt wird, es vollkommen gleichgültig ist, ob die am internationalen Handel tellnehmenden Länder gleiche oder ganz unterschiedliche Formen der Verbrauchsbesteuerung verwenden. Der Grenzausgleich macht sämtliche Unterschiede bel den verwendeten Steuersystemen unschadlich und verhindert das Auptreten von Fällen der Doppelbesteuerung und der Steuerfrelheit.

\section{Modelle ohne steuerlichen Grenzausgleich}

Entsprechend gilt aber auch umgekehrt, daß sich beim Fehlen eines steuerlichen Grenzausgleiches die Unterschiede in den nationalen Steuersystemen automatisch verzerrend auf den Handel auswirken müssen. Will man also im Handel $z$ wischen zwel Ländern aup den Grenzausgleich verzlchten - die Kommission der EG spricht hier auch von Abschaffung der Steuergrenzen -, so ist es zur Vermeidung steuerbedingter Verzerrungen unbedingt erforderlich, die Steuersysteme elnander anzugleichen. Daß dies notwendig ist, zeigt uns das im folgenden Schaubild dargestellte Beispiel: 
Schaubild B-5: Besteuerung grenzüberschreitender Warenströme

Land A: einphasige USt auf die letzte Produktionsstufe Land B: einphasige USt auf die Großhandelsstufe

\begin{tabular}{l|ccc|}
\multicolumn{1}{c|}{$\begin{array}{c}\text { Richtung der } \\
\text { Lieferung } \\
\text { Art Lieferung }\end{array}$} & $\begin{array}{r}\text { Lieferung } \\
\text { von A nach B }\end{array}$ & $\begin{array}{r}\text { Lieferung } \\
\text { von B nach A }\end{array}$ \\
\hline $\begin{array}{l}\text { Unternehmen auf früher Produktions- } \\
\text { stufe liefert an Unternehmen auf } \\
\text { letzter Produktionsstufe }\end{array}$ & BLP & 1 & BLP \\
$\begin{array}{l}\text { Unternehmen auf letzter Produktions- } \\
\text { stufe liefert an Großhandel }\end{array}$ & $\begin{array}{c}\text { Doppel- } \\
\text { besteuerung }\end{array}$ & 1 & $\begin{array}{c}\text { Steuer- } \\
\text { freiheit }\end{array}$ \\
$\begin{array}{l}\text { Großhandel liefert an Einzelhandel } \\
\begin{array}{l}\text { Einzelhandel liefert an Letztver- } \\
\text { braucher }\end{array}\end{array}$ & ULP & 1 & ULP \\
\hline
\end{tabular}

Der steuerliche Grenzausgleich stellt sicher, daß grundsätzlich immer das BLP zur Anwendung kommt. Fehlt der Grenzausglelch, so ergibt sich in Abhängigkelt davon, auf welcher Stufe und in welcher Richtung der Handel stattfindet, ein kunterbuntes Durcheinander von verschiedenen Besteuerungsprinziplen. Dle eindeutig verzerrend wirkenden Fälle der Doppelbesteuerung und der Steuerfreihelt sind nur dann zu vermeiden, wenn, wie im folgenden Beispiel unterstellt, beide Länder zu elnem einheitlichen UStSystem ubergehen.

Schaubild B-6: Besteverung grenzüberschreitender Warenströme

Land A und Land B: einphasige USt auf die Großhandelsstufe

\begin{tabular}{|c|c|c|c|}
\hline $\begin{array}{lr}\text { Art } & \begin{array}{r}\text { Aichtung der } \\
\text { Lieferung }\end{array} \\
\end{array}$ & $\begin{array}{l}\text { Lieferung } \\
\text { von } A \text { nach } B\end{array}$ & $\begin{array}{c}1 \\
1 \\
1\end{array}$ & $\begin{array}{l}\text { Lieferung } \\
\text { von B nach } A\end{array}$ \\
\hline $\begin{array}{l}\text { Unternehmen auf früher Produktions- } \\
\text { stufe liefert an Unternehmen auf } \\
\text { letzter Produktionsstufe }\end{array}$ & BLP & $\begin{array}{l}1 \\
1\end{array}$ & BLP \\
\hline $\begin{array}{l}\text { Unternehmen auf letzter Produktions- } \\
\text { stufe liefert an Großhandel }\end{array}$ & BLP & $\begin{array}{l}1 \\
1\end{array}$ & BLP \\
\hline Großhandel liefert an Einzelhandel & ULP & $\begin{array}{l}1 \\
1\end{array}$ & ULP \\
\hline $\begin{array}{l}\text { Einzelhandel liefert an Letztver- } \\
\text { braucher }\end{array}$ & ULP & 1 & ULP \\
\hline
\end{tabular}


Für mehr- und allphasige UStn lassen sich ähnliche Situationen konstruleren. Auch hler gilt grundsätzllch, daß, sofern ein steuerlicher Grenzausgleich nicht durchgefuhrt wird, die Identität der Steuersysteme eine notwendige Bedingung fur die verzerrungsfrele Besteuerung des grenzüberschreitenden Handels darstellt. Denn nur bel der Verwendung identischer USt-Typen kann gewährleistet werden, daß dle zwel unerwünschten Fülle der Doppelbesteuerung und der Steuerfreiheit nicht auftreten. Dise Aussage soll am Belspiel einer bis auf die Einzelhandlesstufe einschlleßlich erhobenen NettoUSt mit VUA noch elnmal kurz verdeutlicht werden:

Der Verzicht auf den Grenzausgleich impliziert, daß die aup Exportprodukten lastende NettouSt des Ursprungslandes beim Grenzübertritt nicht zurúckerstattet wird. Trotzdem kommt es zu keiner Doppelbesteuerung. Denn im Bestimmungsland entsteht (wegen des VUA) nur dann und nur insoweit eine Steuerpllicht, als der Wert des Importproduktes Im Rahmen eines weiteren Produktions- und/oder Distributionsprozesses erhöht wird. Das an den Konsumenten letztendlich ausgelleferte Fertigprodukt wird also in Abhängigkelt davon, welcher Tell der gesamten Wertschöppung im Ursprungsland und welcher im Bestlmmungsland erbracht worden 1st, tells nach dem BLP und teils nach dem ULP besteuert. Nur in dem Extremfall, daß der Export/ Import-Vorgang erst bel der Lleferung des Einzelhandels an den Letztverbraucher stattfindet, kommt es zur alleinigen Anwendung des ULP.

Schaubıld B-7: Besteuerung qrenzüberschreıtender Warenströme

Land $A$ und Land B: Nettoust mit VUA

\begin{tabular}{|c|c|}
\hline $\begin{array}{lr}\begin{array}{l}\text { Richtung der } \\
\text { Lit } \\
\text { der Lieferung }\end{array} \\
\end{array}$ & \begin{tabular}{c|} 
Lieferung \\
von A nach B
\end{tabular} \\
\hline $\begin{array}{l}\text { Unternehmen auf früher Produktıons- } \\
\text { stufe liefert an Unternehmen auf } \\
\text { letzter Produktionsstufe }\end{array}$ & $\begin{array}{l}\text { tesls BLP, tesls ULP } \\
\text { (BLP überwiegt) }\end{array}$ \\
\hline $\begin{array}{l}\text { Unternehmen auf letzter Produktions- } \\
\text { stufe liefert an Großhandel }\end{array}$ & teils BLP, teils ULP \\
\hline frroßhandel liefert an Einzelhandel & $\begin{array}{l}\text { teils BLP, teils ULP } \\
\text { (ULP überwiegt) }\end{array}$ \\
\hline $\begin{array}{l}\text { Einzelhandel liefert an Letztver- } \\
\text { braucher }\end{array}$ & ULP \\
\hline
\end{tabular}

Festzuhalten bleibt, daß nur dann, wenn die USt-Systeme der einzelnen Länder gewisse Voraussetzungen erfullen, wir sicherstellen können, daß weder der Fall der Doppelbesteuerung noch der der Steuerfrelhelt auftritt. Nur dann haben wir es alleine mit dem BLP und/oder dem ULP zu tun. Das ist elne notwendige, aber noch keine hinreichende Bedingung fur die neu- 
trale Besteuerung des Internationalen Handels. Denn die Beantwortung der Frage, ob dle Anwendung des BLP bzw. des ULP letzten Endes zu einer neutralen Besteuerung des grenzüberschreitenden Handels führt, hängt ganz entscheldend von der Höhe und der Struktur der in den einzelnen Ländern erhobenen USt-Sätze ab.

\subsubsection{Anforderungen an die Steuersătze}

Nach den Steuersystemen wollen wir nun die Relevanz der Steuersätze für den internationalen Handel untersuchen. In einem ersten Schritt soll gepragt werden, inwleweit sich eln unterschiedliches Niveau der indirekten Besteuerung auf die grenzüberschreitenden Güterströme auswirkt. Aus Gründen der Vereinfachung unterstellen wir dabel zunăchst, daß in jedem Land sämtliche Güter mit einem einheltlichen Satz belastet werden. In einem zweiten Schritt soll die genannte Annahme aufgehoben und gefragt werden, ob auch eine $z$ wischen verschiedenen Gutern vorgenommene Satzdifferenzlerung den internationalen Handel beeinträchtigen kann.

\section{Das Niveau der Steuerbelastung}

Wird ein steuerlicher Grenzausgleich durchgefuhrt - und damit alleine das BLP angewandt -, so splelt ein unterschledllches steuerliches Belastungsniveau keine Rolle für den $z$ wischenstaatlichen Handel: Innerhalb eines Landes tragen sämtliche Produkte, wo auch immer sie hergestellt worden sind, eine Identische Steuerlast. Wird auf den Grenzausgleich jedoch verzichtet, so werden, wle schon oben betont, zumindest elnige Güter nach dem ULP besteuert. Das ULP gewăhrlelstet Jedoch nur dann einen verzerrungsfreien Handel, wenn die Steuersătze in allen Lănder ubereinstimmen. Die Begründung lautet dabel wie folgt: Die Kaufentscheidung eines Nachfragers ist dann frel von Verzerrungen, wenn er von elner Anzahl gleicher Produkte das zu den niedrigsten Produktionskosten erstellte erwirbt; werden die Produkte, Je nachdem, in welchem Ursprungs-Land sle hergestellt bzw. vertrieben wurden, mit unterschiedlichen Steuersătzen belastet, so replektieren die für den Nachirager relevanten Bruttopreise der Produkte nicht mehr die Höhe der Produktionskosten; der Nachfrager wird folglich zu einer den grenzuberschreitenden Handel verzerrenden Kaufentscheidung veranlaßt. ${ }^{19}$

Bislang sind wir implizit davon ausgegangen, daß, welche Steuersysteme und -sătze auch immer verwandt werden, die Wechselkurse konstant blelben. Die gemachte Annahme ist durchaus plausibel, solange ein steuerlicher Grenzausgleich durchgefuhrt wird. Unterstellen wir, daß Indirekte Steuern vollständig uberwälzt werden, so kann sich der durch die Erhebung einer USt ausgelöste Prelsniveauanstleg nicht aup die Wechselkurse auswirken, da

19 Ein Pormaler Beweis dieser Argumentationskette findet sich z.B. bei Berglas (1981), S.377fP. 
er Im grenzüberschreitenden Handel durch den ebenfalls erhöhten Grenzausgleich neutralisiert wird. Bel einem Verzicht auf den Grenzausgleich ändert sich jedoch die Lage. Gesetzt die Annahme, daß die Leistungsbilanz eines Landes zum Ausgleich tendiert, kann die USt entweder nicht überwalzt werden - Konstanz von Preisniveau und Wechselkurs - oder aber die Uberwalzung muß zwangsläupig von einer Abwertung der nationalen Währung begleitet werden - steigendes Preisniveau und sinkender Wechselkurs -. Ausgehend von dem grundlegenden Zusammenhang zwischen Preisniveau und Wechselkurs macht das sogenannte Wechselkursargument geltend, daß selbst bel Fortfall des steuerlichen Grenzausgleichs eine Ident1tät der Steuersätze nicht erforderlich 1st, da steuersatzbedingte Preisniveauunterschiede $z$ wischen den miteinander konkurrierenden Ländern durch Wechselkursanpassungen kompensiert werden. Dle Wechselkursanpassung ersetze also, soweit es um den Ausgleich verschiedener Belastungsniveaus geht, den steuerlichen Grenzausgleich.

So uberzeugend das Wechselkursargument klingt, so restriktiv sind die implizit unterstellten Annahmen:

1. Die Annahme, daß dle Lelstungsbilanz uber den Preisniveau- und/oder den Wechselkursmechanismus ausgeglichen wird, dürfte zumindest in der langfristigen Perspektive gerechtfertigt sein. Problematischer ist bereits die Nichtberücksichtigung der zwischen Leistungs- und Kapitalbilanz bestehenden Wechselwirkungen. Aber in Ubereinstimmung mit dem ubberwiegenden Teil der Außenwirtschaftsliteratur kann auch diese Voraussetzung noch als akzeptabel erscheinen.

2. Das Wechselkursargument gilt weiterhin nur, wenn sämtliche End- und Vorprodukte mit einem einheltlichen Steuersatz belastet werden. Die genannte Einschränkung dürfte unmittelbar einleuchten: Der Wechselkurs kann lediglich $\mathrm{zwischen} \mathrm{zwel}$ Lăndern bestehende globale Steuerlastunterschlede - In der EG-Terminologie auch als generelle Wettbewerbsverzerrungen bezeichnet -, nicht aber bel einzelnen Produkten ganz unterschiedliche Satzdifferenzen - spezielle Wettbewerbsverzerrungen - ausgleichen.20 Einphasige Verbrauchsteuern erfüllen die Bedingung eines einheltlichen Steuersatzes nie, da lediglich Produkte der Stufe, auf der der Steuerzugriff erfolgt, mit dem vollen (nominalen) steuersatz belastet sind. Demgegenüber tragen Produkte nachgelagerter Stufen einen geringeren (effektiven) Steuersatz dle zusätzliche Wertschöpfung bleibt steuerfrel -, während Güter vorgelagerter Stufen uberhaupt nicht der Besteuerung unterliegen. Das Wechselkurargument ist daher auf einphasige Abgaben nicht anwendbar. Diese

20 Vgl. z.B. Slevert (1964), S.79ff. Am Rande sei vermerkt, daß auch durchaus elnzelne Steuersatzdifferenzierungen denkbar sind, die die Gultigkeit des Wechselkursargumentes nicht in Frage stellen; hierzu müssen die verwandten Sătze jedoch in elnem ganz bestimmten Verhältnis zueinander stehen; vgl. z.B. Metze (1969), S.145ff.; vgl. a. Fratianni/Christi (1981). 
Tatsache wird in der einschlägigen Literatur ${ }^{21}$ meist übersehen, da i.d.R. mit Modellen gearbeitet wird, in denen es zwar Endprodukte, aber kelne Vorprodukte gibt. Lediglich bei allphasigen Nettoumsatzsteuern fuhrt ein einheitlich erhobener Steuersatz zu einer identischen Belastung von Vorund Endprodukten.

3. Das Wechselkursargument erfordert drittens, daß ein Land gegenüber allen Handelspartnern gleichzeitig auf die Anwendung des steuerlichen Grenzausgleichs verzichtet. Soll der Grenzausgleich demgegenüber nur im Handel zwischen einer begrenzten Anzahl von Ländern abgeschapft werden, während er im Warenaustausch mit Drittländern beibehalten wird, so wird die Anderung des Wechselkurses nicht ausreichen, um die steuersatzbedingten Verzerrungen vollständig zu kompensieren. Darüberhinaus führt elne Anderung des ursprünglichen Wechselkurses in jedem Fall zu Verzerrungen im Handel mit der Außenwelt. Der Kommission der EG schwebt eine nur partielle Beseitigung des derzeit noch üblichen Grenzausgleiches vor: $A b-$ schaffung im intra-Gemeinschaftshandel, Aufrechterhaltung im Drittlandsverkehr. ${ }^{22}$ Das Wechselkursargument kann daher bei der Harmonisierung der indirekten Steuern in der EG nicht zum Zuge kommen.

\section{Dle Differenzlerung der Steuersätze}

Bisher haben wir lediglich diskutiert, inwieweit sich Unterschiede beim globalen Belastungsniveau der indirekten Steuern verzerrend auf den internationalen Handel auswirken können. Jetzt soll noch zusätzlich untersucht werden, ob auch von elner Differenzierung der Steuersätze Innerhalb der einzelnen Länder der grenzüberschreitende Warenverkehr in Mitleidenschaft gezogen werden kann. Betrachten wir zunächst ein Modell mit steuerlichem Grenzausglelch, d.h. mit lückenloser Anwendung des BLP. Gewöhnlich wird hier davon ausgegangen, daß von Land zu Land unterschiedliche Steuersätze über den Grenzausgleich neutralisiert werden und damit unschädlich sind. Das ist, wie wir oben gesehen haben, richtig, sofern es um globale Belastungsunterschiede geht. Es ist aber, wie an dem folgenden Beispiel deutlich werden soll, falsch, wenn einzelne Lănder die Steuersătze je nach Gütergruppe differenzieren:

Nehmen wir an, ein Land belaste ein im Inland nicht hergestelltes bzw. zu 100\% importiertes Produkt wesentlich höher als ein anderes, demselben Verwendungszweck dienendes Substitutionsgut, das aber überwiegend oder nur im Inland produzlert wird. Das BLP schreibt lediglich die steuerliche Gleichbehandlung solcher Güter vor, die gleich oder zumindest gleichartig sind. Handelt es sich bei dem Importgut win rote und bel der inländischen

21 Vgl. z.B. Peffekoven (1983).

22 Shibata hat hierfür den Begriff "restricted origin principle" geprägt; vgl. Shibata (1967), S.193. 
Ware um blaue Autos, so ist die Sachlage elnfach. Da eine gewisse Gleichartigkeit zwelfelsohne gegeben ist, bedeutet die Höherbesteuerung der Importware eine Verletzung des BLP. Was ist aber, wenn belsplelsweise ein nordeuropäisches Land Wein importiert, den es aus klimatischen Gründen im Inland gar nicht herstellen kann? Mangels eines gleichartigen Inlandsproduktes engt das BLP alleine die Wahl des auf (importierten) Wein zu erhebenden Steuersatzes noch nicht ein. Wird nun der Wein wesentlich höher belastet als die nächsten Substitutionsprodukte wie Bler und Spirituosen, so ist zu erwarten, daß die inländischen Brauerelen und Brennereien davon entsprechend profitieren. Die Satzdifferenz zwischen dem höher besteuerten Importgut und den nledriger belasteten, inländisch erstellten Gütern wirkt also letztendlich wie ein Importzoll gleicher Höhe.

Welchen Lösungsvorschlag kann nun ein Okonom anbieten? Will er den Begriff der Wettbewerbsneutralität sauber und streng auslegen, so muß er konsequenterweise das Verbot jeglicher steuersatzdifferenzlerung fordern. Dle Begründung lautet dabei: Alle Güter konkurrieren letztendlich um die gleiche Kaufkraft; Satzdlfferenzlerungen führen folglich zu Verzerrungen bel Produktion und Konsum, die sich unweigerlich auch aup den $z$ wischenstaatlichen Handel auswirken; differenzlerte Sătze können daher protektionistische Wirkungen entfalten oder gar, was für eine Zollunion polltisch noch schwerwlegender wäre, protektionistisch motiviert sein.

Die für eln Modell mit steuerlichem Grenzausgleich fur eine Zollunion abgeleiteten Aussagen gelten in ännlicher Form auch für eine Situation ohne Grenzausgleich. Dies dürte unmittelbar klar werden, wenn man bedenkt, daß auch bel Abwesenhelt elnes Grenzausglelches ein beträchtllcher Tell des $z$ wischenstaatlichen Handels nach dem BLP besteuert wird. Wahrend die von einer Politik der Satzdifferenzierung ausgehenden ökonomischen Effekte einander vergleichbar sind, dürften die politischen Gefahren bel einem Modell ohne Grenzausgleich geringer einzuschätzen sein: Wird auf einen Grenzausgleich verzichtet, so müssen die Steuersätze, ob sie einheitlich oder differenziert sind, in allen Länder miteinander übereinstimmen oder zumindest sehr nahe beleinanderliegen; die in den einzelnen Ländern erhobenen Sătze sind damit Ergebnisse eines gemeinsamen, politischen Verhandlungsprozesses, der es unwahrscheinllch machen dürfte, daß eine Polltik der Satzdifferenzierung die Produkte des einen oder des anderen Landes über Gebuhr benachtelligt. 


\section{Zusammenfassung}

Bevor wir das Kapitel uber die theoretischen Grundlagen der USt-Harmonisierung abschließen, soll Im folgenden Tableau nochmals ein uberbllck über die Eignung unterschiedlicher Formen der Verbrauchsbesteuerung für eine Zollunion gegeben werden.

Schaubild B-8: Besteuerung grenzüberschreitender Warenströme - ein Überblick

\begin{tabular}{|c|c|c|}
\hline & $\begin{array}{c}\text { Mcdelle mit } \\
\text { steuerlichem Grenzausgleich }\end{array}$ & $\begin{array}{l}\text { Modelle ohne } \\
\text { steverlichen Grenzausgliech }\end{array}$ \\
\hline $\begin{array}{l}\text { zur Anwendung } \\
\text { kommendes } \\
\text { Besteuerungsprinzıp }\end{array}$ & BLP & $\begin{array}{l}\text { I teils BLP, teils ULP } \\
\text { sofern die Steuersysteme unter- } \\
\text { I schiedlich sind, auch Steuerfrei- } \\
\text { heit U. Doppelbesteverng möglich }\end{array}$ \\
\hline 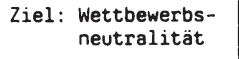 & & $\begin{array}{l}1 \\
1\end{array}$ \\
\hline $\begin{array}{l}\text { a. Anforderungen an } \\
\text { das Steversystem }\end{array}$ & $\begin{array}{l}\text { Steuersystem können unter- } \\
\text { schiedlich sein, müssen } \\
\text { aber die exakte Ermittlung } \\
\text { des Grenzausgleichs zu- } \\
\text { lassen. }\end{array}$ & $\begin{array}{l}\text { Steuersysteme müssen identisch } \\
\text { sein, Art des verwendeten Steuer- } \\
\text { l systems ist jedoch gleichgültig } \\
1 \\
1 \\
1\end{array}$ \\
\hline $\begin{array}{l}\text { die Steuersätze } \\
\text { - Höhe der Sätze }\end{array}$ & $\begin{array}{l}\text { Höhe der Steuersätze ist } \\
\text { gleichgültig }\end{array}$ & $\begin{array}{l}\text { Höhe der Steuersätze muß in allen } \\
\text { Ländern identisch sein, Ausn.: bei } \\
\text { I EinzelhandelsUSt U. NettouSt sind } \\
\text { | kleinere Abweichungen möglich }\end{array}$ \\
\hline $\begin{array}{l}\text { - Differenzierung } \\
\text { der Sätze }\end{array}$ & $\begin{array}{l}\text { Satzdifferenzierung kann } \\
\text { zu Verzerrungen im inter- } \\
\text { nationalen Handel führen }\end{array}$ & $\begin{array}{l}\text { I Satzdifferenzierung kann zu } \\
\text { | Verzerrungen im internationalen } \\
\text { | Handel führen }\end{array}$ \\
\hline
\end{tabular}




\section{Historlsche Entwicklung}

Nach der Erörterung der theoretischen Grundlagen der USt-Harmonisierung sollen nun die wichtigsten geschichtlichen Entwicklungslinien nachgezeichnet werden, durch die bereits vor Gründung der EWG im Jahre 1958 entscheidende Weichen für die spätere Harmonisierungsdiskussion gestellt wurden.

In den zwei ersten Abschnitten wird zunächst auf die steuerpolitischen Auseinandersetzungen in der Benelux- und der Montan-Union eingegangen. In beiden Fällen handelte es sich bei den Unionsstaaten um Mitgliedstaaten der späteren EG der Sechs. Beide Male ist es, mit weitreichenden Folgen für die EG, nicht gelungen, die einzelnen Staaten durch gemeinsam erlassene Regeln steuerpolitisch zu binden.

Ein dritter Abschnitt ist den Uberlegungen und Interessen gewidmet, die während der Verhandlungen zum EWG-Vertrag zur Einbeziehung steuerlicher Vorschriften in das Vertragswerk gefuhrt haben. Dabei soll insbesondere herausgearbeitet werden, aus welchen Gründen die die Mitgliedstaaten unmittelbar bindenden Art.95-97 nur unzulänglich formuliert worden sind. Denn nichts hat die in Art.99 vorgesehene Harmonisierung der indirekten Steuern in der späteren EG mehr vorangetrieben als die eingebauten Unzulänglichkeiten der Art.95-97.

\subsection{Enttäuschung in der Benelux-Union}

\section{Der Vorschlag zu einer USt-Harmonisierung}

Der auch heute noch - unabhängig von der EG - stattfindende Proze $\beta$ der ökonomischen Integration im Benelux-Raum wurde eingeleitet durch den Vertrag über eine Wirtschaftsunion zwischen Belgien und Luxemburg aus dem Jahre 1921. Obwohl belde Staaten damals bereits eine allgemeine USt eingeführt hatten, wurde in dem Vertrag darauf mit kelnem Wort eingegangen. Es mußte daher nachträglich versucht werden, die gravlerendsten der sich aus den unterschiedlichen Steuersystemen ergebenden Probleme durch verschiedene ad hoc-Vereinbarungen abzumildern. Eine über das unbedingt notwendige Maß hinausgehende USt-Harmonisierung wurde dagegen in der Belgisch-Luxemburgischen Wirtschaftsunion nicht ins Auge gefaßt: Dle 
Steuerquoten wie auch die relative Bedeutung von indirekten und direkten Abgaben waren in den beiden Ländern zu unterschiedlich. ${ }^{1}$

Noch während der Zweite Weltkrieg andauerte, verhandelten die Exilregierungen der drei späteren Benelux-Staaten über eine engere ökonomische wie politische Kooperation zwischen ihren Ländern. Der daraufhin 1944 geschlossene Vertrag von London sah nicht nur die Gründung einer Zollunion vor, sondern brachte bereits den wunsch der beteiligten Staaten zum Ausdruck, nach den Zoll- auch auf die Steuergrenzen - d.h. auf den steuerlichen Grenzausgleich - zu verzichten. Es war offensichtlich, daß zur Beseitigung des Grenzausgleiches die Struktur und die Sätze der Akzisen einander angeglichen werden mußten. Eine entsprechende Bestimmung wurde daher im Vertrag von London aufgenommen. Keinerlei Erwähnung fanden demgegenüber die für die Abschaffung der Steuergrenzen viel bedeutsamere USt $^{2}$, was darauf zurückzupühren war, daß die vertragschlleßenden Parteien damals noch gar nicht wissen konnten, ob überhaupt und gegebenenfalls wie der umsatzsteuerliche Grenzausgleich abgeschafft werden konnte. Während bel den Akzisen die im politischen Raum einfach zu verstehende Lösung der Satzangleichung auf der Hand lag, war bei der USt die Arbeit von Fachleuten gefragt.

In 1946 begann eine Gruppe von Finanzexperten mit entsprechenden Untersuchungen, die 1949 mit dem Vorschlag abgeschlossen wurden, die Steuergrenzen unter Beibehaltung der in den drei Benelux-Staaten erhobenen Bruttoust abzuschaffen. Der Entwurf beinhaltete die folgenden, wesentlichen Elemente: ${ }^{3}$

- Vereinheitlichung der Steuersätze;

- Abschaffung des steuerlichen Grenzausgleichs im intra-Unions-Handel: steuerliche Behandlung wie bei inländischen GeschäPten, d.h. keine Belastung (bzw. Entlastung) von Importen (Exporten) aus (in) Staaten der Benelux-Union;

- Beibehaltung des steuerlichen Grenzausgleiches gegenüber Drittländern: möglichst vollständiger Ausgleich der inländischen Steuerlast an den Außengrenzen der Union.

Die Gründe für das Scheitern des Vorschlags

Der Vorschlag der Expertenkommission war von dem Bemühen gekennzeichnet, das Ziel Abschaffung des Grenzausgleiches mit einem minimalen Anpassungsbedarf der nationalen Steuersysteme zu erreichen. Aus diesem Blickwinkel gesehen kann er als durchaus gelungen bezeichnet werden.

1 Vgl. Meade/Liesner/Wells (1962), S.32f. Vgl. a. Scallteur (1974), S.475pr.

2 Vgl. Scailteur (1974), S.4761.

3 Vgl. Meade/Liesner/Wells (1962), S.92ff. Vgl. a. Scailteur (1974), S. 4771 . 
Aber trotzdem wurde der budgetäre Anpassungsbedarf von den Regierungen als immer noch $\mathrm{zu}$ hoch angesehen. Insbesondere Belgien verweigerte seine Zustimmung zu der Satzangleichung, die mit der Herabsetzung des auf Großhandelsumsätze gelegten Steuersatzes erhebliche und anderweitig nicht kompensierbare Einnahmenausfälle mit sich gebracht hätte. ${ }^{4}$

Tabelle B-1

USt-Sätze in den Benelux-Staaten (1949) in \%

\begin{tabular}{|c|c|c|c|c|c|c|}
\hline & Niederlande & $!$ & Belgien & i & Luxemburg & Experten-Vorschlag \\
\hline Produzentenumsätze & 3 & 1 & 4,5 & 1 & 2 & $\begin{array}{l}T \\
1\end{array}$ \\
\hline Großhandelsumsätze & 0,5 & $\begin{array}{l}1 \\
1\end{array}$ & 4,5 & $\begin{array}{l}1 \\
1\end{array}$ & 0,5 & 0,5 \\
\hline Einzelhandelsumsätze & 3 & 1 & - & $\begin{array}{l}1 \\
1\end{array}$ & 2 & 1 \\
\hline
\end{tabular}

Quelle: Meade/Liesner/Wells (1962), S.93.

Aber auch wenn sich die budgetären Probleme nicht gestellt hätten, wäre der Vorschlag in der ursprünglichen Form mit Sicherheit nicht angenommen worden. Die Ursache hierfür liegt in einem zunächst weniger sichtbaren Problem begründet, dem aber, immer wenn der Grenzausgleich irgendwo abgeschapft werden soll, entscheidende Bedeutung zukommt. Es geht um die Vertellung der Steuereinnahmen zwischen den Unions-Staaten. Im Falle einer Verwirklichung des $1949 \mathrm{er}$ Vorschlages hätte sich, bedingt durch die Wirtschaftsstruktur der Benelux-Staaten, automatisch eine Umverteilung des USt-Aufkommens zulasten von Luxemburg ergeben:`3 Luxemburg importierte viele Rohstoffe und Halbfertigprodukte aus Belgien, um sie nach einer Weiterverarbeltung in Drittländern abzusetzen; entsprechend dem Harmonisierungsvorschlag der Experten hatte der belgische Fiskus die USt für die nach Luxemburg gelieferten Produkte vereinnahmt, wăhrend Luxemburg sie beim Export der Fertigprodukte hătte zurückerstatten müssen. Die USt-Harmonisierung hätte daher, um für Luxemburg annehmbar zu sein, Bestimmungen uber die Redistribution der Steuereinnahmen zwischen den nationalen Fiscl enthalten müssen. Daß dies keln einfaches Unterfangen ist, wird an späterer Stelle noch desø̈teren deutlich werden.

\section{Die Folgen des Scheiterns}

Es bleibt Pestzuhalten, daß die Benelux-Staaten nicht in der Lage waren, sich frühzeltig aup elne auch nur partielle Harmonisierung ihrer USt-Systeme $z u$ verständigen. Dles $z o g$ eine für die weitere Harmonislerungsdebatte Im Benelux-Raum als auch in der späteren EG wichtige Konsequenz nach sich: Nachdem zum 1.Januar 1948 Innerhalb der Benelux-Union alle Zollgrenzen gefallen waren, fuhlten slch die einzelnen Regierungen unter

$4 \quad$ Vgl. Scallteur (1974), S.478.

- Vgl. Meade/Liesner/Wells (1962), S.97. 
Druck, vermehrt die Steuergrenzen als Mittel zum Schutz nationaler Industrien einzusetzen. Mangels gemeinschaftlich fixierter Verhaltensnormen konnte dleser Druck auch schon bald erste Ergebnisse zeigen. Deutlich zu sehen war das bel der auf Importe erhobenen USt. Noch nach dem Zweiten Weltkrieg besteuerten alle drel Staaten Importe mit dem Standardsatz ihrer Jewelligen BruttoUSt. Die Niederländer waren 1952 die ersten, die eine bis zu dreiprozentige Zusatzsteuer für Importwaren einfuhrten. Die Belgier zogen schon 1953 mit einer ähnlichen Maßnahme nach. Lediglich die Luxemburger hielten sich, nicht zuletzt wegen ihres sehr niedrigen Steuersatzes von nur 2\%, zurück. Bel der steuerlichen Entlastung der Exporte zeigte sich ein ganz ähnliches Blld. Auch hier übten die Luxemburger Zurückhaltung und befreiten die Exporte lediglich von der USt-Pflicht. Die Niederländer bemühten sich demgegenüber, die auf Exportprodukten lastende USt möglichst weitgehend zurückzuerstatten. Die Belgier schließlich versuchten, einen vergleichbaren Entlastungseffekt zu erreichen, indem sie neben den Exporten auch solche Güter von der USt befreiten, die für die Produktion von Exportprodukten verwandt wurden - sogenannte indirekte Exporte.

Im Laufe der Jahre schaukelten sich Niederländer und Belgier gegenseitig hoch. Da die Eigendynamik der politischen Systeme durch keine aup Benelux-Ebene verabschiedete Verhaltensregel gebremst wurde, năherte sich der steuerliche Grenzausgleich zusehends der effektiven, inländischen USt-Belastung der Produkte. Der 1949er Expertenvorschlag wurde damit nach und nach von der Realität überholt. Statt, wle ursprünglich angeregt worden war, die Steuergrenzen im Handel zwischen den Unions-Staaten abzubauen, wurden immer höhere Grenzausgleichssätze praktizlert. Der Vertrag zu einer Benelux-Wirtschaftsunion vom 3.Februar 1958 zog schließlich die Konsequenz aus dieser Entwicklung: Zwar wird noch grundsätzlich an dem Ziel der Beseitigung des Grenzausgleiches Pestgehalten; von dem wie und dem Wann ist jedoch nicht die Rede, und die USt-Harmonisierung wird namentlich erst überhaupt nlcht erwähnt. ${ }^{6}$

Die wichtigsten Ergebnisse des vorliegenden Abschnittes lassen sich mit der folgenden Darstellung kurz rekapitulieren:

- Vgl. Scallteur (1974), S.478pP. 
Schaubild B-9: Der umsatzsteuerliche Grenzausgleich in der Benelux-Union

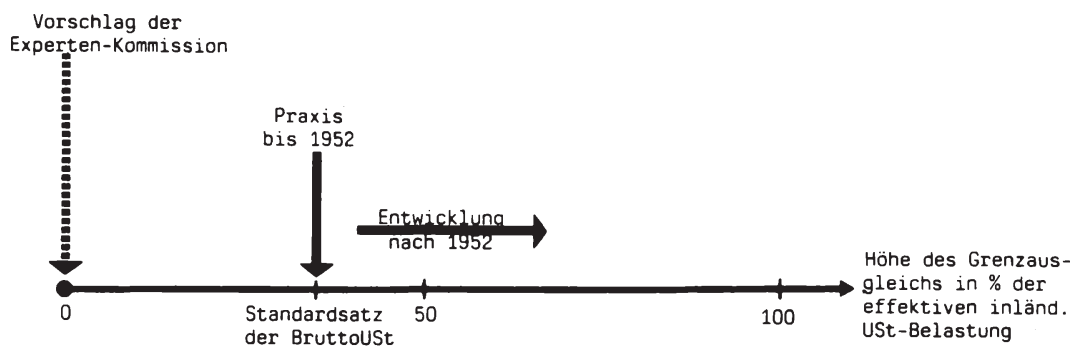

\subsection{Streit in der Montan-Union}

Wie der Benelux-Union, so bereitete auch der Montan-Union die USt-Problematik elniges Kopfzerbrechen. Man war auch hier nicht in der Lage, durch gemeinsam beschlossene Regeln die Freiheit der elnzelnen Mitgliedstaaten im USt-Bereich einzugrenzen. In beiden Fällen hatte die Unfähigkeit zur Einigung weitreichende und in die gleiche Richtung weisende Konsequenzen für die spätere USt-Harmonisierung in der EG: Die nationalen Regierungen wurden bei ihrem Wettlauf um Erhöhungen des steuerlichen Grenzausgleiches nicht gebremst. Die Ursachen für die Pehlgeschlagenen Einigungsbemühungen waren jedoch voneinander verschleden. Waren in der Benelux-Union im wesentlichen budgetäre Gründe ausschlaggebend, so sind in der Montan-Union, wie nachfolgend zu zeigen sein wird, die beiden folgenden Ursachen für die ausgebliebene Steuerharmonisierung verantwortlich zu machen:

- die Beschränkung der Montan-Union aup die Integration nur einiger weniger Branchen - sogenannte Teilintegration;

- die Beschränkung der Hohen Behörde der Montan-Union auf die ökonomischen Aspekte der USt-Problematik; die ebenfalls bedeutsamen politischen und juristischen Gesichtspunkte wurden in der Problemanalyse vollkommen übersehen bzw. als vernachlässigbar erachtet.

Soweit die grundsätzlichen Thesen dieses Abschnitts. Was ist aber nun im sogenannten Steuerstreit der Montan-Union im Einzelnen überhaupt vorgePallen?

$7 \mathrm{Zu}$ der Polgenden Darstellung vgl. insbes. Albers (1953); Meade/ Liesner/Wells (1962), S.310ff.; Regul (1955); Regul (1965), S.296ff; Regul/Renner (1966), S.85ff.; Schmölders (1953b). 
Die Ursachen des Steuerstreits

Am 18.April 1951 schlossen die Staaten, dle sich auch später in der EWG zusammenfanden, den Vertrag zur Gründung einer Europäischen Gemeinschaft für Kohle und Stahl - kurz EGKS genannt. Zu diesem Zeitpunkt fehlte offensichtlich noch eine klare Vorstellung davon, welche Probleme ein Gemeinsamer Markt aufwerfen könnte: "..der Vertrag muß weitgehend als ein Politikum angesehen werden, dessen wirtschaftliche Auswirkungen in vollem Umfang erst nachträgllch erkennbar werden."

Es ließ denn auch nicht lange auf sich warten, bis sich die erste, schwerwiegende Lücke im Vertragswerk zeigte. Noch vor der für den 1.Mal 1953 vorgesehenen Eröffnung des gemeinsamen Eisen- und Stahlmarktes glaubte die deutsche Wirtschaftsvereinigung Eisen- und Stahlindustrie herausgefunden zu haben, daß die deutsche Industrie durch den damals von Frankreich praktizlerten hohen umsatzsteuerlichen Grenzausgleich im Wettbewerb diskriminiert würde. Der damalige Geschäftsführer des Verbandes war "wie besessen von dieser Idee"9. Er machte sich daher daran, die im Bonner Wirtschafts - und Finanzministerium zuständigen Beamten mit "Engelszungen"10 Pür sein Anliegen zu erwärmen. Die Verwaltungsfachleute, sie waren meist Juristen, verstanden die Argumentation der Stahlindustrie zwar nicht in allen Details, hielten die Sache jedoch für plausibel: ein französischer Grenzausgleich von ca.19\% abzüglich eines deutschen Grenzausgleichs von ca.4\% ergibt eine Benachteiligung der deutschen Industrie gegenüber der Pranzösischen von ca.15\%. Da 15\% keine Kleinigkeit sind, relchte man das Problem an die Hohe Behörde nach Luxemburg weiter, die es auf die Tagesordnung einer Ministerratsitzung setzte. Dort kam es dann prompt zum "großen Knall"11: Der Steuerstreit zwischen den beiden Hauptkontrahenten Deutschland und Frankreich war angezettelt.

Da der Vertrag zu dem von Deutschland aufgeworfenen Problem nichts sagte und auch die elligst begonnenen Verhandlungen zwischen den Regierungen zu keinem Ergebnis Pührten, betraute die Hohe Behörde mit Beschluß vom 5.Mărz 1953 einen Sachverständigenausschuß mit der Klärung des Problems. Die vier Wissenschaftler - Vertreter von Deutschland und Frankreich waren bewußt nicht in den Ausschuß berufen worden - tagten unter Vorsitz des Niederländers Tínbergen von Mitte März bis Anfang April "nahezu in Permanenz"12 und konnten bereits zum 8.April thren "Bericht über die durch

\footnotetext{
B Albers (1953), S.162f.

9 Persönliches Interview.

10 Persönliches Interview.

11 Persönliches Interview.

12 Schmölders (1953b), S.94.
} 
die Umsatzsteuer aufgeworfenen Probleme auf dem Gemeinsamen Markt"13 vorlegen.

\section{Dle ausgetguschten Argumente}

Der Standpunkt der beiden Parteien stellte sich wie folgt dar. Die Deutschen waren der Auffassung, daß nur ein Verzicht auf jeglichen steuerllchen Grenzausglelch ${ }^{14}$ Wettbewerbsverzerrungen verhindern könne. Dle deutsche Stahlindustrie fühlte sich durch den französischen Grenzausgleich gleich zwelfach diskriminlert: Zum einen waren die indirekten Steuern in Deutschland wesentlich niedriger als in Frankreich mit seinem traditionellen Ubergewicht bel der Verbrauchbesteuerung; zum anderen glichen die Franzosen die im Inland erhobenen indirekten Steuern fast vollständig an der Grenze aus, wăhrend sich der deutsche Grenzausgleich auf nur knapp die Hulfte der effektiven, durchschnittlichen USt-Belastung erstreckte. Dle Rechnung war damit einfach und ergab, wie oben schon gezeigt, eine Benachteiligung der deutschen Industrle in Höhe von ca.15\%. Dle Franzosen behaupteten demgegenuber, alleine die korrekte Durchfuhrung eines Grenzausglelches bönne Wettbewerbsverzerrungen ausschlleßen. Dabei argumentierten sie wie polgt:

- Die Höhe der direkten Steuern beeinflußt die Wettbewerbsbedingungen nicht, da direkte Abgaben nicht überwälzt werden könnes: und damit die Preise unverändert bleiben.

- Dagegen werden indirekte Steuern uberwälzt, sie verändern die Preise und verursachen daher Verzerrungen; Indirekte Abgaben erfordern folglich elnen Grenzausgleich, um alle durch unterschiedliche Steuersätze bedingten Preisdifferenzen zwischen zwel Ländern zu neutralisieren.

Die Argumente der beiden Seiten klangen überzeugend, waren jedoch Palsch. Man kann den beteillgten Ländern bei dem Stand des damaligen Wissens sicherlich nicht unterstellen, bewußt falsche Argumente produziert $\mathrm{zu}$ haben. Aber es war auch alles andere als ein Zufall, daß die jewells aupgestellten Behauptungen sich in völligem Einklang mit den dahinterliegenden wirtschaftlichen Interessen befanden. Der Tinbergen-Bericht und die sich daran anschlleßende Diskussion entlarvte dle deutsch-französische Kontroverse als eln Scheingefecht. Sobald man flexible Wechselkurse - oder alternativ ein variables Preisniveau - zuläst, wird deutlich, daß, eine einheitliche Belastung in den Jeweiligen Ländern vorausgesetzt, sowohl die vollständige Anwendung als auch der völlige Verzicht auf den Grenzausgleich zu wettbewerbsneutralen Situationen führen, die sich alleine in der

13 Zltiert im Polgenden als Tinbergen-Bericht (1953).

14 Die Abschaffung des Grenzausgleiches setzte man damals meist mit dem Ubbergang zum ULP gleich. Dlese Gleichsetzung ist Jedoch, wle die Ausführungen in Kap.B.1.3. haben deutlich werden lassen, nicht in jedem Fall korrekt. Sie soll daher hier nicht verwandt werden. 
Höhe des gleichgewlchtigen Wechselkurses - oder alternativ des inländischen Preisniveaus - voneinander unterscheiden.

Trotzdem konnte der Tinbergen-Bericht, und das war eine für die weitere Entwicklung sehr wichtige Entscheldung, für die Montanindustrie weder die korrekte Anwendung noch den Verzicht auf den steuerlichen Grenzausgleich empfehlen. Der Grund für dieses vollkommen sachgerechte Urtell lag darin, daß der EGKS-Vertrag lediglich eine wirtschaftliche Teilintegration vorsah.15 Die beiden oben genannten Systeme sind jedoch nur dann neutral, wenn sie für alle Güter gleichermaßen angewandt werden. Frankreich erPüllte diese Bedingung bereits insofern, als bel allen Gütern der Grenzausgleich fast vollständig durchgeführt wurde: Frankreich erhob damals die rudimentäre Form einer NettouSt; der Grenzausgleich erfolgte 1.d.R. in Höhe des nominalen Steuersatzes. In Deutschland jedoch, und ähnliches galt auch für die anderen Mitgliedstaaten der EGKS, erstreckte sich der Grenzausgleich auf durchschnittlich nur knapp die Hälfte der inländischen, effektíven USt-Belastung: Die Deutschen erhoben elne allphasige Bruttoust; der Grenzausgleich war 1.d.R. auf den Standardsatz der USt begrenzt und lag damit erheblich unter der effektiven Belastung. Der Tinbergen-Ausschuß betrachtete die deutsche Regelung zwar nicht als das Optimum, aber zumindest war der Grenzausgleich bel allen Gütern in etwa gleich unvollständig, sodaß der Wechselkurs-Mechanismus die zwischen Deutschland und Frankreich bestehende Preisniveaudifferenz ausgleichen und damit eine annahernd wettbewerbsneutrale situation herbeifuhren konnte. Demgegenüber hätte eine isolierte Regelung alleine im Montanbereich eindeutig zu Verzerrungen geführt:

- Dle Einfuhrung eines vollständigen Grenzausgleiches im Montanbereich hătte, bel ungefăhr gleichbleibenden Wechselkursen, der deutschen Montanindustrie einen eindeutigen Wettbewerbsvortell gegenuber der Pranzösischen Konkurrenz verschafft.

- Der Verzicht aup den Grenzausgleich allelne im Montanbereich wäre für die Deutschen noch attraktiver gewesen, hătte er ihnen doch einen relativen Vortell gegenüber den Franzosen von stolzen 15\% beschert.

\section{Die Bellegung des Steuerstrelts}

Nach "tage- und nächtelangen Verhandlungen"16 mit den beteiligten Gruppen sprach die Hohe Behörde kurz vor Eröpfnung des gemeinsamen Eisenund Stahlmarktes aup der Basis des Tinbergen-Berichtes die Emplehlung aus, bis auf weiteres alles beim Alten zu lassen. Der Hohen Behörde schien damals keine andere Wahl $z u$ bleiben. Eine isollerte Anderung alleine im Montanberelch konnte es nicht geben. Den Ubergang zu elnem vollständigen Grenzausgleich bel allen Gütern wollte niemand. Und eln Verzicht auf den Grenzausgleich bel allen Gütern wäre wegen Frankreich politisch absolut

15 Vgl. z.B. Schmölders (1962), S.14f.

16 Schmölders (1953b), S.102f. 
unmöglich gewesen, da er einen ca.15prozentigen Abwertungsdruck auf den Pranzösischen Franc ausgelöst hätte, der 1953 bereits, aus rein politischen Gründen, um ca.25-33\% überbewertet war. ${ }^{17}$ Ein deutsches Beharren aup der Abschaffung jeglichen Grenzausgleiches hätte die EGKS daher politisch einfach überfordert: "Wahrscheinlich wäre dies der beste Weg, um die Idee der wirtschaftlichen Integration von vorneherein $\mathrm{zu}$ diskreditieren"18 - so der Kommentar eines damaligen Beobachters.

Wie reagierten aber nun die einzelnen Länder aup die Entscheidung der Hohen Behörde? Die Franzosen waren äußerst zufrieden, da die Entscheidung für sie nicht besser hätte ausfallen können. Die Benelux-Staaten hatten ohnehin schon mit der französischen Auffassung sympathisiert, was wohl auf ihre einschlägige Erfahrung mit der Benelux-Union zurückzuführen war. Alleine dle Deutschen waren verärgert, hätte die Entscheidung doch für sle nicht schlechter ausfallen können.19 Um den deutschen Unmut zu kanalisieren, willigten die Anderen in die Gründung einer aus Experten der nationalen Finanzministerien zusammengesetzten Arbeitsgruppe ein, die sich weiter mit den vom Tinbergen-Bericht aufgeworfenen Problemen beschäftigen sollte. Der nach seinem Vorsitzenden benannte Coppé-Ausschuß kam im Juni 1955 mit der einstimmigen Verabschiedung eines Thesenpapiers, das später auch vom Ministerrat förmlich angenommen wurde, zu einem wichti-

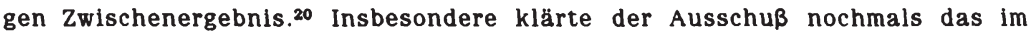
Steuerstreit so wichtige Wechselkursargument. Der Wechselkurs, so wurde festgestellt, ist lediglich in der Lage, Unterschiede der durchschnittlichen Steuerbelastung zweier Länder auszugleichen:

\begin{abstract}
"Ceteris paribus wird daher eine Industrle im internationalen Wettbewerb benachteiligt oder begünstigt sein, je nachdem ob beim Grenzübertritt die steuerliche Belastung ihrer Erzeugnisse höher oder nledriger ist als die durchschnittliche Belastung der übrigen Produkte der eigenen Volkswirtschaft."21
\end{abstract}

Leider vergaßen die einzelnen Staaten wieder überraschend schnell diese wichtige Erkenntnis. Auch die Argumente, mit denen Frankreich und Deutschland den Steuerstreit geführt hatten, waren damit nur vorüberge-

17 Albers (1953), S.172.

10 Albers (1953), S.163.

19 In einer Art Trotzreaktion auf die Empfehlung der Hohen Behörde ermächtigte der Deutsche Bundestag die Bundesregierung noch im Sommer 1953, den für Stahlerzeugnisse erhobenen Grenzausgleich um 4-6\% heraupzusetzen; von der Ermächtigung wurde allerdings nie Gebrauch gemacht; vgl. Regul/Renner (1966), S.88.

20 Vgl. Hohe Behörde, Steuerausschuß, Dok.Nr. 4798/55 v.18.6.55. Vgl. a. Regul (1955), S.315fP, sowle Regul (1965), S.296ff.

21 Hohe Behörde, Steuerausschuß, Dok.Nr. 4798/55 v. 18.6.55. 
hend vom Tisch: Sie alle tauchten später noch mehrmals auf. Aber zunächst einmal konnte der Steuerstreit "beerdigt werden"22:

"Der Ausschuß hălt es im Augenblick weder für opportun noch für notwendig, Vorschläge zu einer Anderung der jetzt bestehenden Regelungen auf dem Geblet der Umsatzsteuerbefreiungen und -vergutungen sowie der Ausgleichsabgaben bei der Einfuhr zu unterbreiten."23

Die Bellegung des Steuerstreits war durch ein Einlenken der deutschen Se1te möglich geworden. Zum einen hatten sich die zuständigen Bonner Beamten, nachdem Mitte 1953 die ersten erhitzten Debatten vorüber waren, mit den Wissenschaftlichen Beiräten des Finanz- und Wirtschaftsministeriums ins Benehmen gesetzt und dort erfahren müssen, daß die von ihnen in Luxemburg vertretenen Argumente aus ökonomischer Sicht nicht aufrechtzuerhalten waren. Diese Einsicht konnte die offizielle deutsche Position jedoch erst in dem Moment verändern, als auch die deutsche Stahlindustrie Kompromißbereltschaft signalisierte: Der deutschen Industrie war langsam klar geworden, daß ihre französischen Konkurrenten unter dem überhöhten Wechselkurs des Franc sehr zu leiden hatten und durch die Maßnahmen zur Stützung des Franc, zu denen auch steuerliche Mittel gehörten, zunehmend belastet wurden. So schllep der Steuerstreit zusehends ein, und im Jahre 1958 hatte es gar den Anschein, als sel er ganz vergessen worden.24 Aber es bedurfte lediglich der Abwertung des Franc im November 1958, und die deutsche Montanindustrie war mit ihren alten Forderungen wieder auf dem Plan.

\section{Die Folgen des Steuerstreits}

Der Steuerstreit wurde also nicht abschließend gelöst, sondern er war nur vorübergehend eingeschläfert worden. Die Empfehlung der Hohen Behörde, zunächst alles beim Alten zu belassen, legte die Mitgliedstaaten der EGKS steuerpolitisch keineswegs fest. So unausweichlich die Entscheidung der Hohen Behörde damals schien, so Polgenschwer war sie fur die Entwlcklung auch in der EWG. Es war klar, daß der Druck der Interessenverbände dle Regierungen der Mitgliedstaaten tendenzlell $\mathrm{zu}$ einer Erhöhung ihres steuerlichen Grenzausgleiches bewegen würde. Von der Möglichkelt, in naher Zukunft elnmal ganz auf den Grenzausgleich verzichten zu können, entfernte man sich damit immer mehr.

Diese Entwicklung hătte abgewendet werden können. Der Tinbergen-Ausschuß hatte in seinem Bericht den Vorschlag unterbreitet, die Mitgliedstaaten auf eine Regel folgenden Inhalts zu verpflichten: Der Grenzausgleich wird der Höhe nach auf den Standardsatz der im jewelligen Land erhobenen

\footnotetext{
22 Persönliches Interview.

23 Hohe Behörde, Steuerausschuß, Dok.Nr. 4798/55 v. 18.6.55.

24 Vgl. z. B. Taussig (1971), S.164.
} 
USt begrenzt. ${ }^{20} \mathrm{Er}$ wollte damit die nach 1945 zunächst in den meisten europäischen Ländern geltende Verfahrenswelse für dle Zukunft lestschreiben.

Man muß sich mit Recht Pragen, ob eine solche Festschreibung uberhaupt wünschenswert gewesen wäre. Ein Grenzausglelch in Höhe des Standardsatzes der USt kann nicht wettbewerbsneutral sein, solange sich die inländische Steuerbelastung verschledener Güter, wie bel der damals üblichen Bruttoust der Fall, voneinander unterscheidet. Die Hohe Behörde grifp dieses rein okonomische Argument auf und lehnte den Tinbergen-Vorschlag mit dem Hinwels $a b$, daß lediglich ein entsprechend der unterschiedlichen Steuerbelastung differenziert vorgenommener Grenzausglelch Neutralitat gewährleisten könne.26 Dle Vertreter der Mitgliedstaaten schlossen sich, unter dem Druck der auf elne Erhöhung der Grenzausgleichssătze drängenden polltischen Kräfte, der Beurtellung der Hohen Behörde an. Auch wenn es niemals zu einem formalen Beschluß kam, so war der Tinbergen-Vorschlag damit Paktisch vom Verhandlungstisch verschwunden. Der TinbergenAusschuß selbst hatte die mit seinem Vorschlag verbundenen Probleme durchaus gesehen. Er glaubte jedoch, daß dle ökonomischen Nachtelle durch elnen entscheidenden politischen Vorteil aufgewogen würden:

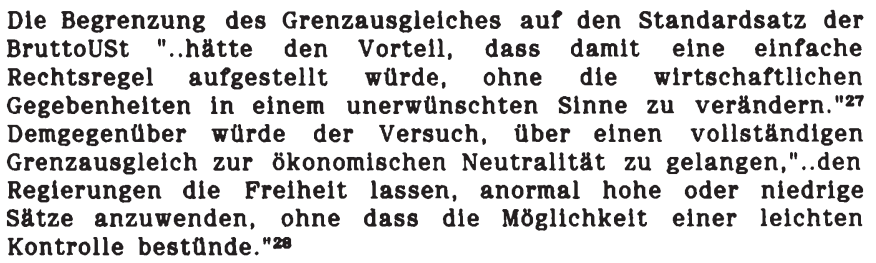

Diese juristischen bzw. politischen Bedenken lleß dle Hohe Behörde jedoch unbeachtet an der Seite liegen. Erst als sich die Grenzausglelchssätze der inländischen Steuerbelastung der jewelligen Güter langsam anzunăhern begannen, wurde die spatere Kommission der EG mit den Kontrollproblemen konfrontiert, auf die der Tínbergen-Ausschuß berelts deutlich hingewiesen hatte.29 Der Zug zu der vom Tínbergen-Ausschuß vorgeschlagenen Lösung

25 Vgl. Tinbergen-Bericht (1953), S.33. Der Tinbergen-Ausschuß war sich dabel noch nicht daruber Im Klaren, wie mit der Pranzösischen NettoUSt verfahren werden sollte; vgl. ebenda, S.16. Dlese Bedenken waren jedoch unbegrundet. Dle bestehende Pranzösische Regelung hătte belbehalten werden können, mögllche Verzerrungen wären uber den Wechselkurs ausgeglichen worden.

26 Vgl. Hohe Behø̈rde, Dok.Nr.4614/54 v. 21.6.54.

27 Tinbergen-Bericht (1953), S.33.

28 Ebenda, S.32.

29 "No use was made, however, of the constructive proposal of the Tinbergen-Report, and subsequent developments in the ECSC and above all in the EEC fully confirmed the rightness of the warnings 
war dann aber berelts abgefahren. Die Entwicklung des umsatzsteuerlichen Grenzausgleichs ist einer Einbahnstraße verglelchbar: Entsprechend dem Druck der Wirtschaftsinteressen bewegen sich die Sätze nach oben und nur in ganz wenigen Ausnahmefăllen einmal nach unten.

Dle wichtigsten Aussagen zum Steuerstrelt in der Montan-Union lassen sich in elnem Schaubild zusammenfassen, das elnen Vergleich mit der steuerpolitischen Auseinandersetzung in der Benelux-Union erlaubt:

Schaubild B-10: Der umsatzsteuer liche Frenzausgleıch in der Montan-Union

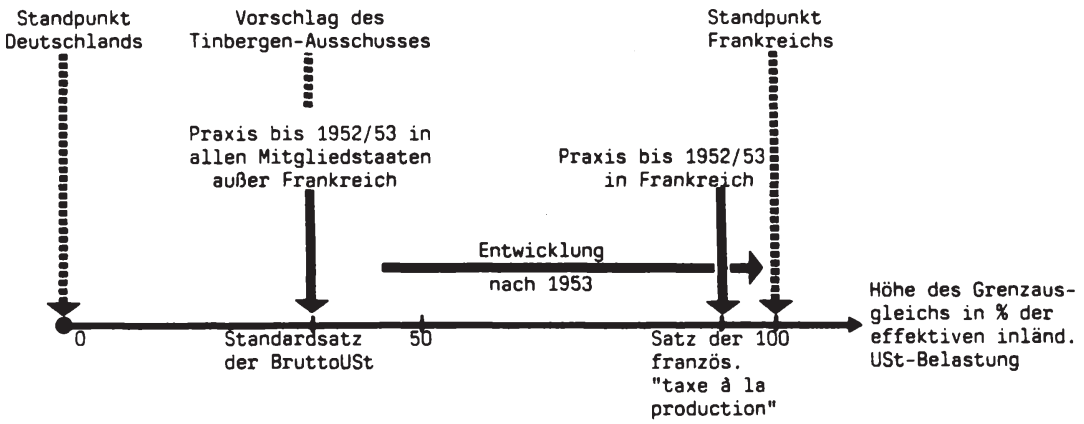

\subsection{Verhandlungen zum EWG-Vertrag}

\section{Der Verlauf der Vertragsverhandlungen}

Mit der Verabschledung des bereits erwăhnten Thesenpaplers durch den Steuerausschuß der EGKS war Ende Junl 1955 ein wichtiger Schritt zur vorläufigen Bellegung des Steuerstreits getan worden. Berelts Anfang desselben Monats hatten die Außenminister der Montanunion-Staaten aup ihrer berühmten Konferenz von Messina einen ihnen unterstellten Regierungsausschuß mit der Prufung elner weltergehenden europalschen Integration beauftragt. Neben vielen anderen Streltpunkten waren damit auch neue steuerpolitische Probleme abzusehen.

Die Vertreter der 6 Regierungen nahmen im Jull 1955 in Brüssel thre Beratungen aup, dle sie endgülig erst Im Aprll des folgenden Jahres mit elnem "Bericht der Delegationsleiter an die Aussenminister"30 abschlleßen konnten.

\footnotetext{
about national manipulations of the rates of compensation." Regul/Renner (1966), S.88.

Zitiert im folgenden als Spaak-Bericht (1956).
} 
Als zentrales Problem sah der unter der Regie von Paul-Henri Spaak (belgischer Außenminister) von Pierre Uri (Direktor bel der Hohen Behörde) und Hans von der Groeben (Leiter der EGKS-Abteilung im Bundeswirtschaftsministerium) abgefaßte Bericht die Gründung eines aup marktwirtschaftlichen Prinzipien beruhenden Gemeinsamen Marktes vor. Obwohl nach wie vor noch viele Melnungsverschiedenheiten in zahlreichen Einzelfragen bestanden, kamen die Im Mal 1956 in Venedig versammelten Außenminister ubberein, auf der Grundlage des Spaak-Berichts in offizlelle Regierungsverhandlungen einzutreten. In nur wenigen Monaten konnte mit dem EWG-Vertrag und dem EURATOM-Vertrag ein umfangreiches Vertragswerk fertiggestellt werden, das am 25.März 1957 in Rom unterzeichnet wurde. ${ }^{31}$

Die herausragende Bedeutung der Wettbewerbsneutralität

Ein Gemeinsamer Markt umfaßt neben einem gemeinsamen Güter- auch einen gemeinsamen Faktormarkt. Trotzdem stand der Güter- bzw. der Zollunionsaspekt deutlich im Vordergrund sowohl der Verhandlungen als auch des späteren Vertrages. Dies dürfte wohl darauf zurückzuführen sein, daß, im Vergleich zu einem gemeinsamen Faktormarkt, ein gemeinsamer Gütermarkt technisch und politisch einfacher zu verwirklichen erschien und damit schnelle, sichere und vorzeigbare Integrationserfolge versprach.

Die Dominanz des Zollunionsgedankens in Verbindung mit der angestrebten marktwirtschaftlichen Grundkonzeption der EWG ließ wettbewerbspolitische Erwägungen in den Mittelpunkt der Verhandlungen rücken. Man mußte unbedingt vermeiden, daß nach Opfnung der Grenzen zwischen den Mitgliedstaaten die grenzuberschreitenden Handelsströme durch private und/oder staatliche Eingriffe künstlich verzerrt würden, da dies die von einem Gemeinsamen Markt erhopfte Effizienzstelgerung der europäischen Wirtschaft hätte zunichte machen können. ${ }^{32}$ Zum einen galt es daher, den Wettbewerb beschränkende Maßnahmen des privaten Sektors - z.B. Kartelle, Monopole, etc. - zu verhindern. Wichtiger war es jedoch, mögllchen protektionistischen Maßnahmen seitens der nationalen Regierungen - z.B. mittels Subventionen, Steuern, etc. - vorzubeugen, da diese nicht nur die wirtschaftlichen Vortelle der EWG zu vermindern, sondern darüberhinaus auch das politische Klima in der EWG zu vergiften drohten. Ein zentrales Anliegen des EWG-Vertrages ließ sich damit auf folgende Formel reduzieren: Der Wettbewerb zwischen den Reglerungen, zumindest sofern er sich protektionistischer Instrumente bedient, soll vermindert und der zwischen privaten Unternehmen verstärkt werden.

Die herausragende politische Bedeutung des Ziels Wettbewerbsneutralität hatte sich in den Verhandlungen zum EWG-Vertrag bereits Prühzeitig abge-

31 Zur Entstehungsgeschichte des EWG-Vertrages vgl. die ebenso ausführliche wie gute Darstellung bel Küsters (1982).

Vgl. z.B. Küsters (1982), S.179fP. 
zeichnet. Als es jedoch an die Umsetzung des Zlels in elnzelne Bestimmungen ging, sahen sich die Väter des Vertrages mehreren Restriktionen gegenubber. Neben dem eng begrenzten zeitlichen Rahmen mußten sie insbesondere daraup achten, bei der Errichtung eines Gemeinsamen Marktes mit einem Minimum an Regelungen auszukommen, die die nationalen Freiheiten einschränkten. Jede einzelne Beschneldung nationaler Souverănităt barg die Gefahr in sich, das $\mathrm{Fa \beta}$ zum uberlaufen zu bringen und den einen oder anderen Staat zur Ablehnung des gesamten Vertragswerkes zu veranlassen. Bei der Identifikation unbedingt regelungsbedürftiger Politikbereiche half, sofern es um durch staatliche Eingriffe verursachte Wettbewerbsverzerrungen ging, eine aus dem Steuerstreit in der Montan-Union resultierende Erkenntnis weiter: die Unterscheldung zwischen allgemeinen und spezifischen Verzerrungen. Werden alle Wirtschaftszweige eines Landes durch eine staatliche Maßnahme in ungefähr demselben Maße be- oder entlastet, so handelt es sich um eine allgemeine Verzerrung, die über den Wechselkurs und/oder das Preisniveau neutralisiert wird. Ein Handlungsbedarf auf Gemeinschaftsebene ergibt sich lediglich im Falle spezifischer Verzerrungen: Einzelne Branchen eines Landes werden überdurchschnittlich belastet oder begünstigt, der Wechselkurs jedoch kann differentielle Belastungsunterschiede nicht ausgleichen. ${ }^{33}$

Die Vernachlässigung der direkten Steuern und der Sozialkosten

Welche einzelstaatlichen Politikinstrumente gehören aber nun in die eine und welche in die andere Kategorie? Wenig Koppzerbrechen bereitete bel den Verhandlungen zum EWG-Vertrag die Einordnung der direkten Steuern, da dlese Frage bereits Gegenstand ausführlichster Erörterungen im Steuerstreit der Montan-Union gewesen war: Werden die direkten Steuern nicht uberwälzt, so haben sie auf den Gütermarkt auch kelnen Einfluß; werden sle uberwälzt, so muß man mangels besserer Informationen davon ausgehen, daß alle Produkte in ungefähr gleichem Ausmaß verteuert werden.34 Ein Bedarf für eine gemeinschaftliche Regelung bestand daher zunăchst nicht.

Wie aber steht es mit der Bewertung der Sozialkosten, die, angefangen von Sozlalbeiträgen uber Arbeitszeitregelungen bis hin zu Mindestlöhnen für Frauen, die Unternehmen belasten? Die Ahnlichkeit zu der Wirkung direkter Steuern liegt auf der Hand, und die Sache hätte damit ebenfalls schnell ad acta gelegt werden können. Aber diese Rechnung war ohne dle Pranzösische Industrie gemacht worden. Sie forderte eine Angleichung der niedrigen Sozialkosten der Punp Nachbarstaaten an das angeblich höhere Pranzösische Niveau und bewirkte damit eine Neuauplage des alten Steuerstreits zwi-

33 Vgl. Spaak-Bericht (1956), S.64fP.

34 Eine OECD-Studie aus den 60er Jahren vermittelt einen guten Eindruck von der Unsicherhelt, der man sich damals bel der Beurteilung der Uberwälzung direkter Abgaben gegenüber sah; vgl. OCDE (1968), S.95fP. 
schen Deutschland und Frankreich, nunmehr interessanterweise mit vertauschter Rollenvertellung. Dle Überelnstimmungen des neuerlichen Schlagabtausches ${ }^{30} \mathrm{mit}$ dem Steuerstreit der Montan-Union sind Prapplerend:

- Die Standpunkte der beiden Hauptkontrahenten stimmten vollkommen überein; man brauchte nur das Wort direkte Steuern durch Sozialkosten zu ersetzen. Die Franzosen bedienten sich der Argumente, die ehemals von den Deutschen vorgebracht worden waren, und vice versa.

- In belden Fällen sahen die am Verhandlungstisch sitzenden Regierungsvertreter bald die Unsinnigkelt wie die Aussichtslosigkelt ihrer Argumentation eln, sie waren jedoch nicht kompromispahig, solange nicht auch die eigene Industrie - dle trelbende Kraft Im Hintergrund zum Einlenken berelt war: "In Wirklichkelt war die Diskussion um die soziale Harmonisierung eln reines Politlkum zur Bepriedigung Pranzösischer Verbandsinteressen. 136

- Beidesmal drohte der Streit um Wettbewerbsfragen den gesamten Integrationsprozeß zum Erliegen zu bringen.

Wăhrend der Steuerstreit wegen der Uberbewertung des Pranzösischen Franc langsam einschlafen konnte, bedurfte es zur Bellegung des Sozlalkostenstreits elnes Gipfeltreffens zwischen Adenauer und Mollet. Auf dem Höhepunkt der Suez-Krise opferte Mollet die Forderungen seiner Industrie der außenpolitischen Notwendigkeit einer engeren Zusammenarbeit mit Deutschland. Der am 6.November 1956 in Parls ausgehandelte Kompromi $\beta$, der nur formal ein Kompromi $\beta$ und inhaltlich eine Niederlage der Franzosen war, markierte den Wendepunkt in den Verhandlungen zum EWG-Vertrag. Der Weg zu einem erfolgreichen Abschluß war Preigegeben. ${ }^{37}$

\section{Das Harmonislerungsgebot für die indirekten Steuern}

Wahrend man bel den direkten Steuern und bel den Sozlalkosten also zunăchst aup eine gemeinschaftlich fixierte Verhaltensregel verzichten konnte, war sle bel den indirekten Steuern und den Subventionen unbedingt erforderlich. Beide Instrumente sind bestens dazu geeignet, zugunsten einzelner Branchen spezlfische Verzerrungen bewußt herbelzupühren und sle damit vor ausländischer Konkurrenz zu schützen. Was die indirekten Steuern betrap, so hatte man ja in der Benelux- und der Montan-Union bereits einschlägige Erfahrungen sammeln können. Es war zu befurchten, daß simultan mit dem vorgesehenen schrittwelsen Abbau der zölle der umsatzsteuerliche Grenzausgleich in gleichem Maße heraufgesetzt werden würde. Ein Regelungsbedarf war damit eindeutig gegeben. Die Frage war nur, was man konkret tun sollte. Aus theoretischer sicht gab es mehrere Lösungsmöglichkeiten:

35 Vgl. Insbes. Küsters (1983), S.162P., S.180f.,S.2991. sowle S.375fP. Vgl. a. Aron (1957).

36 Kústers (1982), S.376.

37 Vgl. Küsters (1982), S.327ff. 
- Eine erste Alternative wäre gewesen, den Mitgliedstaaten generell einen vollständigen Grenzausglelch vorzuschrelben, verbunden mit der Auflage, fortan nur noch solche USt-Systeme zu verwenden, die elne exakte Ermittlung der Ausgleichssătze zulassen. Zwar kannte man Mitte der 50er Jahre noch nicht alle von einer indirekten Steuer ausgehenden Verzerrungen en détail, doch war man sich sehr wohl darüber im Klaren, daß eine solche Regel nahezu perfekt gewesen wäre: aus ökonomischer Sicht neutral und aus rechtlicher Sicht leicht zu kontrollieren. Sie hatte nur den Fehler, daß sie politisch zum Scheitern verurteilt war. Der von den nationalen Volkswirtschaften verlangte Anpassungsbedarf wäre zu groß gewesen.

- Eine zwelte Möglichkelt bestand darin, das Ubel an selner Wurzel zu packen und jeglichen Grenzausgleich zu verbleten. Aber auch dieser Ansatz scheiterte von vornherein an der politischen Durchsetzbarkeit im allgemeinen und am ubberbewerteten Pranzösischen Franc im besonderen. Die ökonomischen Verzerrungen. die eine solche Lösung angesichts unterschiedlicher Steuersätze ohne Frage mit sich gebracht hătte, waren in Anbetracht solch gravlerender Probleme nur noch von sekundărer Bedeutung.

- Zwischen den belden genannten Extremen verblieb als dritte Alternative der Vorschlag des Tinbergen-Ausschusses, den Grenzausglelch aup den Standardsatz der USt zu begrenzen. Inn hatte das Desinteresse der Hohen Behörde jedoch schon in die Vergessenheit abrutschen lassen. Aber selbst wenn er aup dem Verhandlungstisch gelegen hătte, wäre seine Annahme unwahrscheinlich gewesen: Selt 1953 hatten zahlrelche Staaten, allen voran die Benelux-Länder, ihren Grenzausgleich angehoben; und so populär Erhöhungen der Ausgleichssătze sind, so schwlerig ist ihre Verringerung auf den alten Stand.

Sämtliche Lösungen, die in eine rechtlich elndeutige und kontrollierbare Form hätten gegossen werden können, schleden also von vorneherein aus. Was tun? Da dle Zelt Pehlte, nach anderen Lösungsmöglichkelten zu suchen und politische Mehrheiten für sie zu finden, empiahl der Spaak-Bericht, das ganze Problem mit den steuerlichen Verzerrungen elnfach zu vertagen und vom Ministerrat nach Inkrafttreten des EWG-Vertrages lösen zu lassen. Der entsprechende Vorschlag lautete wle folgt: Falls betrachtliche Wettbewerbsverzerrungen - durch Steuern oder andere staatliche Eingriffe entdeckt werden, muß die Kommission dem Rat einen Vorschlag zu ihrer Beseltigung unterbreiten, der darüber einstimmig und nach einer obergangszeit von 4 Jahren mit quallfizlerter Mehrheit beschlleßt. Aber selbst auf dlesen gemaßigten Ansatz reagierten die Regierungsvertreter negativ: Ja zum Aupschieben des Problems, aber bitte keine Mehrheitsentscheldung im Bereich der Steuerpolitik. Das im Spaak-Bericht skizzlerte Verfahren

Vgl. Spaak-Bericht (1956), S.67f. 
wurde daher auf die durch "Rechts- und Verwaltungsvorschriften" hervorgerufenen Verzerrungen begrenzt - Art.101 EWGV -, während die Angleichung indirekter Steuern in einem separaten Artikel - Art.99 EWGV - geregelt wurde, der die Einstimmigkeit im Ministerrat vorsieht. Im Gegenzug zur Einführung des Einstimmigkeitsprinzips wurden die Ziele, Im Hinblick auf die eine "Harmonisierung" der indirekten Steuern vorgenommen werden darf, erweitert. Erlaubt Art.101 nur die Beseitigung von Wettbewerbsverzerrungen, so spricht Art.99 in allgemeinerer Form vom "Interesse des Gemeinsamen Marktes".

Zusammenfassend kann festgehalten werden, daß Art.99 die im Berelch der Indirekten Besteuerung unbedingt notwendige gemeinsame Regelung vertagte mit dem Ziel, die Annahme des EWG-Vertrages nicht durch einen neuerlichen Steuerstreit zu gefährden. Er beruht im wesentlichen auf dem Prinzip Hoffnung: Hoffentlich können sich die nationalen Regierungen in $\mathrm{Zu}$ kunft einmal über etwas einigen, das heute noch nicht mehrheitsfăhig ist, ja das heute vielleicht noch nicht einmal bekannt ist.

\section{Das Diskriminierungsverbot für die indirekten Steuern}

Die Vertragsverhandlungen waren schon fast abgeschlossen, als die Finanzexperten ihre Verhandlungsführer in Brüssel darauf hinwiesen, daß es in dem für politische Auseinandersetzungen besonders anfälligen Bereich der indirekten Besteuerung mit Hoffnung alleine noch nicht getan sei. Es war namentlich der deutsche, bereits Steuerstreit-erfahrene Ministerialbeamte Juretzek, der den Vorsitzenden des Ausschusses für den Gemeinsamen Markt, von der Groeben, hierauf aufmerksam machte. Er forderte, für die Ubergangszeit bis zu einer endgültigen Regelung Im Ministerrat - wer konnte damals schon wissen, wie lange sich die ubergangszeit hinziehen würde - zumindest den bereits bestehenden steuerlichen Vorschriften des GATT vergleichbare Artikel in den EWG-Vertrag aufzunehmen. ${ }^{39}$

Also machte man sich auf die Suche nach einer Übergangsregelung, die für das Erste die wildesten Auswüchse steuerlicher Wettbewerbsverzerrungen unterbinden konnte, ohne dabei den nationalstaatlichen SouveränitätsVerteidigern zu sehr auf ihre empfindsamen Füße zu treten. Das Ergebnis der nicht ungefährlichen Suchaktion waren Art.95-97 EWGV. Sie sind für die Mitgliedstaaten unmittelbar verbindlich in dem Sinne, da $\beta$ die einzelnen Regierungen verpflichtet sind, ihre Steuergesetzgebung im Rahmen der durch die drei Artikel gesteckten Grenzen zu halten.

Die Zustimmung zu dieser sehr strikten Bestimmung konnte nur durch eine weitgehende Aufweichung des strengen ökonomischen Konzeptes der Wettbewerbsneutralität erkauft werden. So wird zwar mit Art.95-97 die Höhe der inländischen effektiven Steuerbelastung als die Obergrenze für den Grenz- 
ausglelch festgesetzt. Aber Art.95-97 verbieten bel weitem nicht alle durch indirekte Steuern hervorgerufenen Verzerrungen. Art.95 untersagt beispielsweise nur solche Verzerrungen, die aus anderen Mitgliedstaaten importierte Produkte diskriminieren. Was das im einzelnen bedeuten könnte, wird uns später noch beschäftigen. Im Augenblick soll nur hervorgehoben werden, daß Art.95-97 alles andere als klare und einfach zu kontrollierende Rechtsregeln sind. Der besonders bedeutsame Art.95 ist im Gegenteil geradezu ein Musterbeisplel für eine alte Lebensweisheit jedes erfahrenen Politikers: Schwammige Formulierungen erleichtern politische Kompromisse, da jeder in sie hineininterpretieren kann, was er gerne möchte; bis der durch Formulierungskünste zugedeckte Dissens offen ausbricht, ist möglicherweise schon ein anderer zuständig und muß die Sache ausbaden.

\section{Zusammenfassung}

Vorläufig war aber erst einmal ein tragbarer Kompromiß für den Bereich der indirekten Besteuerung gefunden worden. Art.99 bot die Basis für eine in mittelfristiger Sicht notwendige Harmonisierung der Steuersysteme, Art.9597 dienten in der $\mathrm{Zwischenzeit} \mathrm{als} \mathrm{Ubergangsregelung.} \mathrm{Bevor} \mathrm{auf} \mathrm{den} \mathrm{Inhalt}$ der einzelnen Bestimmungen näher eingegangen wird, sollen die zentralen Ergebnisses dieses Kapitels nochmals überblicksartig dargestellt werden:

Schaubild B-11: Der umsatzsteuerliche Grenzausgleich nach dem EWG-Vertrag

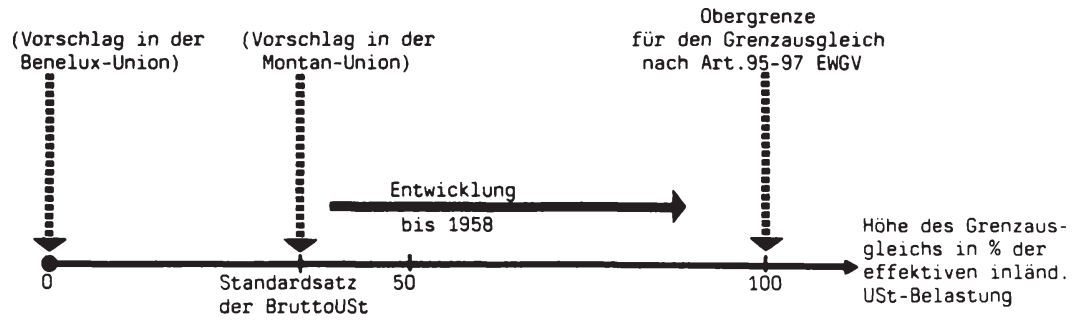




\section{Rechtllche Regelungen}

Die Aufnahme der steuerlichen Vorschriften der Art.95-991 in den EWGVertrag legte die rechtliche Grundlage für eine Steuerpolitik der Gemeinschaft auf dem Geblet der indirekten Abgaben. Einiges zu Inhalt und Problemen der genannten Artikel ist bei der Schilderung ihrer Entstehungsgeschichte bereits angeklungen. Wenn im folgenden auf die rechtlichen Regelungen nochmals vertiefend eingegangen wird, so dient das alleine dem besseren Verständnis des steuerpolitischen Harmonislerungsprozesses in der EG. Eine umfassende rechtliche Kommentierung der Vertragsartikel kann und soll die vorllegende Arbeit nicht leisten. ${ }^{2}$

\subsection{Der Inhalt der Art.95-99 EWG-Vertrag}

\section{Das Diskriminierungsverbot der Art.95-97}

Das an damals bereits bestehende GATT-Vorschriften ${ }^{3}$ angelehnte Diskriminierungsverbot der Art.95-97 war, wie bereits betont, als Ubergangsregelung bis $\mathrm{zu}$ einer endgültigen Harmonisierung der Verbrauchsteuern gedacht. Das Diskriminlerungsverbot untersagt den Mitglledstaaten der EG bel weitem nicht alle steuerlichen Regelungen, die zu Wettbewerbsverzerrungen im internationalen Handel führen können. Verboten werden lediglich solche Verhaltensweisen, die beim intra-EG Handel in anderen Mitgliedstaaten hergestellte Produkte diskriminieren.4 Was darunter im einzelnen $\mathrm{zu}$ verstehen ist, wird in Art.95 und 96 ausgeführt.

Zum einen ist die Höhe des steuerlichen Grenzausgleichs beim Import von Waren aus anderen Mitgliedstaaten auf die effektive Steuerbelastung begrenzt, die "gleichartige inländische Waren unmittelbar oder mittelbar" zu tragen haben (Art.95 Abs.1). Im Gegenzug wird für Exporte in andere Mit-

1 Alle in der vorliegenden Arbelt genannten Artikel beziehen sich, sofern nicht anders vermerkt, auf den EWG-Vertrag in seiner ursprünglichen Version von 1957.

2 Der Leser sel hierzu beisplelsweise auf die folgenden Veröffentlichungen verwlesen: Andel (1983c), Barents (1983), Berlin (1980), Easson (1981a), Wăgenbaur (1975), Wägenbaur (1980).

3 Vgl. hierzu z.B. Couche (1960).

1 Das steuerliche Diskriminierungsverbot der Art.95-97 ist elne Vielzahl ăhnlicher Verbotsvorschriften eingebettet, die alle darauf abzielen, den intra-EG Handel nach dem Wegfall der Zölle vor Verzerrungen mit zollgleicher Wirkung zu bewahren; vgl. Barents (1978) u. Wägenbaur (1980), S.132Pf. 
gliedstaaten vorgeschrieben, daß "die Rückvergütung für inländische Abgaben nicht höher seln (darf) als die aup dle ausgeführten Waren mittelbar oder unmittelbar erhobenen inländischen Abgaben" (Art.96). Die zwel Regeln zusammengenommen begrenzen also die Höhe des steuerlichen Grenzausgleichs nach oben, nicht jedoch nach unten. Darüberhinaus ist festzuhalten, daß der Begriff der Glelchartigkelt dehnbar ist und daher einer Auslegung bedarf. Beldes wird uns später noch beschäftigen.

Art.95 Abs.1 trifft keine Vorsorge für den Fall, daß eln Land zwar Importe tätigt, gleichartige Güter im Inland aber selbst nicht herstellt. Hier greift Art.95 Abs.2, der bestimmt, daß die Mitgliedstaaten "auf Waren aus anderen Mitglledstaaten keine Abgaben (erheben), die geelgnet sind, andere Produktionen mittelbar zu schützen". Es ist offenkundig, daß es sich bel dem Konzept des mittelbaren Schutzeffektes um alles andere als um einen klaren Rechtsbegriff handelt.

In Ergänzung zu Art.95 und 96 beinhaltet Art.97 eine Ausnahmeregelung für solche Mitgliedstaaten - es waren bel Gründung der EG alle außer Frankreich -, dle eine kumulative Bruttoust erheben. Da bel einer mehroder allphasigen Bruttoumsatzbesteuerung die aup einem einzelenen Gut lastende Steuer nicht exakt ermittelt werden kann, wird es den Mitgliedstaaten gestattet, den umsatzsteuerlichen Grenzausgleich aup der Basis von Durchschnittssatzen "für Waren oder Gruppen von Waren festzulegen" (Art.97 Abs.1). Der genannte Artikel sleht darüberhinaus ausdrücklich vor, daß sich diese Pauschalsätze innerhalb der von Art.95 und 96 festgelegten Grenzen halten müssen. Offen blelbt allerdings die Frage, wie die Einhaltung der gesetzten Grenzen im Einzelfall uberhaupt nachgeprüft werden soll: Durchschnittssätze werden ja gerade deswegen vorgesehen, well die effektive Steuerlast einzelner Guter, und damit auch die in Art.95 und 96 festgeschriebene Obergrenze, eben nicht genau bestimmbar ist.

Die Vorschriften der Art.95-97 sind für die Mitgliedstaaten unmittelbar verbindlich in dem Sinne, daß die jeweils entscheidungsbefugten Organe gehalten sind, ihre Steuergesetze und -verordnungen zu jedem Zeitpunkt ${ }^{5}$ innerhalb der vom EWG-Vertrag umschriebenen Grenzen zu halten. Bestehen in elnem konkreten Fall Zwelfel darüber, ob eln Mitgliedstaat dieser Verpflichtung nachgekommen ist, so gibt es zwei Möglichkeiten, die Kompatibilitat des nationalen Steuerrechts mit den EG-Normen zu uberprüen und gegebenenfalls eine Anderung der einzelstaatlichen Regelungen zu veranlassen: 6

- Art.95 Abs.3 1.V.m. Art.8 Abs.1 bestimmen, daß die bel Inkrafttreten des EWG-Vertrages bereits bestehenden Regelungen erst zum 1.1 .62 an dle Vorschriften des Art.95 angepaßt werden mulssen.

6 Vgl. z.B. Wägenbaur (1980), S.124. 
- Die Kommission verklagt den betreffenden Mitgliedstaat in einem Vertragsverletzungsverfahren vor dem Europälschen Gerichtshof - im folgenden kurz EuGH genannt. Das Urteil des EuGH ist für das jeweilige Land sofort nach seiner Verkündung bindend; der EuGH gewährt den Mitgliedstaaten i.d.R. Jedoch eine gewisse Frist zur Anpassung des nationalen Rechts an die von ihm ausgelegten EG-Normen.

- Auf der Basis der Lehre von der unmittelbaren Wirkung der betreffenden Vertragsartikel ${ }^{7}$ verklagen Bürger der Gemeinschaft den Mitgliedstaat wegen des Verstoßes gegen den EWG-Vertrag vor einem nationalen Gericht. Kommen während des Verfahrens Zwelfel über die korrekte Auslegung der Vertragsartikel auf, so kann das jeweilige Gericht, und muß es in bestimmten Fällen sogar, den EuGH in einem sogenannten Vorabentscheidungsverfahren nach Art.177 um eine Interpretationshilfe bltten. Die Entscheidung des EuGH ist für das weitere Verfahren vor dem nationalen Gericht bindend.

Beide Verfahren dienen demselben Zweck: Die in Art.95-97 dem nationalstaatlichen Handeln gesetzten Grenzen werden für den Einzelfall konkretisiert.

\section{Die Ausnahmeregelung des Art.98}

Art.98 hat bislang keine Bedeutung erlangt. Er schreibt vor, daß ein steuerlicher Grenzausgleich für direkte Steuern nur in Ausnahmefällen, auf Vorschlag der Kommission und nachdem der Rat mit qualifizierter Mehrheit zugestimmt hat, für eine begrenzte Frist zulässig ist. Zweck der Vorschrift ist es, den Mitgliedstaaten die Möglichkelt für eine steuerpolitische Bekämpfung temporärer Zahlungsbilanzungleichgewichte zu lassen. Historisch geht Art.98 auf den bereits erwähnten Kompromiß zwischen Adenauer und Mollet während der Verhandlungen zum EWG-Vertrag zurück: Die Franzosen verzichteten faktisch aup ihre Forderung, die Sozialkosten in der kunftigen Gemeinschaft zu harmonisieren; die Deutschen räumten ihnen im Gegenzug das Recht ein, den auf schwachen Füßen stehenden Franc unter bestimmten Voraussetzungen steuerlich zu stützen. ${ }^{8}$ So wurde in einem dem EWG-Vertrag beigefugten "Protokoll über bestimmte Vorschriften betreffend Frankreich" festgehalten, daß Paris seinen damals praktizierten hohen steuerlichen Grenzausgleich, der über der in Art.95-97 fixierten Obergrenze lag, bis auf weiteres beibehalten dürfe. Die den Franzosen zugestandene Ausnahme wurde hinfällig, nachdem der neue Staatschef de Gaulle im November

7 In Abweichung von der Rechtssprechung zu Art.95 und 96 kommt Art.97 keine "unmittelbare Wirkung" zu. So entschied der EuGH in seinem Urtell vom 3.4.68 in der RS 28/67.

B Vgl. Küsters (1982), S.329. 
1958 den Franc stark abgewertet hatte.9 Von der in Art.98 vorgesehenen Ausnahmeregelung selbst mußte in der Folgezeit nie Gebrauch gemacht werden.

Das Harmonisierungsgebot des Art.99

Wesentlich bedeutsamer ist dagegen das in Art.99 niedergelegte Harmonisierungsgebot. Die Kommission wurde hier aufgefordert zu prüfen, "wle die Rechtsvorschriften der einzelnen Mitgliedstaaten uber die Umsatzsteuer, die Verbrauchsabgaben und sonstige indirekte Steuern...im Interesse des Gemeinsamen Marktes harmonisiert werden können" (Art.99 Abs.1). Es ist müßig, darüber zu debattieren, ob Art.99 etwa eine Harmonisierung vorschreibt - Akzent auf dem "wie" - oder ob er sie lediglich als Möglichkeit vorsieht - Akzent aup dem "können" -.10 Genauso überflüssig ist die Frage, ob die "Harmonisierung" der indirekten Steuern bis zu einer Vereinheitliching der nationalen Steuersysteme gehen darf oder ob sie davor bereits haltmachen muß.11 Tatsache ist, daß die Kommission auf Art.99 beruhende Harmonisierungsvorschläge von Anfang an als eine Chance begriffen hat, nicht nur Wettbewerbsverzerrungen abzubauen, sondern auch die politische Integration der Gemeinschaft voranzutreiben. Eine Tatsache ist weiterhin, daß es alleine vom politischen willen des Rates abhängt, ob und bis $\mathrm{zu}$ welchem Grade er eine steuerliche Harmonisierung hinzunehmen bereit ist. Denn es ist der Rat, der, wie Art.99 Abs.2 ausdrucklich vorschreibt, die Vorschläge der Kommission einstimmig billigen muß.

Rein formal durchläuft eine auf Basis von Art.99 vorgenommene Steuerharmonislerung 1.d.R. die folgenden Schritte:12

- Die Dienststellen der Kommission bereiten, in aller Regel in Zusammenarbeit mit einer aus Finanzexperten der nationalen Ministerien zusammengesetzten Arbeitsgruppe, einen Harmonisierungsvorschlag vor. Als zusätzliche Absicherung und u.U. auch Unterstützung holt dle Kommission desöfteren Stellungnahmen der von dem Vorschlag betroffenen Verbände ein.

- Die Kommission beschließt den Im Bedarfsfalle nochmals abgeänderten Entwurf und leitet inn als Vorschlag für eine Richtlinie des Rates an den Rat oder genauer gesagt an den Ausschuß der Ständigen Vertreter - kurz COREPER genannt - weiter.

9 Vgl. Das Problem der Steuerharmonisierung im Gemeinsamen Markt, in: NZZ v. 14.9.61 u. 15.9.61.

10 Vgl. z.B. Muller (1965), S.260.

11 Zum Harmonisierungsbegripf vgl. z.B. Andel (1983c), S.2.

12 Vgl. z.B. Glover/Lévy (1974), S.208p . 
- Auf Anfrage des Rates geben das Europäische Parlament - EP - und der Wirtschafts - und Sozialausschuß der EG - WSA -, jeweils unterstützt durch die entsprechenden Fachausschüsse, ihre Stellungnahmen zu dem Richtlinienvorschlag ab. Zwar schreibt Art.99, Im Gegensatz zu dem allgemeinen Harmonisierungsgebot des Art.100, die Anhörung von EP und WSA nicht zwingend vor. Aus politischen Gründen werden die beiden Gremien jedoch in der großen Mehrzahl der Fälle zur Abgabe einer Stellungnahme aufgefordert. Die Kommission stutzt ihre Richtlinienvorschläge daher neben Art.99 auch regelmäßlg aup Art.100, um die beiden genannten Institutionen von vorneherein in den Entscheldungsproze $\beta$ einzubezlehen. Kommission und Rat können, müssen jedoch nicht, die vom EP und WSA vorgebrachten Abänderungswünsche im Laufe der weiteren Verhandlungen berücksichtigen.

- COREPER beauftragt eine aus Ministerialbeamten rekrutierte Expertengruppe, den Richtlinien-Vorschlag zu untersuchen und über die strittigen Punkte Bericht zu erstatten. Melst kennen die Experten den Vorschlag bereits bestens, da sle als Mitglieder der weiter oben erwähnten Arbeitsgruppe bel der Kommission schon bel dessen Ausarbeltung mitgewirkt haben.

- Auf der Ebene der Experten und von COREPER wird versucht, eine möglichst weitgehende Einigung zwischen den Mitgliedstaaten und der Kommission $\mathrm{zu}$ erzielen. Die jewellige Präsidentschaft - sie wechselt alle sechs Monate - entscheldet dann, ob und wann die noch verbleibenden Probleme auf die Tagesordnung einer Ministerratssitzung gesetzt werden.

- Der Ministerrat beschlleßt die Richtlinie. deren Vorschriften nach dem Durchlaufen der nationalen Gesetzgebungsverfahren zu verbindlichem Recht werden.

Obwohl Art.99 hler keine Festlegung trifft, kleidet die Kommission ihre Harmonisierungs-Vorschläge üblicherweise in die Rechtsform einer Richtlinie. Da eine Richtlinie "für jeden Mitgliedstaat, an den sie gerichtet wird, hinsichtlich des zu erreichenden Zlels verbindlich (ist),...den Innerstaatlichen Stellen dle Wahl der Form und der Mittel" jedoch überläßt (Art.189 Abs.3), können die Probleme gesetzestechnischer Art, die bel der Anpassung des nationalen Rechts an die gemeinschaftlich beschlossenen Regeln unweigerlich auftreten, auf ein Minimum reduzlert werden.

Der Wortlaut des Art.189 scheint nahezulegen, daß die Richtlinien - Im Gegensatz $\mathrm{zu}$ elner Verordnung - lediglich die gesetzgebenden Organe der Mitgliedstaaten binden, in die Rechtsbezlehung zwischen den Mitgliedstaaten und ihren Bürgern jedoch selbst nicht unmittelbar eingreifen. In Analogie zu der unmittelbaren Wirkung eines Vertragsartikels hat der EuGH in 
seiner Rechtssprechung ${ }^{13}$ aber entschieden, daß auch einzelnen Bestimmungen einer Richtlinie, sofern sie dem Mitgliedstaat kein materielles Wahlrecht offenlassen, unmittelbare Wirkung zuzuschreiben ist. Sie konnen damit, noch bevor die Richtlinie in nationales Recht umgesetzt worden ist, von jedem Bürger vor nationalen Gerichten elngeklagt werden.14 Die Lehre von der unmittelbaren Wirkung trägt dazu bel, die Implementlerung einer elnmal beschlossenen Richtlinie zu beschleunigen. In gleichem Maße werden die Mitgliedstaaten Jedoch vorsichtiger wenn es darum geht, Im Ministerrat einer Richtlinie zuzustimmen.

\section{Das Verhältnis von Art.99 zu Art.95-97}

Bisher haben wir das Diskriminierungsverbot nach Art.95-97 und das Harmonisierungsgebot nach Art.99 jewells isoliert untersucht. Es stellt sich nun die zusätzliche Frage, in welchem Verhältnis die belden Vorschriften zuelnander stehen. Unbestritten ist es, daß sich der Rat als ein Organ der EG in seinen Entscheidungen nicht über verbindliche Regelungen des EWGVertrages einfach hinwegsetzen darf. Die vom Ministerrat auf der Basis von Art.99 erlassenen Richtlinien müssen folglich die von Art.95-97 berelts abgesteckten Grenzen respektieren. Damit ergibt sich für das Verhältnis der genannten Artikel zueinander theoretisch die folgende Konstruktion:19

- Art.95-97 schränken die steuerpolitischen Handlungsmöglichkeiten der Mitgliedstaaten unmittelbar ein.

- Art.99 gibt darüberhinaus dem Rat die Möglichkeit, im Rahmen der durch Art.95-97 gesetzten Grenzen den nationalen Handlungsspielraum welter $\mathrm{zu}$ beschneiden.

\subsection{Die Unzulänglichkeiten des Diskriminlerungsverbotes nach Art.95-97}

\section{EWG-Vertrag}

Das Diskriminierungsverbot nach Art.95-97 ist, wle bereits verschiedentlich angeklungen war, weder in der Lage, Jegliche steuerbedingte Wettbewerbsverzerrung im grenzüberschreitenden Handel zu unterbinden, noch handelt es sich um eine klare Rechtsregel. Beides ist, wle ebenfalls schon herausgestellt wurde, auf die politischen und terminlichen Restriktionen während der Verhandlungen zum EWG-Vertrag zurückzuPuhren. Sämtliche durch die indirekte Besteuerung in einem Gemeinsamen Markt aufgeworfenen Probleme wären gelöst gewesen, hätte man im Vertrag einen vollständigen steuerlichen Grenzausgleich - bzw. das BLP - und ein Verbot jeglicher Satz-

13 Zentrale Bedeutung kommt dem Urteil des EuGH v. 4.12.74 in der RS 41/74 zu. Vgl. Dashwood (1977), S.274ff.

14 Zu den vielfältigen Facetten der "unmittelbaren Wirkung" einer Richtlinie vgl. insbes. die umfassende Darstellung bel Timmermans (1979). 
differenzlerung festgeschrieben. Aber weder auf das eine noch auf das andere konnte man sich damals einigen.

Unzulänglichkeiten bel der Festschreibung des BLP

Die in Art.95-97 erfolgte Festschreibung des BLP ist in zweierlel Hinsicht unzulänglich: Zum einen ist für die Höhe des Grenzausgleiches keine Untergrenze festgelegt; zum anderen existiert zwar eine Obergrenze, die aber im Einzelfall nicht exakt bestimmbar ist.

1. Die fehlende Fixierung einer Untergrenze hat zur Folge, daß ein vollständiger Grenzausgleich und damit die Besteuerung nach dem BLP zwar erlaubt - Pakultatives BLP -, aber nicht vorgeschrieben ist - obligatorisches BLP.16 Der den Mitgliedstaaten damit belassene Spielraum gibt innen ein Instrument in die Hand, die internationalen Wettbewerbsverhältnisse zugunsten einzelner Branchen zu verzerren: Llegt der Grenzausgleichssatz, in Relation gesetzt zur effektiven inländischen Steuerbelastung, bel einem Produkt höher als beim Durchschnitt der anderen Güter, so wird der entsprechende Produzent vor ausländischer Konkurrenz geschützt und vice versa. Der beschriebene Mechanismus ist insbesondere bel den allgemeinen Verbrauchsteuern von Bedeutung. Dagegen kann er bel speziellen Verbrauchsteuern vernachlässigt werden, da hier die Mitgliedstaaten ein vitales Eigeninteresse daran haben, den ihnen belassenen Handlungsspielraum in dem Sinne vollständig auszuschöpfen, daß sie den Grenzausgleich auf dle maximal zulässige Höhe hinaufschrauben: Da eine Verănderung des Grenzausgleiches bel speziellen Verbrauchsteuern - im Gegensatz zu einer allgemeinen Verbrauchsteuer - auf den Wechselkurs praktísch keinen Einfluß haben dürte, setzt ein zu niedrig bemessener Grenzausgleich die inländische Produktion automatisch in einen Wettbewerbsnachtell gegenuber der ausländischen Konkurrenz. De facto, wenn auch nicht de jure, schreibt Art.95 1.V.m. Art.96 damit für spezielle Verbrauchsteuern das obligatorische BLP vor.

2. Art.95-97 legt mit der inländischen Steuerbelastung zwar eine Obergrenze für den Grenzausgleich fest, die aber, und dies gilt insbesondere bel der Verwendung kumulativer USt-Systeme, im Einzelfall oft nicht exakt überprüft werden kann. Aber auch bei den speziellen Verbrauchsteuern kann es zu Problemen kommen, wenn, wle oft der Fall, nicht das an den Letztverbraucher verkaufte Endprodukt der Besteuerung unterworfen wird, sondern ein Vorprodukt. Als ein einfaches Beispiel diene die Zuckersteuer: In der Praxis kann nicht nachvollzogen werden, wieviel Zucker elne die Grenze passierende Pralinenschachtel genau enthält bzw. welcher Steuerbetrag auf ihr lastet. Ahnliche Fälle sind die Besteuerung der Stammwürze anstelle des Volumens bel Bier - heute noch praktiziert in mehreren EGStaaten - oder die Belastung des Rohtabaks anstelle der Pertigen Z1-

16 Vgl. Andel (1983c), S.15f. 
garetten - in Irland und Großbritannlen bis zum EG-Beitritt -. Bel allen genannten Steuern ist man bei der Durchführung des Grenzausgleiches auf Schătzungen angewlesen. Und es darf niemanden verwundern, wenn, wie die Praxis oft zeigt, die Schätzwerte in aller Regel zugunsten der heimischen Industrie und $\mathrm{zu}$ Lasten der Importware ausfallen.

\section{Unzulänglichkeiten beim Verbot der Satzdifferenzierung}

Mit dem unzureichenden Verbot von Satzdifferenzierungen kommen wir zur zweiten entscheidenden Lücke der Art.95-97. Wie wir oben bereits gesehen haben, können differenzierte Steuersätze selbst bel korrekter Anwendung des BLP zu protektionistischen Zwecken mißbraucht werden. ${ }^{17}$ Die Vorschriften der Art.95-97 gehen nun nicht so weit, daß sie, was am einfachsten wäre, jegliche Steuersatzdifferenzlerung untersagten. Sie lassen sie vielmehr grundsätzlich $\mathrm{zu}$ und verbleten nur solche Praktiken, die aus anderen Mitgliedstaaten importierte Waren diskriminieren. Die Identifikation einer Diskriminterung bleibt elner Einzelfallprufung überlassen, die sich, wie die bisherige Rechtssprechung des EuGH und die Stellungnahmen der Kommission nahelegen, aus idealtypischer Sicht in insgesamt drei Schritte zerlegen läßt. Die wichtigsten der dabel auptretenden Probleme sollen im folgenden anhand eines Falles herausgearbeitet werden, der vor dem EuGH verhandelt wurde: Das Vereinigte Königreich besteuerte Ende der 70er Jahre Wein, gemessen am Volumen, $5 \mathrm{mal}$ so hoch wie Bier. ${ }^{18}$ Llegt hier eine Diskriminierung vor?

1. Zur Klärung der Frage, ob der Weln zu hoch besteuert wird, ist zunächst in elnem ersten Schritt zu entscheiden, welches andere Gut zum Vergleich herangezogen werden soll. Mit welchem Produkt steht Wein in einer engen Substitutions- bzw. Konkurrenzbeziehung? Ist es Bier, oder sind es Spirituosen, oder gibt es, wie der Weinllebhaber vielleicht argumentieren würde, überhaupt kelne Substitutionsmöglichkeiten? Da die zu lösenden Probleme aus der nationalen Wettbewerbspolitik berelts hinlänglich bekannt sind, sollen sle hier nicht weiter vertieft werden.

2. Ist das relevante Substitutionsgut, in unserem Falle z.B. Bier, festgelegt, muß in elnem zweiten Schritt entschleden werden, welche Meßlatte man zur Ermittlung einer wettbewerbsneutralen Besteuerung anlegen will. Nimmt man den Wert der Güter als Maßstab, so wäre beisplelsweise elne aup belde Güter mit gleichem Satz erhobene ad valorem Steuer als neutral einzustufen. Ohne weiteres könnte man allerdings auch auf das Volumen der beiden Getränke oder den darín enthaltenen Alkohol zurückgreifen. ${ }^{19}$ Bezüglich der neutralen Besteuerung von Wein und Bier hat die Kommission bisher den

17 Vgl. Kap.B.1.3.3.

18 RS 170/78; das Urteil des EuGH erging am 23.7.83. Eine Kommentierung findet sich bei Easson (1984). 
Standpunkt vertreten, die relative Belastung der beiden Getrănke müsse Ihrem relativen Alkoholgehalt entsprechen. Jedem Nicht-Abstinenzler muß bel dem zunächst objektiv anmutenden Ansatz ein kalter Schauer uber den Rücken laufen, scheint die Kommission doch zu unterstellen, daß es der trinkende Konsument alleine auf den Alkohol abgesehen hat, egal in welcher Form auch immer er dargereicht wird. Schon mit diesen kurzen AusPührungen dürfte deutlich geworden sein, daß sich, mehr noch als bei der Ermittlung der relevanten Substitutionsbeziehung, bel der Entscheidung uber den anzulegenden Verglelchsmaßstab ein Element der Willkur weder verleugnen noch vermeiden läßt.

3. Nehmen wir nun an, man habe sich nach längeren Erörterungen darauf einigen können, daß eln Gut steuerlich höher belastet ist als das relevante Konkurrenzerzeugnis. Das heißt aber nun noch lange nicht, daß elne Diskriminlerung importlerter Waren vorliegt. In elnem dritten Schritt ist vielmehr zu prufen, ob das hoher besteuerte Gut uberwiegend im Inland produzlert oder aber uberwiegend importiert wird. Im Falle der britischen Weinsteuer ist die Lage klar: Der zu fast 100\% importierte Wein wird wesentlich höher belastet als das größtentells helmisch produzlerte Bler; die Differenz in der Besteuerung wirkt wie eln Zoll auf Wein und fallt daher unter das Diskriminierungsverbot der Art.95-97. Anders ist jedoch das deutsche Beispiel $\mathrm{zu}$ beurtellen. In der Bundesrepubllk wird Bler höher besteuert als Wein. Trotzdem wird man kaum davon reden können, daß elne solche Regelung den Blerimport unverhältnismäßig behindert, da ja neben den Importen auch und in erster Linie die wesentlich bedeutsamere inländische Blerproduktion unter dem erhohten Steuersatz zu leiden hat.

Die belden Belsplele zelgen, daß die wettbewerbspolitische Beurteilung einer Steuersatzdifferenzierung insbesondere davon abhangt, $\mathrm{zu}$ welchem Anteil das höher belastete Gut Importiert wird.20 Die zwel vorgestellten Fălle sind Extreme: Wăhrend das Vereinigte Königreich Wein nahezu vollständig Importiert, sind die deutschen Blerimporte relativ unbedeutend. Es stellt sich daher die Frage, ab welchem Importantell $z$ wischen 0 und $100 \%$ die Höherbesteuerung des betreffenden Gutes zum wettbewerbspolitischen Problem bzw. zu einer verbotenen Diskriminierung wird. Klar dürfte sein, daß ein Okonom auf diese Frage keine exakte und fur alle streitfalle gultige Antwort zu geben in der Lage ist.

Zusammenfassend kann festgehalten werden, daß jeder der drel bei der Feststellung elner Diskriminlerung zu durchlaufenden Schritte Frelrăume für unterschledlichste Interpretationen eröffnet. Je nachdem, wle die Freirăume Im Einzelfall genutzt werden, llegt das sich ergebende DiskriminierungsKonzept Irgendwo zwischen den beiden Extremen elnes kategorischen Verbots und elner uneingeschränkten Tolerierung von differenzierten Steuer-

20 Easson bezeichnet das genannte Kriterium als die "nationale Dimension" elner Steuersatzdlfferenzlerung; vgl. Easson (1981a), S.540pf. 
sătzen. Auf der juristischen Ebene zeigt sich der beschriebene Auslegungssplelraum insbesondere bel der Konkretislerung der beiden Begriffe gleichartige inländische Waren (Art.95 Abs.1) und mittelbarer Schutzeffekt (Art.95 Abs.2). Es kann daher kelne Uberraschung sein, daß sich der EuGH auf Glatteis begibt, sobald er mit der wettbewerbspolitischen Beurteilung differenzierter Steuersätze konfrontiert wird: Es wäre wohl vermessen zu glauben, daß dle Juristen dort noch festen Boden unter den Füßn haben könnten, wo, wle oben gezelgt, die Okonomen schon lange ins Schwimmen gekommen sind.

\subsection{Die Notwendigkeit einer Harmonislerung nach Art.99 EWG-Vertrag}

Die Unzulänglichkelten des Diskriminierungsverbotes nach Art.95-97 machten es unabdingbar, unmittelbar nach Gründung der EG den in Art.99 vorgesehenen steuerlichen Harmonisierungsprozeß in Angriff zu nehmen. Da das Diskriminlerungsverbot, wie oben gezelgt, keine hinrelchende Bedingung für eine wettbewerbsneutrale Besteuerung darstellt, bleibt den Mitgliedstaaten ein Freiraum für protektionistische Besteuerungspraktiken (ökonomischer Aspekt), die politische Auseinandersetzungen in der Gemeinschapt nach sich zlehen können (politischer Aspekt). Die Harmonisierung indirekter Besteuerung muß daher, wenn auch nicht ausschließlich, so doch in erster Linie, auf das Ziel der Wettbewerbsneutralităt ausgerichtet werden. Die Analyse der Măngel des Diskriminierungsverbotes zelgt uns daruberhinaus, wo die entscheldenden Probleme liegen, Pur die im Rahmen elner Harmonislerung nach Lösungen gesucht werden muß:

Schaubild 8-12: Unzulänglichkeiten des Diskriminierungsverbotes

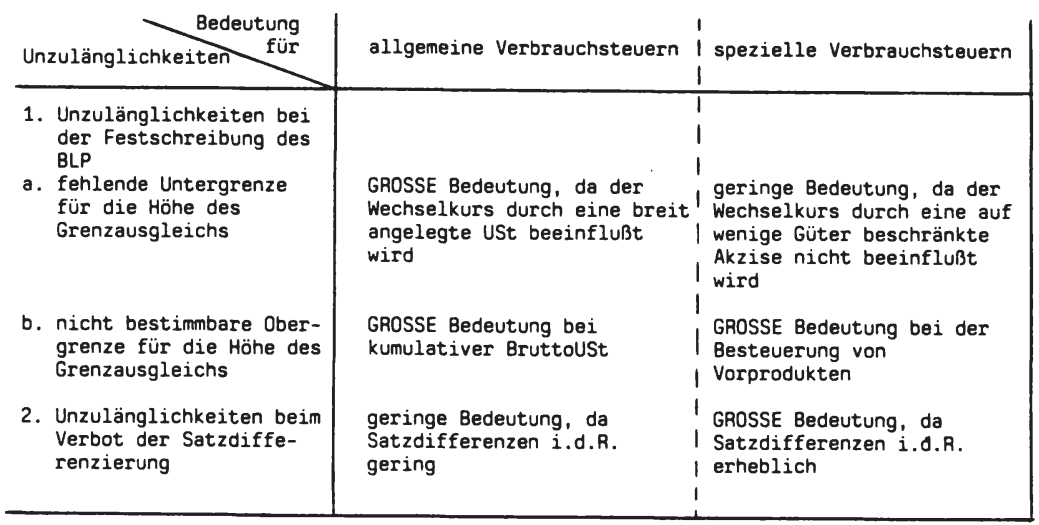


Bel den allgemeinen Verbrauchsteuern werfen, wie das Schaubild deutlich macht, die Manipulationen am Grenzausgleich die gravierendsten Probleme auf. Man mußte daher zunăchst versuchen, durch elne Beseitigung der Bruttoust-Systeme und durch die Festschreibung des obligatorischen BLP klare Rechtsverhältnisse beim Grenzausglelch zu schaffen. Dieser Weg wurde von der Kommission erfolgreich beschritten, und wir werden sogleich ausführlich darauf zurückkommen.

Ganz anders liegen die Dinge jedoch bel den speziellen Verbrauchsteuern. Hier sind es vor allem die in hohem Maße differenzierten Steuersätze, die den internationalen Wettbewerb beeinträchtígen. In Verkennung dieser Tatsache entwickelte die Kommission ihr Harmonisierungsprogramm für die Akzisen in vollständiger Analogie zu dem pür die allgemeinen Verbrauchsteuern: zuerst Vervollkommnung des Grenzausgleiches durch eine Harmonislerung der Steuersysteme; Angleichung der Steuersätze in elnem späteren Schritt. ${ }^{21}$ Einen entsprechenden Harmonisierungsvorschlag, der insbesondere die auf alkoholische Getränke erhobenen Akzlsen betraf, legte die Kommission 1972 dem Rat vor. ${ }^{22}$ Damit jedoch erlebte die Kommission einen kompletten Fehlschlag, was wohl nicht zuletzt darauf zurückzuführen ist, daß sie auf das elgentliche Wettbewerbsproblem, nämlich die Steuersätze, damals nur ganz am Rande elnging. In den polgenden Jahren rückte die Frage der Satzdifferenzierung zunehmend in den Mittelpunkt der Verhandlungen, während das Problem des korrekten Grenzausgleichs in den Hintergrund gerlet. Auf diesem Weg kam man einer Einigung sehr nahe. Allerdings war man, aufgrund taktischer Uberlegungen elnes einzelnen Mitgliedstaates, bis Mitte der 80er Jahre nicht in der Lage, eine entsprechende Richtlinie Im Ministerrat $\mathrm{zu}$ verabschieden. ${ }^{23}$

21 Vgl. z.B. Vandamme (1967).

$22 \operatorname{KOM}(72) 225$ v. 23.2.72.

23 Vgl. z.B. die Berichte zur Ratsitzung am 21.10.81 in AE v. 21.10.81, 22.10 .81 u. 23.10 .81 . 


\section{C: Die Einführung der MWSt in der EG: der große Erfolg der 60er Jahre}

Mit der Einführung der MWSt in der gesamten Gemeinschaft kommen wir zum ersten und bisher bedeutendsten schritt der Steuerharmonisierung in der EG. Die in einem ersten Abschnitt vorgenommene Darstellung der Ziele und Strategien der wichtigsten steuerpolitischen Entscheidungsträger - der Kommission sowie der im Rat vertretenen Mitgliedstaaten - verfolgt den Zweck, die allgemeine Struktur des Entscheidungsproblems zu analysieren. Der eigentliche politische willensbildungsproze $\beta$ wird in elnem zweiten, chronologisch aufgebauten Abschnitt nachgezeichnt. Der analytische wie auch der chronologische Aspekt werden jeweils zunächst aus der Gemeinschaptspersprektive und anschlleßend aus dem nationalen Blickwinkel der einzelnen Mitgliedstaaten heraus beleuchtet. 


\section{Die Zlele und Strateglen der wichtigoten Akteure}

\subsection{Die Gemelnschaftsperspektive: die Harmonislerungszlele der Kommission}

\subsubsection{Kurzfristiges Zlel: Wettbewerbsneutralltat}

\section{Rechtfertigung des Ziels}

Art.99 forderte die Kommission aup zu untersuchen, Inwieweit die indirekten Steuern in der EG "Im Interesse des Gemelnsamen Marktes" harmonisiert werden mußten. Die Erfahrungen des Steuerstreits wie auch die Einordnung der steuerlichen Vorschriften in den wettbewerbspolitischen Tell des EWGVertrages legten nahe, die Frage der Steuerharmonislerung zuallererst unter wettbewerbspolltischen Zlelsetzungen zu betrachten: Von den offentlichen Abgaben sollten weder wettbewerbshemmende noch -verzerrende Einflusse auf den innergemelnschaftlichen Handel ausgehen. Die Verwirklichung dieses Anllegens gewann an Dringllchkelt durch die verbindliche Vorschrift des Vertrages, dle Binnenzolle in genau festgelegten Schritten langsam abzubauen. Es war, wie berelts die Erfahrung mit der ersten Zollsenkung vom 1.Januar 1959 deutlich werden ließ, mit Recht zu befurchten, daß parallel zu der schrittweise vorgenommenen senkung der Zölle die indirekten Steuern immer mehr deren protektionistische Funktion ubernehmen könnten. Da die politischen Folgen einer derartigen Entwicklung unabersehbar waren - elne protektionistische Steuerpolitik bedrohte mit der Zollunion das Herzstück des erneuten europälschen Integrationsversuches -, war ein rasches Eingreifen geboten.

\section{Definition des Ziels}

Wettbewerbsneutrale Steuern zu fordern ist eine Sache; zu sagen, was man darunter konkret verstehen will, aber eine ganz andere. Man sollte erwarten können, daß die Wirtschaftswissenschaftler der Kommission mit einer elndeutigen Definition hätten hllfreich zur Selte stehen können. Aber selbst sie waren sich, wle bereits gezeigt wurde, ${ }^{1}$ alles andere als einig daruber, was im Bereich der indirekten Steuern als neutral und was als verzerrend einzustufen ist. Der Gelehrtenstrelt scheint jedoch nicht bis zur Kommission vorgedrungen $z u$ sein, sodaß Brüssel schon sehr frühzeltig, in Ubereinstimmung mit der herrschenden Lehrmelnung, die weiteren Harmonislerungsuberlegungen aup einer Gleichsetzung von Neutralităt mit allokativer Effizienz aufbaute.

$1 \quad$ Vgl. Kap.B.1.3.1. 
Es wäre jedoch falsch, der Kommission elne rein bkonomische Sichtweise der Neutralitätsproblematik unterstellen zu wollen. Dle Kommission erachtete es vielmehr als ihr primäres Ziel, das in der indirekten Besteuerung angelegte politische Konfliktpotential zu entschärfen. Dle Dominanz des politischen über den zkonomischen Aspekt zeigt sich besonders deutlich daran, daß die Kommission die Harmonislerung der indirekten Steuern forcierte, wăhrend sie die Neutralitat der direkten Abgaben als ein zweltrangiges Problem betrachtete und es zunächst vor sich herschob. Aus einem rein 8konomischen Blickwinkel gesehen ist die Abtrennung der indirekten von den direkten Steuern nicht zu rechtfertigen. Ungeachtet der nicht lösbaren Abgrenzungsprobleme zwischen den belden Steuerarten kann von einer Neutralisierung der Verbrauchsteuern nicht mit Sicherheit eln Wohlfahrtsgewinn erwartet werden, solange die von den direkten Steuern ausgehenden Verzerrungen welterbestehen. Auf diese konkrete Anwendung der bekannten Theorle des Second-Best haben immer wieder Insbesondere deutsche Okonomen hingewlesen und die Beschränkung Brüssels auf die Harmonislerung der indirekten Steuern scharf kritisiert:

"Wir glauben nach allen unseren Erörterungen, daß die Wahr-
scheinlichkelt dafür, daß im Rahmen des Bestimmungslandprin-
zips (hier gleichgesetzt mit Neutralitä der indirekten Steuern,
d.Verf.) steuerbedingte Verzerrungen beseltigt werden, zumin-
dest nicht großßer ist als die Wahrscheinlichkeit dafur, daß -
beabsichtigt oder unbeabsichtigt - neue Verzerrungen geschap-
fen werden."

Aus rein ökonomischer Sicht ist die am Vorgehen der Kommission angebrachte Kritlk fundiert und korrekt. Sie ubersleht jedoch vollständig die der Kommission wesentlich wichtigeren politischen Aspekte der Neutralitat im steuerlichen Bereich. Die Kommission kannte sehr wohl die von den direkten Abgaben aufgeworfenen Probleme, hlelt sie aber aufgrund der folgenden Uberlegungen für weniger dringlich: Im Gegensatz zu den direkten Steuern können die indirekten, bedingt durch die Manipulationsmöglichkelten belm Grenzausglelch, erheblich zlelgerichteter und auch offensichtlicher zur Protektion elnzelner Branchen eingesetzt werden; der in ihnen angelegte politische Sprengstopf ist daher als bel weitem gefahrlicher elnzustufen. Eine aus okonomischer Sicht zu befurwortende integrierte Analyse und Harmonisierung von indirekten und direkten Abgaben birgt die Gefahr in sich, dle unbedingt notwendigen Maßnahmen aup dem Geblet der indirekten Besteuerung um elne politisch nicht vertretbare zelt zu verzögern. ${ }^{3}$

2 Giersch (1962), S.26. Vgl. ähnl. bel Schmölders (1962), S.14ff. Weniger uberzeugend, aber zu demgleichen Ergebnis hinführend, ist die aus einer eher Juristischen Perspektive geschriebene Arbeit von Flume/ Schmidt (1962).

Vgl. z.B. KOM(62)217, S.2f. Vgl. ăhnl. Deringer-Bericht (1963), S.24ff. 
Steuerliche Neutralität bedeutete also, und das gilt auch heute noch, für die Kommission immer zweierlel:

- Neutralität im ökonomischen Sinne, sprich Allokationseffizienz.

- Neutralität im politischen Sinne, sprich die steuerpolitische Befriedung der Gemeinschaft; die Säuberung des steuerpolitischen Instrumentariums der Mitgliedstaaten von solchen Handlungsalternativen, die es einem Land in einem für die anderen unerträglichen Maße erlauben, nationale Interessen auf Kosten der Partner zu verfolgen; Sicherstellung eines fair play durch gemeinschaftlich erlassene und respektierte Verhaltensregeln.

Die beiden Neutralitätskonzepte müssen nicht notwendigerweise, wie wir an dem Beispiel der Abtrennung des Problems der indirekten von dem der direkten Steuern gesehen haben, zu demselben Ergebnis Pühren. Weitere Konplikte ergeben sich, wie im folgenden deutlich werden wird, auch bel der Harmonisierung der indirekten Steuern selbst.

\section{Verwirklichung des Ziels}

Welche Alternativen standen, so müssen wir uns nun Pragen, der Kommission zur Verfügung, um für Neutralität bel den indirekten Steuern zu sorgen? Der Kern aller Probleme mit der USt waren die Manipulationsmöglichkeiten beim Grenzausgleich. Also wieso nicht einfach den Grenzausgleich abschaffen? Unterstützung fand diese einfachste aller Lösungen insbesondere aup Seiten der deutschen Industrie und allen voran bei der deutschen Stahlindustrie, die nach der Franc-Abwertung von Ende 1958 ihre aus dem Steuerstreit stammenden Argumente wleder aus der Schublade hervorkramte umd mit nicht nachlassendem Eifer verbreitete.` Die Vorteile lagen auf der Hand: eine klare Rechtsregel, die zwar nicht notwendigerweise zu ökonomischer Neutralität, aber in jedem Fall zu einer politischen Befriedung der Gemeinschaft geführt hätte. Leider war der Vorschlag für die Kommission ebensowenig akzeptabel wie seinerzeit für die Hohe Behörde der EGKS, und zwar aus ähnlichen Gründen: Der wichtigste war der zu erwartende, ca.15prozentige Abwertungsdruck auf den Pranzösischen Franc.

An elne Herabsetzung der Grenzausgleichssätze war also kaum zu denken. Im Gegenteil gingen die wirtschaftlichen Interessen der Beteiligten dahin, mit sinkenden Zollmauern die Steuermauern zu erhöhen. Wie dies in der Praxis aussah, zeigten Belgien und die Niederlande, die pünktlich zur ersten gemeinsamen Zollsenkung den umsatzsteuerlichen Grenzausgleich entsprechend anhoben.' Andere Mitgliedstaaten drohten nachzuziehen. Die

$4 \quad$ Vgl. z.B. Handelsblatt 17.11.58, FAZ 4.6.59, Industrie Kurier 5.11.59 u. Welt 4.12.59. Vgl. a. die im Auftrag des Verbandes der deutschen Stahlindustrie angefertigten Gutachten von Giersch (1962), Flume/ Schmidt (1962) u. Schmölders (1962).

5 Quelle: Persönliches Interview. Vgl. a. HB 27.2.59, Industrie Kurier 7.3.59 u. 30.6.59. 
Pür die Steuerpolitik der einzelnen Länder unmittelbar verbindlichen Art.95-97 boten keine Handhabe, diesem Treiben Einhalt zu gebieten, erlaubte das darin verankerte fakultative BLP doch ausdrücklich, den Grenzausglelch $z$ wischen einem Satz von $0 \%$ und der inländischen Belastung gleichartiger Güter frei zu variieren. Also was tun?

Auch der alte Vorschlag des Tinbergen-Ausschusses hatte inzwischen keinerlei Aussicht auf Verwirklichung mehr. Der Zug der Grenzausgleichs-Erhöhungen war, einmal ins Rollen gekommen, längst an der vom TinbergenAusschuß anvisierten Marke Standardsatz der USt vorbeigefahren. Der Kommission blieb daher nichts anderes übrig als der Versuch, zu retten, was $\mathrm{zu}$ retten war, und besagten $\mathrm{Zug}$ dort $\mathrm{zu}$ stoppen, wo er gerade angekommen war. Schapfen wollte Brüssel das Bremsmanöver mit einer Stillhalteverpflichtung, die die einzelnen Mitgliedstaaten darauf festlegte, bis auf wenige, genau definierte Ausnahmefälle von weiteren Erhöhungen des Grenzausgleichs abzusehen. Mit Neutralität im ökonomischen Sinne hatte die Festschreibung des Status quo natürlich nichts zu tun. Dafür hoffte man aber, durch eine gemeinsam erlassene Splelregel die in Art.95-97 den Mitgliedstaaten belassenen Freiheiten so einzugrenzen, daß den Anderungen des Grenzausgleichs, soweit sie überhaupt noch vorgenommen werden durften, die das politische Klima in der Gemeinschaft vergiftenden Zähne gezogen werden konnten. Eine entsprechende Regel glaubte man mit der Resolution vom 20.Juni 1960 gefunden zu haben.6 Das jedoch erwies sich sehr schnell als eine Illusion. Die Splelregel, falls sie überhaupt jemals richtig existiert hatte, wurde von den wirtschaftlichen Interessen der Mitgliedstaaten überrollt, dle ihren Grenzausgleich weiter erhöhten: Das Interesse einzelner Länder - zu nennen ist insbesondere die Bundesrepublik -, ihren Grenzausgleich im Rahmen des Vertrages ungehindert zu erhöhen, war stärker als das Bedürfnis, die anderen an genau diesem Verhalten zu hindern.

Je höher die Steuermauern wuchsen und sich der in Art.95-97 definierten Obergrenze näherten, desto mehr wurde die zweite Lücke in den steuerlichen Vorschriften des EWG-Vertrages zum Problem: Die für den Grenzausgleich festgelegte Obergrenze war in Anbetracht der in 5 von 6 Mitgliedstaaten verwandten kumulativen USt-Systeme in der Praxis nicht zu berechnen und damit nicht $z u$ kontrollieren. Die Saat für gegenseitiges Mißtrauen und Vorwürfe der Vertragsverletzung war damit gelegt. Sie ging erstmals auf, als im September 1960 die Italiener mit massiven Erhöhungen der Grenzausgleichssätze der Obergrenze des Vertrages verdächtig nahe kamen und sie in einigen Fällen wohl auch übersprangen. Auch hier dachte die Kommission zunächst daran, den vom Vertrag gelassenen Handlungssplelraum mit einer gemeinsam zu verabschiedenden Spielregel einzuengen: Eine sogenannte gemeinsame Berechnungsmethode sollte die in Art.95-97 theoretisch definierte Obergrenze für den praktischen Gebrauch opera-

6 Vgl. hierzu die ausführliche Darstellung in Kap.B.2.1.3.1. 
tionalisieren. ${ }^{7}$ Aber auch dieser Versuch schlug kläglich fehl. Es waren allen voran die Itallener, die sich mit ihrem Grenzausglelch hart an der Grenze des Erlaubten befanden und sich energisch gegen die Verabschiedung einer Regel sträubten, die Ihren Freiheitssplelraum beschnitten hătte.

Mit dem Stlllhalteabkommen und der gemeinsamen Berechnungsmethode hatte sich die Kommission dem aup ständige Erhöhungen des Grenzausgleichs hinwirkenden Druck entgegenwerfen wollen. Es blleben jedoch zur Erfolglosigkelt verdammte Ruckzugsgefechte, die das stetige Anwachsen der Steuermauern letztendlich nicht aufzuhalten vermochten. Bel all thren glücklosen Versuchen hatte dle Kommission gelernt, daß eine Lösung für das Unwesen mit den Grenzausgleichssătzen, wenn uberhaupt, nur an der vertragllch flxlerten Obergrenze gefunden werden konnte. Wenn die Mitgliedstaaten Ihren Grenzausgleich aber schon so weit hinaufsetzen wollten, dann sollte er wenigstens auf saubere Art und Welse durchgeführt werden. Mit einer kumulativen BruttouSt war das nicht möglich. Sie mußte durch nicht-kumulative Systeme ersetzt werden, die eine einfache Ermittlung der Inländischen Steuerbelastung erlaubten. Dle in Art.95-97 definlerte Obergrenze konnte dann zwelfelsfrel bestimmt und somit der Grenzausgleich exakt und konfliktfrel abgewickelt werden. Das erste Ziel der USt-Harmonisierung war damit formullert: Einfuhrung eines nicht-kumulativen USt-Systems in allen Mitgliedstaaten. Damit konnte eln falr play im innergemeinschaftlichen Handel gewăhrlelstet werden. Die Lösung versprach darüberhinaus sogar, wenn man von Steuersatzdifferenzlerungen sowle direkten steuern und Sozlalabgaben etc. elnmal absleht, ökonomische Neutralităt.

\subsubsection{Langfristiges Zlel: Abschaffung der Steuergrenzen}

\section{Rechtfertigung des Zlels}

Mit fair play im umsatzsteuerlichen Berelch wollte es die Kommission noch nicht bewenden lassen. Sie hatte noch Höheres Im Sinn. Der Gemeinsame Markt sollte, so das von Kommissar von der Groeben geprägte und propagierte Schlagwort, binnenmarktähnliche Verhăltnisse aufweisen, und zwar auch auf steuerlichem Geblet. ${ }^{-}$Der Begriff der binnenmarktähnlichen Verhältnisse taucht im EWG-Vertrag weder explizit auf noch ist er zwischen den Zellen Irgendwo zu finden. Es handelte sich vielmehr um eine Weiterentwicklung des eigentlichen Vertragstextes, die bel den Mitgliedern der ersten EWG-Kommission kelneswegs auf ungeteilte Zustimmung stieß. Der relatlv große Entscheldungssplelraum, der Jedem Kommissar in dem von $\mathrm{hm}$ zu verantwortenden Politikberelch zugestanden wurde, ließ es Jedoch zu, daß sich zumindest in der in die Zuständigkeit des deutschen Kommissars

7 Vgl. hierzu die ausfuhrliche Darstellung in Kap.B.2.1.3.2.

- Vgl. z.B. Groeben (1962), S.9ff. 
von der Groeben Pallenden Wettbewerbspolitik, die die Steuerharmonisierung mit umfaßte, die binnenmarktähnlichen Verhältnisse als Leitmotiv etablieren konnten.

Was sind aber nun binnenmarktähnliche Verhältnisse, wenn es um die Erhebung indirekter Steuern geht? Steln des Anstoßes war wiederum der Grenzausgleich. Aus der Perspektive der Wettbewerbsneutralitat stellten die Manipulationsmöglichkeiten am Grenzausgleich das zentrale Problem dar. Es ging folglich um das Wie des Grenzausgleichs. Unter dem Blickwinkel der blnnenmarktähnlichen Verhältnisse wurde die Existenzberechtigung des Grenzausgleiches selbst in Frage gestellt. Dle Frage nach dem Wie ruckte folglich in den Hintergrund, relevant war nun allelne das ob überhaupt. Der Grund fur die nunmehr geănderte Sichtweise ist einfach einzusehen:

Um den steuerlichen Grenzausglelch, in welcher Höhe auch immer er erhoben wird, verwaltungstechnisch durchführen zu können, muß jemand an der Grenze stehen und die dort passierenden Waren kontrollieren. Solcherart Steuergrenzen haben mit binnenmarktahnlichen Verhälnissen nichts gemein, zelchnen sich doch Binnenmärkte im landläufigen Sinne gerade durch das Fehlen von Grenzkontrollen aus. Der steuerliche Grenzausgleich ist zwar nicht der einzige, aber immerhin einer der wichtigsten Gründe für das Weiterbestehen von innergemeinschaftlichen Grenzkontrollen auch über die Verwirklichung der Zollunion hinaus. Und aus eben diesem Grunde war er der Kommission ein Dorn im Auge. Wăhrend die Zollgrenzen mit dem Ende der Ubergangszelt - der EWG-Vertrag sah ursprünglich den 1.Januar 1970 vor - Pallen sollten, Implizierte die Belbehaltung der Steuergrenzen, da $\beta$ weiterhin die glelchen Personen - die Zöllner - mit dergleichen Frage "Haben Sle etwas anzumelden?" - nun zwar keine Zölle mehr, dafür aber noch Steuern abkassieren sollten. Es war klar, daß der einfache Bürger für derlel spitzfindige Unterscheidungen nur wenig Verstăndnis zelgen würde. Er wüde vielmehr aus der lästigen Frage der Grenzbeamten schließen, daß es mit den Erfolgen der EG so weit wohl nicht her sein könne.' Neben berechtigtem Unmut verursachen die Grenzkontrollprozeduren aber auch handfeste ökonomische Kosten, deren deutlichstes äußeres Zeichen die an den Grenzen wartenden LKW-Kolonnen sind. ${ }^{10}$

All dies wăre aber so lange noch keln gravierendes Problem gewesen, hătte sich die EG als elne reine Wirtschaftsgemeinschaft verstanden. Aber die Gemeinschaft empfand slch Im Gegentell als die Keimzelle elnes auch polltisch geeinten Europas. Und auf dem Weg dorthin mußten, das stand außer Frage, die Schlagbăume an den Grenzen fallen. Dle Forderung, daß dle Steuergrenzen spătestens mit den Zollgrenzen verschwinden müßten, ergab

- Vgl. ahnl. Deringer-Bericht (1963), S.32.

10 Eine umfassende Begründung des Zlels "Abschaffung der Steuergrenzen" findet sich in elner Grundsatzrede, dle Kommissar von der Groeben am 17.10.63 vor dem EP hlelt; vgl. Groeben (1963). 
sich also ganz automatisch und war zunächst überwiegend politisch motiviert.

\section{Definition des Ziels}

Um die steuerlich bedingten Grenzkontrollen - sprich die Steuergrenzen abschapfen zu können, muß der steuerliche Grenzausgleich verschwinden. So lautete zunächst die Grundthese der Kommission. Aber im Laufe der Diskussion stellte sich alsbald heraus, daß die Sache so einfach nicht war. Erstens wurde deutlich, daß die Abschaffung der Grenzkontrollen nicht notwendigerwelse mit dem Verzicht aup einen Grenzausgleich einhergehen muß. Ein entsprechender niederländischer Vorschlag sah vor, unter Beibehaltung des Grenzausgleichs die notwendigen Kontrollmaßnahmen durch einige verwaltungstechnische Reformen von der Grenze ins Inland zu verlagern.11 Zweitens wurde klar, daß die Beseitigung der Steuergrenzen eine Sache ist, die daraus eventuell resultierende Umverteilung des USt-Aufkommens zwischen den Mitgliedstaaten eine ganz andere. Ein steuerlicher Grenzausgleich, zumindest soweit er vollständig erfolgt, weist das Aupkommen automatisch dem Land zu, auf dessen Territorium das belastete Gut verbraucht wird. Und kelner der Mitglledstaaten zeigte die Bereitschaft, an diesem Prinzip rütteln zu lassen. Es war daher in Betracht zu ziehen, daß, sofern die Abschaffung der Steuergrenzen am Status quo etwas ändern sollte, gegebenenfalls ein Umverteilungsmechanismus - ein sogenanntes clearing - installiert werden mußte. Das ursprünglich undifferenziert gesehene Ziel Abschaffung der Steuergrenzen spaltete sich somit in insgsamt drei verschiedene Stufen auf:

- Abschaffung der physischen Grenzkontrollen unter Beibehaltung des Grenzausgleichs (niederländischer Vorschlag).

- Abschaffung des Grenzausgleichs bei gleichzeitiger Installierung eines clearing.

- Abschaffung auch des clearing; vollständige rechtllche und verfahrenstechnische Gleichbehandlung aller im EG-Raum gehandelten Güter.

Die Kommission mußte sich nun entscheiden, welche der drei Stufen sie anzustreben beabsichtigte. Die dritte Stufe erschien ihr als ein wenig $z u$ hoch gegriffen, da der Verzicht auf ein clearing, wie das Beispiel der Pöderalistisch organisierten Bundesrepublik deutlich machte, zur Voraussetzung hatte, daß sämtliche USt-Einnahmen innerhalb der EG in einen gemeinsamen Topf pließen. Und daran war sobald nicht zu denken. Auf der anderen Seite hielt sie die Abschaffung der physischen Warenkontrollen an den Grenzen für ein wenig zu dürftig. Europa, so schien die Einstellung der Kommission zu sein, kann nicht alleine auf verwaltungstechnische Tricks aufgebaut werden.12 Die Kommission entschied sich mit der zweiten

11 Vgl. ausführlicher in Kap.C.2.1.2.2.

12 Eine deutsche Zeitung kommentierte damals, die Annahme des niederländischen Vorschlages hieße die Abschaffung der Steuergrenzen "..zu 
Stufe für den goldenen Mittelweg. Zur Klarstellung dessen, was man meinte, wurde fortan in den meisten offiziellen Dokumenten der Begriff Steuergrenzen mit Besteuerung der Einfuhr und die steuerliche Entlastung der Ausfuhr umschrieben. ${ }^{13}$

\section{Verwirklichung des Zlels}

Hatte man das Ziel festgelegt, so war als nächstes nach dem Weg dorthin zu Pragen. Welche Voraussetzungen mußten geschaffen werden, um den steuerlichen Grenzausgleich abschaffen zu können? Im Laufe der Debatte wurde rasch deutlich, daß zwei Postulate zu erfüllen waren:14

1. Alle Mitgliedstaaten müssen ein identisches USt-System anwenden. Es ergab sich sofort die nächste Frage, welches Steuersystem dies sein könnte. Technisch ist es möglich, die Steuergrenzen bei jedem bellebigen USt-Typ abzuschaffen. Trotzdem schied die Mehrheit der Alternativen sehr bald aus, da sie in dem einen oder dem anderen Mitgliedstaat politisch nicht hätte durchgesetzt werden können. Da gab es zum einen den aus den frühen Jahren der Benelux-Union stammenden Vorschlag, auf die Steuergrenzen unter Belbehaltung einer kumulativen BruttoUSt zu verzichten. Das Konzept basierte jedoch auf einem USt-System deutschen Typs, wie er Ende der 50er Jahre nur noch in der Bundesrepublik und in Luxemburg anzutreffen war. Eine Rückkehr zu einer solch archaischen Abgabe war in den anderen Staaten undenkbar und erschien der Kommission auch nicht wünschenswert, da es für eine die Arbeitsteilung und das Wachstum hemmende Steuer in der EG keine Zukunft geben konnte. Von den nicht-kumulativen Systemen war aus der Sicht der Gemeinschaft eine einphasige USt, erhoben aup der Einzelhandels- oder der Großhandelsstufe, die ideale Lösung. ${ }^{15}$ Probleme mit der Aufkommensverteilung hätte es bei einer solchen Steuer praktisch nicht gegeben, da die große Masse des grenzüberschreitenden Handels auf einer dem Großhandel vorgelagerten (und damit unbesteuerten) Stufe abgewickelt wird. Aber leider war auch dies, wie später noch zu erläutern sein wird, Pür die Mehrheit der Länder keine politisch akzeptable Alternative. Als einzige Möglichkeit und Hoffnung blieb die MWSt. In Frankreich existierte

einer Frage der EWG-Public-Relations zu degradieren"; Industrie Kurier 7.7.60.

13 So z.B. In Art.4 Abs.1 der 1.USt-Richtlinie. Es sei daraup hingewiesen, $\mathrm{da} \beta$ bei den meisten Richtlinien des Rates, Richtlinienvorschlägen der Kommission sowie den Stellungnahmen von EP und WSA aup einen Quellennachweis im Text verzichtet wird. Die entsprechendon Informationen sind in Anlage II der Arbeit zusammengestellt. Lediglich bei solchen Richtlinien, die wegen ihrer geringen Bedeutung für die Arbeit in die genannte Anlage nicht aufgenommen wurden, wird in elner Fußnote auf die jewellige Fundstelle in einer Amtlichen Veröpfentlichung der EG aufmerksam gemacht.

14 Die theoretische Fundlerung der folgenden Ausführungen findet sich in Kap.B.1.3.; vgl. insbes. das Schaubild am Ende des Kapitels.

Vgl. z.B. Mersmann (1959b), S.372f. 
sle bereits in rudimentärer Form, und in Deutschland, dem einzigen Land der Gemeinschaft, wo man sich damals ernsthafte Gedanken über eine Reform der USt machte, wurde ihre Einfuhrung als wichtigste Alternative zur bestehenden BruttoUSt erwogen. Es lag also nahe, zumindest den Versuch zu wagen, auch den anderen Låndern elne MWSt schmackhaft zu machen.

2. Neben der Elnheitlichkeit der USt-Systeme ist für die Abschaffung der Steuergrenzen noch eln weiteres Postulat zu erfullen. Die in den einzelnen Mitgliedstaaten erhobenen Steuersătze müssen elnander angenăhert werden, um zu verhindern, daß dle Verbraucher nach Abschaffung des Grenzausgleichs inre Käufe von Hoch- in Niedrigsteuerländer verlagern. In Anbetracht der unterschledlichen Bedeutung der Verbrauchsbesteuerung in den verschledenen Mitgliedstaaten hatte elne solche Angleichung schwerwiegende budgetăre Konsequenzen:

Tabelle C-1

Anteil der Verbrauchsteuern

am gesamten Steueraufkommen des Staates (1959) in \%

$\begin{array}{lccc} & \text { Verbrauchstevern } & \text { davon USt } & \text { davon Akzisen } \\ \text { Luxemburg } & 31,0 & 16,2 & 14,8 \\ \text { Niederlande } & 32,3 & 19,0 & 13,3 \\ \text { Deutschland } & 42,5 & 25,3 & 17,2 \\ \text { Belgien } & 47,5 & 29,1 & 18,4 \\ \text { Frankreich } & 57,5 & 34,7 & 22,8 \\ \text { Italien } & 60,1 & 20,4 & 39,7\end{array}$

Quelle: Neumark-Bericht (1962), S.28.

Sollen zum Zwecke eines generellen Verzichtes aup die Steuergrenzen neben den Sätzen der allgemeinen auch die der speziellen Verbrauchsteuern harmonislert werden, so kann der notwendige Budgetausgleich nur uber eine Veränderung der direkten Steuern erfolgen. Wie schon beim Ziel der Wettbewerbsneutralitat besteht also auch hler ein enger Zusammenhang zwischen der Anglelchung der Indirekten Steuern auf der einen und der der direkten auf der anderen Selte. Und abermals war dle Kommission bestrebt, Ihr Harmonisierungskonzept fur die indirekten steuern von den umstrittenen Fragen der direkten Besteuerung loszulösen: Um sich nicht in endlosen Diskussionen zu verlleren, bestand sie mit Nachdruck darauf, daß die in Zukunft elnmal notwendige Harmonisierung der direkten Abgaben keineswegs ein Hinderungsgrund für die sofortlge Inangriffnahme der USt-Harmonisierung sein dürfe. ${ }^{16}$ War die Angleichung der USt erst elnmal politisch durch-

16 Vgl. z.B. Groeben (1963), S.5Pf. 
gesetzt, so ergab sich die der direkten Steuern als logische und von der Kommission durchaus geschatzte Folge ganz wie von selbst: "Dle Umsatzsteuer ist...der Hebel, mit dem die allgemelne Harmonislerung der Steuern in Bewegung gebracht werden kann."17

\subsubsection{Strategle: Entwicklung eines Stufenprogrammes}

Das ausgewogene Stufenprogramm

Beschrănken wir uns wleder aup den Bereich der USt, so waren es zweí Ziele, die die Kommission Im Auge hatte: Wettbewerbsneutralltăt in kurzfristiger und Abschaffung der Steuergrenzen in langfristiger Sicht. Ziele alleine aber reichen für die Etablierung einer Politik noch nicht aus. Sie bedurfen vielmehr der Ergänzung durch eine Strategie, die anglbt, in welcher Reihenfolge und mit welchen Mitteln die Ziele errelcht werden sollen. Die Kommission entwickelte, in Oberelnstimmung mit den Empfehlungen des aus Wissenschaftlern zusammengesetzten Steuer- und Finanzausschusses ${ }^{18}$, eln vierstufiges Harmonisierungsprogramm, das sich in dieser Form auch im Vorschlag fur eine 1.USt-Richtlinie von 1962 niederschlug:

Schaubild C-1

Das Stufenprogramm der Kommission

\begin{tabular}{|c|c|c|c|}
\hline & Mittel & 1 & Ziele \\
\hline 1. Schritt & $\begin{array}{l}\text { Einführung einer } \\
\text { nicht-kumulativen USt }\end{array}$ & 1 & $\begin{array}{l}\text { Wettbewerbsneutralität im } \\
\text { polit. und ökonom. Sinne }\end{array}$ \\
\hline 2. Schritt & Einführung einer MWSt & 1 & $\begin{array}{l}\text { 1. Voraussetzung für die } \\
\text { Abschaffung der Steuergrenzen }\end{array}$ \\
\hline 3. Schritt & Angleichung der Steuersätze & 1 & $\begin{array}{l}\text { 2. Voraussetzung für die } \\
\text { Abschaffung der Steuergrenzen }\end{array}$ \\
\hline 4. Schritt & $\begin{array}{l}\text { Verzicht auf den } \\
\text { steuerlichen Grenzausgleich }\end{array}$ & $i$ & Abschaffung der Steuergrenzen \\
\hline
\end{tabular}

Kennzeichen der steuerpolitischen Strategie Brüssels war ihre Ausgewogenhelt, und zwar in zwelerlel Hinsicht. Zum elnen lehnte sich das Stufenprogramm eng an das Konzept des EWG-Vertrages an, der ebenfalls mehrere Schrltte fur die Verwirklichung des Gemeinsamen Marktes und Insbesondere der Zollunion vorsah. Ein ausgewogenes Voranschreiten der umsatzsteuerlichen Harmonislerung mit der zunehmenden Integration in anderen Politik-

17 Deringer-Bericht (1963), S.32.

18 Năheres hlerzu findet sich in Kap.C.2.1.2.1. 
bereichen war damit sichergestellt. Zum zweiten versöhnte das Stufenprogramm die von Pinanzwissenschaftlicher Seite hervorgehobene Notwendigkeit ökonomischer Neutralität mit der Errelchung politisch motivierter Zielvorstellungen - Garantie eines fair play und Abschaffung der Steuergrenzen. So sollte z.B. auf den Grenzausgleich erst dann verzichtet werden, wenn nach einer vorhergehenden Harmonisierung der nationalen Steuersysteme und -sätze davon ausgegangen werden konnte, daß ökonomische Verzerrungen nicht mehr aufträten.

\section{Der unausgewogene Sohl-Vorschlag}

Das von der Kommission entwickelte Stufenprogramm unterschied sich grundsätzlich von einem zweiten Strategievorschlag, der insbesondere von der Wirtschaftsvereinigung der deutschen Eisen- und Stahlindustrie und den ihr verbundenen Wissenschaftlern vertreten wurde. Das in Brüssel kurz als Sohl-Vorschlag - Sohl war Präsident des besagten Verbandes - gehandelte Konzept zeichnete sich durch eine extreme Unausgewogenheit aus. Es rollte das gesamte Problem der Steuerharmonisierung von der genau entgegengesetzten Seite auf, indem es den vierten Schritt an den Anfang setzte und den sofortigen Verzicht auf den umsatzsteuerlichen Grenzausgleich forderte. Die Begründung war bestechend einfach: Die beiden der Kommission wichtigen politischen Ziele - fair play und Abschaffung der Steuergrenzen - können bereits im ersten Schritt erreicht werden; selbstverständlich führt ein plötzlicher Wegfall der Steuergrenzen in Anbetracht der Unterschiedlichkeit der Steuersysteme zu Verzerrungen größeren Ausmaßes; die unter dem neuen steuerlichen Regime benachteiligten Branchen werden jedoch bei ihren nationalen Regierungen auf Steuerreformen drängen und damit aus einem wirtschaftlichen Eigeninteresse heraus auf eine UStHarmonisierung in der EG hinwirken, die die zuvor ganz bewußt herbeigePuhrten Verzerrungen ex post wieder beseltigt.19 $\mathrm{Zu}$ ergänzen bleibt, daß der Sohl-Vorschlag die Harmonisierung ex post keineswegs als eine secondbest Lösung gegenüber der Harmonisierung ex ante empfand, sondern vielmehr als die einzige realistische Möglichkeit, überhaupt jemals zu einer Angleichung der europäischen Steuersysteme zu gelangen:

"Es ist mehr die Logik der Tatsachen, als die Beschlüsse von Kommissionen, und mehr das wirkliche oder vermutete Eigeninteresse, als das hohe Ziel der europäischen Gemeinsamkeit, das diesen Prozeß (der Steuerharmonisierung, d.Verf.) bisher vorwärtsgetrieben hat; es dürfte sich empfehlen, auch für die Harmonisierung der Steuersysteme in der EWG mehr auf diese starken Kräfte spontaner nationaler Regelungen zu vertrauen als auf die wenig konkreten Bestimmungen der römischen Verträge und ihre Interpretation." 20

19 Vgl. z.B. Glersch (1962) und Schmölders (1962).

20 Schmölders (1962), S.26P. 


\section{Vergleich der beiden Strategien}

Die spätere Entwicklung sollte zeigen, wle recht Schmölders damals hatte. Aber zunächst war der Sohl-Vorschlag für die Kommission aus zwelerlei Gründen nicht akzeptabel:

1. Jede Steuerharmonisierung, egal ob ex ante oder ex post, verlangt von Jedem elnzelnen Mitgliedstaat eine Anpassung der Steuergesetzgebung. Die Frage ist lediglich, wie die Anpassungslasten auf die verschiedenen Länder verteilt werden sollen. Der Kommissionsvorschlag ließ die Verteilungsfrage noch weitgehend offen, da er nichts darüber aussagte, in welcher Richtung - nach oben oder nach unten - die Steuersätze einander angeglichen werden sollten. Demgegenüber stellte der Sohl-Vorschlag die Anpassungskosten einseitig den Franzosen in Rechnung, da eine sofortige Abschaffung des Grenzausgleichs, wie bereits mehrfach betont, wegen der hohen Grenzausgleichssätze der französischen Taxe sur la Valeur Ajoutée einen ca.15prozentigen Abwertungsdruck auf den Franc ausgelöst hätte. Schmölders war sogar so ehrlich, sprich undiplomatisch, dies offen zuzugeben: "Der Vortell dieses Verfahrens wäre es, das Problem der TVA vor aller Augen deutlich als Pranzösisches Sonderproblem herauszustellen"21. Der Kommission konnte an einer politischen Isollerung des sowieso schon mit Vorsicht zu behandelnden französischen Partners verständlicherweise nichts gelegen sein.

2. Eine sofortige Abschaffung des Grenzausgleichs hätte für sämtliche Mitgliedstaaten einen Sprung ins kalte Wasser bedeutet, und der war, darüber war sich Brüssel nur zu sehr im Klaren, jedem leichter abzuringen als den tendenziell eher konservativ orientierten Finanzpolitikern. Vorsicht in höchstem Maße scheint, gewährt sie doch die höchste Überlebenschance im gefährlichen Geschapt der Finanzpolitik, eine typische Verhaltensmaxime eines jeden Steuerpolitikers zu sein. Und so hatten hohe Beamte der Brüsseler Wettbewerbsdirektion für den Sohl-Vorschlag nur ein Wort übrig: "nalv"22. Der Kommission blieb nichts anderes übrig, als sich in kleinen und in ihren Auswirkungen uberblickbaren Schritten und Schrittchen langsam an ihr Endziel Abschaffung der Steuergrenzen heranzuarbeiten. Große Würfe waren hier nicht zu landen.

In kurzfristiger Sicht war das Kommissions-Programm als Optimum zu betrachten, da es nach Abschluß des ersten Schrittes Verzerrungen auch vorübergehender Natur weitgehend vermled. Aus einer langfristigen Perspektive betrachtet hätte jedoch dem Sohl-Vorschlag der Vorzug gegeben werden müssen, da er bewußt ein Ungleichgewicht schaffte und anschließend daraup bauen konnte, da $\beta$ die hierdurch aktivierten wirtschaftlichen Interessen

\footnotetext{
21 Schmölders (1962), S.29.

22 Persönliches Interview.
} 
quasi-automatisch die notwendige Steuerharmonisierung bewirken. ${ }^{23}$ Aup Hilfe vitaler Eigeninteressen konnte die Kommission nur bel der Verwirklichung ihres ersten Schrittes bauen, da såmtlichen Ländern an einer Heraufsetzung lhrer Grenzausgleichssătze sowle, in begrenztem Maße, an elner Beendigung der steuerpolitischen Manipulationen und Auseinandersetzungen gelegen war. Bel den welteren Schritten blleb die Kommission jedoch im wesentlichen auf sich allelne gestellt. Sle konnte lediglich darauf hoffen, daß elnzelne Mitgliedstaaten das politisch motivierte Ziel Abschaffung der Steuergrenzen unterstützten und bel seiner Reallsierung mithalfen. Aber reichte das Prinzlp Hoffnung alleine schon aus?

Anfang der 60er Jahre durfte die Kommission noch mit Recht glauben, daß der mit dem EWG-Vertrag begonnene wirtschaftliche Integratlonsproze $\beta$ nur der Anfang einer Entwlcklung war, dle bald auch in elne politische Integration einmulnden wäde. Als aber die politische Zukunft der Gemeinschaft nach de Gaulles Politik des leeren Stuhls von 1965/66 in immer weitere Ferne ruckte, schwanden auch zunehmend die Chancen fur eine Abschaffung der Steuergrenzen. Dle ab Mitte der 60er Jahre zu beobachtende politische Stagnation der EG wird damit zum Haupterklärungsfaktor fur die selt dieser Zelt langsam Ins Stocken geratene Arbeit an der USt-Harmonlsierung. Aber dazu spăter.

\subsection{Dle nationale Perspektive: die steuerpolitischen Zlele der Mitglledstaaten}

\subsubsection{Binnenpolitische Ziele: Dominanz des Plskalischen Ziels}

Sowohl den sechs ursprunglichen Mitgliedstaaten der EG als auch in den drel spăter neu hinzugekommenen kam es im Laufe der 50er oder spätestens der 60er Jahre Irgendwann einmal zu Uberlegungen, die Jewells bestehenden USt-Systeme zu reformleren. Bedingt durch sich verăndernde Rahmenbedingungen im allgemeinen und einen stelgenden Finanzbedarf im besonderen vergrößerten sich mit der Zeit verschiedene Nachtelle, die die

23 Der Gegensatz zwischen den belden Konzepten findet eine interessante Parallele Im Bereich der Entwicklungstheorle: Wahrend das Konzept des "balanced-growth" daraup bedacht ist, in jedem Entwicklungsstadium eln bkonomisches Gleichgewicht bzw. Optimum aufrechtzuerhalten, will das Programm des "unbalanced-growth" aber die bewußte Schaffung elnes Ungleichgewichtes den knappen Faktor "unternehmerisches Potential" aktivieren, der durch die Beseitigung des Ungleichgewichts den angestrebten Entwicklungsproze $\beta$ erst initllert. Der einzige Unterschled zu unserem Problem liegt darin, daß es dem Sohl-Vorschlag um den knappen Faktor "politischer Einigungswille" ging. 
althergebrachte USt in sich barg. Die dadurch jewells belasteten wirtschaftlichen Interessen ubten Druck auf die politischen Instanzen aus, die wlederum mit entsprechenden Reformüberlegungen reagierten. Dles zelchnete sich als allgemeine Struktur eines Prozesses $a b$, der jedoch in allen Mitgliedstaaten, wle später noch anhand verschledener Belsplele gezelgt werden wird,24 in sehr unterschiedlichen Bahnen verliep. Bereits jetzt soll versucht werden, all diese Entwicklungen in einen systematischen Zusammenhang zu stellen und die wichtigsten Variablen herauszuarbeiten, die Intensităt und Richtung der Reformdiskussion in den einzelnen Ländern bestimmten.

\section{Erste Determinante: bestehendes USt-System}

Die erste Determinante jeder USt-Reform 1st die Ausgestaltung der bereits bestehenden USt. Eln mit der Lebensweisheit eine "alte Steuer ist eine gute Steuer" bestens vertrauter Steuerpraktiker wird diese Behauptung als nicht erwăhnenswerte Selbstverständlichkelt elnfach hinnehmen. Einem der reinen Wirtschaftstheorle verschriebenen Finanzwissenschaftler kann sie Jedoch nicht unmittelbar einleuchten, ist doch die bereits erhobene USt nur eine Alternative unter vielen, die allesamt und völlig gleichberechtigt im Rahmen elner rationalen Finanzpolitik auf ihren Zlelerrelchungsgrad hin uberpruft werden müssen. Es wäre zu elnfach, die unleugbare, sich Jeder Veränderung wledersetzende Trägheit elnes elnmal bestehenden Steuersystems alleine der Irrationalitat und Bequemlichkeit der fur die Finanzpolitik Verantwortlichen zuschreiben zu wollen. Fur die vermeintliche Irrationalität gibt es vielmehr handfeste polit-ökonomische Gründe.

Da sind zum einen die Steuerzahler, dle, von einer Reformdebatte aus threr gellebten Ruhe aufgeschreckt, ihre sozialen Besitzstände zu verteldigen versuchen. Und well ihnen die Erfahrung gezelgt hat, daß elne Reformdiskussion wesentlich einfacher abzublocken als erfolgreich zu Ende zu fuhren 1st, ist es vollkommen rational, wenn die durch das Reformvorhaben besser Gestellten sich nicht ruhren, wahrend dle anderen Zeter und Mordio schrelen.25 Noch schlechter ist es um die Erfolgsaussichten der Steuerreform bestellt, wenn die durch sie bewirkten Umverteilungseffekte nicht bekannt bzw. nur schwlerig ermittelbar sind. Die auf Sicherheit bedachten Unternehmer - der dynamische und risikofreudige Typ ist in der Realltat nur sehr selten anzutreffen - werden die Front der jede Anderung ablehnenden Kritiker weiter stärken. Umvertellungseffekte gibt es aber nicht nur zw1schen Steuerzahlern, sondern in dezentral organisierten Gemeinwesen auch zwischen verschledenen Fiscl, die um das Steueraufkommen konkurrieren.

24 Vgl. Kap.C.2.2.

29 "Nach einer alten Erfahrung nimmt derjenige, der weniger zu zahlen braucht, das ohne besondere Gefuhlsăußerungen zur Kenntnis, wăhrend derjenige, der mehr zahlen muß, sich laut daruber beklagt." Dichgans (1963), S.195. 
Ganz parallel zum Verhalten der Steuerzahler werden auch sie einer Reform eher ablehnend als befürwortend gegenüberstehen. Als dritte Gruppe potentieller Reformkritiker blelbt die Finanzbeamtenschaft zu erwähnen. Für sie bedeutet eine Steuerreform in erster Linie: Erlernen neuer Paragraphen; Erlaß neuer Durchführungsverordnungen; Arger mit der Kundschaft, sprich den Steuerzahlern, die die neuen Regeln ja auch erst verstehen müssen; etc. Wer will ihnen da noch verdenken, daß sie es des öfteren am nötigen Reformeifer fehlen lassen?

Ubrig bleiben die politischen Entscheidungsträger. Von den ökonomischen Vorteilen einer Steuerreform verstehen sie oft nicht gar zu viel. Dafür hören sie umso deutlicher die lautstarke Kritik an Ihren Refomplänen. Und da Im Laufe Jahrelanger Diskussionen die nächsten wahlen immer näher rücken, wird aus einer umfassenden Reform langsam ein Reförmchen, und auch das fallt oft noch ganz unter den Tisch. Eine Steuerpolitk im Sinne der Theorie rationaler Wirtschaftspolitik kann es in einer Demokratie nicht geben. Steuerpolitik in der Praxis heißt vielmehr: "Deux pas en avant, un pas en arrière"26 - auch unter dem Namen piecemeal-policy bekannt. Dabel kommt natürlich dem jewells bestehenden steuersystem, in unserem Falle also der jeweiligen USt, eine zentrale Bedeutung zu.

\section{Zweite Determinante: Zlele der Finanzpolitik}

Die zweite wesentliche Determinante nationaler Steuerpolitik sind die finanzpolitischen Ziele, die mit der Erhebung einer USt verbunden werden. Es ist das fiskalische Ziel, das in der EG der Sechs zur Einführung einer allgemeinen Verbrauchsteuer gefuhrt und seltdem die Reformdiskussion ganz klar dominiert hat: Die USt ist in erster Linie ein Einnahmenbeschaffer. Die Aufkommensansprüche, die jewells an die USt gestellt wurden, hingen neben der Entwicklung des staatlichen Finanzbedarfs auch vom Verhältnis zwischen direkter und indirekter Besteuerung ab. Der allgemeine Finanzbedarf und mit ihm die Steuerquote stiegen in allen westeuropäischen Staaten in ähnllcher Weise an, zunächst eher sprunghaft - Erster Weltkrieg, Weltwirtschaftskrise, Zweiter Weltkrieg, Wiederaufbau - und später durch die stetig wachsenden Aufgaben insbesondere im sozlalen Bereich kontinulerlich. Demgegenüber entwickelte sich das relative Gewicht von direkten und indirekten Abgaben sehr unterschiedlich. Während die nordischen Länder - die Niederlande, Luxemburg und Deutschland - mehr auf die Erhöhung direkter Abgaben bauten, sahen sich die romanisch geprägten Länder - Frankreich, Belgien und Italien - einer in Sachen Steuerhinterziehung äußerst einfallsreichen Bevölkerung gegenüber. Sle wichen daher von den direkten auf die leichter kontrollierbaren indirekten steuern aus.

Mit zunehmenden Steuersätzen wurden auch automatisch die dem jeweiligen USt-Typ immanenten Verzerrungen stärker spürbar. Sie wurden insbesondere 
dann Gegenstand massiver Kritik, als mit Beendigung der Wiederaupbauphase die westlichen Volkswirtschapten zu einem Wettlaup um die höchsten Wachstumsraten antraten und gleichzeitig die zölle zu sinken begannen: Der internationale Konkurrenzdruck nahm auf Unternehmens- wie aup wirtschaftspolitischer Ebene zu. Wollte oder konnte man den Steuersatz nicht auf einem niedrigen Niveau belassen, so blieb alleine die Möglichkeit, den Ubergang von einer Verbrauchsteuer mit niedrigem Aufkommenspotential z.B. einer Bruttoust - zu einer mit höherem Aufkommenspotential - z.B. modipizierte BruttouSt oder NettoUSt - in Erwägung zu ziehen.

Als eine weitere Handlungsalternative bot sich daneben an, über dle Verminderung unerwünschter Verzerrungen hinauszugehen und die USt bewußt $\mathrm{zu}$ allokations- und verteilungspolitischen $\mathrm{Zwecken}$ einzusetzen. Solcherart prozeßpolitische Eingriffe in den Wirtschaftsablauf wurden am konsequentesten von den Deutschen zurückgewiesen, díe das USt-System als Tell eines ordnungspolitischen Rahmenwerkes ansahen, das die Allokationsentscheidungen des privaten Sektors mögllchst wenig beeinflussen sollte. Die Sicherung einer gewissen Verteilungsgerechtigkelt wurde den direkten Abgaben und dem sozialen Sicherungssystem als Aufgabe übertragen. Gewichtige Befürworter fand diese Aupfassung auch schon früh im eher interventionlstisch geprägten Frankreich ${ }^{27}$ : Dle USt wurde unter das Primat der Neutralităt gestellt. Im Gegensatz zu Deutschen und Franzosen konnten sich die Nlederländer und Belgier für den Gedanken PInanzpolitischer Neutralität nur wenig erwärmen. Und ganz anders lagen die Dinge auch, whe so oft, auf den britischen Inseln: Die Briten waren bis weit in die 60er Jahre hinein einem steuerlichen Interventionismus verschrieben, wie er innerhalb der Sechser-Gemeinschaft seinesgleichen suchte. Klar ist, daß die Meinungsverschiedenheiten über die richtige Pinanzpolitische Phllosophle ihren Niederschlag auch in der Wahl eines adăquaten USt-Systems finden mußten: Eine Einphasensteuer ist als Eingriffsinstrument wesentlich besser zu gebrauchen als die neutrale MWSt.

\section{Dritte Determinante: Restriktionen der Finanzpolitik}

Den Weg, den dle Reformbemühungen in den elnzelnen Ländern nahmen, hing neben den finanzpolitischen Zielen auch von den Restriktionen ab, die den Handlungsspielraum der nationalen Reglerungen begrenzten. Eine erste entscheidende Restriktion blldete der Komplexitätsgrad der jewelligen Volkswirtschaft, der selnerseits durch Größe und Industrialisierungsgrad des Wirtschaftsraums erklärt wird. Je komplexer die Wirtschaftsstruktur ist, desto schwerer fallt es, die durch eine Bruttoust verursachten Verzerrungen durch einzelne Modifikationen - wie Zusatzsteuern, Phasenpauschallerung, etc. - abzumildern: Dle verwaltungstechnischen Komplikationen stelgen schnell ins Unüberschaubare.

27 Vgl. z.B. Lauré (1952), S.6pf. 
Eine zweite wichtige Restriktion stellt die Kompetenzvertellung zwischen Gesetzgeber und Finanzverwaltung dar. Da sich Wirtschaftsstrukturen rasch ändern können, bedarf eine systemimmanente Reformierung der Bruttoust einer flexiblen Handhabung und ständigen Anpassung. Die langwlerigen Gesetzgebungsprozeduren sind hierfür zu schwerfällig. Sie müssen, um die Funktionsfähigkeit des USt-Systems zu gewährleisten, durch den kurzen Verordnungsweg ersetzt werden. Ist jedoch der Gesetzgeber nicht gewillt, oder, wie es in der Bundesrepublik der Fall war ${ }^{28}$, nicht in der Lage, der Exekutive die dafür notwendigen Vollmachten zu übertragen, so ist der Weg einer systemimmanenten Reform der Bruttoust von vornherein versperrt.

Als dritte den Handlungsspielraum begrenzende Restriktion bleibt das Zollsystem zu erwähnen. Die entsprechende Argumentation lautet dabel in ihrer populärwissenschaftlichen Form wie folgt: Die USt wird als indirekte Steuer auf die Preise überwälzt; da bei einer reinen BruttouSt der Grenzausgleich erheblich niedriger liegt als die effektive inländische Steuerbelastung, wird die heimische Wirtschaft in einen Wettbewerbsnachteil gegenüber dem Ausland gesetzt; der Nachteil läßt sich technisch am einfachsten über die Erhebung entsprechend höherer Importzölle ausgleichen; sollen dle Zölle jedoch, z.B. wegen des Beitritts zu einer Zollunion, wegfallen, so wird ein vollständiger Grenzausgleich unabdingbar; er ist bei einer BruttouSt, wie jede andere systemimmanente Modifikation auch, mit zahlreichen Schwierigkeiten verbunden und fördert daher den ubergang zu einer nicht-kumulativen USt.

Die hier gezogene Schlußpolgerung ist korrekt, alleine die Begründung erscheint fragwürdig. Die in der Literatur vlel $\mathrm{zu}$ häufig $\mathrm{zu}$ findende $\mathrm{Be}-$ hauptung, die USt werde überwälzt und bedürfe daher eines Grenzausgleiches, kann in dieser Form sicherlich nicht aufrechterhalten werden. Denn oft ist ein steuerlicher Grenzausgleich - oder Zollerhöhungen als Substitut - nur deswegen eingeführt worden, um eine Uberwälzung der USt zu erleichtern oder sle sogar erst zu ermöglichen. Akzeptieren wir nämlich die Theorie vom internationalen Preiszusammenhang und gehen wir davon aus - eine bis in die 60er Jahre hinein reallstische Annahme -, daß die Wechselkurse zumindest in kurz- und mittelfristiger Sicht fixiert sind, so wird, im Falle eines kleinen Landes, das inländische Preisniveau von den Weltmarktpreisen bestimmt. Eine nur in diesem Lande erhobene USt muß daher vollständig von den Produzenten getragen werden. Da die Interessenvertretung der Produzenten aber besser organisiert ist als die der Konsumenten, trennte man mit Hilfe eines Grenzausgleiches das inländische vom

28 Vgl. ausfürlicher in Kap.C.2.2.2. 
Weltmarkt-Preisniveau ab, ermöglichte damit die Steuerüberwälzung und schuf gleichzeitig die politische Voraussetzung für weitere Erhöhungen der USt.

Uberblick: Reformdruck und Reformtendenzen

So verschieden die finanzpolitischen Zlele und Restriktionen in den einzelnen Ländern waren, so unterschledlich waren auch die Wege, die sie im Bereich der Umsatzbesteuerung beschritten. Es kann daher nicht überraschen, daß die Mitgliedstaaten der Sechser-EG, obwohl sie alle einmal mit einer ähnlichen BruttouSt begonnen hatten, Anfang der 60er Jahre ganz unterschiedliche Steuern erhoben. Auch der zu dieser Zeit in den einzelnen Ländern auf eine (weitere) USt-Reform hinwirkende Druck und die Richtung einer möglichen Anderung unterschieden sich, wie das auf der nächsten Seite abgedruckte Schaublld deutlich macht, grundlegend vonelnander.

Wir werden später noch Gelegenheit haben, die USt-politische Entwicklung in einzelnen Ländern ausführlich zu analysieren. ${ }^{29}$ Der im Tableau gegebene Uberblick dürfte jedoch berelts jetzt zwel Dinge deutlich werden lassen:

- Der Kommissionsvorschlag einer allgemeinen Einführung der MwSt mußte in 4 von 6 Mitgliedstaaten aup erhebliche innenpolitische Widerstände treffen.

- Die Vereinheitlichung der ust-Systeme wäre, hätte das Vereinigte Königreich schon zu den Gründungsmitgliedern gezăhlt, entweder nie oder bestenfalls erst wesentlich später verwirklicht worden.

29 Vgl. Kap.C.2.2. 
Schaubild C-2: Steverpoltische Situation in den Mitgliedstaaten der EG Anfang der 60er Jahre

(Zusatzinformation: Vereinigtes Königreich)

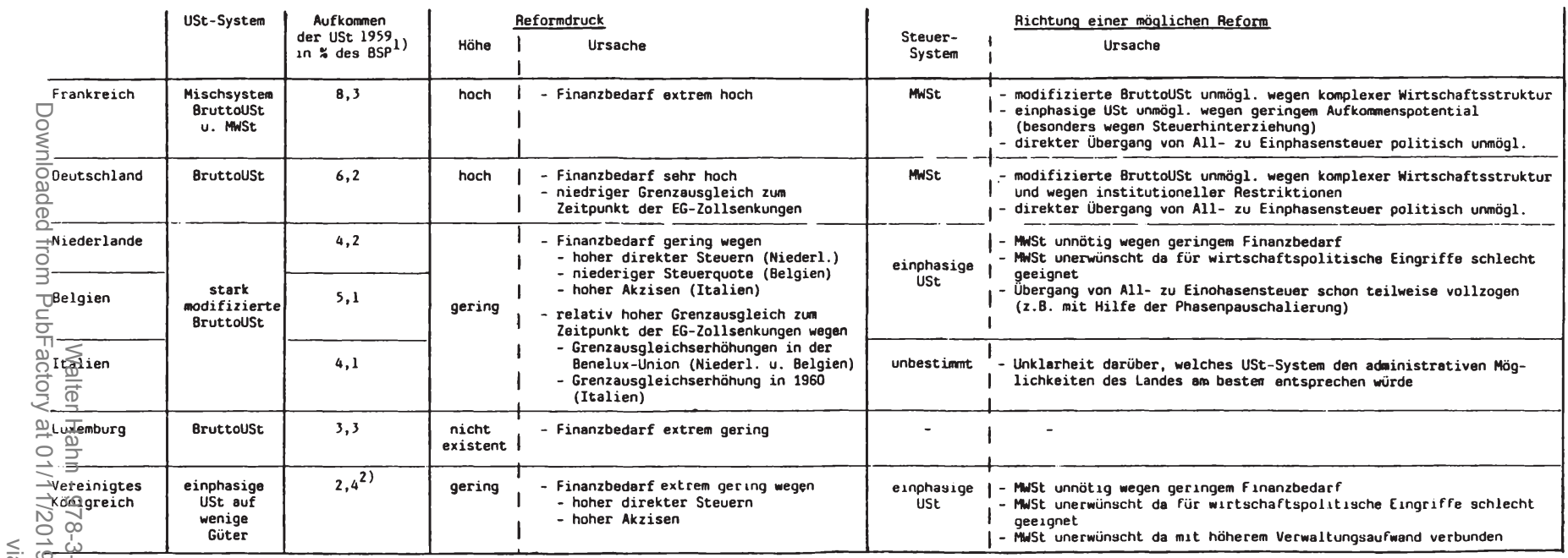

Quelle: Neumark-Bericht (1962), S.16 u. S.28.

gilt für das Jahr 1960.

列

Statistical office (ed.), Financial Statistics, London: HMSO 1962, S.9. 
1.2.2. Außenpolitische Zlele: Beurteilung der Ziele der Kommission

\section{Zum Ziel der Wettbewerbsneutralität}

Die Haltung der Mitgliedstaaten gegenüber dem Harmonisierungsprogramm der Kommission hing neben rein binnenpolitisch motivierten tberlegungen auch davon $a b$, wie die einzelnen Regierungen die von der Kommission gesehenen Probleme beurtellten. Was zunächst den Strelt über die Veränderung des Grenzausgleiches angeht, so sollte man eigentlich vermuten, daß, vorausgesetzt jeder hätte ein gleich starkes Interesse an der EG gehabt, alle gleichermaßen um die Beilegung der lästigen Auseinandersetzungen bemüht waren. Die Interessenslage war jedoch wesentlich komplizierter, da an dem Spiel mit den Erhöhungen des Grenzausgleichs die einzelnen Länder sehr unterschiedlich beteiligt waren. Sie hing letztendlich davon ab, wie hoch der von den verschiedenen Staaten praktizierte Grenzausgleich im Verhältnis zu der in Art.95-97 fixierten Obergrenze lag. ${ }^{30}$

Den Franzosen kam anfangs eine Sonderrolle zu. Sie hatten das zweifelhafte Glück, die von der Kommission anvisierte MWSt ansatzweise bereits zu haben. Der von ihnen angewandte Grenzausgleich lag damit nahe der vertraglich festgelegten Obergrenze, was ihnen verbot, sich an dem allgemeinen Spiel der anderen mit den Erhöhungen des Grenzausgleichs zu beteiligen. Frankreich blleb daher nichts anderes übrig als der Versuch, die Partner durch politischen Druck zum Stlllhalten zu bewegen. Die Bemühungen waren, wie bereits vermerkt, zum Scheitern verurteilt. Die anderen 5 Mitgliedstaaten trieben ihr Spiel weiter, auf Kosten Frankreichs. Alle fünf konnten sich vorstellen, längerfristig einmal zu einer nicht-kumulat1ven USt überzugehen, zum einen, um dadurch den nach Art.95-97 erlaubten Splelraum vollends auszuschöpfen, zwelfelsohne aber auch, um der lästigen Streiterei eln Ende zu bereiten. Aber das hie $\beta$ noch lange nicht, daß irgend jemand mit einer derartigen Umwälzung der inländischen Steuersysteme sonderliche Elle gehabt hätte.

Frankreich auf der anderen Seite stand der Einführung einer neutralen USt in den Partnerstaaten etwas ambivalent gegenüber, da der damit verbundene Abwertungseffekt der Währungen der wichtigsten Handelspartner den Franc unter Druck gesetzt hätte. Erst als den Franzosen langsam klar wurde, daß die anderen Mitgliedstaaten mit den Grenzausgleichserhöhungen nicht eher ruhen würden, bis sie die vertraglich vereinbarte Obergrenze erreicht hätten, begannen sie sich dafür stark zu machen, dem bösen Spiel lieber heute als morgen durch eine gemeinschaftliche USt-Reform ein Ende $\mathrm{zu}$ bereiten. $\mathrm{Zu}$ ergänzen bleibt, daß auch die Italiener nach einer massiven Pührten umsatzsteuerlichen Grenzausgleich vgl. z.B. Mesenberg (1960). 
Heraufsetzung ihres Grenzausgleichs vom September 1960 die in Art.95-97 gegebenen Möglichkeiten weitgehend ausgereizt hatten. Sie schwenkten daher in der Folgezeit auf die Pranzösische Position ein. Insgesamt ergab sich damit das folgende Bild:

Schaubild C-3

Die Position der Mitgliedstaaten der EG

zum Ziel der Wettbewerbsneutralität (Anfang der 60er Jahre)

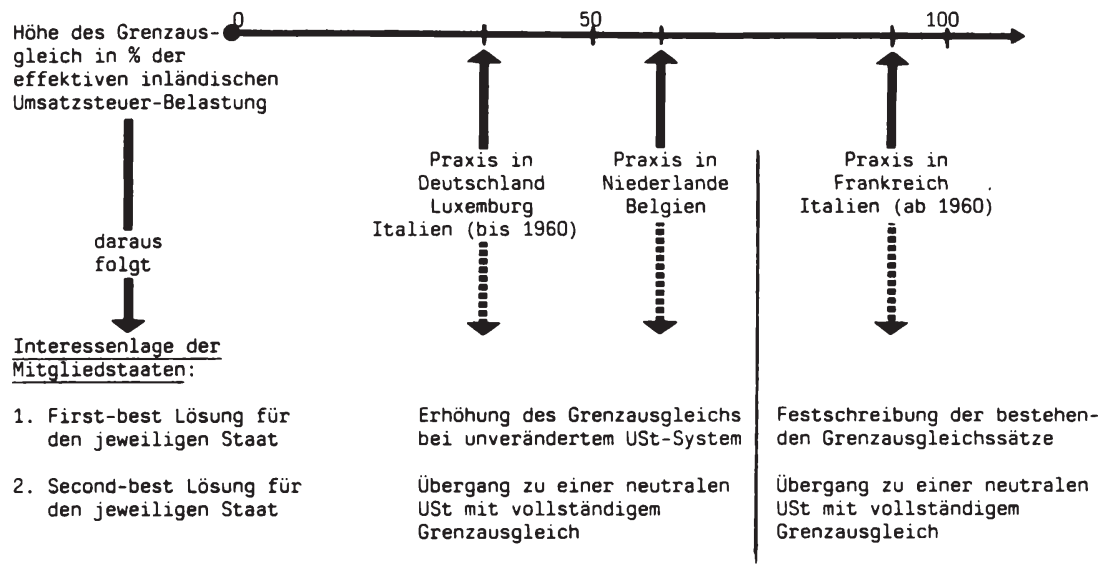

\section{Zum Ziel Abschaffung der Steuergrenzen}

Das zweite Zlel der Kommission, die Beseitigung der Steuergrenzen, wurde von den Mitgliedstaaten aus einer in erster Linie politischen Perspektive heraus beurteilt: Das Recht, Befreiungen und Sätze der aufkommensstarken USt zu regeln, sollte auf die Gemeinschaftsebene verlagert werden. Die weitreichenden budgetären Konsequenzen waren offensichtlich. Da aber budgetäre Effekte einer der wenigen Aspekte der Steuerpolitik sind, wo die meisten Politiker sich kompetent wähnen, wollten sie auch, solange dies möglich erschlen, das Sagen behalten.

Frankreich war anfangs das einzige Land, das bel einer Satzangleichung hin zum EG-Durchschnitt beträchtliche Aufkommensverluste hätte hinnehmen müssen. Die fehlende Pranzösische Begeisterung für das Einreißen der Schlagbăume wird damit leicht verständlich. Hinzu kam, daß die ubertragung steuerpolitischer Souveränitätsrechte an die ungeliebten Gemeinschafts-Institutionen schon aus prinzipiellen Uberlegungen nicht in das gaullistische Europa-Konzept hineinpaßten. Auf europäische Institutionen und dle Verbrüderung der Völker kann, so die Auffassung Präsident de 
Gaulles, ohne weiteres verzichtet werden, wenn sich nur die nationalen Regierungen gut vertragen. Genau umgekehrt lagen die Dinge in Deutschland. Das mit der USt erzielte Aufkommen lag unter dem EG-Durchschnitt, und die deutsche Industrie versprach sich von einer USt-Harmonisierung eine Verschiebung von den die Gewinne belastenden direkten Abgaben hin zu den leichter überwälzbaren Verbrauchsteuern. Darüberhinaus glaubten die deutschen Politiker, mit der Abschaffung der Steuergrenzen einen Hebel in der Hand zu haben, der nicht nur die politische Einigung Europas voranzutreiben in der Lage ist, sondern der auch für einen Gleichschritt der Integration im Industriebereich mit der bei Agrargütern sorgen kann.

Die Benelux-Länder hielten zwar eine Abschaffung der Steuergrenzen für grundsätzlich wünschenswert, hatten aber in langer Benelux-Erfahrung bereits lernen mủssen, wie sehr budgetäre Erfordernisse die Versuche zu einer Satzangleichung dominieren und unmöglich machen können. Nachdem sie schon in ihrer kleinen Gemeinschapt frustriert worden waren, hielten sie ähnliche Pläne im Europa der Sechs für, wenn überhaupt, nur sehr langfristig reallsierbar. Auch die Italiener standen der Beseitigung der Steuergrenzen äußerst skeptisch gegenüber. Zum einen gingen Anfang der 60 er Jahre die steuerpolitischen Uhren südlich der Alpen anders als im Rest der EG, und niemand wußte, wie lange es dauern würde, bis Italien sich hier angepaßt hätte. Zum anderen hatten die Italiener noch einen sehr handfesten Grund für ihre Zurückhaltung, der mit ihrer geographischen Lage zusammenhing. Die Abschaffung der Steuergrenzen bedeutete für sie bestenfalls ein Wegfall der Gren\%kontrollen an der Landgrenze zu Frankreich. Besagte Grenze ist aber recht kurz, und nur ein minimaler Teil des italienischen Außenhandels wurde über sie abgewickelt. Wofür also, so fragte sich Rom mit Recht, der ganze Aufwand mit der Harmonisierung der Steuersätze?

\subsubsection{Strateglen: Jeder will etwas anderes}

Binnen- und außenpolitische Ziele determinierten zusammengenommen die Haltung, die die Regierungen der Mitgliedstaaten zum Harmonisierungsprogramm der Kommission einnahmen. Als sich Anfang der 60er Jahre die Pläne der Kommission konkretisierten und erste Gespräche darüber begannen, konnte bei keinem einzigen der anvisierten Schritte tbereinstimmung festgestellt werden. Offensichtlich war der Dissens bei der Abschaffung der Steuergrenzen und, damit verbunden, der Angleichung der Sätze: Alleine die Deutschen machten sich dafür stark, während die Franzosen strikt dagegen waren und alle anderen das Vorhaben für langfristig wünschenswert, mittelfristig aber nicht realisierbar hielten. 
Auf grundsätzliche Zustimmung stieß das Ziel der steuerlichen Neutralität Im grenzüberschreitenden Handel. Aber schon der Weg dorthin war umstritten. Zunächst versuchten sämtliche Mitgliedstaaten, ihre jeweilige firstbest Lösung - Erhöhung des Grenzausgleichs bei unverändertem Steuersystem für die einen und Festschreibung des bestehenden Grenzausgleiches für die anderen - durchzusetzen. Erst als sie feststellten, daß dieser Versuch politisch zum Scheitern verurteilt war, zeigten sie sich gegenüber der second-best Lösung - Ubergang zu einer neutralen USt - aufgeschlossener. Die Benelux-Länder und Italien erklärten sich anfangs nur zur Einführung einer nicht näher definierten, neutralen USt bereit. Aup eine MWSt wollten sie sich aus innenpolitischen Gründen nicht festlegen lassen. Demgegenüber bestanden Frankreich und Deutschland ausdrücklich auf dem europaweiten Ubergang zu einer MWSt. Der erste Harmonisierungsschritt Einführung einer nicht-kumulativen USt - wurde von Paris und Bonn als eine reine Zeitverschwendung abgelehnt. Folgende Gründe waren für diese Position ausschlaggebend:

- Die Franzosen hatten jahrelang erfolglos versucht, ihre im wesentlichen auf die Industrie begrenzte MWSt auch auf andere Wirtschaftssektoren auszudehnen. Mit einer EG-Richtlinie zur allgemeinen Einführung einer MWSt verband Paris - unausgesprochen, wie sich versteht - die Hopfnung, slch von Brüssel genau das vorschreiben zu lassen, was man selbst schon lange wollte und bls dato aufgrund innenpolitischer Widerstände nicht durchzusetzen vermocht hatte.

- Innenpolitische Uberlegungen ahnlicher Art waren auch für die Deutschen von Bedeutung. Bonn betrachtete aber darüberhinaus die Abschaffung der Steuergrenzen als das notwendige Endziel der UStHarmonisierung. Voraussetzung dafür war die Verwendung eines einheltlichen USt-Systems in allen Mitgliedstaaten. Es ist daher verständlich, daß die Deutschen die Pür sie als Alternative zur Bruttoust alleine in Frage kommende MWSt auch in den anderen Ländern eingefuhrt sehen wollten, und zwar möglichst rasch. 
$\mathrm{Zu}$ Beginn der 60er Jahre stellte sich daher die Haltung der Mitgliedstaaten zum Harmonisierungsprogramm der Kommission im Uberblick wie folgt dar:

Schaubild C-4

Die Position der Mitgliedstaaten der EG

zum Stufenprogramm der Kommission (Anfang der 60er Jahre)

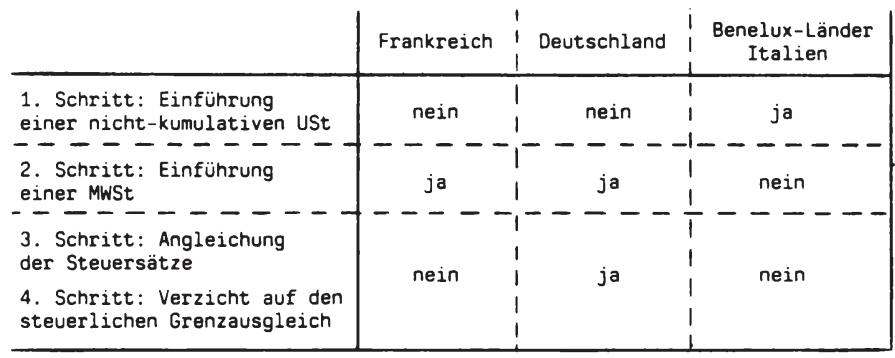




\section{Der Fillensblldungsproze}

2.1. Die Gemeinschaftsperspektive: die Einführung der MWSt in der EG

\subsubsection{Erste Uberlegungen und Vorentscheidungen: 1958-1960}

Institutionelle Weichenstellung bei der Kommission

Am 1.Januar 1958 traten die Römischen Verträge zur Gründung einer EWG und einer EAG in Kraft. Von der in Art.95-99 EWGV vorgesehenen Steuerpolitik der Gemeinschaft war in den ersten beiden Jahren der EG nur wenig zu spüren. Die Kommission als die Hüterin der Verträge war anfangs noch in erster Linie mit sich selbst beschäftigt. Zunächst galt es, einen schlagkräftigen Verwaltungsapparat aufzubauen und ihn zum Arbeiten zu bewegen. ${ }^{1}$ Schon dabei fiel allerdings eine wichtige Vorentscheidung für den Weg, den die USt-Harmonisierung der EG später nehmen sollte: die Dominierung der Steuerpolitlk durch wettbewerbspolitische Uberlegungen. Ein solches Konzept war nicht nur im EWG-Vertrag angelegt, sondern es wurde in der Organisationsstruktur der Kommission auch fest verankert.

Als es an die Kompetenzvertellung innerhalb der ersten Kommission der EWG ging, war zunăchst daran gedacht worden, den gesamten Bereich der Wirtschafts- und Finanzpolitik entlang der Linie kurzfristig/langfristig zwischen dem Franzoseri Marjolin und dem Deutschen von der Groeben aufzuteilen. Eines Tages kam jedoch Marjolin iit das Büro seines Kollegen und forderte mit der Begründung, daß die Wirtschaftspolitik auf der Basis von Fristigkeitserwägungen nicht sinnvoll unterteilt werden könne, das gesamte Ressort für sich. Dem war weder inhaltlich noch politisch - die Deutschen stellten mit Hallstein bereits den Kommissionspräsidenten und mußten daher den anderen bei der Ressortverteilung den Vortritt lassen - viel entgegenzusetzen. Von der Groeben sicherte sich seinerseits neben der Wettbewerbspolitik im engeren Sinne - Kartelle, Monopole, etc. -, die "sowieso niemand wollte"2, auch die Subventions- und Steuerpolitik, was er von dem "glücklichen Sieger"3 Marjolin auch ohne viel Widerstand zugestanden bekam.4 Alle wettbewerbspolitisch relevanten Fragestellungen waren damit in der Hand eines Kommissars vereint. Die spätere Steuerabteilung der

1 Zu den frühen Jahren der EG vgl. Groeben (1982), S.57ff.

2 Persönliches Interview.

3 Persönliches Interview.

4 Vgl. z.B. Groeben (1982), S.81. 
Kommission wurde Teil der Generaldirektion IV Wettbewerbspolitik, deren Leitung der Niederländer VerLoren van Themaat übernahm. Diese organisatorische Struktur als auch die Besetzung ihrer Spitzenpositionen blieb bis 1967 erhalten. Sie prägte nachhaltig dle wettbewerbspolitische Ausrichtung der Brüsseler USt-Politik.

\section{Erstes Problem: Entwicklung einer steuerpolitischen Gesamtkonzeption}

Zwar hatte die Kommission nun eine Steuerabteilung, eine Steuerpolitik aber gab es noch lange nicht. Hier und da tauchte das Schlagwort der Steuerharmonisierung schon einmal in der Opfentlichkeit aup, nur wußte niemand so recht, was darunter konkret zu verstehen war. Um die Ratnicht in Tatenlosigkeit umschlagen zu lassen, ging man bei der Kommission und in den einzelnen Hauptstädten zunächst einmal daran, eine Bestandsaufnahme der verschiedenen Steuersysteme zu erstellen und sie miteinander zu vergleichen. Man kam dabei zu dem nicht unerwarteten Ergebnis, da $\beta$ gewisse Unterschiede existierten und daß daraus Probleme für den Gemeinsamen Markt erwachsen könnten.' Andere erinnerten sich des in der Montan-Union gefuhrten Steuerstreits und kramten aus aktuellem Anlaß - Abwertung des Franc - ihre altbekannten Argumente wieder aus der Schublade hervor. Da aber die wenigsten mit deren Inhalten etwas anzufangen wußten, vergrößerten sie eher die allgemeine Unsicherheit. Trotzdem war zumindest eines erreicht: Eine Diskussion kam in Gang, die die Opfentlichkeit für die Probleme unterschiedlicher Steuersysteme in der EG sensibilisierte.

Die Diskussion wollten auch die Finanzminister der Mitgliedsiänder nicht ganz unbeteiligt an sich vorüberzlehen lassen. So trafen sle sich, aup Initlative des deutschen Ministers Etzel - er war vorher Vizepräsident der Hohen Behörde gewesen und schon von daher für steuerpolitische Probleme der EG sehr ansprechbar - und des Kommissars von der Groeben im Juli $1959 \mathrm{zu}$ einem informellen Meinungsaustausch unter dem Motto: "Was können die Finanzminister zum Gemeinsamen Markt beitragen?"6 Die Konferenz endete zwar nicht mit einer erschöpfenden Antwort auf die sich selbst gestellte Frage, dafür aber mit einer Gemeinsamkeit demonstrierenden Dampferfahrt auf dem Rhein und dem Versprechen, sich fortan alle drei Monate wieder zu treffen. Die informellen Quartalstreffen der Finanzminister wurden in der Folgezeit ein wichtiges Instrument für die Steuerpolitik der EG. Auch wenn konjunktur- und währungspolitische Probleme meist die Diskussionen beherrschten, so kam doch auch regelmäßig die Steuerharmonisierung zur Sprache. Im Gegensatz zu den Zusammenkünften des Rates, bei denen im Regelfall offizielle und bereits vorbereitete

$5 \quad$ Vgl. z.B. Le Monde 7.6.59, Industrie Kurier 23.7.59 u. Süddeutsche Zeitung 4.8.59.

$6 \quad$ Titel eines Artikel in der Süddeutschen Zeitung v. 18.7.59. 
Stellungnahmen ausgetauscht werden, erlaubte die informelle Atmosphäre der Quartalstreffen der Kommission,

- schon im Vorfeld formeller Richtlinienvorschläge an den Rat deren Erfolgschance auf politischer Ebene abzutasten,

- Pestgefahrene Expertengesprăche von der Ministerebene her unter Druck zu setzen bzw. zu beschleunigen,

- Anregungen für weitere Aktivitäten zu erhalten.

Aber zurück in die Jahre 1958/59. Mit ihrer Unsicherheit befanden sich die nationalen Steuerexperten in guter Gesellschaft, da die für Fragen der Steuerharmonisierung ja in erster Linie zuständige Wirtschaftswissenschaft auch keinen schlüssigen Rat anzubieten hatte. Nach der Einschläferung des Steuerstreits war das Interesse an internationalen Steuerproblemen merklich erlahmt. Als in der europäischen Aufbruchstimmung der späten 50er Jahre die Zahl der wissenschaftlichen Veröpfentlichungen langsam anzusteigen begann, mußte man praktisch wieder beim Punkte Null anfangen. Die früheren Arbeiten waren von nur begrenztem Wert, da im Vergleich zur MontanUnion die EWG breiter angelegt war (Voll- statt Tellintegration) und höher gesteckte Ziele verfolgte (evtl. Wirtschafts- oder sogar politische Union).

Zusammen mit allen anderen tappte auch die Kommission anfangs im Dunkeln. Zwar war ihr bereits klar, daß die Steuern bis zu einem gewissen Grade harmonislert werden mußten. Aber welche Steuern und wie und in welcher Reihenfolge? - das war eine andere und bislang unbeantwortete Frage. Es war an der Kommission, eine Antwort zu finden und damit der einmal Initiierten Diskussion eine Richtung zu geben. In Anbetracht der verwirrenden Lage verdichtete sich Anfang 1960 in Brüssel die Aupfassung, eine aus Nationalökonomen zusammengesetzte Arbeltsgruppe mit den aufgeworfenen Fragen zu betrauen. Sie sollte Licht in das steuerpolitische Dunkel werfen und eine Gesamtkonzeption erarbeiten, an der sich die Kommission später orlentieren konnte. Auf Initiative des Kommissars von der Groeben genehmigte dle Kommission schlleßlich im Frühjahr 1960, einen sogenannten Steuer- und Finanzausschuß ins Leben zu rufen.

\section{Zweltes Problem: dringender Handlungsbedarf bel der USt}

Wenn auch ein Gesamtkonzept noch lange nicht in Sicht war, so war sich die Kommission doch schon sehr frühzeitig über einzelene Aspekte ihrer zukünftigen Steuerpolitik im klaren. Evident war, da $\beta$ bei den direkten Steuern nicht viel zu erreichen war. Die Einkommensteuer war nicht nur ein wichtiger Einnahmenbeschaffer, sondern stellte auch ein flexibles Instrument für eine Vlelzahl unterschiedlich motivierter Eingriffe in das Wirtschaftsleben dar. Jeglicher Harmonisierungsversuch wäre "ans Eingemachte gegangen"7, und es lag daher nahe, zunächst die Finger davon zu lassen. Ganz anders bel den indirekten Abgaben: Hier "brannten die Pro-

7 Persönliches Interview. 
bleme auf den Nägeln"8. Wie schon die Văter des Vertrages so richtete auch die erste Kommission - es handelte sich oft um die gleichen Personen ihr besonderes Augenmerk auf die Gewährleistung eines freien Warenverkehrs. ${ }^{9}$ Die relativ wenigen, die Ende der 50er Jahre die Geschichte des Aupstiegs des umsatzsteuerlichen Grenzausgleichs noch kannten, erinnerten sich daran, daß er als eln Instrument protektionistischer Handelspolltik und als Vergeltungswaffe im Handelskrieg seinen Anfang genommen hatte. ${ }^{10}$ Sie fragten sich daher, ob nicht die Ausbreitung des Grenzausgleichsmechanismusses eine historische Fehlentwicklung gewesen sel, für die es in einem Gemeinsamen Markt keinen Platz mehr geben könne. Die so begründete Abneigung gegen den Grenzausgleich mochte manchem als ein wenlg abstraktphilosophisch erscheinen. Aber die Realität lleferte schon bald schlagkräptige Beweise für ihre Existenzberechtigung.

Erstes Anschauungsmaterial bot die für den 1.Januar 1959 vorgesehene erste Zollsenkung. In Anbetracht der prekären Lage in Frankreich - nach einer innenpolitisch außerst labilen Phase hatte General de Gaulle gerade die Macht übernommen - und angesichts des EG-Skeptizismus bel Bundeswirtschaftsminister Erhard war die Kommission hellfroh, daß der erste Schritt zur Zollunion überhaupt gut über die Bühne gegangen war."1 Es waren nun ausgerechnet die Europa-treuen Niederländer und Belgier, die just im Januar 1959 ihren umsatzsteuerlichen Grenzausglelch heraupsetzten. Auch heftige Dementis seitens der betreffenden Finanzministerien konnten die Vermutung nicht aus der Welt schaffen, daß zwischen der Zollsenkung auf der einen und der Grenzausgleichserhöhung auf der anderen Selte ein gewisser Innerer Zusammenhang bestand. Die Kommission sah sich um ihren ersten großen Erfolg betrogen: Solange die Zölle nicht gesenkt, sondern lediglich durch Steuern ersetzt wurden, konnte die Wirtschaft kaum von den Vortellen der EG überzeugt werden. Es galt zu handeln, bevor das Benelux-Beispiel Schule machte.

Die Kommission setzte sich daher im Frühjahr 1959 intensiv mit der USt auseinander. Die wichtigsten Probleme wurden herausgearbeltet: Art.95-97 sind nicht in der Lage, fur Neutralitat im grenzuberschreitenden Handel zu sorgen; die Auprechterhaltung der Steuergrenzen ist unerwünscht. Auch wurde klar, daß ein Verzicht auf den Grenzausgleich unter Beibehaltung der BruttoUSt unweigerlich okonomische Verzerrungen nach sich ziehen würde. So schälte sich schon sehr früh eine Präferenz der Kommission fur eine Angleichung der USt-Systeme heraus. Und mit der MWSt wurde in der deutschen und Pranzösischen Presse auch hier und da bereits der Steuertyp genannt, der sich die größten Aussichten aup eine EG-weite Einführung

\footnotetext{
8 Persönliches Intervlew.

9 Vgl. Z.B. Jansen (1961), S.107ff.

10 Vgl. z.B. Jahrmarkt (1969).

11 Vgl. Groeben (1982), S.38P. u. S.66P.
} 
machen konnte. Uberraschen kann das nicht: Die Finanzministerien in Bonn und Paris stellten 1959 ernsthafte Uberlegungen darüber an, ob und wie man zu einer MWSt übergehen könne. Auch der Chef der Brüsseler USt-Abteilung Jansen - das niederländische Finanzministerium hatte mit inm "seinen besten Mann"12 zur Kommission geschickt - hatte sich schon aup die MWSt festgelegt: Er versprach sich von der Einführung einer so gewichtigen Steuer, abgesehen von sachlichen Erwägungen, einen großen politischen wie auch persönlichen Erfolg.

Aber bis dahin sollten noch elnige Jahre vergehen. Zunächst lud die Kommission im Juni 1959 die leitenden Steuerbeamten der Mitgliedstaaten zu elner erstmaligen Fühlungnahme nach Brüssel ein. Sie konnten sich auf Vorschlag der Kommission daraup einigen, die im Bereich der indirekten Abgaben sich stellenden Probleme in drei aus Experten der nationalen Finanzministerien zusammengesetzten Arbeitsgruppen näher zu untersuchen:

- AG I: Harmonislerung der USt-Systeme.

- AG II: Gemelnsame Berechnungsmethode zur Bestimmung des Grenzausgleiches bel einer Bruttoust.

- AG III: Probleme bel den speziellen Verbrauchsteuern. ${ }^{13}$

B1s Ende 1959 konnte die AG I als erstes Ergebnis ihrer Beratungen festhalten, daß bei einem Welterbestehen der Bruttoust weder eine neutrale Besteuerung sichergestellt noch auf eine Abschaffung der Steuergrenzen gehopft werden könne.14 Dieses Resultat wurde unterstrichen durch den Verlauf der Diskussionen in der AG II, wo die Suche nach einem Berechnungsmodus für den Grenzausgleich auf vielfältige Schwierigkeiten gestoßen war. Beldes bestätigte die ursprüngliche Vermutung der Kommission, daß allein von der Harmonislerung der USt-Systeme elne Lösung erwartet werden könne.

Wăhrend sich dle Finanzexperten zur Klausur zurückgezogen hatten, spitzte sich das Problem an der politischen Front immer mehr zu. Gerüchte sickerten nach Brüssel durch, daß sich nach den Benelux-Staaten nun auch die Deutschen und Itallener mit dem Gedanken trügen, die Grenzausgleichssätze in größerem Stil anzuheben. Dle Franzosen waren aufgeschreckt und setzten die Kommission unter Druck, dem Einhalt zu gebieten. Angesichts des heraufzlehenden politischen Unwetters sah sich Brüssel gezwungen, die Steuerdiskussion von der Experten- auf die politische Ebene hochzuhiefen und auf baldige Entscheidungen $\mathrm{zu}$ drängen. In einem Schreiben vom

12 Persönliches Interview.

13 Auch für die Gründung der AG III gab es einen aktuellen Anlaß: So hatten beisplelsweise dle Deutschen die Senkung der Zölle auf Kaffee und Tee mit der Erhöhung der entsprechenden Verbrauchsteuern beantwortet. Vgl. z.B. Industrle Kurler 30.6.59.

14 Dok. IV/5285/59 v. 17.12.59. Engültige Verabschiedung des Berichts am 20.2.60, Dok. IV/1359/60. 
5.November 1959 wandte sich Kommissar von der Groeben direkt an die Finanzminister mit der dringenden Bitte, als Sofortmaßnahme ein Stillhalteabkommen für den Grenzausgleich abzuschließen. ${ }^{15}$ Darüberhinaus forderte er sie auf, sich schon jetzt auf die Zlele Wettbewerbsneutralität und $A b-$ schaffung der Steuergrenzen zu verpflichten, um so von politischer Seite her den Experten eine Richtung für ihre weitere Arbeit zu weisen.

\section{Der Stand der Dinge 1960}

Verschledene aktuelle Anlässe hatten also bis 1960 den umsatzsteuerlichen Grenzausgleich in den Mittelpunkt der Diskussion um die Steuerharmonisierung rücken lassen. Mit den Konzepten Wettbewerbsneutralität und $A b-$ schaffung der Steuergrenzen hatten sich die Harmonislerungsziele der Kommission konkretisiert. Und es wurden, neben den schon im EWG-Vertrag vorgesehenen Institutionen, Foren geschaffen, innerhalb derer künftig nach Problemlösungen gesucht werden sollte:

- die Quartalskonferenzen der Finanzminister auf der politischen Ebene;

- die AGs und der Steuer- und Finanzausschuß auf der technischen Ebene;

- die Zusammenkünfte der Leiter der nationalen Steuerverwaltungen als Bindeglied zwischen beiden Ebenen.

Der Druck der Tagesereignisse im allgemeinen und der Frankreichs im besonderen waren in der Lage, die Suche nach einer Stillhaltevereinbarung für den Grenzausgleich im Frühjahr 1960 auf die Agenda der politischen Instanzen zu setzen. Der Verlauf der entsprechenden Diskussionen bis zu lhrem endgültigen Scheitern 1963 wird uns später noch beschäftigen.16 Demgegenuber war die Frage der Harmonisierung der nationalen USt-Systeme noch mit zu vielen Unwägbarkeiten verbunden, als daß sich die politischen Entscheidungsträger nach ihren anfänglichen Diskussionen $1959 \mathrm{zu}$ einer Beschlußfassung - selbst wenn diese nach Vorstellung der Kommission nur auf die Ziele der Harmonisierung begrenzt sein sollte - hätten durchringen können. Hinzu kam, daß in den beiden elnzigen EG-Lăndern, in denen die Einführung einer allgemeinen MWSt erwogen worden war, die noch im Jahr 1959 erfolgversprechend erscheinenden Reformbestrebungen schon 1960 auf hartnäckigen Widerstand gestossen waren: Die Pranzösische Nationalversammlung wies den von der Regierung vorgelegten Gesetzesentwurf zurück ${ }^{17}$, und das deutsche Kabinett legte den vom Finanzministerium ausgearbeiteten MWSt-Entwurf bis auf weiteres auf Eis ${ }^{18}$. Alles zusammen bewirkte, daß die USt-Harmonisierung 1960 von der Tagesordnung der politischen Gremien der Gemelnschaft verschwand und für einige Zeit in dle Welt

15 Vgl. z.B. FT 10.11.59.

16 Vgl. Kap.C.2.1.3.

17 Vgl. ausführlicher in Kap.C.2.2.1.

18 Vgl. ausführllcher in Kap.C.2.2.2. 
der Ausschüsse hinabtauchte. Dort nahmen sich, wie im folgenden eingehender dargestellt werden soll, der Steuer- und Finanzausschuß sowie dle AG I ihrer an.

\subsubsection{Die erfolgrelche Erarbeltung eines Harmonislerungsprogrammes auf der technischen Ebene: 1960-1962}

\subsubsection{Der Steuer- und Finanzausschuß}

\section{Zlele des Steuer- und Finanzausschusses}

Angesichts der in den ersten EG-Jahren bel Steuerfragen zu beobachtenden allgemeinen Konfusion hielten es die Steuerpolitiker der Kommission Pür geboten, einen wissenschaptlichen Ausschuß mit der Erstellung eines konsistenten Gesamtkonzeptes für thr zukünftiges Vorgehen zu betrauen. Anfang 1960 nahm daher Kommissar von der Groeben, auf Empfehlung seines wettbewerbspolitischen Beraters, Prof. Möller, Kontakt mit dem deutschen Finanzwissenschaftler Prof. Neumark auf und bat ihn, ein Mandat für einen Steuer- und Finanzausschuß ausarbelten zu helfen. Das Papier wurde den Kommissaren bel ihrer Sitzung am 7.April 1960 vorgelegt und stie $\beta$ dort auf grundsätzliche Zustimmung. Verlangt wurde lediglich, daß eine Abstimmung mit der bisher nicht konsultlerten und für Finanzfragen ja elgentlich zuständigen Generaldirektion Wirtschaft und Finanzen des Kommissars Marjolin herbeigeführt werden müsse. Auch wenn einzelne Mitarbeiter dieser Generaldirektion an späteren Ausschußsitzungen tellnahmen, so gelang es doch den Wettbewerbspolltikern in der Kommission, das steuerpolitische Heft auch weiterhin fest in ihrer Hand zu behalten.

Neben der Klärung offenstehender Sachpragen waren es noch zwei weitere Zlele, die die Kommission bel der Grüdung des nach ihrem Vorsitzenden benannten Neumark-Ausschusses im Auge hatte. Zum elnen ging es ihr darum, die Opfentlichkeit, aber insbesondere die für Harmonisierungsfragen bis dato nur wenig empfänglichen Finanzpolitiker und -beamte der Mitgliedstaaten fur die durch die EG neu aufgeworfenen Fragen zu sensibilisieren: "Die Leute mußten erst einmal damit vertraut gemacht werden"19 - so Kommissar von der Groeben. Solange bel den nationalen Entscheidungsträgern kein Problembewußtsein vorhanden war, konnte die Kommission nicht hoffen, etwas in ihrem Sinne verändern zu können.

Zum anderen war Brussel daran gelegen, anerkannte und einflußreiche Wissenschaftler fur die Mitarbeit im Ausschuß zu gewinnen. Uber die Erarbeltung einer fachlichen Autorităt sah die Kommission die Möglichkeit, sich

19 Persönliches Interview. 
auch gleichzeitig eine politische Legitimität für die suche nach und die Durchsetzung von steuerlichen Reformvorschlägen aufzubauen. Denn die formaljuristische Legitimation der Art.99 und 100 reichte noch lange nicht aus, um auf die als ureigenste Domäne nationalstaatlichen Handelns betrachtete Steuerpolitik auch tatsächlich Einfluß nehmen zu können. Berelts die erste vorsichtige Kontaktaufnahme der Kommission mit den nationalen Steuerbeamten hatte Anlaß zu der Frage gegeben: "Wle souverän darf Brüssel sein?"20 Da die Mitgliedstaaten die Absichten der Kommission durchaus erkannt hatten, versuchten einzelne Finanzministerien, gezlelt auf die Zusammensetzung des Neumark-Ausschusses Einfluß zu nehmen. Und die Rechnung der Kommission sollte teilweise auch aufgehen: So wurde beispielsweise die positive Haltung der italienischen Regierung zum späteren MWSt-Vorschlag der Kommission nicht unwesentlich von einem der italienischen Vertreter im Steuer- und Finanzausschuß, Prop. Cosciani, geprägt.

\section{Ergebnisse des Steuer- und Finanzausschusses}

Für die Erarbeitung eines steuerpolitischen Rahmenkonzeptes hatte die Kommission dem Neumark-Ausschuß die "Errichtung eines Gemeinsamen Marktes unter Herbeiführung und Sicherung binnenmarktähnlicher Bedingungen"21 als Leitbild vorgegeben. Dabel sollte die grundsätzliche "..Erwünschtheit einer Nichteinmischung in die aup eine Aufrechterhaltung natürlich bedingter und/oder historisch gewachsener nationaler Besonderheiten gerichteten Politik der Mitgliedstaaten.."22 respektiert werden. Ziel konnte daher keine Vereinheitlichung, sondern nur eine Harmonisierung der nationalen Steuersysteme sein, die den steuerpolitischen Notwendigkeiten eines Gemeinsamen Marktes Rechnung trägt, ohne den einzelstaatlichen Bewegungssplelraum über Gebühr einzuschränken.

Wichtigstes Ergebnis des Neumark-Berichts ${ }^{23}$ war die Kennzeichnung der Steuerharmonislerung als ein dynamischer Prozeß, der in Abhängigkeit von der Entwicklung der einzelnen Volkswirtschaften und parallel zu der weiteren Integration der Märkte voranschreiten sollte. Uber Geschwindigkeit und Richtung der Harmonisierung ließen sich damit keine eindeutigen Aussagen machen. ${ }^{24}$ Trotzdem schlugen die Professoren auf Basis der gegebenen Informationen einen Stufenplan vor, der die verschiedenen Harmonislerungsmaßnahmen entsprechend ihrer Dringlichkeit und politischen Durchsetzbarkelt ordnete. Die uns interessierende USt stand ganz oben auf der Liste. ${ }^{23}$

\footnotetext{
20 Titel eines Artikels im Industrie Kurier v. 30.6.59.

21 Neumark-Bericht (1962), S.3.

22 Neumark-Bericht (1962), S.4.

23 Vgl. hlerzu a. Mersmann (1964a).

24 Vgl. Neumark-Bericht (1962), S.88pf.

25 Vgl. Neumark-Bericht (1962), S.9 u.S.91ff.
} 
Da die Kommission bereits vor Gründung des Neumark-Ausschusses entschleden hatte, die Harmonisierung der USt mit Prioritat voranzutreiben und in der AG I en détall zu diskutieren, beschäftigte sich der Steuerund Finanzausschuß mit den dabel aufgeworfenen Einzelfragen nur ganz am Rande. Nahezu elnig waren sich die Wissenschaftler in der Verurteilung der BruttoUSt. Die Meinungen gingen jedoch auseinander, als es um die Frage nach der besten Alternativlösung ging. Wăhrend insbesondere die italienischen Vertreter sich nur auf ein neutrales USt-System festlegen wollten sie fürchteten, die hochentwlckelte MWSt könne zu einem Alptraum für dle italienische Finanzverwaltung werden - verlangten andere mit dem Blick aup die "..aus psychologischen und politischen Gründen.."26 wichtige Abschaffung der Steuergrenzen die EG-weite Einfuhrung einer MWSt. Letzteres konnte sich schließlich, unterstützt vom Ausschußvorsitzenden Neumark er hatte sich schon in der deutschen Reformdebatte mehrmals für die MWSt stark gemacht - und seinem amerikanischen Kollegen Shoup - auch er war erklärter Befürworter der MWSt und hatte sle schon früher zur Einführung in Japan empfohlen - als Mehrheitsvotum durchsetzen. ${ }^{27}$

Nach ersten Vorbereitungen im Winter und Frühjahr 1960 hatte der Steuerund Finanzausschuß im Jull 1960 seine erste Sitzung abgehalten. Dle Kommission drängte zur Eile, da sle dle Arbeit der Professoren und die der AG I gleichzeitig zum Abschluß bringen wollte. Aup der Basis eines vorläuPigen Berichts konnte schließlich ein steuerpolitisches Kolloquium organislert werden, zu dem unter anderem die Leiter der nationalen Steuerverwaltungen geladen waren. ${ }^{2 \theta}$ Die Prühzeitige Einbezlehung der nationalen Entscheidungsträger in die Dískussion verschaffte dem Neumark-Bericht nicht nur elnen gewissen ofpiziösen Charakter, sondern bereitete sle auch rechtzeitig auf den Vorschlag für eine 1.USt-Richtlinie vor. Ihre Diskussionsbeiträge gaben der Kommission elnen ersten Vorgeschmack auf die zahlreichen Widerstände, auf die ihre Harmonisierungsbemühungen noch stoßen sollten: Alleine die Deutschen waren für die Abschaffung der Steuergrenzen und für die MWSt; dle Franzosen konnten allein das letztere unterstützen, wăhrend Belgier und Itallener sich nur auf eine nicht-kumulative USt Pestlegen lassen wollten; und die Niederländer sprachen dem Neumark-Bericht schlicht die Berechtigung ab, als Grundlage politischer Entscheidungen dienen zu können; man solle sich, so meinte der nlederländische Vertreter höflich, aber bestimmt, lieber konkreteren und kurzfristig auch lösbaren Problemen zuwenden.

Damit waren recht klar die Fronten abgesteckt, die auch die späteren Verhandlungen bestimmten. Die endgültige Fassung des Neumark-Berichts lag Ende 1962 vor. Trotz gewisser theoretischer Schwächen, die sich beim da-

26 Neumark-Bericht (1962), S.80.

27 Vgl. Neumark-Bericht (1962), S.42Pf.

$28 \quad$ Vgl. z.B. NZZ 19.5.62. 
maligen Stand der Forschung kaum vermeiden lleßen, wurde er zur Bibel der europäischen Steuerharmonisierung.

\subsubsection{Die Arbeitsgruppe I}

Wăhrend der Steuer- und Finanzausschuß nach einem steuerpolitischen Gesamtkonzept suchte, war es Aufgabe der aus Steuerexperten der nationalen Ministerialbürokratien zusammengesetzten AG I, die Einzelfragen der vordringlich erscheinenden USt-Harmonisierung $\mathrm{zu}$ klären. Nach der Verabschledung ihres ersten Berichts beschloß die Arbeltsgruppe in ihrer Sitzung vom 20.Februar 1960, drei Untergruppen - genannt UG A, B und C - zu bllden und dort die bis dato ungelösten Probleme aus der Perspektive der von dęr Kommission vorgegebenen Ziele Wettbewerbsneutralität und $A b-$ schaffung der Steuergrenzen eingehender zu analysieren. ${ }^{29}$

UG B und C: MWSt versus Einphasensteuer

Die UG $B$ und $C$ untersuchten eine Anzahl nicht-kumulativer UStn, die als Alternativen zur Bruttoust prinzipiell in Frage kamen. Eine einphasige EinzelhandelsUSt war dabel von vorneherein aus den tberlegungen ausgeschlossen worden, da, mit Ausnahme von Frankreich und Deutschland, sich aus steuertechnischen wle politischen Gründen keines der EG-Länder vorstellen konnte, die Vlelzahl kleiner Einzelhändler überhaupt der Umsatzbesteuerung $\mathrm{zu}$ unterwerfen. Und auch Frankreich und Deutschland wollten sich nicht für die Idee erwärmen, das relativ hohe Steueraufkommen, das belde aus der USt bezogen, alleine bel den Einzelhändlern zu erheben.

Als weitere Möglichkelt blieb eine einphasige USt, erhoben aup der letzten Produktions- oder der Großhandelsstufe. Selbstverständlich ist, bedingt durch die bei steigendem Steuersatz sich vergrößernden steuertechnischen Probleme und Verzerrungen, das Aufkommenspotential solcher Abgaben begrenzt. Wichtiger für die Melnungsblldung in der AG I dürfte allerdings die Tatsache gewesen sein, daß bel zunehmendem Steuersatz auch der politische Widerstand gegen eine Einphasensteuer ansteigt:
"Es ist einleuchtend, dass eine Einphasensteuer, die zu einem hohen Steuersatz ganz alleine auf der Vorstufe zum Einzelhan- del erhoben wird, eine untragbare Belastung besonders für die Großhändler darstellen würde, deren Gewinnspanne häufig sehr bescheiden ist." 30

Ein solches Argument gegen die einphasige USt und für die MWSt zu verwenden ist aus ökonomischer Sicht alles andere als einleuchtend, da elne

Zum Polgenden vgl. Untergruppen-Bericht (1962). Vgl. a. Jansen (1961), S.112ff. und Juretzek (1962), S.110pf. 
GroßhandelsUSt und eine bis zur Großhandelsstufe erhobene MWSt hinsichtlich der Verteilung der effektiven Steuerlast als vollkommen gleichwertig einzustufen sind. Aber finanzwissenschaftliche Erkenntnisse sind, wie wir im folgenden noch öfters sehen werden, im politischen Alltag nicht notwendigerweise von Relevanz: Die Steuerpflichtigen verstehen nicht viel von ökonomischer Inzidenz, sehen aber dafür umso deutlicher die von ihnen an den Fiskus abzuführende Steuerzahllast und wehren sich dagegen. Alle Aspekte zusammengenommen veranlaßten Frankreich und Deutschland - sie hatten die höchste USt-Last in der EG und besteuerten als einzige sämtliche Poduktions- und Verteilungsstufen -, sich gegen eine EinphasenUSt auszusprechen. Sie wollten eine MWSt, die durch ihr System der Praktionierten Zahlungen die Steuerzahllast über eine große Zahl von Unternehmen verteilt. Die anderen Experten sahen zwar durchaus die Vorteile der MWSt, fürchteten aber den mit ihr verbundenen höheren Verwaltungsaufwand und tendierten daher, zumindest als Ubergangslösung, zu einer Einphasensteuer. Die Fronten waren damit abgesteckt: Deutsche und Franzosen gemeinsam für die MWSt und gegen den Rest.

UG A: das "System Tuk"

Die UG A setzte sich mit einer Idee auseinander, die von der niederländischen Delegation in Brüssel präsentiert worden war und nach ihrem geistigen Vater im Haager Finanzministerium kurz als System Tuk bezeichnet wurde. Die ausgesprochene Unlust der niederländischen Finanzbürokratie, das von ihr konzipierte und verwaltete USt-System einer europäischen Harmonisierung auszusetzen, hatte die Phantasle einiger Beamter beflügelt und sie einen Mechanismus erdenken lassen, der die von der Kommission so gellebte Beseitigung der Grenzkontrollen ermöglichte, ohne gleichzeitig eine Harmonisierung der USt zu erfordern: Der Grenzausgleich sollte beibehalten, die damit verbundenen Kontrollen jedoch von der Grenze ins Inland verlagert werden. Auf Sympathie stieß der Vorschlag bei den Belgiern, die die Motive ihrer Nachbarn teilten. Alle anderen lehnten ihn ab, und zwar aus ganz verschiedenen Gründen:

- Italien, well es mit der Abschaffung der Steuergrenzen sowieso nichts im Sinne hatte; die Anpassungskosten wären in jedem Falle hoch, der potentielle Nutzen in Form eines Wegfalls der Grenzkontrollen an der kurzen Grenze mit Frankreich jedoch gering gewesen.

- Frankreich, weil es in erster Linie dem allgemeinen Spiel mit den Manipulationen am Grenzausgleich eln Ende setzen wollte; und die würden ja, auch nach elner Verwirklichung des System Tuk, in alter Weise weitergehen.

- Deutschland, weil es über eine Angleichung der Steuersätze die wirtschaftliche und politische Integration voranbringen und die Franzosen zu einer Anhebung der direkten Steuern zwingen wollte.

Von den elgentlichen Beweggründen hörte man in den offiziellen Verlautbarungen jedoch nur wenig. Gesprochen wurde vielmehr von Steuerhinterzie- 
hung und den weiterhin bestehenden Wettbewerbsverzerrungen. Abgesehen von den nicht beseitigten Verzerrungen im internationalen Warenverkehr entlarvten sich alle anderen Argumente bel näherem Hinsehen als fadenscheinig:

- Das Poblem vermehrter Steuerhinterziehung hängt mit der Abschaffung der physischen Grenzkontrollen zusammen; es ist damit nicht dem System Tuk immanent, sondern würde sich in gleicher Schärfe auch nach einer vorangegangenen Harmonisierung der USt-Systeme stellen.

- Wenn die Mitgliedstaaten wegen der durch die Bruttoust im Inland hervorgerufenen Verzerrungen so besorgt gewesen wären, wie sie nach außen taten, so hätten sie diese, jeder für sich, durch eine USt-Reform im elgenen Lande schon längst abstellen können.

Aber letztendlich zählten nicht die Beweggründe, sondern alleine die Tatsache, daß der niederländische Vorschlag bei einer Mehrheit der Regierungsvertreter auf Ablehnung stieß. Die Kommission ihrerseits stand der ganzen Geschichte mit etwas gemischten Gefühlen gegenüber. Auf der einen Seite sah sie die Gefahr, daß durch eine Annahme des System Tuk die von ihr Pavorisierte durchgreifende Harmonisierung der USt auf die lange Bank geschoben werden könnte. Auf der anderen Seite konnte man nicht sicher sein, ob das hochgesteckte Ziel der Satzangleichung überhaupt zu erreichen war. Die Kommission entschied sich daher dafür, elne Steuerharmonisierung erst einmal anzustreben, die Tür zur Einführung des System Tuk aber offenzulassen für den Fall, daß man bei der Harmonisierung írgendwo steckenbllebe:
"Man könnte jedoch gewisse Möglichkeiten technischer Art prüfen, die es ermöglichen würden, die Steuergrenzen zu beseltigen, ohne den Mitgliedstaaten ihre Autonomie auf dem Gebiet der Abgaben und Bepreiungen völlig zu nehmen."31

Dle genannte Formel war im ersten internen Kommissionsentwurp für eine 1.USt-Richtlinie noch Teil des Art.4. Sie wurde, nach einer entsprechenden Intervention des Pranzösischen Kommissars Marjolin, zum Zwecke einer Abschwächung dort wieder herausgenommen und fortan in den Vorspann zur eigentlichen Richtlinie verbannt.

\section{Ergebnis der Expertenberatungen}

Die UG A, B und C hatten sich im April $1960 \mathrm{zu}$ ihren ersten Gesprächen zusammengefunden. In einer gemeinsamen Abschlußsitzung am 15.Januar 1962, also einige Monate Prüher als der Neumark-Ausschuß, waren sie in der Lage, einen Gesamtbericht ${ }^{32}$ zu verabschieden. Mit der darin enthaltenen detaillierten Analyse der verschiedenen USt-Systeme hatte die Kom-

\footnotetext{
31 1.USt-Richtlinle, Begründung.
}

32 Untergruppen-Bericht (1962). 
mission eine solide Basis, aup die sie sich bei ihrem weiteren Vorgehen stützen und berufen konnte.

Die Kommission hatte aber noch mehr erreicht. Die zentrale Rolle, die den nationalen Steuerbeamten - sie waren meist von den Finanzministerien entsandt worden - schon bei der Vorbereitung der späteren Harmonisierungsvorschläge zugemessen wurde, sollte sich in Zukunft als ein kluger Schachzug erweisen. In zahlreichen Sitzungen lernten die Experten sich gegenseltig und die von einem Gemeinsamen Markt aufgeworfenen Besteuerungsprobleme besser kennen. Sie waren gezwungen, sich intensiv mit den Schwächen ihrer jeweiligen nationalen USt und mit möglichen Reformansätzen auselnanderzusetzen, alles Fragen, über die sich viele von ihnen überhaupt noch keine Gedanken hatten machen müssen. Im Kontakt mit den In MWSt-Fragen bestens bewanderten Franzosen und dem Leiter der Brüsseler USt-Abteilung Jansen lernten sie die für die meisten ganz neue MWSt kennen und auch schätzen. In den UG A, B und C wurde damit eine umfassende Refomdebatte entfacht, die von den Steuerbeamten, bedingt durch ihre Doppelfunktion in Brüssel und in den einzelnen Hauptstädten, direkt in die Finanzministerien hineingetragen wurde. Dort half sle entscheidend mit, die Verteidigungshaltung der nationalen Finanzbürokratie, an der jeder aus Brüssel kommende Veränderungsvorschlag von vorneherein zu scheitern drohte, prüheitig und langsam von innen her aufuubrechen.

Die Haltung der Steuerbeamten ist zwar, wie wir später an Beispielen noch zelgen werden, ${ }^{33}$ von zentraler Bedeutung für den Erfolg eines Steuerreformvorhabens. Die letztendliche Entscheidung darüber liegt aber auf der politischen Ebene. Und die Polltiker waren, als die Beamten ihre Beratungen bereits abgeschlossen hatten, noch mit einem notwendigen Vorspiel zur eigentlichen Reform der USt-Systeme beschäftigt.

\subsubsection{Dle vergeblichen Bemühungen um elne Ubergangslösung auf politischer Ebene: 1960-1963, eine Parallelentwicklung}

\subsubsection{Das Scheitern einer Stillhaltevereinbarung}

\section{Das Problem}

Ab 1960 standen, wie schon vermerkt, die umsatzsteuerlichen Zukunftspläne nicht mehr auf der politischen Agenda der Gemeinschapt. Zeit zum Schlafen blieb aber auch den Polltikern nicht. Sie mußten sich mit den von der BruttoUSt aufgeworfenen Tagesproblemen herumschlagen: die Manipulationen am Grenzausgleich. Die Niederländer und Belgier hatten mit ihrer Grenzaus- 
gleichserhöhung vom Januar 1959 bereits einen Vorgeschmack darauf gegeben, was bei weiteren Zollsenkungen noch zu erwarten war. Geubt in jahrelanger Benelux-Erfahrung waren sle bereits relative Meister im Heraufsetzen des Grenzausgleichs. Die nationalen Parlamente hatten den Regierungen hierfür weltgehende Vollmachten ertellt, soda $\beta$ auch von der institutionellen Seite her solche Erhöhungen schnell und problemlos vonstatten gehen konnten. Ganz anders bei den Deutschen und Italienern, denen es an der den Benelux-Staaten eigenen Routine fehlte. Geschützt durch nationale Zollmauern hatten sie es nicht nötig gehabt, ihren Grenzausgleich wesentlich $\mathrm{zu}$ verfeinern. Ende der 50er Jahre erhoben sie daher im Regelfall immer noch einen Grenzausgleich in Höhe des Standardsatzes der Bruttoust. Die effektive inlandische Steuerlast lag im Durchschnitt mehr als doppelt so hoch. ${ }^{34}$ Als die EG ihnen die ersten Zollsenkungen abverlangte, dauerte es eine geraume Zelt, bis die in solchen Dingen noch ungeübte institutionelle Maschinerle langsam anfing, auf eine Erhöhung des Grenzausgleiches hinzuarbeiten. Ende 1959 sickerten erste Gerüchte nach Brüssel durch, daß nun auch in Bonn und Rom entsprechende Arbeiten in Gange seien.

Der politische Barometer bei der Kommission stand auf Sturm. Die Volkswirtschaften Deutschlands und Itallens waren wesentlich größer als die der Benelux-Staaten. Zudem hatten Deutschland und Italien, im Vergleich zu den Niederlanden und Belgien, einen weltaus höheren Nachholbedarf bei den Grenzausgleichssätzen. Die Franzosen waren bereits aufgeschreckt und reagierten zutiefst verärgert auf das, was da im Anzug war: Da sie selbst beim Grenzausgleich die zulässige Höchstgrenze schon fast erreicht hatten, konnten sie von weiteren Erhöhungen der anderen nur Negatives erwarten. ${ }^{30}$ Hier ging es nicht mehr um Wettbewerbsverzerrungen in dem Sinne, da $\beta$ ein Unternehmen ein paar Prozent mehr oder weniger Steuern zahlt als ein anderes. Es ging vielmehr darum, einen handelspolitischen Schlagabtausch mit steuerlichen Mitteln zu vermeiden. Die Kommission riep daher schon ab 1959 nach einem Stillhalteabkommen. Nach entsprechenden Bemühungen des Kommissars von der Groeben wandte sich am 20.Januar 1960 sogar Präsident Hallstein in einem persönllchen Schreiben direkt an die Außenminister der Mitgliedstaaten: er äusserte sich "sehr besorgt"36 über

34 Die Situation in Luxemburg war ähnlich. Angesichts eines extrem niedrigen Steuersatzes von nur $2 \%$ und einer guten Handelsbilanzsituation konnten sie es sich jedoch auch in Zukunft erlauben, bei einem niedrigen Grenzausgleich zu bleiben. Sie beteiligten sich daher auch nur wenig an der Auseinandersetzung über die Stillhaltevereinbarung.

35 Ein Uberblick über den Anfang der 60er Jahre praktizierten Grenzausgleich und die sich daraus ergebende Interessenskonstellation findet sich in Kap.C.1.2.2.

Persönliches Interview. 
die ernsten politischen und psychologischen Folgen weiterer unkontrollierter Manipulationen am Grenzausgleich und forderte baldige Erörterung und Beschlußfassung auf Ratsebene.

Die Stillhaltevereinbarung vom 20.Juni 1960

Aup einer für den 6.April 1960 anberaumten Ratssitzung machte sich der französische Finanzminister erwartungsgemäß für ein sofortiges und totales Stillhalteabkommen stark. Die Franzosen blieben aber, wie eine Sitzung der Staatssekretäre der Finanzen vom 19.Mai zeigte, mit ihrer Aupfassung alleine. Die anderen wollten sich ihr vertraglich zugesichertes Recht auf Erhöhungen des Grenzausgleichs keinesfalls nehmen lassen. ${ }^{37}$ Einigkeit bestand lediglich insofern, als alle eine protektionistische Steuerpolitik ablehnten und einen neutralen Grenzausgleich wollten. Nur verstand man unter neutral ganz verschiedene Dinge: Die Franzosen meinten den Status quo, die anderen die nach Art.95-97 zulässige Obergrenze. Die Kommission ihrerselts liebäugelte mit dem Pranzösischen Standpunkt, was nicht nur ein Resultat Pranzösischer Repressionen war, sondern auch ihren eigenen Interessen am besten entsprach:

- Bis zum Erreichen der im EWG-Vertrag vorgesehenen Obergrenze konnte noch einige Zeit vergehen. Darüberhinaus hörte ja der Streit auch dann noch nicht auf, da Uberschreitungen der Grenze in Anbetracht der gebräuchlichen BruttoUSt überhaupt nicht zu kontrollieren waren. Eine Festschreibung des Status quo versprach daher die schnellste und nachhaltigste Beilegung des Familienstreits.

- Eine Festschreibung des Grenzausgleiches auf einem möglichst niedrigen Niveau gab den betroffenen Staaten den Anrelz, einmal gemeinsam, wie von der Kommission gewünscht, zu einer nicht-kumulativen USt mit vollständigem Grenzausgleich überzugehen.

Nur war es im April 1960 um die Annahme einer Stillhaltevereinbarung leider denkbar schlecht bestellt. Die Kommission beschloß daher, ihren ursprünglich recht streng formullerten Stillhalte-Vorschlag aufzuweichen, um so die Chance für eine friedliche Einigung zu erhöhen. Aber COREPER kam bel einer entsprechenden Sitzung zu dem Ergebnis, daß nur Luxemburg der neuen Fassung zustimmte, ein wahrlich geringer Trost. Zudem kämpften die Italiener hart und machten von Anfang an klar, daß die Erhöhungen des Grenzausgleichs, die gerade die langsam malende römische Gesetzgebungsmaschinerie durchliefen, in jedem Fall von elnem Ubereinkommen ausgenommen werden müßten, egal wie auch immer dies aussähe. Und von den Belgiern hörte man, daß sie schon die nächste Anhebung planten, um, sollte es wirklich zu einem standstill kommen, selbst nicht zu schlecht dazu-

37 Vgl. z.B. Handelsblatt 5.5.60 u. Industrie Kurier 24.5.60. 
stehen. ${ }^{38}$ Mit diesen alles andere als hopfnungsvollen Voraussetzungen ging man in die Ratsitzung vom 20.Juni 1960, aup deren Tagesordnung u.a. die Stillhalte-Problematik gesetzt worden war. Nach langen Diskussion kam man zur allgemelnen Uberraschung dennoch zu einer Ubereinkunft, die Inhaltlich jedoch, wie sich rasch herausstellte, nicht viel hergab. Im Prinzip versprach man sich gegenseitige Maßigung und sonst nichts:

\begin{abstract}
"Um die wirtschaftlichen und psychologischen Nachtelle derartiger Anderungen (des Grenzausglelchs, d.Verf.) zu verhüten, enthalten sich die Mitgliedstaaten einer Anderung der bestehenden Verhältnisse. Es sel denn, sie machten bei der Kommission und den anderen Mitgliedstaaten Grunde geltend, die diese Anderungen legitimieren können." ${ }^{39}$
\end{abstract}

Die Mitgliedstaaten wurden somit lediglich auf ein Konsultationsverfahren verpflichtet, in dem die Kommission den impliziten Konflikt zwischen Frankreich und den anderen hopfte lösen zu können. Dies war angesichts der massiven Wirtschaftsinteressen, die hinter den jeweiligen Positionen standen, die reine Illusion. Und es war zu dürftig für eine Resolution des Rates. Also reicherte man die Entschließung, zumindest zum Schein, noch mit einer ausdrücklichen Verbotsvorschrift an:

"Es ist anerkannt, dass eine Anderung der Rückvergütungen
und der Ausgleichssteuern,..., nicht aus wirtschapts-, handels-
oder währungspolitischen Gründen, sondern nur aus steuer-
technischen Erwägungen vorgenommen werden darf." 40

Man beachte den Begriff steuertechnische Erwägungen. Alle waren mit dem Kompromi $\beta$ einverstanden, da hierunter jeder das verstehen konnte, was er wollte. Man hatte Einigkeit demonstriert und sich doch auf nichts festgelegt. Der Begriff steuertechnische Erwägungen ist geradezu ein Beispiel par excellence dafür, wle eln fundamentaler politischer Dissens hinter geschickten Formulierungskünsten versteckt wird: Die Ratsitzung und die unvermeldliche Pressekonferenz waren gerettet, der elgentliche Konflikt bis auf welteres vertagt.

Jeder, der sich uber den wahren Charakter der als Stillhalteabkommen bezeichneten Entschließung irgendwelchen Illusionen hingab, wurde schon bald eines Besseren belehrt. Den ersten Schlag lieferten die Itallener. Sie hatten sich eine Ausnahmeregelung für die bereits auf den Gesetzgebungsweg gebrachte Erhöhung des Grenzausgleichs ausbedungen und dies im Protokoll der Ratsitzung auch zugebilligt bekommen. Im Spătsommer 1960 wurde

38 Vgl. z.B. Le Monde 10.3.60.

39 Art.2 der Stillhaltevereinbarung des Rates v. 20.6.60, Quelle: Persönliches Interview.

40 Art.1 der Stillhaltevereinbarung des Rates v. 20.6.60, Quelle: Persönliches Interview. 
klar, daß Rom den Grenzausgleich auf breiter Front, d.h. Pür hunderte von Produkten gleichzeitig, in teils beachtlichem Ausmaß anheben wollte.41 Der Kommission und den anderen Mitgliedstaaten verschlug es die Sprache. Sie ärgerten sich, konnten aber nichts dagegen tun. Die Italiener hatten zwar nicht gegen den Wortlaut der Resolution vom 20.Juni verstoßen, aber mit dem Geist des Ubereinkommens, falls es einen solchen jemals gegeben hatte, war es dahin.

Der Streit um das deutsche 12.USt-Anderungsgesetz

Nach mehreren Scharmützeln mit den verschledensten Staaten - ausgenommen Frankreich, wie sich versteht - stand 1963 mit dem 12.UStAndG der Deutschen die Schlacht ins Haus, in der die Stillhaltevereinbarung endgultig unterging. Berelts Anfang 1963 war abzusehen, da $\beta$ die Bundesregierung den Grenzausgleich für die Notleidenden der deutschen Industrie - Stahl, Textll und Leder, Papier und Zellstopf -, denen die DM-Aufwertung vom Mai 1960 allesamt nicht so recht bekommen war, von $4 \%$ auf bis zu $10 \%$ heraufsetzen wollte. ${ }^{42}$ Nun ging es den betreffenden Sektoren in den anderen EG-Staaten auch nicht gerade blendend. Die Partner, allen voran die Franzosen, hatten daher das durchaus berechtigte Gefühl, daß die Deutschen ihre eigenen wirtschaftlichen Probleme einfach auf die Anderen abwallzen wollten.

Die Deutschen aup der anderen Seite ließen sich mit dem Beginn des Konsultationsverfahrens viel Zeit und fuhrten es dann mit der "linken Hand"43 durch. Sie hatten nichts Besseres $\mathrm{zu}$ tun, als sich in elnem juristischen Gutachten bescheinigen $\mathrm{zu}$ lassen, daß aufgrund verschledener Formmängel die Resolution vom 20.Juni 1960 unter völkerrechtlichen Gesichtspunkten lediglich "als steuerpolitische Maxime ohne normative Bindung zu werten"44 sel. Aber wle auch immer die Rechtslage war, vor der politischen Auseinandersetzung mit Frankreich konnte sich Bonn damit nicht drücken.

Angesichts des seit Jahren schwebenden und unlösbaren Strelts über den Begriff steuertechnisch war der Kommission von Anfang an klar, daß sle hler auf verlorenem Posten stand. Aber dem aufgestauten Arger und den wirtschaftlichen Interessen der anderen Mitgliedstaaten war Genüge zu tun. Erst auf Sachverständigenebene und, als die Verkündung des 12.UStAndG zum 1.Juni 1963 anstand, auch mit größeren Geschützen in Form öpfentlicher Erklärungen versuchte die Kommission, den Deutschen Einhalt zu ge-

4 Vgl. z.B. Jansen (1961), S.111. Vgl. a. Stuttgarter Nachrichten 25.8.60 u. Blick durch die Wirtschaft 10.11.60.

42 Vgl. z.B. NZZ 13.1.63. Vgl. a. Regul/Renner (1966), S.98ff.

43 Christ und Welt 28.3.63. Vgl. a. Süddeutsche Zeitung 10.6.63.

44 Persönliches Interview. 
bieten. ${ }^{45}$ Das Ergebnis war eine, wie es im diplomatischen Sprachgebrauch umschrieben wird, politische Verstimmung zwischen Bonn und Brüssel. Der Ministerrat beschäpigte sich mit dem Thema auf seinen sitzungen am 30.Mai, 18.Juni, 15.0ktober und 5.November; zahlrelche Zusammenkünfte von COREPER und auf Expertenebene Panden statt, ohne Ergebnis. Die Fronten bei der Interpretation des Begriffs steuertechnisch waren festgefahren.

Aup der einen Seite standen, wie bereits 1960, die Franzosen, die für eine sehr restriktive Auslegung eintraten. Sie wurden unterstützt von den Italienern, die inzwischen klammheimlich die Fronten gewechselt hatten: Nach den radikalen Erhöhungen ihres Grenzausgleichs von Ende 1960 hatten sle dle Möglichkeiten, die der EWG-Vertrag bot, weitgehend ausgerelzt; ihnen war verständlicherweise daran gelegen, die Partner daran zu hindern, dem elgenen Beisplel zu folgen. Auf der anderen Seite standen die Deutschen und die Benelux-Länder, die eine weite Auslegung des Begriffs steuertechnisch befürworteten. Die deutsche Interpretation war in der Tat so weit, daß sie, wie die Kommission feststellen mußte, das Stillhalteabkommen zu einer "Goodwill-Erklärung"46 reduzierte, von den Anderungen des Grenzausgleichs nur maßvoll Gebrauch zu machen. Beide Seiten untermauerten ihre jeweilige Position mit Zitaten aus dem Ratsprotokoll vom 20.Juni 1960. Aber damals war so viel so unklar gesagt worden, daß jede bellebige Aupfassung mit entsprechenden Stellen zu belegen war.

Die Kommission sympathisierte, wie schon in 1960, mit dem Pranzösischen Standpunkt. Da der aber auf keine Mehrheit hoffen konnte, präsentlerte sie den Mitgliedstaaten eine Kompromißformel: Um sich nicht weiter in endlosen Theoriediskussionen $\mathrm{zu}$ verlieren, sollte für einige beispielhafte Fälle gemeinsam entschieden werden, ob es sich um steuertechnische Erwägungen handelte oder nicht. ${ }^{47}$ Die Kommission akzeptierte Erhöhungen des Grenzausgleichs aufgrund gestlegener Steuersätze und/oder elnes veränderten Integrationsgrades der Wirtschaft. Sie erklärte sich auch mit einer allgemelnen Anhebung des Grenzausgleichs - Wirkung wie die einer Abwertung elnverstanden. Selektiven Erhöhungen stand sie jedoch wegen der dahlnter vermuteten protektionistischen Tendenzen sehr zurückhaltend gegenüber. Sie sollten nach Auffassung der Kommission nur dann zulässig sein, wenn die Sătze für einzelne Waren unter dem allgemeinen Niveau des Grenzausgleichs lägen.

Es war der letzte Punkt, an dem die Standpunkte von Brüssel und Bonn auseinandergingen. Der Kommlssionsvorschlag wurde erstmals am 10.Mai mit den Leitern der natlonalen Steuerverwaltungen diskutiert und von allen

\footnotetext{
45 Vgl. z.B. Welt 13.6.60.

46 Persönliches Interview.

47 Vgl. z.B. Le Monde 24.8.63 u: FT 4.10.63.
} 
Delegationen gebilligt, mit Ausnahme der deutschen. Die Argumente der Kommission gegen bestimmte selektive Erhöhungen der Ausgleichssätze waren aus ökonomischer Sicht vollkommen korrekt. Sie hatten bereits den Kern des Tinbergen-Berichts von 1953 geblldet. Und die Deutschen hatten sie in 1956 selbst benutzt, um bei den Verhandlungen zum EWG-Vertrag die von Frankreich verlangte Harmonislerung der Sozlalkosten abzublocken. Aber all das sollte in 1963 keine Rolle mehr spielen. Massive Wirtschaftsinteressen überfuhren, wieder elnmal, die ökonomische Rationalität. Die von der Kommission vorgebrachten Argumente wurden von deutscher Seite ignoriert: aup Sachverständigenebene, in COREPER, im Rat und bel bilateralen Kontakten. ${ }^{40}$ Kommissar von der Groeben erwog daher zeitweise, der Begriffstutzigkeit der Deutschen mit Art.101 nachz̈lhelfen: Die genannte Vorschrift eröffnet die Möglichkelt, durch einzelne Mitgliedstaaten verursachte Wettbewerbsverzerrungen per Mehrheitsentscheldung zu unterbinden.49 Aber die Idee wurde aufgrund juristischer und politischer Bedenken wieder fallengelassen.

Nach unzähligen Sitzungen auf allen möglichen Ebenen wurden die Einigungsversuche in der Ratsitzung vom 5.November 1963 endgültig begraben. Dle deutsche Delegation versuchte, sich mit Hinweis auf die Arbeiten zur Einführung einer MWSt zu exkulpieren, und blieb ansonsten hart: Sle setzte sich durch. Die Franzosen hatten wieder einmal vergeblich versucht, die ewigen Manipulationen am Grenzausglelch zu stoppen: Sle waren sichtlich Prustriert. Und der Kommission blieb alleine dle Hoffnung, daß der gemeinsame Ubergang zur MWSt der unaufhörlichen Streiterel irgendwann einmal ein Ende setzen würde. ${ }^{30}$

\subsubsection{Das Scheitern der gemeinsamen Berechnungsmethode}

\section{Das Problem}

Bel den Bemühungen um ein Stillhalteabkommen ging es darum, den Spielraum einzuengen, der den Mitgliedstaaten in Art.95-97 für die Festlegung ihres Grenzausgleichs ausdrückllch zugebilligt worden war. Je mehr die Stillhaltevereinbarung zur Makulatur wurde und je näher die einzelnen Staaten mit ihrem Grenzausgleich an die vertraglich fixierte Obergrenze herankamen, desto Pühlbarer wurde die zweite Lücke des Diskriminierungsverbots: Angesichts der Verwendung einer Bruttoust war die inländische Steuerbelastung in der Praxis weder $\mathrm{zu}$ bestimmen noch $\mathrm{zu}$ kontrolleren. Unklare Rechtsregeln schaffen Unsicherheit und Streit. Seit Mitte 1959

\footnotetext{
48 Vgl. 2.B. Handelsblatt 1.11.63.

49 Vgl. z.B. Industrie Kurier 31.8.63.

so Vgl. z.B. NZZ 6.11.63.
} 
beschäftigte sich daher eine Expertengruppe - die AG II - mit der Frage, wie die vertraglich fixierte Obergrenz durch eine gemeinsame Berechnungsmethode für die praktische Anwendung operationalisiert werden könnte. In der bereits bekannten Resolution vom 20.Juni 1960 sprachen sich alle Staaten für eine Beschleunigung dieser Arbeit aus: Damit legte man sich ja noch nicht fest. Im Oktober 1961 konnte die AG II ihre Uberlegungen mit einem Bericht und einem Richtlinienentwurf abschließen. Als es dann langsam ernst wurde mit der Berechnungsmethode, hatten die Mitgliedstaaten plötzllch ganz unterschiedliche Auffassungen. Es waren insbesondere zwei Probleme, dle einer Einigung im Wege standen:

1. Seitdem die Italiener Ende 1960 ihren Grenzausgleich massiv erhöht hatten, lehnten sle eine gemeinsame Berechnungsmethode strikt ab. Sle machten prinziplelle viberlegungen geltend und brachten juristische und andere Einwände vor. Bei näherem Hinsehen zeigte sich jedoch rasch, daß die Argumente weniger prinzipleller als vielmehr recht praktischer Natur waren. Nach allgemeiner Einschätzung lagen die italienischen Ausgleichssätze hart an der zulässigen Obergrenze und tellwelse sogar über $100 \%$ der inländischen Steuerbelastung, während die gemeinsame Berechnungsmethode zu Sätzen geführt hätte, die in ihrer Mehrheit wahrscheinlich unter $100 \%$ gelegen hätten.

2. Das zweite zentrale Problem war, in welchem Verhältnis die Berechungsmethode zur Ubereinkunft vom 20.Jun1 1960 stehen sollte. In Entsprechung $\mathrm{zu}$ den unterschledlichen Interpretationen der Stillhaltevereinbarung gab es auch hier zwel voneinander verschiedene Auffassungen. Auf der elnen Selte standen wieder die Franzosen, die eine Berechnungsmethode als reine Ergänzung eines restriktlv auszulegenden Stillhalteabkommens wollten: Die Berechnungsmethode sollte nur dort Anwendung finden, wo nach der Stillhalteverelnbarung überhaupt eine Anderung des Grenzausglelchs zulässig war. Ganz anders die Deutschen. Sie betrachteten, in alt bekannter Weise unterstützt von den Benelux-Ländern, die Berechnungsmethode als Ersatz für das Stillhalteabkommen und damit als Frelschein Pür die Erhöhung des Grenzausgleichs unter Vermeldung der mlt dem Stillhalteabkommen verbundenen Scherereien.

\section{Der Verlauf der Beratungen}

Das Verhältnis der Kommission zur gemeinsamen Berechnungsmethode war ambivalenter Natur. Auf der einen Seite empfand sie den Zustand mit dem unkontrollierbaren Stillhalteabkommen als unbepriedigend: "Erörterungen mit den Experten ohne Resultat, gegenseitiges Mißtrauen, Androhung von Vergeltungsmaßnahmen, unangenehme psychologische Auswirkungen".51 Auf der anderen Selte fürchtete sie jedoch, daß die Annahme der Berechnungsmethode die USt-Harmonisierung gefăhrden könnte: Je perfekter der Grenz-

51 Zitiert aus einem internen Kommissions-Dokument von Ende 1961. 
ausgleich bel der bestehenden Bruttoust war, desto geringer war der Handlungsbedarf. Zwar Panden auch 1962 noch Expertengespräche statt, aber Brussel hatte sich grundsätzlich dafur entschieden, die Sache auf politischer Ebene zunächst nicht zu forcieren und stattdessen die Berichte des Neumark-Ausschusses und der AG I sowie deren Folgen abzuwarten.

Die Berechnungsmethode wurde wieder aktuell, als sich Anfang 1963 der Streit uber das deutsche 12.UStAndG abzeichnete. Die Kommission erwog nun die Vorlage des seit langem fertiggestellten Richtlinienentwurps als Tell eines Kompromisses zwischen Deutschen und Franzosen. Kurz vor der Ratsitzung vom 15.0ktober 1963 ließ sich Kommissar von der Groeben von seinen Kollegen sogar ermächtigen, den Richtlinienvorschlag bel Bedarf noch während des Trepfens den Ministern präsentieren zu können. Aber es kam nicht zu einem Beschluß des Rates. Die Itallener hatten nach wie vor grundsătzliche Vorbehalte gegen die Berechnungsmethode. Aber das ist nur ein, und zwar der unwichtigere Tell der Geschichte. Die Deutschen hatten im September 1962, nach Konsultationen mit der Wirtschaft, verschiedene Bedenken technischer Art gegen den Richtlinienentwurf vorgebracht.92 Aber auch diese konnten nicht der wahre Grund Pur die Ablehnung des Kommissionsvorschlages seln: Die Berechnungsmethode war ausdrücklich als ein Naherungsverfahren gedacht; wer versuchte, es zu perfektionieren, mußte sich daruber Im Klaren seln, daß er damit das gesamte Konzept zu Fall bringen würde. Und genau das war es, was dle Deutschen wollten. Bonn war gegen die Berechnungsmethode, falls dadurch die Freiheit, den Grenzausgleich im Rahmen des Vertrages beliebig zu gestalten, auch nur irgendwie elngeschränkt würde. Für Frankreich aber war die Berechnungsmethode wertlos, solange nicht genau dlese Einschränkung vorgesehen wurde.

Es war also der aus der Debatte über das Stillhalteabkommen bereits bekannte Interessenkonflikt, der auch hler eine Einigung unmöglich machte. Wie schon belm Stillhalteabkommen setzte sich der deutsche wille durch, und die Franzosen hatten das Nachsehen. Die gemelnsame Berechnungsmethode verschwand wieder in der Schublade. Paris mußte weiterhin tatenlos zusehen, wle die Nachbarländer munter mit ihrem Grenzausgleich herumspielten. Frankreich blleb daher nur elnes ubrig: daraup zu drăngen, daß die im eigenen Land bereits erhobene MWSt möglichst bald in der gesamten EG elngefuhrt wurde. Genau das war der Inhalt elnes Resolutionsentwurfes, den die Franzosen in die Ratsitzung vom 5.November 1963 einbrachten. 
2.1.4. Die Harmonisierung der USt als einziger Ausweg: 1962-1967

2.1.4.1. Der erste Harmonisierungsvorschlag der Kommission

Der Entwurf für eine 1.USt-Richtlinie

Nachdem im Sommer 1960 die deutschen und französischen Bemühungen um elne durchgreifende Reform der jeweiligen USt-Systeme vorläufig gescheitert waren, ${ }^{53}$ rutschte auch in Brüssel die Frage der USt-Harmonisierung von der Tagesordnung der politischen Gremien der Gemeinschaft ab in das Reich der Ausschüsse. Die Politiker der EG versuchten fortan erfolglos, den Streit über die Manipulationen am Grenzausgleich beizulegen, ohne an der bestehenden Bruttoust etwas zu verändern. Sie waren, wie wir gerade sahen, nicht in der Lage zu verhindern, daß auch weiterhin "ein Mitgliedstaat den anderen betrog"54. Der einzige Ausweg aus dem endlos erscheinenden Kreislauf elnseltiger Grenzausgleichserhöhungen, gegenseitiger Beschuldigungen und anschlleßender Vergeltungsmaßnahmen bestand in der Einführung einer nicht-kumulativen USt. Die Kommssion machte sich daher gleich nach Verabschiedung des Berichts der AG I daran, einen entsprechenden Harmonisierungsvorschlag auszuarbeiten. Schon im Juni 1962 lag ein erster Entwurf vor, der elnen Monat später mit den Finanzministern auf deren informeller Quartalskonferenz in Echternach diskutiert wurde. ${ }^{55}$

Der Vorschlag für elne Richtlinie des Rates zur Harmonisierung der Rechtsvorschriften betreffend die USt - kurz 1.USt-Richtlinie genannt - wurde am 5.November 1962 offiziell dem Rat zugeleitet. ${ }^{36} \mathrm{Er}$ enthielt in fünf kurzgefaßten Artikeln das oben berelts vorgestellte 4-Stufen Programm der Kommission. ${ }^{57}$ Nach der für eine Ubergangsphase vorgesehenen Einführung einer Prei wahlbaren, neutralen USt - erster Schritt - sollten alle Mitgliedstaaten bis spätestens $1970 \mathrm{zu}$ einer MWSt übergehen - zweiter Schritt -. Dle Abschaffung der Steuergrenzen - vierter Schritt - wurde in dem Richtlinienvorschlag als das Endzlel der USt-Harmonisierung Pestgehalten. Zwar war es nach Auffassung der Kommission ebenso wünschenswert wie notwendig, vorher die Steuersätze einander anzugleichen - dritter

53 Auf einer Finanzministerkonferenz im Oktober 1960 erklärte der Bonner Vertreter seinen Kollegen, da $\beta$ man bis vor kurzem noch an eine baldige Einführung der MWSt geglaubt habe. Er fugte hinzu: "Wir haben aber dann gesehen, daß eine solche MWSt einer Revolution gleich käme"; persönliches Interview.

54 Persönliches Interview.

s5 Vgl. FAZ 10.7.62 u. NZZ 12.7.62.

36 Vgl. z.B. Le Monde 7.11.62. Eine Begründung der Richtlinie gab Kommissar von der Groeben u.a. In: Bulletin der EWG, 6.1963, Heft 1, S.1ff.

37 Vgl. die Darstellung in Kap.C.1.1.3. 
Schritt -. Man hielt es jedoch für "taktisch nicht klug"58, einen solch tiefgreifenden Eingriff in die nationale Finanzautonomie schon 1962 als unumgängliche Forderung hinzustellen, da die weitverbreitete Opposition gegen dle Satzharmonisierung dazu hătte führen können, daß einzelne Mitgliedstaaten ihre Mitarbeit bereits bei den ersten beiden Harmonisierungsschritten verweigerten. Die Kommission zog es daher vor, ihre wahren $A b-$ sichten verdeckt zu halten und sich nur sehr vorsichtig zu äußern:

"Die Kommission prüt, in welcher Weise und binnen welcher Frist die Harmonisierung der Umsatzsteuern ihr Endziel erreichen soll, nämlich die Beseltigung der Besteuerung bei der Einfuhr und der steuerlichen Entlastung bel der Ausfuhr zwischen den Mitglledstaaten unter Wahrung der Neutralität der Umsatzsteuern in bezug auf diesen Warenaustausch."59

\section{Erste Reaktionen auf den Vorschlag}

Mit ihrem Entwurf für eine 1.USt-Richtlinle wollte die Kommission, ohne das Gemeinschaftsinteresse aus den Augen zu verlieren, eln möglichst kompromißpähiges Harmonisierungs-Paket zusammenschnüren. Es enthielt, wie jedes politísche Paket, für alle Staaten ein Zuckerstückchen und schwer Verdauliches gleichzeitig. ${ }^{60}$ Entsprechend gemischt waren die Reaktionen, die sich Ende 1962 und im Laufe des Jahres 1963 nach und nach einstellten. Eine weitgehend positive Aufnahme fand der Vorschlag alleine in Deutschland. Schon seit Mitte 1962 hatte Bonn gegenüber den Brüsseler Plänen eine wohlwollende Haltung eingenommen. Sle verwandelte sich in offene Unterstützung, nachdem Finanzminister Dahlgrün im Februar 1963 dem Deutschen Bundestag die baldige Einführung einer MWSt angekündigt hatte. Von da an drängten die Deutschen auf rasche Fortschritte in der EG: Die von der Kommission vorgeschlagene USt-Harmonisierung ging linnen nicht schnell und nicht weit genug.61 Klar zum Ausdruck kam die deutsche Position in der Stellungnahme des EP vom 17.0ktober 1963. Der von dem deutschen Abgeordneten Deringer ausgearbeitete Bericht ${ }^{62}$ und Entschliessungsantrag forderte die Kommission auf,

- den Rat darauf zu verpflichten, bis 1969 eine Entscheidung über die Satzharmonisierung und die anschließende Abschaffung der Steuergrenzen herbeizuführen,

50 Persönliches Interview.

59 Art.4 Abs.1 des Vorschlages für eine 1.USt-Richtlinie. Die Floskel "unter Wahrung der Neutralität" war als klare Absage an den SohlVorschlag gedacht; vgl. hierzu Kap.C.1.1.3.

Vgl. Taussig (1971), S.179pr.

61 Vgl. die Entschließung des Deutschen Bundestages v. 24.4.63 Bundestags-Drs. IV/1179 - zur 1.USt-Richtlinie. Vgl. a. Mersmann (1963b), S.6P. Vgl. a. Industrle Kurler 16.2.63.

Vgl. Deringer-Bericht (1963). 
- den ersten Schritt wegen des damit verbundenen Zeitverlustes zu überspringen,

- die MWSt schon bis 1967 in allen Mitgliedstaaten einführen zu lassen.

Demgegenüber standen alle anderen EG-Staaten dem Vorschlag für elne 1.USt-Richtlinie sehr zurückhaltend gegenüber. Frankreich zeigte sich zwar aufgeschlossen, was die allgemeine Einführung einer MWSt betraf, hielt die Sache jedoch zunächst für nicht sonderlich dringend und wollte sich daher auch nicht dafür stark machen. Italien und die Benelux-Länder lehnten die MWSt ganz ab und sahen sich bestenfalls in der Lage, einer nicht näher definierten, neutralen USt zuzustimmen. Während sich die deutsche Position in dem auf eine Stärkung der Gemeinschaft ausgerichteten EP durchsetzen konnte, waren die Zögerer in dem von Wirtschaftsinteressen dominierten WSA in der Mehrheit. Der vom Pranzösischen Verbandsvertreter Malterre ausgearbeitete und am 2.Jull 1963 vom WSA verabschledete Entschlleßungsantrag empfahl daher,

- bel der Abschaffung der Steuergrenzen äußerste Zurückhaltung zu wahren,

- zur Vermeidung von Anpassungsschwlerigkeiten den 1. und 2. Schritt zusammenzulegen und die Mitgliedstaaten darauf festzulegen, bis 1970 zu einer gemeinsamen "MWSt mit oder ohne fraktionierte Zahlungen" überzugehen. ${ }^{63}$

Der seltsam anmutende Ausdruck MWSt ohne fraktionierte Zahlungen bezeichnet im Klartext eine EinphasenUSt. Die umständliche Formulierung wurde vom WSA gewählt mit der Absicht, den Konfllkt zwischen den Interessen der französischen Industrie - für eine MWSt - und denen der Wirtschaftsverbände der Benelux-Länder - eher für eine einphasige Abgabe verbal zu verwischen und zugleich eine nicht vorhandene Uberelnstimmung mit dem Kommissionsvorschlag vorzutäuschen

Nach der offiziellen Vorlage des Richtlinienentwurfes hatten die Finanzminister bel ihrem Quartalstreffen in Baden-Baden im Mărz $1963^{64}$ und in Spa im Juni $1963^{65}$ erstmals wieder Gelegenheit, sich zu steuerpolitischen Fragen zu äußern. Auch wenn man über eine Diskussion allgemeiner Art nicht hinauskam, so schapfte es die sich abzeichnende Koalition zwischen

63 Vgl. 2.B. Industrie Kurier 6.7.63.

64 Vgl. FT 26.3.63 u. FAZ 27.3.63.

$65 \mathrm{Vgl}$. Le Monde 9.6.63 u. NZZ 13.3.63. 
Bundesreglerung und Kommission doch immerhin, die anderen Mitgliedstaaten auf eine Fortführung der Beratungen festzulegen. Beschlossen wurde,

- auf der Ebene der nationalen Steuerdirektoren - sie sollten sich in Zukunft als Ausschuß der Leiter der nationalen Steuerverwaltungen. im folgenden kurz ALSV genannt, regelmäßig treffen - die im Zusammenhang mit der Abschaffung der Steuergrenzen sich stellenden Fragen weiterzuverfolgen,

- die Kommission zu beauftragen, die Grundlinien eines gemeinsamen MWSt-Systems auszuarbeiten.

\subsubsection{Die Diskussion der 1.USt-Richtlinie}

\section{Die unergiebige Auseinandersetzung über die Steuergrenzen}

Mit dem in puncto Steuergrenzen sehr vorsichtig abgefaßten Entwurf für eine 1.USt-Richtlinie hatte die Kommission die Absicht verbunden, die UStHarmonisierung bis zur Einführung einer MWSt voranzutreiben, ohne gleichzeitig in eine langwierige Debatte über die Angleichung der Steuersătze und ähnliche Fragen einsteigen zu müssen. Bei einer Mehrheit der Mitglledstaaten stie $\beta$ ein solches Vorgehen aup Sympathle. Sie faßten die Beseitigung der Steuergrenzen ohnehin nur als Fernzlel auf und sahen daher keinen Anlaß, sich schon jetzt darüber die Köpfe heißzureden. Aber die Rechnung war ohne die Niederländer gemacht worden. Sle wollten, so behaupteten sie zumindest in der Opfentlichkeit, bel der USt-Harmonisierung nur dann mitspielen, wenn die Angleichung der Steuersätze und der Verzicht auf die Grenzkontrollen das erklärte Endzlel des ganzen Unternehmens selen.66

Das Ziel des niederländischen Beharrens auf dem kurzfristig nicht erreichbaren Ziel Abschaffung der Steuergrenzen war es, die Gemeinschaft in eine umfassende Pinanz- und wirtschaftspolitische Debatte hineinzumanövrieren und damit jeden konkreten Schritt bis auf weiteres zu blockieren.67 DenHaag zeigte daher auch immer großen Eifer, wenn es darum ging, die anderen Mitgliedstaaten hinzuweisen auf die unübersehbare Vielfalt der "Punkte, die bei einer Beurteilung des Problems der Beseltigung der Steuergrenzen berücksichtigt werden müssen". Ein Papier entsprechenden Inhalts leitete Staatssekretär van der Berge im November 1963 selnen Kollegen im ALSV zu. Das niederländische Konzept lief darauf hinaus, die ungellebte USt-Harmonisierung solange hinauszuschieben, bis alle anderen Politikbereiche vergemeinschaftet wären und die EG das Stadium einer Wirtschafts-

66 Vgl. z.B. Industrie Kurier 12.3.63, FAZ 27.3.63 u. NZZ 28.3.63.

$67 \mathrm{Zu}$ den politischen Hintergründen der niederländischen Position vgl. die Darstellung in Kap.C.2.2.4. 
oder gar politischen Union erreicht hätte. Dieser sogenannten Krönungstheorie widersprach Kommissar von der Groeben ganz entschieden:

"Ich möchte...elne Absage erteilen an die Aupfassung, daß wir warten, daß wir eine Maßnahme zurückstellen sollen, well angeblich erst eine andere Maßnahme erfolgen muß, oder - was ja häufig auch gesagt wird - daß gewisse Maßnahmen erst dazu geeignet sind, das ganze Werk zu krönen. Ich glaube, wenn wir herumpragten, wäre jeder der Meinung, daß die Maßnahme, auf die er gerade angesprochen ist, erst ganz zum Schluß als Krönung kommen dürfe."68

Aber die für die niederländische Finanzpolitik Verantwortlichen ließen slch nicht davon überzeugen, daß gerade sie es sein sollten, die den ersten Schritt zur Wirtschaftsunion tun sollten. Sle wünschten die USt-Harmonislerung nicht und forderten daher immer wieder von neuem "ein weiteres tlefgrelfendes Studium"69 der durch die Abschaffung der Steuergrenzen aufgeworfenen Probleme.

Da sich die unergiebige Debatte über die Steuergrenzen nicht mehr abwenden ließ, biß die Kommission in den sauren Apfel und machte sich auf der technischen Ebene daran, Im Laufe der Jahre 1963/64 eine größere Anzahl umfangreicher Papiere über die budgetären Konsequenzen der Satzangleichung, das optimale Verhältnis zwischen direkten und indirekten Steuern, die Möglichkeiten eines clearing, etc. zu produzieren. Die Untersuchungsergebnisse wurden mit dem ALSV und hin und wieder auch auf den Quartalstreffen der Finanzminister besprochen.70 Das trockene Material war nicht dazu geeignet, bel den Franzosen, Itallenern oder Belgiern eine Euphorie für das Einreißen der Schlagbäume auszulösen. Auch die Hoffnung, daß die Niederländer unter der Masse des ihnen präsentierten Papiers zusammenbrechen und so zur Kapitulation gezwungen werden könnten, ging nicht in Erfullung. DenHaag Pand immer neue Probleme, mit der man die Kommission und die anderen Mitgliedstaaten beschäftigen und von konkreten Entscheidungen abhalten konnte.

Erfolgversprechender als der endlose Papierkrieg mit den Studien schien ein zweiter Weg zu sein, den die Kommission auf der politischen Ebene beschritt. Klar war, daß die Bundesrepublik der einzig wirkliche Befürworter und Frankreich der entschiedenste Gegner einer Abschappung der Steuergrenzen war. Zur gleichen Zelt forderten die Franzosen eine Senkung des deutschen Getreidepreises als Voraussetzung für die von Paris gewünschte Getreidemarktordnung. Kommissar von der Groeben nutzte seine Verbindungen nach Bonn und forderte deutsche Minister und Kanzler wiederholt aup,

68 Groeben (1963), S.8.

69 Persönliches Interview.

70 Vgl. NZZ 12.9.63, FAZ 12.2.64, Le Monde 5.4.64, FAZ 9.6.64, Handelsblatt 29.9.64 u. Industrie Kurler 8.4.65. 
die beiden Materien zu einem Junktim zu verknüpfen und sle gemeinsam mit Frankreich zu verhandeln. Im Rahmen dieser Bemühungen ging die Kommission im Oktober 1964 sogar so weit, dem Rat in ihrer Initiative 1964' mit dem 1.Januar 1970 einen festen Termin für die Beseitigung aller Grenzkontrollen vorzuschlagen. Obwohl von deutscher Seite mehrmals versucht, ${ }^{72}$ scheiterte das Junktim schließlich. Unter erheblichem Pranzösischen Druck stimmte die Bundesregierung im Dezember 1964 der Getreidepreissenkung $\mathrm{zu}$, ohne entsprechende Gegenleistungen fest zugesagt bekommen zu haben. ${ }^{73}$ Der Pranzösische Finanzminister Giscard d'Estaing zeigte sich zur Jahreswende 1964/65 zwar gegenüber der Abschaffung der Steuergrenzen wesentlich aufgeschlossener als früher, auf eine Terminplanung wollte er sich aber noch nicht einlassen.74

Die Italiener hatten sich während der gesamten Diskussion über die Steuergrenzen geschickt hinter den Franzosen versteckt gehalten. Kaum zeigten sich aber die ersten Anzeichen für eine Lockerung der Pranzös1schen Ablehnungshaltung, sahen sie sich zu einer Klarstellung in eigener Sache veranlaßt. In einem Memorandum lie $\beta$ man die Kommission wissen, da $\beta$, egal was auch immer Frankreich bei der Abschaffung der Steuergrenzen zuzugestehen bereit sel, Italien dabei aup absehbare Zeit nicht mitmachen würde. ${ }^{75}$ Aber Rom konnte beruhigt seln. Da die Pranzösische Industrie auf den plötzlichen Sinneswandel ihres Finanzminlsters äußerst nervös reagiert hatte, kehrte auch Paris bald wieder zu seiner alten Position zurück. Und wenige Wochen nach dem itallenischen Memorandum stürzte die Gemeinschaft in eine politische Krise, in der alle Träume von einer baldigen Beseitigung der Grenzkontrollen endgültig untergehen sollten.

Fortschritte bel der Einführung der MWSt

Wie schon bei dem unergiebigen Streit uber die Steuergrenzen, so kam es auch bei der Diskussion der ersten belden Schritte der USt-Harmonisierung $\mathrm{zu}$ einer engen Zusammenarbeit zwischen der Kommission und den Deutschen. Die Bonn-Brüsseler Koalition schaffte es, die Frage der Einführung einer MWSt von den langwierigen Auseinandersetzungen über die Steuergrenzen abzuschirmen und unabhängig davon voranzutreiben. Mit vereinten Kräften gelang es, dle anderen Mitgliedstaaten, obwohl damals noch sehr zurückhaltend gegenüber der MWSt, auf der Quartalskonferenz im Mărz 1963 dazu zu überreden, die Kommission mit der Ausarbeltung der Grundlinien eines gemelnsamen MWSt-Systems zu beauftragen: damit legte sich ja noch niemand Pest.

71 In Auszügen abgedruckt in: Bulletin der EWG, 7.1964, Heft 11, S.55ff.

72 Vgl. z.B. Industrie Kurier 19.11.63.

73 Vgl. Groeben (1982), S.233Pf.

74 Vgl. NZZ 21.1.65, NZZ 27.1.65 u. Le Monde 27.1.65.

75 Vgl. z.B. Stuttgarter Zeitung 29.5.65. 
Die von der Kommission daraufhin zusammengerufene alte UG C - sie war mit der MWSt bereits vertraut - traf sich zu ihrer ersten Sitzung im Mai 1963. Das Treffen verlief in einer "ausgezeichneten Atmosphäre der Zusammenarbeit"76. Man kannte sich bereits gegenseitig, sah in dem neuen Auptrag eine Bestätlgung der in 1960/61 geleisteten Arbeit und stellte sich mit Elan der Herausforderung, auf dem Reißbrett eine ganz neue Steuer zu entwerfen. Die in der UG C versammelten Steuerbeamten waren von den Vorzügen der MWSt wesentlich überzeugter als die innen übergeordneten Steuerdirektoren und Finanzminister oder die zuhause gebliebenen Kollegen. Neben ihrem hohen Kenntnisstand in Sachen MWSt dürfte dies wohl auch darauf zurückzupühren seln, daß jeder von ihnen, sollte es wirklich zur Einführung der MWSt kommen, auf eine Verbesserung seiner persönlichen Stellung im jewelligen Heimatland hoffen konnte.

Schon Im Oktober 1963 legte die UG C einen ersten Bericht vor, der im ALSV diskutiert und anschließend weiter ausgefellt wurde. Die Finanzminister beschäftigten sich mit der Materie erstmals wieder aup inren Quartalstrepfen in Rom im Februar ${ }^{77}$ und in Luxemburg im April ${ }^{78}$ 1964. Zur großen Freude der Kommission $\mathrm{kam}$ es dabel zu einem Durchbruch. Neben den Deutschen stellten sich nun auch die Franzosen, Italiener und Luxemburger eindeutig hinter die MWSt:

- Die Franzosen hatten nach dem ergebnislosen Streit über das deutsche 12.UStÅng ihre Hoffnungen auf ein Stillhalteabkommen endgültig begraben müssen. Sie glaubten, sich daher vor weiteren Manipulationen am Grenzausgleich nur durch eine USt-Harmonisierung schützen zu können. Hinzu kam, daß Finanzminister Giscard d'Estaing im Sommer 1963 einen erneuten Anlauf zur Reform der Pranzösischen TVA unternommen hatte, damit aber schon im Herbst aup unerwartet heftige Opposition im eigenen Lande gestoßen war. Er wußte daher Schützenhilfe aus Brüssel in Form einer europäischen MWSt-Richtlinie durchaus zı schätzen. ${ }^{79}$

- Seit 1962 arbeitete in Rom ein Expertengremium an der Frage, wie das völlig überalterte italienische Steuersystem an die Bedürfnisse eines in internationaler konkurrenz stehenden Industriestaates angepaßt werden könnte. Die Leitung der Gruppe hatte Prof. Cosciani inne, ehemals Mit-

\footnotetext{
76 Persönliches Interview.

77 Vgl. z.B. FAZ 12.2.64, New York Times 12.2.64, Le Monde 13.2.64, FAZ 14.2.64 u. Welt 17.2.64.

78 Vgl. z.B. FT 3.4.64, Le Monde 3.4.64, Stuttgarter Zeitung 4.4.64 u. Handelsblatt 6.4.64. Vgl. a. Taussig (1971), S.187ff.

79

Vgl. ausführlicher in Kap.C.2.2.1.
} 
glied des Neumark-Ausschusses. Er empfahl, obwohl sein für Verbrauchsteuern zuständiger Mitarbeiter Forte persönlich einer Einphasensteuer den Vorzug gegeben hätte, die Einführung einer MWSt. ${ }^{80}$ Und er hatte den Einfluß, um seinen Vorschlag der Regierung schmackhaft zu machen: Cosciani selbst war Chepberater des italienischen Industrieverbandes und sein Mitarbeiter Visentini persönlicher Berater des Finanzministers. Der Minister selbst sah zwar die unübersehbare Vielfalt administrativer Probleme, die mit der MWSt verbunden waren, wollte sich aber nicht einer Entwicklung entgegenstellen, die zur Ubbernahme einer modernen und zugleich europäischen Steuer führte. Er gab in Brüssel, ohne bislang genau zu wissen, wann und wie und in welcher Form die MWSt in Italien einmal eingefuhrt werden könnte, grünes Licht für die 1.USt-Richtlinte.

- Die Luxemburger hatten sich vor 1964 noch kelne Gedanken über eine Reform ihrer USt machen müssen: Der von ihnen erhobene Steuersatz war mit $2 \%$ derart gering, daß das kleine Fürstentum elgentlich mit jedem bellebigen USt-System hätte gut leben können. Das Luxemburger Ja zur MWSt kann daher nur als Teil einer Politik verstanden werden. die traditionell der europäischen Integration höchste Priorität einräumt.

Nur die Niederländer - sie waren die Wortführer - und die Belgier - sie hielten sich hinter ihren Nachbarn versteckt - stellten sich auch weiterhin quer. Die von der Kommission hinter dem niederländischen Widerstand vermuteten "Steuerfritzen"81 reagierten auf den Anfang 1964 erkennbar gewordenen Meinungsumschwung mit einer ihrer ebenso berühmten wie umfangreichen Denkschriften. Da Generaldirektor VerLoren van Themaat keinen Sinn darin sah, daraup mit immer neuen studien $\mathrm{zu}$ antworten, regte er an, DenHaag politisch $z u$ isolieren und so zum Einlenken zu zwingen. Nach dem Anfang 1964 erzielten Durchbruch fuhlte sich die Kommission stark genug, die Arbelt an der USt-Harmonisierung zu beschleunigen.

Belgien wie auch die Niederlande liebäugelten 1963/64 mit dem Übergang zu einer elnphasigen USt. Dieser Weg sollte den beiden Benelux-Ländern abgeschnitten werden. Im Junl 1964 unterbreitete die Kommission dem Rat einen abgeänderten Entwurf für elne 1.USt-Richtlinie: Die erste Harmonisierungsstufe wurde ersatzlos gestrichen und der sofortige Ubergang zur MWSt empfohlen. Gleichzeitig präsentlerte sle den Mitgliedstaaten einen Uberblick ubber "Die Struktur und die Anwendungsmodalitäten des gemeinsamen Mehr-

- Ein Uberbllck über den vollständigen Bericht der Expertengruppe findet sich in Tax Reform Proposals, in: European Taxation, 5.1965, S.251fr. 
wertsteuersystems"82. Das in Zusammenarbeit mit der UG C erstellte Papier wurde, um eine Diskussion im EP und WSA und den damit verburidenen Zeitverlust $\mathrm{zu}$ vermelden, statt in die Rechtsform einer Richtlinie in die einer "Stellungnahme der Kommission" gekleidet. Beide Initiativen befriedigten das deutsche und französische Interesse an raschen Fortschritten bei der MWSt und waren zugleich dazu geeignet, die letzten widerstandsnester in Belgien und den Niederlanden durch eine Politik der vollendeten Tatsachen in die Defensive zu zwingen.

Die Rechnung ging auf. Nach Jahrelanger Diskussion in den informellen Gremien der Gemeinschapt beschäftigte sich der Rat ab Herbst 1964 mit der 1.USt-Richtlinie. In Absprache mit der Kommission machte sich die Bundesregierung in COREPER dafür stark, die Beratungen in der Gruppe Finanzfragen des Rates - die dort versammelten Steuerbeamten kannten als Mitglieder der UG C den Richtlinienentwurf ja bereits bestens - auf ein Minimum zusammenzustreichen und sie baldigst auf Ministerebene hochzuhiefen. Die 1.USt-Richtlinie kam auf die Tagesordnung der Ministerratsitzung vorn

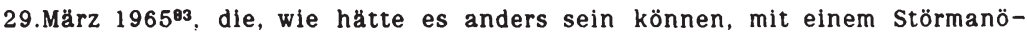
ver der Niederlande ihren Anfang nahm. DenHaag versuchte in altbekannter Welse, eine allgemeine Diskussion über die Steuerpolitik der Gemeinschaft anzuregen. Man hatte sogar schon elnen entsprechenden Entschließungsantrag vorbereitet. Aber der Ablenkungsversuch DenHaags stie $\beta$ bei den anderen auf kein Verständnis mehr. Sle beschlossen, den Richtlinlenvorschlag Punkt Pür Punkt durchzugehen. Bel allen Fragen konnte, von den Niederländern elnmal abgesehen, elne weitgehende Ubereinstimmung festgestellte werden. Nur die Belgler äußerten sich noch zurückhaltend. Sie wollten. wie sie sagten, vor einer endgültigen Zustimmung $\mathrm{zu}$ MWSt zunächst die in einer 2.USt-Richtlinle $\mathrm{zu}$ regelnden Anwendungsmodalitäten vorliegen haben. Das war ganz offensichtlich ein Vorwand. Die belgischen Steuerbeamten waren an der Ausarbeltung der kurz vor der Fertigstellung stehenden 2.USt-Richtlinie betelligt gewesen und kannten sie daher bereits in allen Einzelhelten. Aber die anderen Mitgliedstaaten akzeptierten die politischen $\mathrm{Zwänge,} \mathrm{in} \mathrm{denen} \mathrm{sich} \mathrm{Belgien} \mathrm{damals} \mathrm{befand:} \mathrm{Es} \mathrm{standen} \mathrm{Wahlen}$ ins Haus. Sie konnten daraup bauen, daß auch Belgien uber kurz oder lang grünes Licht für die MWSt geben würden. Somit standen die Niederländer mit ihrer Fundamentalopposition isoliert da.

a2 Zitiert im folgenden als "Stellungnahme der Kommission". Zur Quellenangabe vgl. Anlage II unter 2.USt-Richtlinie. 


\subsubsection{Die Diskussion der 2.USt-Richtlinie}

\section{Uberblick}

Während die 1.USt-Richtlinie das Grundkonzept für die USt-Harmonisierung in der EG festlegte, wurden die genauen Anwendungsmodalitäten der angestrebten MWSt Gegenstand einer 2.USt-Richtlinie. Als die UG C im Mai 1963 zu ihrer ersten Sitzung zusammenkam, konnte die Kommission schon Analysen zu einzelnen Problembereichen vorlegen. Ein Zwischenergebnis der Beratungen schlug sich in der Stellungnahme der Kommission vom Juni 1964 nieder ${ }^{84}$, die Zuleitung des endgültigen Richtlinienvorschlages an den Rat erfolgte am 14.April 1965 . $^{85}$

Die von Paris nach Brüssel entsandten Steuerbeamten kannten die Geschichte der Pranzösischen Taxe sur la Valeur Ajoutée seit ihren Anfängen im Jahre 1948 und konnten daher der Diskussion in der UG C wichtige Impulse geben. Vorbildcharakter für die europäische MWSt konnte die TVA, das war allen klar, aber nicht haben. Selbst der als externer Berater zeitweise hinzugezogene Maurice Lauré - er gilt als der Vater der TVA war ein erklärter Kritiker der zahlreichen Unzulänglichkeiten des langsam gewachsenen Pranzösischen USt-Systems. Als Modell bot sich da schon eher der historlsch weitgehend unbelastete deutsche Entwurf für ein MWSt-Gesetz vom Jull 1964 an. Da die Bundesregierung ihren Vorschlag alleine wegen einer anderslautenden Richtlinie aus Brüssel nicht noch einmal abändern wollte, versuchten die Deutschen, ihr Konzept auch den Partnern schmackhaft zu machen. Und sie waren recht erfolgreich dabei: Sowohl die Stellungnahme der Kommission von $1964^{86}$ als auch der endgültige Richtlinienvorschlag von $1965^{87}$ widersprachen dem deutschen Gesetzentwurf in nur wenigen Punkten. Auch die Steuerexperten aus den Benelux-Staaten arbeiteten, obwohl ihre Vorgesetzten den widerstand gegen die MwSt lange aufrechterhielten, eifrig an der 2.USt-Richtlinie mit. Nur die Italiener zogen es vor, sich etwas im Hintergrund zu halten: Sle hatten zwar nichts gegen die MWSt, innen war es jedoch ein Rätsel, wie ein solch komplizierter Mechanismus jemals von der römischen Finanzverwaltung beherrscht werden sollte.

Offen ist bislang noch die Frage, wieso sich die Gemeinschaft überhaupt anschickte, die Struktur der MWSt über das zur Gewährleistung eines korrekten Grenzausgleichs notwendige Minimum hinaus auf EG-Ebene zu verelnheltlichen. Es llegt auf der Hand, daß der Kommission mit Blick auf ihr

\footnotetext{
84 Vgl. z.B. Schüle (1964a).

6s Vgl. Müller (1965) u. Wachweger (1965b).

o6 Vgl. Juretzek (1964b).

e7 Vgl. Mesenberg (1965).
} 
Endziel Abschaffung der Steuergrenzen daran gelegen war, schon im ersten Harmonisierungsschritt eine möglichst weitgehende Vereinheitlichung der Steuersysteme $\mathrm{zu}$ erreichen. ${ }^{8}$ Mußten aber nicht umgekehrt die Mitgliedstaaten versuchen, sich einen möglichst großen Gestaltungsspielraum zu sichern, um die MWSt optimal an die jewelligen nationalen Verhältnisse anpassen zu können? Die Antwort lautet überraschenderweise Nein. Die einzelnen Regierungen waren in einer Vielzahl von Fällen daran interessiert, sich durch die Aufnahme verbindlicher Regeln in die 2.USt-Richtlinie selbst die Hände zu binden. So glaubte man, dem aup die Gewährung von Sondervorteilen abzielenden Druck der unzähligen Interessengruppen widerstehen und die MWSt vor einer zunehmenden Durchlöcherung - das traurige Schicksal so vieler Steuern - bewahren zu können. Man war also schon aus rein innenpolitischen Gründen bemüht, gemeinschaftliche Regeln festzuschreiben. Sie Pehlen somit in der 2.USt-Richtlinie auch überall dort, wo die Divergenzen $z$ wischen den nationalen Vorstellungen eine Einigung nicht zuließ.

\section{Der Anwendungsbereich der MWSt}

Festzulegen war in der 2.USt-Richtlinle zunächst der Anwendungsbereich der gemeinsamen MWSt. Ubereinstimmung bestand schon sehr frühzeitig darüber, daß, uın die Einfachheit und Neutralität der Abgabe zu gewährleisten, im Idealfall alle Unternehmen der Steuerpflicht unterworfen werden müßten: "Die Ausnahmen von der normalen Regelung werden deshalb streng begrenzt."89

Ganz vermeiden ließen sich Sonderregelungen und Bepreiungen aber nicht. Da gab es zum einen die vielen kleinen Einzelhändler, die der Finanzverwaltung und den Politikern Kopfzerbrechen bereiteten. Die Pranzösische Regierung wollte die Detalllisten gerne besteuern und drängte darauf, ihr genau das in einer EG-Richtlinie vorzuschreiben. Ahnliche Stimmen waren auch von einigen belgischen Vertretern zu hören. Da aber Italien eine Besteuerung des Einzelhandels für technisch wie politisch unmöglich hielt, mußte man letzten Endes jedem Mitgliedstaat die Preie Wahl lassen, wie er mit den Einzelhändlern verfahren wollte.90

Dle Deutschen drückte der Schuh an anderer Stelle. Die Preien Berufe und die Handwerker wehrten sich vehement gegen die MWSt. Bundesfinanzminister Dahlgrün wandte sich daher in einem Schreiben vom April 1964 an die Kommission mit der dringenden Bitte, Ihm bei diesem "zlemlich delikaten

Vgl. z.B. Jansen (1966).

89 Stellungnahme der Kommission, Pkt.II.1.

90 Vgl. Art.2 Abs.4 der 1.USt-Richtlinie. 
Problem"91 Rückendeckung zu geben. Leider konnte ihm Brüssel diesen Gefallen nicht tun, da, bedingt durch die sehr unterschiedlichen Wirtschaftsstrukturen in den Mitgliedstaaten, die nationalen Aupfassungen zu weit auseinandergingen. Dle den einzelnen Staaten belassene WahlPreiheit wurde bel den Dienstleistungen nur tellwelse ${ }^{92}$ und bel der für Klelnunternehmen zulässigen Sonderregel praktisch gar nicht ${ }^{93}$ eingeschränkt.

Ein Problem ganz besonderer Art bildete, wie so oft, wenn es um Steuern geht, die Landwirtschaft. Der Steuerdirektion der Kommission hätte am liebsten die Bauern, wie alle anderen Unternehmer auch, der MwSt unterworfen. Aus Kompromißbereitschaft wollte sie jedoch auch eine Sonderregelung akzeptieren, die die Landwirte von den Buchfuhrungspilichten entlastet, gleichzeitig aber zumindest im Durchschnitt eine korrekte Besteuerung gewährleistet. Auf Sympathie stieß der Vorschlag bei den Steuerbeamten der UG C: Sie vermochten nicht einzusehen, wieso bel jeder steuer von neuem für dle Bauern eine Extrawurst gebraten wurde. Vorbehaltlos zustimmen konnten sie dem Konzept aber nicht, da Jedem von ihnen die Agrarlobby des elgenen Landes im Nacken saß. Und den Steuerbeamten der Kommission ging es da nicht viel besser. Dle für Agrarpragen zuständige Generaldirektion und ihr Kommissar Mansholt wurden erstmals Im März 1965 bel ihren Steuerkollegen vorstellig und machten unmißverständlich klar, daß fü dle Landwirtschaft die Last der Buchführung als auch die der Steuer selbst aus sozialpolitischen Gründen auf eln Minimum zu begrenzen sel. Der Strelt $z$ wischen den Steuerpolitikern auf der einen und den Agrarpolitikern auf der anderen Seite setzte sich auf nationaler Ebene wie auch innerhalb der Kommission bis in das Jahr 1966 hinein und darüber hinaus fort. Dem Rat blieb daher, als er Anfang 1967 uber die 2.USt-Richtlinie entscheiden mußte, nichts anderes übrig, als sich mit der allgemeinen Aupforderung zu begnügen:

"Die Kommission unterbreitet dem Rat sobald wie möglich Vorschläge für Richtlinien über die gemeinsamen Modalitäten für die Anwendung der Mehrwertsteuer auf den Umsatz von landwirtschaftlichen Erzeugnissen." 94

\section{Die Regelung des Vorsteuerabzugs}

Neben dem Anwendungsbereich der MWSt war es insbesondere das Problem des VSAs, das während der Verhandlungen über die 2.USt-Richtlinie zu Auseinandersetzungen führte. Ein erster strittiger Punkt war die Frage, ob auch Güter, die zur Tătlgung steuerbepreiter Umsătze eingekauft und ver-

\footnotetext{
$91 \quad$ Persönliches Interview.

92 Vgl. Art.6 Abs.2 der 2.USt-Richtlinie.

93 Vgl. Art.14 der 2.USt-Richtlinie.

94 Art.15 Abs.1 der 2.USt-Richtlinie.
} 
wandt worden sind, zum VSA zugelassen werden sollten. Um eine unerwünschte Steuerkumulation aup der năchsten Produktions- bzw. Verteilerstufe zu vermeiden, wäre der VSA zwingend erforderlich gewesen. Aber nur die Niederlande sprachen sich für eine solche Regelung aus. Alle anderen Mitglledstaaten wollten bel befreiten Umsätzen den VSA generell untersagen, wofür sie auch gute Gründe hatten. Zum einen sahen es die nationalen Finanzbeamten als eine höchst unsinnige Tätigkeit an, mit der linken Hand MWSt zu kassieren, um sie mit der rechten an USt-befreite Unternehmen wleder zurückzuzahlen. ${ }^{95}$ Zum anderen graute es den elnzelnen Reglerungen vor dem Gedanken, die unzähligen Verbände könnten über sie herfallen mit dem einen $\mathrm{Zlel}$, in den Genuß einer Befrelung zu kommen. Wenn man sich schon bel der Diskussion über den Anwendungsbereich der MWSt nicht auf eine verbindliche Liste von Befrelungen hatte einigen können, so wollte man doch zumindest die Steuerbefreiung durch ein Verbot des VSA so unattraktiv wie nur möglich gestalten und dadurch ihrer weiteren Ausbreitung einen Rlegel vorschieben. Da slch die Niederländer jedoch aus Innenpolitischen Gründen standhaft weigerten, ein Verbot sogenannter Null-Sätze - eine Steuerbefreiung in Verbindung mit dem Recht aup VSA führt $z u$ einem epfektiven Steuersatz von $0 \%-\mathrm{zu}$ akzeptieren, ${ }^{96}$ landete das Problem aup dem Tisch des Ministerrates, wo es durch einen Kompromi $\beta$ gelöst werden konnte. ${ }^{97}$

Eine zweite Streitfrage war der VSA für Investitionsgüter. Wăhrend sich die Mehrheit der Mitgliedstaaten für einen Sofortabzug beim Kauf einsetzte, hatten die Deutschen in ihrem Gesetzentwurf, um das Preisniveau beim Ubergang zur MWSt stabil zu halten, einen VSA pro-rata-temporis ${ }^{98}$ vorgesehen. Die in Brüssel ein- und ausgehenden Mitarbeiter des Bonner Finanzministeriums gaben der Kommission aber zu verstehen, daß in Deutschland lediglich das Wirtschaftsministerium und elnige Parlamentarier den VSA pro-rata-temporis befürworteten. Demgegenüber setzte slch sowohl die Finanzverwaltung - aus administrativen Gründen - als auch die deutsche Wirtschaft - aus Kostengründen - Pür den Sofortabzug ein. Der Kommission ihrerseits war die genaue Regelung gleichgültig, sle sollte nur einheltlich sein. Man schlug also den Sofortabzug vor'9 und bemühte sich fortan in Koalition mit der deutschen Finanzbürokratie, den Widerstand im Bonner Wirtschaftsministerium $\mathrm{zu}$ brechen. Von der Kommission ausgearbe1tete Papiere, die die Vorzuge des Sofortabzugs auch im Hinblick aup die europäische Integration priesen, wurden über das Finanzministerium dem Finanzausschuß des Bundestages zugeleitet. Die Finanzbeamten ihrerseits

\footnotetext{
95 Vgl. z.B. Heilmann (1975), S.282f.

96 Vgl. FAZ 11.10 .66 u. 1.2.67.

97 Vgl. die Darstellung im folgenden Kapitel.

$98 \mathrm{Vgl}$. zu diesem Begriff die Darstellung in Kap.B.1.1.

$99 \quad$ Vgl. Art.9 Abs.3 des Vorschlages Pü eine 2.USt-Richtlinie.
} 
erstellten mit der Einführung des Sofortabzuges in mehreren Stufen einen Kompromißvorschlag, den sle vom Industrie - und Handelstag - der indirekte Weg über die Wirtschaft gibt den Steuerbeamten einen größeren Einfluß auf das Parlament - an den Finanzausschuß herantragen ließen. Nachdem die Abgeordneten erfolgreich weichgeknetet worden waren, brach auch der Widerstand im Wirtschaftsministerium zusammen: Die Deutschen konnten dem Sofortabzug in Brüssel zustimmen.100

\subsubsection{Von der Krise bis zur Annahme der beiden Richtlinien}

Im Sommer 1965 stürzte die Gemeinschaft in ihre erste und bisher wohl auch Polgenschwerste Krise. Der Anlaß war ein Vorschlag der Kommission zur Finanzierung der gemeinsamen Agrarpolitik: Dle Schapfung eines Systems Eigener Einnahmen der EG sollte verknüpft werden mit elnem Mehr an Budgetbefugnissen für das EP. General de Gaulle war zwar für das erste, aber ausdrücklich gegen eine stärkung der ungeliebten Gemeinschaftsorgane. Um seinen Vorstellungen über den künftigen Weg Europas eines Europas der nationalen Regierungen, ohne supranationale Organe Nachdruck zu verleihen, konfrontierte er die EG ab Jull 1965 mit einer Politik des leeren Stuhls: Die französischen Vertreter erschlenen nicht mehr $\mathrm{zu}$ den in Brüssel anberaumten Sitzungen. Verständlich ist, daß sich das Integrationsklima daraufhin zusehends verschlechterte: "Die Leute waren einfach sauer". ${ }^{101}$

Da man vor Ausbruch der Krise mit den Beratungen über dle MWSt berelts recht weit gekommen war, konnte sie die Annahme der beiden ersten UStRichtlinien glücklicherweise nicht wesentlich verzögern. Bedingt durch die Haltung de Gaulles war mit der politischen Einigung Europas auch die Abschaffung der Steuergrenzen in weite Ferne gerückt. Das war zwar langfristig bedauerlich, hatte aber in kurzer Sicht den durchaus positiven Effekt, daß der unerglebige Streit über die Steuergrenzen die Einführung der MWSt nicht länger belasten konnte. Was die MWSt selbst anbelangte, so gaben die Belgier, wie von den anderen erwartet, ihre Zurückhaltung im Laufe des Jahres 1965 endgültig auf. Uberraschend kam dagegen der Sinneswandel, der sich ab Frühjahr 1965 aufgrund innenpolitischer Veränderungen in den Niederlanden vollzog. Der neue Staatssekretär im Haager Finanzministerium, Hoefnagels, zeigte sich in einem im März 1966 mit Generaldirektor VerLoren van Themaat geführten Gespräch bereit, die MWSt für sein Land zu akzeptieren. Dle einzige Bedingung für die Zustimmung zur 1.USt-Richtlinie -

100 Vgl. Art.11 Abs.3 der 2.USt-Richtlinie.

101 Persönliches Interview. Zu Ursachen, Verlaup und Beilegung der Krise vgl. Groeben (1982), S.268Pf. 
darauf bestanden auch die Belgier - war die gleichzeltige Verabschiedung der 2.USt-Richtlinie.102 Der Vorschlag Pür eine 2.USt-Richtlinie lag zwar seit April 1965 auf dem Tisch, der Rat mußte aber vor einer Beschlußfassung noch die Stellungnahmen des EP und des WSA abwarten. Mit ihren Entschließungen vom März bzw. Januar 1966 erklärten sich die beiden Gremlen, von wenigen Kritikpunkten abgesehen, mit dem Kommissionsentwurp elnverstanden und gaben damit grünes Licht für die weiteren Beratungen.

Obwohl also whhrend der Krise mit dem Rat das legislative Organ der Gemeinschaft vollkommen lahmgelegt war, machte der Meinungsbildungsproze $\beta$ zur USt-Harmonisierung weitere und für den endgültigen Erfolg unabdingbare Fortschritte. In zwei Außenministersitzungen vom Januar 1966 konnte die Krise mit dem sogenannten Luxemburger Protokoll belgelegt werden. Nach einer entsprechenden Initiative der Kommission einigten sich die Mitgliedstaaten Ende Februar 1967 darüberhinaus in einem package deal auf eine Anzahl von Maßnahmen, die in ihrem gegenseitigen Interesse lagen und in der nächsten Zeit verwirklicht werden sollten. Teil des Pakets war eine Entscheidung über die beiden USt-Richtlinien bis zum 31.Januar 1967.103 Damit schien der Weg zur Elnführung der MWSt endgültig Prei. In der Gruppe Finanzfragen des Rates wurden mit Hochdruck die noch ausstehenden Detallfragen der 2.USt-Richtlinie behandelt. Die Finanzminister zeigten sich im September 1966 optimistisch, die vereinbarte Frist einhalten zu können. ${ }^{104}$ Aber kurz danach kam nochmals Unsicherheit auf.

Zum einen brach in DenHaag eine Regierungskrise aus, die zur Bildung eines Ubergangskabinetts unter dem Wirtschaftsexperten Zijlstra Pührte. Gerüchte breiteten sich aus, daß die Niederländer wieder von ihrer Zustimmung zur MWSt abrücken könnten.105 Der deutsche Finanzminister Strauß sah sich daher genötigt, bel den Quartalstreffen im Dezember 1966 und Januar 1967 ein schweres Geschütz gegen seinen niederländischen Kollegen aufzufahren: Die Entscheidung uber die MWSt habe, so lautete die unverhohlene Drohung, für Deutschland dengleichen politischen Stellenwert wle die gemeinsame Agrarpolitik im allgemeinen und die für Mitte 1967 zugesagte Getreidepreissenkung im besonderen.106 Aber der deutsche Druck war überflüssig. Zijlstra - er war gleichzeitig für das Finanzressort zuständig hatte sich schon für die MWSt entschieden, konnte dies mit Rücksicht auf den Widerstand im Haager Parlament aber noch nicht eingestehen.

\footnotetext{
102 Die Hintergründe für die geänderte Haltung Belgiens und der Niederlande sind in den entsprechenden Abschnitten des Kap.C.2.2. dargestellt.

103 Vgl. Wachweger (1966), S.137. Vgl. a. Handelsblatt 11.2.66 u. Le Monde 2.3.66.

104 Vgl. z.B. NZZ 14.9.66.

109 Vgl. Welt 17.12.66 u. Times 21.12.66.

106 Vgl. Z.B. FAZ 17.1.67 u. 20.1.67.
} 
Zum anderen wartete der Pranzösische Finanzminister Debré bei dem Quartalstreffen am 20.Dezember 1966 mit der Forderung auf, daß neben der USt auch alle anderen Steuern in der EG einander angeglichen werden müßten.107 Da Debré als "gelehriger Schüler seines Herrn und Meisters de Gaulle"108 bekannt war, traf seine Initiative auf erstaunte Gesichter: Hatte Debré wirklich an elner Harmonislerung der direkten Steuern Interesse z.B. um Paris als Zentrum eines europäischen Kapitalmarktes zu etablleren ${ }^{109}$ - oder zielte sein Kolossalprogramm darauf ab, die USt-Harmonislerung zum Erliegen zu bringen?110 Sicher war an dem Pariser Forderungskatalog nur, daß er eine institutionelle Provokation enthielt: Debré sprach von actions concertées der nationalen Regierungen, versuchte den im EWG-Vertrag benutzten Ausdruck Harmonisierung kramplhaft zu vermeiden und erwähnte die Rolle der Gemeinschaptsorgane mit keinem Wort. ${ }^{111}$ Dies löste bel der Kommission elne fleberhafte Aktivităt aus. Um sich das steuerpolitische HePt der EG nicht von Paris aus der Hand nehmen zu lassen, erstellte sie innerhalb weniger Tage ein Aktionsprogramm für die kunftige Steuerharmonislerung in der Gemeinschaft112, das der nächsten Quartalskonferenz der Finanzminister vorgelegt und dort auch positiv aufgenommen wurde.113 Aber nach wie vor drohte der französische Vorsto $\beta$ die abschließenden Beratungen der ersten belden USt-Richtlinien zu belasten. Erst am Abend vor der entscheidenden Ratsitzung konnte dle GePahr gebannt werden, daß Paris mit elnem eigenen Entschließungsantrag über die Steuerpolitik der EG elnen Kompromiß über die USt unnötig erschwerte. Eine institutionelle Debatte ließ sich aber, wie sogleich gezeigt werden wird, nicht mehr verhindern.

Nach unzähligen Sitzungen der Gruppe Finanzfragen und des COREPER trat am 8. ur.t 9.Februar 1967 schlleßlich der Rat der Finanzminister zusammen, um für die noch verbleibenden Probleme der USt-Richtlinten eine Lösung zu finden. Anlaß zur Auselnandersetzung gab zum elnen die Forderung DenHaags, Steuersătze von $0 \%$ nicht generell zu untersagen. Zwar hatten weder die nlederländische Regierung noch ihre Steuerbeamten ernsthafte Absichten, Null-Sătze auch wirklich einzupuhren. Aber Premier Zijlstra benötigte ein Zugeständnis bei den Null-Sătzen, um sich damit bel seinem eigenen Parlament die gewünschte Zustimmung zur MWSt erkaufen zu kön-

107 Vgl. Les Propositions Francaises d'Actions Fiscales Concertées, in: Revue des Contributions Indirects, 1967, S.137ff.

100 Persönliches Interview.

109 Vgl. FT 21.12.66.

110 Vgl. Industrie Kurier 22.12.66 u. Süddeutsche Zeitung 22.12.66.

111 Vgl. z.B. Le Monde 21.12.66 u. 22.12.66.

112 Vgl. Programm der Steuerharmonisierung, abgedr. In: Bulletin der EWG, 10.1967, Bellage zu Heft 8. Vgl. a. NZZ 23.7.67.

113 Vgl. Süddeutsche Zeltung 16.1.67, NZZ 16.1.67 u. Handelsblatt 19.1.67. 
nen. Auf Vorschlag der Kommission stimmte man daher einer Kompromißformel zu, die den niederländischen Bedürfnissen entgegenkam, und die gleichzeitig die anderen Regierungen weltgehend vor innenpolitischem Druck schützte: Steuersätze von $0 \%$ wurden bel der MWSt nur erlaubt, "soweit sich diese Maßnahmen insgesamt nicht stärker auswirken als die bel dem derzeitigen System angewandten Erleichterungen".114

Ein zweiter strittiger Punkt war die Frage, unter welchen Bedingungen es elnem Mitgliedstaat gestattet werden sollte, zum Zwecke einer vereinfachten Steuererhebung von den Bestimmungen der 2.USt-Richtlinle abzuweichen. Frankreich, Italien und Deutschland fürchteten Verzerrungen im grenzüberschreitenden Handel und verlangten daher, jede Ausnahme von elner einstimmigen Genehmigung des Rates abhängig zu machen. Da das Einstimmigkeitsprinzip implizlerte, daß schon ein elnzelnes Land jegliche Sonderregel hătte blockleren können, bestanden die Niederlande auf dem Mehrheltsprinzip. Der "uberzeugte Europäer"11s Zijlstra nutzte den beschriebenen Dissens, um den "Nationalist reinsten Wassers"116 Debré zu einem Rededuell uber die institutionelle Zukunft der Gemeinschaft herauszufordern. In einem langen Zwiegespräch - "die anderen Minister saßen einfach da und konnten nicht mehr folgen"117 - diskutierten die beiden Kontrahenten die Frage, inwieweit durch eine Schiedsrichterfunktion der Kommission ein Kompromi $\beta$ erleichtert werden könnte. Zur allgemeinen Uberraschung war es schlleßlich Debré, der klein beigab und selbst das folgende Verfahren vorschlugi18: Die Kommission entscheidet, ob eine Ausnahmeregelung geeignet ist, die Wettbewerbsbedingungen zwischen den Mitgliedstaaten $\mathrm{zu}$ verzerren; kommt die Kommission $\mathrm{zu}$ einer bejahenden Antwort, muß der Rat den Antrag einstimmig genehmigen, im anderen Fall genügt die qualifizierte Mehrheit.119

Nach der Zustimmung zur französischen Kompromißformel stand der Verabschiedung der beiden USt-Richtlinien nichts mehr im Wege. Mit dem Beschluß des Rates über die allgemelne Einführung der MWSt hatte die Kommission erstmals seit der Krise 1965/66 wieder einen großen Erfolg zu verbuchen. Die Gemeinschaft hatte ihre Lebenskraft bewiesen und Monsieur Debré eine wichtige Lektion gelernt: Ohne die Ubertragung einzelner Befugnisse an supranationale Organe muß jede wirtschaftliche Integration schon im Ansatz steckenbleiben.

\footnotetext{
114 Art.17 5.Bindestrich der 2.USt-Richtlinie.

119 Persönliches Interview.

116 Persönliches Interview.

117 Persönliches Intervlew.

118 Vgl. Le Monde 9.2.67, Stuttgarter Zeitung 10.2.67, FAZ 10.2.67, Figaro 10.2.67 u. Le Monde 11.2.67.

119 Vgl. Art.13 der 2.USt-Richtlinie.
} 
2.1.5. Die schleppende Implementierung der beiden USt-RIchlinien:

$\underline{1967-1973}$

Art.1 der 1.USt-Richtlinie verlangte von den Mitgliedstaaten, ihre nationale Gesetzgebung bis zum 1.Januar 1970 an das neu erlassene Gemeinschaftsrecht anzupassen. Da zum Zeitpunkt der Verabschledung der beiden ersten USt-Richtlinien in Frankreich und Deutschland die Vorbereitungen für die Steuerreform bereits nahezu abgeschlossen waren, konnten die beiden Staaten ihrer Verpflichtung schon zum 1.Januar 1968 nachkommen. In beiden Fällen zog der Ubergang zur europäischen MWSt eine Erhöhung des Grenzausglelchs nach sich, die in Frankreich bel knapp über $1 \%$ und in Deutschland bel durchschnittlich ca.3\% lag. Insbesondere mit der faktischen Abwertung der ohnehin schon starken D-Mark kam ein Steln ins Rollen, der auch andere Staaten zum Handeln $\mathrm{zwang.}{ }^{120}$ In erster Linie betroffen war die Benelux-Union, die im Warenaustausch mit den belden großen Nachbarn einen bedeutenden Tell ihres Volkseinkommens erwirtschaftet. Die Industrie drängte die jewelligen Reglerungen, möglichst frühzeitig die MwSt einzuführen und als Sofortmaßnahme den bestehenden Grenzausgleich anzuheben. Ahnliche Stimmen waren auch in Italien und sogar noch außerhalb der EG - z.B. in Osterreich ${ }^{121}$ und der Schweiz'122 - zu vernehmen. Und als sich schlleßlich immer mehr europälsche Länder anschickten, zu einer MWSt überzugehen, fühlten slch selbst dle Vereinigten Staaten herausgefordert und grlffen wiederholt den hohen Grenzausglelch der neuen Abgabe als ein Instrument protektionistischer Handelspolitik an. ${ }^{123}$

Brüssel akzeptierte, daß die Staaten, die den Deutschen und Franzosen bei der Einführung der MWSt noch hinterherhinkten, zum Schutz ihrer eigenen Volkswirtschaften den Grenzausglelch anheben mußten. Die Gefahr, daß einzelne Lănder dabei über die vertraglich fixierte Obergrenze hinausschießen würden, war jedoch nicht zu übersehen. Dle Kommission entschloß sich daher Im Juni 1967, den alten Entwurf für eine gemeinsame Berechnungsmethode zu entstauben und ihn als offiziellen Richtlinienvorschlag dem Rat zu unterbreiten. ${ }^{124}$ Uneingeschränkte Unterstützung fand die Initiative in Paris. Man befürchtete, Rom könnte während der zu erwartenden langwieri-

120 Vgl. Süddeutsche Zeltung 20.3.67, NZZ 1.4.67 u. New York Times 27.2.68.

121 Vgl. z.B. Die Presse 10.3.67.

122 Vgl. z.B. NZZ 23.2.68.

123 Vgl. z.B. Can a Tax Be Wrong, in: European Taxation, 8.1968, S.28f. Vgl. a. E.E.C./U.S.A.: Taxes and Non-Tariff Barriers - a Trade War in the Making?, in: European Taxation, 10.1970, S.I/81ff.

Vgl. AB 1967/201, S.21ff. 
gen Debatten über die MWSt gezwungen sein, den ohnehin schon sehr hohen italienischen Grenzausgleich weiter anzuheben. Da Paris mit seiner Vermutung so falsch nicht lag, kam der heftige und aus den Jahren 1962/63 schon bekannte italienische Widerstand gegen die Berechnungsmethode auch nicht überraschend. Nachdem auch von seiten der Niederlande geäußerte Bedenken in langen Verhandlungen ausgeräumt worden waren, blieb Italien das einzige Land, das sich gegen den Richtlinienvorschlag sträubte. ${ }^{125}$ Aber die Itallener halten, wie die Erfahrung der EG zeigt, dem gemeinschaftlichen Druck der anderen nur selten länger stand. So stimmten sie der Richtlinie schließlich $\mathrm{zu}^{126}$, waren sich allerdings, wie so oft, dabei keineswegs sicher, ob sie die damit eingegangenen Verpflichtungen auch wirklich würden einhalten können.

Nach den Deutschen und Franzosen führten zum 1.Januar 1969 die Niederländer und ein Jahr später die Luxemburger dle MWSt ein. Auch die belgische Regierung hatte zunächst den 1.Januar 1970 vorgesehen, bekam jedoch, als der Termin näher rückte, zunehmend Angst vor elner Anhelzung der Inflation und entschied daher kurzerhand, die steuerreform auf den 1.Januar 1971 zu verschieben.127 Den Verstoß gegen Art.1 der 1.USt-Richtlinie glaubten die Belgier sich erlauben $\mathrm{zu}$ können, hatte sich doch zwischenzeitlich südlich der Alpen noch viel Schlimmeres zusammengebraut.

Trotz der im Februar 1967 eingegangenen Verpflichtung war die Vorbereitung für die Steuerreform in Italien nur im Schneckentempo vorangekommen.128 Im Jahre 1969 lag zwar ein Gesetzentwurf der Regierung vor ${ }^{129}$, der aber vom Parlament überhaupt noch nicht behandelt worden war. Nachdem Rom schon seit Ende 1968 der Kommission mehrmals zu verstehen gegeben hatte, daß sich der Termin 1.Januar 1970 vorraussichtlich nicht elnhalten lasse, beantragten die Italiener am 14.Juli 1969 in Brüssel offizlell, ihnen einen zweljährigen Aufschub für die Implementierung der belden UStRichtlinien zu gewähren. Die anderen Mitglledstaaten reagierten verärgert. Der italienischen Industrie ging es damals ausgezelchnet, was man nicht zuletzt auf den nach wie vor sehr hohen Grenzausgleich zurückführte. Auch die Kommission konnte nicht akzeptieren, daß sich einzelne Staaten einfach

$125 \mathrm{Vgl}$. FT 6.3.68, Welt 6.3.68 u. NZZ 7.3.68.

126 Vgl. AB 1968/L 115, S.14ff.

$127 \mathrm{Vgl}$. ausfuhrlicher in Kap.C.2.2.3.

128 Zum folgenden vgl. die umfassendere Darstellung bel Puchala (1984), S.88ff.

129 Vgl. z.B. Fraenkel-Haeberle (1968) u. Pret1 (1968). Vgl. a. Italy - The Tax Reform Blll of 1967, in: European Taxation, 7.1967, S.240ff. 
über geltendes EG-Recht hinwegsetzen wollten. Aber was sollte sie tun? Ein Vertragsverletzungsverfahren vor dem EuGH hätte zu nichts gefuhrt. Kommissar von der Groeben fuhr daher erst einmal zu Gesprächen nach Rom. Dort fand er elnen Finanzminister vor, der "ganz traurig war"130. Die Italienische Reglerung hatte zwar den guten willen zur Einführung einer MWSt, sah sich aber "entsetzlichen Schwierigkeiten"131 gegenüber: Die Păhigen Beamten des römischen Finanzministeriums waren, wegen schlechter Bezahlung, zuhaup in die private Wirtschaft abgewandert; die Wirtschaft sah durch dle mit der MWSt verbundene Buchführungspplicht die weit verbreitete Hinterzlehung der Einkommensteuer gefahrdet; usw. usw.

Die Kommission zeigte großes Verständnis für die Italienischen Probleme, mußte auf der anderen Selte aber auch dem Arger der anderen Mitgliedstaaten Rechnung tragen und zugleich im elgenen Interesse daraup achten, daß die römische Sonderrolle nicht die weitere USt-Harmonisierung in der Gemeinschaft verzögerte. Brüssel entschied sich daher in elnem Vorschlag für eine 3.USt-Richtlinie dafür, eine Fristverlängerung für Belgien und Italien von zunächst einem Jahr mit der Bedingung zu verknüpfen, die geltenden Grenzausgleichssätze pauschal herabzusetzen. ${ }^{132}$ Da Italien sich den harten Auplagen strikt widersetzte, der Stichtag 1.Januar 1970 aber unmittelbar vor der Tür stand, begann im Rat eine hektische Suche nach Kompromißlösungen, die von einer regen Reisetätigkeit zwischen Brüssel und Rom begleitet wurde.133 Man einigte sich schließlich am 9.Dezember 1969: Im Austausch für einen zweijährigen Terminaufschub verpflichteten sich Italien und Belgien, den Grenzausgleich nicht welter zu erhöhen und einige Sătze sogar zurückzunehmen. ${ }^{134}$

während Belgien, wie vorgesehen, am 1.Januar 1971 zu seiner MwSt kam, war das Itallenische Intermezzo noch nicht beendet. Es bedurfte noch zwei weiterer Verlängerungen um jewells 6 Monate - gewährt in der 4. und 5.USt-Richtlinie -, bevor die MWSt am 1.Januar 1973 endlich auch aup der

\footnotetext{
130 Persönliches Interview.

131 Persönliches Interview.

132 Vgl. z.B. NZZ 11.9.69, Times 22.9.69, FT 26.9.69 u. Stuttgarter Zeitung 2.10.69.

133 Vgl. z.B. FT 1.10.69, FAZ 18.10.69 u. Handelsblatt 20.10.69.

134 Vgl. 3.USt-Richtlinie.
} 
Apenninenhalbinsel eingeführt werden konnte. Am gleichen Tag stleßen drel neue Mitglledstaaten zur Gemeinschaft. Irland ${ }^{139}$ und Großbritannien ${ }^{136}$ hatten die MWSt bereits gut vorbereltet und konnten sie schon zum 1.November 1972 bzw. zum 1.April 1973 elnführen. Und bei den Dänen gab es zum Zeitpunkt ihres EG-Beitritts überhaupt keinen steuerlichen Anpassungsbedarf mehr: Sle erhoben schon seit dem 3.Jull 1967, also fruher als jeder andere Staat, eine nach dem Brüsseler Modell gestaltete MWSt. ${ }^{137}$

Spanier und Portugiesen erwiesen sich, zumindest was die MWSt anbelangt, als Musterschüler der EG. Die europälsche MWSt hlelt am 1.Januar 1986 und damit exakt am Tage des Beltritts der beiden Länder zur Gemeinschaft Einzug auf der iberischen Halbinsel. Alleine die Grlechen, seit 1981 Mitglied der EG, hinken noch Immer hinter der allgemeinen Entwicklung hinterher. Zwar hatten sle sich in ihren Beitrittsverträgen verpflichtet, bis spätestens zum 1.Januar 1984 zur MWSt uberzugehen. Aber die guten Absichten gingen in einem Chaos politischer Widerstände, administrativer Schwlerigkelten und eines völlig überalterten Steuersystems ${ }^{138}$ unter. In einer 15.USt-Richtlinie wurde Griechenland eln zwejahriger Aufschub gewährt. Inzwischen liegt berelts ein Vorschlag für eine 21.USt-Richtlinie vor, der den Einfuhrungstermin für die MWSt auf den 1.Januar 1987 hinausschlebt. Es bleibt mit einer gewissen Skepsis abzuwarten, ob die neuerliche Frist elngehalten werden kann.

135 Vgl. Third Report of the Commission on Taxation, Indirect Taxation, Dublin: Statlonary Office 1984, S.195ff. Vgl. a. Ireland - Proposals for a Value Added Tax, in: European Taxation, 11.1971, S.I/110ff. Vgl. a. MacCormac (1967).

136 Vgl. ausfuhrlicher in Kap.C.2.2.5.

137 Vgl. Fuchs (1965), Moller (1967) u. Shoup (1969a). Vgl. a. Frankfurter Rundschau 10.2.65, Suddeutsche Zeitung 31.1.66, Frankfurter Rundschau 20.4.66, Süddeutsche Zeitung 16.3.67, NZZ 2.4.67, FAZ 12.8.67 u. 25.9.67. Auch die Einfuhrung der MWSt in Dänemark war, obwohl sle Jahre vor dem dänischen EG-Beltritt lag, stark von der Gemeinschaft beeinflußt. Ein Kanal, über den Kopenhagen damals seine Informationen aus Brüssel bezog, war der enge Kontakt, den der dănische Botschafter bel der EG zu Generaldirektor VerLoren van Themaat pllegte. 
2.2. Die nationale Perspektive: die USt-Reformdebatte in den Mitglledstaaten

Die Verabschledung und Implementlerung der ersten beiden USt-Richtlinien haben wir bislang lediglich aus der Sicht der Gemelnschaft heraus betrachtet. Dle Verhandlungspositionen, die die Vertreter der Mitgliedstaaten während der Brüsseler Harmonisierungsgespräche einnahmen, können aber nur vollständig verstanden werden vor dem Hintergrund der politischen Zwänge, denen die nationalen Reglerungen Im jewelligen Heimatland ausgesetzt waren.

Dle für die Position der elnzelnen Mitgliedstaaten maßgeblichen innenpolltischen Entwicklungen sind vereinzelt berelts kurz angesprochen worden. Sie sollen nun in das Zentrum der Analyse gerückt werden. Aufgabe des folgenden Kapitels ist es daher, anhand einiger typischer Beisplele ${ }^{1}$ und im Rahmen einer jeweils recht breit angelegten Darstellung en détall herauszuarbeiten, wie die USt-Reformdebatte in verschledenen EG-Staaten verlief. Am Ende eines jeden Abschnitts bleibt dann jewells abschlleßend zu Pragen, welcher Art die Wechselbezlehungen waren, die in jeder Phase der Verhandlungen $z$ wischen den nationalen Hauptstädten einerseits und Brüssel andererseits bestanden und die den politischen willensbildungsproze $\beta$ vorangetrieben haben.

Als "typische Belspiele" werden Frankrelch, Deutschland, Belgien, die Nlederlande und Großbritannien naher beleuchtet. Die USt-Reformdebatte in Italien war der in Belgien vergleichbar; ähnliches gllt für Irland und Großbritannien. 


\subsubsection{Frankreich: der Erfinder der MWSt}

Obwohl das Konzept der MWSt zum erstenmal in der deutschen² und der amerikanischen ${ }^{3}$ Literatur Erwähnung fand, erheben die Franzosen den Anspruch darauf, die MWSt erfunden zu haben: "La T.V.A. est une invention Prançalse." 4 Das ist auch insofern gerechtfertigt, als sle es ja waren, die bereits in 1948 und damit als erster Staat der Welt beschlossen, eine MWSt-ahnliche Abgabe einzuführen und in der Praxis zu erproben. Die Entscheidung der Pranzösischen Reglerung hatte, wie wir schon sehen konnten, weitreichende Konsequenzen fur die USt-Harmonisierung in der EG.

\section{Die Vorgeschlchte der Pranzösischen MWSt: $1917-1948^{\circ}$}

Die Einführung der MWSt war weniger das Ergebnis relflicher Uberlegungen als vielmehr die eher zufällige Folge einer ebenso langen wie wechselvollen Vorgeschichte, die 1917 ihren Anfang nahm. Damals war Frankreich, wie andere Länder während und kurz nach dem Krieg auch, auf der verzweifelten Suche nach zusätzlichen Steuerquellen. Paris versuchte sein Glück zunächst mit der Erhebung einer 0,2prozentigen Stempelsteuer aup Einzelhandelsverkäufe. Da deren Aufkommen aber - nicht zuletzt wegen eines massiven Steuerbetrugs seltens der Detalllisten - viel zu gering war, beschloß die Reglerung 1920, die Stempelsteuer durch eine nach deutschem Vorbild gestaltete allphasige Bruttoust $z u$ ersetzen. Der Steuersatz wurde im ersten Jahr auf 1,1\% festgesetzt und 1926 auf $2 \%$ angehoben. Der widerstand gegen die neue Abgabe kam von allen Seiten und zwar sehr massiv. Der USt wurden Regressivität und verzerrende Effekte vorgeworfen, und außerdem wehrten sich die Unternehmer gegen eine Kontrolle ihrer Buchhaltung. Die in der Opposition befindlichen Linksparteien sagten der Taxe sur le Chiffre d'Affalres den kompromißlosen Kampf an und lösten damit elne Kette von Steuerreformen aus, die jahrzehntelang nicht mehr abreißen sollte.

Die Reglerung beantwortete die Kritik mit einer Einengung des Anwendungsbereiches der USt. Nachdem die Landwirtschaft und die frelen Berufe schon von Anfang an von der USt ausgenommen worden waren, kam ab 1923 auch das gesamte Handwerk in den Genuß einer Steuerbefreiung. Den anderen Kleinunternehmern und insbesondere den Einzelhändlern wurden weitreichende Vereinfachungen der Steuererhebung - z.B. Pauschalierungen - zugestanden. 1924 übernahm die französische Linke die Reglerungsgeschäte. Abschaffen, wie sle in der Hitze des Wahlkamples versprochen

2 Vgl. Slemens (1919).

3 Vgl. Adams (1917), S.187ff.

4 Cozian (1971), S.37.

- Vgl. z.B. Due (1957), S.115ff., Muller (1965), S.16ff., Phillppe (1973), S.21ff. Eine sehr ausfuhrliche Darstellung findet sich bel Frenkel (1976). 
hatte, konnte sle die USt aus budgetären Grüden nicht. Um Ihren Reformelfer trotzdem unter Bewels zu stellen, nahm die neue Regierung elnzelne Gutergruppen aus der USt heraus und unterwarf sle stattdessen einphasig erhobenen taxes uniques ${ }^{6}$. Mit zunehmender Zahl der Gesetzesänderungen gewannen die Reformen an Elgendynamik. In schmerzhaften Erfahrungen mußte Paris lernen, daß in einem so großen Land wie Frankrelch einer systemimmanenten Modifikation der Bruttoust kein dauerhafter Erfolg beschieden sein kann. ${ }^{7}$ Jede Gesetzesänderung löste ein Problem und warf dafür an anderer Stelle zwei neue auf: ".., la réglementation étalt tombée de Charybde en Scylla." $\mathrm{Da}$ der Weg zurück aus politischen Gründen nicht gangbar war, blleb nur die Flucht nach vorne, in immer neue Reformen.9 $\mathrm{Zwischen} 1925$ und 1935 vervielfachte sich die Zahl der taxes uniques, die verwaltungstechnischen Probleme stiegen ins Unermeßliche:

\begin{abstract}
"On aboutit \& ce résultat que, dans une même entreprise qui Pabrique ou vend directement des denrées alimentaires, certains produits sont soumis au chiffre d'affaires, d'autres sont totalement exonérés, d'autres enfin supportent des taxes uniques dont le montant est variable. D'où une comptabilité à colonnes multiples, un contrôle fiscal tatillon et forcément minutieux, des erreurs Préquentes et inévitables, en un mot, un régime vraiment inextricable, qui ne profite qu'aux praudeurs."10
\end{abstract}

Als Konsequenz aus den Problemen, die sich in den vergangenen 15 Jahren angestaut hatten, wurde in 1936 dle gesamte Bruttoust durch elne Taxe $\dot{a}$ la Production ersetzt. Bel der neuen Produktionssteuer handelte es sich um die Verallgemeinerung eines vorher bel den taxes uniques schon entwickelten Prinzips: steuerpflichtig waren alleine die Produzenten; da die melsten Lieferungen $z$ wischen den Produzenten en suspension de taxe erfolgten, wurde die Abgabe de facto nur auf der letzten Herstellerstufe erhoben. Die Produktionssteuer war technisch elnfacher und 8konomisch neutraler als das vorherige System und hatte zudem noch den großen Vortell, daß die sich ständig beklagenden Händler endlich von der Besteuerung befreit worden waren.

- Verfahren der "Phasenpauschallerung", vgl. die Darstellung in Kap.B.1.2.1.

7 Am Rande sel vermerkt, daß in den wesentlich kleineren BeneluxStaaten systemimmanente Reformen der Bruttoust mit durchaus beachtlichem Erfolg Verwendung fanden; vgl. die Darstellung in Kap.C.2.2.3. ul. C.2.2.4.

- Phlllppe (1973), S.25.

- Dle große Zahl der USt-Reformen war also eln Ausdruck bitterer Notwendigkeit und nicht, wie Schmölders melnt, eln Zelchen für "dle Freude der Franzosen am Experimentleren"; Schmölders (1949), Sp.203.

10 Ein Abgeordneter Im Pranzösischen Parlament in 1936, zitlert In: Lauré (1952), S.55f. 
Der neue Steuertyp konnte als eine durchaus beachtliche Errungenschaft gewertet werden: Mit der Einfuhrung des système suspensif war der Grundstein fur eine echte Nettoust gelegt. Trotzdem beschloß Paris 1948, zum Prinzip des VSA bzw. zu elnem, wie die Franzosen es nannten, régime des palements fractionnés uberzugehen: Die für die Lleferungen zwischen Produzenten zu zahlende USt wurde nicht mehr suspendiert, sondern sie mußte nun vom Verkăufer an den Fiskus abgeführt werden und wurde anschllessend dem Kăufer als Vorsteuer wieder zuruckerstattet. Warum, so stellt sich die Frage, dieser plötzliche Wechsel?

Er war, trotz anderslautender Beteuerungen aus Paris' ${ }^{11}$, reln budgetär motiviert. Mit elnem kleinen Trick stellte die Regierung nämlich sicher, daß der Systemwechsel ihr elnen zwar elnmaligen, aber dafur ganz beachtlichen Betrag in die Kassen schwemmte: Der Verkäufer mußte die USt unmittelbar im Anschluß an dle năchste Steuererklärung an den Fiskus abpuhren, der Kăufer aber, so die règle du décalage d'un mols, durfte selnen VSA erst mit elnmonatiger Verspätung geltend machen.

"Autrement dit, le régime des palements fractionés qui est le
nôtre maintenant, n'a pas été voulu pour ses vertus particu-
lières. Il a été institué pour falre rentrer dans les caisses de
l'Etat Prançais, en 1948,13 mols d'impôt au lieu de 12 par le
jeu du décalage d'un mols."12

Der mit dem Dekret vom 25.September 1948 verordnete Ubergang zum VSA war, obwohl die Abgabe damals noch Produktionssteuer hie $\beta$, dle Geburtsstunde der französischen MWSt. Zu verdanken haben wir ihre Einführung ironischerweise alleine dem décalage d'un mois, einer Regel also, die wegen ihrer kumulativen Effekte mit dem Grundgedanken einer neutralen Nettoust nicht zu vereinbaren ist.

\section{Dle verungluckte Reform von $1954^{13}$}

Mit der rudimentären Form einer MWSt verwendeten die Franzosen Ende der 40er/Anfang der 50er Jahre eine USt, die, gemessen an der damals in anderen Lăndern üblichen BruttouSt, als durchaus modern gelten konnte. Das aber war auch fast schon alles. Sehen wir uns nämlich das Pranzösische USt-System ein wenig năher an, dann stellt sich schnell heraus, daß es in elnem miserablen Zustand war. Zum einen entsprach die Produktionssteuer bel weitem nicht dem Idealbild einer neutralen MWSt. Da der VSA nur für solche Guter erlaubt war, die in das Endprodukt der betreffenden Unternehmung physisch elngingen - déduction physique -, blieben Investitions-

11 Das Argument der Regierung, mit dem Systemwechsel die Steuerhinterzlehung bekämpfen $\mathrm{zu}$ wollen, war nicht stichhaltig, da sich beide Verfahrensweisen aus rein technischer sicht nur wenig voneinander unterschieden; vgl. z.B. Lauré (1957), S.104 Pि.

12 Egret (1967), S.34.

13 Vgl. inbesondere Due (1957), S.120ff., und Muller (1965), S.33ff. 
guter, Aufwendungen für Forschung und Entwicklung, etc. mit der auf der Vorstufe erhobenen USt belastet. Die daraus resultierende Kumulationswirkung gab der Produktionssteuer den Charakter einer "taxe sur le progrès techniques"14. Zum anderen war die Produktionssteuer aup einen viel zu kleinen Anwendungsbereich - die Industrie - begrenzt. Für die anderen Bereiche der Pranzösischen Volkswirtschaft gab es ein kunterbuntes Durcheinander unterschiedlichster Regelungen:

- Die Landwirtschaft, die Preien Berufe, das Handwerk und öfentliche Versorgungsleistungen waren steuerbefreit.

- Die Dienstleistungsunternehmen unterlagen seit 1936 elner seperaten Taxes sur les Prestations de Services in Form einer Bruttoust.

- Der Handel wurde seit 1941 ebenfalls mit elner Bruttoust belastet, die als Lokalsteuer - Taxe Locale - den Kommunen zuploß.

- Für Mineralöl gab es noch aus der Zeit vor 1936 und für Fleisch und Wein seit 1951 jeweils unterschiedliche taxes uniques.

- Daruberhinaus existierte seit 1939 noch eine 1prozentige AllphasenBruttouSt, dle dem Modell von 1920 nachgeblldet worden war; man hatte sie zunăchst nur vorubergehend als Taxe d'Armement eingepührt, sle aber schon ein Jahr spater in Taxe sur les Transactions umbenannt und damit als fester Bestandteil des Steuersystems anerkannt.

Seit Einfuhrung der Produktionssteuer im Jahre 1936 war das Pranzösische USt-System also zunehmend unübersichtllcher geworden. Auch waren die Sătze der meisten Abgaben sprunghaft - der Satz der Produktionssteuer erhöhte sich z.B. von 6\% in 1936 auf $15,35 \%$ in 1952 - angestiegen mit dem Ergebnis, daß die Unzulänglichkeiten des Steuersystems immer stärker spurbar wurden. In einer 1952 veröffentlichten Studie arbeitete Maurice Lauré - später bekannt als "le père de la T.V.A."15 - klar heraus, daß, um dle Wachstumskrăfte der französischen Wirtschaft zu stärken, eine durchgrelfende Reform der USt unabdingbar war.16 Die USt dürfe, so die Forderung Laurés, die vom Markt getroffenen Allokationsentscheidungen nicht systematlsch verzerren. Zur Gewăhrleistung einer neutralen Besteuerung müsse erstens der Im Rahmen der Taxe à la Production gewährte VSA generalisiert und zweitens der Anwendungsbereich der Produktionssteuer aup die gesamte Volkswirtschaft ausgedehnt werden. Dle Produktionssteuer könne dann, wie Lauré vorschlug, in Taxe sur la Valeur Ajoutée umbenannt werden.

14 Lauré (1952), S.129.

15 Cozlan (1971), S.14. Die von Lauré propaglerte Idee war aber auch im französischen Schriftum nicht ganz neu, vgl. z.B. Dagby (1939). Unter dem Pseudonym "Dagby" schrieb ein gewisser J. Roger, seines Zeichens hoher Beamter im Pranzösischen Finanzministerium; vgl. Frenkel (1976), S.22419., sowle Le Monde 7.1.66.

Vgl. Lauré (1962). 
In 1952/53 legten drel verschiedene Regierungen nacheinander drel verschiedene Gesetzesentwürfe vor, die sich an den Vorschlägen Laurés orientierten. Erst die letzte Version wurde im April 1954 vom Pranzösischen Parlament angenommen. ${ }^{17}$ Die Reform führte zwar mit T.V.A. anstelle von Taxe à la Production elnen neuen Namen in das Pranzösische USt-Recht ein, blieb aber ansonsten weit hinter dem von Lauré entworfenen Konzept zurück:

- Das wichtigste Ergebnis der Reform war die Ausdehnung des Im Rahmen der TVA gewahrten VSA auf alle Vorleistungen, die von elnem Unternehmen für betriebliche Zwecke angekauft wurden: Die déduction physique wurde ergänzt durch eine déduction financière. Nicht aufgehoben wurden dagegen die den VSA beschränkenden und vollkommen systemwidrigen Regeln des décalage d'un mois und des butolr ${ }^{\mathbf{B}}$.

- Fast keine Fortschritte machte man bel der von Lauré ebenfalls geforderten Erweiterung des Anwendungsbereiches der TVA. Alleine die einprozentige BruttouSt wurde abgeschapft. Die jeweils separaten Abgaben für den Dienstlelstungsbereich und den Handel blieben demgegenüber erhalten. Man unternahm lediglich den Versuch, die TVA auf der einen und die Dienstleistungs- bzw. die Lokalsteuer aup der anderen Seite an den problematischen Schnittstellen ein wenig aufeinander abzustimmen.

Angesichts der labilen innenpolitischen Verhältnisse im damaligen Frankreich konnte die USt-Reform von 1954 die in sle gesetzten Erwartungen nicht erfullen: "La période de mis au point de la taxe sur la valeur ajoutée a été fertile en actions engagées pour la défense des situations aquises, actions qui ont laissé des traces profondes dans la structure de la T.V.A."19 Das Pranzösische USt-System war und blieb ein Flickwerk, und es kann daher nicht uberraschen, daß schon in 1956/57 wleder Kritik daran laut wurde.20 Abermals war es Lauré, der in forderster Front stand und der, entsetzt über die verunglückte Reform von 1954, rief: "Au secours de la T.V.A." 21

17 Lol N2 54-404 v. 10.4.54, vgl. hlerzu z.B. Merigot (1954). Einige Elemente der USt-Reform von 1954 wurden durch das Dekret No 53-942 v. 30.9.53 berelts vorweggenommen, andere durch das Dekret $\mathrm{N}^{2}$ 65465 v. 30.4 .55 erst in die Tat umgesetzt. Alle drei Rechtsakte zusammengenommen sind gemeint, wenn hier von der USt-Reform von 1954 gesprochen wird.

18 Auch der "butoir" fand in 1948 Eingang in das Pranzösische UStRecht. Er besagt in Kurzfassung, daß, sollte die zu zahlende TVA in elner Perlode geringer sein als die davon abzugsfähige Vorsteuer, der entsprechende Differenzbetrag nicht vom Fiskus erstattet wird, sondern nur als (zinsloser) Steuerkredit auf spătere Perloden ubertragen werden darf.

19 Lauré (1957), S.22.

20 Vgl. L'Economie 2.2.56, 1.3.56 u. 30.8.56, Le Monde 3.5.57.

21 Titel elner Veröffentlichung Laurés aus dem Jahre 1957, vgl. Lauré (1957). 
AuP die Kritik der Regierung wurde, wie meist in solchen Situationen, mit der Einberufung einer Expertengruppe reaglert, die die zahlreichen Reformalternativen gegeneinander abwăgen sollte. ${ }^{23}$ Im Jull 1959 legte der Finanzminlster dann einen Gesetzesentwurf vor, der darauf abzielte, die TVA auf Grossisten und große Elnzelhändler auszudehnen und Im Gegenzug die Taxe Locale abzuschaffen. Die Pariser Nationalversammlung wies die Vorlage, die inres Erachtens die finanziellen Interessen der Kommunen nicht hinrelchend berücksichtigte, ohne Diskussion an die Regierung zurück. Dem ersten folgte Im Juni 1960 ein zwelter Gesetzentwurf, der, sowelt es um die kommunalen Finanzen ging, den Elnwänden des Parlaments etwas entgegenkam, der aber ansonsten, da neben Tellen des Handels auch alle sonstigen Dienstleistungen in die TVA einbezogen werden sollten, wesentlich ehrgelziger als sein Vorgänger war. Auch er flel im Parlament durch. Das Plenum der Nationalversammlung wies den Reglerungsentwurf im Jull 1961 an den zuständigen Ausschuß zurück, wo das Papler in der Folgezelt langsam verstaubte. ${ }^{24}$

Den Reformbemuhungen der Franzosen war also keln Erfolg beschleden. Zum einen lag das an den in der Nationalversammlung uberproportional vertretenen Burgermeistern. Sle wollten sich auf eine Abschapfung der Taxe Locale nicht einlassen, füchteten sie doch um die finanzielle Unabhänglgkelt ihrer Kommunen vom Staat. ${ }^{20}$ Zum anderen konnte sich aber auch die franzosische Industrie fur die Gesetzesvorlage nicht erwärmen. Sle wollte eine ebenso elnfache wie neutrale Steuer und versuchte gleichzeltig sicherzustellen, daß die Abschaffung der Taxe Locale nicht uber eine Erhőhung der MWSt-Sătze finanzlert würde. Für die Industrie ergab sich daher als unverzlchtbarer Bestandtell elner USt-Reform eine Einbezlehung des gesamten Handels in die TVA.26 Einen solchen Vorschlag aber wagte die Regierung nicht vorzulegen. Den Politikern aller Partelen steckte der Poujadisme der fruhen 50er Jahre noch in den Knochen. Damals hatten sich die

22 Vgl. z.B. La Taxe sur la Valeur Ajoutée - Son Evolution et ses Perspectives, In: Revue des Contributions Indirects, 1965, S. 523fP., 1966, S.19PP. u. S.116Pf.

Vgl. z.B. La Réforme des Taxes sur le Chlffre d'Affalres, in: Revue des Contributions Indirects, 1959, S.305fe. u. S.351ff.

24

Vgl. z.B. La Réforme des Taxes sur le Chiffre d'Affalres, In: Revue des Contributions Indirects, 1961, S.487ff. Vgl. a. Suppression de la Taxe Locale et Financement des Budgets Locaux, in: Revue des Contributions Indirects, 1960, S.395fe. Vgl. a. Renfert (1964) sowle Le Monde 23.6.61.

25 Vgl. z.B. Le Monde 28.6.61. Zu den Vortellen der "Taxe Locale" aus der Slcht der Kommunen vgl. Dubols (1964).

28

Vgl. z.B. Egret (1967), S.40ff. Vgl. a. Le Monde 4.4.60 u. L'Economie 12.4.62. 
kleinen Selbständigen gegen die ihnen von den Finanzbehörden auferlegten Buchhaltungs- und Steuerzahlungspllichten zur Wehr gesetzt. Es war zu gewaltätigen Ausschreitungen und sogar zur Wahl einiger Poujadisten in die Nationalversammlung gekommen.

Nach den belden Mißerfolgen von 1959 und von 1960/61 schreckte die französische Reglerung davor zurück, das heiße Eisen USt so bald wieder anzufassen. Man gab sich mit ein paar kleinen Modifikationen zufrieden und ließ die große Reform bis auf welteres ruhen. Erst Mitte 1963 erklärte der neue Finanzminister Giscard d'Estaing seine Bereitschaft, einen nochmallgen Vorsto $\beta$ zu wagen. ${ }^{27} \mathrm{Da}$ aber die zu erwartenden Widerstände nach wie vor erheblich waren, gingen die Arbeiten der Reglerung nur schleppend voran. Es wurde Juni 1965, bis der Finanzminister dem Parlament den inzwischen dritten und glelchzeltig auch ehrgeizigsten Reformvorschlag unterbreiten konnte: Bis auf die relativ kleinen Betriebe sollte, so die Absicht der Reglerung, der gesamte Handels- und Dlenstlelstungsberelch in die MWSt elnbezogen werden. ${ }^{28}$ Das Projekt wurde im Dezember 1965 von belden Hăusern des französischen Parlaments verabschledet28 und zum 1.Januar 1968 in Kraft gesetzt. ${ }^{30} \mathrm{Da}$ das Reformpaket den ersten belden USt-Richtlinien schon weitgehend entsprach, ergab sich aus der Entscheidung des EG-Ministerrates vom Februar 1967, von wenigen Ausnahmen abgesehen, kein steuerlicher Anpassungsbedarf mehr für Frankrelch.

Wie, so drängt sich die Frage auf, ist es zu erklären, daß das französische Parlament Irgendwann zwischen 1961 und 1965 seine Auffassung zur UStReform so grundlegend veränderte? Fur den Melnungsumschwung verantwortlich zu machen ist in erster Linie die Tatsache, daß sich Anfang der $60 e r$ Jahre der Strukturwandel im Pranzðsischen Einzelhandel zu beschleunigen begann. Kaufhăuser und Supermärkte waren im Kommen. Aufgrund ihres enormen Investitionsbedarfs forderten sle unablässig, die Taxe Locale abzuschaffen und den Einzelhandel stattdessen der TVA zu unterwerfen: Nur so konnten sie in den Genuß einer Rulckerstattung der aup den Investitionsgutern lastenden TVA kommen. ${ }^{31}$ Die stetig wachsenden Supermäkte rannten beim jungen Finanzminister Giscard d'Estaing offene Türen eln. Er und sein Premier befurworteten die rasche Modernisierung des Handels, versprachen sie sich doch davon nicht zuletzt einen Druck auf die Preise

27 Vgl. z.B. Le Monde 9.5.63.

20 Eine ausfuhrliche Analyse des Reformvorschlages findet sich bel Muller (1965), S.289ff. Zur Aupnahme des Gesetzentwurfes in der Offentlichkelt vgl. Le Monde 29.6.65, 16.6.65, 24.6.65, 25.6.65 u. 26.6.65.

29 Vgl. z.B. Le Monde 23.12.65, 24.12.65 u. 25.12.65.

30 Ein Uberblick über die Reform findet sich z.B. bel Flockermann (1966) u. Mercler (1967).

31 Vgl. z.B. Vernholes (1968). 
und damit einen wichtigen Beitrag zu ihrem Stabilisierungsprogramm. ${ }^{32}$ Widerstand kam, verständlicherwelse, von den in ihrer Existenz bedrohten kleinen Einzelhăndlern. Sie vermochten die Reform der TVA - Insbesondere durch thr negatives Votum im Assises Nationales du Commerce von Ende $1963^{33}$ - eine zeltlang aufzuhalten, verhindern aber konnten sie sle, da ihre Kraft mit fortschreitendem Konzentrationsproze $\beta$ schwand, letzten Endes aber nicht. Widerstand wurde auch, wie schon erwähnt, von selten der Kommunen mobllisiert. Die Einigung uber die Abschaffung der Taxe Locale war aber im Grunde genommen nur elne Frage des Prelses, den die Regierung an die im Parlament sitzenden kommunalen Interessenwahrer zu zahlen berelt war. Als der Innenminister 1965 den Kommunen eine Steuerquelle anbot, die ergleblger war als die Taxe Locale und die zudem noch schneller zu wachsen versprach, konnten einige ihrer Vertreter nicht mehr Nein sagen.

\section{Europa und die Franzosen}

Müssen wir aus den blsherigen Ausfuhrungen schließen, daß die Ende 1965 von Paris beschlossene RePorm der TVA auf rein innenpolitische Grunde zurückzufuhren war und mit der USt-Harmonisierung in der EG in keinem direkten Zusammenhang stand? Richtig ist sicherlich, daß Finanzminister Giscard d'Estaing die TVA in jedem Fall und ganz unabhängig von dem, was in Brussel verhandelt wurde, reformleren wollte. Richtlg ist aber auch, da $\beta$ die Franzosen jahrelang erhebliche Schwierigkeiten hatten, dle TVA-Reform aus elgener Kraft durchzuführen. Selbst nachdem das betreffende Gesetz nach langem Hin und Her im Dezember 1965 endlich verabschiedet worden war, kam noch einmal Unsicherheit auf: Da man eine Revolte der kleinen Einzelhändler befürchtete, wurde die Inkraftsetzung der neuen Vorschriften vom 1.Januar 1967 auf den 1.Januar 1968 verschoben; die Reglerung nutzte dle gewonnene Zelt, um, ein außerst ungewöhnliches Vorgehen Im technokratischen Frankreich, umfangreiche Konsultationen mit den betroffenen Gruppen durchzuführen. In Anbetracht der zahlreichen Widerstände, die sich gegen eine Reform der TVA sperrten, konnte Paris politische Rückendeckung aus Brüssel sehr gut gebrauchen: Dle europäische USt-Harmonisierung war "une alde polltique qui n'est pas négligable"34.

Vgl. z.B. Les Echos 2.12.63 u. Le Monde 4.4.64.

33 Bel dem genannten Organ handelt es sich um eine Ständevertretung der Händler, die im Sommer 1963 von der Regierung gegründet worden war mit dem Auftrag, die Modernislerung des Handels im allgemeinen und die Reform der TVA im besonderen zu erörtern. Der Ende 1963 vorgelegte Bericht - auf Betrelben der kleinen Einzelhändler enthlelt er nur eln "Jeln" zur TVA-Reform - enttăuschte die Hoffnungen des Finanzminister und hielt thn davon $a b$, die Arbeiten an dem neuen Gesetzentwurf zu beschleunigen. Vgl. z.B. Les Echos 28.11.63, 29.11.63 u. 2.12.63. 
Insbesondere ab Ende 1963 drängte die französische Reglerung daher auf rasche Fortschritte bel der USt-Harmonisierung mit dem Ziel, das europaische Argument in der innenpolitischen Diskussion nutzbringend elnsetzen zu können. Zugegebenermaßen tauchte der Hinwels aup die europäische Steuerharmonisierung in der Pranzösischen Reformdebatte seltener auf als etwa das Stlchwort Modernislerung des Handels. Da aber der Erfolg der TVA-Reform Jahrelang auf des Messers Schneide stand, kann davon ausgegangen werden, daß das von Reglerungsselte gerne verwandte Harmonlsiedurungsargument - pur viele damals "un mot un peu magic"30 - eine, wenn auch nicht ausschlaggebende, so doch nicht unwesentliche Rolle in Fankreich gesplelt hat.

\subsubsection{Deutschland: die trelbende Kraft}

Mehr noch als die Franzosen machten sich die Deutschen in Brussel fur die USt-Harmonislerung stark. Wahrend die französische Position zur europaweiten Einführung einer MwSt durch binnen- und außenwirtschaftspolitische Zlele $^{36}$ gleichermaßen bestimmt war, war die deutsche Haltung fast ausschlleßlich binnenpolitisch motiviert. Im Laufe elner langen Geschichte der deutschen USt hatte slch in der Bundesrepublik, mehr noch als in Jedem anderen Mitgliedstaat der EG, eln Reformdruck angestaut, der durchgreifende Maßnahmen verlangte, die aber ohne Hilfe der EG innenpolitisch nicht durchsetzbar waren. ${ }^{37}$

\section{Dle Stabilisierung der Bruttoust: $1916-1950^{38}$}

Die Deutschen waren die Ersten in Europa, die, durch den ungeheuren Finanzbedarf des Ersten Weltkrieges dazu gezwungen, 1916 eine 0,1prozentige Bruttoust unter dem Namen Warenumsatzstempel einfuhrten. Da das Aufkommen dieser Abgabe weit hinter den Erwartungen zurückblleb, ersetzte man sle bereits 1918 durch elne 0,5prozentige Umsatzsteuer mit elner nunmehr verbreiterten Bemessungsgrundlage. Nach dem Zusammenbruch des Kaiserreiches ubernahm die Nationalversammlung im Herbst 1919 das UStGesetz von 1918 im wesentlichen unverăndert in dle Weimarer Republik, er-

35 Personliches Interview.

$36 \mathrm{Zu}$ den außenwirtschaftspolitischen Zielen vgl. Kap. B.2.1.

37 Zum Verlauf der deutschen USt-Reformdiskussion vgl. insbes. die Arbeit von Heilmann (1975) sowle die Kurzdarstellung bel Muller (1966). Taussig (1971), S.153ff., widmet sich in erster Linie den Wechselwirkungen zwischen der Einfuhrung der MWSt in Deutschland und der USt-Harmonislerung in der EG. Dle Darstellungen bel Puchala (1984), S.43ff. u. Puchala/Lankowski (1977), S.159ff. bauen im wesentlichen auf den Ergebnissen von Taussig aup.

39 Vgl. z.B. Fischer (1961). Vgl. a. Hübschmann (1956), $146 \mathrm{Pf}$. 
höhte jedoch kräftig den Steuersatz auf 1,5\%. Der Satz wurde bis 1923 in zwel welteren Schritten auf 2,5\% angehoben.

Mit stelgenden Sătzen vergrößerten sich die Nachtelle des kumulativen Systems, und Deutschland erlebte selne erste USt-Debatte: "Dle Geschlchte der deutschen Umsatzsteuer 1st zuglelch die Geschichte ihrer Reform."39 Oder richtiger: Sle ist die Geschichte einer Reformdiskussion. Denn wirklich reformiert hat man bls zur Einfuhrung der MWSt Im Jahr 1968 vergleichswelse wenig. In mehreren Anläufen, jewells pünktlich nach elner Erhöhung des Steuersatzes, tauschten Befurworter und Gegner elner Reform immer wieder im wesentlichen gleichblelbende Argumente aus. Auch die wichtigste Alternative zur kumulativen Bruttoust hatte sich schnell herausgeschălt: Bereits im Jahre 1918 hatte Gehelmrat Wilhelm von Siemens unter dem Namen Veredelte USt die Einfuhrung einer allphasigen NettoUSt vorgeschlagen. ${ }^{40}$ Obwohl es den Deutschen an Konzepten und Argumenten also nicht mangelte, an der bestehenden Bruttoust änderten sle alle für lange Zelt nichts.

Die erste deutsche Reformdiskussion, ausgelobst durch die Satzanhebungen zwischen 1919 und 1923, läßt sich auf die Jahre zwischen 1921 und 1925 datieren. Nach dem Motto "Die Senkung der USt ist ihre beste Veredelung"41 konnte Jedoch der Steuersatz in den Jahren 1924 bls 1926 in mehreren Schritten auf $0,75 \%$ gesenkt werden, was sämtliche Reformbewegungen für das Erste zum Einschlafen brachte. Der deutschen Bruttoust wurde damit, in krassem Gegensatz zum Schicksal Ihrer französischen Leidensgefăhrtin, eine dringend benötigte Verschnaufpause gegönnt. Sle bekam Gelegenheit, sich zu stabilisieren, zu altern und an der Jeder alten Steuer innewohnenden Träghelt zu gewinnen, die sie gegen Angriffe von außen schützt. Der Alterungsproze $\beta$ wurde noch elnmal kurz gefăhrdet, als Anfang der $30 \mathrm{er}$ Jahre dle - in 1932 in die Tat ungesetzte - Absicht der Relchsregierung bekannt wurde, den Steuersatz abermals auf $2 \%$ anzuheben. Die $z$ welte deutsche Reformdiskussion endete zwar mit dem neuen UStGesetz von 1934, das jedoch an der grundlegenden Struktur der BruttouSt nichts veränderte. Nach 1934 wurde dle Reformdebatte dann, von Staats wegen, für einige Jahre ad acta gelegt.

BruttoUSt, "Kleine Reform" oder "Große Reform": 1951-1960

Das USt-Gesetz von 1934 wurde schlleßlich, wiederum im wesentlichen unverändert, in das Steuersystem der neugegründeten Bundesrepublik ubernommen. Nachdem der Steuersatz bereits in 1946 von den Allilerten aup 3\% angehoben worden war, machte der wegen des Wiederaufbaus sprunghaft

39 Hellmann (1975), S.76.

40 Vgl. Siemens (1919).

41 Dieser Ausspruch wird dem damaligen Relchskanzler Luther zugeschrieben, zitlert in: Popitz (1928), S.61. 
angestlegene Finanzbedarp des jungen Staates elne weitere Erhöhung aup nunmehr 4\% erforderlich. Damit war die dritte Runde der Reformdiskussion eingeläutet, die sich, durch einen kontinuierlich hohen Steuersatz von $4 \%$ am Leben erhalten, mit nur kurzen Unterbrechungen bis 1967 fortsetzte. Immer wieder stellte sich in immer neuen Varianten die Frage, ob die Nachtelle der BruttouSt durch elne Reform am System - eine KleIne Reform - hinrelchend abgemildert werden könnten oder ob nicht vielmehr eine Reform des Systems - elne Große Reform - notwendig sel. Die Vertreter der zwelten Auffassung meldeten sich gleich Anfang der 50er Jahre zu Wort. Insbesondere von wissenschaftlicher seite her kam der Vorschlag, die Brutto- durch elne Nettoust zu ersetzen.42 Damit wurde nicht nur an eine Vorkriegstradition angeknupft, sondern auch eine Anregung aufgenommen, die von den Pranzösischen Steuerreformen in 1948 und 1954 ausging. Als Gegner eines Systemwechsels formierten sich die Praktiker unter den Finanzexperten:

\begin{abstract}
"Die Verteidigung des bestehenden Systems ubernahmen in dieser Zelt Past ausschließlich Persönlichkeiten, die nicht als betroffene Unternehmer, sondern als Steuerjuristen und Verwaltungsbeamte mit der Umsatzsteuer zu tun hatten, insbesondere Beamte des Bundesfinanzministerlums, der Finanzgerichtsbarkeit, Kommentatoren des Umsatzsteuerrechts und Steuerberater, Persönllchkeiten also, die ein großes 'geistiges Kapital' in das uberkommene Umsatzsteuerrecht und seine komplizlerten Verfelnerungen investiert hatten. "43
\end{abstract}

Der in erster Linie an der Stabllitat elnes hohen Steueraufkommens interessierte Finanzminister Schaffer zeigte sich von dem Strelt der Experten nur wenig beelndruckt. Er setzte in 1954 eine Kleine Reform durch, die Insbesondere der Aufkommensstelgerung diente. Der "Leldensweg der Umsatzsteuerreform"44 war um eine weitere Station verlängert, aber noch lange nicht abgeschlossen. Obwohl die Gegner der Bruttoust gerade erst begonnen hatten, sich auch im Deutschen Bundestag zu formieren, konnten sle das Plenum dazu bewegen, der Reglerung aus Anlaß der Verabschledung der Kleinen Reform den Auftrag zu ertellen, "..Untersuchungen darüber anzustellen, ob und in welcher Weise eine Anderung des Umsatzsteuerrechts erforderlich ist,.."4s Damit war immerhin gewährleistet, daß sich das Finanzministerium der Diskussion stellen mußte. Die Bundesregierung wartete daraufhin im Dezember 1955 mit elner "Denkschrift uber elne Anderung

42 Als Belspiele selen genannt: Wissenschaftlicher Beirat (1953), Schmölders (1953a), Reischl (1953), Zlerold-Pritsch (1954). Die letztgenannte Arbeit stammt aus der Feder eines Beamten des Finanzministeriums; Zlerold-Pritsch hatte sle schon 1952 fertiggestellt, konnte sie aber, wegen des Desinteresses selnes Ministers, erst nach der Versetzung in den Ruhestand veröpfentlichen.

Hellmann (1975), S.99.

44 Schmölders (1960), S.83.

45 Bundestags-Drucksache II/1924, S.4. 
des Umsatzsteuergesetzes"46 auf, die sich auf Kleine Reformen konzentrierte und nur ganz am Rande die Moglichkelt eines Systemwechsels erwahnte. Die Autoren rechtfertigten ihr Vorgehen mit dem spitzfindigen Hinwels, der Bundestag habe elne Analyse der Reform des USt-Rechts, nicht Jedoch elne des USt-Systems erbeten. Einer der Initiatoren der Bundestagsentschließung kommentlerte dazu spăter:
"..es hat selnerzeit sehr listige Leute gegeben, die es ver- standen haben, diese Entschlleßung geschickt auszulegen, und ich habe sogar den Verdacht, daß sich schon unter den Mit- verfassern dieser Entschlleßung solche listigen Leute befunden haben." 47

Dle an einer durchgreifenden USt-Reform interessierten Krelse - insbesondere die Vertreter des Mittelstandes - reagierten auf die Denkschrift mit herber Kritlk. Sle erzwangen im Dezember 1956 eine zwelte Entschlleßung des Bundestages, in der, diesmal ganz elndeutig formullert, eine Untersuchung über die "..Moglichkeiten des Umbaus des heutigen kumulativen Umsatzsteuersystems in ein nicht kumulatives Umsatzsteuersystem.."48 verlangt wurde. Wahrend die Denkschrift noch in Arbeit war, wurde, nach den Neuwahlen Ende 1957, Finanzminister Schäfer durch den ehemaligen Vizepräsidenten der Hohen Behörde Etzel ersetzt. Etzel, der dem Mittelstandsflügel seiner Partel nahestand, brachte elner Großen Reform wesentlich mehr Sympathien entgegen als sein Vorgănger. Selner Einflußnahme ist es zu verdanken, daß die im Dezember 1958 veröffentlichte zweite Gedenkschrift49 eine "Art Stoffsammlung zum Thema Umsatzsteuer"so - nur noch eine unwesentliche Tendenz zugunsten der althergebrachten Brutto-USt erkennen ließ. ${ }^{01}$ Zugleich ergriff Etzel die politische Initiative und betraute im Verlauf des Jahres 1959 insgesamt drel Ausschüsse mit der Arbelt an einer Großen USt-Reform:

- Die Kommission zur technischen Prüfung der Umsatzsteuer-Reformvorschläge analyslerte insgesamt eln Dutzend verschledene Ansatze, die in den vergangenen Jahren fur elne große Reform vorgeschlagen worden waren. Der Anfang 1960 veroffentlichte Abschlußbericht ließ, wohl nicht zuletzt beeinflußt durch das Votum des Ausschußvorsitzenden Habschmann - er war Mitverfasser des UStGestzes von 1934 -, durchblicken,

46 Bundestags-Drucksache II/1924.

47 Kurlbaum (1958), S.61. Es bleibt zu ergănzen, daß besagte Entschllessung vom Vorsitzenden des Unterausschusses USt Eckhardt, selnes Zelchens Steuerberater und Anwalt Pur Steuerrecht, in Zusammenarbeit mit den Beamten des Finanzministeriums verfaßt worden ist; vgl. Heilmann (1975), S.112f.

48 Bundestags-Drucksache II/2234.

49 Bundestags-Drucksache III/730.

so Industrie Kurier 18.12.58.

51 Vgl. Hellmann (1975), S.122ff. 
daß er für die Beibehaltung der altbewăhrten BruttouSt eintrat. Er kam aber auch zu dem Ergebnis, daß, falls eine Große Reform einmal angestrebt werden sollte, die MwSt die beste aller Alternativen sel. ${ }^{52}$

- Der Wissenschaftliche Belrat beim Finanzministerium wurde ebenfalls gebeten, elnen Vorschlag für eine USt-Reform zu unterbreiten. Auch wenn die Professoren ihr Gutachten aus Zeitgründen erst 1962 fertigstellen konnten, so war doch von vornherein klar, daß sie sich, ganz in Ubereinstimmung mit der von Ihnen schon in 1953 abgegebenen Empiehlung, für eine MwSt aussprechen würden. ${ }^{33}$

- Als drittes Gremium beauftragte Etzel die aus Finanzexperten und einer repräsentativen Auswahl von Unlonsabgeordneten zusammengesetzte Arbeltsgruppe USt-Reform, das polltische Umfeld für eine Große Reform auszutasten. Der unter Vorsitz des Staatssekretärs a.D. Hartmann Hartmann war ebenfalls an der Abfassung des UStGestzes von 1934 betelligt gewesen und war, whe sein Prüherer Kollege Hubschmann, erklärter Verteldiger der Bruttoust - tagende Ausschuß stellte Pest, daß eine Große Reform wăhrend der laufenden Legislaturperiode in der Bundestagsfraktion der Reglerungspartelen nicht mehrheitsfahig sel. Zwar machte sich der Arbeitskrels Mittelstand der Unlonsfraktion für eine solche Reform seit langem stark. Inm gegenuber standen aber die sogenannten Finanzexperten der Partel, die unter allen Umstănden an der Bruttoust festhalten wollten.94

Finanzminister Etzel ließ sich von dem negativen Resultat des HartmannBerichts nicht den Mut nehmen. Er gab, um die Debatte uber die Große Reform weiter voranzutreiben, seinen Beamten den Auftrag, einen Entwurf fur ein MWSt-Gesetz auszuarbeiten. Aber bevor das Papler Im August 1960 veroffentlicht werden konnte, ${ }^{\Delta B}$ war es am $27 . J u l l$ in einer etwas mysterios anmutenden Kabinettsitzung vom Tisch gefegt worden: "Nach kurzer Erörterung hat das Kabinett diese Studie als nicht geelgnet angesehen, als Diskussionsgrundlage verwertet $\mathrm{zu}$ werden"s6 - soweit die Verlautbarung der Bundesreglerung.

Was war geschehen? Der Kanzler hatte von der Arbeit seines Finanzministers Wind bekommen und die Sache kurzfristig auf die Tagesordnung setzen lassen. Der "..auf das Wăhlervolk eingepeilte.."97 Adenauer be-

82 Vgl. Wilhelml (1960).

53 Vgl. Wissenschaftlicher Beirat (1962). Vgl. a. Mersmann (1963b), S.2ff. Zum Hartmann-Bericht vgl. z.B. Mersmann (1964b).

so Bundesministerium der Finanzen, Studie zu elner Mehrwertsteuer mit Vorsteuerabzug in der Form eines Gesetzentwurfes mit Erlauterungen, Bonn 1960. Vgl. a. Wallis (1960).

B6 Erklärung der Bundesregierung, zitlert in: Splegel 10.8.60.

s7 Splegel 10.8 .60 . 
Pürchtete Preisstelgerungen, und sein Außenminister schreckte vor elner Belastung der Bezlehung zu Frankreich zurück, die der mit der MwSt unweigerlich verbundene Abwertungseffekt der Mark verursacht häte. Den Ausschlag düfte das Votum von Wirtschaftsminister Erhard gegeben haben, der angesichts der Hochkonjunktur und stelgender Exportuberschusse eine steuerllch bedingte Abwertung nicht gebrauchen konnte. Dle MwSt paßte in die wirtschaftliche und politische Landschaft des Jahres 1960 nicht hinein und wurde daher fallengelassen wie eine heiße Kartoffel.

Die zentralen Argumente: zum Stand der Diskussion in 1960

1. Im Verlaup der 50er Jahre hatten die Deutschen die Frage Bruttoust oder Kleine Reform oder Große Reform ausfuhrlich diskutlert. Ein erstes wichtiges Ergebnis der Debatte bestand in der Erkenntnis, daß elne Große Reform der USt, wenn sle uberhaupt in Frage kam, nur die Einfuhrung einer MWSt bedeuten konnte. Das war insofern kelne Uberraschung, als es sich bel der Mehrzahl der im Hubschmann-Ausschuß analysierten Alternativen um Pragwurdige Kompromißlösungen zwischen einer Bruttoust auf der einen und einer neutralen MWSt auf der anderen Seite handelte. Oberraschend war allein die Tatsache, daß die Deutschen elner einphasigen USt, erhoben auf der Einzel- oder der Großhandelsstufe, nur geringe Beachtung schenkten. Immer wieder betonten deutsche Finanzexperten, daß elne Einphasensteuer technisch viel schwleriger zu erheben sei als elne MWSt. Dlesem Argument vermochten Experten anderer Länder - sle gingen von der genau entgegengesetzten Annahme aus - nicht zu folgen:

"On the whole, the knowledge of the operation of single stage sales taxes on the part of the German experts in the sales tax field appears to be very limited; much of the condemnation of this form of tax is based on imaginary evils which are not significant in practice." 38

Aber selbst wenn man die verwaltungstechnischen Bedenken der Deutschen gelten laßst, so vermögen sle alleine noch nicht zu erklären, warum die Einphasensteuer schon sehr früh aus der deutschen USt-Reformdebatte ausschled. Dle ausgesprochene Abnelgung der Deutschen gegen elnphasige Abgaben ist denn auch weniger auf objektive Gründe denn auf subjektive Voreingenommenheiten und politische Erwăgungen zuruckzufuhren:

- Die Steuerfachleute Innerhalb und außerhalb der öfentlichen Admintstration zogen elne mehrphasige gegenuber einer einphasigen Abgabe vor, weil sich die im Rahmen der Bruttoust berelts verwandten Rechtsbegriffe ohne größere Probleme zu einer allphasigen MWSt hinuberretten ließen.

- Der Ubbergang von elner mehr- zu elner einphasigen USt schien polltisch nicht durchsetzbar, da die gesamte Steuerzahllast von der Indu-

s8 Due (1957), S.70. 
strle weggenommen und allein dem Handel als "schwăchstem Glled der Kette"59 aufgebürdet worden wäre.

Selbstverstandlich sind Zahllastverglelche aus ökonomischer Slcht blanker Unfug. Der Okonom orientiert sich an der effektiven Inzldenz, die, bestimmte Annahmen vorausgesetzt, bel einer MWSt und einer EinzelhandelsUSt vollkommen identisch sind. Trotzdem wurde die politische Diskussion, wle später nochmals deutlich werden wird, von Zahllastvergleichen domlniert. Der Grund ist einfach: Das Konzept ist zwar falsch, dafur aber wesentlich leichter verständlich.

2. Die eingangs formulierte Fragestellung hatte sich damit auf das Problem BruttoUSt oder Klelne Reform oder MWSt reduziert. Geschwăcht wurde die Front der Befurworter der MwSt immer wleder durch dle bel den verschiedensten Gruppen genährte Hoffnung, Im Rahmen Kleiner Reformen elne Verbesserung fur sich selbst verbuchen und damit "..die Nachtelle des Systems in individuelle Vortelle verwandeln zu können."Bo Noch in den 20er und 30er Jahren stand die Finanzverwaltung Kleinen Reformen ganzlich ablehnend gegenüber. Sle befürchtete vollkommen zu Recht: "Der Urinstinkt des Egolsmus würde Orglen felern."61 Erst als in der Nachkriegszelt die nach elner durchgrelfenden Reform der BruttouSt rufenden Stimmen lauter wurden, zelgte sich die Administration aufgeschlossener gegenuber Kleinen Reformen, sah sle darin doch praktlsch die elnzige Möglichkelt, dle von ihr hochgeschătzte Bruttoust gegen die zunehmenden Angriffe der Systemveranderer zu verteidigen.

Aber der Weg kleinerer Abänderungen der Bruttoust konnte in Deutschland, wle wahrend der 50er Jahre rasch deutlich wurde, nicht zum Erfolg fuhren. Diese Erfahrung hatten die Franzosen schon zwischen 1920 und 1936 machen müssen. Und da die Größe Deutschlands und die Komplexität seiner Wirtschaftsstruktur der des Nachbarlandes vergleichbar waren, bestand kein Anlaß fur den Glauben, daß den Deutschen mehr Glück beschleden sein sollte. Im Gegentell: Die Deutschen hatten, vergllchen mit den Franzosen, noch eln zusătzliches Problem, daß ihnen den erfolgrelchen Elnsatz von taxes uniques, Zusatzsteuern und ăhnlichen Instrumenten von vornhereln unmöglich machte. Das Problem bestand, wie im Polgenden zu zeigen ist, in Art.80 des Grundgesetztes der Bundesrepublik.

\& 8 des UStGesetzes von 1934 - vergleichbare Bestimmungen gab es auch in anderen Låndern - ermächtigte die Regierung, "..Maßnahmen zum Ausglelch der verschledenen Umsatzsteuerbelastung der elnstufigen und mehr-

\footnotetext{
59 Mersmann (1959b), S.372. Vgl. ăhnl. Dichgans (1963), S.196.

so Pohmer (1960), S.62. Vgl. ahnl. Lutzke (1967), S.110r.

61 Popitz (1928), S.13.
} 
stufigen Unternehmen zu treffen."62 Dle genannte Ermächtigung wurde in das USt-Gesetz von 1951 ubernommen und dazu benutzt, um eine Zusatzsteuer fur sämtliche Lieferungen elnzufuhren, die von Herstellern direkt an Letztverbraucher gehen. Rasch kamen jedoch Zweifel darluber auf, ob die der Reglerung in $8 \quad 8$ UStGesetz gegebene Blankovollmacht mit dem im Grundgesetz der Jungen Republik nledergelegten Prinzip der Gewaltentellung zu vereinbaren war. Art.80 Abs.1 Satz 2 GG schreibt nămlich vor, daß "..Inhalt, Zweck und Ausmaß der erteilten Ermächtigung im Gesetz bestimmt werden müssen". In voller Ubereinstimmung mit der damaligen Aupfassung der Finanzverwaltung entschied der Bundesfinanzhof, Art.80 GG dürfe Im USt-Recht nicht zu eng ausgelegt werden, man musse vielmehr der Exekutive den nötigen Handlungsspielraum lassen. ${ }^{63}$ Dem jedoch widersprach das Bundesverfassungsgericht in einem Urtell vom 5.Mărz 1958. In Steuergesetzen, so die Richter, músse man ganz besonders strenge Maßstäbe an die Erfullung des Art.80 GG anlegen; $\$ 8$ UStG entspreche dem nicht und sel daher verfassungswidrig. ${ }^{64}$

Damit hatte das Verfassungsgericht noch nicht jede Zusatzsteuer verboten. Es hatte lediglich festgestellt, $d a \beta$ es nicht genüge, Im Gesetz allein das Zlel (Gleichbehandlung eln- und mehrstufiger Betriebe) niederzulegen und der Exekutive die Wahl der Mittel (Einführung konkreter Zusatzsteuern) zu uberlassen. Nach wie vor schien also die Möglichkelt zu bestehen, Zusatzsteuern per Gesetz einzufuhren. Hier lief man jedoch Gefahr, durch die gesetzliche Festlegung der Mittel die Anpassungsflexibilitat eines Systems von Zusatzsteuern derart zu vermindern, daß das Zlel selbst (dle Glelchbehandlung) nicht mehr hätte errelcht werden können. Konflikte mit Art.3 GG (Glelchheltsgrundsatz) wären damit vorprogrammiert gewesen.6s Der deutsche Gesetzgeber befand sich also in einem klassischen Dilemma. Der Versuch, in langwierigen Auseinandersetzungen mit den Gerichten den $\mathrm{zwl}$ schen Art.3 und Art.80 GG Pur Zusatzsteuern noch bestehenden Splelraum auszuloten, hătte viel Zeit gekostet und wäre mit einer erheblichen Unsicherhelt für die betroffenen Unternehmen einhergegangen. Andere Instrumente wie z.B. die Pranzösischen taxes uniques hätten ăhnliche Probleme aufgeworfen und kamen daher ebenfalls nicht in Frage. Der Weg kleinerer Reformen der Bruttoust war den Deutschen damit de facto versperrt.

3. Wir können Pesthalten, daß sich bis 1960 das Problem BruttouSt oder MWSt als die KernPrage der deutschen USt-Reformdiskussion herauskristall1slert hatte. Die Frage war so alt wle die deutsche USt selbst. Die wichtig-

62 Zur Geschichte und Bedeutung der genannten Vorschrift vgl. z.B. Eckhardt (1957).

63 Zum zitierten Urteil des BFH vgl. Schmölders (1958), S.395.

o4 Vgl. hlerzu Schmölders (1958).

6o Vgl. z.B. Plúckebaum/Molitzky (1966), Bd.2, S.483ff. Vgl. a. Lutzke (1967), S.111 u. Wallis (1960), S.169. 
sten Argumente pro und contra fanden sich bereits in der "Denkschrift der Reichsreglerung uber eine Abänderung der jetzlgen Umsatzbesteuerung"66 vom 27.Jull 1924. Auch wenn die gegen die MWSt vorgebrachten Einwände unhaltbar waren, hielt das die Verteidiger der alten und bis $1960 \mathrm{~lm}$ wesentlichen unveränderten Bruttoust nicht davon $a b$, sie im Laufe der $50 \mathrm{er}$ und bls weit in die 60er Jahre hinein in immer neuen Variationen aufzuwärmen. Schauen wir uns die belden wichtigsten der vermeintlichen Argumente ein wenig năher an.

Eine erste Gruppe von Einwänden beruhte auf einem schlichten Mißverständnis daruber, wie sich die MWSt auf die Wirtschaft auswirkt. Großer Beliebtheit erfreute sich dabel insbesondere ein Argument, das in Kurzfassung etwa wie folgt lautet: $\mathrm{Da}$ kapitalintensive Betriebe viel, arbeltsintensive Betriebe aber wenig Vorsteuer abzuziehen haben, diskriminiert eine MWSt die arbeitsintensive Produktion.67 Ohne hier auf die zahlreichen Verirrungen elngehen $\mathrm{zu}$ wollen, die in dieses Argument Eingang gefunden haben könnten, ${ }^{60}$ ist hervorzuheben, daß die Argumentation auf einem elnfachen Zahllastverglelch von Brutto- und NettoUSt beruht. So Palsch Zahllastvergleiche sind, so populär waren sle wăhrend der gesamten USt-Debatte, sind sie doch mit erheblich weniger geistigem Aufwand verbunden als saubere Analysen der effektiven Steuerinzidenz. Breiten Raum nahmen sie ein in der von Schmölders als "volkswirtschaftliche Anfängerarbeit"69 abqualifizlerten Denkschrift der Bundesregierung von 1955. Auch in der Denkschrift von 1958 und selbst in dem späteren deutschen MWSt-Gesetzentwurp panden sle sich wieder. So rechnete belspielswelse das Finanzministerium aus, daß unter der Annahme eines MwSt-Satzes von 10\% sämtliche Betriebe mit elner Wertschoppungsquote - Antell der Wertschöpfung am Umsatz - von über 41,7\% durch eine MWSt höher belastet würden als durch eine Bruttoust. ${ }^{70}$ Daraufhin machte sich eine große Anzahl von Verbănden mit großem Eifer an die ökonomisch vollkommen unsinnige Beschäftigung, die durchschnittlichen Wertschöplungsquoten Ihrer Mitgliedsunternehmen auszurechnen. Diese öffentliche Konfusion um die MWSt wurde, wenn uberhaupt, erst kurz vor Einfuhrung der MwSt beseltigt. Konnte sie das Kommen der MWSt auch letztendlich nicht verhindern, so verzögerte sie doch nachhaltig den Proze $\beta$ der politischen willensbildung.

Eine zweite Gruppe von Einwänden stellte administrative Uberlegungen in den Vordergrund: "..Im Mittelpunkt allen umsatzsteuerlichen Tuns muß die

so Deutscher Relchstag, Drucksache II/558. Vgl hierzu a. Hellmann (1975), S.87Pf.

67 Entsprechende Gedanken Panden sich z.B. in der Begründung des UStGesetzes von 1934, vgl. z.B. Hellmann (1975), S.90. Vgl. z.B. Schmidt (1963), S.49.

Hellmann (1975), S.117.

Vgl. Hellmann (1975), S.62fp. 
Verwaltung stehen."71 Dle alte BruttouSt sei, so wurde behauptet, wesentlich einfacher zu verwalten als eine MWSt. Wenn auch der Wahrheitsgehalt des genannten Argumentes nicht eindeutig widerlegt werden konnte, so waren doch $\mathrm{Zwelfel}$ an seiner Stichhaltigkeit angebracht. Die wiederholten Versuche, die Bruttoust durch kleinere Modiflkationen vor Kritik zu schüzen, hatten $\mathrm{zu}$ elner erheblichen "..Durchlöcherung und Komplizierung des in seinen Grundzugen klaren und einfachen Gesetzes von $1934 \quad$. ."72 gefuhrt. Man Ist daher genelgt, das gegen die MWSt vorgebrachte Verwaltungskosten-Argument mit einer gewissen skepsis zu beurtellen: "Ihre technischen Schwlerigkeiten dürften wohl Im wesentlichen daran llegen, daß die MWSt neu und unbekannt, die kumulative Allphasensteuer dagegen alt und bekannt ist." 73

\title{
BruttoUSt versus MWSt: $1960-1967$
}

Da Kleinen Reformen der Bruttoust, wie gezeigt, in Deutschland äußerst enge Grenzen gesetzt waren, hatte sich bis 1960 eln erheblicher Reformbedarf angestaut. Allein er war noch nicht stark genug, als daß er die Zögerer in der Bundesreglerung dazu hätte bewegen können, den großen Sprung von der altbekannten BruttouSt zu der völlig neuen MWSt zu wagen. An Kritikern der BruttouSt mangelte es nicht. Aber die Zahl derer, die entschieden für einen Ubergang zur MwSt eintraten, war noch viel zu gering. Die Spitze des Finanzministeriums hatte sich an der MWSt die Finger verbrannt und war $\mathrm{zu}$ welteren Initiativen vorerst nicht bereit. Die Mittelstandler in der Unionsfraktion konnten sich gegen ihre als Finanzexperten auftretenden Kollegen nicht durchsetzen. Und die Wissenschaftler schlleßlich waren alleine viel zu schwach:

\begin{abstract}
"Dle Gegner elner systemändernden Neuordnung der deutschen Umsatzbesteuerung...verschanzen sich hinter Nebensächlichkelten, abwegigen Argumenten und vor allen Dingen vermeintlichen 'Erfahrungen', die durch ihre Vielzahl und das ständige Wiederholen zwar nichts an Stichhaltigkeit gewinnen, dapur aber die Opfentlichkeit mehr beeindrucken als das Urtell der zuständigen wissenschaftlichen Disziplinen. Diese Propaganda wird wirksam durch das Mittel unterstutzt, die wissenschaftliche Forschung als das Werk ehrbarer und verdienstvoller, aber weltfremder Trottel hinzustellen,.."74
\end{abstract}

Das Im Jull 1960 ausgesprochene Neln des Kabinetts zur MWSt bedeutete daher das vorlăufige Aus für die MWSt-Debatte. In Deutschland verbesserten sich auch nach den Wahlen von 1961 nicht die Aussichten für elne baldige Wiederaufnahme der Reformdiskussion aus elgener Kraft. Im Gegentell nahrte ein kurz vor der Wahl noch schnell auf den Weg gebrachtes

\footnotetext{
71 Habschmann (1956), S.151.

72 Muller (1966), S.291.

$73 \quad$ Rqu (1963), S.31.

74 Pohmer (1960), S.51.
} 
11.UStAndG bel manchem noch elnmal die Hoffnung, sich mit elner Politik der kleinen Geschenke eine weitere Legislaturperiode durchwursteln und damit die Große Reform auf dle lange Bank schieben zu können. Hinzu kam, daß nach der Wahl mit Minister Etzel der bekannteste Befürworter der MwSt das Finanzministerium verließ. Die konservativen und auf die Beibehaltung der Bruttoust hinarbeitenden Krafte der Finanzverwaltung drohten, Im Ministerium wieder die Oberhand zu gewinnen. Auch dle Wirtschaft ruhrte sich nicht. Diejenigen Branchen der deutschen Industrie, in denen die vertikale Integration bereits weit fortgeschritten war - z.B. Chemie, Elektronik, Mineralöl - profitlerten von der BruttouSt. Da der Bundesverband der Deutschen Industrie Streit $\mathrm{zwischen}$ den Mitgliedern vermeiden wollte, zog er es vor, sich zur MWSt nicht zu außern.79 Der Großhandel und die Landwirtschaft lebten mit den ihnen unter der Bruttoust gewährten Privileglen - reduzierter Steuersatz bzw. Steuerbefreiung - recht gut und sahen daher ebenfalls keinen Anlaß, sich für die MwSt stark zu machen. Und die Mehrzahl der Unternehmen, die Nutznleßer der MwSt gewesen wären, schwlegen elnfach. Von seiten der Wirtschaft waren also, das war klar, Initiativen nicht zu erwarten: "Dle Unternehmen Pangen erst an zu uberlegen, wenn ein Gesetzentwurf aup sie zukommt."76 Insgesamt schien Mitte 1962 dle Einfuhrung elner MwSt in weite Ferne gerulkt zu sein.

Eln Vorsto $\beta$ zur Wlederbelebung der Reformdebatte kam in der zweiten Hälfte 1962 von den Mittelständlern im Deutschen Bundestag. ${ }^{n}$ Ein Tell der Unionsfraktion sowle die geschlossene SPD-Fraktion legten im Oktober bzw. November zwel MWSt-Gesetzentwurfe vor, die die Bundesregierung zu einer Stellungnahme provozieren sollten. Sie wurden ergänzt durch Große Anfragen der SPD- und der FDP-Fraktion. Zunächst schien es, als selen diese neuerlichen Inltiativen allesamt zur Erfolglosigkeit verdammt:

- Die Gesetzentwürfe der Abgeordneten enthielten zahlreiche Konzessionen an Kleinunternehmen, die Landwirtschaft und die frelen Berufe. Dle Verwirklichung eines derart von interessenspolltischen Standpunkten geprägten Konzeptes war weder wünschenswert noch wahrscheinllch.

- Der damalige Finanzminister Starke äußerte sich "betont vorsichtig"78 zu einer durchgrelfenden USt-Reform. Er scheute das mit einer umfassenden Reform verbundene Risiko und lle $\beta$ die parlamentarischen Anfragen zur USt wochenlang in seinem Schreibtisch verschwinden.

Die deutsche Reformdiskussion befand sich, wie schon in 1960, in einer kritischen Phase. Noch fehlte eln entscheldender Anstoß, der die Reglerung

70 Zur willensbildung innerhalb des BDI vgl. Braunthal (1965), S.257ff.

76 Persönliches Intervlew.

$n$ Vgl. Mersmann (1963b), S.2ff.

78 FAZ 14.3.62. Vgl. a. Welt 23.8.62. 
dazu hătte veranlassen können, den Sprung ins kalte Wasser zu wagen und sich hinter die MWSt zu stellen. Der Anstoß kam, auf zwel ganz verschiedenen Wegen, aus Brüssel:

- Unbemerkt von der OPfentlichkeit hatten die mit der USt befaßten Beamten des Finanzministeriums ihre Auffassung zur MwSt selt 1960 grundlegend gewandelt. Nach langen Gesprăchen mit ihren Kollegen aus anderen Ländern sahen sle ein, daß den Nachtellen der BruttouSt mit Kleinen Reformen nicht belzukommen war. Sie begannen, die Funktionswelse der komplizierten MWSt langsam zu verstehen: "Abends saßen wir bel einem Bier in Brüssel und spielten, mit einem Mark- und einem 10Pfennig-Stück auf dem Tisch, den gesamten Wirtschaftszyklus durch: Besteuerung $=10-$ Pfennig-Stück hinzu, Vorsteuerabzug $=10-$ PfennigStück wieder weg, etc."79 Langsam kamen die Experten unter sich zu einer positiven Bewertung der MWSt. Nach Abschluß der Ausschußberatungen war es nur noch elne Frage der Zeit, bis die Kommission mit einer entsprechenden Richtlinie aufwarten würde. Die deutschen Deleglerten, wieder zurück in Bonn, drängten daher ihren Minister, dem Parlament so bald als möglich einen MWSt-Gesetzentwurf zu unterbreiten: "Wenn schon eine MWSt kommen wird, dann ist es besser, wir marschieren voran." 80 Mit einem fertigen Gesetzentwurf in der Hand hoffte man, sich elnen gewichtigen Einfluß auf die Brüsseler Verhandlungen $\mathrm{zu}$ sichern, wenn es dort einmal an die Frage der gemeinsamen Anwendungsmodalitäten für die MwSt ging.

- Den parlamentarischen Initiativen Im Bundestag wurde nachhaltig der Rücken gestärkt durch die Ende 1962 in der Opfentlichkeit bekanntgewordenen Plăne der Kommission, in der gesamten EG eine MWSt einzuPühren. ${ }^{11}$ Die Bundesreglerung verschob, nicht zuletzt um die Vorschläge der Kommission abzuwarten, die durch die Großen Anfragen notwendig gewordene Bundestagsdebatte auf Februar 1963.82 Das gab den politischen Entscheidungsträgern Zeit, die sich abzeichnende europäische Entwicklung in ihre Meinungsbildung einfließen zu lassen. Europäische Erwägungen trugen entscheldend dazu bel, daß die Finanzexperten der CDU/CSU-Fraktion Im Januar 1963 ihren langjährigen Widerstand gegen die MwSt aufgaben. Ein entsprechender Beschluß des Arbeitskreises Finanzen und Steuern der Unionsfraktion signalisierte der Regierung, daß die MwSt nunmehr in der gesamten Fraktion mehrheitsfăhig war. ${ }^{23}$

\footnotetext{
79 Persönliches Interview.

- Personllches Interview.

81 Vgl. z.B. FAZ 11.7.62.

82 Vgl. Trussig (1971), S.168.

Q3 Vl. Handelsblatt 24.1.63.
} 
Gedrängt von selnen Beamten und ermutigt durch das positive Votum der Unionsfraktion entschloß sich der im Dezember 1962 neu ins Amt eingeführte Finanzminister Dahlgrün, die Initiative zu ergreifen. In elner am 15. Februar 1963 abgegebenen Reglerungserklärung gab er bekannt, daß er eine MWSt einzufüren gedenke. Gleichzeitlg forderte er, daß die Arbeiten an der europäischen USt-Harmonislerung unbedingt beschleunigt werden müßten. Damit verslcherte er slch politischer Rückendeckung aus Brussel, die er in Bonn bitter nötig hatte. Denn nach wie vor gab es zahlreiche Widerstandsnester, die sich gegen die MWSt zur Wehr setzten.

Widerstand kam zum einen, wie schon in all den Jahren zuvor, von seiten der Finanzverwaltung. Zwar hatten sich inzwischen wichtige Mitarbeiter des Bonner Ministeriums, bedingt durch ihre Einbindung in die Brusseler Verhandlungen, für die MWSt entschleden. Das galt jedoch nicht pür die Finanzbeamten draußen im Lande. Deren Meinung kam recht deutlich zum Ausdruck in der Stellungnahme, die der Finanzausschuß des Bundesrates im Oktober 1963 zur MWSt abgab: Das sich aus Vertretern der Landerfinanzministerien zusammensetzende Gremium lehnte die MwSt rundweg ab. Es war der "dringenden Empfehlung"ø des saarländischen Finanzministers Senf das Saarland hatte während der Zeit unter französischer Verwaltung bereits mit der MWSt gearbeitet - zu verdanken, daß der Bundesrat sich doch noch zu einer Zustimmung durchringen konnte.

Darüberhlnaus erhob sich nach der Vorlage des MWSt-Gesetzentwurfes im Sommer 1963 - erwartungsgemăß - das Wehgeschrel weiter Telle der deutschen Wirtschaft.os Die Strategie der Unternehmer zielte nicht darauf ab, die MWSt zu verhindern: Dle Verbände elnzelner Branchen waren zu schwach, als daß sle die MwSt erfolgreich hätten aufhalten können, und die Spitzenverbände der Wirtschaft verzichteten, um interne Streitigkeiten zu vermeiden, auf elne grundsätzliche Stellungnahme. Das Bestreben der Unternehmer war vielmehr darauf gerichtet, dle ihnen im Rahmen der BruttoUSt gewăhrten Privilegien so gut es ging in die neue Steuer hinuberzuretten. Jede Sonderregelung bedrohte das Steueraufkommen und führte zu einer unnotigen Komplizierung der MWSt. Finanzminister Dahlgrun und Wirtschaftsminister Erhard versuchten daher Hand in Hand, die von der Wirtschaft und auch von einigen Ministerkollegen vorgebrachten Sonderwunsche abzuwehren. Dahlgrün drängte in Brüssel persönlich und immer wieder darauf, die Anwendungsmodalităten der gemeinsamen MWSt zügig auszuarbeiten. Er brauchte den Rückhalt der EG, um innenpolitischem Druck lelchter widerstehen zu können: Je weniger Freirăume die 2.USt-Richtlinle ließ, desto weniger gab es in Deutschland zu debattieren.

Der MWSt-Gesetzentwurf wurde, wle schon gesagt, im Sommer 1963 von der Bundesregierung vorgelegt. Der Finanzausschuß des Bundestages nahm im

o4 Zierold-Pritsch (1964), S.73. Vgl. a. Hellmann (1975), S.212ff.

Bo Zum MWSt-Gesetzentwurf vgl: z.B. Zlerold-Pritsch (1964), S.73Pf. 
Frühjahr 1964 selne Beratungen aup, mußte sle aber schon im Juni wegen anderer wichtiger Vorlagen unterbrechen. Im Hinblick auf die in 1965 anstehenden Wahlen tat sich auch in diesem Jahr nicht viel. Erst Anfang 1966 ging es weiter. Nach einem großen Hearing der Verbände im Juniø war die Entscheldung für dle MWSt relf. Ein Zurück zur Bruttoust wurde nach langjăhriger Debatte Immer undenkbarer. ${ }^{87}$ Es wurde schließlich ganz und gar unmöglich, nachdem das Bundesverfassungsgericht im Dezember 1966 entschieden hatte, daß die Bruttoust gegen das Gleichheitsgebot des Grundgesetzes verstoße und daher baldigst durch eine neutrale USt ersetzt werden müsse. Das MWSt-Gesetz wurde im April 1967 verabschledet und, da 1969 schon wieder Wahlen anstanden, bereits zum 1.Januar 1968 in Kraft gesetzt.

\section{Europs und die Deutschen}

Die Brüsseler Harmonisierungsverhandlungen und die deutsche MwSt-Diskussion standen, und zwar in jeder Phase des Melnungsbildungsprozesses, in elner außerst engen Wechselbezlehung. ${ }^{99}$ Nachdem sich im Verlauf der 50er Jahre herauskristallisiert hatte, daß die deutsche BruttouSt nur durch einen Ubergang zur MWSt reformiert werden konnte, war die Richtung der europäischen USt-Harmonislerung vorgezelchnet. Da die Kommission zur Verwirklichung threr weitreichenden Pläne einen gewichtigen Koalitionspartner brauchte, Frankreich elne rudimentare MWSt schon hatte und die Benelux-Lander und Italien elne Reformdiskussion uberhaupt noch nicht kannten, konnte die europäische USt nur MWSt heißen. Der deutsche Finanzminster Etzel förderte 1959/60 dle MWSt-Pläne der Kommission aus innenpolitischen Gründen und wollte die MWSt in Deutschland nicht zuletzt auch wegen Europa.

Das Im Jull 1960 ausgesprochene Neln der Bundesregierung bedeutete, zumindest auf der Ebene der politischen Entscheidungsträger, das vorläufige Ende der deutschen Reformdebatte. Es bedeutete aber nicht, daß die Deutschen keine Notwendigkeit mehr zu einer USt-Reform gesehen hätten. Im Gegenteil: In keinem anderen Land der EG waren die Nachtelle der bestehenden USt stärker spürbar. Der deutschen BruttoUSt wurde ein Aupkommen abverlangt, das, relativ zum Sozlalprodukt gesehen, damals nur noch von der französischen MWSt übertropfen wurde. Aup der anderen Selte war es den Deutschen, Im Gegensatz zu allen anderen EG-Staaten, nur sehr begrenzt möglich, die kumulativen Effekte der BruttoUSt durch kleinere Modiflkationen abzumildern. Aus der Diskrepanz zwischen elnem hohen Steuersatz auf der elnen und einem seit 1918 im wesentlichen unverănderten

\footnotetext{
* Vgl. Rau (1966), S.1691.

87 Vgl. Maller (1966), S.294.

o Vgl. Juretzek (1967a).

e9 Vgl. Strauß (1967), S.144. Vgl. a. Mersmann (1963b), S.2.
} 
USt-System auf der anderen Selte resultierte eln erheblicher Reformbedarf. Die Reformdiskussion konnte daher von der Bundesreglerung nur vorübergehend unterdruckt werden.

Whahrend die Debatte in Bonn verstummt war, ging sie In Brüssel weiter, und zwar, was sich später als wichtlg herausstellen sollte, unter der Betelligung deutscher Finanzbeamter. Die Kommission konnte thre Arbelten abschließen, bevor die deutsche Reformdiskussion mit den parlamentarischen Initiativen von Ende 1962 ans Tageslicht zurückkam. Nun war dle EG in der Lage - direkt uber Ihren Richtlinienvorschlag und indirekt uber die in Brüssel zur MWSt ubergelaufenen Bonner Beamten -, den Deutschen den letzten Ansto $\beta$ zu geben, der nötig war, damit die Bundesreglerung den großen Sprung von der archaischen BruttouSt zur neuen MWSt wagte.

Ab der Regierungserklärung von Finanzminister Dahlgrun im Februar 1963 waren Bonn und Brüssel auf Gedelh und Verderb aufelnander angewlesen. Dle Kommission brauchte die Deutschen als treibende Kraft, um die MWSt gegenuber den zögernden Mitgliedstaaten durchsetzen zu können. Umgekehrt benötigte Bonn die 1.USt-Richtlinie, um denen, die die MWSt als weltere "Vorleistung Deutschlands im Interesse des Gemeinsamen Marktes"so hinstellten, den Wind aus den Segeln nehmen zu können. Und Bonn wollte möglichst schnell eine 2.USt-Richtlinie, um das in Brüssel entwickelte und von der Bundesreglerung in ihrem Gesetzentwurf fur gut befundene Konzept elner neutralen MWSt gegen die Durchlöcherungsversuche der unzähligen Interessengruppen wirksam verteidigen zu können.

9o Beck (1962), S.188. 


\subsubsection{Belgien: ein Mitläufer}

Wăhrend Franzosen und Deutsche die europaweite Einfuhrung einer MWSt befürworteten und bel der Kommission auf rasche Fortschritte drängten, zeigten sich die Belgier zunächst sehr zurückhaltend. Als sich dann aber unter den Mitgliedstaaten eine klare Mehrhelt zugunsten der MWSt abzuzelchnen begann, gaben auch die Belgler, ohne daß es dazu eines besonderen Druckes der anderen bedurft hätte, schlleßlich thre Zustimmung. Die Belgler gehörten nicht zu den ersten, die Ja zur MWSt sagten, waren aber auch nicht die letzten, die von ihrem anfänglichen Nein Abstand nahmen. Sie fielen bei den Brüsseler USt-Verhandlungen weder als Antreiber noch als Bremser auf und bereiteten den Steuerleuten der Kommission zu keinem Zeitpunkt sonderliche KopPschmerzen. Ihr Verhalten wird erklärbar, wenn wir uns die steuerpolitische Situation ein wenig näher anschauen, in der sich Belgien zu Beginn der 60er Jahre befand.91

\section{Zufriedenheit mit der Bruttoust: $1921-1960$}

Entscheidend für das Verständnis der belglschen Verhandlungsposition bel der EG ist dle Tatsache, daß die Belgier in 1960 mit ihrer USt recht zuPrleden waren. Dle von thnen als taxe de transmission bzw. Overdrachts Taxe bezeichnete Abgabe ${ }^{92}$ hatte mit der USt, wie sle in 1921 ursprunglich einmal elngefuhrt worden war, fast nur noch den Namen gemeinsam. Damals, kurz nach dem Krieg und in großer Finanznot, hatten die Belgler, dem deutschen und Pranzösischen Beispiel folgend, mit der Erhebung einer mehrphasigen BruttoUSt - der Einzelhandel war steuerbefreit - begonnen. Statt, wie zunăchst gehofft, dle unpopuläre USt bald wieder abschaffen zu können, mußte der 1921 auf 1\% festgelegte Steuersatz fün Jahre spatter auf $2 \%$ angehoben werden. Um die nunmehr stärker spürbaren kumulativen Effekte der Bruttoust abzumildern, fuhrte die belgische Regierung nach und nach - jewells in den Branchen, die sich gerade am lautesten beklagten unter dem Namen taxes forfaitaires die uns von Frankreich schon bekannten taxes uniques ein. Der Steuersatz stleg weiter, von $2 \%$ in 1926 uber $2,625 \%$ in 1939 und $4,5 \%$ in 1941 bis aup $5 \%$ in 1955. Gleichzeitig erhlelt die Reglerung vom Parlament "..les plus larges pouvoirs pour adapter la taxe de transmission aux circonstances économiques et, notamment, pour établir des taxes forfaltaires." $93 \mathrm{Da}$ dle Regierung in großem Umpang von

91 Ein Kurzuberblick zur Entwicklung der USt in Belgien findet sich z.B. bel Scallteur (1974), S.456 Pf.

92 Eine Darstellung dieser Steuer glbt z.B.: Belgium - Survey of Turnover Taxation on Transfers of Goods, in: European Taxation, 6.1966, S.177ff. Neben der "taxe de transmission" gab es noch 11 weltere Abgabe, die als Ergänzungssteuern dienten. Sle alle zusammengenommen bildeten die belgische USt und wurden unter dem Oberbegriff "taxes assimilée au timbre" zusammengefaßt.

Persönliches Interview. 
Ihrer Ermăchtigung Gebrauch machte, stleg die Zahl der taxes forfaltaires in der Folgezelt rapide an. Bls Ende der 50er Jahre waren sie de facto die Regel, und die eigentliche Bruttoust war zur Ausnahme geworden.94

Die Geschichte der belgischen USt bis 1960 und die der französischen USt vor 1936 zeigen eine auffallende Parallelitat. In beiden Fallen wurde versucht, die wiederholten Rufe nach elner durchgrelfenden Reform der BruttoUSt mit kleineren Modifikationen zum Verstummen zu bringen. Was jedoch im großen Frankrelch trotz eines geringen Steuersatzes von damals nur 2\% zur Erfolglosigkeit verdammt war - dle Pranzösische Bruttoust ging in 1936 unter -, das gelang den Belgiern selbst noch bel elnem steuersatz von Immerhin 5\%. Ihr Land war klein, die Struktur der Wirtschaft war vergleichsweise einfach zu uberschauen, und das Management einer großen Zahl von taxes forfaitaires warf daher, in krassem Gegensatz zu Frankrelch, aus verwaltungstechnischer sicht keine unuberwindlichen Probleme auf. Belgien konnte alles in allem mit seiner außerst anpassungsfahigen taxe de transmission gut leben. Nennenswerte Stimmen, die nach elner großen Reform der BruttouSt verlangt hatten, waren 1960 noch nicht zu vernehmen:

\begin{abstract}
"It is suggested by some persons well acquainted with the tax that the discriminatory and arbitrary features of the tax cause less Injury than might be expected, partly because of the willingness of the government to make modifications of specific features,..., whenever complaints become serious, and partly because of the ability of flrms to evade the tax whenever the burden becomes particularly injurious to them."
\end{abstract}

\title{
Entscheidung fur dle MWSt: 1961-1967
}

Erst zu Beginn der 60er Jahre kam die umsatzsteuerpolitische Szene Belgiens langsam in Bewegung. Hierfur verantwortlich zu machen waren insbesondere die drel Polgenden Entwicklungen:

- Ein erster Grund war rein Innenpolitischer Natur. Noch gegen Ende der 50er Jahre lebte Belgien mit der geringsten Steuerquote in der gesamten EG. Aber bald danach schon begann der Finanzbedarf des belgischen Staates - bedingt insbesondere durch den Ausbau der Sozialleistungen und die verstärkte offentliche Wachstumspolitik - krätig anzustelgen. Nach den direkten Steuern wurde daher zum 5.Mal 1961 auch die USt angehoben, und zwar von $5 \%$ auf $6 \% .96$ Damit schien elne kritische Grenze überschritten. Erstmals wurden sun in Belgien Uberlegungen darüber angestellt, inwlewelt der Weg kleinerer Modifikationen

\footnotetext{
94 Vgl. D'Haeze (1959), S.84.

90 Due (1957), S.99.

9 Vgl. z.B. Handelsblatt 12.5.61.
} 
der Bruttoust mittlerweile ausgereizt sel und ob er nicht besser zugunsten elner systemverändernden Steuerreform aufgegeben werden sollte.

- Der sich nach und nach abzelchnende Reformbedarf wurde verstärkt durch Belgiens Beitritt zur EG. Dle extrem offene Volkswirtschaft Belgiens stöhnte unter den Folgen der Außenhandelsliberalislerung gegenuber den belden wichtigsten Handelspartnern Frankrelch und Deutschland. Die Unternehmer drängten die Regierung, im Gegenzug zum Abbau der Zollbarrieren den umsatzsteuerlichen Grenzausglelch hinaupusetzen. Zwar hatte Belgien schon kurz nach Grundung der Benelux-Union begonnen, die auf Importwaren erhobene USt schrittweise zu erhöhen.97 Auch wurde diese Praxis nach dem belgischen EG-Beitritt verstärkt fortgesetzt. Aber bislang kannten die Belgier, aus rein budgetären Grunden, noch keine steuerliche Ruckerstattung fur exportierte Guter. Die zunehmenden Klagen der belgischen Exportwirtschaft waren daher verstandlich.

- Gleichzeitig nahmen leitende Beamte des belgischen Finanzministeriums an den von der Kommission organislerten Gesprăchen zur USt-Harmonislerung tell. In langen Auseinandersetzungen mit ihren Kollegen aus den anderen EG-Staaten wurde ihnen bewußt, daß sich das belgische USt-System in Einzelregelungen aupulösen drohte und daß es so langPristig nicht weitergehen könne.9 Nach und nach erwärmten sie sich fur den Gedanken, die zahlrelchen Unzulänglichkeiten ihrer USt durch einen Systemwechsel mit einem Schlag vom Tisch zu bekommen.

In den Jahren 1962/63 war damit in Belgien eine erste, wenn auch noch sehr vorsichtige und auf wenige Expertenzirkel beschränkte, USt-Reformdiskussion in Gang gekommen. Nachdem die Belgier 1962 elne Reform der direkten Steuern erfolgreich durchgezogen hatten, 99 rückten in der Folgezeit die indirekten Abgaben in den Mittelpunkt des Interesses. Die uberwiegende Mehrhelt der Beamten Im belgischen Finanzministerium häte zu gerne an der bestehenden USt festgehalten:

"La fiscalité n'est pas matière d'expérimentation. C'est pourquol il seralt peu sage d'abondonner ce quil existe, ce que l'on connaît et ce qui a fait ses preuves, pour une construction nouvelle dont le profit à en retirer n'est pas sûr."100

Da sle den "Sprung ins Ungewisse"101 scheuten, eine Reform gleichzeltig aber immer unausweichlicher wurde, schlugen die Finanzbeamten 1963 eine

\footnotetext{
97 Vgl. z.B. Jahrmarkt (1969), S.111P.

* Vgl. Scallteur (1967), S.131.

99 Vgl. z.B. NZZ 23.1.62.

100 Scallteur (1957), S.29.

101 Scallteur (1962), S.50.
} 
Politik der kleinen Schritte vor. Der mit der Elnführung der taxes forfaitaires bereits begonnene Umbau der BruttouSt in eine elnphasige Abgabe sollte, so die Vorstellung der Verwaltung, beschleunigt werden mit dem Ziel, bis spätestens 1967 uber eine GroßhandelsuSt nach dem Vorbild der britischen Purchase Tax zu verfügen. Mit diesem Konzept rannten die Beamten bel Ihrem damaligen Minister Dequae offene Türen eln. Dequae hatte die mit der Reform der direkten Steuern verbundenen Schwlerigkeiten hautnah miterlebt, war daher vorsichtig geworden und genelgt, einer steuerlichen peacemeal-policy gegenuber großen Reformen den Vorzug zu geben. Dle belgische Reglerung beschloß denn auch kurze Zelt später, daß die exportintensive Stahl- und Metallindustrie zum 1.Januar 1964 den Anfang machen und $\mathrm{zu}$ elner GroßhandelsUSt ubergehen sollte. Aber die Maßnahme mußte, aus konjunkturellen Gründen, kurzfristig wleder abgesagt werden. ${ }^{102}$

Damit hatten die Belgier Zeit, sich uber die Zukunft lhrer USt noch einmal in Ruhe Gedanken zu machen. Entscheldend beeinflußt wurden die belgischen Uberlegungen durch dle Tatsache, daß slch Anfang 1964 vier der sechs Mitglledstaaten der EG Pür elne MWSt ausgesprochen hatten. Das gab Finanzminister Dequae zu denken. Im Februar 1964 beauftragte er eine interministerielle Arbeitsgruppe mit der Untersuchung der Frage, wle ein belgisches MWSt-System aussehen könnte und welche Alternativen es dazu gäbe. Vieles sprach in Belgien dafur, anstelle der von der Kommission gewanschten MWSt eine einphasige USt einzufuhren:103

- Die belgische USt war eine Stempelsteuer. Der Finanzverwaltung war an der Belbehaltung dieser Erhebungsmethode gelegen, scheute sle doch vor dem zusatzlichen Arbeitsaupwand und dem Arger zurück, den die Kontrolle der Unternehmensbuchhaltung mit sich zu bringen drohte. Eine Einphasensteuer hătte als Stempelsteuer erhoben werden können, eine MWSt - wegen des VSA - aber nicht.

- In Belgien war es Tradition, die USt-Sătze aus preis-, vertellungs- und strukturpolitischen Gründen zu differenzleren. Dle Fortsetzung einer Politik der Satzdifferenzlerung wäre mit einer Einphasensteuer wesentlich einfacher möglich gewesen als mit elner MwSt.

- Da die Belgler einphasige Abgaben schon von den zahlreichen taxes forfaitaires her gut kannten, hätte der Ubergang zu einer EinphasenUSt, wle dle Pranzősische Erfahrung von 1936 ja bewles, ohne größere Probleme uber die Buhne gehen konnen. Demgegenuber waren die mit

102 Vgl. z.B. Welt 9.10.63 u. Handelsblatt 13.12.63.

103 Vgl. Carbonelle (1963) u. Ceulemans (1964). Vgl. a. de Ausfuhrungen des Ministers Dequae in Dequae (1964). 
elner MWSt verbundenen Probleme uberhaupt noch nicht uberschaubar: "La T.V.A. était, par conséquent, une 'terra incognita'"104 - so der Kommentar eines leitenden Beamten im Finanzministerium.

Für Belgien wăre es Im Jahre 1964 also das Năchstllegende gewesen, die eigene Version der Bruttoust in Richtung auf eine neutrale Einphasensteuer hin welterzuentwickeln. Später hătte es dann immer noch die Möglichkelt gegeben, bel Bedarf, d.h. wenn welter anstelgende Steuersătze die Belbehaltung elner einphasigen USt nicht mehr zugelassen hătten, die Einführung einer MwSt zu erwagen. Trotzdem empfahl die von Minister Dequae eingesetzte Arbeitsgruppe im Jull 1964, den direkten Ubergang zur MWSt zu wagen. Der Grund fur diese Entscheidung lag aup der Hand: "Ce fut en particulier le fait que la pluspart des pays de la C.E.E. s'orientaient vers la T.V.A. qui porta le groupe de travail à choisir ce système d'imposition." ${ }^{00}$ Die Kommission und die Mehrheit der Mitgliedstaaten, das konnte den Belglern nicht verborgen bleiben, wollten sich 1964 auf ihrem Weg zur MWSt nicht mehr stoppen lassen. Da Belgien an elner politischen Isolation nichts gelegen war, das Finanzministerium und die Wirtschaft einen zweimaligen Systemwechsel aber aup jeden Fall vermeiden wollten, wurden die Plăne für eine Einphasensteuer Ende 1964 endgültig Pallengelassen.

Das hieß aber noch lange nicht, daß sich die belgische Regierung von nun an für die MWSt stark machte. Im Gegentell: "Le Ministère des Finances et le Ministre lui-même eurent, ¿ l'époque considerée, une attitude reservée." 106 Zwar signalislerte Finanzminister Dequae aup der Ratsitzung im März 1965, daß seln Land berelt sel, die 1.USt-Richtlinie mitzutragen. Aup der anderen Selte versuchte er aber auch, die unausweichliche innenpolitische Auseinandersetzung uber die MwSt sowelt hinauszuschieben wle möglich. In jedem Fall wollte er zunächst abwarten, bis sich die EG auf die 2.USt-Richtlinie und damit auf die besonders umstrittenen Anwendungsmodalitaten der MwSt geeinigt hatte.

Dle Implementlerung der MWSt: $1968-1971$

Bis 1967 waren an der belgischen MWSt-Debatte allein die Finanzverwaltung, der Finanzminister, elnige andere Ministerien und vereinzelte Steuerexperten aus der Wirtschaft betelligt gewesen. Die belgische Offentlichkeit hatte von alledem noch nichts mitbekommen, und selbst das Kabinett hatte sich vor der Entscheldung des EG-Ministerrates vom Februar 1967 noch nicht mit der MWSt beschaftigt. Anfang 1967 aber befand sich die belgische Regierung plotzlich in Zugzwang. Sle war nicht nur der EG gegenüber ver-

\footnotetext{
104 Personlliches Interview.

100 Personliches Interview.

106 Persønliches Interview.
} 
pflichtet, die MWSt bls 1970 einzuführen, sondern mußte auch aus innenpolitischen Gunden rasch handeln:

- Nach der Ende 1965 vorgenommenen Erhöhung des USt-Satzes auf 7\%107 waren dle Nachtelle der alten taxe de transmission nicht mehr tragbar. Abhilfe war nur von einer durchgrelfenden Steuerreform zu erwarten.

- Die Deutschen wollten berelts zum 1.Januar 1968 zur MwSt ubergehen. Der damit verbundene Abwertungseffekt der Deutschen Mark sollte, so die Forderung der Féderation des Industries Belges, durch eine baldige Reform der belgischen USt zumindest teilweise wieder kompenslert werden. ${ }^{100}$

Ein Anfang 1967 bel der Finanzverwaltung in Auftrag gegebener MwSt-Gesetzentwurf wurde im Dezember desgleichen Jahres fertiggestellt. Er konnte, da die Wahlen vom Mărz 1968 eine Verzögerung mit sich brachten, aber erst Im Oktober 1968 dem Parlament unterbreitet werden. ${ }^{109}$ Nun sollte sich răchen, daß die belgische Offentlichkelt so lange aus dem steuerpolitischen Melnungsbildungsproze $\beta$ ausgeschlossen worden war.

Widerstand gegen die MwSt kam zum einen aus dem Lager der in Belgien ebenso zahl- wie einflußreichen kleinen Selbständigen. Deren Einwände (sie richteten sich vor allem gegen die als zu aufwendig erachteten Bucheuhrungsplichten) voraussehend hatte der 1967 amtlerende Finanzminister Henrion bereits vorsorglich darauf verzichtet, die Einbezlehung des Einzelhandels in die MWSt vorzuschlagen. ${ }^{110}$ Genau das aber verlangte sowohl die Industrle (sle war, um den Steuersatz niedrig zu halten, an elner brelten Bemessungsgrundlage interessiert) als auch die Kaufhäuser und supermarktketten (sle wollten, wie ihre französischen Kollegen, die auf Invest1tionsgütern lastende USt als Vorsteuer abzlehen können). Das belgische Wirtschaftsministerium nahm sich den Interessen der letztgenannten Gruppen an und machte geltend, daß die Befrelung des Einzelhandels dem Grundgedanken der MWSt widerspreche und von der Kommission der EG ohnehin nur als Ubergangsregelung vorgesehen sel. Erst der im Mărz 1968 neu ins Amt elngefuhrte Finanzminister Baron Snoy et d'Oppuers sah sich nach langem Hin und Her in der Lage, eine für alle Seiten akzeptable Kompromißlösung vorzulegen: Der Anwendungsberelch der MwSt war auf den Einzelhandel auszudehnen, die von den kleinen Detaillisten abzufuhrende MWSt sollte aber bel den thnen vorgelagerten Großhändlern als sogenannte taxe d'égalisation erhoben werden.111

107 Vgl. z.B. Welt 23.11.65 u. FT 3.12.65.

100 Vgl. NZZ 23.11.67.

109 Vgl. NZZ 22.10.68.

110 Henrion hatte zunăchst zwel Gesetzentwürfe - einen mit und einen ohne Einzelhandel - ausarbeiten lassen, Ende 1967 aber dann doch dem letzteren Konzept den Vorzug gegeben.

111 Es sei daraup hingewiesen, daß dieses nur in Belgien bekannte VerPahren notwendigerweise zu Schwierigkelten mit der EG fuhrte, als 
Widerstand gegen die Einfuhrung der MwSt kam zum zweiten von seiten der belgischen Bevölkerung und den Gewerkschaften. Die Belgier hatten Angst vor steigenden Prelsen. Es dauerte nicht lange, bis das Kurzel T.V.A. im Volksmund mit tout va augmenter ubersetzt wurde. Zurückzupuhren waren diese Befürchtungen vor allem auf die weit verbreitete Unkenntnis über die Tatsache, daß dle nominal recht hohen Sätze der MwSt - die Regierung hatte einen Standardsatz von $20 \%$ vorgesehen - die effektive USt-Last in Belgien keineswegs erhøhten. Die Angst wuchs sich zu einer Psychose aus, nachdem die Belgier in der Presse hatten lesen können, daß die zum 1.Januar 1969 vorgenommene MWSt-Einführung bel den niederländischen Nachbarn die dortige Inflationsrate angeblich um 5\% erhöht hătte.

Dle Pür Mărz 1969 in der Brüsseler Abgeordnetenkammer angesetzte MWStDebatte stand also unter schlechten Vorzelchen. Der Gesetzentwurf konnte vom Finanzminister nur erfolgrelch durchgeboxt werden, nachdem die Reglerung zugesichert hatte, daß sie die endgültigen Steuersătze erst im Herbst des Jahres und nach eingehenden Beratungen mit den Gewerkschaften festlegen wurde. ${ }^{112}$ Aber zu den versprochenen Verhandlungen kam es nicht. Dle Regierung schreckte nach der Sommerpause vor elner Konfrontation mit den Arbeltnehmervertretern zurück und gab Anfang September bekannt, daß sle dle ursprünglich für den 1.Januar 1970 vorgesehene MWSt-Elnführung um ein Jahr verschieben würde.113 Damit verstie $\beta$ Belgien zwar gegen eine gegenüber der EG elngegangene Verpflichtung, aber die Regierung sah keine andere Möglichkeit, sich zumindest vorubergehend aus einer innenpolitischen Zwangslage zu befrelen:

Dle Regierung brauchte fur die von $\mathrm{hhr}$ gewunschte Steuerreform dle $\mathrm{Zu}-$ stimmung der Gewerkschaften. Dle aber welgerten sich bislang, die in Belgien ubliche Indexierung der Löhne für eine Ubergangszeit außer Kraft zu setzen.114 Elne Ingangsetzung der gefährlichen Prels-Lohn Spirale wäre nur zu vermelden gewesen, wenn die Reglerung zu erheblichen Zugeständnissen bel der Höhe der Steuersătze bereit gewesen wăre. Das aber hătte die ohnehin schon prekäre Finanzlage der öfentlichen Hand zusätzlich belastet. Weitere Einnahmenausfälle konnte sich die belgische Regierung nicht leisten, da der ubergang von der alten taxe de transmission (sie wurde als Stempelsteuer erhoben und mußte daher an den Fiskus bezahlt werden, bevor die steuerpflichtigen Umsătze ausgeführt wurden) zur neuen MWSt (bel ihr kommt der Fiskus erst dann in den Genuß einer Einnahme, wenn fertige Produkte an den Letztverbraucher gellefert werden) in jedem Fall mit der

sich die Kommission später daranmachte, in der 6.USt-Richtlinie die Bemessungsgrundlage der europälschen MWSt zu harmonisieren; vgl. die Darstellung in Kap.D.2.1.

112 Vgl. Z.B. NZZ 28.3.69.

113 Vgl. z.B. FT 11.9.69, Le Monde 12.9.69, NZZ 12.9.69 u. FT 23.9.69.

114 Vgl. Gulllaume/Waelbroeck (1972), S.99. Vgl. a. Stuttgarter Zeltung 30.4.69. 
vorubergehenden Verminderung des Steueraufkommens verbunden war. ${ }^{115}$ Das Dilemma zwischen den Preisen auf der elnen und den budgetären Erfordernissen auf der anderen Seite wurde verschärft durch die Tatsache, daß sich Belgien damals in einer Phase der konjunkturellen Oberhitzung befand. Preiserhohungen waren also außerst wahrscheinlich, wahrend Budgetdefizite auf dem ohnehin schon angespannten Kapitalmarkt nur schwer zu finanzleren waren. HInzu kam, daß Anfang 1970 landeswelte Kommunalwahlen anstanden.

Die Verschlebung der MWSt-Einführung gab der belgischen Reglerung Zeit, auf elne Beruhigung der konjunkturellen Situation zu warten und Lösungen für das skizzlerte Prels-Budget Dilemma zu finden. Obwohl auch 1970 wleder Stimmen laut wurden, die einen nochmaligen Aufschub verlangten, gelang es den Belgiern, die MWSt zum 1.Januar 1971 einzufuhren.116 Dazu war elne ganze Palette von Maßnahmen erforderllch:

- Eine In Belgien bls dato einmalige staatliche Informationskampagne verfolgte den Zweck, Wirtschaft und Verbraucher über Arbeltswelse und Folgen der MwSt aufzuklären und damit die Diskussion zu versachllchen. Abkommen mit den Wirtschaftsverbänden und Gewerkschaften sowie verschärfte Preiskontrollen sollten eine neuerliche Prelspsychose verhindern. ${ }^{117}$

- Der zeitlich begrenzte Verzlcht auf eine vollständige steuerliche Entlastung der Exportgüter sowle dle von den Steuerpflichtigen belm Fiskus zu hinterlegenden Garantiesummen ${ }^{118}$ dienten dazu, die budgetären Konsequenzen der MWSt-Einfürung abzumildern. ${ }^{119}$

Alles in allem verlief der Ubergang zur MwSt überraschend ruhig. Zwar gab es Anfang 1971 noch vereinzelte Nachwehen - so z.B. ein von den Kleinunternehmern ausgerufener elntägiger Generalstrelk, der sich gegen die Garantiesummen richtete ${ }^{120}$-, aber nennenswerte MWSt-induzierte Preiserhöhungen waren, entgegen der vorherigen Befurchtungen, nicht zu beobachten.

115 Vgl. z.B. Scallteur (1967), S.142.

116 Vgl. Guardian 29.4.70, FAZ 16.11.70, Le Monde 19.12.70, Times 2.1.71, FAZ 11.1.71 u. 15.1.71.

117 Vgl. Z.B. NZZ 25.12.70.

118 Dle Steuerpilichtigen sollten, wle elne Reglerungsverordnung ursprünglich vorsah, ein Drittel der Im ersten Halbjahr $1971 \mathrm{zu}$ erwartenden MWSt-Schuld als sogenannte "Garantlesumme" beim Fiskus zinslos hinterlegen.

119 Vgl. Z.B. Handelsblatt 21.8.70 u. NZZ 22.8.70.

120 Vgl. z.B. Guardian 5.2.71 u. 6.2.71, NZZ 7.2.71, Frankfurter Rundschau 10.1.71, FT 19.2.71 u. Le Monde 20.2.71. 


\section{Europa und die Belgler}

Ohne die in der EG diskutierte USt-Harmonisierung hätten die Belgler Anfang der 70er Jahre mit Sicherhelt keine MWSt elngefuhrt. Das helit nicht, daß sle thre alte taxe de transmission unverändert beibehalten hätten. Im Gegentell war sowohl durch den in ten 60er Jahren angestiegenen Steuersatz als auch wegen der MWSt-Einführung in Deutschland eine Reform unauswelchlich geworden. Alle Anzeichen sprachen aber dafür, daß Belgien von der mit zahlreichen taxes forfaitaires berelts durchsetzten Bruttoust zu einer einphasigen Abgabe übergegangen wäre, ein Schritt, wie ihn in ähnlicher Weise dle Franzosen schon 1936 gegangen waren. Es waren die Brüsseler Harmonisierungsgespräche, die elnzelne Beamte des belgischen Finanzministeriums von der technischen Machbarkeit sowle von verschledenen Vorzügen einer MWSt nach und nach überzeugten. Da es eine öpfentliche USt-Reformdebatte vor 1967 in Belgien nicht gab, war die Regierung in ihrer Entscheldung, welchem Steuertyp sie den Vorzug geben wollte, relativ Prel. Der Finanzminister entschied sich, um eine politische Isollerung innerhalb der EG zu vermeiden, für die MWSt. Sein Vertreter in der entscheldenden Ratsitzung vom Februar 1967 erhielt von ihm die Weisung: "Je recus comme instruction de donner un accord pur et simple, parce qu'll fallalt éviter sur ce point un isolement politique au sein de la C.E.E."121

Die in 1965 informell und in 1967 dann formell gegebene Zustimmung des belgischen Finanzministers $z u$ den ersten beiden USt-Richtlinien wurde wesentlich erleichtert durch die Tatsache, daß die belgische MWSt-Debatte bis 1967 auf wenige Experten beschrănkt war. Das Versăumnis, die OPfentlichkelt fruhzeltig in den Melnungsbildungsproze $\beta$ einzubeziehen, sollte der Regierung aber nach 1967 das Leben schwer machen. Denn kaum war der MWSt-Gesetzentwurf bekanntgeworden, regte sich Widerstand von allen Selten. Es dauerte eine gewisse Zeit, bls die sehr vorsichtig operierende belgische Regierung nach einer groß angelegten Informationskampagne und dem elnen oder anderen Zugeständnis den wirtschaftlich und politisch opportunen Augenblick für die Einfuhrung der MwSt gefunden hatte. Trotz der zwischen 1968 und 1970 nachgeholten öpfentlichen Debatte konnte die neue MWSt, Im Gegensatz zu den Pranzösischen Erfahrungen von 1954, vor einer Durchlöcherung weitestgehend bewahrt werden. Entscheidende Hilfestellung gab dabel die 2.USt-Richtlinie. Mit $\mathrm{hr}$ im Rücken gelang es dem belgischen Finanzminister, mehr als 50 in der Abgeordnetenkammer gegen den ursprünglichen Gesetzentwurf vorgebrachte Anderungsanträge abzublocken.

121 Persönliches Interview. 
Insgesamt konnten die belgischen Finanzpolitiker mit sich und ihrer MWSt zufrieden sein. Mit Hilfe der EG hatten sie den Ubergang von einer stark modifizierten BruttoUSt zu einer neutralen MWSt, berücksichtigt man die gesamte Diskussion, in ungefăhr elnem Jahrzehnt über die Bühne gebracht. Fur genau diegleiche Reform hatten die Franzosen ganze 32 Jahre gebraucht. ${ }^{122}$

122 Der angegebene Zeitraum ist gerechnet von der Debatte um die Einführung der Produktionssteuer in 1936 bis zur MWSt-Reform von 1968. 


\subsubsection{Nlederlande: der Bremser}

Bel den Niederlanden handelte es sich, sowelt es um die USt-Harmonisierung in der EG ging, gleich in zwelerlel Hinsicht um einen Extremfall. Zum einen waren sie ab 1965 der einzige Mitgliedstaat, der an seiner Ablehnungshaltung gegenüber der MWSt festhlelt. Lange Zeit versuchten sie sich als Bremser zu betätigen, eine Position, die sie offiziell erst Anfang 1967 aufgaben. Zum anderen schapften es die Niederländer, die MWSt, nachdem sle ihr zugestimmt hatten, in einer Rekordzeit von weniger als zwei Jahren einzuführen. In beiden Fällen erklärt sich die niederländische Sonderrolle aus einem komplexen Wechselspiel zwischen den $\mathrm{Zwängen} \mathrm{nationaler} \mathrm{Steuer-}$ politik aup der einen und der europäischen USt-Harmonisierung aup der anderen Seite. Kommen wir zunächst auf die niederländische Steuerpolitik $\mathrm{zu}$ sprechen. ${ }^{123}$

\section{Zur Vorgeschichte der niederländischen USt: 1934-1954}

Noch in den 20er Jahren war DenHaag in der glücklichen Lage, ohne eine allgemelne USt auskommen zu können. Aber die Weltwirtschaftskrise ließ das Budgetdefizit dann doch steigen, und die Politiker mußten sich nach elner neuen Einnahmenquelle umsehen. Nachdem das Parlament eine nach belgischem Vorbild gestaltete Mehrphasensteuer abgelehnt hatte, fuhrte man zum 1.Januar 1934 als "temporary emergency measure"124 und zunăchst zeitlich auf 5 Jahre begrenzt elne an das kanadische Vorbild angelehnte einphasige Produzentensteuer von $4 \%$ - Pür Luxusguter $10 \%$ - eln. Einmal an diese attraktive Aufkommensquelle gewöhnt, schaffte die Regierung 1938 die fabrikantenbelasting nicht ab, sondern verlängerte sie um weitere funf Jahre und erhohte 1940 gar ihre Sătze auf 6\% bzw. 12\%. Dieser Entwicklung der niederländischen USt setzte die deutsche Besatzungsmacht eln jähes Ende, als sie DenHaag, beginnend am 1.Januar 1941, in einer Art Zwangsharmonisierung die deutsche BruttouSt in der Form des UStGesetzes von 1934 aufdiktierte. Der Steuersatz wurde zunächst auf 2,5\% festgelegt.

Nach der Befrelung der Niederlande von der deutschen Besetzung wurde die Abschaffung des deutschen USt-Systems niemals ernsthaft in Erwägung gezogen. Das Aufkommen der USt hatte inzwischen eine solche Höhe erreicht, daß weder an einen völligen Wegfall dieser Staatseinnahme noch an eine Substitution der Allphasen-USt durch die frühere Produzentensteuer - die Sătze hätten sehr hoch sein müssen, um ein gleiches Aufkommen zu erbringen - zu denken war. Im Gegentell ließ die planwirtschaftlich/korpora-

123 Ein Uberblick über die Geschichte der niederländischen USt findet sich bel Reugebrink (1973), S.33pp, in englischer Sprache sehr kurz a. bel Cnossen (1981), S.224fP. Insbesondere mit dem Wechselsplel zwischen DenHaag und Brüssel beschäftigt sich Puchala (1980), vgl. ăhnl. Puchala (1984), S.65ff.

Due (1957), S.93. 
tistische Industrialisierungs - und Landgewinnungspolitik der Nachkriegszeit den Mittelbedarf des Staates und damit auch die Sătze der USt weiter krätig ansteigen. Im Jahre 1951 erreichte der Standardsatz der USt eine bis dahin elnmalige Höhe von 6\%. Mit jeder Satzerhöhung kamen die Nachteile der kumulativen Bruttoust stärker zum Vorschein und lösten elnen politischen Druck aus, der auf Reformen drăngte:125

- Zum elnen nahmen mit dem Anstieg des Steuersatzes die regressive Effekte der USt zu. Um dieser Tendenz entgegenzuwirken, wurde mit jeder Satzanhebung auch die Zahl der Befreiungen für lebensnotwendige Güter erhöht. Bereits Anfang der 50er Jahre hatten die Befreiungen einen Umpang errelcht, wie er in Europa nur noch von der britischen Purchase Tax übertroffen wurde. ${ }^{126}$ Ein weiteres progressives Element fügte man durch die Einführung von erhöhten Sätzen für Luxusgüter hinzu, die mit bis zu $30 \%$ besteuert wurden. Die während der Zeit des rasanten Anstieges der Steuersătze entwickelte Ubung, mittels der USt Preis- und Einkommenspolitik zu betreiben, wurde später fortgesetzt. Dle Ende 1955 eingeführte Steuerbefreiung für Textilen ist nur ein Belsplel hierfur. ${ }^{127}$ Als man 10 Jahre später in der EG über Steuerharmonisierung diskutierte, sprach man daher davon, daß die Niederländer ihre USt traditionell mehr als jeder andere Mitgliedstaat $\mathrm{zu}$ sozialpolitischen $\mathrm{Zwecken}$ einsetzten.

- Zum zweiten nahmen mit jeder Erhø̋hung des USt-Satzes die Klagen der nlcht-integrierten Unternehmen $z u$, sle würden gegenüber den vertikalintegrierten steuerlich benachteiligt werden. Das Finanzministerium erwog daher in einem 1952 vorgelegten Reformvorschlag, durch die möglichst vollständige Erhebung von Zusatzsteuern auf integrlerte Produktionsprozesse integrierte und nicht-integrierte Unternehmen steuerlich gleichzustellen. Der genannte Vorschlag löste jedoch zunächst einen erbitterten Streit mit den Großunternehmen aus, dle in der Lage waren, ihren Widerstand gegen die Zusatzsteuern bis in das Parlament hineinzutragen.

- Das dritte sích bei einer Steuersatzanhebung verschärfende Problem war der unzureichende Grenzausgleich im Außenhandel. Er machte der extrem offenen niederländischen Volkswirtschaft - 1954 betrugen die Exporte $54 \%$ des Volkseinkommens - besonders zu schaffen. Hinzu kam, daß wegen der Liberalisierung im Benelux-Raum auch die Zölle keinen Schutz mehr gegenüber den Belgiern boten. Anfang der 50er Jahre wur-

125 Zum Polgenden vgl. insbes. Hijszeler (1953).

126 Vgl. hierzu die Darstellung in Kap.C.2.2.5.

127 Vgl. Kohmann (1956), S.302ff. 
den daher die Stimmen immer lauter, die nach einer Beseitlgung der steuerlichen Wettbewerbsverzerrung gegenuber den belgischen Nachbarn riefen.

In den frühen 50er Jahren drückte den Nlederländern also der USt-Schuh an allen Ecken und Enden. Irgendetwas mußte getan werden. Da von seiten der Benelux-Union keine erfolgversprechenden Harmonisierungsinitiativen in Sicht waren, entschied man sich für einen Alleingang. Um der Wirtschaft schnelle Linderung zu verschaffen wurde zunăchst der Steuersatz von $6 \%$ auf 4\% herabgesetzt und der Finanzminister ermächtigt, ab 1952 die auf Importe erhobene USt um bis zu 3\% hinaufzusetzen. Ebenfalls 1952 wurde dem Parlament eln Reformvorschlag vorgelegt, der unter Beibehaltung eines Mehrphasensystems versuchte, dessen Nachteile möglichst weitgehend zu beseitigen. Nach längeren Diskussionen und vielen Kompromissen kam es 1954 schließlich zur Verabschledung eines Reformpaketes, das ab 1.Januar 1955 endgültig die deutsche durch eine niederländische Bruttoust ersetzte.

\section{Zupriedenheit mit der BruttoUSt: $1955-1965$}

Da die Im Jahre 1955 in Kraft getretene USt-Reform entscheidenden Einfluß auf die spätere Position der Niederlande zur europäischen MWSt gehabt hat, sollen hier kurz lhre wesentlichen Elemente beschrieben werden: ${ }^{128}$

- Die Interessenvertretungen des Einzelhandels hatten sich schon länger dafür stark gemacht, die ca.100000 Detaillisten von der verwaltungsaufwendigen USt $\mathrm{zu}$ befrelen und wieder zum steuerlosen Vorkriegszustand zurúckzukehren. Diesem Druck wurde in der 1955er Reform durch die Bepreiung des Elnzelhandels nachgegeben. Der Steuerausfall wurde durch eine Anhebung des Steuersatzes von $4 \%$ auf $5 \%$ ausgeglichen.

- Das neue Steuergesetz unternahm den Versuch, den Grenzausgleich dem Niveau der Inländischen Belastung anzunăhern. Neben der Beibehaltung der Zusatzsteuer auf Importe von bis zu $3 \%$ wurde die gesetzliche Möglichkelt geschaffen, die aup Exportgüter lastende USt möglichst vollständig zurückzuerstatten. Im Anschluß an die Reform von 1955 waren ständig zahlreiche Beamte der Finanzverwaltung mit der Aufgabe betraut, die Höhe der Rückerstattungen jewells auszurechnen.

- Zum Zwecke der Angleichung der Belastung von integrierten und nichtIntegrierten Unternehmen wurden gleich mehrere Instrumente geschapfen. Zum einen kamen Zusatzsteuern zur Anwendung, die aber wegen des Widerstandes der Großindustrie und administrativer Schwierigkeiten nur auf einen Tell der integrierten Produktionsprozesse erhoben wurden. Um die Verwaltung $\mathrm{zu}$ vereinfachen, wurden dle Zusatzsteuern, nach

128 Vgl. Due (1957), S.84ff, Kohmann (1956), S.276ff. u. Tuk (1959), S.292fP. 
belgischem Vorbild, vereinzelt durch taxes forfaitaires ersetzt. Als weiteres Instrument wurde das Konzept der fiskalischen Elnheit eingefürt: Ahnlich der umsatzsteuerlichen Organschaft des deutschen UStRechts wurden mehrere rechtliche selbständige Unternehmungen fur steuerliche Zwecke zu einer Unternehmenseinheit zusammengefaßt mit dem Ergebnis, daß Lleferungen zwischen den Tellunternehmen nicht mehr der USt unterlagen. Das genannte Konzept konnte in den Niederlanden besonders problemlos und damit erfolgreich angewandt werden, da die niederländische Industrle damals noch wenig entwickelt war und sich im wesentlichen aus einer überblickbaren Zahl von Großbetrieben und deren zulleferern zusammensetzte. Die niederländische Finanzverwaltung machte daher solch eifrigen Gebrauch von diesem Instrument, daß "zum Schluß fast ganz Holland eine fiskalische Einheit war"129.

Die nlederländische USt-Reform von 1955 läßt sich damit wie folgt kennzeichnen: Das Parlament gab der Reglerung weltestgehende Vollmachten, die Nachtelle einer kumulativen Mehrphasensteuer durch die verschledensten Maßnahmen, je nach Bedarf und Schritt für Schritt, zu beseltigen. Als Vater der USt-Reform von 1955 gilt der Finanzbeamte Tuk. Er war es auch, der bis in die 70er Jahre hinein im Haager Ministerie van Financien fur UStFragen zuständlg war. Von dieser Position aus wußte er die der Exekutive gegebene "Blankovollmacht"130 zu nutzen, um der BruttouSt eln solches Belastungsprofll zu geben, wie es einer allgemeinen Verbrauchsteuer in Form einer Einzelhandelsust entspricht. ${ }^{131}$ Auf der Basis einer gut funktionlerenden Verwaltung und einer ausgebauten Unternehmensbuchhaltung entfernte slch die nlederländische USt weiter von ihrem kumulativen Ursprung als in jedem anderen Mitglledstaat der EG. Die Folgen einer solchen Politik lagen klar auf der Hand. Als in Deutschland und bel der Kommission die große Diskussion um die Einfuhrung der MwSt begann, war in den Niederlanden fast jeder mit der dortigen USt zufrieden:

- Die vertikal integrierte Großindustrie fürchtete, durch den Ubergang von einer Brutto- zu einer NettouSt schlechter gestellt zu werden.

- Auch die nur mäßig integrierten Kleinunternehmen verlangten nach kelner durchgrelfenden Reform. Ihre Wettbewerbsnachtelle waren bereits und wurden ständig weiter abgemildert.

- Die Einzelhändler befürchteten von einer MWSt die erneute Einbeziehung in die Besteuerung, eine Vorahnung, die sich spater als vollkommen gerechtfertigt herausstellen sollte.

- Exporteure und die mit Importen konkurrierenden Unternehmen hatten mit der Liberalisierung in der EG keine Probleme. Zwar war der Grenz-

\footnotetext{
129 Persönliches Intervlew.

130 Persönllches interview.

131 Vgl. Tuk (1959), S.288.
} 
ausgleich nicht 100prozentig wie bei den Franzosen, aber das niederländische System war doch perfektionierter als das der Belgier oder gar der Deutschen, den beiden wichtigsten Handelspartnern.

Für diese Zufriedenhelt mit slch und ihrer Steuer bezahlten die Niederländer auch einen Preis. Schon zu Beginn der 50er Jahre war von Beobachtern der niederländischen Steuerpolltlk vorgeschlagen worden, wegen der Komplizlerthelt der USt elne "slence of tax paying"132 zu begründen. Aber dles war nur der Anfang:

"Over time, the Dutch turnover tax became excessively unwiedly (particularly after attempts at simplification) - so much so that it was sald that only its priniciple draftsman was fully cognizant of all the intricacles."133

Immerhin: Herr Tuk behielt also den überblick. Er befand die von ihm geschaffene Steuer für in Ordnung und sah keinerlel Anlaß dafür, sein Werk durch eine europalsche MWSt ersetzen zu lassen" ${ }^{134}$ : $\mathrm{Er}$ mochte die MWSt nicht"130.

Mit dieser Ansicht stand Tuk in den Niederlanden keineswegs alleine da. Unterstützt wurde er über lange Jahre hinweg insbesondere vom Staatssekretär Im Finanzministerium van der Berge, der während seiner von Ende 1959 bis April 1965 dåuernden Amtsperiode den Harmonisierungsplänen der Kommission ein kompromißloses Nein entgegensetzte. ${ }^{136}$ Zum einen war van der Berge nicht gerade einer der begeisterungsfähigsten Europäer, den die Nlederlande aufubleten hatten, sondern eher einer derjenigen, die befriedigt waren, wenn de Gaulle den weiteren Integrationsproze $\beta$ wieder einmal aufhlelt. Zum anderen handelte es sich um einen eher konservativen und auf Sicherheit bedachten Finanzpolitiker, der "seln eigenes Haus in ordnung halten wollte"137. Er war bestrebt zu verhindern, daß gerade auf dem von $\mathrm{thm} \mathrm{zu}$ verantwortenden steuerpolitischen Geblet Kompetenzen unwiderruflich nach Brüssel verlagert wurden, wăhrend ăhnliches in anderen Polltikbereichen noch lange nicht in Sicht war. Insbesondere die Abschaffung der Steuergrenzen war ihm nicht geheuer: Sollten die Niederlande etwa darauf festgelegt werden, die nledrige Indirekte Besteuerung auf das in Frankrelch oder Italien übliche Niveau anzuheben? Wenn aber die Beselt1gung der Steuergrenzen nicht Endzlel der USt-Harmonisierung sein konnte oder sollte, so bestand, wie er vollkommen zu Recht argumentierte, auch

\footnotetext{
132 Hijszeler (1953), S.89.

133 Cnossen (1981), S.226.

134 Vgl. Tuk (1959), S.322f. Vgl. a. Tuk (1961).

130 Persönliches Interview.

136 Vgl. z.B. Le Monde 9.3.63.

137 Persönliches Interview.
} 
keinerlel Grund dafür, den Niederlanden die Einführung elner MWSt vorzuschreiben.138 Das Nein van der Berges zur MWSt bedeutete gleichzeltig das Nein der Nlederlande, da

- das Finanzministerium bei europapolitischen Fragen dann nicht übergangen werden kann, wenn die Steuerpolitik Im Splel ist; ${ }^{139}$

- dem Staatssekretăr Im Finanzministerium im steuerpolitischen Willensbildungsproze $\beta$ der Nlederlande eine zentrale Funktion zukommt, die van der Berge Im Falle der MwSt auch voll zur Geltung zu bringen wußte;

- die nlederländische Industrle und der Handel der MwSt aus den oben beschriebenen Gründen abwartend bls ablehnend gegenüberstanden.

Van der Berge stellte dem Anliegen der Kommission zwar kein offenes und schlichtes Neln entgegen, aber er formulierte endlose Fragen, die den ganzen Entscheldungsproze $\beta$ erst einmal lahmlegen sollten. Die Kommission erkannte recht Pruhzeitig dieses "holländische Widerstandsnest"140. Kommissar von der Groeben fuhr daher bereits im April 1964 mit elnem Mitarbelterstab zu zweltägigen Gesprächen mit van der Berge nach DenHaag, um der europälschen MWSt den Weg zu ebnen.141 Auch wenn dle Begegnung in einer nach Augenzeugenberichten persönlich sehr angenehmen Atmosphäre verlief, inhaltlich kam dabel nichts heraus. Mit den beiden Hauptakteuren "stießen zwel Welten aufelnander"142. Wahrend van der Berge die Auswirkungen von allem und jedem wissen wollte, bevor er zu einer Tat bereit war, wies von der Groeben, mehr mit der Haltung eines Geschätsmannes, darau hin, daß Jede Anderung eln gewisses Risiko beinhalte und daß man dieses Rísiko nicht beseitigen, sondern es nur hinnehmen könne.

Uberraschen konnte der negative Ausgang der Gesprăche nicht. Ohne einen auf eine USt-Reform hinwirkenden Druck von seiten der nlederländischen Finanz- und Wirtschaptspolitik selbst brauchte van der Berge seine ablehnende Position keinen Millimeter welt $\mathrm{zu}$ bewegen. Dies war auch Brüssel schnell klar, kamen doch glelch zwel an der USt-Harmonisierung betelligte Mitarbeiter der Kommission aus den Niederlanden. So blieb allein die Hopfnung, daß der entprechende Druck in DenHaag einmal entstehen und/ oder van der Berge bald als Staatssekretär abgelost werden würde. Belde Hoppnungen sollten im Laufe des Jahres 1965 in Erfullung gehen.

\footnotetext{
138 Vgl. ahnl. Antal (1963).

139 Vgl. Puchala (1980), S.217.

140 Persőnliches Interview.

141 Vgl. z.B. NZZ 22.4.64.

142 Persönliches Interview.
} 
Dle Einführung der MwSt: $1966-1968$

Was von der Groeben 1964 nicht gelingen wollte, das schafften zwei voneinander unabhăngige Entwicklungen, die die USt-Reform in den Niederlanden okonomisch notwendig und dann auch politisch moglich werden ließen. Die erste der beiden Entwicklungen war Innenpolitischer Natur. Bel etwa gleichblelbender Bedeutung des Aufkommens aus der USt - selt 1955 betrug der USt-Satz unverändert 5\% - mußte der ansteigende Finanzbedarf zunehmend durch Erhőhungen der direkten Steuern gedeckt werden. Bereits Anfang der 60er Jahre setzte sich in den Niederlanden immer mehr die Aupfassung durch, daß die direkten Abgaben nicht weiter angehoben werden dürften, sondern im Gegentell reduziert werden müßten.143 Auch bel der USt war nicht mehr Geld zu holen, da elne Erhöhung des Steuersatzes auf 6\% die Nachteile der Bruttoust - auch in der modifizierten niederländischen Version - zu groß hätte werden lassen. Da in Anbetracht der angespannten Konjunkturlage in den fruhen 60er Jahren auch noch eine eher restriktive Finanzpolltlk angezeigt war, blleb den Polltikern allelne die Möglichkelt, bel den Ausgaben sehr zurlickhaltend zu sein. ${ }^{144}$

Dieses labile finanzpolitische Gleichgewicht wurde nachhaltig gestört, als sich Im Fruhjahr 1965 mit dem Eintritt der Sozialisten in die Regierungskoalition unter Premier Cals eln grundlegender Kurswechsel in der niederländischen Polltik ankündigte. Nach jahrelanger öfentlicher Sparsamkeit verschaffte sich nun der wunsch nach mehr staatlichen Aktivitäten Gehör: Die Sozialisten hielten zusătzllche Staatsausgaben für nötig und ordneten sle an. "Hollands Regierung braucht Geld"145 - das war die unauswelchliche Folge der neuen Politik. Da die direkten Steuern ausgereizt waren, versuchte es der sozlalistische Finanzminister Vondeling u.a. mit der Wiedereinfuhrung der USt auf Textillen. Den Vorschlag mußte er jedoch unter dem geballten Druck von Wirtschaftsverbänden und Gewerkschaften wieder zurucknehmen.146 Das Staatsdefizit stieg und mit ihm die Inflation und die Wahrscheinlichkelt einer Reglerungskrise. ${ }^{147}$ In einer Art Verzweiflungstat unterschrieb Vondeling noch am 6.0ktober 1966 elne allgemeine Erhöhung der USt von $5 \%$ auf $6 \%$. Aber es war zu spät. Die Unfăhigkeit der Regierung, die Staatsfinanzen in Ordnung zu bringen, löste bereits am 14.Oktober elne Regierungskrise aus, die zum Sturz der Reglerung Cals/ Vondellng fuhrte. ${ }^{148}$

\footnotetext{
143 Vgl. z.B. Schendstock (1964).

14 Vgl. Schendstock (1964). Vgl. a. Dle Presse 20.9.65.

140 Titel eines Artikels in Die Presse v. 20.9.65.

146 Vgl. z.B. FAZ 4.10.65 u. Industrie Kurier 13.11.65.

147 Vgl. Z.B. Handelsblatt 21.9.66.

148 Vgl. z.B. FAZ 23.11.66.
} 
Was war Vondelings Problem gewesen? Er brauchte Geld, und das konnte er nur von der USt bekommen. Eine partlelle Erhøhung der USt nur für bestimmte Wirtschaftszwelge erzeugt hohen polltischen Gegendruck: Das bekam Vondeling - wie andere Finanzminister zu anderen Zeiten in anderen Ländern auch - deutlich zu spüren. Eine allgemeine Erhø̋hung der USt war angesichts des nach wie vor kumulativen Systems recht problematisch: Das wußten die Niederländer spätestens seit 1951, und sie hatten daher das Aufkommen aus der USt auch nicht mehr zu stelgern versucht. ${ }^{149}$ Was allein helfen konnte, war eine grundlegende Reform der nlederländischen USt, um auf dieser Basis mehr Spielraum für eine Erhöhung der indirekten Steuern zu haben. Das war auch Vondeling rasch klar geworden, und er llebăugelte daher mit der Einführung elner MwSt.

Von selten seines Finanzministeriums hatte Minister Vondeling seit Anfang 1965 keinen unüberwindlichen widerstand mehr zu befürchten. Staatssekretär van der Berge war ersetzt worden durch Hoefnagels, der sich für UStFragen nur wenig interessierte. In dleser Hinsicht hatte Vondeling also frele Hand. Wovor er aber zuruckschreckte, war seine eigene Partel. Die Sozialisten betrachteten die MWSt als regressiv und stimmten später in der Zweiten Kammer des niederlăndischen Parlaments ihrer Einfuhrung auch nicht zu. ${ }^{150}$ Vondeling blleb damit nur elnes ubrig: Er bereitete dort, wo er politisch nur schwer kontrolliert werden konnte, langsam den Boden fur die Einfuhrung der MwSt vor.

Vondellng verpflichte sich Anfang 1966 gegenüber den anderen Mitglledstaaten in der EG, bls Januar 1967 elne Entscheldung über die europalsche MwSt herbeifuhren zu helfen.101 Desweiteren setzte er im Finanzministerium unter Leitung des Beamten Millenaar elne Arbeitsgruppe ein, dle einen Vorschlag für elne niederländische MWSt ausarbeiten sollte. Der "Studienentwurf fur ein Mehrwertsteuergesetz"182 wurde Im Jull 1966 veroffentlicht und an die Wirtschaftsverbände gesandt, um dort eine öfentliche Debatte uber die MWSt anzuregen. Um nicht die politische Verantwortung hierfur ubernehmen zu müssen, grifp Vondeling zu dem für nlederländische Verhălt-

149 Vgl. z.B. Jansen (1967), S.81f. Vgl. a. NZZ 26.10.67. Jahre später Pand man in Zeltschriftenveröffentlichungen: "Infolge des ... progressiven Ansteigens der Sătze der Umsatzsteuer in den Niederlanden wuchsen ... die durch das kumulative System hervorgerufenen Verzerrungen." Millenaar (1969), S.127; vgl. ăhnl. Cnossen (1981), S.226. Dlese Darstellung trifft nicht den Kern der Sache, war doch gerade das speziPisch niederländische Problem, daß der USt-Satz von 1955 bis kurz vor Einfuhrung der MWSt nicht erhöht werden konnte!

150 Vgl. FAZ 19.1.67.

101 Vgl. Kap.C.2.1.4.4.

152 In deutscher Fassung abgedr. In: Bulletin for International Fiscal Documentation, 20.1966, s.488f1. 
nisse vollkommen neuen Verfahren, den Studienentwurf nicht selbst zu unterzeichnen, sondern ihn unter dem Namen des Finanzbeamten Millenaar zu veröfentlichen.

Bel der hier beschriebenen Entwicklung hin zur MWSt handelte es sich um eine eher langfristige Tendenz, die letztendlich aup den Anstieg des staatlichen Finanzbedarps zurückzufuhren ist. Daneben gab es 1966 noch eine zweite Entwicklung, die ebenfalls eine Entscheidung zugunsten der MwSt Immer dringlicher werden ließ: Es wurde deutlich und bel der EG auch immer offener gesagt, daß dle Deutschen sehr bald, und notfalls auch ohne ihre Partner in der EG, zur MWSt ubergehen wüden. Bislang hatte der in den Nlederlanden ubliche Grenzausglelch über dem der Deutschen gelegen. Sollte Deutschland nun plötzlich die MwSt elnfüren, so wüde sich dieses Verhältnis mit einem Schlag umkehren. Nachdem die niederländische Zahlungsbilanz von 1965 auf 1966 sowleso schon ins Defizit gerutscht war ${ }^{193}$, hatte die Quasi-Abwertung des großßten Handelspartners die WettbewerbsPahigkeit der nlederländischen Wirtschaft empfindlich getroffen. Wollte man eine Abwertung des Guldens vermeiden, so gab es nur eines: die Flucht nach vorne in eine Steuerreform. ${ }^{104}$

Vondellng konnte mit Rücksicht auf seine sozialistische Partel die erforderliche Flucht nur halbherzig und zu spät antreten. Er hătte die MwSt zur Finanzlerung seiner Ausgabenpolitlk bitter nötlg gehabt. Aber Im November 1966 war seine Zeit abgelaufen. Die Reglerung Cals/Vondeling stürte wegen der zerrutteten Staatsfinanzen, der Inflation und des Zahlungsbilanzdefizits. Kurz danach bildete sich ein Ubergangskabinett unter Leitung des welthin als Finanzexperten geachteten Prof. Zijlstra, der neben dem Stuhl des Premiers auch gleich das Finanzministerium mit ubernahm. ${ }^{105}$ Zjjlstra verwirklichte mit seiner Autorităt, wozu Vondeling die Kraft gefehlt hatte. Nachdem er noch im Dezember in der Zweiten Kammer des Parlaments mit wechselnden Mehrheiten ein hartes Steuererhöhungspaket durchgesetzt hatte, ${ }^{106}$ stimmte er bereits im Februar 1967 im Ministerrat der EG der EinPührung der MwSt zu. Für diese Tat wurde er in Brüssel als "großer Europăer"107 gefelert. Obwohl er dies auch ohne Frage 1st, so war es neben seinem europäischen Geist doch auch die Einsicht in das Pinanzpolitisch Notwendige, das thn den ersten belden USt-Richtlinien zustimmen ließ.

Unter dem Druck der deutschen Entscheidug, die MWSt bereits zum 1.Januar 1968 einzuruhren, legte dle neugewählte niederländische Reglerung schon im

\footnotetext{
193 Vgl. z.B. Handelsblatt 21.9.66.

134 Vgl. z.B. Le Monde 9.2.67.

150 Vgl. z.B. Frankfurter Rundschau 23.11.66.

186 Vgl. FAZ 20.12.66.

107 Persönliches Interview.
} 
Oktober 1967 ihrem Parlament einen Gesetzesvorschlagis8 vor. Das politisch brisanteste Problem des Regierungsentwurfs war zwelfellos die Einbezlehung des seit 1955 steuerbefreiten Einzelhandels in die MwSt. Aber die Finanzverwaltung wollte es - "Steuerbefrelungen haben in einer MwSt keinen Platz"199 - und die Organisationen des Großhandels ubten einen entsprechenden Druck aus, sodaß auch dieses Problem gelöst und die MWSt berelts zum 1.Januar 1969 eingepuhrt werden konnte. ${ }^{160}$

Wie sehr das durch die MWSt ermöglichte zusätzliche Steueraufkommen in den Niederlanden benötigt wurde, zeigte sich deutlich an der Entwicklung der Steuersätze. Nachdem der Satz der alten USt selt 1955 bei 5\% verharrt hatte - Mitte 1967, also kurz vor Einfuhrung der MWSt, war er noch schnell auf 6\% angehoben worden -, stieg der Standardsatz der MWSt in einer auch für andere Lănder atemberaubenden Geschwindigkelt von $12 \%$ im Jahre 1969 auf 18\% sleben Jahre später an.

Europa und dle Nlederländer

Es war also in langfristiger Sicht der ansteigende Finanzbedarf und in kurzfristiger Sicht die deutsche Entscheidung für dle MWSt - "Wir haben die MWSt eingefuhrt, weil sle die Deutschen eingefuhrt haben"161 -, die die Niederlande für die MWSt votieren ließen. Die Kommission und der Rat waren nicht in der Lage, auf die Entscheldung in DenHaag direkten Einfluß zu nehmen, wie man ihn sich etwa in folgender Form vorstellen könnte: Auf die Niederlande wurde auf allen Ebenen politischer Druck ausgeubt, bis schlleßlich der Europäer Zulstra kam und der MWSt zustimmte. ${ }^{162}$ Der Einfluß der EG auf DenHaag war subtilerer Art, dafur aber nicht minder wirkungsvoll.

In der Periode bis 1965 beeinflußte dle EG uber die verschledensten in Brüssel tagenden Arbeltsgruppen die Diskussion im Haager Finanzministerlum. Finanzbeamte unterhalb der Ebene von Tuk und van der Berge waren seit 1960 in die Brüsseler Uberlegungen zur USt-Reform im allgemeinen und zur MWSt im besonderen eingebunden. Auch wenn van der Berge seinen Mitarbeitern einschärfte: "Fahren Sie nach Brüssel, hören Sle gut zu, sagen

180 Beschrieben in: 1968 Bill to Introduce a Turnover Tax on Value Added, In: European Taxation, 8.1968, S.30ff. Vgl. a. Wagner (1967).

159 Persönliches Intervlew.

160 Vgl. Millenaar (1969) u. Millenaar (1970).

161 Persönllches Intervlew.

162 Puchala scheint eine in diese Richtung gehende Erklärung vorzuschlagen; vgl. Puchala (1980), S.217f. 
Sie aber nichts"163 - die Dinge liefen anders. Die Order wurde eingehalten, solange die "Politiker"164 in Brüssel anwesend waren. Ansonsten aber arbeltete man Pleißig an der europäischen MWSt mit. So wurden die nlederländischen Finanzbeamten für die Probleme ihrer USt sensibilisiert, die MWSt wurde als elne machbare Alternative schätzen gelernt und in ihren Detalls ausgearbeitet. Als 1965/66 Immer mehr handfeste ökonomische Grunde für die Einführung der MWSt sprachen, waren die Finanzbeamten dazu bereit und bestens auf lhre Aupgabe vorbereltet. In kürzester Zeit konnte daher 1966 unter der Federfuhrung von Millenaar der Studienentwurf und 1967 von Reugebrink und Simons der endgaltige Gesetzesentwurf ausgearbeltet werden: Alle drel der genannten Finanzbeamten hatten vorher thr Land bei den Beratungen in Brtissel vertreten.

Es wird hier deutlich, daß sich die nlederländische gänzlich von der deutschen MWSt-Debatte unterschieden hat. In Deutschland riefen selt Anfang der 50er Jahre einflußreiche Wirtschaftskreise nach einer Reform der USt, und die Finanzverwaltung blockierte sle auf Jahre. In den Niederlanden rief Anfang der 60er Jahre nlemand nach einer Reform, aber die Finanzverwaltung war bereits darauf vorbereltet.

Nachdem Ende 1965/Anfang 1966 die ökonomischen Notwendigkeiten elne Einfuhrung der MWSt in den Niederlanden als immer dringllcher erscheinen ließen, gab die EG den niederländischen Finanzpolitikern die Ruckendeckung, die nötig war, um dle MwSt möglichst schnell und möglichst unverfälscht durchsetzen zu können. Vondeling legte, wle schon erwähnt, sein Land in Brussel daraup fest, bis Anfang 1967 eine Entscheldung uber die MWSt herbelzufuhren. Wahrend dies damals in Holland nicht weiter bemerkt wurde - und damit für Vondeling ungefährlich war -, konnte sich Zijlstra später darauf berufen, Indem er erklärte, nlcht er sel für die MWSt verantwortlich, sondern Vondeling hătte sich gegenuber der EG bereits dazu verpflichtet. Als schlleßlich im Oktober 1967 der Gesetzentwurf vorgelegt wurde, war in der Begrünung zu lesen, daß die MWSt ausschlleßlich wegen der EG eingeruhrt werden mulsse. Das war zwar elne "polltische Lüge"160, verkürzte Jedoch wesentlich die innenpolitische Diskussion aber dieses Thema. Eine Grundsatzdebatte uber die Einfuhrung der MwSt mit deren uberaus zahlreichen Kritlkern innerhalb und außerhalb des Parlaments war von vornherein ausgeschlossen. Der entsprechende Brüsseler Beschluß war ja nicht mehr zu ändern. Dle EG machte es darüberhinaus möglich, die sich eng an die EG-Richtlinien anlehnende Regierungsvorlage weitestgehend gegen die vielen vom Parlament vorgebrachten Sonderwünsche zu verteldigen. Wăhrend der Pünftägigen Parlamentsdebatte konnte der zuständige Staatssekretär Grapperhaus zahlreiche Abănderungsantrăge mit dem Hinweis

\footnotetext{
103 Persönliches Interview.

164 Personliches Interview.

160 Persönllches Interview.
} 
abblocken, dies verstoße gegen die EG-Richtlinien. Das genannte Argument gebrauchte er zwar extensiver, als die Richtlinien es bel genauem Hinsehen zulleßen, aber die Strategle war überaus erfolgreich. Die meisten Anderungsanträge wurden abgelehnt, die MWSt war angenommen und konnte bereits zum 1.Januar 1969 eingefuhrt werden. Den Preis hierfür bezahlten besonders die Parlamentarier: Sle verließen die MWSt-Debatte am Ende sichtlich frustriert. ${ }^{166}$

Auch hier zeigt sich wieder deutlich der Unterschied zur deutschen MWStDiskussion. Bls zur Einführung der MWSt hatten die Deutschen elne über 15 Jahre lange öffentliche Diskussion hinter sich. Mit Hilfe der in Deutschland gemachten Erfahrungen und der EG schafften die Niederlande das gleiche in nur zwel Jahren und kamen dabei zu einer MWSt, dle zumindest in einigen Aspekten der ein Jahr früher eingeführten deutschen bereits überlegen war. ${ }^{167}$

Abschlleßend bleibt zu sagen, daß sich DenHaag über kurz oder lang vielleicht in der ersten Hälfte der 70er Jahre - sicherlich auch ohne die EG zu einer durchgreifenden USt-Reform durchgerungen hätte. In diesem Fall aber wäre der Name der neuen USt wohl kaum MWSt gewesen. Wie in Belgien so hătten auch die flnanzpolitischen Traditionen der Niederlande den Ubergang $\mathrm{zu}$ elner einphasigen Abgabe nahegelegt. Berelts zu Beginn der 60er Jahre hatte sich das Haager Finanzministerium uber Einphasensteuern Gedanken gemacht, die Uberlegungen aber in einem frühen Stadium wieder eingestellt, da die Zeichen in der EG in eine andere Richtung deuteten.

166 Vgl. FT 10.6.68, Frankfurter Rundschau 18.6.68 u. Observer Foreign News Service 21.6.68.

167 Vgl. Schindler (1970). 
Bel der Verabschledung der ersten belden USt-RIchtlinien konnten die Briten, da ihnen damals dle Tür zur EG noch verschlossen war, natülich nicht mitreden. Umgekehrt aber hatte die umsatzsteuerliche Entwicklung in der EG einen nicht unerheblichen Einfluß auf die Steuerpolltik Großbritanniens. Da zudem die vor dem britischen EG-Beitritt auf der Insel beschlossene Einfuhrung der MwSt von großer Bedeutung fur den spăteren Fortgang der europäischen Steuerharmonisierung war, erscheint es sinnvoll, dle USt-Reform Im Vereinigten Königreich ein wenig aus der Nahe zu betrachten.

\section{Die erste MWSt-Debatte: $1960-1963$}

Eine Abgabe, die man guten Gewissens als allgemeine USt bezelchnen kann, gab es in Großbritannien vor Einfuhrung der MWSt strenggenommen nicht. Am ehesten noch könnte die sogenannte Purchase Tax unter die genannte Kategorie Pallen. Bel der Ende 1940 als Kind der Not aus der Taufe gehobenen Purchase $\operatorname{Tax}^{160}$ handelte es sich um eine einphasige GroßhandelsuSt. Sle war "unique among the sales taxes of the world"169. Ihre Steuersatze errelchten schwindelerregende Hohen - der höchste Satz lag wăhrend des Krieges bel $100 \%$ und noch 1957 bel $90 \%$ - und waren in extremer Welse differenziert - nach anfänglich $z$ wel wurden 1957 sieben verschiedene Steuersătze erhoben. Die Bemessungsgrundlage war, da alle Güter eines sehr welt definierten Grundbedarfs von der Steuer befrelt waren, sehr schmal. Das Aufkommen der Steuer blieb daher vergleichsweise gering und wurde von dem der Tabaksteuer oder dem der Mineralblsteuer bei weitem ubertroffen. ${ }^{170}$

Sonderlich zufrieden waren die Briten mit ihrer Purchase Tax schon in den 50er Jahren nicht. ${ }^{171}$ Probleme bereitete dle korrekte Abgrenzung der zu besteuernden Großhandels-Stufe wie auch die saubere Unterscheidung $\mathrm{zw1}$ schen (steuerpflichtigen) Konsum- und (steuerPreien) Investitionsgutern. Anlaß zur Kritlk gaben darüberhinaus die enorme Höhe der Steuersätze, deren großen Zahl und insbesondere die Tatsache, daß die Sătze ebenso hăufig wie für die Wirtschaft unvorhersehbar abgeăndert wurden. All die genannten Schwierigkeiten hätte man ohne weiteres mit einer systemimmanenten Reform der Purchsse Tax in den Griff bekommen können. Es wäre vollig ausreichend gewesen, die Bemessungsgrundlage der bestehenden

168 Das Konzept der Purchase Tax war schon 1922 entwickelt worden, konnte aber erst in der Pinanzlellen Zwangslage des Krieges politisch durchgesetzt werden. Zu ihrer Geschichte vgl. z.B. Due (1957), S.202ff. Vgl. a. Prest (1964), S.17fP.

169 Due (1957), S.202.

170 Vgl. Butler (1968), S.349. Vgl. a. Richter (1968), S.23.

171 Vgl. Due (1957), S.210pP. 
Steuer auszuwelten und Im Gegenzug die Höhe und die Zahl ihrer Sătze zu verringern. Selbstverständlich wären die mit der Definition des Großhandels und der Investltionsgüter verbundenen Probleme nicht gänzlich verschwunden. Bel einem relativ geringen Steuersatz - er lag angesichts des niedrigen Aufkommens der Purchase Tax durchaus im Bereich des Moglichen hätten sie allerdings zur Bedeutungslosigkelt reduzlert werden können. Einen ersten und sehr vorsichtigen Schritt in die hler skizzlerte Richtung unternahm die britische Regierung 1958. Die Zahl der Steuersătze wurde von sleben auf vier und der Höchstsatz von $90 \%$ auf $60 \%$ herabgesetzt. Weitere Maßnahmen aber blleben, von wenigen Einzelfallen abgesehen, in der Folgezeit aus. Stattdessen begannen die Briten ab 1960 damit zu llebaugeln, dle Purchase Tax durch eine MWSt zu ersetzen. Dle Frage drăngt sich auf: warum?

Ausgelöst wurde die erste britische MWSt-Debatte durch die Tatsache, daß der Inselstaat an den Kontinent heranzurucken begann. Im Jahre 1959 hatte das Vereinlgte Königreich der EG ein erstes Beitrittsgesuch unterbreitet. Dle populär werdenden Gegenüberstellungen der elgenen Volkswirtschaft mit denen der EG machten die Probleme der Briten vor aller Augen sichtbar: erschreckend nledrige Wachstumsraten und eine chronisch defiz1täre Zahlungsbilanz. Auf der Suche nach den Ursachen wurden internationale Polltikvergleiche angestellt. War es vielleicht, so wurde rasch die Frage gestellt, die in Frankreich berelts erhobene und nun in Brüssel von der EG diskutierte MWSt, die dem von der britischen Krankheit befallenen Königreich Linderung verschaffen könnte? Entsprechende Stimmen waren zunächst nur vereinzelt zu høren, wurden aber 1962 Immer lauter. Sle kamen zum elnen von dem in 1961 als "pressure group for growth"172 gegründeten National Economic Development Office. Das NEDO schlug in elnem zum Thema "Conditions Favourable to Faster Growth"173 erstellten Bericht vor, baldigst auch in Großbritannien elne MWSt elnzufuhren. Ahnlich äußerte sich eine Arbeitsgruppe von Finanzpolitikern der Konservativen Partel.174 Vor diesen Rufen konnte auch Tory-Schatzkanzler Maudling seine Ohren nicht länger verschließen. Er kundigte in seiner Budget Speech vom 3.Aprll 1963 die Gründung einer unabhängigen Expertenkommission an, die die Wirkungen der Einfuhrung einer MWSt auf die britischen Exporte und das Wachstum analysieren sollte. ${ }^{175}$ Das nach seinem Vorsitzenden benannte Richardson-Committee kam, nach Anhörung betroffener Wirtschaftskreise und zuständiger Wissenschaftler, Anfang $1964 \mathrm{zu}$ elnem elndeutig negativen

\footnotetext{
172 Brittan (1964), S.329.

173 NEDO, Conditions Favourable to Faster Growth, London 1963.

174 Vgl. Times 14.3.63. Aufgeschreckt durch die Entwicklung in der EG beschaftigten sich auch Finanzbeamte und Akademiker mit der MWSt; vgl. FT 23.11.62; vgl. a. Prest (1963), Stout (1963) u. Wheatcroft (1963).

175 Vgl. Times 4.4.64.
} 
Ergebnis. ${ }^{176}$ Die Ablehnung der MWSt wurde gerechtfertigt mit den folgenden beiden Argumentationssträngen:

- Als Ersatz für die Purchase Tax konnten die Experten der MWSt keine Vorteile abgewinnen: Elne Belastung für den Außenhandel stellte die elnphasige Purchase TaX - im Gegensatz zu einer Bruttoust - nicht dar, und die anderen Probleme waren mit systemimmanenten Reformen hinrelchend zu lösen.

- Auch als Alternative zur Profit Tax kam die MwSt für den RichardsonAusschuß nicht in Frage: Eine Belebung der Exporte war von der MWSt nicht zu erwarten, da sie, als indirekte Steuer, im Gegensatz zur direkten Profit Tax in die Preise eingeht und so den erhöhten steuerlichen Grenzausglelch vollständig kompensiert; darüberhinaus regt eine Senkung der Profit Tax auch die Investitionen nicht an, da die Unternehmer, nach elgenen Aussagen, die Gewinnsteuer nicht in ihr Investitionskalkül einbezlehen.

Das erste der beiden Argumente ist vollkommen korrekt, das zweite aber läßt sich nicht auprechterhalten. Die Behauptung, eine Gewinnsteuer habe, obwohl sie nicht überwälzt wird, keinen Einfluß auf die Investitionstätigkelt, gilt nur unter ganz extremen Annahmen und dürfte in der Realität keine Rechtfertigung finden. Hätten die Unternehmer die Implikationen ihrer Aussagen durchschaut, so hätten sie wohl alles widerrufen und auf dem Gegenteil bestanden: "If it were true that profits taxation affect neither prices nor investment the Government would have an ideal source of revenue."177

Fraglich allerdings ist, ob es die dürftige Qualität der im RichardsonAusschuß ausgetauschten Argumente war, die letztendlich zur Ablehnung der MWSt geführt hat. Ein damaliger Mitarbeiter des NEDO und erklärter MWSt-Befurworter erinnert sich: Der Richardson-Ausschuß "..did not really listen to our arguments."178 Man brauchte ihnen nicht zuzuhören, da, abgesehen von dem NEDO und ein paar Einzelgängern, niemand in Großbritannien den MwSt-Vorschlag wirklich unterstützte:

- Die für indirekte Abgaben zuständige Finanzbehörde HM Customs and Excise "flercly resisted"179 eine MWSt wegen der damit verbundenen Flut

\footnotetext{
176 Vgl. Cmnd 2300, London: HMSO 1964. Eine Kommentierung des vom Richardson-Ausschuß erstatteten Berichts findet sich bel Richter (1968), S.85P.

177 Butler (1968), S.42.

178 Persönliches Intervlew.

179 Brittan (1964), S.225.
} 
neuer Steuerpflichtiger: "They always found new arguments"180, die gegen die MWSt ins Feld geführt werden konnten.

- Die mittelständischen Unternehmen Pürchteten die mit der MWSt auf sie zukommenden Buchfürungspflichten.

- Die anderen Unternehmen waren sehr zurückhaltend wie bel allen Reformvorhaben, die thnen keine in Pfund und Pence ausdrückbare Steuererleichterung beschert. Die von den Briten angestellte differentielle Wirkungsanalyse MWSt versus Gewinnsteuer - eine Fragestellung übrigens, die so in Brüssel nie diskutiert wurde - trug, da sie mit zahlreichen Unwägbarkeiten behaftet ist ${ }^{181}$, zur Verunsicherung der Unternehmer und damit zu deren Ablehnungshaltung maßgeblich bei.

- Die Labour Party und die Gewerkschapten lehnten die MwSt als regressiv ab. Vertellungsgerechtigkeit war schon uber Jahrzehnte hinweg eines der Hauptzlele britischer Steuerpolitik gewesen.182 Im traditionsverbundenen Großbritannien kam dabel der Steuerfrelheit von Lebensmitteln - man sprach von einem 100 Jahre alten Prinzip und rekurlerte damit auf die Corn Laws von 1846 - elne ganz besondere Bedeutung zu.

- Die meisten britischen Finanzpolitiker hatten mit steuerlicher Neutralität - die Stärke der MWSt - nur wenig im Sinn. Ihre Wirtschaftspolitik war vielmehr, spätestens seit den Tagen der Kriegswirtschaft, von interventionistischem Gedankengut geprägt. ${ }^{183}$ Gestützt aup ein mechanistisches Bild von der Funktionsweise einer Volkswirtschapt glaubten sie daran, wirtschaftliche Größen wie Wachstum und Zahlungsbilanz mittels staatlicher Eingriffe gezielt beeinflussen zu können. Neben den direkten Steuern war auch die Purchase Tax, da ihre Sätze ohne größere administrative Reibungsverluste differenziert werden konnten, ein ideales Eingriffsinstrument. Die neutrale MWSt paßte, ganz offensichtlich, in ein solches Konzept nicht hinein.

Zuviele Gründe sprachen in Großbritannien gegen die Annahme der MWSt. Da, nachdem de Gaulle 1963 das britische Beitrittsgesuch zur EG schropp abgewiesen hatte, dem Königreich die Tür zur Gemeinschaft auf einige Jahre hinaus verschlossen worden war, war inzwischen auch der eigentliche Anlaß weggefallen, der die ganze Reformdebatte provoziert hatte. Das An-

\footnotetext{
180 Persönliches Interview.

181 "..specific forecasts are more likely obtained through the arts of the astrologer rather than the science of the economist, given the present state of knowledge." Prest (1967), S.21.

183 Vgl. Z.B. Richter (1968), S.35.
} 
Pang 1964 ausgesprochene Nein des RIchardson-Committee bedeutete daher das vorläufige Aus für die MWSt in Großbritannien.

\section{Weichenstellungen unter Labour: $1964-1966$}

Ein Wahlsieg der Labour Party beendete im Frühjahr 1964 eine 14jăhrige Reglerungszeit der Konservativen. Während sich die Finanzpolitik der Tories durch eine große Kontinuităt ausgezeichnet hatte ${ }^{104}$, machte sich die Arbeiterpartel nun daran, das alte britische Steuersystem an die Bedürenisse elnes hochindustrialislerten Landes anzupassen. ${ }^{185}$ Es war Pech für die MWSt, das sie just am Beginn elner Ara von Steuerreformen von der politischen Tagesordnung gestrichen worden war. Labour hatte aus vertellungspolitischen Gründen kein Interesse daran, die abgesetzte MWSt-Debatte wiederzubeleben. Und auch der okonomische Chefberater der Partel, der außerordentlich elnflußreiche Niklas Kaldor, hielt von der MWSt nicht viel.106 Der einzige Vorteil der MWSt lag, so Kaldor, in ihrer Fähigkeit begründet, über cross-checks der Steuerhinterziehung belzukommen. Was in Frankreich vielleicht unumgänglich war, das hatte man seiner Ansicht nach auf der fur ihre hohe Steuermoral bekannten britischen Insel gar nicht nötig.

Auch wenn sich die neue Regierung mit der MWSt nicht weiter beschäftigte, so wurden unter Labour doch wichtige Weichen für die zweite britische MWSt-Debatte gestellt. Als erstes und eines der wichtigsten Ergebnisse sozialistlscher Finanzpolitik ist die Erhöhung der Abgabenquote zu erwăhnen. Sie stieg von 33,3\% Im Jahre 1964 auf Immerhin 44\% 1970.187 Erhöht wurden, begleitet von einigen Reformen, in erster Linle die direkten Steuern. Demgegenuber blieb bel den Verbrauchsabgaben zunächst alles belm Alten. Da man die Bemessungsgrundlage der Purchase Tax wegen Innerpartellicher Widerstände nicht auszudehnen wagte, fuhr man notgedrungen mit der unter den Konservativen entwlckelten Praxis fort, die Steuersătze auf elnem ertrăglichen Niveau zu halten. Erst 1968 und unter dem Druck eines stelgenden Budgetdefizits entschloß sich die Labour-Reglerung, die Sătze der Purchase Tax zum ersten Mal seit 10 Jahren wieder anzuheben.

Der Erhöhung des Steueraufkommens diente auch dle in 1966 erstmals erhobene Selective Employment Tax, kurz SET genannt. Entstanden war die SET in der Studlerstube des Lord Kaldor. ${ }^{108}$ Es handelte sich um eine von den Unternehmern fur die Beschätigung des Faktors Arbeit zu entrichtende

\footnotetext{
194 Vgl. z.B. Davies (1962), S.81, Richter (1968), S.11, Shoup (1961).

180 Vgl. Robinson/Sandford (1983), S.1.

106 Vgl. Kaldor (1964), S.288. Vgl. a. Robinson/Sandford (1983), S.68f.

187 Vgl. Robinson/Sandford (1983), S.5.

10 Zur Geschlchte und Ausgestaltung der SET vgl. z.B. Robinson/Sandford (1983), S.31Pf. u. S.127ff.
} 
Steuer. Die Abgabe war selektiv in dem Sinne, daß die im Dienstleistungsbereich beschätigten Arbeitnehmer stärker belastet wurden als die in der Industrie tätigen. ${ }^{189}$ Ziel der Satzdifferenzierung war es, den Faktor Arbeit zu einer Wanderung weg von dem arbeitsintensiven Dienstleistungsbereich und hin zu den unter Arbeltskräftemangel leidenden Industrieunternehmen zu bewegen. Damit sollte die Gesamtproduktivität der britischen Wirtschaft gestelgert werden. Begrundet wurde die Satzdifferenzlerung oft mit dem Argument, daß die Dienstlelstungen, im Gegensatz zu vielen Industrieprodukten, nicht der Purchase Tax unterliegen wüden. Die Labour Regierung scheint also die SET als eine Ergänzungssteuer zur Purchase Tax verstanden zu haben. Sle wăhlte für die Ausweltung der Bemessungsgrundlage der Purchase Tax einen indirekten Weg, weil der direkte innerhalb der eigenen Partel nicht durchzusetzen war. ${ }^{190}$ Auch die Wirtschaft und die Gewerkschaften hielten dle SET für elne indirekte Steuer, wiesen sie doch immer wleder daraup hin, daß die Erhebung der SET unwelgerlich zu Preiserhöhungen fulhrte. Dem stand die Behauptung des Lord Kaldor gegenüber, die SET als direkte Steuer konzipiert zu haben. Da die Faktorintensitäten der einzelnen Betriebe unterschiedlich seien, könne die SET, so Kaldor, nicht uberwälzt werden. Aber, so pügte er hinzu: "Melne Steuer ist niemals richtig verstanden worden."191

Ob verstanden oder nicht, jede Interessengruppe fand ein Argument, die SET zu verdammen. Da die Reglerung aus budgetären Gründen auf die neue Abgabe nicht verzichten konnte, versuchte sie immer wieder, die Kritiker mit kleineren Abänderungen der Steuer zu beschwichtigen. Ansatzpunkte für Modifikationen bot die SET zuhauf. Die mit der SET gemachten Erfahrungen wurden zu einem Beisplel par excellence für die politischen Folgewirkungen einer als interventionistisches Eingriffsinstrument konzipierten Steuer:

"With this form of tax the Government had clearly stirred up a veritable hornets' nest, giving tremendous scope to Members (of Parliament, d.Verf.) to express their special interests and the needs of the particular constituencies. ... Hardly any economic activity was without at least one defender. ... The Government, trying to cope with all these pressures on details of the tax, was rather in the position of the Dutch boy, trying to stem the flood by a finger in the dyke."192

189 Darüberhinaus waren die Steuersätze der SET auch nach den Kriterien Alter und Geschlecht der Arbeitnehmer, nach regionalen Gesichtspunkten, etc. differenziert.

190 Vgl. z.B. Butler (1968), S.349.

191 Persönliches Interview.

192 Robinson/Sandford (1983), S.129P. 
Die SET wurde zu einer politischen Katastrophe. Die Stimmung gegen die als "silliest tax since the tax on windows"193 bezeichnete Abgabe war emotional aufgeheizt. Opposition kam von allen Seiten: Unternehmer und Gewerkschaften, Konservative und selbst Teile der Labour Party liefen Sturm. Bald schon hatten die Tories das Gerangel um die SET satt. Sie verpflichteten sich bereits 1967, die Steuer im Falle eines künftigen Wahlsieges sofort abzuschaffen.194 $\mathrm{Da}$ sie ihr Versprechen wiederholt öffentlich bekräftigten, wurde es für die Konservativen immer schwieriger, nach einer Regierungsübernahme davon wieder abzurücken. Woher aber, so stellte sich die Frage, sollte das von der SET bislang erbrachte Steueraufkommen herkommen?

\section{Dle zwelte MWSt-Debatte: $1967-1970$}

Seit Anfang 1964 war die MWSt, auch wenn sie innerhalb des NEDO und von einigen Finanzpolitikern der Konservativen Partei weiter diskutiert worden war, aus dem Blickfeld der britischen Offentlichkeit verschwunden. Erst zu Beginn des Jahres 1967 kam sle aus dem Dunkel der Expertenzirkel zurück ans Tageslicht. ${ }^{195}$ Ausgelöst wurde die zweite britische MwSt-Debatte durch die belden folgenden Entwicklungen:

- Die Labour-Regierung war auf der Suche nach zusätzlichen Finanzquellen, und die konservative Opposition brauchte eine Alternative zur SET.

- Im Februar 1967 hatte der EG-Ministerrat die beiden ersten USt-Richtlinien verabschiedet. Da sich die Regierung Wilson 1967 mit einem neuerlichen Beitrittsgesuch an die Gemeinschaft wandte, war es nur noch eine Frage der Zeit, bis die Briten von Brüssel verpflichtet würden, ebenfalls elne MWSt einzuführen. Schon im Fruhjahr 1967 forderte Oppositionsführer Heath die Regierung daher auf, "with an eye on the prospective entry into the Common Market"196 baldigst einen MWSt-Gesetzentwurf vorzulegen.

Im Zentrum der zweiten britischen MWSt-Debatte standen, wie schon 1962/63, das NEDO und die Finanzpolitiker der Konservativen. 1966 hatte das NEDO, auf Wunsch des damaligen Labour-Schatzkanzlers, eine Arbeitsgruppe ins Leben gerufen, die sich mit der MwSt beschäftigen sollte. Da Grund zur Eile nicht bestand, konnte man sich ein gründliches Vorgehen leisten. Erfahrungen, die kontinentaleuropäische Länder mit der MWSt

193 Schatten-Schatzkanzler Macleod auf der Jahreskonferenz seiner Konservativen Partei in 1967, zitiert in: Robinson/Sandford (1983), S.75.

194 Vgl. Butler (1968), S.275.

195 Zum folgenden vgl. insbes. Robinson/Sandford (1983), S.34ff., S.74ff. u. S.111ff. Vgl. a. Puchala (1984), S.109Pf.

196 Zitiert in: Tímes 14.4.67. 
bereits gemacht hatten, wurden gesammelt und ausgewertet. Darüberhinaus bemühte man sich, von möglichst allen Branchen der britischen Wirtschaft eine Stellungnahme einzuholen. Erstmals waren die Unternehmer nun gezwungen, sich intensiv mit dem Problem MWSt auseinanderzusetzen. Für die MWSt sprachen sich insbesondere die Wirtschaftszweige aus, die unter hohen Sätzen der Purchase Tax zu leiden hatten. Alle und insbesondere die kleinen Betriebe hatten Angst vor elner Komplizierung ihrer Buchführung. Auf der anderen Seite befurwortete der Großtell der Wirtschaft den EGBeitritt Großbritanniens. Man war bereit, als Preis dafür die Einführung der MWSt zu akzeptieren. Angesichts des weiten Spektrums unterschiedilcher Auffassungen konnte sich der 1969 von der NEDO-Arbeitsgruppe veröffentlichte Abschlußbericht ${ }^{197}$ nur wage äußern. Er machte zwar deutlich, daß eine broad based sales tax durchaus erwünscht sei, ließ aber offen, ob dieses Ziel durch die Einführung der MWSt oder aber mittels einer Reform der Purchase Tax errelcht werden sollte.

Auch die Finanzpolitker der Tories setzten sich verstärkt mit der MWSt auseinander. Im Jahre 1967 war der konservative Schatten-Schatzkanzler Maudling - er war nie ein Freund der MWSt gewesen - durch Ian Macleod ersetzt worden. Macleods Ehrgeiz war es, rechtzeitig vor den nächsten Wahlen das Konzept für eine große Steuerreform präsentieren zu können. Abgeschreckt durch das von der SET verursachte Chaos wandte er der interventionistischen Finanzpolitik der Vergangenhelt den Rücken zu. Steuerliche Neutralltat hieß das neue Schlagwort, das Macleod und seine Mitarbeiter auf ihre Fahnen schrieben. ${ }^{198} \mathrm{Zu}$ einem neutralen Steuersystem gehörten, so stellte ein im November 1968 ein Parteichep Heath übermittelter Bericht heraus, niedrige direkte Abgaben sowie eine allgemeine Verbrauchsteuer. ${ }^{199}$ Als Alternativen für die von Macleod geforderte, breit angelegte Verbrauchsteuer kamen, wie bereits mehrfach betont, die MwSt und eine umfassend reformierte Purchase Tax in Frage. Bereits 1967 fiel die Wahl der Tories auf die MWSt. Der Grund dafür lag klar auf der Hand. Edward Heath war, schon seit Ende der 50er Jahre, ein glühender Verfechter des britischen EG-Beitritts. Zwar wußte er, daß es in der Wirtschaft erhebliche Widerstände gegen die MWSt gab. Aber or konnte darauf bauen, daß die große Mehrheit der Unternehmen die MWSt als Eintrittspreis zur EG zu zahlen bereit war. In engem Kontakt mit Unternehmern und Akademikern bereitete Macleod die Einführung der MwSt vor. Im Oktober 1969 konnte er der in Brighton versammelten Partel mitteilen, daß die Arbeiten weit fortgeschritten seien und auch ein Gesetzentwurf bereits vorbereitet würde. 200 Die Konservativen waren fest entschlossen, im Falle einer Regierungsübernahme die MWSt zu implementieren. Um jedoch das in der Bevölkerung um-

197 Vgl. NEDO, Value Added Tax, London 1969.

198 Vgl. Fisher (1973), S.300fr. Vgl. a. FT 21.8.72.

199 Vgl. Times 8.11.68.

200

Vgl. z.B. Times 10.10 .69 . 
strittene Thema nicht zum Gegenstand des unmittelbar bevorstehenden Wahlkampfes werden zu lassen, zogen sle es vor, sich in der Opfentlichkeit nur mit Zurückhaltung zu äußern:

"No opposition could commit Itself finally in advance of an election to a major new tax of this kind, which would need detalled consultation with the Clvil Service."201

Die von der konservativen Opposition gepuhrte MWSt-Debatte ging an der Labour-Reglerung lange Zelt unberührt vorbel. Erst im Oktober 1969 gab Schatzkanzler Jenkins zu erkennen, daß auch er die Einführung einer MWSt aus finanz- wie auch aus europapolitischen Gründen fur erwägenswert halte. ${ }^{202}$ Aber schon wenige Tage nach dieser Verlautbarung wurde Jenkins von seinem Premier Wilson schroff zurückgepfiffen.203 Der Regierungschef wollte, so kurz vor den Wahlen, unter allen Umständen eine innerpartelliche MWStDiskussion verhindern, die die Labour Party entlang den Linien Rechts/ Links und Europäer/Nicht-Europäer zu spalten drohte. Er stellte daher klar, daß elne von thm gefuhrte Regierung die MWSt nur dann einfuhren würde, wenn sich das wegen des britischen EG-Beltritts elnmal als unvermeidbar erwelsen sollte. Gleichzeltig richtete er an die konservative Adresse den Vorwurf, die als regressiv und preistrelbend geltende MWSt auch ganz unabhänglg von der EG zu befurworten.

Wilsons Rechnung ging auf. Dle in der britischen Bevorlkerung außerst unpopuläre MWSt wurde zu einem heißen Eisen im Wahlkampp. Die in die steuerpolitische Defensive gedrängten Torles waren gezwungen, eine öfentliche Festlegung auf die MWSt zu vermeiden. Darüberhinaus sahen sie sich veranlaßt, den Kritikern der MWSt zahlreiche Zugeständnisse zu versprechen für den Fall, daß dle neue Abgabe wirklich einmal eingefuhrt werden sollte. Der Handlungssplelraum einer zukünftigen konservativen Regierung wurde damit zunehmend enger.

Die Einführung der MWSt: $1971-1973$

Die Vorsicht der Konservativen sollte sich im Nachhinein als begründet erweisen. Aus den im Junl 1970 abgehaltenen Wahlen ging Edward Heath als knapper Sieger hervor. Dle neue Regierung war zur Einführung der MWSt entschlossen. Sie wollte allerdings gewăhrlelstet wissen, daß zwischen dem Termin der Steuerrefom und den năchsten Parlamentswahlen ein gebührender zeitlicher Abstand lag. Schon im Herbst 1970 erging daher an die Finanzverwaltung der Auftrag, alle Vorbereitungen zu treffen, um bis spätestens Ende 1972/Anfang 1973 zur MWSt übergehen zu können.

201 Election Manifesto 1970 der Konservativen Patel, zitiert in: Johnstone (1975), S.13. Vgl. a. Times 13.4.70, 27.5.70 u. 2.6.70.

202 Vgl. Stephenson (1970), S.316f. Vgl. a. Times 24.10.69.

203 Vgl. Tímes $30.10 .69,8.12 .69,23.1 .70$ u. 16.6.70. 
Der Zeltraum von gut zwel Jahren war außerst knapp bemessen und ohne die Kooperationsbereitschaft der Finanzbeamten nicht elnzuhalten. Das Glück kam der in Terminnöten steckenden Reglerung zu Hilfe. Die Mitarbeiter von Customs and Excise hatten namllch Ende der 60er Jahre thren anpanglich entschledenen Widerstand gegen die MWSt aufgegeben. Der plötzllche Sinneswandel war verursacht worden durch eine damals anstehende Reorganisation der Finanzbehörde: Dle mit der MWSt verbundene Aufstockung des Personalbestandes um ca.6000 Mitarbeiter bedeutete fur Customs and Excise eine wesentliche Erleichterung bel der Durchsetzung innerbehördlicher Versetzungen. Schon Ende 1969 hatte Customs and Excise daher damit begonnen, die Grundstruktur elner kunftigen Value Added Tax - kurz VAT genannt - zu erarbeiten. Als die Regierung Heath Im Herbst 1970 grünes Licht für die MWSt gab, waren die Beamten auf ihre Aufgabe vorbereitet und gewillt, den Kampl gegen dle Uhr aufzunehmen. ${ }^{204}$

Nach sechsmonatiger Arbeit im Verborgenen trat Schatzkanzler Barber ${ }^{209}$ Im Mărz 1971 erstmals an dle britische Offentlichkelt heran. Er ubergab dem Parlament eln Grünbuch, das die wesentlichen Aspekte der künftigen VAT beschrieb. 206 Zugleich wurde eine beim Treasury eingerichtete Arbeitsgruppe - die Leitung übernahm Staatssekretär Higgins, ehemals enger Mitarbeiter von Macleod - damit betraut, das MWSt-Konzept der Reglerung gegen die zu erwartenden Angriffe zu verteidigen. Widerstand gegen die MwSt regte sich insbesondere an den folgenden belden Fronten:

- Der Ubergang von der Purchase Tax zur MwSt vervielfachte die Zahl der Steuerpflichtigen. ${ }^{207}$ Das gab zu der welt verbreiteten Sorge Anlaß, dle MWSt könne zu elnem administrativen Alptraum werden. Um derlel Angsten entgegenzuwirken hatten die Konservativen schon Ende der 60er Jahre versprochen, in Großbritannien die elnfachste MWSt Europas einzupuhren. Bestandteil dieses Versprechens war dle Bereitschaft, den Kleinunternehmen die von ihnen lautstark geforderte Steuerbefreiung einzurăumen. Dle spăter Pestgelegte Grenze, unterhalb derer eine Befrelung gewährt werden sollte, lag mit 5000 Pfund Jahresumsatz erheblich uber dem EG-Durchschnitt.

- Der MWSt wurden darüberhinaus vertellungs- und preispolitische Argumente entgegengehalten. Die Labour Party, die Gewerkschaften, einige back benchers der Konservativen und die jewells betroffenen Wirt-

204 Eine detalllerte Beschreibung der von Customs and Excise geleisteten Arbeiten findet sich bel Johnstone (1975).

203 Barbers Vorgănger Macleod - die "midewlfe" der britischen MWSt; Fisher (1973), S.301 - war kurz nach der konservatlven Reglerungsubernahme verstorben.

206 Vgl. Cmnd 4621, London: HMSO 1971. Vgl. a. Times 31.3.71.

207 Wăhrend die Purchase Tax ca. 60.000 Steuerpflichtige betraf, waren es bel der MWSt uber 1 Million. 
schaftsverbände verlangten von der Regierung, eine breite Palette sogenannter Grundbedarfsgüter von der MWSt $\mathrm{zu}$ befrelen und die verbleibenden Waren mit einem nur gemäßigten Steuersatz zu belasten. Schon vor den Wahlen hatten sich die Torles das Zugeständnis abringen lassen, bel Lebensmitteln sowle bel Büchern und Zeltschriften von einer steuerlichen Belastung abzusehen. ${ }^{208}$ Die Regierung Heath konnte daher nur noch versuchen, eine Ausweitung der in den Genuß eines NullSatzes kommenden Güter soweit als möglich zu verhindern. Angesichts des enormen politischen Druckes, der damals auf den Konservativen lastete, war das keine einfache Aufgabe. Im Verlauf der Auseinandersetzungen sah sich Schatzkanzler Barber daher gezwungen, auch Medikamente, Kinderbekleidung etc. von der MWSt Preizustellen.

Dem Grünbuch vom März 1971 folgte ein Jahr später ein Weißbuch, das den endgültigen Gesetzentwurf des Treasury enthielt.209 Obwohl die Labour Party bestrebt war, einen Aupschub zu erzwingen, 210 gelang es der konservativen Reglerung, die MWSt wle geplant zum 1.April 1973 elnzuführen. Nicht erreicht wurde jedoch das Ziel, mit Hilfe der MWSt die indirekten Steuern in Großbritannien zu erhöhen und im Gegenzug die direkten abzusenken. Der relativ niedrige Steuersatz von $10 \%$ in Verbindung mit dem sehr breiten Anwendungsbereich des Null-Satzes führte dazu, da $\beta$ die MWSt noch nicht einmal in der Lage war, das mit der Abschaffung der Purchase Tax verlorengegangene Steueraufkommen auszugleichen. Die enormen Widerstände, auf die die Einfuhrung der MWSt damals traf, ließen ein Anzapfen ihres hohen Aufkommenspotentials nicht zu.

208 Es scheint so, als hätten die Konservativen zunächst erwogen, ihr Versprechen mit Hilfe einer einfachen Steuerbefrelung einzulösen; vgl. Staatssekretär Macmillan in H.C.Debates, Vol.817, col.1057ff.; vgl. a. Johnstone (1975), S.42f., Lawton (1971), S.195, Guardlan 31.7.71. Da eine Steuerbefrelung, wegen des fehlenden VSA aup der nächsten Stufe, kumulative Effekte nach sich gezogen hätte, entschieden sie sich später aber dann doch für Null-Sätze.

209 Vgl. Cmnd 4929, London: HMSO 1972. Vgl. a. FT 22.3.72.

210 Vgl. z.B. Times 6.12.72. 
Europa und die Briten

Vor und nach den Wahlen von 1970 behaupteten die Konservativen standhaft, die MWSt alleine aus Plnanzpolitischen Gründen und ganz unabhängig von der EG einfuhren $z$ wollen. Das jedoch war eine politische Notlüge. Richtig ist, daß die Tories entschlossen waren, das System der indirekten Besteuerung zu reformieren. Richtig ist aber auch, daß die Modifikation der Purchase Tax der nächstllegende, bel weitem einfachste und vielleicht sogar langfristig beste 211 Weg für elne solche Reform gewesen wäre. Hätte es keine Bestrebungen gegeben, der EG belzutreten, so wăre die Reglerung Heath wohl kaum gewillt gewesen, die gegen die MWSt gerichteten Angriffe auf sich zu nehmen. Auch hätte, ohne die EG, die britische Wirtschaft der MWSt einen wesentlich höheren widerstand entgegengebracht. Es war also Europa, das die Konservativen dazu veranlaßte, anstelle einer Reform der Purchase Tax die MWSt zu wahlen.212 Das aber stritten sie in der Opfentlichkelt entschieden $a b$. Da die Tories den EG-Beitritt befürworteten, die Sache in der Offentlichkelt aber außerst umstritten war, wollte die Regierung Heath unter allen Umständen verhindern, daß die schwierige Debatte über Europa mit der unpopulären MWSt noch zusătzllch belastet wurde. Fur die Konservativen war es daher eln Gebot politischer Klugheit, belde Themenkomplexe vonelnander abzutrennen.

Dle Einführung der MWSt war im Vereinigten Kønigreich mit erheblichen Schwlerigkeiten verbunden. Sle führten dazu, daß die VAT mit elner hohen Umsatzgrenze für die Steuerbefrelung von Kleinunternehmen sowle mit zahlreichen Null-Sätzen versehen wurde, zwel Aspekte der britischen MwSt, die der Gemeinschaft bei der weiteren USt-Harmonisierung noch einige Kopfschmerzen bereiten sollten. Wären die Briten, was eine interessante Annahme 1st, der EG schon zu Beginn der 60er Jahre belgetreten, so wäre eine Einigung über die europaweite Einfuhrung einer MwSt wahrscheinllch nie zustande gekommen. Die in Belgien und den Niederlanden damals zu beobachtende Entwicklung hin zu einer Einphasensteuer wăre verstărkt worden und hätte langfristig zu einer USt-politischen Spaltung Europas gefuhrt: Mehrphasensteuern in Deutschland, Frankreich und Italien und einphaslge Abgaben in den Ländern des Nordens.

\footnotetext{
211 "In many ways the value added tax is a retrograde step for the UK." Prest (1967), S.4.

212 Vgl. Z.B. Eason (1971), S.335, Malnprice (1976), S.230, Puchala (1984), S.113. Vgl. a. Times 11.12 .72 .
} 


\section{Die Harmonisierung der MWSt- Bemessungsgrundlage: der ungeplante Zwischenschritt der 70er Jahre}

Die im Februar 1967 verabschledeten ersten beiden USt-Richtlinien reichten aus, um die für das Integrationsklima schädlichen Manipulationen am steuerlichen Grenzausgleich in Zukunft $\mathrm{zu}$ unterbinden. Selbstverständlich Lle $\beta$ das nunmehr gemeinschaftlich fixierte MwSt-System noch die eine oder andere gravlerende Lucke offen, die vor Errelchung des Endziels Abschaffung der Steuergrenzen ausgefullt werden mußte. Bis gegen Ende der 60er Jahre hatte die Kommission Jedoch nicht vor, sich bel der über die 2.UStRichtlinie hinausgehenden Harmonlsierung der MWSt-Bemessungsgrundlage länger aufzuhalten. Ihre erklärte Absicht war vielmehr, auf die ersten belden USt-Richtlinien lediglich noch eine dritte ${ }^{1}$ folgen $\mathrm{zu}$ lassen, die bis spätestens Anfang der 70er Jahre die noch fehlenden Voraussetzungen für die Beseltigung der Steuergrenzen - insbesondere die Angleichung der Sătze - schaffen und damit die USt-Harmonislerung abschließen sollte.

Aber es kam anders. In der ersten Hälfte der 70er Jahre sah sich die Kommission veranlaßt, Ihre aup die baldige Verwirklichung des alten Stufenprogrammes $^{2}$ ausgerichteten Harmonisierungspläne zu revidieren und der endgultigen Abschaffung der steuerlichen Grenzkontrollen zunachst elnen Zwischenschritt vorzuschalten: die umfassende Vereinheitlichung der MWSt-Bemessungsgrundlage.

Verursacht wurde die umsatzsteuerpolitische Neuorientierung Brüssels durch zwel voneinander ganz unabhängige Entwicklungen. Zum einen scheuten die Mitgliedstaaten davor zurück, das helße Eisen Anglelchung der Steuersätze anzufassen. Um nicht vollständig zur Untätigkeit verurtellt zu sein, widmete sich die Kommission der Harmonislerung der Bemessungsgrundlage, und zwar in einem Ausmaß, wie sle es ursprunglich gar nicht vorgesehen hatte. Zum anderen flel Im April 1970 die Entscheidung, elnen Tell des nationalen

1 Bis 1966 wurde in Brussel von einer 3., danach von einer 4.UStRichtlinle gesprochen, da sich eine gesonderte Richtlinie zur Besteuerung der Landwirtschaft ab Ende 1966 bereits in Ausarbeitung befand.

Vgl. Kap.C.1.1.3. 
MWSt-Aufkommens in dle EG-Kasse Pließen zu lassen. Dies erforderte, so zumindest nach Ansicht der Kommission, eine Verelnheitlichung der MwStBemessungsgrundlage, die über das zur Abschaffung der Steuergrenzen notwendige Maß weit hinausging. ${ }^{3}$

Der Zwischenschritt Harmonisierung der Bemessungsgrundlage war insolern ungeplant, als er das ursprüngliche Konzept der Kommission sowohl inhaltlich - hinsichtlich des Grades der angestrebten Anglelchung - als auch zeitlich - er nahm die gesamten 70er Jahre in Anspruch und ist bis heute noch nicht abgeschlossen - sprengte. Im folgenden soll nun dargestellt werden, welche Zlelvorstellungen dabel im elnzelnen elne Rolle spielten - 1.Abschnitt - und wie sich der politische willensbildungsproze $\beta$ vollzog - 2.Abschnitt -.

\section{Die Ziele der wichtigsten Akteure}

\subsection{Das alte Zlel: Wettbewerbsneutralität}

Die Gewăhrleistung einer wettbewerbsneutralen Besteuerung war das ausschlaggebende Motiv für die ersten beiden USt-Richtlinien gewesen. Dieses Zlel war auch insofern erreicht worden, als die Hothe des Grenzausgleichs nun eln für alle Mal festlag. Verzerrungen gab es aber nach wle vor. Verursacht wurden sie durch zahlreiche Steuerbefreiungen und Sonderregelungen, die mit der reinen MWSt im Sinne der Theorie $z$ war nicht zu vereinbaren sind, die aber den Mitgliedstaaten zur Erlelchterung elnes Kompromisses in der 2.USt-Richtlinie zugestanden werden mußten. Dle elnzelnen Regierungen schöpften die ihnen gewăhrten Gestaltungsspielrăume auch aus, um den Ubergang zur MwSt so relbungslos wie möglich uber die Bühne zu bringen. Da die technischen und polltischen Voraussetzungen für elne UStReform in den Mitgliedstaaten sehr unterschledlich waren, konnte es nicht überraschen, daß die 6 bzw. später 9 MWSt-Systeme der Gemelnschaft nur

3 Die Abschaffung der Steuergenzen setzt elne begrenzte Harmonisierung der MWSt-Bemessungsgrundlage voraus. Eine weltgehende Vereinheitllchung ist aber, wle in Kap.D.2.3. ausfuhrlicher dargestellt wird, nicht erforderlich. 
in ihren Grundlinien übereinstimmten. Einige der verbleibenden Divergenzen beeinträchtigten, zum Leidwesen der Kommission, auch weiterhin die Wettbewerbsbedingungen in der EG.4

Die Steuerpolitiker der Mitgliedstaaten wandten sich nach der Verabschiedung der 1. und 2.USt-RIchtlinie Im Februar 1967 von Europa ab und den nationalen Problemen zu. Sie mußten zuhause ein MWSt-Gesetz durch das Parlament boxen und anschließend die komplizlerte Maschinerie in der Praxis zum Laufen bringen. Nach diesem Kraftakt - die Einfuhrung der MWSt bedeutete für die Mehrzahl der betroffenen Länder die einschneldendste Steuerreform seit Kriegsende - wollten sie erst einmal Ruhe an der MWSt-Front. Dle von der Kommission immer wieder monierten Verzerrungen wurden zwar durchaus gesehen, in der Mehrzahl der Fälle jedoch für nicht hinreichend gravierend gehalten, um eine weitere USt-Harmonisierung $\mathrm{zu}$ rechtfertigen.

Der Grund für den fehlenden Harmonisierungs-Enthusiasmus auf seiten der nationalen Entscheldungsträger war zwelfacher Art. Erstens hatte man sich uberall dort, wo Kompromisse elnfach zu finden waren, schon in der 2.UStRichtlinie auf gemeinsame Regeln verständigt. Rasche Fortschritte waren also in Zukunft nicht mehr zu erwarten. Zweitens war die entscheldende Triebkraft für die Vereinheitlichung der MWSt-Basis in der 2.USt-Richtlinie die Hoffnung der einzelnen Regierungen gewesen, sich in der labilen ubergangsphase zur MWSt durch eine EG-Vorschrift vor innenpolitischem Druck absichern zu können. Nachdem die MWSt aber erst einmal eingeführt war, büßte dieses Motiv zunehmend an Kraft eln. Die MWSt stabilislerte sich und gewann an der jeder alten Steuer Immanenten Trägheit, die sie vor Angriffen interessierter Gruppen schützte.

Im Laufe der Zelt begannen die nationalen Steuerbeamten, die jewellige MwSt-Version als die ihre zu begreifen: "Falls die Steuerleute gut gearbeltet haben, ist das nationale Steuersystem optimal an die jewelligen Verhaltnisse angepaßt; jede Harmonisierung im Sinne einer Anderung der einzelstaatlichen Regeln bedeutet damit eine Verschlechterung." ${ }^{\circ}$ So der Kommentar eines USt-Experten, der die generelle Einstellung der europäischen Finanzbeamtenschaft kurz nach Einfühung der MwSt und auch heute noch treffend. wiederspiegelt. ${ }^{6}$ Von der hier angesprochenen optimalen $\mathrm{Be}-$ steuerungstechnik versteht man auf politischer Ebene erfahrungsgemäß wenig. Dort denkt man eher in den Kategorien budgetäre Erfordernisse und Wählerstimmen, was aber bereits ausreicht, um jeder noch so kleinen Anderung der MWSt mit äußerster Skepsis zu begegnen: Führt elne Maßnahme zu

Vgl. z.B. Easson (1980b), S.120ff. Vgl. a. Scallteur (1974), S.519ff.

5 Persönliches Interview.

- Vgl. z.B. ăhnl. Vogelaar (1970), S.335. 
einem steuerlichen Minderaufkommen, so bringt sie den Finanzminister in Rage; Ist sie umgekehrt mit elnem Mehraufkommen verbunden, so löst sie bel den zur Kasse gebetenen Gruppen ein Wehgeschrel aus, das dem Ergebnis bel den nächsten Wahlen nur abträglich seln kann.

Aus Falrneßgründen bleibt hinzuzufügen, daß die Mitgliedstaaten nicht jeden Brüsseler Harmonislerungsvorschlag von vorneherein abblockten. Eine Initlative der Kommission fand immer dann ihre Zustimmung, wenn sle Wettbewerbsverzerrungen durch die Ubertragung der eigenen Regelung auf alle anderen Mitgliedstaaten abzubauen versprach. Damit war und ist der Kommission natürlich nicht gedient. Auf Fortschritte und die damit verbundenen Zugeständnisse konnte sle nur hoffen, wenn einzelne Verzerrungen die Interessen eines oder mehrerer EG-Staaten in einem Maße bedrohten, daß diese sich bereit fanden, ihre steuerpolitische Ruhe für eine weitere Harmonisierungsanstrengung zu opfern.

Ein solcher Ausnahmefall lag beispielswelse bel der Besteuerung der Landwirtschaft vor. Da man sich in der 2.USt-Richtlinie auf keine gemeinsame Regel hatte einigen können, brachten es die "kräftigen Streiter der Grünen Front"7 im Deutschen Bundestag fertig, sich Im MWSt-Gesetz eine indirekte Subventionierung zu erkämpfen. Ihnen wurde ein pauschaler VSA in Höhe von 5\% ihres Umsatzes gewährt, obwohl nach Ansicht des Bonner Finanzministeriums die Vorsteuerbelastung der deutschen Landwirtschapt im Durchschnitt nicht höher als $3,5 \%$ lag. Von den Deutschen - die Niederländer praktizierten im ubrigen Ahnliches - aup die Füße getreten fuhlten sich insbesondere die Franzosen, die aus budgetären Gründen ihre Landwirtschaft von der MWSt befreit und damit jeden VSA ausgeschlossen hatten. Um den drohenden Konflikt abzuwenden, prăsentierte die Kommission, nach langen internen Querelen, dem Rat im Februar 1968 endlich einen Richtlinienentwurf zur Besteuerung der Landwirtschaft.9 Dle darin enthaltene Pauschallerungsmethode Pand, von elnem Vorbehalt Frankreichs abgesehen, die grundsätzliche Unterstützung der Mitgliedstaaten. Mit dem darüberhinaus vorgeschlagenen einheltlichen und reduzierten steuersatz für alle landwirtschaftlichen Produkte in der EG - das war der Preis, den die Steuerleute der Kommission an ihre Agrar-Kollegen für deren Zustimmung zur neutralen Pauschalierung bezahlen mußten - hatte sich die Kommission aber zu welt vorgewagt. Die Mitgliedstaaten stellten sich der Satzanglelchung geschlossen entgegen. Darüberhinaus fühlten sich Frankrelch, Deutschland und die Nlederlande herausgefordert, dem Kommissionsvorschlag

7 Persönllches Intervlew.

- Vgl. Kap.C.2.1.4.3.

$9 \mathrm{AB} 1968 / \mathrm{C} 48, \mathrm{S.2fP}$. Vgl. a. die Kurzdarstellung in: Bulletin der EG, 1.1968, Heft 4, S.41Pf. Vgl. a. Le Monde 28.2.68 u. Blick durch die Wirtschaft 27.5.68. 
auf der Ratsitzung vom 27.Januar 1969 elgene Richtlinlenentwürfe entgegenzustellen, die thren jeweiligen Interessen näher lagen. An eine baldige Einigung war damit nicht mehr zu denken.

Neben der Landwirtschaft war es insbesondere der grenzüberschreitende Austausch von Dienstleistungen, der zu einigem Kopfzerbrechen Anlaß gab. Bel der Aushandlung der 2.USt-Richtlinie hatte man sich, da jeder Staat auf der Beibehaltung seiner eigenen Regelung bestand, nicht auf eine einheltliche Definition des Ortes, an dem eine Dienstleistung besteuert werden soll, einigen können. Von Land zu Land unterschledliche Regelungen mußten zunächst hingenommen werden mit der Konsequenz, daß exportierte Dienstleistungen teils elnmal, tells uberhaupt nicht und tells doppelt besteuert wurden. Gemeinsamen Handlungsbedarf sahen in erster Linie die Niederländer, die insbesondere im Transportwesen eine bedeutende wirtschaftliche Stellung zu verteidigen hatten. Nach der EG-Erweiterung von 1973 wurden sie unterstützt von den Briten, die für ihre weltwelt tätigen Banken und Versicherungen günstige steuerliche Voraussetzungen schaffen und absichern wollten. Da die Mehrwertbesteuerung einer Dienstleistung - im Gegensatz zu elner gegenständlichen Ware ist der Grenzübertritt einer Dienstlelstung nicht elndeutig bestimmbar - technisch außerst komplexe Probleme aufwirft, war es verständlich, daß sich die Vorarbeiten für einen Richtlinienvorschlag lange hinzogen und bis 1969 noch nicht abgeschlossen werden konnten. Ab 1970 flossen dannn sämtliche auf die Sicherstellung der Wettbewerbsneutralitat gerichteten Bemühungen der Kommission in die Vorbereltung einer 6.USt-Richtlinie eln. Das gilt auch für die Besteuerung der Landwirtschaft; der bereits auf dem Tisch liegende Richtlinienvorschlag wurde daher soäter von der Kommission wleder zurückgenommen. ${ }^{10}$

\subsection{Das Endziel: Abschaffung der Steuerorenzen}

Mit dem Ausbruch der Krise im Jahre 1965 hatte die Kommission das umsatzsteuerliche Endzlel Abschaffung der Steuergrenzen zunächst ad acta gelegt und ihre Bemühungen auf die Einführung der MWSt konzentriert. Anfang 1969 - seit der Verabschiedung der ersten beiden USt-Richtlinien waren nun schon zwel Jahre verstrichen, und ihre Implementierung in den noch fehlenden Staaten stand, wle man damals noch hoffen konnte, kurz bevor - hielten Kommissar von der Groeben und seine Leute den Zeitpunkt Pür gekommen, einen erneuten Anlauf zur Beseitigung der Grenzkontrollen zu wagen. Die alten Studien wurden wieder hervorgeholt und auf den aktu- 
ellen Stand gebracht, neue Untersuchungen wurden angefertigt ${ }^{11}$ und alles zusammen mit den Mitgliedstaaten auf der Ebene des ALSV und darunter diskutiert. ${ }^{12}$

Der von der Kommission in Aussicht genommene Terminplan für die Abschafpung der Steuergrenzen - man sprach intern vom 1.Januar 1974 - geriet aber in Gefahr, als sich im Sommer 1969 Italien und Belgien endgültig entschlossen, die Einführung der MWSt hinauszuzögern. Da Brüssel dies schon nicht verhindern konnte, wollte man zumindest versuchen, die unausweichliche Fristverlängerung für die Anwendung der ersten beiden UStRichtlinien mit einem weiteren Harmonisierungsschritt zu verknupfen, der zur Erreichung des Endziels unabdingbar war: Dle Mitgliedstaaten sollten sich in der 3.USt-Richtlinie daraup verpflichten, den Einzelhandel in die MWSt miteinzubezlehen und die Zahl der Steuersätze auf zwel zu reduzleren. ${ }^{13}$ Der Rat strich, da er sich in Zeitdruck befand, ohne längere Diskussion den betreffenden Artikel aus dem Richtlinienvorschlag der Kommission wieder heraus und verbannte inn in eine Entschließung des Rates ${ }^{14}$, die am 9.Dezember 1969 gleichzeitig mit der 3.USt-Richtlinle verabschledet wurde, für die Regierungen aber rechtlich nicht bindend war.

Kurz bevor die Kommission diese Niederlage einstecken mußte, hatte sich auf dem Europäischen Gipfeltreffen am 1. und 2.Dezember in DenHaag bereits eine neue Entwicklung abgezeichnet, an die sich die Brüsseler Steuerleute mit ihren Plänen für die Abschaffung der Steuergrenzen anhängen konnten. Dle Staats- und Reglerungschefs der Gemeinschaft standen unter Entscheidungsdruck. Dle Aupbauphase der EG ging mit dem 1.Januar 1970 ihrem vertraglich flxierten Ende entgegen. Die wirtschaftliche Integration war im großen und ganzen zur Zufriedenheit aller verlaufen, wurde aber von den sich in den späten $60 \mathrm{er}$ Jahren ankündigenden währungspolltischen Turbulenzen und dem Beitrittsgesuch vier nordeuropaischer Länder in ihrer Existenz bedroht. Der Gipfel Paßte den Mut, das einmal Erreichte durch eine Flucht nach vorne in die 70er Jahre hinuberzuretten: Aus der Zollunion sollte eine Wirtschafts- und Wahrungsunion - Im folgenden kurz WWU genannt - werden. Ein Ausschuß unter Leitung des Luxemburger Premiers Werner wurde beauftragt, einen entsprechenden Stufenplan zu erarbeiten. ${ }^{15}$

11 Vgl. z.B. Kommission (Hrsg.), Budgetäre, wirtschaftliche und soziale Auswirkungen der Harmonislerung der MWSt-Satze in der EG, Relhe Wettbewerb und Rechtsangleichung Nr.16, Brussel 1970.

12 Vgl. z.B. Groeben (1969).

13 Art.5 des Vorschlages Pür eine 3.USt-Richtlinie.

14 Vgl. AB 1969/C 196, S.1.

15 Vgl. AB 1970/C 136, S.17. Vgl. a. Rifflet (1969). 
Der Werner-Ausschuß nahm Anfang 1970 seine Beratungen aup. Unterstützt vom EP16 versuchte Kommissar von der Groeben energisch und immer wieder, seine weitreichenden Harmonisierungsvorhaben in den Beschlüssen zur Erreichung einer WWU unterzubringen. ${ }^{17}$ Das war nicht nur das politisch Klügste, sondern es war auch sachlich durchaus gerechtfertigt. Die Integration im steuer- sowie die Im währungs- und allgemein finanzpolitischen Bereich beeinflussen sich gegenseitig positiv bzw. sind, im ökonomischen Jargon, komplementäre Güter:

- Die Angleichung der MWSt-Sătze in der EG erfordert eine Verlagerung finanzpolitischer Kompetenzen von der nationalen auf die europălsche Ebene; dies war in den Entwürfen für eine WWU bereits vorgesehen.

- Die Abschaffung der steuerlichen Grenzkontrollen reduziert lhrerselts die Transaktionskosten Im EG-Binnenhandel, fördert das Zusammenwachsen der nationalen Gütermärkte und steigert damit die von elner WWU zu erwartenden Wohlpahrtsgewinne. ${ }^{18}$

Und die stetigen Bemühungen der Kommission trugen schließlich Früchte. Die Steuerharmonisierung wurde als integraler Bestandtell einer WWU in die "Entschließung des Rates und der Vertreter der Reglerungen der Mitglledstaaten ubber die stufenwelse Verwirklichung der Wirtschafts- und wăhrungsunion"19 vom 22.März 1971 aufgenommen. Was die MWSt betrifft, so versprach der Rat, bis zum 1.Januar 1974 uber die noch verblelbende Harmonisierung der Anwendungsmodalitäten zu entscheiden und sich mit der Angleichung der Steuersätze zu befassen. Fast auf den Tag genau ein Jahr später bekräptigte der Rat nochmals seine guten Absichten.20

Aber aus den großen Worten sollte nichts werden. Schon 1973 glaubte kein Mensch mehr ernsthaft an die Möglichkeit, die Steuergrenzen noch im laufenden Jahrzehnt beseltigen zu können. Die Gründe hierfür sind auf drei unterschiedlichen Ebenen zu suchen. Zum einen war von Anfang an kein einziger Mitgliedstaat von der Idee der Kommission begeistert, die UStHarmonisierung in dle WWU-Plăne aufzunehmen.21 Selbst die Deutschen, dle

16 Vgl. z.B. AB 1970/C 151, S.23ff., Pkt 11. Vgl. a. AB 1972/C 36, S.31ff., Pkt.16.

17 Vgl. Groeben (1970). Vgl. a. Handelsblatt 25.2.70 u. 18.3.70, Stuttgarter Zeitung 19.5.70.

18 Als theoretischen Hintergrund vgl. z.B. Mundells "Theory of Optimum Currency Areas" - Mundell (1961) -, die den Zusammenhang zwischen einem integrierten Faktormarkt auf der einen und einer gemeinsamen wahrungspolitik auf der anderen Seite herausarbeitet. Der Ansatz läßt sich ohne weiteres auf die Gutermärkte und die Finanzpolitik ausweiten.

Vgl. AB 1971/C 28, S.1ff.

Vgl. Entschließung v. 21.3.72, AB 1972/C 38, S.3P.

21 Vgl. Industrie Kurier 20.5.70, Stuttgarter Zeitung 20.5.70, Bonner Rundschau 25.2.71 u. Handelsblatt 24.7.72. 
Anfang der 60er Jahre noch so tapfer für die Abschaffung der Steuergrenzen gekämpft hatten, äußerten sich nach der 1965er Krise genauso vage und zurückhaltend wie die anderen.22 Sie waren mit internen Steuerreformvorhaben beschätigt, wollten sich dafür von der EG keine Fesseln anlegen lassen und zogen es daher vor, die Harmonislerung aup die lange Bank zu schleben. Die Franzosen standen der Sache genauso ablehnend gegenüber wie schon immer, da eine Senkung der MWSt um ca.5 Prozentpunkte hin zum EG-Durchschnitt für die Pariser Reglerung politischen Selbstmord bedeutet hätte. Zum zweiten brachen 1973 die WWU-Pläne rasch in sich zusammen.23 EG-intern konnte man sich nicht daraup einigen, ob man zuerst dle pinanzpolitische - unterstützt von Deutschland, den Niederlanden und Italien oder die geldpolitsche Integration - die Position Frankreichs, Belgiens und Luxemburgs - Porcieren sollte. Und EG-extern änderten sich mit dem Untergang des Bretton-Wood Systems und dem ersten Olschock die weltwirtschaftlichen Rahmenbedingen. Zum dritten verschwanden mit der zum 1.Januar 1973 erfolgten Erweiterung der Gemeinschaft um Großbritannien, Irland und Dänemark großartige Zukunftspläne ohnehin erst einmal von der Tagesordnung. Das Gebot der Stunde war die Stabilislerung dessen, was die Sechs vorher muhsam aufgebaut hatten.

Noch 1970 mußte derjenige, der in Experten- oder Ministergesprächen im Rat die Abschaffung der Steuergrenzen auf die 80er Jahre hinausschieben wollte, mit den lauten Buh-Rufen der anderen rechnen. Schon 1973 wurde dasselbe Zlel von den europäischen Entscheldungsträgern nur noch als ein fernllegender Traum begriffen. Selbst die Kommission mußte zugestehen, da $\beta$ an die Anglelchung der MWSt-Sätze erst "in einer sehr viel späteren Phase der Integration"24 gedacht werden könne. Im Laufe der 70er Jahre waren daher vom USt-politischen Endzlel der Kommission keine positiven Impulse mehr auf den Fortgang der MWSt-Harmonisierung zu erwarten. ${ }^{25}$

\subsection{Das neue Ziel: Schaffung von MWSt-Eigenmitteln}

Auf dem bereits erwähnten Haager Gipfeltreffen einigte man sich nicht nur auf die schaffung einer WWU, sondern beschloß daruberhinaus, die direkten Beitrage der Mitgliedstaaten zum Gemeinschaftsbudget durch ein System Eigener Einnahmen der EG $\mathrm{zu}$ ersetzen. Einen entsprechenden Vorschlag

22 Vgl. 2.B. Strauß (1967).

23 Vgl. z.B. die "Mitteilung der Kommission an den Rat uber die Fortschritte während der 1.Stufe und den Ubergang zur 2.Stufe der WWU", KOM(73)570 v. 19.4.73, abgedr. In: Bulletin der EG, 6.1973, Bellage 5 . Vgl. a. AE 14.4.73, 16.5.73, 10.10.73, 11.10.73, 12.11.73, 14.12.73 u. 17.12.73. Vgl. a. Tsoukalis (1977a) u. Tsoukalis (1977b).

Antwort der Kommission auf die Schriftliche Anfrage Nr.189/75, AB $1975 / C 209$, S.34.

Vgl. z.B. Welt 6.8.74. 
hatte die Kommission schon einmal im März 1965 vorgelegt.26 Damals war er jedoch aup den erbitterten Widerstand der Franzosen gestoßen, die ihn zum Anlaß ihrer Politik des leeren Stuhls machten. Es vergingen vier Jahre, bis die Kommission wieder Mut faßte und den Rat abermals aufforderte, die Zölle und Agrarabschöpfungen direkt in das Gemelnschaftsbudget flleßen zu lassen. ${ }^{27}$ Zunächst war diskutlert worden, den verbleibenden Finanzbedarf der EG mittels am BSP der Mitgliedstaaten orientierter Beitrăge zu decken. Paris stellte sich aber quer und etablierte einen link zwischen der vollständigen Eigenfinanzlerung der Gemelnschaft auf der einen und der Eröffnung offizieller Beitrittsverhandlungen aup der anderen Seite. Ziel der Franzosen war es, die Pür Frankreich lukrative gemeinsame Agrarpolitik auch über die Erweiterung der EG hinaus Pinanziell abzusichern. ${ }^{20}$ Erst in mehrtägigen Beratungen des Ministerrates, die sich an den Gipfel von DenHaag anschlossen, konnte man sich schließlich daraup einlgen, der EG die MWSt als dritte Finanzquelle zu erschließen: Die MWSt war die einzige Abgabe, die berelts bis zu einem gewissen Maße harmonisiert war und deren Bemessungsgrundlage zudem in einem engen Verhăltnis zum BSP stand. Der im Dezember 1969 ausgehandelte Kompromiß wurde am 21.April 1970 im Rahmen eines ganzen Paketes formal verabschiedet:

\begin{abstract}
"Ab 1.Januar 1975 wird der Haushalt der Gemeinschapten vollständlg aus eigenen Mitteln der Gemeinschaften gedeckt. Diese Mittel umfassen die in Artikel 2 genannten Einahmen (Zölle und Agrarabschöpfungen, d.Verf.) sowie die Mehrwertsteuereinnahmen, die sich aus der Anwendung eines Satzes ergeben, der $1 \%$ einer steuerpflichtigen Bemessungsgrundlage nicht überschreiten darf, welche einheitlich für die Mitgliedstaaten nach Gemeinschaftsvorschriften bestimmt wird."29
\end{abstract}

Dle Franzosen konnten mit dem Erreichten zufrieden sein. Sie zahlten unter der neuen Regelung weniger als zuvor, alle anderen staaten wurden dafür stärker zur Kasse gebeten. Da Paris im Gegenzug der in erster Linle von den Niederlanden vorgetragenen Forderung zustimmen mußte, dle Budgetbefugnisse des EP zu erweitern, konnten auch die Straßburger Parlamentarier einen Pluspunkt für sich verbuchen.

Unzufrieden war demgegenüber die britische Regierung. Zum einen wurde Großbritannien durch das neue Finanzierungssystem der Gemelnschaft im

26 Abgedr. In: Bulletin der EWG, 8.1965, Beilage zu Heft 5 .

27 Vgl. AB 1969/C 123, S.24ff., sowie AB 1969/C 152, S.32f. Vgl. a. FAZ 10.9.68 u. 11.9.68, NZZ 31.10.68, Le Monde 11.5.69, NZZ 4.7.69 u. 19.7.69.

28 Vgl. z.B. FT 20.12.69 u. Tímes 20.12.69.

29 Art.4 Abs.1 Satz 1 u. 2 des "Beschluß des Rates über die Ersetzung der Finanzbeltrage der Mitgliedstaaten durch eigenen Mittel der Gemeinschaften", AB 1970/L 94, S.19ff. Vgl. a. Schneider (1970). Vgl. a. Figaro 16.12.69, NZZ 17.12.69, Le Monde 21.12.69, FT 22.12 .69 u. 23.12.69. 
ganzen, wle schon während der Verhandlungen in 1969 bekannt, erheblich belastet. Zum anderen störten die Briten die MWSt-Eigenmittel im besonderen, da sie, bedingt durch ihre vergleichsweise hohe Steuermoral und geringe Investitionsquote, relativ zum BSP betrachtet mehr zahlen mußten als andere Staaten. ${ }^{30}$ Verhindern konnten sie den Ratsbeschluß vom 21.April 1970 aber nicht: Sie standen damals noch draußen vor der Tür. Auch der Versuch der Reglerung Heath, im Rahmen der Beitrittsverhandlungen eine Nachbesserung zu erwirken, war nicht von Erfolg gekrönt. London erhielt lediglich die Zusage, die Eigenmittel in vollem Umfang erst ab 1978 zahlen zu müssen. Damit wollte sich die Labour Party nicht zufrieden geben. Als sie Anfang $1974 \mathrm{im}$ Vereinigten Königreich die Macht übernahm, erzwang sle von der Gemeinschaft unter Androhung eines Austritts aus der EG sogenannte renegotiations der Beitrittsverträge, wăhrend derer auch die Eigenen Einahmen der EG wleder in Frage gestellt wurden.

Widerstand gegen die MWSt-Eigenmittel gab es darüberhinaus von seiten der europälschen Steuerbeamten. Solange die Bemessungsgrundlage der MWSt nicht fixiert war, konnten die Mitgliedstaaten durch eine Ausdehnung ihrer Steuerbefrelungen und Sonderregelungen ihre Zahlungsverpllichtungen gegenüber der EG manipulieren. Um elne faire Verteilung der MWSt-Beitrăge zu gewährlelsten, mußte daher deren Bemessungsgrundlage vereinheitlicht werden. Die Steuerexperten der nationalen Finanzministerien jedoch lehnten eine Harmonisierung der MWSt alleine wegen der Schaffung der EG-Eigenmittel als sachfremd ab. Wie die Briten, so konnten aber auch sie den Ratsbeschluß vom 21.April 1970 nicht verhindern: Die fur die Finanzierung der EG jewells zuständigen Beamten der Finanzministerien hatten während der entscheidenden Verhandlungen in Brüssel die Kollegen von der MWStAbtellung uberhaupt nicht nach deren Meinung gefragt! Die Entscheldung im Ministerrat flel also "light-hearted"31 und ohne Berücksichtigung der Konsequenzen für die nationalen MWSt-Systeme. Die von den Konsequenzen unmittelbar betroffenen Steuerbeamten fühlten sich durch den Brüsseler Beschluß "überrascht"32 und hintergangen. Da sie ihn aber nicht mehr rückgängig machen konnten, blleb ihnen nur noch der Versuch zu retten, was zu retten ist. Sie regten daher an, zur Berechnung der EG-Eigenmittel nicht eine in allen Detalls vereinheitlichte MWSt heranzuziehen - sogenannte fiskalische Methode -, sondern auf Gemeinschaftsebene nur eine fiktive Bemessungsgrundlage festzulegen, die in den einzelnen Mitgliedstaaten mit Hilfe bereits vorhandenen statistischen Datenmaterials jährlich bestimmt wird -volkswirtschaftliche Methode - ${ }^{33}$ Der Berichterstatter des

30 Vgl. z.B. Daily Telegraph 3.7 .74 .

31 Persönliches Intervlew.

32 Persönliches Interview.

33 Ein ahnlicher Vorschlag findet sich z.B. In der Stellungnahme des Deutschen Bundestages zum Ratsbeschluß v. 21.4.70; vgl. BundestagsDrs. VI/1374. 
EP hlelt eln solches Vorgehen mit dem oben zitierten Ratsbeschluß für durchaus vereinbar. ${ }^{34}$ Dieser Rechtsauffassung widersprach jedoch die Kommission mit Entschiedenhelt: Sie bestand mit dem Hinwels auf das Wort steuerpflichtige Bemessungsgrundlage nachdrücklich auf einer Harmonisierung der in den Mitgliedstaaten tatsächlich erhobenen MWSt. ${ }^{35}$

Zusammenfassend bleibt festzuhalten, daß weder das Nahziel Wettbewerbsneutralität noch, zumindest nach dem Zusammenbruch der WWU-Pläne 1973, das Fernziel Abschaffung der Steuergrenzen elne tragfähige Grundlage für eine erfolgreiche Fortsetzung der USt-Harmonisierung in den 70er Jahren versprach. Anla $\beta$ zur Hoffnung gab letzten Endes nur der Ratsbeschluß von 1970 zur Schaffung der MWSt-Eigenmittel. Aber auch das damit etablierte neue Ziel konnte erst dann eine positive Wirkung auf die USt-Harmonisierung entfalten, nachdem der Widerstand der britischen Regierung und der europäischen Steuerbeamten gebrochen war. Wie sich der Meinungsbildungsproze $\beta$ zur Harmonisierung der MWSt-Bemessungsgrundlage in den Jahren nach 1970 entwickelte, soll nun im einzelnen nachgezeichnet werden.

34 Vgl. EP Dok.360/73, S.35f. Vgl. ähnl. Albers (1973), S.596.

30 Vgl. z.B. Art.2 des Kommissionsvorschlages Pür elne "Verordnung des Rates gemä dem Beschluß vom 21.April 1970 uber die Ersetzung der Finanzbeiträge der Mitgliedstaaten durch elgene Mittel der Gemeinschaften", AB 1970/C 74, S.5ff. 


\section{Der Fillensblldungsprozeß}

2.1. Die hart erkämpfte 6.USt-Richtlinie: $1970-1977$

\subsubsection{Ausarbeitung des Kommissionsvorschlages}

\section{Vorbereitungen auf der technischen Ebene}

Im Anschluß an die Verabschledung der beiden ersten USt-Richtlinien im Jahr 1967 hatte die Kommission eine Vielzahl von Aktivităten entfaltet, die alle darauf ausgerichtet waren, verbleibende Wettbewerbsverzerrungen abzubauen und die Voraussetzungen für elne Abschaffung der Steuergrenzen zu schaffen. Grelfbare Erfolge waren bls 1970 jedoch nlcht zu verzelchnen: Die vorbereltenden Untersuchungen aber die Definition des Ortes einer Dienstleistung, die Angleichung der Steuersătze sowie eln Clearing-System waren noch nicht bis zur Vorlage einer Richtlinle gereift, und der bereits erwähnte Vorschlag zur Besteuerung der Landwirtschaft steckte im Rat fest.

Der Beschluß des Rates vom 21.April 1970 leitete in der Brüsseler Steuerdirektion eine Neuorientierung ein. Von Anfang an bestand die Kommission, da sie glaubte, damlt "zwei Fliegen mit einer Klappe"1 schlagen zu können, auf der fiskalischen Erhebungsmethode: Sie erschien nicht nur politisch wesentlich interessanter als die volkswirtschaftliche Methode - zwischen dem europäischen Steuerzahler und der EG wurde elne direkte Verbindung hergestellt -, sondern bot darüberhinaus auch einen Rechtfertigungsgrund, die Harmonisierung der MWSt-Basis weit über das Maß hinaus voranzutreiben, das zur Beseitigung merklicher Verzerrungen oder zur Abschapfung der Steuergrenzen notwendig gewesen wăre. Ab 1970 konzentrierten daher dle Steuerleute der Kommission ihre Kräfte aup die Ausarbeitung eines einzigen Richtlinienentwurfes, der die Bemessungsgrundlage der europăischen MWSt umfassend regeln sollte.

Was aber war, so stellte sich die erste Frage, im Falle der MWSt unter dem Begriff Bemessungsgrundlage - die Pranzösische Version des Ratsbeschlusses vom April 1970 sprach von l'assiette - überhaupt zu verstehen? Einigkelt herrschte insofern, als l'assiette offensichtlich mehr beinhaltete als nur le champ d'application. Für den inzwischen zum Leiter der Brüsseler USt-Ab-

$A B$ Anhang 1974/173, S.74. 
tellung ernannten Franzosen Guleu war die Harmonisierung der MWSt-Basis gleichbedeutend mit der Angleichung aller nationalen Gesetzesregelungen mit Ausnahme der über Zahl und Höhe der Steuersätze. Mitarbeiter Guleus und mit ihnen die nationalen Steuerbeamten vertraten demgegenuber die Auffassung, da $\beta$ eine solche Interpretation doch etwas $z u$ weit ginge und selbst mit der fairen Erhebung der MWSt-Eigenmittel nicht mehr zu rechtfertigen wäre. Aber der Standpunkt des Chefs setzte sich durch. Er wollte nicht nur eine MWSt-Richtlinie, sondern ein "europäisches MWSt-Gesetz"2, das den Mitgliedstaaten nur noch bei den Steuersätzen eine letzte Wahlfreiheit zugestand. Die von ihm anvislerte Verlagerung der MWSt-Gesetzgebungskompetenz von der nationalen auf die europäische Ebene war, wie wohl zu Recht vermutet, nicht zuletzt von der Hoffnung getragen, daß sich die EG langfristig mit einer sehr begrenzten Betelligung am MWSt-Aufkommen der Mitgliedstaaten nicht zuprieden geben würde, sondern eines Tages den Spleß herumdrehen könnte: die MWSt als europäische Abgabe, an der nun umgekehrt die nationalen Fisci beteiligt werden sollte. Auch wenn eine solche Moglichkeit noch welt in der Zukunft lag, so sollten doch schon fruhzeitig die institutionellen Weichen hierfür gestellt werden. Deutlich zum Ausdruck kamen die Brüsseler Absichten insbesondere in den Artikeln des späteren Richtlinienentwurfes, die die Schaffung elnes sogenannten MwStAusschusses - zusammengesetzt aus nationalen Steuerbeamten - vorsahen. Der Vorschlag lief daraup hinaus, daß immer dann, wenn sich der MwStAusschuß und der Rat - jeweils mit quallfizlerter Mehrhelt - dem nicht gemeinsam entgegenstellen, die Kommission verbindliche Durchführungsverordnungen für dle europäischen USt-Richtlinien erlassen darf. ${ }^{3}$

Mit der Guleuschen Definition des Begrifps Bemessungsgrundlage war der Rahmen für die zu leistende Arbelt abgesteckt. Zu einigen Fragestellungen gab es, wie erwähnt, schon Voruntersuchungen, die man in das neue Projekt einfließen lassen konnte. Die verbleibenden Probleme waren dennoch ebenso zahlreich wie komplex und forderten eine ganze Reihe weiterer Studien', die, wle prüher schon, regelmäßlg mlt den Steuerexperten der Mitgliedstaaten durchgesprochen wurden. Guleus erklärtes Ziel war eine "TVA épuré"s, also eine reine oder geläuterte MWSt. Aber schon in der Vorbereltungsphase des Richtlinienentwurps mußte er Abstriche an seinem Konzept hinnehmen. Eine aus theoretischer Sicht z.B. wünschenswerte Abschaffung von Steuerbefreiungen erschlen, sofern eine Mehrzahl von Staa-

2 Persönliches Interview.

3 Vgl. Art.29-31 des Vorschlages für eine 6.USt-Richtlinie.

4 Die umfangreichsten Paplere wurden von der Kommission in der Reihe "Studien: Wettbewerb - Rechtsangleichung" herausgegeben; vgl. zur Besteuerung der Grundstucksumsätze Heft Nr.21 v. 1971, der Bankund Finanzgeschäfte Heft Nr.22 v. 1973, der Kleinunternehmen Heft Nr.23 v. 1973 und der Landwirtschaft Heft Nr.24 v. 1973.

Persönliches Interview. 
ten eine derartige Befreiung gewährten, politisch nicht durchsetzbar. ${ }^{6}$ Und die von der Steuerdirektion für sinnvoll gehaltene radikale Einschränkung der Sonderregelung für die Landwirtschaft schelterte bereits an den Agrarpolitikern im elgenen Haus.

Die entsprechenden Untersuchungen und Abstimmungsprozesse zogen sich lange hin. Oft kündigte die Kommission die baldige Vorlage des Richtlinienentwurfs $a n^{7}$, konnte ihre Versprechungen dann aber doch nicht einhalten. Dle Verzögerungen lagen zum einen darin begründet, daß die Brüsseler UStAbtellung der 1970 plötzlich auf sie zukommenden Aufgabe zunächst personell nicht gewachsen war. Hinzu kam, daß sonderliche Elle solange politisch nicht opportun erschien, wie die Einfuhrung der MwSt in Italien noch immer in der Luft hing. Aber auch die für den 1.Januar 1973 geplante EG-Erwelterung warf ihre Schatten voraus. In Großbritannien war der EG-Beitritt ebenso umstritten wie der glelchzeltig diskutierte ubergang zur MWSt. Die Regierung Heath kämplte mit dem Rúcken an der Wand, und es war zu befürchten, daß die Prühzeitige Vorlage eines sehr weitrelchenden MWSt-Harmonislerungsplanes deren Gegnern noch zusätzliche Munition in die Hände gegeben hătte. ${ }^{8}$

\section{Vorbereitungen auf politischer Ebene}

Im Herbst 1972 konnten die Vorbereitungen für den Richtlinienvorschlag auf technischer Ebene endlich abgeschlossen werden. Die Kommissare ließen das Papier aber zunăchst liegen, da sle Entscheldungen von solcher Tragweite lleber der nach dem 1.Januar 1973 neu zu bildenden Kommission uberlassen wollten. Erst als die EG die mit der Erwelterung verbundenen personellen und organisatorischen Veränderungen langsam verdaut hatte, kam man in der Brüsseler Chefetage dazu - es war Inzwischen Mal 1973 geworden -, sich über die Harmonisierung der MWSt intensivere Gedanken zu machen. Dle Kommissare mußten noch uber einige wenige Punkte entscheiden, die aufgrund ihrer politischen Brisanz im Entwurf der Steuerdirektion offengelassen worden waren. Das dabel mit Abstand dellkateste Problem blldeten ohne Zweifel die Null-Sătze.

Die Nlederländer, auf deren alleiniges Verlangen hin die begrenzte Verwendung von Null-Sätzen in der 2.USt-Richtlinie erlaubt worden war, machten von thnen in nur wenigen Ausnahmefallen und jeweils gegen den widerstand des Finanzministeriums Gebrauch. Die Steuerdirektion wollte daher gerne die mit der neuerlichen Richtlinie sich bletende Gelegenheit am Schopfe ergreifen und die Null-Sätze, sowohl im Hinblick auf die Erhebung der MWSt-Elgenmittel als auch zur Vorbereltung einer späteren Angleichung

$6 \quad$ Vgl. z.B. Söhn (1976a), S.18.

7 Anfang 1971 sprach Brüssel z.B. davon, dle Richtlinie bis Jahresende fertiggestellt zu haben; vgl. FAZ 2.4.71 u. 27.4.71.

Vgl. z.B. FAZ 8.7.71. 
der Steuersätze, ganz untersagen. Uneingeschränkte Unterstützung Pand sie, wie schon in den 60er Jahren, in Deutschland und Frankreich. Die Pariser Finanzverwaltung lehnte Null-Sätze strikt ab: "C'est la négation de l'impôt et surcroît dangereuse car par contamination elle tue toute forme de taxation."9 Im Hintergrund der Pranzösischen wie auch der deutschen Haltung stand die Furcht vor einer epedemieartigen Ausbreitung der Null-Sätze. Und die Furcht war, wie sich in den Jahren 1974 und 1975 zelgen sollte, durchaus gerechtfertigt: Die französischen Sozialisten deuteten im Wahlkampf die Reduktion der MWSt-Sătze für Grundbedarfsgüter auf $0 \%$ an ${ }^{10}$, und die deutschen Zeitungsverleger kämpften in ihren Blättern für eine Freistellung der Presse von der MWSt.

Während sich in der EG der Sechs ein Kompromiß ohne weiteres hätte finden lassen, war er in der nunmehr erwelterten Gemeinschaft unmöglich. Die britische Regierung mußte sich aus innenpolitischen Gründen gegen eine Abschaffung der Null-Sätze zur Wehr setzen: Da die britischen Lebensmittelpreise wegen der EG-Agrarpolitik ohnehin zum Ansteigen verurteilt waren, reagierten die Gewerkschaften und die Opfentlichkelt gereizt auf alles, was mit Prelserhøhungen zu tun hatte und dazu noch aus Brüssel kam. Nach heftigen Kommissions-internen Auselnandersetzungen konnte sich der für Steuerangelegenhelten nunmehr zuständige Kommissar Simonet im Verein mit seinen belden britischen Kollegen gegen "the theologians of the Brussels taxation department"11 durchsetzen. Mit Rücksicht auf die Zwangslage der britischen Reglerung sollten solche Null-Sătze auch in Zukunft erlaubt sein, die am 1.April 1973 - dem Tag der MWSt-Einfuhrung in Großbritannien - in Kraft waren und die den Bestimmungen der 2.USt-Richtlinie entsprachen. Um jedoch die Piskalische Erhebung der MWSt-Eigenmittel nicht in Frage zu stellen, sollte Jeder Unternehmer verpflichtet werden, auch für die mit $0 \%$ belasteten Umsätze eine ordnungsgemäße Steuererklärung abzugeben. ${ }^{12}$

Der endgültige Entwurf wurde dem Rat am 29.Juni 1973 als Vorschlag für elne 6.USt-RIchtlinie offlziell zugeleitet. ${ }^{13}$ Der WSA und das EP gaben im Januar bzw. im Mărz 1974 ihre Stellungnahmen ab. Sie hielten den Kommissionsentwurf zwar im ganzen für eln wenig zu perfektionistisch, gaben inm aber, von ein paar Kritikpunkten abgesehen, ihr Placet. Wieder waren es insbesondere die Null-Sătze, die zu Kontroversen Anlaß gaben und dle das

$9 \quad$ Lebrun (1979), S.115.

10 Vgl. z.B. Les Echos 10.5.74, Le Monde 5.9.74 u. 10.9.74.

11 Economist 5.5.73. Vgl. a. Guardian 1.2.73, FT 17.3.73, AE 14.5.73, Guardian 16.5.73, AE 22.6.73, Economist 23.6.73, Le Monde 26.6.73, Times 3.7.73 u. AE 7.7.73.

12 Vgl. Art.28 Abs.2 des Vorschlages fur eine 6.USt-Richtlinie.

13 Eine Kurzkommentlerung des Richtlinienvorschlages findet sich z.B. bei Sarrazin (1973), Söhn (1976a) u. Wachweger (1974). Vgl. a. Handelsblatt 31.7 .73 u. Blick durch die Wirtschapt 1.11.73. 
EP quer durch alle Fraktionen hindurch in zwel Lager spalteten. Entgegen dem Mehrheitsvotum des Haushaltsausschusses konnte sich in einer Kamppabstimmung des Straßburger Plenums ein von den britischen Abgeordneten getragener Entschließungsantrag durchsetzen, der die Null-sătze auch langfristig als Tell eines europälschen MWSt-Systems nicht ausschließen wollte. ${ }^{14}$ Als Reaktion auf die vom WSA und EP vorgebrachten Anderungswünsche legte die Kommission im August 1974 einen modifizierten Richtlinlenentwurf vor, der in selnen Grundzügen jedoch mit dem ein Jahr alteren Vorschlag übereinstimmte. ${ }^{15}$

\subsubsection{Toter Punkt in den Verhandlungen}

\section{Widerstände auf der technischen Ebene}

Nach der Vorlage der 6.USt-Richtlinie im Jull 1973 hatten sich die gleichen Steuerbeamten, die schon an ihrer Ausarbeitung beteiligt gewesen waren, in der Gruppe Finanzfragen des Rates zusammengefunden, um dle elnzelnen Artikel mit ihren Kollegen von den drel neuen Mitgliedstaaten nochmals durchzugehen. Kein einziger der Experten war von dem Vorschlag der Kommission begelstert. Alle hielten das Papler für zu umfangreich und detailliert. Díe Franzosen sprachen von einer "proposition extrèmement large et technocratique"16, und die Deutschen kritisierten die "..Harmonisierungsperfektion, die uber die Erfordernisse elnes gemeinsamen Marktes weit hinausgeht"17. Auch die aus der Wirtschaft kommenden stimmen fielen nicht positiver aus. So mißfiel der Confederation of British Industry "..the needless rigidity of the harmonized system proposed by the Commission"18, und die Spitzenverbände der deutschen Wirtschaft bestanden darauf, daß "..nur dort $z$ wingende gemeinsame Vorschriften erlassen werden, wo im Interesse der Wettbewerbsgleichheit eine einheitliche Regelung unerläßlich ist." 19

Die im Rat versammelten Steuerbeamten weigerten sich schlichtweg, ihre USt-Systeme Innerhalb von nur wenigen Jahren elner zweiten, grundlegen-

14 Vgl. Pkt.13 der Stellungnahme des EP zur 6.USt-Richtlinie.

19 Vgl. Sarrazin (1974), S.285fe. Vgl. a. Wachweger (1975). Vgl. a. AE 31.7.74.

16 Persönliches Intervlew.

17 Höppner (1977), S.131. Vgl. ähnl. Sarrazin (1973), S.209.

18 Confederation of British Industry, Annual Report 1973, S.9. Vgl. a. das CBI-Memorandum in: Papers of the House of Lords, 1975/76: H.L.281. Eine ähnliche Haltung vertrat die niederländische Wirtschaft; vgl. z.B. Blick durch die wirtschaft 20.7.73.

DIHT, BDI U.a., Stellungnahme zum Vorschlag einer 6.Richtlinie des Rates der EG zur Harmonisierung der Rechtsvorschriften uber die USt, Köln/Bonn 18.7.75, S.2. 
den Reform zu unterziehen. Man vertrat vielmehr, übrigens in vollkommener Ubereinstimmung mit dem WSA, die Ansicht, daß zunăchst "..eine Pause eingelegt werden sollte, um die Unternehmen erst einmal zum Atmen kommen zu lassen."20 Aber auch mittelfristig sahen sie keine Notwendigkelt für eine umfassende Harmonisierung der MWSt-Basis. Man war mit der elgenen MWSt zuprieden und wollte sie nicht durch die 6.USt-Richtlinie "in Unordnung bringen"21 lassen. So behaupteten die Dänen, die "elnfachste"22 MwSt in Europa zu haben, die Briten beanspruchten das gleiche Adjektiv für sich, die Deutschen sprachen von ihrer MWSt als der "saubersten und elegantesten"23, etc. Wofur also, so fragten sich die Steuerexperten, sollten sle "all die Mühen mit der Harmonisierung"24 aup sich nehmen, wenn noch nicht einmal die elgene Wirtschaft, von wenigen Punkten abgesehen, einen Handlungsbedarf sah? "The countries have to get something in return for their concessions"25 - Zugeständnisse der anderen aber, die eine Umwälzung der elgenen MWSt hatten rechtfertigen konnen, waren weit und breit nicht in Sicht. Hinzu kam, daß die Steuerbeamten sich ihren gesamten Einfluß auf die nationale MWSt-Gesetzgebung nicht einfach durch eine Vereinheitlichung der Bemessungsgrundlage von Brüssel aus der Hand nehmen lassen wollten.

Für die Steuerexperten der Mitgliedstaaten gab es also mehr als genug Argumente gegen und kein einziges stichhaltiges für die 6.USt-Richtlinie. Man saß zwar Im Rat belsammen und mußte die Meinungsverschiedenheiten über die elnzelnen Artikel auch diskutieren, kam sich dabei jedoch, zur Zufriedenhelt aller, mit Ausnahme der Kommission, kein stück năher. Von Zeit zu Zelt wagten sich die Briten vor mit der Anregung, zumindest in Tellberelchen auf die fiskalische Erhebung der MWSt-Eigenmittel zu verzichten, um damit den Harmonisierungsbedarf zu verringern. Abgesehen von den Franzosen, die dem statistischen Datenmaterial der anderen nicht trauten, konnte die britische Initlative auf die Sympathie aller zählen. ${ }^{26} \mathrm{Da}$ aber die Kommissionsvertreter auf solcherlel Anllegen regelmaßig äußerst "excited"27 reaglerten, lleßen die Briten schlleßlich die Finger davon und fugten sich mit den anderen in das Schicksal, stundenlang zu reden und doch aup der Stelle zu treten.

\footnotetext{
20 Stellungnahme des WSA zu Art.1 der 6.USt-Richtllnie.

21 Persönliches Interview.

22 Persönliches Interview.

23 Persönliches Interview.

24 Persönliches Interview.

20 Persönliches Interview.

26 Vgl. z.B. Sarrazin (1974), S.281.

$27 \quad$ Persönliches Interview.
} 
Um möglicher Kritik von außen vorzubeugen, mußten die Expertengespräche aber eln vorzelgbares Resultat llefern. Man beschloß daher, eine Liste der Probleme zusammenzustellen, die aufgrund ihrer politischen Delikate $\beta$ nur vom Ministerrat entschieden werden konnten. Die Liste wurde sehr umfangreich und enthielt neben den bereits erwăhnten Null-sătzen unter anderem die nun folgenden Punkte.

\section{Widerstände auf der politischen Ebene}

1. Ein erster Streltpunkt war die Frage, bis zu welcher Größenordnung Kleinunternehmen in den Genuß welcher Sonderregelung kommen sollten. Die Kommission schlug eine steuerbefrelung vor, die durch eine steuerermaßigung ergänzt werden konnte. Im Hinblick auf die Reinheit der MwSt legte sie die Höchstgrenze Pür den Jahresumsatz, unterhalb dessen elne Sonderregelung erlaubt sein sollte, vergleichswelse nledrig fest.20 Widerstand gegen den Brüsseler Entwurf regte sich an allen Fronten. Dle belgische Finanzverwaltung wollte uberhaupt keine Steuerbefreiung - "pour aucun prix"29 - sondern stattdessen ihre Pauschalregelung beibehalten, die sich im Umgang mit den ebenso schwierigen wie einflußreichen Kleinunternehmen des Landes bestens bewăhrt hatte. Andere Staaten störten slch vor allem an den zu restriktiven Höchstgrenzen. Belsplelhapt skizziert sel hier die innenpolitische Situation Im Vereinigten Königrelch.

Zwar waren die britischen Kleinunternehmen nur schlecht organisiert, machten dafür aber umso mehr "noise"30 und konnten sich daher berelts bel der Einfuhrung der MWSt, wie oben gezelgt, eine weltgehende Freistellung von der Besteuerung erkämpfen. Unterstützung für ihr Anllegen, die großzügige britische Sonderregelung gegen die Kommission zu verteidigen, fanden sie bel der Confederation of British Industry, die Anfang der 70er Jahre in Konkurrenz mit einem anderen Verband unter den Kleinunternehmen Mitglieder zu werben versuchte. ${ }^{31}$ Auch Customs and Excise wollte die Ausnahmevorschrlften eher ausdehnen als einschränken, hatte doch die Finanzbehörde mit den Kleinen nichts als Arger. Bel der Einführung der MWSt hatte man die aus elner uber 1000jăhrigen Geschichte stammenden, sehr weltgehenden Kontrollbefugnisse der Zollbehörde völlig unreflektiert auf die MWSt übertragen. Dle von den Kleinen als rüde empfundene Steuererhebungspraxis der Zolleute zog Schlagzellen nach sich - "VAT led to suicide"32 oder "Man found dead 'was depressed' by VAT raiders"33 -, die dem Image von Customs and Excise nur abträglich sein konnten und zum

\footnotetext{
28 Vgl. Art.25 des Vorschlages fur elne 6.USt-Richtlinie.

29 Persönliches Interview.

30 Persönliches Interview.

31 Vgl. Grant (1972), S.279. Vgl. a. FT 8.3.75.

32 Times 11.10 .73 .

33 Times 8.7.76.
} 
Tell sogar erhitzte Debatten Im Parlament auslösten. ${ }^{34}$ Ein offenes Ohr fur ihre Forderungen fanden die Kleinunternehmen, da sle als Bollwerk gegen die Gewerkschaften galten, insbesondere bel der Konservativen Partel. Die Parlamentarier standen ihnen daher zur Seite und zwar mit Argumenten "All over Europe, small business-men and their wives sit down on Sundays to bring their VAT records up-to-date"35 -, die dem Leser nur die Tränen in die Augen trelben können.

2. Ahnliches Mitgefuhl wurde nur noch den Bauern in der Gemeinschaft zutell. Auch hler besaß die Kommission die Kaltschnäuzigkeit, einen Vorschlag zu präsentleren, der auf die schrittweise vorzunehmende Einbezlehung zumindest der größeren Landwirte in die MwSt abzlelte. ${ }^{36}$ Und wieder kam die Opposition von fast allen Selten. $\mathrm{Da}$ de in den meisten Landern ubliche Pauschalregelung den Landwirten gleich zwel Vortelle bescherte - keine Buchfuhrung und bel zu hoch bemessener Vorsteuerpauschale auch eine indirekte Subventionierung -, wollte die Bauern-Lobby verständlicherweise unter allen Umständen daran Pesthalten. Zwar waren mit der Kommission auch die nationalen Finanzministerien gegen eine Sonderbehandlung der Bauern. Sie konnten sich aber gegen die Grüne Front aup den Straßen, in den Parlamenten und Landwirtschaftsministerien nicht durchsetzen, und stellten daher nur resignierend Pest: "Bauern düren, da sie nicht schrelben und nicht lesen können, weder belästlgt noch belastet werden."37 Auch die Wirtschaftsverbände ärgerten sich zwar manchmal uber die zugunsten der Landwirtschaft gemachten Ausnahmen, fanden sich aber ansonsten in "Lethargle und Apathie"s damit ab.

Unterstutzt wurde das Konzept der Kommission nur von Dänemark und Großbritannien, den beiden einzigen EG-Staaten, die bis dato ihren Landwirten überhaupt keine Sonderregelung gewăhrt hatten. Die Urache für diese Besonderheit llegt beidesmal in den Steuersätzen der genannten Lănder begründet: Dänemark erhob als einziges EG-Land nur einen Steuersatz - die Buchführung ist wesentlich einfacher als bel einem Mehrsatzsystem und Großbritannien besteuerte neben den landwirtschaftlichen Outputs auch die meisten Inputs mit $0 \%$ - damit fallen viele Landwirte automatisch aus der MWSt heraus -.

Vgl. z.B. Times 13.7.73.

Das Zitat stammt von einem britischen Abgeordneten des EP; $A B$ Anhang 1983/1-306, S.24.

Vgl. Art.27 des Vorschlags fur elne 6.USt-Richtlinie.

Persönliches Interview.

Persönliches Interview. 
3. Der Vorschlag der Kommission, die eine oder andere Steuerbefrelung abzuschaffen, ${ }^{39}$ trat den unterschiedlichsten Gruppen und Gruppchen auf die Füße. In Dänemark waren es "unerfindliche politische Gründe"40, die das Finanzministerium dazu zwangen, sich in Brüssel für die Beibehaltung bestimmter Befreiungen - z.B. für den Personenverkehr - stark zu machen. In Bonn litt der Postminister seit der Vorlage des Kommissionsentwurps unter schlaplosen Nächten und bat inständig seinen Kollegen von den Finanzen, die traditionelle Befrelung des deutschen Post- und Fernmeldewesens zu verteidigen. Dem Pariser Finanzministerium graute vor dem Gedanken, den in der französischen Nationalversammlung überproportional vertretenen Berufsstand der Rechtsanwälte zu besteuern.41

Die von der Kommission gewünschte partielle Einbezlehung der Immobilienumsätze in die MWSt sorgte in den meisten Mitgliedstaaten für Schwierigkeiten. $\mathrm{Zu}$ den Ländern, die den Kommissionsentwurf in diesem Punkt ablehnten, zählte auch die Bundesrepublik. Zwar hatten sich die deutschen Wirtschaftsverbände, in Ubereinstimmung mit Brussel, seit Einfuhrung der MWSt für eine Ausdehnung der MWSt auf Grundstücksumsätze umd damit für die Abschaffung der Grunderwerbsteuer ausgesprochen. ${ }^{42} \mathrm{Da}$ aber die MWSt Bund und Ländern gemeinsam zusteht, während die Grunderwerbsteuer nach Art.106 Grundgesetz allein den Ländern zufleßt, hätte eine solche Maßnahme eine Neuregelung des Finanzausgleichs und gegebenenfalls sogar eine Anderung der Verfassung vorausgesetzt. Da man in Bonn vor einem derartigen Aufwand zurückschreckte, forderte man in Brüssel, die bisherige Regelung belbehalten zu dürfen.43

4. Ein ganz alleine auf Frankreich begrenztes Problem stellte das im Kommissionsentwurp enthaltene Verbot des décalage d'un mois dar. ${ }^{44}$ Die Sache hătte elgentlich Mitte der 70er Jahre schon längst vom Tisch sein können, da Art.11 Abs.3 der 2.USt-Richtlinle die genannte Pranzösische Spezialität ausdrücklich untersagte. Paris hatte auch 1971/72 die Abschaffung des décalage erwogen, dann aber doch nichts unternommen, da

39 Insbesondere geregelt in Art.4-7 in Verbindung mit Art.14-16 des Vorschlages für eine 6.USt-Richtlinie.

40 Persönliches Interview.

4 Vgl. z.B. Handelsblatt 22.10.76.

42 Vgl. DIHT, BDI u.a., Stellungnahme zum Vorschlag einer 6.Richtlinie des Rates der EG zur Harmonislerung der Rechtsvorschriften über die USt, Köln/Bonn 18.7.75, S.9f.

43 Vgl. z.B. Suddeutsche Zeltung 25.11.75. Vgl. a. die Stellungnahmen des Bundestages - Bundestags-Drs. VII/1879 - und des Bundesrates Bundesrats-Drs. 493/73 - zum Vorschlag für elne 6.USt-RIchtlinie.

Vgl. Art.18 Abs.2 des Vorschlages für eine 6.USt-Richtlinie. Der "décalage d'un mois" besagt in Kurzfassung, daß die MWSt-Abführung des Lieferanten und der VSA-Abzug des Kunden nicht zeltglelch erfolgen, sondern daß der VSA erst nach elner elnmonatigen Wartefrist erlaubt ist; vgl. ausführlicher die Darstellung in Kap.C.2.2.1. 
die Reform sehr teuer, aber wenig publikumswirksam gewesen wăre: "Ca ne fait pas un titre dans le Franc Solr."49 Die Kommission häte nicht nur die Möglichkelt gehabt, sondern wăre genaugenommen sogar verpflichtet gewesen, die französische Unregelmäßigkeit vor den EuGH zu bringen. Darauf verzlchtete sie jedoch bel dem décalage ebenso wie bel zahlreichen Verstößen anderer Länder gegen die 2.USt-Richtlinle. ${ }^{46} \mathrm{Zwar}$ schrieb Brüssel Immer wieder Brlefe an die betreffenden Reglerungen, in denen die Abweichungen angemahnt wurden. Um jedoch den Mitglledstaaten die zur Annahme der 6.USt-Richtlinie notwendige Integrationsstimmung nicht $\mathrm{zu}$ verderben, ließ sie es aber in keinem Fall bis zu einer Klage kommen.

Frel von solcherart politischen Rücksichtnahmen waren die Unternehmen, die durch das unrechtmäßige Verhalten der jewelligen Mitglledstaaten finanziell belastet wurden. In dem elnen oder anderen Fall griffen sie zur Selbsthilfe und klagten ihre Rechte vor nationalen Gerichten ein.47 Allein, das Patronat Français "verschllep"48 selne große Chance, den schon seit über 20 Jahren erfolglos bekämpften décalage ${ }^{\wedge}$ per Richterspruch hinwegfegen zu lassen. Entschuldigend muß man den Pranzösischen Arbeitgebern zugute halten, daß der Ausgang einer Klage mlt sehr vielen Unwägbarkeiten behaftet gewesen wăre: Erstens akzeptierten die Pranzösischen Gerichte die vom EuGH entwickelte Lehre von der unmittelbaren Wirkung zuerst überhaupt nicht und dann nur widerwillig; und zweitens droht jede gegen die Administration gewonnene Klage, da dle sich für elne Verurtellung zu revanchleren pllegt, zu einem Pyrrhussieg für den Kläger zu werden. Wer immer auch die Schuld trug. Tatsache war, daß Paris Mitte der 70er Jahre seinen décalage noch immer hatte und berelt war, thn wahrend der Verhandlungen uber die 6.USt-Richtlinie standhaft zu verteidigen.

\section{Toter Punkt der Verhandlungen in 1974}

Jeder der in der 6.USt-Richtlinile enthaltenen Artikel bereitete einem oder mehreren Mitgliedstaaten Schwierigkelten. Zusammengenommen türmten sie sich auf zu einem Berg von Widerständen, die die nationalen Regierungen nicht glaubten uberwinden zu können. Und dle Steuerbeamten der Finanzministerien sorgten an der Heimatfront dafür, daß der Berg möglichst hoch wurde: Mittels einer geschickten Informationspolitik veranlaßte man die nationalen Parlamente, Bedenken zu ăußern, über die sich die Politíker dann nicht mehr hinwegsetzen konnten.

\footnotetext{
40 Persönliches Intervlew.

46 Vgl. Nasini (1973a), S.113ff.

47 Vgl. z.B. Blick durch die Wirtschaft 20.6.72.

48 Persönliches Interview.

49 Vgl. z.B. Les Echos 11.1.72.
} 
Aber kehren wir zurück nach Brüssel in die Gruppe Finanzfragen des Rates, wo die Steuerexperten, wie bereits vermerkt, sich 1973 anschickten, alle politisch brisanten Probleme aufulisten. Das Ergebnis der ohne übermäßige Hast vorangetriebenen Bemühungen war ein 9 Punkte umfassender Bericht, der Im Jull 1974 an COREPER weitergeleltet wurde.30 COREPER seinerselts stellte 4 der angerissenen Problemberelche erst einmal zuruck und setzte dle verbleibenden 5 - Null-Sätze und stark reduzierte Sătze, Sonderregelung für Klelnunternehmen und Landwirte. Immobillenbesteuerung - auf die Tagesordnung der Ministerratsitzung vom 19.Dezember 1974. Aber die Finanzminister wußten sich des Schwarzen Peters schnell wieder zu entledigen: Man besprach zunăchst eine Vielzahl haushalts- und wăhrungspolitischer Probleme; als man schließlich zur 6.USt-Richtlinie kam, hatten die meisten Minister den Verhandlungssaal bereits verlassen; zwischen den verbliebenen Beamten kam es zu einer kurzen Diskussion, die ergebnislos abgebrochen und an COREPER zurücküberwiesen wurde. ${ }^{01}$

Dle Verhandlungen hatten damit Ende 1974 endgültig ihren toten Punkt erreicht. Solange die Experten und Politiker der Mitglledstaaten die Verantwortung nur gegenseitig aufeinander abschoben, waren Fortschritte bei der 6.USt-Richtlinie nicht zu erwarten. Dle Ursachen des dead locks lagen klar auf der Hand. Es war der Zusammenbruch der WWU-Pläne und die EG-Erweiterung, die ihre Nachwirkungen zeigten und die Vorstellung von einem Europa ohne Steuergrenzen in die Welt der Zukunftstrăume abgleiten ließ. Und es waren die renegotiation demandso der Anfang 1974 neu gewählten britischen Labour-Regierung, die das gesamte System der eigenen Einnahmen der EG elnschlleßlich der MwSt-Eigenmittel in Frage stellten. Da das eine Ziel (die Abschaffung der Steuergrenzen) nicht mehr ernstgenommen und das andere (die schapfung von MWSt-Eigenmitteln) durch die Briten blockiert wurde ${ }^{53}$, war dem Vorschlag für eine 6.UStRichtlinie die Existenzberechtigung entzogen. Wleder in Gang gebracht werden konnte die USt-Harmonislerung nur von politischer Selte her. Die relevanten Zlelvorstellungen waren neu zu definleren, ein Proze $\beta$, der das gesamte Jahr 1975 und die 1.Halfte 1976 in Anspruch nahm. Schritt Pur Schritt wurden die Widerstände aus dem Weg gerăumt, die elnem Kompromiß uber die 6.USt-Richtlinle entgegenstanden.

so Vgl. Sarrazin (1974), S.281ff. u. Wachweger (1975), S.197f. Vgl. a. Tímes 3.7.74, AE 4.4.74 u. 29.1.75.

51 Vgl. AE 21.12.74 u. 29.1.75.

32 Am 1.April 1974 den in Luxemburg versammelten Außenministern der EG oppiziell übermittelt; abgedr. in: Cmnd 5593, London: HMSO 1974. Vgl. a. Welt 6.8.74.

53 Am Rande sel daran erinnert, daß das dritte Ziel - die Wettbewerbsneutralität - allelne elne umfassende Harmonisierung der MWSt-Basis auf keinen Fall hätte rechtfertigen können. 


\title{
Oberwindung des toten Punktes
}

1. Eine erste Voraussetzung für die spätere Verabschledung der 6.UStRichtlinie wurde von den Staats- und Reglerungschefs geschaffen, die im März 1975 die der Gemeinschaft von den Briten aufgezwungene Neuverhandlung der Beitrittsvertrăge beenden konnten. Das System der EG-Eigenmittel wurde nicht, wie von London zunächst verlangt, in seinen Grundzügen zur Disposition gestellt. Das vom Europäischen Glpfel verabschledete Dublin-Agreement versprach der britischen Reglerung stattdessen, die von der Erhebung der Eigenmittel ausgehenden finanziellen Nachteile durch Beitragsrückzahlungen ex post wleder auszugleichen. ${ }^{\text {s4 }}$ Damit konnten die als Pragmatiker bekannten Briten durchaus zufrieden sein:

\begin{abstract}
"From the outset of the renegotiation the Government considered that the form of the original contributions would be much less important once an effective mechanism was superimposed on them to ensure that refunds would be available if Britian's contribution went significantly beyond what was fair in relation to our share in Community GNP"ss
\end{abstract}

Nachdem im Jun1 1975 die britischen wăhler den Kompromiß in einem Referendum gebilligt und damit ihren Verblelb in der EG erklärt hatten, war, zumindest von der Seite Londons her, der Weg für die vollständige Implementlerung des Eigenmittel-Finanzierungssystems frel. Aber auch jetzt zeigten die Finanzminister der Gemeinschaft noch immer keinen sonderlichen Enthusiasmus für die 6.USt-Richtlinie. Solange sie noch nicht unter Entscheldungsdruck standen, sahen sle keinen Grund, sich auf die muhsellge Suche nach Kompromißlösurigen für die zahlreichen strittigen Punkte zu begeben. Also schoben sie die Sache weiter vor sich her.

2. Der nötige Druck wurde nach und nach vom EP aufgebaut. Neben den Direktwahlen war es insbesondere die vollständige Finanzierung der Gemeinschaft mit Eigenmitteln, mit deren Hilfe die Straßburger Abgeordneten ihre politische Rolle im europäischen Kräftespiel festigen wollten. Im Juni $1975^{56}$ und wieder im Jull $1976^{57}$ debattlerte das Parlament über die 6.UStRichtlinie. Es konnte sich vollkommen zu Recht "..des Eindrucks nicht erwehren, daß das langsame Verfahren im Rat auf die Abwesenheit eines politischen Willens zurückzuführen ist." 58 Um der Entscheidungsfreude der

\footnotetext{
54 Vgl. Dodsworth (1975) u. Emerson/Scott (1977).

95 "Report on Renegotiation" der britischen Regierung an das Parlament, abgedr. in: Cmnd 6003, London: HMSO 1975. Vgl. a. Times 11.3.75, 12.3.75 u. 13.3.75.

$36 \mathrm{Vgl}$. AB 1975/C 157, S.85P.

37 Vgl. AB 1976/C 178, S.27P.

$58 \mathrm{AB} 1975 / \mathrm{C} 157, \mathrm{~S} .86$.
} 
Finanzminister etwas nachzuhelfen, drohte man dem Ministerrat an, inn wegen fortgesetzter Untätigkeit nach Art.175 vor dem EuGH zu verklagen und bel Bedarf sogar einen Haushaltsplan der EG komplett abzulehnen.99

In den Hauptstädten der EG machte sich zusehends eine gewisse Unruhe brelt. Dle weitere Verzögerung der 6.USt-Richtlinie drohte sich langsam aber sicher $\mathrm{zu}$ einem handfesten politischen Skandal auszuwachsen. Die Finanzminister sahen sich immer mehr unter dem Druck ihrer Kollegen von den Außenministerien, die einfach nicht elnsehen wollten, was an der Anderung von eln paar Paragraphen des USt-Gesetzes so unüberwindbar schwlerig seln sollte. Es war schlleßlich der itallenische Finanzminister Italien hatte im 2.Halbjahr 1975 die Präsidentschapt inne und trat traditionell für eine Stärkung des EP ein -, der sich im Herbst 1975 in einem Gespräch mit Kommissar Simonet berelt erklärte, Im November eine ausschließlich der 6.USt-Richtlinie gewidmete Ministerratsitzung elnzuberufen. Auf die Tagesordnung kamen abermals die 5 Punkte, die die Minister elgentlich schon im Dezember 1974 hätten diskutieren sollen.60

3. Die zwischen 1974 und 1976 im EP über die 6.USt-Richtlinile geführten Debatten spiegeln deutlich wieder, wie sich die politischen Prioritaten der Gemeinschapt langsam verschoben. Während die Schaffung von MWSt-Eigenmitteln von Mal zu Mal an Bedeutung gewann, wurde dem Aspekt der Steuerharmonislerung eln immer geringeres Gewicht belgemessen. Es war nun an der Kommission, die Konsequenzen aus dieser Entwicklung zu zlehen. Brüssel sollte, so der Wunsch des EP wie auch der Mitgliedstaaten, "..flexibel genug sein, den Rat zu Schritten zu bewegen."61 Flexibilităt heißt hier im Klartext: Ein Tell der Harmonislerungssubstanz sollte geopfert werden, um die baldige Annahme der 6.USt-Richtlinie und damit die vollständige Eigenfinanzierung der EG zu ermöglichen.

Die Entscheidung fiel der Kommission und insbesondere ihren Steuerleuten recht schwer. Erleichtert wurde sle durch die 1974 erlebten Frustrationen: Man trat nicht nur bei der 6.USt-Richtlinie aup der Stelle, sondern hatte darüberhinaus auch hinnehmen müssen, daß ein Vorschlagsbündel zur Harmonisierung der spezlellen Verbrauchsteuern vom Rat ganz auf Eis gelegt worden war. Es war Kommissar Simonet, der schon Prühzeltig dle Initiative ergriff und, um die Steuerharmonislerung wenigstens in abgemagerter Form wleder in Bewegung zu bringen, einen new pragmatic approach ankündigte, der die Abschaffung der Steuergrenzen in die ungewisse Zukunft einer europälschen WWU hinausschob.62 Brüssel wolle sich, so der Tenor eines

59 Vgl. z.B. AB Anhang $1975 / 197$, S.88.

$60 \quad$ Vgl. AE 25.9.75.

61 AB Anhang 1976/205, S.141.

62 Vgl. Simonet (1975). 
Steuerpolitischen Aktionsprogrammes vom Jull 1975, in den nächsten Jahren aup das Machbare und die "absolut unerlaßlichen Maßnahmen"63 beschränken.

Unerläßlich für die Erhebung der MWSt-Eigenmittel war die 6.USt-Richtlinie. Sie aber war solange nicht durchsetzbar, wie der Harmonisierungsbedarp nicht entscheldend gesenkt wurde. Ein Durchbruch bel der 6.USt-Richtlinie lie $\beta$ sich, wie während der Verhandlungen in 1975/76 zunehmend deutlich wurde, nur entlang der folgenden Linie erzielen: Auf EG-Ebene wird, wie von der Kommission gewünscht, elne gemeinsame MWSt-Basis festgelegt; uberall dort, wo im Ministerrat keine Einstimmlgkeit hergestellt werden kann, werden den Mitglledstaaten für eine Ubergangszeit Abweichungen von der gemeinsamen Regel gestattet; jede das Steueraufkommen verändernde Abweichung löst automatisch eine Kompensationszahlung aus, die sicherstellen soll, daß die an die EG abgeführten MWSt-Eigenmittel immer dem entsprechen, was sich bel sofortiger Anwendung der gemeinsamen Bemessungsgrundlage ergeben hätte.

Die sich abzeichnende Kompromißlösung lief also auf eine Mixtur aus fiskalischer - dort, wo die gemeinsamen Regeln angewandt wurden - und volkswirtschaftlicher Erhebungsmethode - dort, wo von Abweichungsrechten Gebrauch gemacht wurde - hinaus. Sie wurde im Herbst 1975 in COREPER vorbereitet und vom Ministerrat am 24.November 1975 für alle auf der Tagesordnung stehenden Probleme endgültig sanktioniert.64

4. Mit dem Prinzlp der Kompensationszahlungen glaubte man, den Schlüssel für die Lösung aller politisch brisanten Streitfragen gefunden zu haben. Zumindest auf der politischen Ebene war damit der tote Punkt in den Beratungen der 6.USt-Richtlinie uberwunden. Aber nach wie vor gab es eine große Anzahl sehr komplexer technischer Probleme, von denen die Politiker nichts verstanden und die daher nur von den Steuerbeamten behandelt werden konnten. Und dle zeigten, da sle Ende 1975 für ein europälsches MwSt-Gesetz immer noch nicht zu begeistern waren, auch weiterhin keinerlel Eile. Obwohl sie nun schon selt Jahren die 6.USt-Richtlinie "..mit der Uberschallgeschwindigkeit von einem Artikel pro Sitzung.."68 in allen Detalls hin- und herdiskutiert hatten, wollte sich keiner der Experten von der Kommission größere Zugeständnisse abringen lassen. Die Beratungen in der

63 KOM(75)391 v. 23.7.75, Ziff.4; abgedr. in: Bulletin der EG, 8.1975, HePt 9, S.114ff. Vgl. a. Le Monde 12.8.75 u. Handelsblatt 14.8.75.

64 Vgl. z.B. Bulletin der EG, 8.1975, Heft 11, Ziff.2126. Vgl. a. Wachweger (1976). Vgl. a. Figaro 21.11.75, AE 22.11.75 u. 24.11.75 u. 26.11.75, Handelsblatt 26.11.75 u. FAZ 26.11.75. 17.6.76. 
Gruppe Finanziragen des Rates verliefen daher, wie die Franzosen es in der thnen elgenen diplomatischen Art ausdruckten, "assez négative"66. Für den Berichterstatter des EP war die Frage der Schuldzuweisung schnell beantwortet: "..ich habe den Eindruck, daß nichts so komplizlert ist, daß es durch die Einschaltung von Ministerialbeamten nicht noch komplizierter werden könnte."67 Aus der Perspektive der nationalen Steuerbeamten aber sah die Sache anders aus: "Die Experten sind zăh, aber das ist auch gut so, da es die Politiker dann sowleso verhunzen"60 - eln Argument, das sich nicht ohne weiteres von der Hand weisen läßt.

Anfang 1976 gingen die Verhandlungen auf technischer Ebene zunächst im altbekannten Schneckentempo weiter. Das Blld wandelte sich erst, nachdem die Außen- und Finanzminister der EG auf einer gemeinsamen sitzung im April 1976 beschlossen hatten, das System der Eigenmittel bis spätestens 1.Januar 1978 vollständig zu implementieren.69 Die Entscheidung implizierte, daß, um den Mitgliedstaaten ausreichend Zeit für die Umstellung ihrer UStSysteme lassen zu können, die 6.USt-Richtlinie noch im Jahre 1976 verabschiedet werden mußte. Mit der Unterstützung der natlonalen Regierungen im Rücken trug nun auch der Druck der Kommission auf die Finanzexperten erste Früchte. Und der Druck kam nicht nur aus Brüssel, sondern baute sich in zunehmendem Maße auch innerhalb der einzelnen Hauptstadte auf. Immer offer wurden die Steuerexperten von Ihren Kollegen in den Europaabtellungen der Finanz-, Wirtschafts- und Außenministerien aufgefordert, ihre Arbeiten an der 6.USt-Richtlinie zu beschleunigen.

\subsubsection{Verabschledung durch den Rat}

\section{Dle Verhandlungen in der 2. Halfte 1976}

Bis Mitte 1976 waren somit die Beratungen sowohl aup der politischen als auch aup der technischen Ebene wieder in Gang gekommen. Die Steuerexperten kannten, da sie jeden Punkt bereits hundertmal durchdiskutiert hatten, den Richtlinienvorschlag im Schlaf. Die Politiker hatten mit dem Kompensationsprinzip den Weg für eine Kompromißlösung bei allen politisch heiklen Fragen gewiesen. Gepragt war nunmehr jemand, der eine Entscheidung erzwang und den aus unzähligen Detallproblemen gewobenen gordischen Knoten durchschlug. Sollte das nicht gelingen, so würde, wie die EGErfahrung nur zu deutlich beweist, die 6.USt-Richtlinie für sehr lange Zeit vom Verhandlungstisch verschwinden. Angesichts dieser Situation muß es

\footnotetext{
66 Persönliches Interview.

67 AB Anhang 1975/192, S.245.

68 Persönliches Interview.

69 Vgl. z.B. AE 1.4.76, Süddeutsche Zeitung 5.4.76, AE 6.4.76, FT 6.7.76 u. FAZ 7.4.76.
} 
als ein glücklicher Umstand gewertet werden, daß die Niederländer in der 2.Hălfte 1976 die Präsidentschapt im Rat ubernahmen. Da DenHaag sich schon seit Anbeginn der EG immer wleder für elne Stärkung des EP eingesetzt hatte, konnte es nicht überraschen, daß die niederländische Regierung im Jull 1976 den Straßburger Parlamentariern versprach, sowohl einen Beschluß über die Direktwahlen herbelführen zu helfen als auch die 6.UStRichtlinie bis Jahresende im Rat durchzupauken.70

Die Ausführung des letztgenannten Versprechens übernahm der junge Finanzminister Duisenberg, der sich damit nicht zuletzt einen persönlichen Erfolg erkämpłen wollte. Nach Beendigung der Brüsseler Sommerpause setzte er ab Ende August immer häufiger Sitzungen der nationalen Steuerbeamten an. Ab Ende September gingen die Niederländer zu Marathontreffen uber ${ }^{71}$, wobel Marathon im Klartext bedeutete: Fünf Tage die Woche wurde in Brüssel non-stop verhandelt, das Wochende verbrachte man dann im heimatlichen Finanzministerium, um den inzwischen überlaufenden Schreibtisch notdürftig abzuarbeiten. Am 21.0ktober wurde eine Ministerratsitzung einberufen, um einige politisch delikate Probleme $z u$ behandeln. ${ }^{72}$ Anschlleßend ging es in der Expertengruppe in der gehabten Manier.weiter.

Die Tatsache, daß den Steuerbeamten von den eigenen Regierungen "politische Daumenschrauben"73 angelegt worden waren, schwächte ihre Verteidigungskraft gegenüber den Attacken des niederländischen Vorsitzes und der Kommission merklich ab. Um der Kompromißbereitschaft der Steuerbeamten zusätzlich auf die Sprünge zu helfen, versuchten es die Niederländer mit einer in Brüsseler Steuerverhandlungen bis dato unbekannten Taktik: Die mannigfaltigen Aspekte einer jeden StreitPrage wurden aup eine einzige Dimension reduzlert; als mögliche Stellungnahme der nationalen Delegationen war damit nur noch ein Ja oder ein Nein erlaubt; auf der Basis der Antworten wurden Päckchen geschnürt, die den Steuerbeamten nach dem Prinzip "Priß oder stirb"74 vorgelegt wurden. Die Experten setzten sich gegen die als rude empfundene Methode zur Wehr. Aber was sollten sie machen? Sperrte sich eine Delegation gegen den Mehrheitswillen, so bedeutete dies automatisch, daß der betreffende Punkt auf die Tagesordnung der năchsten Ministerratsitzung kam. Damit zogen sich die Beamten den Unwillen ihrer Vorgesetzten zu. Zudem mußten sie befurchten, daß die dann verhandelnden Minister angesichts ihres mangelnden Fachwissen unter Umständen mehr zum Schlechten als zum Guten wenden würden. Sie kamen

70 Vgl. Z.B. AE 1.7.76 u. 9.7.76.

71 Vgl. AE 27.9.76 u. 29.9.76.

72 Vgl. Economist 16.10.76, AE 21.10.76 u. 22.10.76, Welt 22.10.76, AE 23.10.76 u. NZZ 26.10.76.

73 Persönliches Interview.

74 Persönliches Interview. 
daher zumindest bei sehr technischen Fragen nicht umhin, selber eine einigermaßen akzeptable Kompromißlösung zu finden.

Auch die Dienststellen der Kommission arbeiteten aup Hochtouren. Sle mußten auf Geheiß des Rates innerhalb weniger Wochen prufen, ob die anvisierten Kompensationszahlungen technisch überhaupt machbar waren. Das Ergebnis fiel, nicht zuletzt, weil elne negative Antwort die Verhandlungen zum Erliegen gebracht hătte, positiv aus. ${ }^{70}$ Aber die Kompensationen blleben, zumindest aus der Sicht der Kommission, ein höchst gefährliches Instrument. Sie erleichterten $\mathrm{zwar}$ eine Kompromißfindung, reduzierten aber gleichzeitig die Harmonisierungssubstanz der 6.USt-Richtlinie. Ständig versuchten die Mitgliedstaaten, sich gegenseitig Abweichungen von der gemeinsamen Bemessungsgrundlage zuzuspielen. Als Beispiel kann die britische Position dienen: Die Briten wollten zwar gerne eine gemeinsam fixierte Sonderregel für die Landwirtschaft, um den MwSt-Subventionen insbesondere der Deutschen an ihre Bauern Einhalt zu gebieten, hielten die Sache aber als "potential threat"76 unter dem Tisch, da sle die deutsche Zustimmung für die den britischen Kleinunternehmen gewährte großzügige Freigrenze benötigten. Oder die Niederländer: Sie wünschten sich zwar eine Ausdehnung ihres Verfahrens der Importbesteuerung ${ }^{77}$ auf die gesamte EG, forcierten ihr Anliegen aber nicht, da sie an anderer Stelle wieder auf das Wohlwollen der Partner angewiesen waren. Die Kommission Pocht einen gefährlíchen Kamp̧. Sie versuchte, möglichst viel an Harmonisierungssubstanz zu retten, mußte aber gleichzeitig daraup bedacht sein, die Kompromißfahigkelt der Mitgliedstaaten nicht zu uberfordern und damit das ganze Projekt zum Scheitern zu bringen. Oft war Brüssel gezwungen, sich auf die 2.UStRichtlinie - sle sollte aup keinen Fall aufgewelcht werden - als letzte Verteidigungslinie zurückzuzlehen. Und selbst diese Grenze blleb nicht ganz unbeschädigt:

- Ein Kratzer wurde ihr in der Frage der Null-Sătze zugefügt. Mit der Regelung, daß die Null-Sătze nur wăhrend einer nicht năher definierten Ubergangsperiode belbehalten werden dürfen, konnten sich die Briten durchaus abfinden: ".., pragmatists claim that tax harmonization is in effect a dead issue for the rest of the decade and therefore there is no problem."78 Darüberhinaus aber beanspruchten die Briten für sich das Recht - man sprach von einem "matter of principle"79 -, auch in Zukunft neue Null-Sătze einführen zu dürfen. Unterstützt von den

79 Vgl. $\mathrm{KOM}(76) 610$ v. 17.11 .76$.

76 Persönliches Interview.

77 Wir werden hierauf noch unter dem Stichwort 14.USt-Richtlinie zu sprechen kommen.

78 Times 13.3.75.

79 Vgl. Papers of the House of Lords, 1975/76: H.L.281. 
Benelux-Ländern, Deutschland und Frankreich - "..nous leur demandons de conserver cette horreur à l'intérleur de leurs irontlèrs"80 - widersprach die Kommission diesem Ansinnen mit Hinwels auf Art.17 der 2.USt-Richtlinie. Letzten Endes verständigte man sich daraup, die genannte Vorschrift, ohne daß über deren unterschledliche Interpretation elne Einigung zwischen London und Brussel herbelgeführt worden wäre, einfach in Art.28 der 6.USt-Richtlinie zu ubernehmen. Die Kommission drohte lediglich, im Fall der Einfuhrung neuer Null-Sätze die Briten umgehend vor dem Luxemburger Gerichtshof zu verklagen. ${ }^{\text {o1 }}$

- Klar überschritten wurde die genannte Grenze zugunsten der Franzosen. Da keln einziger Mitgliedstaat eln wirtschaftliches Interesse an der Abschaffung des décalage d'un mols hatte, konnte Paris ohne größere Mühen durchsetzen, daß, entgegen dem ausdrücklichen Verbot in der 2.USt-RIchtlinie, in Art.28 der 6.USt-Richtlinie eine entsprechende Ausnahmegenehmigung vorgesehen wurde.

\section{Dle Ratsitzung vom 16. Dezember 1976}

Nach monatelangen Marathonverhandlungen in der Gruppe Finanzfragen des Rates wurde fur den 16.Dezember 1976 die entscheidende Ministerratsitzung angesetzt, in der die uber 30 offenen Fragen beantwortet werden sollten. Dle in der europäischen Arena schon erfahrenen Kämpfer bereiteten sich gut vor. So ließen sich belsplelswelse die Deutschen vom Bundeskabinett elne Liste von essentials absegnen, die der nach Brüssel fahrenden Delegation den Rucken stärken sollte. Dle von der Bonner Finanzverwaltung gewanschte Definition des Ortes einer Dienstleistung stand, da das Kablnett für solch komplizlerte Dinge leider kein Verständnis hatte, nicht auf der Liste mit der Konsequenz, daß der deutsche Verhandlungsführer während der sitzung umflel, Zugeständnisse machte und den Steuerleuten damit Probleme bereltete, mit denen sie sich noch Jahre spăter herumschlagen mußten. Als zweite Vorbereitungsmaßnahme legten sich die Erfahreneren unter den Tellnehmern einen größeren Vorrat an Obst und Fruchtsäften zu. Solcherlel Vorsicht mag befremdlich erscheinen, hat aber ihre guten Gründe: Bel wichtigen sltzungen werden in Brüssel, um den europăischen Gelst der Tellnehmer zu stärken, vorzugsweise alkoholische Getränke gereicht.

Am 16.Dezember kam man nach dem Frühstück dann zur Sache. Der Vorsitzende Dulsenberg präsentierte zunächst elnen umfassenden Kompromißvorschlag und gab den Delegationen anschlleßend Gelegenheit, ihre abweichende Meinung $\mathrm{zu}$ politisch heiklen Fragen kundzutun. Um die Mittagszeit wurde die Gangart härter. Punkt für Punkt wurde durchdiskutiert. Duisen-

o Lebrun (1979), S.115. Vgl. a. Handelsblatt 25.11.75.

81 Vgl. Wachweger (1976b), S.22. Vgl. a. AE 26.11.75. 
berg schnürte entsprechend dem Prinzip, daß Jeder Mitgliedstaat vergleichbare Zugeständnisse machen müsse, Pakete zusammen - "der Holländer hat das meisterhaft verstanden"82 -, die den Delegationen vorgesetzt wurden. Eine solche Unverfrorenhelt war den Finanzleuten noch nicht untergekommen. Jeder hopfte darauf, daß eine andere Delegation Einwände machte, hinter denen man sich dann selbst hătte verstecken können. Aber niemand wagte es, die politische Verantwortung für das Scheitern elnes ganzen Pakets und damit vielleicht der gesamten 6.USt-Richtlinie aup sich zu nehmen. Zögerten die Verhandlungsführer, so hatte Duisenberg - "es gibt sogar bei den Bauern nur ganz wenige, dle so hart sind"»3 - elne pur die eher feinen Finanzpolitiker ebenfalls völlig neue Erfahrung parat: "Er schrie sie an und schmlerte lhnen im nächsten Moment wieder Honig um den Mund"84.

Mit später werdender Stunde wurden die Pausen und die Zelt für interne Beratungen der Delegationen immer mehr verkürzt. Insgesamt fünfmal rief Duisenberg die Verhandlungsfuhrer hinter verschlossene Türen, um ihnen, von den Steuerbeamten verlassen und damit fachlich hilflos, Zugeständnisse abzupressen. Und das geschickt inszenierte "Wechselbad der Gepuhle" zeigte Erfolge. Kurz vor der Morgendämmerung des nächsten Tages hatte man alle Punkte behandelt. In einer 18stündigen Sitzung hatte es der Nlederländer Duisenberg geschafft, die Meinungsverschiedenheiten uber die 6.USt-Richtlinie, von ein paar Vorbehalten einzelner Mitgliedstaaten abgesehen, auszuräumen. Ohne seine extrem harte Verhandlungsführung wäre, nach ubereinstimmender Aussage von Augenzeugen, ein solcher Erfolg nlemals denkbar gewesen. Dle Verhandlungstellnehmer waren völlig erschöpft und konnten nur noch feststellen: "Wir sind...doch alle vergewaltigt worden." 86

\section{Verzögerungen bis zur Verabschledung der Richtllnle}

Die nationalen Reglerungen sollten sich bis Anfang 1977 dazu ăußern, inwieweit sie ihre Vorbehalte aufrechterhalten wollten. Die weitaus meisten der nach und nach in Brüssel eingehenden Paplere stellten den Rat vor keine unüberwindlichen Probleme. Alleine die belgische Regierung - in Belgien waren inzwischen vorgezogene Neuwahlen angesetzt worden - wagte

\footnotetext{
82 Persönliches Interview.

83 Persönliches Intervlew.

84 Persönliches Interview.

8s Persönliches Interview.

66 Zitat eines deutschen Beamten, wiedergegeben in der Wirtschaftswoche v. 21.1.79. Zur Ratsitzung vom 16.12.76 vgl. a. AE $16.12 .76 \mathrm{u}$. 17.12.76, NZZ 17.12.76, AE 18.12.76, FAZ 18.12.76, FT 18.12.76, Le Monde 18.12.76, NZZ 19-20.12.76, Süddeutsche Zeltung 29.12.76. Zum Stand danach vgl. a. Schllenkamp (1977b).
} 
es, ein 150 Selten starkes Dokument vorzulegen, in dem sle neben zahlreichen technischen Anderungswünschen insbesondere forderte, die in Belgien gültige Sonderregelung für Kleinunternehmen belbehalten zu dürfen. Die anderen Mitgliedstaaten und die Kommission reaglerten gereizt. Sie wollten das im Dezember ausgehandelte Paket unter keinen Umständen wieder aupschnüren, da es dann auseinanderzufallen drohte. Am Rande mehrerer Ministerratsitzungen setzten sle daher Belgien gemeinsam und ganz massiv mit dem Vorwurf unter Druck, die gesamte 6.USt-Richtlinie zu Fall bringen zu wollen. In einer eigens wegen der belgischen Sonderrolle am 22.Mărz 1977 anberaumten Ratsitzung standen die Zeichen auP Sturm. Der belgische Finanzminister de Clercq war daher gezwungen, klein bel zu geben, ohne wesentliche Zugeständnisse erreicht $\mathrm{zu}$ haben. ${ }^{87} \mathrm{Da}$ die 6.UStRichtlinie als Ganzes danach nicht mehr gefahrdet war, konnten die Belgier, als es an die Ubersetzung des Textes in die Amtssprachen der EG ging, trotzdem noch einige ihrer wünsche durchbringen.

Eine weltere Verzögerung erfuhr die Verabschledung der Richtlinie durch ein von Dănemark provoziertes Intermezzo. Die Dänen machten, wie sie in der Ministerratsitzung am 5.April 1977 deutlich werden ließen, ihre Zustimmung zur USt-Harmonisierung von der Abschaffung des Wăhrungsausglelchs für Agrargüter abhängig. Aber auch die Dänen wurden schließlich unter dem geballten Druck der anderen zum Einlenken gezwungen und mit einer Erklärung abgespelst, die lediglich den Ubergangscharakter des wahrungsausgleichs betonte. ${ }^{86}$

Die endgultige Verabschledung der 6.USt-Richtlinie am 17.Mal 1977 war dann nur noch elne reine Formsache. ${ }^{99}$ Die Briten felerten den Kompromi $\beta$, obwohl sie nicht viel dazu belgetragen hatten, als einen Erfolg ihrer Präsidentschaft. Alle waren Proh, daß die 6.USt-Richtlinie, die zeitweise zu einem Drama mit elner unbegrenzten Anzahl von Akten auszuufern gedroht hatte, nun endlich gut uber die Bühne gebracht worden war. Die Freude uber die Harmonie im Rat war so groß, daß man sich sogar verpllichtete, die Vorschriften bls zum 1.Januar $1978 \mathrm{zu}$ implementieren: Die Entscheldung flel in dem vollen Bewußtsein, daß der Termin in elnigen Mitgliedstaaten schon rein gesetzgebungstechnisch nicht eingehalten werden konnte.

87 Vgl. z.B. AE 26.2.77, 19.3.77 u. 23.3.77, Guardian 23.3.77, AE 24.3.77 u. NZZ 24.3.77.

๑ Vgl. AE 6.4.77, 7.5.77 u. 14.5.77.

89 Vgl. 2.B. AE 18.5.77. Vgl. a. Bulletin der EG, 10.1977, Heft 5, S.18ff. Ein Uberblick uber die Bestimmungen der 6.USt-Richtlinie Pindet sich z.B. bei Easson (1980b), S.125ff., Guleu (1977), Guleu (1979), Georgen (1977), Phillppe (1980), Reugebrink (1978) u. Wachweger/Schlienkamp/ Schütz (1977). 
2.1.4. Die Implementlerung in den Mitglledstaaten

Verzögerungen bel der Implementlerung der 6.USt-Richtlinie

Die Verabschiedung der 6.USt-Richtlinie war zeltlich abgestimmt aup die bereits in Beratung befindliche Finance Bill des Jahres 1977, die London wie versprochen auch sofort nutzte, um als erster Staat die nationale MWSt an das neue EG-Recht anzupassen. Als zweite folgten, wohl nicht zuletzt dank des positiven Einflusses des inzwischen zum belgischen Finanzminister avancierten Kommissars Simonet, Ende 1977 die Belgier. Allen anderen Mitgliedstaaten gelang es nicht, die notwendigen USt-Reformen im Rahmen der gesetzten Frist durchzufuhren. Abgesehen vom EPso regte sich auch nlemand über die Verzðgerung sonderlich auf.

Sieben von neun Mitgliedstaaten befanden sich damit ab 1.Januar $1978 \mathrm{im}$ Widerspruch zu geltendem europäischen Recht. Ihnen drohte, da verschiedene Bestimmungen der Richtlinle vom EuGH für direkt anwendbar erklärt werden konnten, Finanzgerichtsklagen seitens solcher Unternehmen, die aufgrund der 6.USt-Richtlinie bessergestellt werden mußten. Zwar hatten die Mitgliedstaaten versucht, die unmittelbare Wirksamkeit der fur Klagen in erster Linie in Frage kommenden Steuerbefreiungsvorschriften durch eine langatmige Einführungsfloskel ${ }^{91}$ zu verhindern. Da man aber nle sicher sein konnte, wie der EuGH in einem konkreten Fall entscheiden würde, ${ }^{92}$ forderten dle Reglerungen die Kommission ab Anfang 1978 aup, sofort einen neuen Richtlinienvorschlag vorzulegen, der den Einfuhrungstermin der 6.USt-Richtlinie um mindestens ein Jahr verschieben würde. Dle Kommission zogerte zunăchst, da sie die Mitglledstaaten in ihrem elgenen Saft schmoren lassen und so zu einer zugigen Rechtsanpassung bewegen wollte. Im Mai 1978 mußte sle sich aber schlleßlich doch dem Druck beugen. Der Rat verabschledete am 26.Juni 1978 eine sogenannte 9.USt-RIchtlinie, die den Termin wie gefordert auf den 1.Januar 1979 hinausschob.93

90 Vgl. z.B. AB Anhang 1978/225, S.281ff. U. AB Anhang 1978/226, S.130 P.

91 "Unbeschadet sonstiger Gemeinschaftsvorschriften befreien die Mitglledstaaten unter Bedingungen, dle sle zur Gewährlelstung elner korrekten und einfachen Anwendung der nachstehenden Befrelungen sowie zur Verhutung von Steuerhinterzlehungen, Steuerumgehungen und etwaigen Mißbrăuchen festsetzen, von der Steuer:"; Art.13.A. Abs.1 der 6.USt-Richtlinie; entsprechend werden auch Art.13.B., Art.14 u. Art.15. eingefuhrt.

In der Tat zeigte sich der EuGH in den Rechtssachen $8 / 81$ - Urtell v. 19.1.82 - und 255/81 - Urtell v. 10.6.82 - von der oben zitierten Floskel nicht beeindruckt und erklärte die zur Diskussion stehenden Regeln für unmittelbar wirkam. Der Kommentar eines Steuerbeamten: "Hătten wir das damals schon gewußt, dann hătten wir Art.13-15 der Richtlinie so niemals verabschiedet." - Personliches Interview.

Vgl. z.B. Times 17.3.78, Guardian 21.3.78, AE 22.3.78, 24.5.78 u. 5.6.78. 
Aber auch nach der Fristverlängerung konnte das Kapitel 6.USt-Richtlinle noch nicht abgeschlossen werden. Frankrelch schaffte es mit Muhe und Not gerade noch 1978, und vier anderen Mitgliedstaaten gelang es erst 1979 , die Richtlinie zu implementleren. Mit langen Gesetzgebungsprozeduren waren die neuerlichen Verzögerungen nicht mehr zu begründen. Auch gab es kelne bedeutenden innenpolitischen Widerstănde, die sich gegen einzelne, durch das neue EG-Recht notwendig gewordene Anderungen der nationalen MWStGesetze gerichtet hätten. Die Schwierigkeiten, mit denen sich die Regierungen bel der Umsetzung der Richtlinie ab Mitte 1978 konProntiert sahen, lagen vielmehr in spezifischen innenpolitischen Konstellationen begründet, die mit dem Inhalt der 6.USt-Richtlinie nur ganz am Rande etwas zu tun hatten. Greifen wir uns drel Belspiele heraus:

- Als Ende 1978 der Gesetzentwurf für eine MwSt-Reform in der Pariser Nationalversammlung zur Verabschiedung anstand, stimmten neben der Linksopposition auch ganz unerwartet dle Gaullisten dagegen. Ihr Fuhrer Chirac nutzte die sich mit der 6.USt-Richtlinle bietende Gelegenhelt, um vom Krankenbett aus elnen Feldzug gegen die Europapolitik des Präsidenten Giscard d'Estaing zu fuhren. Hand in Hand mit den Kommunisten verteufelte er die Richtlinie als ein Brüsseler Machwerk, das die nationale Souveränität und die Rechte des Pranzösischen Parlaments untergrabe. Erst als Reglerungschef Barre drohte, die zwelte Abstimmung uber die MWSt-Reform mit der Vertrauensfrage zu verbinden, gab seln Koalitionspartner Chirac nach und lleß den Gesetzentwurf das Parlament passleren.a

- Itallen war das elnzige Land, das ein vitales Eigeninteresse an der Implementlerung der 6.USt-Richtlinie hatte. Wăre es Rom gelungen, seine MWSt noch 1978 zu reformieren, so hätten sich die an die EGKasse 1979 abzufuhrenden Zahlungen - die Finanzbeiträge wären automatisch durch MWSt-Eigenmittel ersetzt worden - um ca.150 Millionen ECU reduzlert. Aber auch bel der USt bestätigte sich wieder eine ErPahrung, dle der Kommission nicht neu war: Selbst wenn elne Maßnahme den Italienern nützt, gelingt es ihnen oft nicht, gemeinsam festgesetzte Termine elnzuhalten. Die häufig wechselnden Regierungen und die schwerfallig arbeltende Bürokratle erlaubten es erst Im Frühahr 1979, die italienische MWSt an die EG-Vorschriften anzupassen.

- Als Italien seine neue MWSt bereits hatte, war in Deutschland immer noch keine Entscheidung gefallen. Bonn war das uberaus pelnlich. Die Kommlssion hatte nicht nur eln Vertragsverletzungsverfahren eingele1tet, sondern sogar noch ausgerechnet, daß die reichen Deutschen durch elgene Schlamperei alleine 1979 bel thren EG-Beitrăgen einen drel-

Vgl. Le Monde 2.12.78, FT 1.12.78, FAZ 2.12.78, Le Monde 3-4.12.78 u. 5.12.78, Süddeutsche Zeltung 5.12.78, FAZ 7.12.78, L'Humanité 7.12.78, Le Monde 7.12.78, FT 8.12.78 u. Le Monde 8.12.78. 
stelligen Millionenbetrag einsparten. ${ }^{95}$ Die Rechnung war insofern falsch, als die Itallenisch Mehrzahlung von 150 Millionen ECU einfach auf die anderen Staaten umgelegt worden war. Aber unangenehme Schlagzeilen gab es trotzdem. Das Bonner Finanzministerium wäre selner Verpflichtung auch umgehend nachgekommen, hatte nur das Parlament den selt Marz 1978 auf dem Tisch liegenden Gesetzentwurf endlich verabschledet. Aber am Anfang hatte der Finanzausschuß des Bundestages wegen anderer Aufgaben monatelang kelne Zelt, sich der MWSt zu widmen, und später nahm dann der bayerische Ministerprăsident Strauß eine vollkommen nebensăchliche Bestimmung des neuen USt-Gesetzes zum Anlaß, um dem SPD-Kanzler Schmidt elne umfassende deutschlandpolitlsche Debatte aufzudrücken. Erst als sich die Gemuter langsam wieder beruhigt hatten, gab auch der von der Opposition beherrschte Bundesrat selne Zustimmung zur MWSt-Reform.\% Die Bundesrepubllk implementlerte die 6.USt-Richtlinie mit Wirkung vom 1.Januar 1980 und blldete damit gemelnsam mit Luxemburg das Schlußlicht.

Von den ersten Arbeiten der Kommission an der 6.USt-Richtlinie bis zu Ihrer vollständigen Umsetzung in nationales Steuerrecht waren damit 10 Jahre verstrichen. Hat sich, so müssen wir uns abschlleßend fragen, der ganze Aufwand uberhaupt gelohnt?

\section{Eine Bewertung der 6.USt-Richtlinie}

1. Die 6.USt-Richtlinie wurde dem Rat gegenüber mit der Plskalischen Erhebung der MWSt-Eigenmittel gerechtfertigt. Dleses Ziel wurde aber nicht erreicht. Es konnte nicht erreicht werden, da die von der Kommission vorgeschlagene fiskalische Methode ${ }^{97}$, mit oder ohne vorherige Harmonisierung der MWSt-Bemessungsgrundlage, in jedem Fall fur die meisten Länder mit einem viel $\mathrm{zu}$ hohen Verwaltungsaufwand verbunden gewesen wäre. Aus der Sicht der Harmonisierungs-unwilligen Mitgliedstaaten waren also all die Mühen mit der 6.USt-Richtlinie "für die Katz" Das aber vergegenwärtigten sie sich - glücklicherwelse, wle man hinzufugen muß - erst, als es schon zu spät und die 6.USt-Richtlinle bereits verabschledet war! Denn es wurde Früsommer 1977, bis man Zelt Pand, sich uber die technischen Aspekte der Erhebung der MWSt-Elgenmittel uberhaupt einmal Gedanken zu machen.

Dle Belgier waren die ersten, dle auf die von der fiskallschen Methode aufgeworfenen Probleme hinwiesen und mit elnem volkswirtschaftlichen

95 Vgl. z.B. AE 2.11.78, 23.12.78, 8.1.79 u. 12.1.79, Stuttgarter Zeltung 27.1.79, Handelsblatt 9.8.79 u. Guardian 13.10.79.

\$ Vgl. Schmidt (1984), S.2091. Vgl. a. Rau (1979), S.75f. Vgl. a. FAZ 29.6.79 u. 13.7.79, Handelsblatt 6.11.79.

97 Vgl. KOM(77)120 v. 20.4.77, abgedr. In: AB 1977/C 110, S.2ff. Vgl. ahnl. das altere Papier $\operatorname{KOM}(76) 210$ v. 17.11.76.

- Zitat elnes deutschen Diplomaten, wledergegeben in: Zelt v. 24.6.76. 
Verfahren eine machbare Alternativlösung anboten. Sle fand bel den anderen Mitgliedstaaten ein solches Interesse, daß es zu einem größeren Ansturm aup das Brulsseler Finanzministerium kam. Der Rat beschlo $\beta$ daraufhin im Dezember 1977, den Reglerungen die Prele Wahl zu lassen und ihnen zu erlauben, die an die EG abzufuhrenden MWSt-Eigenmittel entweder an Hand der Steuererklärungen - also flskalisch - oder an Hand der Elnnahmen mittels Daten der volkswirtschaftlichen Gesamtrechnung - zu ermitteln. ${ }^{99}$

2. Die 6.USt-Richtlinie brachte daruberhinaus auch nur einen relativ geringen Harmonisierungsfortschritt bel der MWSt-Basis: ".., les modifications des législations nationales sont essentlellement marginales et, parfois, purement formelles."100 Die melsten der unzăhligen technischen Veränderungen blleben für die Steuerpflichtigen ohne direkten Einfluß. Zu einschneldenden Reformen der nationalen Steuergesetzgebung kam es nur in wenigen Ausnahmefallen und nur dort, wo die betreffende Reglerung die Anderung selbst wollte, aufgrund innenpolitischer widerstande oder einfach wegen zeltllcher Restriktionen sle aber bisher noch nicht hatte durchsetzen können. Als entsprechende Belsplele kőnnen die Neufassung der Sonderregelung für Kleinunternehmen in Deutschland - das Bundesverfassungsgericht hatte die alten Vorschriften als bedenklich angesehen und eine Reform gefordert ${ }^{101}$ - oder dle Mehrwertbesteuerung elniger Prelberuflicher Tatigkeiten in Frankreich - die Ausweitung der Steuerpplicht setzte die lange Entwicklungsgeschichte der TVA konsequent fort, war vom Pariser Finanzministerium gewollt und wurde durch die 6.USt-Richtlinie erlelchtert ${ }^{102}$ - dienen.

3. Was die 6.USt-Richtlinie unzwelfelhaft schaffte war, elne Mauer um die nationalen MWSt-Systeme zu errichten, dle sle an einem weiteren Auseinanderdriften hinderte. In der Mehrzahl der Făle wurden die durch die EGRichtlinie gesetzten Grenzen von den Finanzministern und ihren Beamten zunächst als beengend und als großes Zugeständnis an die Gemeinschaft empfunden. Nach und nach konnten sle dem von der Kommission scharf bewachten "fence"103 Jedoch auch durchaus Vortelle abgewinnen. Mit der 6.USt-Richtlinie Im Rücken war es eln Leichtes, Forderungen verschieden-

99 Verordnung des Rates v. 19.12.77, abgedr. In: AB 1977/L 336, S.8ff. Vgl. a. AE 19.10.77 u. Handelsblatt 19.10.77.

100 Guleu (1979), S.30. $\mathrm{Zu}$ den Anderungen In Deutschland vgl. z.B. Schllenkamp (1978). Zu Frankreich vgl. La Sixième Directive rélative au Système Commun de TVA, in: Bulletin de Documentation Pratique des Taxes sur le Chiffre d'Affaires et des Contributions Indirects, 43.1977, S.365ff. Zum Vereinigten Königrelch vgl. UK: 1978 VAT Changes, in: Intertax, 1978, S.247ff. Einen Uberblick uber alle Mitglledstaaten glbt Timmermans/Joseph (1980).

101 Vgl. z.B. Rau (1979), S.249ff.

102 Vgl. z.B. NZZ 5.9.70 u. Les Echos 14.9.78.

103 Persönliches Interview. 
ster Interessengruppen zurückzuweisen und die Verantwortung fur die eigene Unnachgiebigkeit auf Brussel abzuschieben. Besagter Lerneffekt stellte sich bel den Briten schon recht schnell ein. Hatten sle Prüher noch ihre Freiheit bel den Null-Sătzen mit allen Mitteln zu verteidigen versucht, so wußten sie schon bald nach der Verabschledung der Richtlinie zu schätzen, daß die Kommlssion Ihnen unter Androhung eines Gerichtsverfahrens dle Einführung neuer Null-Sătze untersagt hatte: "Anything more than marginal adjustments would make a nonsense of the tax"104 - so der Labour-Staatssekretär Lawson Im Londoner Unterhaus. Auch die französischen Sozialisten waren, nachdem sie Anfang der 80er Jahre die Regierungsgeschäte ubernommen hatten, "hellfroh"109, daß ihnen die USt-Richtlinie verbot, ihr früheres Versprechen einzulösen und auf breiter Front Null-Sătze und stark reduzierte Sătze einzuführen.

4. Die 6.USt-Richtlinie setzte den MwSt-Systemen der Mitgliedstaaten nicht nur einen Rahmen, sondern wies ihnen auch die Richtung, in die sie sich in Zukunft weiterentwickeln sollten. ${ }^{106}$ Selbst bei den Steuerbefrelungen war man, entgegen vorheriger Befürchtungen, bel jedem Umsatz in der Lage zu sagen, ob er langfristig besteuert oder aber befrelt werden sollte. Lediglich in solchen Fällen - z.B. bei der Besteuerung von Gebrauchtwaren -, bel denen der beengte Terminplan eine hinrelchende Beratung nicht zulle $\beta$, wurde auf die Eingrenzung einer endgüligen Vorschrift gänzlich verzichtet. Einschränkend muß vermerkt werden, daß die Ubergangszelt, innerhalb derer die Mitgliedstaaten von ihren zahlreichen Freiheiten noch Gebrauch machen durften, trotz entsprechender wunsche der Kommission zeltlich nicht begrenzt wurde. Das hatte zur Folge, da $\beta$ weitere Harmonislerungsschritte nach wie vor von der Zustimmung jeder einzelnen Reglerung abhingen.

Alles in allem läßt sich der Inhalt der 6.USt-Richtlinie aup elne recht einfache Formel bringen: Es handelt sich um eln Stlllhalteabkommen, verbunden mit dem Versprechen, in Zukunft dort, wo eine Einigung noch nicht möglich war, aup dem Weg der Harmonisierung welter voranzuschreiten. ${ }^{107}$ Uns verblelbt es nun zu untersuchen, inwlewelt das Versprechen in den Jahren nach 1977 vom Rat eingelöst wurde.

\footnotetext{
104 H.C.Debates, Vol.921, col.619.

109 Persönliches Interview.

106 Vgl. Guieu (1979), S.6 u. S.29f. Vgl. a. Lebrun (1979), S.112f.

107 Das Versprechen war in Art.35 der 6.USt-Richtlinie ausdrücklich festgehalten.
} 
2.2. Zahlreiche Aktivitäten ohne spektakuläre Erfolge: 1977-1985

\subsubsection{Verwaltung der 6.USt-Richtlinie}

Bevor man sich neuen, großen Harmonisierungsaufgaben stellen konnte, galt es zunächst, das mit der 6.USt-Richtlinie Erreichte zu stabilisieren, es zu verwalten. Bls 1977 waren de facto allelne die nationalen Reglerungen fur die Verwaltung der MWSt zustandig. Dle Mitgliedstaaten mußten zwar die durch das EG-Recht gesetzten Grenzen respektleren, konnten jedoch, da die ihnen in den ersten beiden USt-Richtlinien belassenen Freirăume beachtlich waren, im USt-Bereich nach wle vor weitgehend unabhänglg voneinander agieren.

Das änderte sich grundlegend durch die Verabschiedung der 6.USt-Richtlinie. Mit einem business-as-usual in den nationalen Hauptstädten unter eher bellăufiger Beachtung der Gemeinschaftsvorschriften war es jetzt nicht mehr getan. Die zum Tell bis in verwaltungstechnische Detalls hineinreichenden Regeln des neuen europäischen MWST-Gesetzes brachten vielmehr die Notwendigkeit mit sich, Maßnahmen des umsatzsteuerlichen Tagesgeschäfts, die bis dato in elgener Regle abgewlckelt werden konnten, mit der Kommission und den Partnern in der EG abzustimmen.

Die Im einzelnen fur den gemeinsamen Handlungsbedarf maßgeblichen Ursachen waren vielfaltig. Anzusprechen sind zum einen die zahlreichen Lücken und Unzulänglichkeiten der 6.USt-Richtlinie, die bel umfassenden Gesetzgebungswerken nlemals ganz zu vermeiden sind und die daher Nachbesserungen erforderlich machen. Als zusatzliche Komplikation erwelst sich bel allen europalischen Rechtsakten das Sprachenproblem. Es ist überaus schwlerig, elnzelne Begriffe in die Amtssprachen der EG-Staaten mit ihren ebenso unterschledlichen Rechtsterminologien wie Rechtsauffassungen zu übertragen. Auf dem Weg der Ubersetzung werden aus elner einzigen oft ganz verschledene Bedeutungen, die spăter wleder einander năhergebracht werden müssen. Auch schaffen die detalllierten Vorschriften der 6.UStRichtlinle zahlreiche Berührungspunke zwischen europälschem und einzelstaatlichem Recht, die ihrerseits zu Auseinandersetzungen uber die korrekte Auslegung der betreffenden Bestimmungen Anlaß geben können. Will darüberhinaus ein Mitgliedstaat von einer Regel der 6.USt-Richtlinie abweichen - z.B. zum Zwecke der vereinfachten Steuererhebung nach Art.27 -, so muß er zuerst die Zustimmung des Rates als auch die der Kommission einholen. Die Vielschichtigkeit der Probleme kommt deutlich zum Ausdruck in dem "Bericht der Kommission an den Rat uber das Funktionieren des gemeinsamen Mehrwertsteuersystems"100, den die Kommission erstmals im September

100 Erster Bericht erstattet gemä dem in Art.34 der 6.USt-Richtlinie ertellten Auftrag, KOM(83)426 v. 14.9.83. Vgl. a. Schllenkamp (1984). 
1983 vorlegte und den sie danach alle zwel Jahre aup den neuesten Stand zu bringen hat.

Alle Aspekte zusammengenommen bewirkten, daß sich ab 1977 das Management der bestehenden MWSt-Systeme etwas von den nationalen Finanzministerien hin in Richtung auf Brussel verschob. Gedeckt wurde der gemeinsame Handlungsbedarf in den allermeisten Fälen ohne die Einschaltung des Rates. Bedeutung erlangte neben vielen bilateralen Kontakten insbesondere der in Art.29 der 6.USt-Richtlinie institutionalisierte MwSt-Ausschuß, der sich aus nationalen Steuerbeamten rekrutiert und unter dem Vorsitz der Kommission regelmäßig tagt. Auch wenn der Rat dem Ausschuß nur eine beratende Funktion zuerkannt hat, so versucht die Kommission doch, die Mitgliedstaaten zumindest moralisch an die Beschlüsse des Expertengremiums zu binden. Den Im Anschluß an die Ausschußsitzungen abgepaßten guidelines mißt Brüssel daher den Charakter einer Emplehlung bel, dem mit Mehrhelt oder manchmal auch nur mit den Stimmen einiger Mitgliedstaaten unterstützen Standpunkt der Kommission Folge zu leisten.

Kommt im MWSt-Ausschuß kelne Einigung zustande, so ist auch elne Diskussion in der Gruppe Finanzfragen des Rates wenlg erfolgversprechend: Beide Gremien sind mit denselben Personen besetzt. Der Kommission bleibt daher oft nur die Möglichkeit, dem bei den speziellen Verbrauchsteuern in den 70er Jahren schon vorexerzierten Beisplel zu folgen und gegen einzelne Mitgliedstaaten ein Vertragsverletzungsverfahren - Versto $\beta$ gegen dle 6.USt-Richtlinie - vor dem EuGH einzuleiten. In stelgendem Maße wurde von dieser Mögllchkelt ab 1982/83 Gebrauch gemacht. Auf das Wohlwollen des Rates ist die Kommission nur dann angewiesen, wenn es uber reine Auslegungsfragen hinaus um eine Abänderung der 6.USt-Richtlinie geht. Als Beisplele angefuhrt werden können hier dle 10.USt-Richtlinle - Vorschlag vom April 1979, verabschiedet im Jull $1984^{109}$-, die 11.USt-Richtlinie Vorschlag vom Dezember 1979, verabschiedet Im Mărz $1980^{110}$ - und die 19.USt-Richtlinle - Vorschlag vom November 1984, bis Ende 1985 noch nicht verabschiedet ${ }^{111}$-.

109 Gegenstand der Richtlinie ist die Neudefinition des Ortes einer Dlenstleistung für den speziellen Fall der Vermietung beweglicher, körperlicher Gegenstände.

110 Bel der Verabschledung der 6.USt-Richtlinle war man von der Annahme ausgegangen, daß die Richtlinle nicht für die französischen ubberseedepartements gelten würde. Da der EuGH in der RS 148/77 - Urtell v. 10.10.78 - zu elner anderen Auslegung des EWG-Vertrages kam, wurde eine nachträgliche Abänderung des Geltungsbereiches der 6.USt-Richtlinle erforderlich.

111 Der Vorschlag geht unmittelbar auf den zitlerten Bericht der Kommission über das Funktionleren des gemeinsamen MWSt-Systems zurück und enthält eine ganze Relhe verschiedenster Punkte. 
2.2.2. Vervollständigung der gemeinsamen Bemessungsgrundlage

Die gemeinschaftliche Verwaltung inklusive kleinerer Modifikationen des europäischen MWSt-Systems gab zu relativ wenig Kontroversen Anlaß. Demgegenuber war nach der Verabschledung der 6.USt-Richtlinie im Mal 1977 die weltergehende Harmonislerung der MwSt-Basis zunächst kein Thema mehr. Die nationalen Steuerbeamten benötigten nach den Anstrengungen der letzten Monate Zeit und Ruhe, sich um die Implementlerung der EG-Vorschriften zu kummern. Alleine die Kommission wollte sich, beflugelt durch den erzielten Erfolg, mit dem Erreichten und dessen Verwaltung nicht zufrieden geben. Obwohl sich Brüssel ab Sommer 1977 verstärkt den speziellen Verbrauchsteuern zuwandte, war es die erklärte Absicht der Kommission, die bel der MWSt in Fahrt gekommene Harmonisierungsdebatte auszunutzen und auf eine weitere Einengung des den Mitglledstaaten noch belassenen Splelraums hinzuwirken.

\section{Fortschritte bel der 8.USt-Richtlinie}

Schon Im Januar 1978 schob sle daher zwel entsprechende Richtlinienvorschläge nach. In beiden Fällen handelte es sich um Harmonisierungsmaßnahmen, für deren Berücksichtigung in der 6.USt-Richtlinie keine Zeit mehr geblleben und deren Bearbeitung der Kommission daher ausdrucklich aufgetragen worden war. Der Rat hatte sich sogar - obwohl genau abzusehen war, daß der Termin nicht elngehalten werden konnte - verpllichtet, bis Ende 1977 eine Entscheldung herbelzupühren. Bel der 8.USt-Richtlinie hielt sich die Verzögerung einem in für europälsche Verhältnisse akzeptablen Rahmen. Ihr Gegenstand war die Rückerstattung von Vorsteuerbeträgen, die die in einem Mitgliedstaat ansässigen Unternehmen in elnem anderen EGStaat gezahlt hatten. Viele Regierungen waren schon lange an elner derartigen Regelung interessiert. Nachdem die wenigen technischen Probleme geklärt waren, konnte die Richtlinie im Oktober 1979 vom Rat verabschledet werden.112 Als Ergänzung der 8.USt-Richtlinie folgte Im Jull 1982 der Vorschlag für eine 13.USt-Richtlinie, die die Frage der Vorsteuererstattung zwischen der EG und Drittländern regeln sollte. Der Entwurf wurde im Jull 1983 von der Kommission abgeändert, ist bisher aber vom Rat noch nicht angenommen worden.

\section{Widerstände gegen den Vorschlag pür elne 7.USt-Richtlinie.}

Ein der 8.USt-Richtlinie vergleichbares Glück war der 7.USt-Richtlinie die Vorschläge waren gleichzeltig vorgelegt worden - nicht beschieden. Mit der Besteuerung von Gebrauchtwaren ging es hier um ein schon von der

112 Vgl. Z.B. AE $15.10 .79,17.10 .79$ u. 18.10.79. Vgl. a. den Bericht der Kommission über das Funktionieren des in der 8.USt-Richtlinie geregelten Erstattungsverfahrens, KOM(85)586 v. 31.10 .85 . 
technischen Seite her heißes Eisen, das zudem noch gewichtige budgetäre Konsequenzen in den Mitgliedstaaten heraupbeschwor.113 Dle von der Kommission vorgeschlagene Gemeinschaftslösung stieß bereits im EP und WSA auf erhebliche Widerstände, worauf Brüssel im Mal 1979 dem Rat einen abgeănderten Richtlinienvorschlag präsentierte. Aber auch fur die neue Version waren die Mitgliedstaaten nicht $\mathrm{zu}$ begeistern. Die Reglerungen wollten aus budgetären und ihre Beamten aus verwaltungstechnischen Gründen an den jeweiligen nationalen Regelungen festhalten. Auch die Wirtschaftsverbände, die, je nachdem ob sle durch die 7.USt-Richtlinie besser oder schlechter gestellt wurden, ganz unterschledliche Auffassungen vertraten, konnten den Beratungen der Richtlinie keine positiven Impulse geben.114 Da keiner der Mitgliedstaaten für Zugestăndnisse zu gewinnen war, fuhren sich die Verhandlungen Im Rat fest und wurden Anfang der 80er Jahre ganz eingestellt. ${ }^{115}$

In Bewegung gebracht wurde dle Diskussion der Gebrauchtwaren-Besteuerung erst wieder durch das vom Mai 1982 datierte Urtell des EuGH in der Rechtssache 15/81. Dem inzwischen beruhmt gewordenen Fall Gaston Schul lag das folgende Problem zugrunde: Eine (nlcht-steuerpflichtige) Privatperson kauft in einem anderen EG-Land - Ursprungsland - von einer zwelten (nicht-steuerplichtigen) Privatperson eine Gebrauchtware und importiert sie in sein Heimatland - Bestimmungsland -. Die Luxemburger Richter entschieden auf der Grundlage des Art.95 EWGV, daß das Bestimmungsland den Importvorgang nicht mit der vollen Höhe des inländischen Steuersatzes belasten dürfe, sondern von der EinfuhruSt die im Ursprungsland bereits erhobene und dem noch nicht ganz verbrauchten Gut innewohnende RestMWSt abziehen müsse.116

Das Urteil des EuGH löste eine allgemeine Uberraschung aus. Da die Kommission elnen dem EuGH-Urtell vergleichbaren Vorschlag schon in der 6.USt-Richtlinie vorgesehen hatte, damit aber im Rat gescheitert war, ${ }^{117}$

113 Zum Inhalt der 7.USt-Richtlinie vgl. Guieu (1983a), S.10f. Vgl. a. Easson (1980b), S.97f. Vgl. a. EP Dok.647/78.

114 Die Stellungnahme der britischen Verbände ist skizziert in: Papers of the House of Lords, 1977/78: H.L.187; vgl. a. Times 8.7.78. Die Forderung des deutschen Gebrauchtwagenhandels, die 7.USt-Richtlinie anzunehmen, wurde von Bonn aus budgetären Gründen zurückgewiesen; vgl. Frankfurter Rundschau 22.11.77.

$115 \mathrm{Vgl}$. 2.B. Antwort des Rates auf eine mündliche Anprage Im EP v. 17.2.82, AB Anhang 1982/1-280, S.63.

116 Urteil v. 5.5 .82 in der RS 15/81. Die Rechtslage wurde, da die vom EuGH verurtellte niederländische Finanzverwaltung in die Berufung ging, vom Gerichtshof in der RS 47/84 - Urtell v. 21.5.85 - nochmals klargestellt. Bel der hier wiedergegebenen Darstellung des Richterspruchs handelt es sich um eine grobe Vereinfachung. Eine ausfuhrliche Beschreibung der Rechtslage findet sich z.B. in: European Taxation, 22.1982, S.287fP.

117 Art.15 Abs.9 des Vorschlages für eine 6.USt-Richtlinle. 
wurde der Richterspruch in Brüssel mit großer Freude aufgenommen. Ganz ungetrubbt allerdings war die Freude dennoch nicht. Das Urteil enthlelt zwel Aspekte, die der Kommission Sorgen machten. Erstens sprach der EuGH zwar von einer Minderung der Importsteuer, nicht jedoch explizit von einer Steuerrückerstattung für den Fall, daß der Steuersatz des Ursprungslandes den des Bestimmungslandes überstelgt. Zweitens implizierte das vom EuGH vorgeschlagene Verfahren, nimmt man das im EWG-Vertrag dominierende BLP als Referenzsituation, eine Umverteilung des Steueraufkommens vom Bestimmungs- hin zum Ursprungsland der Ware.118 Um die belden genannten Probleme zu lösen, schlug die Kommission in elnem Entwurf fur eine 16.USt-Richtlinle vor, die Mehrzahl der von Privat an Privat uber die Grenze hinweg gelleferten Gebrauchtwaren dem Im gewerblichen Handel ublichen Grenzausgleichsverfahren zu unterwerfen. Der im Jull 1984 vorgelegte Richtlinienentwurf war bis Anfang 1986 vom Rat noch nicht verabschiedet worden.

\section{Ablehnungsfront gegen den Vorschlag Pür eine 12.USt-Richtlinie}

Nach den mit der 7.USt-Richtlinie erlebten Frustrationen sah die Kommission von welteren Richtlinienvorschlägen erst einmal ab und wartete, bis dle anderen Fristen, die in der 6.USt-Richtlinie Pur weltere Harmonisierungsschritte gesetzt worden waren, nach und nach ausliefen. Als nächster Programmpunkt stand der Ausschluß des VSA für solche Güter an, die neben betrieblichen auch privaten $\mathrm{Zwecken}$ zu dienen geelgnet sind. Frankreich untersagte den VSA traditionell, aus budgetären Gründen und da man sich anders der verbreiteten Steuerhinterziehung nicht glaubte erwehren zu können, für eine ganz beachtliche Liste von Gütern. Demgegenüber waren die Unternehmen der meisten anderen Mitgliedstaaten im Genuß wesentlich liberalerer Regelungen. Angesichts dieser betrăchtlichen Unterschiede sah sich die Kommission gezwungen, einen Kompromiß in der Mitte zwischen den beiden Extremen vorzuschlagen.

Die Reaktionen aup den im Januar 1983 vorgelegten Entwurf für eine 12.USt-Richtlinle waren ebenso vorhersehbar wle elndeutig. Abgesehen von den Pranzösischen Unternehmen, die von einer Harmonisierung in Jedem Fall nur profitieren konnten, liefen die Wirtschaftsverbände aller anderen Mitglledstaaten 119 sowie sämtliche Regierungen gegen den Kommissionsvorschlag Sturm. Wăhrend Paris von seinen restriktiven Bestimmungen mit Rücksicht auf dle prekäre Lage des Staatshaushaltes auf keinen Fall abgehen wollte,

\footnotetext{
118 Vgl. z.B. Tugendhat (1983), S.10.
}

119 Vgl. z.B. Confederation of British Industry, Submission on the Draft 12th Directive on VAT, London 6.5.83. Zur ablehnenden Stellungnahme von UNICE vgl. AE 17.6.83. Die deutschen Unternehmen sprachen von einem "gefahrlichen Elngriff in das europäische Umsatzsteuersystem" Handelsblatt 23-24.9.83 - und, da die Richtlinie ein Verbot des VSA Pur PKWs vorsah, von einem "Attentat auf die Fahrzeugindustrie" NZZ 3.2.83 -. Vgl. a. FT 3.2.83 u. Handelsblatt 23.9.83. 
bestanden die anderen Regierungen im Interesse ihrer Wirtschaft auf der Belbehaltung der liberalen Lösung. ${ }^{120}$ Als Reaktion auf die breite Widerstandsfront legte Brüssel im Februar 1984 elnen abgeänderten Richtlinienentwurf vor, der mit einem llberaleren Konzept der Mehrheit der Mitgliedstaaten entgegenkam. ${ }^{121}$ Da aber keine Anzelchen für eine Verănderung der französischen Position zu erkennen sind, kann sich auch der neue Vorschlag keine Hopfnungen auf eine baldige Verabschledung machen.

Dle ungewisse Zukunft des Art.28 der 6.USt-Richtlinle sowle der

Sonderregelungen Pur Klelnunternehmen und Landwirte

Mit threm Vorschlag für eine 12.USt-Richtlinie war die Kommission also mitten in das große Fettnäpfchen der Gemeinschaft hineingetreten. Als năchstes sah die 6.USt-Richtlinle vor, die Sonderregelungen für Kleinunternehmer und Landwirte sowle die den Mitgliedstaaten in Art.28 zugebllligten Ausnahmeregelungen auf die Möglichkelt einer weltergehenden Harmonisierung hin zu untersuchen. Bel den genannten Problemen handelte es sich ausnahmslos um "politisch brisante Fallgruppen"122. Sie hatten schon bei der Aushandlung der 6.USt-Richtlinie zu scharfen Auseinandersetzungen Anlaß gegeben und waren daher wohlweislich, so weit es ging, in die $\mathrm{Zu}-$ kunft hinausgeschoben worden. 1983 war vereinbarungsgemä $\beta$ der Zeitpunkt fur ein nochmaliges Uberdenken gekommen. Aber in den bis dahin verstrichenen 6 Jahren hatte sich nichts geändert, das dle Hoppnung aup eine nunmehr leichtere Einigung häte rechtfertigen können.

Die Kommission hatte keinen Bedarf, nach der 12.USt-Richtlinie schon wleder den allgemeinen Unmut auf sich zu zlehen. Sie beschränkte sich daher 1983 zunächst darauf, die in den Mitglledstaaten angewandten Regelungen $\mathrm{zu}$ analysieren und den Regierungen mit der Ankündigung weiterer Richtlinienvorschläge $\mathrm{zu}$ drohen. ${ }^{123}$ Bisher hat lediglich der $\mathrm{zu}$ Art.28 der 6.UStRichtlinie erstattete Bericht einen offiziellen Richtlinienvorschlag an den Rat - Vorschlag fur elne 18.USt-Richtlinie vom November 1984 - nach sich gezogen. Und auch er ist sehr vorsichtig abgefaßt: Abweichungen, die der elnen oder anderen Reglerung $\mathrm{zu}$ sehr ans Herz gewachsen sind - z.B. Null-Sătze in Großbritannien und Irland, Steuerbefreiung fur die Post in Deutschland und den Personenverkehr in Dänemark, etc. -, werden von dem Richtlinienentwurf überhaupt nicht berührt; für die verbleibenden Aus-

120 Zur deutschen Position vgl. z.B. Umsatzsteuer Rundschau, 32.1983, S.1909. Zur britischen Haltung vgl. British Tax Review, 1983, S.C185. Vgl. a. Handelsblatt 17.1 .83 u. 15.12.83.

121 Vgl. z.B. AE 5.3.84 u. Handelsblatt 16.5.84.

122 Uelner (1977), S.463.

123 Bericht zu Art.28 der 6.USt-Richtlinie: KOM(82)855 v. 17.1.83, abgedr. In: Intertax, 1983, S.137ff. Bericht zur Sonderregelung für Klelnunternehmen: KOM(83)748 v. 15.12 .83 . Bericht zur Sonderregelung für Landwirte: $K O M(83) 435$ v. 12.7 .83 . 
nahmegenehmigungen sleht die Kommission nicht eine sofortige, sondern eine Abschaffung in mehreren Schritten vor.

\section{Ein Rückschritt}

Wăhrend die Kommission bei Art.28 der 6.USt-Richtllnie noch darauf hopfen kann, den einen oder anderen Fortschritt zu erzlelen, wurde sie im Fall der Sonderregelung für die Landwirtschaft in 1984 zu einem Rückschritt gezwungen. Den politischen Hintergrund des Rückschritts bildete die Abschapfung des Währungsausgleichs für Agrarprodukte ${ }^{124}$ und die lautstark vorgetragene Forderung der deutschen Bauernverbände, den damit verbundenen Einkommensausfall durch staatliche Belhilfen auszugleichen. Als Subventionsmethode schlugen die deutschen Landwirte eine mehrprozentige Anhebung des pauschalen VSA vor, eine Maßnahme, die schon im Anschluß an die DM-Aufwertung von 1969 erfolgreich erprobt worden war. ${ }^{125}$ Gegen eine Subventionierung mit Hilfe der MWSt sprachen sich sowohl das Bonner Finanzministerium als auch die SPD-Opposition aus: Dle Erhöhung der Vorsteuerpauschale kostete viel Geld, kam aber in erster Linle den umsatzstarken und damit ohnehin wohlhabenden Landwirten zugute. Aber der von den Großbauern dominierte Verband konnte seinen Willen durchsetzen. Finanzminister Stoltenberg wurde auf einer Wahlkampfrelse von grünen Störkommandos systematisch "zermürbt"125, und die SPD konnte im Bundestag von der konservativen Mehrheit überstimmt werden. ${ }^{127}$ Bundeskanzler Kohl machte daraufhin während des Gipfels von Fontalnebleau seine Zustimmung zur EG-Finanzreform von der Erlaubnis abhängig, in Abweichung von der 6.USt-Richtlinie die deutsche Landwirtschaft in den Genuß eines um bis zu 5\% erhöhten VSA kommen zu lassen. Da die Kommission den Pür die EG lebenswichtigen Budgetkompromiß nicht gefährden konnte, entsprach sie dem Bonner Verlangen und legte Im Jull 1984 einen entsprechenden Richtlinienentwurf - Vorschlag für eine 20.USt-Richtlinie - vor. ${ }^{12 \theta}$

124 Verordnung des Rates v. 31.3.84, vgl. AB 1984/L 99, S.1 ff.

125 Damals geregelt im Aufwertungsausgleichgesetz - vgl. z.B. European Taxation, 1970.10, S.II/ 35f. - und für elne Ubergangsfrist genehmigt von der EG - vgl. AB 1969/L 312, S.4 -. Die Niederländer folgten später dem deutschen Beispiel nach der Aufwertung ihres Guldens, vgl. AB $1973 / \mathrm{L} 321$, S.1.

126 Persőnliches Interview.

127 Vgl. z.B. Handelsblatt 15.3.84 u. Sozlaldemokratischer Pressedienst 12.7.84.

128 Bonn wendet, obwohl die 20.USt-Richtlinie erst im Sommer 1985 vom Rat verabschiedet wurde, den erhöhten VSA seit dem 1.7 .84 bereits an. Unterdessen hat das EP, das die an die deutschen Landwirte gewährten Subventionen für zu weitgehend hält, die Rechtmäßigkeit der Ratsentscheidung angezwelfelt. Dle Parlamentarier machen geltend, vor der Verabschledung der Richtlinie nicht hinreichend konsultiert worden zu sein; vgl. AB 1985/C 262, S.105\%. Um den EuGH nicht mit einer politisch hochbrisanten Frage in Verlegenheit $\mathrm{zu}$ bringen, verzichtete die Kommission bislang darauf, die Sache, wie vom EP gefordert, vor 


\subsubsection{Vereinfachung der Grenzformalitäten}

\section{Aktivitäten der Steuerdirektion vor 1980}

Da bel der Vervollständigung der 6.USt-Richtlinie ein entscheidender Durchbruch nicht zu erzielen war, verlegte sich die Kommission im Laufe der Zeit zunehmend daraup, durch einzelne, in der Mehrzahl sehr technisch anmutende Modifikationen der MWSt-Bemessungsgrundlage aup eine Vereinfachung der beim Uberschreiten der EG-Binnengrenzen abzuwickelnden Formalitäten hinzuarbeiten. Entsprechende Bemuhungen lassen sich bis in das Jahr 1969 zurückverfolgen. Damals galt das allgemeine Interesse in erster Linle den äußerst publikumswirksamen Steuerbefreiungen für Güter, die im privaten Relseverkehr mitgepuhrt werden.129 1975 folgten dann zwel Richtlinienvorschläge, die ebenfalls den nicht-umsatzsteuerpflichtigen Privatpersonen zugute kommen sollten:

- Steuerbefrelung der endgültigen Einfuhr von persönlichen Gegenständen durch Privatpersonen aus elnem EG-Staat. ${ }^{130}$

- Steuerbefreiung innerhalb der Gemeinschaft bei vorübergehender Einfuhr bestimmter Verkehrsmittel.131

Einzelne Bestimmungen, die daraup abzielten, neben den Privatpersonen auch den umsatzsteuerpflichtigen Unternehmern das Uberqueren der Grenzen zu erleichtern, wurden auch in der 6.USt-Richtlinie vorgesehen.132 Der in der 6.USt-Richtlinie geschaffene Rahmen wurde 1980 durch zwel weltere Richtlinienvorschläge ausgefullt und ergănzt:

- Steuerbefrelung bestimmter endgültiger Importe von Gegenständen. ${ }^{133}$

- Gemeinsame Regelung der MwSt und der Akzisen auf den Bordbedarf von Luft- und Wasserfahrzeugen sowle Zügen im internationalen Verkehr. ${ }^{134}$

Alle der genannten Richtlinienentwürfe zeichneten sich durch eine enge Verknüpfung von steuerrechtlichen Bestimmungen und zollrechtlichen VerPahrensvorschriften aus. ${ }^{130}$ Lange Zeit widmete ihnen die Steuerdirektion der Kommission nur wenig Aufmerksamkeit. Ihr besonderes Interesse galt vielmehr der wesentlich anspruchsvoller erscheinenden Aufgabe, die ge-

den Gerichtshof zu bringen. Vgl. a. VWD Europa 11.3.85, Handelsblatt 15.3.85, VWD Europa 12.6.85 u. 13.9.85.

129 Auf die sogenannten Reiseverkehrsrichtlinien werden wir noch in Kap.E.2.1.1. ausführlicher zu sprechen kommen.

130 Vgl. AB 1975/C 267, S.11 fp.

131 Vgl. AB 1975/C 267, S.8ff. Zu den beiden genannten Richtlinien vgl. a. Guieu (1983b), S.8ff.

132 Vgl. z.B. КОМ(83)426 v. 14.9.83, S.581.

$133 \mathrm{Vgl}$. AB 1980/C 171, S.8Pf.

$134 \mathrm{Vgl}$. AB 1980/C 31, S.10 $\mathrm{Cu}$ den beiden genannten Richtlinien vgl. a. Guieu (1983a), S.14f.

139 Vgl. Burke (1981), S.9P. 
meinsame MWSt-Basis dort, wo noch bedeutende Lücken bestanden, zu vervollständigen. Erst die seit Anfang der 80er Jahre insbesondere von seiten der Brüsseler Zollexperten propagierte Binnenmarktpolitik der Kommission gab den Anstoß, den dornenrelchen Weg einer schrittweise erfolgenden Vereinfachung der Grenzformalitäten konsequent weiterzugehen.

\section{Entwicklung einer Binnenmarktpolltik}

Dle Tatsache, daß die Beseitigung der innergemelnschaftlichen Zölle für die Schaffung eines Gemeinsamen Marktes noch nicht ausreichte, war seit Anbeginn der EG bekannt. Gegen Ende der 70er Jahre waren es insbesondere die Zollexperten innerhalb der Kommission, die unablüssig die zahlreichen Formalitäten anprangerten, denen der grenzüberschreitende Verkehr nach wie vor ausgesetzt war. ${ }^{136}$ Auf ein lebhaftes Echo stießen die angesprochenen Probleme im EP. In dem umfassenden Nyborg-Bericht vom März $1978^{137}$ und in ungezahlten Resolutionen ${ }^{13}$ sprachen sich die Parlamentarier dafur aus, die zwischen den Mitgliedstaaten noch existierenden Handelshemmnisse zu beseitigen, die Zollunion damit zu vollenden und die EG zu einem echten Binnenmarkt welterzuentwickeln.

Aber auf Ratsebene tat sich lange Zeit nichts. Begrundet lag die Untätigkeit nicht zuletzt darin, daß der Ende der 70er Jahre für Zollfragen zuständige Kommissar Davignon und mit inm die gesamte Kommission sich der Vollendung des Binnenmarktes nur halbherzig widmeten. Das änderte sich erst Anfang der 80er Jahre. Angesichts der sich nach dem 2.Olschock von 1979 verschärfenden Weltwirtschaftskrise erlagen die nationalen Regierungen Immer häufiger der Versuchung, inre Mărkte mit allerlel Tricks gegeneinander abzuschotten. Die Zahl der vor dem EuGH anhängigen Vertragsverletzungsverfahren ging sprunghaft in dle Höhe. Es war der neue deutsche Kommissar Narjes, der die Initiative ergriff und für eine Stärkung des Binnenmarktes der EG zu werben begann. Durch die Schaffung eines von Handelshemmnissen befreiten Raumes sollte, wie die Kommission in einer Mittellung an den Rat von 1981 herausstrich, die Konkurrenzfahigkeit der europäischen Wirtschaft wledergewonnen, dle in den 80er Jahren anliegenden Strukturwandlungen erleichtert und damit die Arbeltslosigkelt langfristig und wirksam bekämplt werden.139 Der kurz daraup in Luxemburg

136 Vgl. z.B. die "Mittellung der Kommission an den Rat und das Europäische Parlament uber den Stand der Zollunion der EG". KOM(77)210 v. 13.6.77. Vgl. ăhnl. KOM(75)67 v. 25.2.75.

137 Vgl. EP Dok.557/77.

138 Vgl. z.B. AB $1977 / \mathrm{C} 118$, S.30; AB $1977 / \mathrm{C} 163$, S.44; AB 1978/C 108, S.29P.

139 Vgl. KOM(81)313 v. 17.6.81. Weitere Stellungnahmen der Kommission zur Binnenmarktpolitik Pinden sich z.B. In: KOM(82)399 v. 24.6.82, KOM(82)735 v. 12.11 .82 , КОМ(83)80 v. 23.2 .83 , КОМ(84)134 v. 11.4.84, KOM(84)305 v. 13.6 .84 . 
tagende Europälsche Gipfel nahm das Programm positiv aup140, aber konkrete Aktionen lleßen zunächst weiter auf sich warten. Erst nach dem Kopenhagener Gipfel vom Dezember 1982 belebte sich die Tătigkeit des Rates. Zur Beschleunigung der Entscheidungsprozesse wurde ein Interdisziplinăr zusammengesetzter Binnenmarktrat geschaffen, der allelne während des Jahres 1983 achtmal zusammenkam.141

\section{Partielle Einbezlehung der Steuer- in die Binnenmarktpolitik}

Als die Binnenmarktpolitik der Kommission langsam an Gestalt zu gewinnen begann, wollte auch die Brüsseler Steuerdirektion nicht länger Im Abseits stehen. Mit einem Im Mal 1981 vorgelegten "Gemeinschaftsprogramm zur Vereinfachung der Im innergemeinschaftlichen Handel angewandten Verfahren und Formalitäten auf dem Geblet der Mehrwertsteuer"142 hängte sie sich an den anfahrenden Zug an. In das Programm wurden die oben bereits erwăhnten Richtlinienentwürfe aufgenommen und weitere Vorschlage angekundigt. Bls heute sind dem Rat daraufhin u.a. dle Polgenden Richtlinien zugeleitet worden:

- Zahlungsaufschub für die von den Steuerpflichtigen bel der Einfuhr geschuldete Steuer; Vorschlag für elne 14.USt-Richtlinle vom Jull 1982.

- Mehrwertsteuerbefrelung bel der vorubergehenden Einfuhr anderer Gegenstände als Verkehrsmittel; Vorschlag für eine 17.USt-Richtlinle vom August 1984.

Die Steuerdirektion tat gut daran, die MWSt-Harmonisierung zumindest teilwelse in die Binnenmarktinitiative der Kommission elnzubinden. Alle USt-Richtlinien, die unter die Kategorie Vereinfachung der Grenzformalitäten flelen, konnten damit rechnen, Im Rat mit Priorltät behandelt zu werden. Und Erfolge blieben nicht aus. Am 28. März 1983 verabschledete der Binnenmarktrat glelch drel Richtlinienvorschläge. ${ }^{143}$ Der von der Kommission als die weltaus bedeutendste Initlative angesehene Vorschlag fur eine 14.USt-Richtlinie konnte aber, trotz intensiver Verhandlungen Im Rat, bis heute nicht verabschiedet werden. Hierauf kommen wir in Kapitel $E$ noch ausführlich zu sprechen.

\footnotetext{
140 Vgl. z.B. AE 1.7 .81 u. 3.7.81.

141 Vgl. Moltke (1984), S.141ff.

$142 \mathrm{KOM}(81) 195$ v. 14.5.81, abgedr. In: $A B$ 1981/C 244, S.4ff.

143 Vgl. AB 1983/L 105, S.38ff. Der Vorschlag Pur elne 17.USt-Richtlinie wurde im Jull 1985 verabschledet.
} 


\subsubsection{Gesamtschau der Entwicklung}

Stillstand bei der Harmonisierung der MWSt-Bemessungsgrundlage

Spektakuläre Erfolge gab es nach der Verabschledung der 6.USt-Richtlinie kelne mehr. Betrachtet man die vom Rat seit 1977 verabschiedeten Ríchtlinien, so ist man geneigt, sle allesamt in die schublade "housekeeping type"144 einzuordnen. Aus der als Stillhalteabkommen konzipierten 6.UStRichtlinie wurde also de facto ein Stillstand. Daran vermochten auch die umfassenden Berichte nichts zu ändern, die zum Thema Steuerharmonislerung in der EG seit 1978 nacheinander vom WSA, von der Kommission und vom EP vorgelegt wurden.145 Sie zeugen nicht von raschen Fortschritten bel der Steuerharmonisierung, sondern sind Im Gegentell als Ausdruck einer allgemeinen Hilflosigkeit gegenüber der ausgesprochenen HarmonisierungsUnlust des Rates zu werten.

Trotz des offensichtlichen Desinteresses der Mitgliedstaaten in Sachen UStHarmonisierung ließ es sich die Kommission nicht nehmen, dem Rat immer neue Richtlinienentwurfe zu unterbreiten. In den Jahren zwischen 1977 und 1985 legte Brüssel mehr als 30 Vorschläge aup den Tisch, die alle die Bemessungsgrundlage der gemeinsamen MwSt berühten, deren jewellige Bedeutung aber für den Außenstehenden kaum noch zu durchschauen war. Mit zunehmender Zahl der im Rat steckengebliebenen Richtlinien verlegte sich die Kommission Immer mehr darauf, die Mitgliedstaaten wegen des elnen oder anderen Verstoßes gegen die 6.USt-Richtlinie zu verklagen. Vor dem EuGH kam es, wle ein Insider verärgert kommentierte, zu "a hundred bloody VAT infraction cases for not dotting this $i$ or not crossing this t."146 Angesichts der Vielzahl und der Vielfalt der Brüsseler Aktivitaten kann es nicht verwundern, daß sich außerhalb der Kommission eine gewisse Desorientierung darüber elnstellte, wofur die eine oder andere Inltiative denn eigentlich gut sei. So sprachen der EG durchaus wohlgesonnene wirtschaftskreise unter der Hand von elnem "Aktionismus"147, den sie aber lächelnd entschuldigen wollten mit dem Hinweis, daß die Kommission für die Ausarbeitung von Richtlinien und die Einleitung von Vertragsverletzungsverfahren ja schlleßlich bezahlt werde. Auch die Straßburger Parlamentarier verloren, wie der folgende, im Rahmen der Aussprache über die 7.UStRichtlinie gemachte Redebeitrag nahelegt, desöfteren die Ubersicht über die MWSt-Harmonisierung: "Wir haben einen Bericht produzlert, weil wir etwas tun müssen, aber ehrlich gesagt glaube ich im Augenblick nicht, daß wir den Mut haben zu Pragen, was dies mit der Schaffung einer Europäischen

\footnotetext{
144 Easson (1981b), S.329.

145 Vgl. FredersdorP-Bericht (1978), Kommission (1980) u. Rogalla-Bericht (1983).

146 Persönliches Intervlew.

147 Persönliches Interview.
} 
Gemeinschaft zu tun hat."148 Vlelen Entscheldungsträgern, sowohl innerhalb als auch außerhalb der EG-Institutionen, ging es sehr ähnlich.

Fehlender Harmonisierungswille des Rates in Verbindung mit einer weitverbreiteten Konfusion über Sinn und Zweck elnzelner Initiativen beschreiben also die traurige Situation, in der sich die Harmonisierung der MwSt-Basis In den Jahren zwischen 1977 und 1985 wiederfand. Fragen wir nach den Ursachen hierfür, so müssen wir uns nur aup die Ziele zurückbesinnen, die im ersten Abschnitt des Kapitels vorgestellt wurden. Mit dem Ziel Wettbewerbsneutralltăt war, wle oben bereits vermerkt, schon selt der Verabschledung der 2.USt-Richtlinle nichts mehr zu gewinnen. Das Ziel Abschaffung der Steuergrenzen hatte sich 1973 von der polltischen Bühne verabschledet. Und auch das Zlel Schaffung von MWSt-Eigenmitteln verlor, nachdem die 6.USt-Richtlinie durchgeboxt worden war, seine Bedeutung für die USt-Harmonislerung. $\mathrm{Da}$ es an elnem kräftigen Zugpferd mangelte, mußte die Harmonisierung der MwSt-Bemessungsgrundlage zwangsläufig zum Erllegen kommen.

Den Jahren zwischen 1977 und 1985 lassen sich jedoch auch durchaus positive Selten abgewinnen. Im Rückblick stellen sie sich als eine Phase der Neuorientierung dar, wahrend derer das in den $60 \mathrm{er}$ Jahren so helß diskutierte umsatzsteuerpolitische Endziel Abschaffung der Steuergrenzen, nunmehr im Rahmen der Binnenmarktpolitik der EG, schrittweise ein comeback felern konnte. Kommen wir nun auf die einzelnen Punkte eln wenig ausfuhrlicher zu sprechen.

\section{Das Zlel Wettbewerbsneutralität ist weitgehend erreicht}

Das von der Kommission vielfach bemühte Zlel der Wettbewerbsneutralitat leistet keine entscheidenden Impulse mehr fur die Harmonisierung der MWSt-Basis. Spürbare Verzerrungen im internationalen Handel, die mindestens einer Regierung eine weitergehende Harmonislerung der Bemessungsgrundlage als wünschenswert erscheinen lassen könnten, gibt es kaum mehr. Nehmen wir als eln Beisplel den Vorschlag für eine 12.USt-Richtlinie: Welches Interesse sollten die Mitglledstaaten daran haben, durch elgene Zugeständnisse Paris zur Lockerung einer Regelung zu bewegen, die alleine die Pranzösische Wirtschalt gegenulber ihren Konkurrenten in der EG benachteiligt? Läge eine merkliche Wettbewerbsverzerrung vor, so bedürfte es $\mathrm{zu}$ ihrer Beseitigung keiner Richtlinie, sondern lediglich einer einseitigen Pranzösischen Maßnahme. Aber selbst die Behauptung der Kommission, daß eine Beeintrăchtigung des Wettbewerbs gegeben ist ${ }^{149}$, läßt sich in Zweifel ziehen: Gehen wir davon aus, daß es einen funktionsfählgen gemelnsamen Gütermarkt gibt, dann kann die Pranzösische Wirtschaft die vom Abzug ausgeschlossene Vorsteuer nicht auf die Preise uberwälzen; die dadurch

\footnotetext{
148 AB Anhang 1979/241, S.18.
}

149 Vgl. z.B. Guleu (1983a), S.11f. 
geschmälerten Gewinne beeintrăchtigen nicht den gemeinsamen Güter-, sondern alleine den gemeinsamen Kapitalmarkt, der aber aufgrund der fehlenden Harmonislerung bel den direkten Abgaben überhaupt noch nicht existiert.

Harmonislerungsbedare besteht dagegen trotz der Neuregelung in der 6.UStRichtlinie nach wie vor bel der Definition des Ortes elner Dienstleistung. Da sich die Probleme aber immer wieder neu stellen - z.B. In Jüngerer Zeit bel der Entwicklung und dem Vertrieb von software-Paketen -, kann von einer einmaligen Richtlinie keine Losung erwartet werden. Gerragt ist vielmehr elne kontinuierliche Feinabstimmung der nationalen Vorschriften, fü die die regelmäßigen Treffen des MWSt-Ausschusses wesentlich besser geelgnet sind als die langwierigen Entscheldungsprozeduren im Rat.

Das Zlel Schaffung von MWSt-Eigenmitteln hat keine Zugkraft mehr

Das ausschlaggebende Motiv fur dle erfolgreiche Verabschledung der 6.UStRichtlinie bestand nach ubereinstimmender Aussage von Verhandlungstellnehmern in der Schaffung der MWSt-Eigenmittel: "If there had not been the pressure from the own-resources scheme, the 6 th Directlve would probably have been discussed to the end of time."1so Spatestens nachdem man 1977 eingesehen hatte, daß die fiskalische Erhebungsmethode entgegen ursprünglicher Hoffnungen doch nicht praktikabel war, hatte das Zlel Schaffung von MWSt-Eigenmitteln seine Zugkraft für die weitere USt-Harmonislerung eingebußt. Zugegebenermaßen welst die seltdem verwandte Erhebungsmethode Unzulänglichkelten auf. Immer wieder kommt der Verdacht auf, daß der eine oder andere Staat die an dle EG abzupuhrenden MWSt-Betrăge zu seinen Gunsten manipullert. Berechnung und Kontrolle der Elgenmittel ließen sich durch elne weitergehende Harmonislerung der MWSt verbessern. Aber eine mit diesem Argument gerechtfertigte Anglelchung der nationalen Rechtsvorschriften muß in den Augen einer Mehrzahl von Reglerungen solange eine Farce blelben, wle dle wesentlich bedeutsameren Unterschlede bel dem in den einzelnen Lăndern anzutreffenden Grad der Steuerhinterziehung weiterbestehen. ${ }^{101}$

\section{Das Ziel Abschaffung der Steuergrenzen felert eln come-back}

Als treibende Kraft für elne weltere Harmonisierung der MwSt kam nach 1977 also nur noch das Zlel Abschaffung der Steuergrenzen in Betracht. Bis zu dessen Ruckkehr auf die politische Buhne der Gemeinschaft sollte allerdings noch eine geraume Zelt vergehen. Daß die ersehnte Reaktivierung uberhaupt möglich wurde, ist letztendlich alleine dem Erfolg der von der Kommission auf den Weg gebrachten Binnenmarktinitiative zu verdanken.

100 Persönliches Interview.

181 Vgl. z.B. EP Dok.360/73, S.38. 
Neu war das Binnenmarkt-Konzept nicht. Schon in den 60er Jahren gab es die binnenmarktăhnlichen Verhältnisse als eln Leitmotiv, mit dem u.a. auch die Abschaffung der Steuergrenzen gerechtfertigt worden war. Das Konzept ging in den WWU-Plänen auf und mit innen unter. ${ }^{152}$ Als es Anfang der 80er Jahre wiederentdeckt wurde, war das Zlel immer noch dasselbe: die ungehinderte Beweglichkeit von Gütern, Dienstleistungen, Personen und Kapital in der EG. Allelne die Probleme hatten slch ein wenig verschoben: Neben den Grenzkontrollen nahmen nun die sogenannten technischen Schranken - Normen, Sicherheits - und Gesundheitsstandards, etc. - einen breiter werdenden Raum ein. Das Modell für mögliche Lösungen stellte die kleine Benelux-Union zur Verfugung. Im Gegensatz zur EG hatte sle es nicht versäumt, ihren Binnenmarkt im Laufe der 70er Jahre welterzuentwickeln.

Nachdem, wle oben schon vermerkt, die Binnenmarktpolltlk der EG 1981/82 zunăchst schleppend ihren Anfang genommen und 1983 dann an Fahrt gewonnen hatte, zeichnete sich 1984 ein Durchbruch ab. Die Probleme des Binnenmarktes ruckten in das Zentrum des Ringens um die Zukunft der Gemeinschaft. Zurückzufuhren ist der Durchbruch auf elne Relhe ganz unterschiedlicher Entwicklungen:103

- Dle tagelange LKW-Blockade an den Alpengrenzen Im Februar 1984 fuhrte den Politikern deutlich vor Augen, daß der europalische Bürger die Grenzkontrollen schon lange nur noch als uberflüssige Schikane betrachtet.

- Das EP nahm die zweiten Direktwahlen zum Anlaß, lautstark auf sichtbare Fortschritte in der EG zu dringen.

- Nach harten Internen Auseinandersetzungen mit den Franzosen und Italienern konnten sich die Industrieverbände der EG daraup einigen, gemeinsam die elgenen Reglerungen unter Druck zu setzen, den Binnenmarkt welterzuentwickeln.104

- Die für den 1.Januar 1986 anvisierte Suderwelterung der EG verlangte, sollte die Gemeinschaft nicht $\mathrm{zu}$ elnem entscheidungsunfuhigen Kolo $\beta$ degenerieren, elne früzeitige Weichenstellung für die Zukunft der EG.

Die Liste der das Jahr 1984 prägenden Entwlcklungen lleße sich welter fortfuhren. Ihnen allen gemeinsam ist es zuzuschreiben, daß die Binnenmarktpolitik selt Fontainebleau aus den Erklärungen der Europäischen Gipfel nicht mehr wegzudenken ist. Im Juni 1985 legte die Kommission daraufhin ein ehrgeiziges Welßbuch vor, das pur die Vollendung des Binnenmarktes den Endtermin 1992 setzt und zugleich die bls dahin zu ergreifenden Maßnahmen beschrelbt. Dle Staats- und Reglerungschels der EG

\footnotetext{
102 Vgl. die Darstellung In Kap.C.1.1.2. u. D.1.2.

153 Ein umfassender Oberblick findet sich bei Moltke (1985), S.143fP.

104 Vgl. z.B. Union des Industrie de la C.E., La Consolidation du Marché Intérleur, Brüssel 19.7.84.
} 
nahmen das Dokument positiv auf, sahen sich bisher aber nicht in der Lage, auch die institutionellen Konsequenzen daraus zu ziehen. Das im Dezember 1985 verabschiedete Paket zur Reform der EG-Verträge blieb hinter den Wünschen der Kommission weit zurück: Die für den Bereich der Binnenmarktpolitik geforderten Mehrheltsentscheidungen des Rates wurden in nur begrenztem Umfang vorgesehen und zudem noch mit zahlreichen Schlupplöchern ausgestattet; der Termin 1992 wurde nicht als rechtlich verbindliches Ziel, sondern nur als politische Verpflichtung in den Vertragstext aufgenommen.190 Es bleibt also abzuwarten, ob es die Mitglledstaaten Ernst melnen mit lhrem Versprechen, den Binnenmarkt 35 Jahre nach Gründung der EG zu vollenden.

Soweit zur Entwicklung der Binnenmarktpolitlk im allgemeinen. Die Einbeziehung der USt-Harmonisierung in die Binnenmarktinitiative der Kommission vollzog sich in zwel Schritten. Zu Beginn wurden lediglich solche UStRichtlinien unter dem Stichwort Binnenmarkt gefuhrt, die, dem BeneluxBelspiel folgend, mit einem möglichst geringen Anpassungsbedarf der nationalen MWSt-Gesetze die steuerlichen Grenzformalitäten zu vereinfachen suchten. Solch bescheidene Ziele warf man später uber Bord. Dazu trug zum einen der Erfolgskurs der Binnenmarktinitiative bel. Die Grenzkontrollen, so die neue Vorstellung, sollten möglichst bald und vollständig abgeschapft werden: "Why, in what is meant to be a common market, are there any customs offlcers at all?"186 Zum anderen stagnierte zur gleichen Zeit die Arbeit der Finanzminister an den USt-Richtlinien, die bls dato noch nlcht als binnenmarktrelevant klassifiziert worden waren. Die Brüsseler Steuerdirektion ergriff daher die mit dem Weißbuch sich bletende Gelegenheit preudig am Schopfe und packte mit der Argumentation, daß die Abschaffung der Steuergrenzen sowohl eine Angleichung der Steuersätze als auch eine weitgehende Vereinheltlichung der MWSt-Bemessungsgrundlage voraussetze, alle bis dahin vorgelegten Richtlinienentwürfe in das neue Projekt hinein. Damit war die USt-Harmonislerung vollständig in die Binnenmarktpolitik integriert.

Der steuerpolitische Teil des Weißbuches wurde von den Finanzministern der Gemelnschaft mit ebenso großer Uberraschung wie Zurückhaltung aufgenommen. ${ }^{157}$ Sie konnten sich Innerhalb ihrer nationalen Regierungen schnell mit der Auffassung durchsetzen, daß in der Steuerpolitik Mehrheitsentscheidungen nicht akzeptabel seien. ${ }^{100}$ Auch auf die steuerpolitischen Maßnahmen, die für die Vollendung des Binnenmarktes notwendig sind, wollten

150 Neuer Art.8a des EWG-Vertrages. Eine Kurzdarstellung der Reformen findet sich z.B. bel Kramer (1985).

136 Economist 23.6.84.

107 Vgl. z.B. Economist 22.6.85.

150 Vgl. z.B. Handelsblatt 30.9 .85 , FAZ 7.10.85, AE 7-8.10.85 u. 9.10.85, Welt 11.10 .85 u. 29.10.85, Handelsblatt 29.10.85. 
sie sich noch nicht festlegen lassen. Art.99 des EWG-Vertrages wurde durch das Reformpaket von Ende 1985 denn auch nicht abgeăndert, sondern nur neu formuliert:

\begin{abstract}
"Der Rat erläßt auf Vorschlag der Kommission und nach Anhörung des Europäischen Parlaments einstimmig die Bestimmungen zur Harmonisierung der Rechtsvorschriften über die Umsatzsteuern, die Verbrauchsabgaben und die sonstigen indirekten Steuern, soweit dlese Harmonislerung für die Errichtung und das Funktionieren des Binnenmarktes innerhalb der in Artikel $8 \mathrm{a}$ vorgesehenen Frist notwendig ist."
\end{abstract}

Da der neue Art.8a den Begriff Binnenmarkt als Raum ohne Binnengrenzen definiert, wurde aber zumindest eines erreicht: Das Zlel Abschaffung der Steuergrenzen wurde, wenn auch nicht explizit, so doch implizit, aup die Stufe eines vertraglich Pestgelegten Zieles angehoben. Ob den großen Worten auch Taten folgen, muß die Zukunft zelgen. Angesichts des perfektionistischen Konzepts, das dem steuerpolitischen Tell des Weißbuches der Kommission zugrunde liegt, ist überschwenglicher optimismus Jedenfalls noch nicht angebracht.

\title{
2.3. Das perfektionistische Binnenmarktprogramm: der aktuelle Stand der Dinge
}

Der die MWSt betreffende Teil des Weißbuches der Kommission - für die Akzisen wurde ein analoges Vorgehen festgelegt - ist schnell umrissen. Erklärtes Ziel ist die Abschaffung der Steuergrenzen. In mehreren Schritten sollen die beiden grundlegenden Voraussetzungen dafür geschaffen werden: weltgehende Harmonisierung der Bemessungsgrundlage, Angleichung von Zahl, Anwendungsbereich und Höhe der Steuersätze. ${ }^{159}$ Wie ist, so müssen wir uns Pragen, die Initiatve der Kommission zu bewerten?

Uneingeschränkt positiv $\mathrm{zu}$ beurtellen ist die längst fällige, konsequente Neuausrichtung der MWSt-Harmonisierung auf das Endziel Abschaffung der Steuergrenzen hin. Das Binnenmarktprogramm weist eine klare Richtung, in die die USt-Harmonisierung voranschreiten soll, und es glbt den Entscheidungstrăgern ein eindeutiges Kriterium an die Hand, mit dessen Hilfe elnzelne Richtlinienentwürfe bewertet werden können. Ihm ist es $\mathrm{zu}$ verdanken, daß sich der Rat der Wirtschafts- und Finanzminister am 18.November 1985 erstmals seit uber einem Jahrzehnt wieder mit den Grundsatzfragen der Beseitigung steuerlicher Grenzkontrollen auseinandergesetzt hat. ${ }^{160}$ Kurz darauf kam der Rat überein, auf der Ebene der Steuerdirektoren einen Ad-

\footnotetext{
159 Vgl. Kommission (1985), Ziff.160fP.

160 Vgl. Frankfurter Rundschau 19.11.85 u. AE 20.11.85.
} 
hoc-Ausschuß zu gründen, der sich mit den Im Welßbuch angerissenen Problemen näher beschäftigen soll.161

Negativ zu vermerken ist der dem steuerpolitischen Tell des Weißbuches innewohnende Perfektionismus. Die Forderung, daß zunächst die MWSt-Basis und die MwSt-Sätze sehr weitgehend harmonisiert werden mußten und daß erst dann der Abbau der Steuergrenzen in Angriff genommen werden könnte, Ist weder sachlich gerechtfertigt noch ist sle politisch durchsetzbar. Sie ist sachlich nicht zu rechtfertigen, da auch nach Abschaffung der Steuergrenzen elnzelne Unterschiede zwischen den nationalen USt-Systemen durchaus welterbestehen können. Und sle ist politisch nlcht durchzusetzen, da ein umfassendes Harmonisierungs-Programm fur die MWSt bei einer Vielzahl unterschledllchster Gruppen Widerstände provoziert. Die von der einen oder der anderen Harmonislerungsmaßnahme jeweils betroffenen Entscheidungsträger - die nationalen Regierungen, Ministerialbürokratien, Wirtschaftsverbände, etc. - werden sich zu einer Koalition zusammenschließen, die in der Lage ist, jeden auch noch so kleinen Fortschritt nachhaltig zu blockieren.

Hoffnung auf eine baldige Abschaffung der Steuergrenzen besteht daher nur, wenn die Erreichung des Endziels Schritt für Schritt angegangen wird und wenn gleichzeltig die für einen einzelnen Schritt jeweils notwendige MWSt-Harmonisierung auf ein unerläßliches Minimum zusammengestrichen wird. Welche Harmonisierungsmaßnahmen aber, so stellt sich dann die Frage, sind als Voraussetzung für den Abbau der steuerlichen Grenzkontrollen wirklich unabdingbar?

\section{Zur Harmonisierung der Bemessungsgrundlage}

Auf die Im Weißbuch der Kommission vorgesehene, sehr weitgehende Vereinheitlichung der MWSt-Bemessungsgrundlage kann, wle im polgenden anhand einiger Beispiele verdeutlicht werden soll, ohne weiteres verzichtet werden.162 Weder die Vorschläge für eine 7., 12., 13., 16. und 19.USt-Richtlinie noch die angekündigte Harmonisierung der Sonderregelungen Pür Kleinunternehmer und Landwirte lassen sich mit der Abschaffung der Steuergrenzen hinreichend rechtfertigen:

- Greifen wir uns als eln erstes Beispiel den Entwurf für eine 16.UStRichtlinle heraus. Das darin vorgesehene Grenzausgleichsverfahren für

161 Vgl. Handelsblatt 11.12.85, VWD Europa 20.1.86, Frankfurter Rundschau 22.1.86 u. Süddeutsche Zeitung 22.1.86.

162 Die Kommission stellt die Behauptung, da $\beta$ die Abschaffung der Steuergrenzen eine weltrelchende Harmonislerung der MWSt-Bemessungsgrundlage voraussetze, in ihrem Weißbuch auf, gibt aber bezeichnenderwelse kelne Begründung dafur; vgl. Kommission (1985), Zlff.193ff u. ZifP. 206P. Frühere Stellungnahmen gleicher Art finden sich z.B. in Kommission (1980), Ziff.15, sowle In Burke (1981), S.20. 
Gebrauchtwaren wird mit der Beseitigung der Grenzkontrollen hinfallig, da dann die von Privaten innerhalb der EG getätigten Importe ohnehin von der MWSt befreit werden müssen. Das EP hat denn auch konsequenterweise, in Anwendung eines inzwischen schon altbekannten Verfahrens, eine Stellungnahme zur 16.USt-Richtlinie verwelgert und gefordert, alle von Privat an Privat gelieferten Gebrauchtwaren, von wenigen Ausnahmen abgesehen, von der MWSt $\mathrm{zu}$ befrelen. Dle Kommission scheint mittlerwelle bereit, dle Unsinnigkeit ihres ersten Entwurfs einzusehen und auf das EP zuzugehen. ${ }^{163}$

- Ein wenig anders liegen die Dinge bei dem Vorschlag fur eine 7.UStRichtlinie. Kommen Gebrauchtwaren nicht in den Genuß einer Sonderregelung, so wird, wie z.B. belm deutschen Gebrauchtwagenhandel der Fall, die entsprechende Branche automatisch in elnen Wettbewerbsnachteil gegenüber den ausländischen Konkurrenten gesetzt. Die Wettbewerbsverzerrung besteht ganz unabhängig davon, ob es Steuergrenzen gibt oder ob sie abgeschafft sind. Wäre die Bundesreglerung über die Benachtelligung ihres KFZ-Handels sonderlich besorgt, so hätte sle das Problem, ganz ohne elne EG-Richtlinle, schon längst vom Tisch schaffen können.

- Bezulglich des Vorschlages für eine 12.USt-Richtlinie gilt genau dasgleiche. Sofern eine Wettbewerbsverzerrung vorllegt, besteht sie ganz unabhängig von der Existenz oder Nicht-Existenz von Steuergrenzen und kann jederzeit mittels einseitiger, nationaler Maßnahmen beseitigt werden. Es wăre also völlig widersinnlg, in der Verabschiedung der 12.USt-RIchtlinie elne Voraussetzung für dle Abschaffung der Steuergrenzen sehen $z u$ wollen. Das elne hat mit dem anderen nichts zu tun.

Zugegebenermaßen kann der eine oder andere Unterschled in den nationalen MWSt-Bemessungsgrundlagen einzelne Wettbewerbs- und auch Steuerkontrollprobleme aufwerfen, die sich nach einem Wegfall der Steuergrenzen verschärfen. Auf der anderen Selte sollte man sich aber daruber im Klaren sein, daß elne durchgreifende Vereinheitlichung der MWSt-Bemessungsgrundlage massive Wirtschafts- und Finanzinteressen bedroht und damit eine politische Opposition zu mobilisieren in der Lage 1st, die sich schnell gegen jeden aus Brussel kommenden Harmonisierungsvorschlag richten kann. Hinzu kommt, daß sich die Steuerexperten der Mitglledstaaten heute noch keineswegs einig darüber sind, welche Elemente der nationalen Bemessungsgrundlagen elnander angeglichen werden müßten und wo Divergenzen hingenommen werden könnten. Will man den Abbau der Grenzkontrollen in nächster Zukunft nachhaltig vorantrelben, so erscheint es daher sinnvoll, die Bemessungsgrundlage nicht vorher und auf Vorrat, sondern erst bel Bedarf, d.h. wenn die Abschapfung der Grenzkontrollen schon erfolgt ist oder zumindest unmittelbar bevorsteht, und dann ganz gezielt zu harmonisieren.

Vgl. Blick durch die Wirtschaft 4.10.84, Handelsblatt 1.2.85 u. 31.1.86. 


\section{Zur Harmonisierung der Steuersätze}

Bedenklich erscheint im Weißbuch der Kommission neben der weitgehenden Vereinheitlichung der MWSt-Bemessungsgrundlage auch die alte und im Binnenmarktprogramm nur wiederholte Forderung Brüssels, da $\beta$ dem Abbau der Steuergrenzen unbedingt eine Annäherung der Steuersätze vorausgehen müsse:

"Ein...Problem ist - im Gegensatz zu dem, was bei anderen Zlelen getan werden kann -, daß dle Steuergrenzen nicht schrittwelse abgeschafft werden können. Wenn die Kontrollen an den Grenzen beseitigt werden sollen, ist eine ausreichende und gleichzeltige Annäherung der Sätze für die Mehrwersteuer und alle Verbrauchsteuern erforderlich. Solange diese Sätze für eine dieser Steuern wesentlich voneinander abweichen, müssen die Kontrollen aufrechterhalten werden." 164

Die Argumentation ist insofern unbestritten richtig, als nur dann aup jegliche Grenzkontrollen verzlchtet werden kann, wenn die Sätze der indirekten Abgaben vorher hinreichend angeglichen worden sind. Eindeutig falsch ist allerdings die Behauptung, daß die Steuergrenzen nicht schrittweise abgebaut werden könnten. Die Erfahrung der Benelux-Staaten hat gelehrt, da $\beta$ es sehr wohl Möglichkeiten gibt, nach und nach die steuerbedingten Grenzkontrollen entscheidend $\mathrm{zu}$ verringern mit dem Ziel, dann, wenn die Steuersätze einmal angenähert sind, ganz auf sie zu verzichten.

Zweifelsohne ist der Gedanke, die Schlagbäume an den EG-Binnengrenzen in einer einmaligen Aktion wăhrend der Nacht des 31.Dezember 1992 niederreißen zu können, politisch äußerst reizvoll. Angesichts der zahlreichen Widerstände, die sich in den Mitgliedstaaten gegen eine Annăherung der Sătze genauso sperren wie gegen eine Vereinheitlichung der Bemessungsgrundlage, gilt es aber auch hier wieder zu bedenken: Ein zu hoch gestecktes Ziel ermutigt nicht, sondern schreckt vielmehr davon ab, einen ersten Schritt in die gewünschte Richtung zu tun. Es erscheint daher sinnvoll, eine peacemeal-Politik zu konzipieren,"..rather than (to) beat one's head permanently against the solld brick wall of substantial national differences in VAT rates." 160

\section{Abschließende Bewertung}

Die hier geforderte Beschränkung auf das unbedingt Notwendige, die Annäherung an das Endziel Abschaffung der Steuergrenzen Schritt für Schritt, deckt sich mit den Plänen, für die der bis 1984 Pür Binnenmarktpragen zuständige Kommissar Narjes immer wleder geworben hat:

"Im Kern hebt das Benelux-Konzept ja die vielfach verbreitete These aus den Angeln, wonach substantielle Fortschritte bei

\footnotetext{
164 Kommission (1980), ZlfP.18. Vgl. ähnl. Kommission (1985), ZlfP.175. 
der Vereinfachung des innergemeinschaftlichen Warenverkehrs von einer vorherigen abschlleßenden Harmonisierung in den vielfältigsten Bereichen abhängig gemacht werden, etwa auf dem Gebiet der indirekten Steuern, der Statistiken etc. Solche Einwände, dle wir nur allzu oft gehört haben und die 25 Jahre Fortschritte verhindert haben,.."166 Und weiter: "Uberdies zeigen auch die mehr als zehnjährigen Benelux-Erfahrungen, da $\beta$ selbst bel vorläufigem Fortbestand uneinheitlicher Steuersätze und sonstiger administrativer Vorschriften durchaus unausgeschöpfte und beträchtliche Rationalisierungsmöglichkeiten von Förmlichkeiten bestehen." 167

Angesichts des in der Zitatstelle deutlich werdenden konstruktiven Ansatzes ist es bedauerlich, daß die Kommission in ihrem Weißbuch von 1985 $\mathrm{zu}$ einem Konzept zurückgekehrt ist, das sie bereits in den $70 \mathrm{er}$ Jahren erfolglos zu verkaufen versucht hatte. Es wäre aber blauäugig, den im steuerpolitischen Tell des Weißbuches zum Ausdruck kommenden Perfektionismus alleine der Brüsseler Steuerdirektion in die Schuhe schieben $z u$ wollen. Vielmehr sind es die Mitgliedstaaten, die das Ziel Abschaffung der Steuergrenzen - andere Vorschläge der Kommission erlebten ein ähnliches Schicksal - systematisch mit einer so großen Zahl von Vorbedingungen bePrachten, daß der gesamte Plan unausweichlich zum Einstürzen kommen muß: Die Experten bestehen auf einer weitgehenden Harmonisierung der Bemessungsgrundlage als Voraussetzung für die Abschaffung der Steuergrenzen, da sie überall Steuerhinterziehung wittern; eine Harmonisierung der $\mathrm{Be}-$ messungsgrundlage erscheint aber solange nicht sinnvoll, wie vollkommen ungewi $\beta$ ist, ob die Angleichung der Steuersätze politisch überhaupt machbar ist; die Politiker ihrerseits wollen die Sätze nicht angleichen, solange es noch "offen gebliebene Probleme"160 bei der Bemessungsgrundlage gibt. Jeder sperrt sich, einen ersten Schritt zu tun, der eine schiebt die Verantwortung auf den anderen $a b$ mit dem Ergebnis, daß in Brüssel alle Räder stillstehen. Man darf vermuten, daß genau das von den Verantwortllchen in den Mitgliedstaaten beabsichtigt ist.

Der steuerpolitische Teil des Weißbuches ist überdimensioniert. Das Binnenmarktprogramm liefert den auf einem Gipfeltreffen versammelten Staatsund Regierungschefs eine willkommene Gelegenheit, bewegende Erklärungen über das Europa von Ubermorgen abzugeben. Aber die guten Absichten drohen, wie der Verlaup der bisherigen Beratungen der Finanzminister befürchten laßkt, schon bald auf der strecke zu bleiben. ${ }^{169}$ Sicherlich ist es lobenswert, daß die Kommission in ihrem Welßbuch ein steuerpolitisches Idealprogramm entworfen hat. Soll aber gewährleistet werden, daß zumindest der eine oder andere Schritt in die richtige Richtung getan wird, dann müssen

166 Kommissar Narjes in: AB Anhang 1983/1-293, S.163P.

167 Kommissar Narjes in: AB Anhang 1983/1-293, S.164.

168 Der deutsche Finanzminister Matthöfer in einer 1979 gehaltenen Rede, Matthöfer (1979), S.205.

169 Vgl. AE 18.1.86 u. 20.1.86, Süddeutsche Zeitung 31.1.86. 
die Maximalforderungen im Laufe der nun stattfindenden Verhandlungen reduziert werden.

Eine uber das berelts erreichte Maß hinausgehende Harmonisierung der MWSt-Bemessungsgrundlage 1st, wie oben gezeigt wurde, nicht zwingend erforderlich und sollte daher zunächst für einige Zelt zurückgestellt werden. Ein dringender Harmonislerungsbedarf besteht demgegenuber unzweifelhaft im Bereich der MwSt-Sätze und der MwSt-Verwaltung. Welche Maßnahmen hier ergriffen werden müssen, welche Erfahrungen bisher schon gemacht wurden und wie es im Hinblick auf die Abschaffung der Steuergrenzen weltergehen könnte, soll daher en détall im nun folgenden Kapitel diskutiert werden. 


\section{E. Die Harmonisierung der MWSt-Sätze und der MWSt-Verwaltung: noch vor der Jahrhundertwende?}

Die Harmonislerung der MwSt-Sätze und die der Finanzverwaltung bilden den dritten und vorerst letzten Schritt der USt-Harmonisierung in der EG. Wahrend der erste Schritt - Einfuhrung der MWSt - von wettbewerbspolitischen und der zweite Schritt - Harmonisierung der MWSt-Bemessungsgrundlage - von der Schaffung der MWSt-Elgenmittel dominiert war, rückt nunmehr das Zlel Abschaffung der Steuergrenzen in den Vordergrund. Die bisher zum Thema Steuergrenzen in der Opfentlichkeit geführte Diskussion legt die Vermutung nahe, alleine die nationalen steuersätze müßten einander angenähert werden und die fiskalisch motivierten Grenzkontrollen könnten dann quasi-automatisch wegfallen. Dem soll hier entschieden widersprochen werden. In einem ersten Abschnitt ist vielmehr herauszuarbelten, daß

- das Ziel Abschaffung der Steuergrenzen in zwel Unterzlele aufgespalten werden kann, dle gänzlich unterschledliche Problemstellungen aufwerfen,

- und daß jedes der beiden Unterziele in einzelnen, aufeinander aufbauenden Tellschritten einer Verwirklichung năhergebracht werden kann.

Ein zweiter Abschnitt ist, wie schon bel den vorhergehenden Kapiteln, dem Willensbildungsproze $\beta$ gewidmet. Da im Hinblick auf die Abschapfung der Steuergrenzen erst wenig versucht und noch weniger erreicht worden ist, bleibt die Darstellung der bisherigen Entwicklung notgedrungen vergleichsweise kurz. Neben den sogenannten Reiseverkehrs-Richtlinien ist insbesondere von dem Vorschlag für eine 14.USt-Richtlinie zu berichten, der, obwohl inzwischen im Rat steckengeblleben, ausführlich analysiert werden soll, da er äußerst interessante Einblicke in nationale wie supranationale Entscheidungsmechanismen gewăhrt. Der Rückblick auf das bisher Gewesene wird Jewells durch einen Ausblick auf das in den nächsten Jahren Notwendlge und Mögliche ergänzt.

Es ist zwar theoretisch durchaus denkbar, aber praktisch wenig sinnvoll, dle umsatzsteuerlichen Grenzkontrollen in der EG zu beseitigen, sie bei den speziellen Verbrauchsteuern dagegen auprechtzuerhalten. Da zudem die in beiden Bereichen sich stellenden Probleme eng miteinander verwandt sind, erscheint es angebracht, die nun folgende Analyse der MWSt hin und wie-

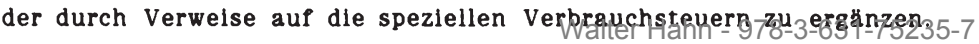




\section{Das Ziel Abscharfung der Steuergrenzen}

\section{Definition des Ziels}

Der Begriff Steuergrenze laßst, wie alle im politischen Raum beliebten Schlagwörter, mannigfaltige Interpretationen $\mathrm{zu}$. Obwohl er weiter oben bereits definiert und des öfteren verwandt wurde', sollten wir uns noch einmal vor Augen führen, was unter einer Steuergrenze im einzelnen konkret $\mathrm{zu}$ verstehen ist.

Steuergrenzen gibt es zum einen in einem engen und gegenständlichen Sinne in der Form fiskalisch motivierter Kontrollen an den Binnengrenzen der EG: die Frage "Haben Sie etwas anzumelden?", der Blick in den Kofferoder Laderaum, das Ausfüllen, Abgeben und Abstempeln ebenso umfangreicher wie unverständlicher Formulare, die Zahlung oder Rückerstattung von Steuern. Da die genannten Prozeduren neben volkswirtschaftlichen Kosten auch eine gewisse Verstimmung bel den davon Betroffenen verursachen, hat die Kommission allen Anlaß, auf eine baldige Beseitigung der physischen Grenzkontrollen zu dringen.

Steuergrenzen existieren darüberhinaus aber auch noch in einem weiteren und übertragenen Sinne. Werden alle zur Zeit an der Grenze durchgeführten Kontrollen durch verwaltungstechnische Verfahrensänderungen lediglich ins Inland verlagert, so übersteigen, selbst wenn es dann keine Schlagbäume mehr gibt, die im grenzüberschreitenden Handel abzuwickelnden Formalitäten noch immer die Verplichtungen, die bei identischen, im Inland ausgeführten Transaktionen zu erfullen sind. Der erhöhte Verwaltungsaufwand belastet auch weiterhin den intra-EG Handel und bildet dadurch ökonomische wie psychologische Barrieren, die die nationalen Märkte voneinander abtrennen. Von einer vollständigen Abschaffung der Steuergrenzen kann also erst dann gesprochen werden, wenn die den Wirtschaftssubjekten bei grenzüberschreitenden Geschäften vom Fiskus auferlegten Verpllichtungen denen entsprechen, die sie auch im inländischen Handel zu erfüllen haben. Oder anders ausgedrückt: Das Ziel ist es, in jedem Mitgliedstaat der EG das EG-Ausland zum umsatzsteuerlichen Inland werden zu lassen.

Die unterschledlichen Begriffsdefinitionen erlauben es, die Abschaffung der Steuergrenzen in einzelne Schritte zu zerlegen. Während der Abbau und die anschließende Beseitigung der physischen Grenzkontrollen als Nahziele zu betrachten sind, stellt die USt-rechtliche Gleichstellung des EG-Binnenhandels mit dem inländischen Handel das langfristig anzustrebende Endziel der EG dar.

1 Vgl. insbesondere Kap.C.1.1.2. 
Erstes Unterziel: die Abschaffung der Steuergrenzen für (nichtsteuerpllichtige) Letztverbraucher

Fragen wir nach den Voraussetzungen für die Abschaffung der Steuergrenzen, dann müssen wir zwischen den USt-pPlichtigen Unternehmern auf der einen und den nicht der USt-Pflicht unterliegenden Letztverbrauchern aup der anderen Seite unterscheiden.

Kommen wir zunächst auf die zur letzteren Gruppe zählenden privaten Haushalte zu sprechen. Die Steuergrenzen für die privaten Letztverbraucher können dann als vollständig beseitigt gelten, wenn dle von ihnen importierten Waren von der Pflicht zur Zahlung der inlandischen MWSt genauso freigestellt werden wie die im Inland erworbenen Güter. Die Befrelung von der EinfuhruSt geht einher mit dem Wegfall des Rechtes, die auf der Importware lastende ausländische MWSt zurückerstattet zu bekommen. Bestehen zwischen den einzelnen Ländern jedoch erhebliche Unterschiede bei den Steuersätzen, dann könnten sich die Bürger der EG veranlaßt sehen, ihre Einkäufe in ein niedriger besteuerndes Land zu verlagern. Fiskalisch bedingte Wettbewerbsverzerrungen Im grenzüberschreitenden Handel sind die unausweichliche Folge. Auf den steuerlichen Grenzausgleich und die damit verbundenen Kontrollen kann also erst dann völlig verzichtet werden, wenn die MWSt-Sătze der EG-Staaten einander weitgehend angenähert sind.

Aber auch schon vor einer Angleichung der Steuersätze gibt es Möglichkeiten, die den privaten Reiseverkehr betreffenden Grenzkontrollen zu verringern. So kann man beisplelsweise vorsehen, daß die von Privaten getätigten Importe bis $\mathrm{zu}$ einer gewissen Höchstgrenze von der Einfuhrbesteuerung befreit werden. Da beim Überschreiten der in Wert- oder Mengeneinheiten festgelegten Obergrenze automatisch ein Grenzausgleich durchgeführt wird, bleiben die auftretenden Wettbewerbsverzerrungen in einem engen Rahmen. Die den Bürgern gewährten Freimengen können mit zunehmender Annäherung der Steuersätze heraufgesetzt werden. Da gleichzeitig der Anreiz, gegen die noch bestehenden Beschränkungen $\mathrm{zu}$ verstoßen, immer kleiner wird, lassen sich die im Reiseverkehr durchgeführten Stichprobenkontrollen schrittweise verringern.

Bisher noch nicht gesprochen haben wir über die Offentlichen Hände und die steuerbefreiten Unternehmer, die, wie die Privatpersonen, ebenfalls der Gruppe der nicht-steuerpflichtigen Letztverbraucher zuzurechnen sind. ${ }^{2}$ Die durch unterschiedliche Steuersătze aufgeworfenen Probleme - Verlagerung von Einkäufen - gelten für sie ganz analog. Solange die Steuersätze noch nicht weitgehend angeglichen sind, bietet es sich an, auch sie in den Genuß der im privaten Reiseverkehr erlaubten Freimengen kommen zu lassen.

2 Unter den Begriff der steuerbefreiten Unternehmer sollen hier auch steuerpflichtige Unternehmer subsumiert werden, soweit sie steuerbefreite Umsätze tätigen. 
Da die Offentlichen Hände wie auch die steuerbefreiten Unternehmer in aller Regel über eine geordnete Buchfürung verfugen, kommt darüberhinaus noch eine zweite Ubergangslösung in Betracht: Die beiden Gruppen werden, insoweit als sie Vorprodukte aus dem Ausland bezlehen, wle steuerplichtíge Unternehmer behandelt mit dem einzigen Unterschied, daß nicht der Output, sondern der importlerte Input mit dem inländischen MWSt-Satz belastet wird; die aup der Importware lastende ausländische MWSt wird, wie bel allen steuerpflichtigen Unternehmern, zum VSA zugelassen. ${ }^{3}$

\section{Zweites Unterzlel: Abschaffung der Steuergrenzen für (steuerpflichtige)} Unternehmer

Wăhrend bel der Abschaffung der Steuergrenzen für (nicht-steuerpplichtige) Letztverbraucher der Steuersatzdifferenz eine zentrale Bedeutung zukommt, ist das Problem beim Handel zwischen (steuerpplichtigen) Unternehmern völlig anders gelagert. Das Endzlel muß hler sein, den steuerlichen Grenzausglelch durch eln nunmehr erweitertes Recht auf VSA zu ersetzen. Ist es im Augenblick nur erlaubt, die im Inland gezahlte Vorsteuer abzuziehen, so muß es dann auch möglich sein, dle in anderen EG-Staaten in Rechnung gestellte MWSt vom nationalen Fiskus zurückerstattet zu bekommen. "Wettbewerbsverzerrungen können selbst dann nicht auftreten, wenn die Steuersätze der elnzelnen Länder noch welt auselnanderklaffen. Das Recht auf VSA veranlaßt nämlich die Unternehmer, ihre Kaufentscheidungen grundsătzlich immer an Nettopreisen ohne MWSt auszurichten. Umgekehrt sind die Konsumenten, sofern sie im Inland einkaufen, bel elnem Gut immer mit demselben Steuersatz konfrontiert, und zwar unabhängig davon, ob der Hersteller bzw. Händler seine Vorprodukte vom In- oder Ausland bezogen hat.

Das aus einem einzelnen Land bekannte MWSt-Modell wird somit einfach auf den gesamten EG-Raum übertragen mit dem Ergebnis, daß der Grenzausglelch und damit auch die Kontrollen an den Binnengrenzen wegfallen können. Der Vorschlag hat lediglich einen Haken: Die nationale Finanzverwaltung hat kelne Mögllchkelt nachzuprüen, ob die von einem Unternehmer in Abzug gebrachte Vorsteuer vom ausländischen Lieferanten auch wirklich

3 Da die Steuerbefrelung von Unternehmerumsätzen in einem MWStSystem sowieso ein Fremdkörper ist, sollte ganz unabhängig von der Abschaffung der Steuergrenzen erwogen werden, ihre Zahl schrittwelse zu reduzieren.

4 Blehl bezeichnet das in diesem Verfahren zum Ausdruck kommende Besteuerungsprinzlp als "Gemeinsamer Markt Prinzlp" (GMP); vgl. Blehl (1969), S.132 pf. Da das GMP auf einer anderen Ebene liegt als das BLP und das ULP, führt Blehl daruberhinaus auch ein "Ausfuhrland-" sowle ein "Einfuhrlandprinzip" ein. Auf der Suche nach einer exakten Abgrenzung $\mathrm{zwischen}$ dlesen Prinziplen laß Biehl den Leser in der zitlerten Arbelt aber alleine. Der Begriff GMP soll daher in der vorliegenden Arbeit nicht weiter verwandt werden: Der zusätzliche Erkenntniswert würde durch dle gestiftete Verwirrung uberkompensiert werden. 
an dessen Fiskus abgeführt wurde. Um der Steuerhinterzlehung nicht Tür und Tor zu öffnen, ist es daher unerlällch, die Finanzverwaltungen der EG-Staaten mitelnander zu vernetzen und den Grad der Kooperation auf ein Niveau anzuheben, wie es heute schon zwischen den verschiedenen Finanzämtern eines einzelnen Landes existiert. Beschränken wir uns aup den Handel zwischen (steuerpplichtigen) Unternehmern, so würde sich die Situation nach vollständiger Abschaffung der Steuergrenzen etwa wle folgt darstellen:

Schaubild E-1: Modell ohne Steuergrenzen

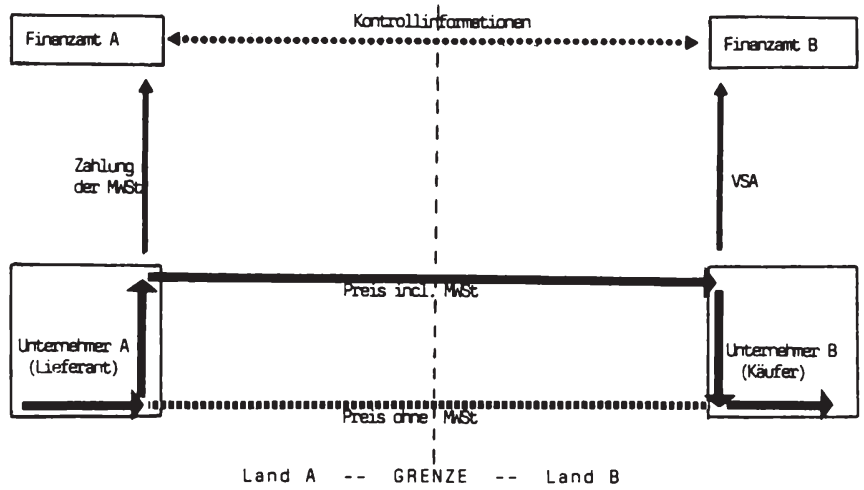

Demgegenuber sieht das Modell mit Steuergrenzen, zumindest in der Theorie, so aus: Das von Land A nach Land B gelleferte Gut wird belm Grenzubbertritt von der Zollverwaltung $A$ steuerlich entlastet und auf der anderen Selte des Schlagbaumes von der Zollverwaltung B mit dem in Land B Jewells erhobenen MWSt-Satz belastet. Zur Unterbindung von Steuerhinterziehungen werden zwischen der Finanz- und der Zollverwaltung der elnzelnen Lănder Kontrollinformationen ausgetauscht.

Schaubild E-2: Modell mit Stevergrenzen

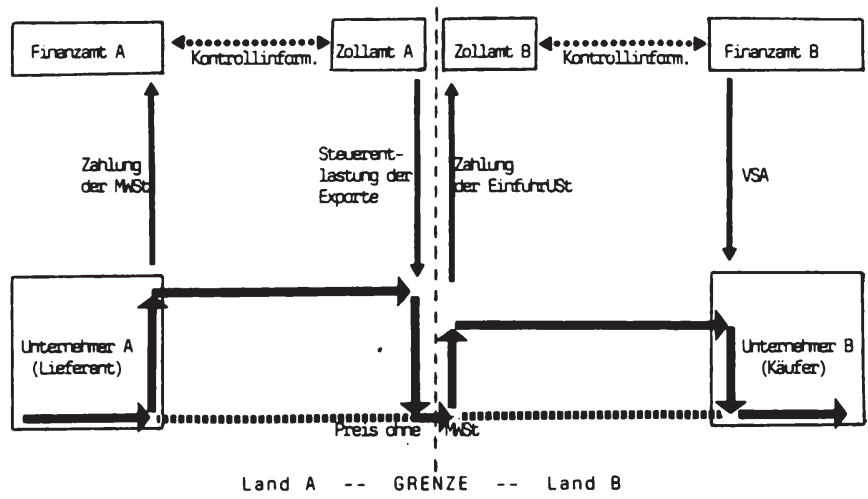


Das idealtypische Modell mit Steuergrenzenº läßt sich in einer beliebigen Anzahl von Schritten modifizieren und so langsam in das Modell ohne Steuergrenzen überführen. Nach und nach werden die an den Grenzen zu erledigenden Formalitäten reduziert mit dem Ziel, sie eines Tages ganz durch eine Kooperation zwischen den nationalen Finanzverwaltungen zu ersetzen. Denkbar ware beispielswelse das folgende Vorgehen:

1. In einem ersten Schritt wird das Besteuerungsverfahren auf der Seite des Exportlandes abgeändert: Die Finanzverwaltung A verzichtet bei zu exportlerenden Gütern von vorneherein auf die Erhebung der MWSt; die Zollverwaltung $A$ kontrolliert die Ausfuhr der betreffenden Ware und und erstattet der Finanzverwaltung, bei Bedarf, darüber Meldung (Schaubild E-3).

2. Eine in eine ăhnliche Richtung gehende Vereinfachung des Grenzausgleiches ist auch auf der Seite des Importlandes möglich: Das Zollamt B stellt an der Grenze lediglich den Importvorgang Pest, während die Zahlung der EinfuhruSt im Inland und 1.d.R. elnige Wochen später erfolgt (Schaubild E-4).

Schaubild E-3 Modell mit Steuergrenzen 1. Modifikation
Schaubild E-4 Modell mit Steuergrenzen 2. Modifikation

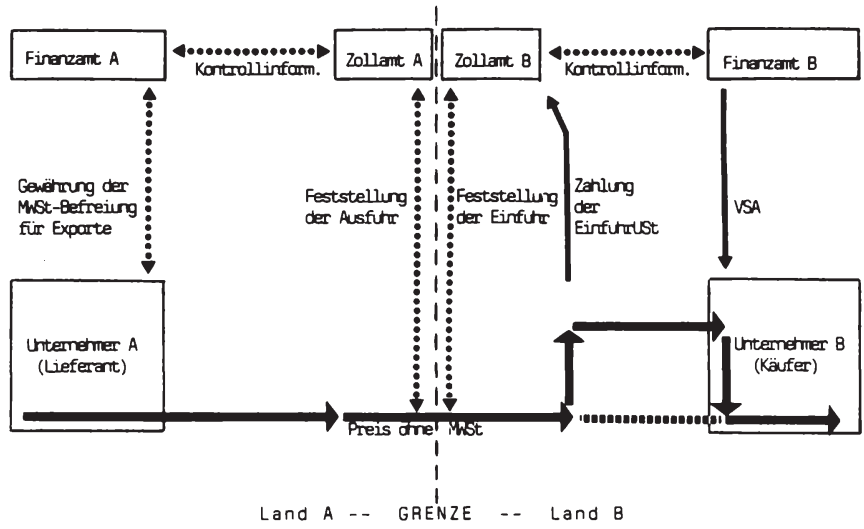

$5 \quad$ Am Rande sei darauf hingewiesen, daß es in der Praxis der EG bereits zahlreiche kleinere und größere Abweichungen von diesem idealtypischen Modell gibt. Die in den Mitgliedstaaten heute jeweils üblichen Verfahrensweisen unterscheiden sich von Land $\mathrm{zu}$ Land, betreffen alle Steuerpplichtigen oder aber nur bestimmte Gruppen, sind tells obligatorisch und tells Pakultativ, etc. Auf eine detailllerte Darstellung der in den eínzelnen EG-Staaten zur Zeít gültigen Regelungen muß jedoch verzichtet werden: Sie würde den Rahmen der vorliegenden Arbeit bei weitem sprengen. 
3. In einem weiteren Schritt kann im Importland auf die beiden sich gegenseitig auphebenden Zahlungsströme - Zahlung der EinfuhrUSt und anschließender VSA in gleicher Höhe - verzichtet werden: Dem importierenden

Unternehmer B wird die Zahlung der EinfuhruSt erlassen; er bleibt jedoch verpflichtet, selnem Finanzamt eine Meldung uber die MwSt-frel aus dem Ausland bezogenen Güter zu erstatten; die Meldung ist notwendig, um auszuschlleßen, daß der Unternehmer B beim Wiederverkaup der Güter die dann făllige MWSt unterschlägt; zugleich ergeht eine Kontrollmitteilung vom Zollamt B zum Finanzamt B über die Einfuhr. Das skizzierte System entspricht in seinen Grundzügen dem in der 14.USt-Richtlinie gemachten Vorschlag der Komission.

Schaubild E-5: Vorschlag für eine 14.USt-Richtlinie

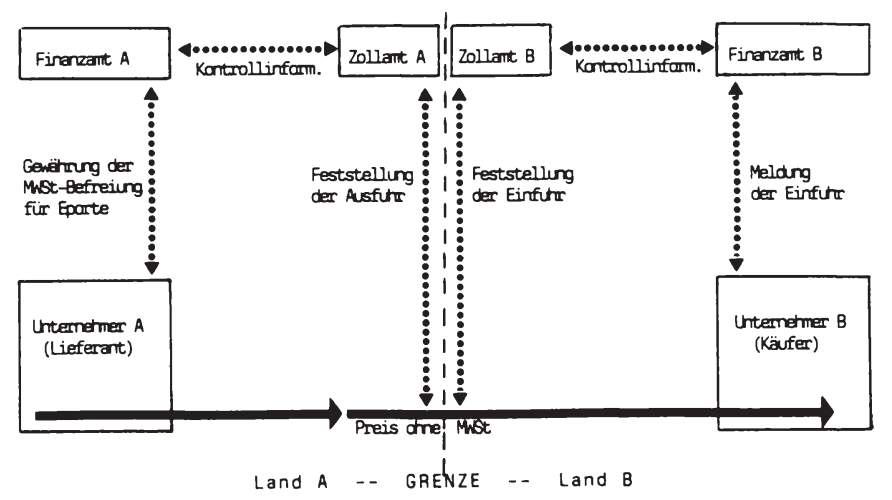

4. Als năchster Schritt kommt eine Vereinfachung der an den Grenzen durchgefuhrten Kontrollen in Betracht. So könnte beispielsweise auf die zwelfache Feststellung des Grenzübertritts einer Ware verzichtet werden. Es würde ausreichen, wenn das Zollamt des Importlandes die hereinfließenden Güterströme kontrolliert und die entsprechenden Informationen indirekt über die Zollstation aup der anderen Seite der Grenze oder gleich direkt an dle Finanzverwaltung des Exportlandes weiterreicht. Der Vortell eines solchen Verfahrens liegt insbesondere darin, daß hler elne intensive Kooperation zwischen zwei nationalen Verwaltungen institutionalisiert wird, die damit die Möglichkeit erhalten, die Zusammenarbeit zu erproben und Vertrauen zueinander zu fassen.

5. Der grenzüberschreitende Informationsfluß könnte in einem weiteren Schritt wle folgt ausgebaut werden: Auf die Grenzkontrolle wird ganz ver- 
zichtet; der Lieferant erhält die MwSt-Befreiung für die von ihm exportierten Güter aber erst dann, wenn der Kăufer seinem Finanzamt Meldung über die Einfuhr erstattet hat; zur Verhinderung möglicher Mißbräuche tauschen die belden zuständigen Finanzämter $\mathrm{A}$ und $\mathrm{B}$ Kontrollinformationen aus.

Schaubild E-6: Modell ohne Grenzkontrollen

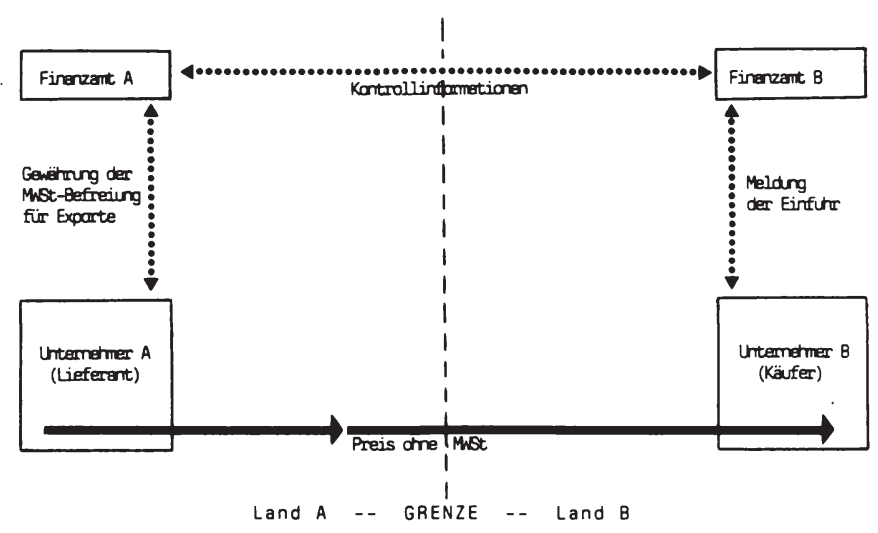

Sobald die physischen Grenzkontrollen beseitigt und durch eine funktionierende Zusammenarbeit $\mathrm{zwischen}$ den nationalen Finanzverwaltungen ersetzt worden sind, ist es nur noch eln kleiner Schritt bis zur völligen umsatzsteuerlichen Gleichbehandlung von inländischen und grenzuberschreitenden Transaktionen: Entsprechend Schaublld 1 entfällt die MWSt-Befreiung für Exporte, Im Gegenzug erhalt der Importeur das Recht aup VSA; die beiden zuständigen Finanzämter tauschen nach wie vor bel Bedarf Kontrollinformationen aus, deren Inhalt jetzt aber eln anderer ist.

\section{Interdependenzen $z$ wischen den Unterzielen}

Zusammenfassend bleibt zunächst Pestzuhalten, daß die Abschaffung der Steuergrenzen fur (nicht-steuerpllichtige) Letztverbraucher Wettbewerbsprobleme aufwirft und daher eine Annaherung der Steuersätze erfordert. Demgegenüber setzt die Erreichung desselben Zieles bel den (steuerpflichtigen) Unternehmern, um die Gefahr der Steuerhinterzlehung zu verringern, eine Vernetzung der nationalen Finanzverwaltungen voraus.

Zwischen den beiden Unterzielen bestehen einzelne Interdependenzen, die verlangen, daß bel der fortschreitenden Zlelverwirklichung aup einen gewis- 
sen Gleichschritt in beiden Bereichen geachtet wird. Begründet liegen die Interdependenzen in der Tatsache, daß

- erstens für Letztverbraucher und für Unternehmer bestimmte Güter gleichzeitig die Binnengrenzen uberschreiten, und daß

- zweitens die Zollbeamten es den Jewelligen Personen nicht ansehen können, ob sie die mitgeführten Güter als Letztverbraucher oder aber im Auftrag eines Unternehmers importieren.

Das hier angesprochene Unterscheidungsproblem spielt offensichtlich solange keine Rolle, wie alle Güter beim Grenzübertritt der gleichen Verfahrensregel - z.B. sofortige Vornahme der Einfuhrbesteuerung an der Grenze - unterworfen werden. Auch die Gewăhrung begrenzter Frelmengen im privaten Reiseverkehr wirft noch keine nennenswerten Probleme auf: Selbst wenn ein Unternehmer vorgeben sollte, als Letztverbraucher $\mathrm{zu}$ handeln, so blelbt der hierdurch entstehende volkswirtschaftliche Schaden vernachlässigbar klein. Bedeutung erlangt das Unterscheldungsproblem dann, wenn auf die Steuergrenzen im privaten Relseverkehr völlig verzichtet werden soll, während der kommerzielle Verkehr aber gleichzeitig noch Kontrollen unterliegt. Da

- erstens die Unternehmer in bestimmten Făllen einen Anreiz haben, sich an der Grenze als Letztverbraucher auszugeben, und da

- zweltens die Letztverbraucher ihrerseits, selbst wenn sle es möchten, Paktlsch keine Möglichkeit haben, an der Grenze lhre Konsumenteneigenschapt nachzuweisen,

können die Beschränkungen im privaten Relseverkehr solange nicht vollständig aufgehoben werden, wie im gewerblichen Verkehr Kontrollen weiterhin durchgefuhrt werden.

Die gemachte Aussage gilt auch in der umgekehrten Richtung: bestehen noch irgendwelche Beschränkungen im privaten Reiseverkehr, dann kann auch im kommerziellen Verkehr nicht vollständig auf Kontrollen verzichtet werden. Da Privatpersonen sich widerrechtlich als Unternehmer ausgeben könnten, muß die Unternehmerelgenschapt beim Grenzübertritt zumindest in Stichproben - mittels von der Finanzverwaltung ausgestellter Ausweise und/oder bel den Grenzstellen vorhandener Kartelen bzw. Terminals uberpruft werden. Zusammenfassend festhalten läst sich damit das folgende: Die Grenzkontrollen lassen sich für die Letztverbraucher und für die Unternehmer ganz unabhängig vonelnander vereinfachen; vollständig abgeschafft werden können sie aber nur pur beide Gruppen gleichzeitig.

Bevor wir den Abschnitt über die Interdependezen abschließen können, muß noch kurz auf ein weiteres Argument eingegangen werden. Oft wird behauptet, daß ohne eine vorangehende Angleichung der Steuersätze dle Aufhebung der Grenzkontrollen im kommerziellen Verkehr die Möglichkelt zu einer Steuerhinterziehung der folgenden Art eröffnen würde: Eín importle- 
rendes Unternehmen und sein ausländischer Lieferant kommen überein, auf eine Meldung der Einfuhr zu verzichten; die ausgetauschten Güter werden Im niedrigbesteuernden Exportland ordnungsgemä $\beta$ versteuert, im hochbesteuernden Importland aber verkauft. ${ }^{6}$ Ganz von der Hand zu weisen ist die Behauptung nicht. Sie sollte aus den folgenden Gründen aber auch nicht uberstrapaziert werden:

- Der Anrelz zur Verlagerung der indirekten Besteuerung ist gering, wenn man bedenkt, daß Länder mit nledriger MWSt in aller Regel hohe direkte Steuern erheben und vice versa.

- Die Steuerhinterziehung nach obigem Strickmuster ist mit einem erheblichen Aufwand verbunden, setzt sie doch elne zwischen beiden Vertragspartnern koordinierte Manipulation der Käufe und Verkäufe, der Lagerbuchhaltung, der Zahlungsströme, etc. voraus; unterlaufen dabei geringe Fehler, so kann sie im Rahmen der üblichen Betriebsprüfungen ohne weiteres aufgedeckt werden.

- Die Steuerhinterziehung kann nur dann gelingen, wenn und soweit sowohl das exportierende als auch das importierende Unternehmen Umsätze mit (nicht-steuerpplichtigen) Letztverbrauchern abwickeln; ${ }^{7} \mathrm{da}$ der Bereich eines möglichen Mißbrauches somit stark eingeschränkt ist, wird die Steuerkontrolle im Inland wesentlich vereinfacht.

- Wie mit Hilfe der Betriebsprüungen Steuerhinterziehungen der beschriebenen Art unterbunden werden können, weiß die Finanzverwaltung schon bestens aus dem Bereich der Dienstleistungen: Dort sind bereits heute, das ergibt sich aus der Natur der Sache, kelne physischen Grenzkontrollen mehr möglich.

- Eine Steuerhinterziehung nach der oben beschriebenen Methode ist auch innerhalb ein- und desselben Landes möglich, wenn, wie oft der Fall, die Endprodukte eines Unternehmens mit einem höheren Steuersatz belastet werden als die Vorprodukte; es besteht keine Veranlassung, an die Kontrolle grenzuberschreltender Transaktionen strengere Maßstäbe anzulegen, als sle bel InlandsgeschäPten üblich sind.

Insgesamt laßst sich eine weitgehende Angleichung der Steuersätze mit dem Unterziel Abschaffung der Steuergrenzen also nicht rechtfertigen. Spätestens wenn die MWSt-Sätze soweit angenähert sind, daß die Beschränkungen Im privaten Reiseverkehr wegfallen können, kann und muß auch aup die Kontrollen im gewerblichen Verkehr verzichtet werden.

$6 \quad$ Vgl. z.B. Kommission (1985), Ziff.173.

7 Begründung: Das exportierende Unternehmen muß seine Inlandsverkäufe noch oben manipulieren. Da Lieferungen an steuerpflichtige Unternehmen durch den VSA des Kunden gegenkontrolliert werden können, kommen hlerfür nur Verkäufe an nicht-steuerpflichtige Letztverbraucher in Frage. Das importierende Unternehmen muß umgekehrt seine Verkäufe nach unten manipulieren. Da steuerpflichtige Kunden, um das Recht auf VSA nicht zu verlieren, auf das Ausstellen einer Rechnung bestehen werden, können dem Fiskus nur Lieferungen an Letztverbraucher unterschlagen werden. 


\section{Ein weiteres Problem: die Vertellung des Steueraufkommens}

Der vollständige Verzicht auf den Grenzausgleich, ob für Letztverbraucher oder für Unternehmer oder für beide Gruppen gemeinsam, stellt die EG daruberhinaus noch vor ein weiteres Problem, das ebenfalls einer Lösung bedarf. Gemeint ist die Verteilung des MwSt-Aufkommens zwischen den verschiedenen Mitgliedstaaten. Solange der Grenzausgleich durchgeführt wird, vereinnahmt automatisch dasjenige Land die MWSt, innerhalb dessen Grenzen das jewellige Gut verbraucht wird. Fallt jedoch mit Abschaffung der Steuergrenzen der Grenzausgleich weg, so flleßt, sofern eine Aufkommensumverteilung nicht erfolgt und die Verbrauchsteuersätze in allen Ländern miteinander ubereinstimmen, das Steueraupkommen dem Fiskus des Landes $z u$, in dem das Gut produzlert bzw. der Mehrwert erstellt worden ist. Die Beseitigung der Steuergrenzen provoziert also elne Aufkommensumvertellung zugunsten der Staaten, die im intra-EG Handel einen Uberschuß der Exporte uber die Importe erzielen.

Entgegen den Vorschlägen des Deringer-Berichts ${ }^{8}$ haben die Mitglledstaaten seit Anbeginn der EG darauf bestanden, daß, was auch immer in Zukunft einmal mit den Steuergrenzen geschehen sollte, das Steueraupkommen nach wie vor dem Land des Verbrauches zufließen sollte. Begründet wurde diese Forderung mit dem Hinweis darauf, daß die MWSt als indirekte Steuer letztendlich vom Verbraucher getragen werde. Die unterstellte Oberwälzungshypothese läßt sich angesichts der Tatsache, daß die Steuergrenzen gegenüber Drittländern in jedem Fall aufrechterhalten werden sollen, nicht in Frage stellen. Prinziplell unzulăssig ist allerdings der Schluß von dem Sein aup ein Sollen. Auch der Glaube, dle Mitgliedstaaten hätten sich bel ihrem Beharren aup dem Verbrauchsland-Prinzip von elnem Gefuhl der Gerechtigkeit leiten lassen, wäre reine Augenwischerei. Uber Gerechtigkeit läßt sich bekanntlich streiten, und im politischen Tagesgeschät splelt sie ohnehin nur eine untergeordnete Rolle. Die Realitat sah und sieht noch heute anders aus: Mit der Forderung, das MWSt-Aufkommen entsprechend dem ort des Verbrauches zu vertellen, wollten die Mitgliedstaaten der EG alleine den einmal errelchten Status quo festschreiben. Damit konnten sie sicherstellen, daß die Frage nach einer supranationalen Einkommensumvertellung von Anfang an aus der Debatte über die Steuergrenzen ausgeschlossen wurde. "Wenn es an's Geld geht, werden die Leute empilindlich"s - so der Kommentar elnes langjährigen Tellnehmers an den Brüsseler Verhandlungen. $\mathrm{Da}$ sich an dieser Einstellung in năchster Zukunft kaum etwas åndern dürfte, muß, um das Ziel Abschaffung der Steuergrenzen nicht von vornherein zum Scheitern zu verurtellen, der Verzicht aup den Grenzausgleich elnhergehen mit der Implementlerung eines Umvertellungsmechanismusses,

\footnotetext{
- Vgl. Deringer-Bericht (1963), S.37f.

9 Persönliches Interview.
} 
der eine mögllchst weitgehende Erhaltung der bisherlgen Aufkommensverteilung $\mathrm{zwischen}$ den Mitglledstaaten garantiert.

Bei der Wahl eines geelgneten Systems findet man sich rasch in einem nicht zu vermeidenden Dilemma: Je exakter die Annäherung an die MWStVerteilung nach dem Ort des Verbrauches, desto größer der zu erledigende Verwaltungsaufwand und vice versa. Eine relativ perfekte Lösung des Umverteilungsproblemes gewährlelstet ein sogenanntes clearing. Dle Unternehmer machen in ihrer USt-Erklärung Angaben darüber, inwieweit die von Ihnen in Abzug gebrachte Vorsteuer auf EG-Importe entfällt; anschließend beantragt die nationale Finanzverwaltung bei elner zentralen ClearingStelle die Rückerstattung der entsprechenden Vorsteuerbeträge vom Herkunftsland der Importe. Als Alternative bietet sich das in Schaubild E-6 skizzierte Modell an: $\mathrm{Da}$ dle Güter die EG-Binnengrenzen ohne jegliche MWSt-Last überschreiten - man spricht daher auch von zero-rate notification -, kommt das MWSt-Aufkommen, ohne daß eine Umverteilung nbtig wäre, automatisch dem Land des Verbrauches zugute. Keines der beiden Systeme ist in der Lage, die von nicht-steuerpflichtigen Privatpersonen importierten Guter zu erfassen. Das aber dürfte sich, da die von Privaten getatigten Einfuhren vergleichsweise gering sind und da durch die Wechselseitigkelt des Reiseverkehrs ein gewisser Ausgleich stattfindet, durchaus verschmerzen lassen. Demgegenüber können dle OPfentlichen Hănde und die steuerbefreiten Unternehmer, sofern sie, wie oben vorgeschlagen wurde, Im Rahmen Ihrer EG-Importe der USt-Pflicht unterliegen, ohne welteres in den Umverteilungsmechanismus integriert werden. Beide der hier diskutierten Systeme haben Ihre spezlfischen Vor- und Nachtelle. Während dem clearing ein hoher Verwaltungsaufwand zugeschrieben wird, erscheint die zero-rate notification, da die Guter auf ihrem Weg über die Grenze mit keinerlei MWSt belastet sind, für Steuerhinterzlehungen anfälliger zu sein.

Die mit der Umvertellung des Steueraufkommens verbundene Verwaltungsarbelt läßt sich nur reduzleren, wenn man auf den Aufkommens-Ausgleich für jedes einzelne Importgut verzichtet und stattdessen gesamtwirtschaftliche bzw. statistische Daten zur Grundlage des Umvertellungsmechanismusses macht. Dafur in Frage kommen neben Informationen über den EG-Binnenhandel Insbesondere Angaben über Höhe und Struktur des privaten und öpfentlichen Verbrauches in den Mitgliedstaaten. Elne weltere Möglichkeit besteht darin, die sich in den Jahren vor der Beseitigung des Grenzausgleiches ergebende Verteilung des Aufkommens zu ermitteln und sie entsprechend der gesamtwirtschaftlichen Entwicklung der Mitgliedstaaten und der Veränderung der Steuersätze anschließend fortzuschreiben. Sämtliche erdenkbaren Variaten sind allerdings Năherungslösungen und als solche mit Mängeln behaptet. So verlangen sle zum einen - eine bisher nicht erfullte Voraussetzung - ein in allen Ländern der EG gleichermaßen hoch entwik- 
keltes statistisches Erfassungssystem. Schwer wlegt zum anderen auch das Problem, wie nach Abschaffung der Grenzkontrollen zuverlässige Daten über den EG-Binnenhandel erhoben werden können. Werden sie in detalllierter Form bel den Unternehmen erfragt, so sind wir schon fast wieder bel einem Clearing-System angelangt. Fehlen sie jedoch ganz, können kunftlge Anderungen der Import/ Export-Strukturen nicht im Umvertellungsmechanismus berücksichtigt werden. Die entscheidende Frage ist dann, ob die Mitgliedstaaten das daraus für ihr zukünftiges MWSt-Aufkommen erwachsende Risiko zu tragen bereit sind.

Wird die Aufkommensvertellung erst elnmal auf der Grundlage statistischer Daten vorgenommen, dann ist es aus technischer Sicht nur noch eine reine Formsache, zu einem steuerlichen Verbund-System nach bundesrepublikanischem Vorbild uberzugehen: Statt die MWSt in verschiedenen nationalen Töpfen zu sammeln und anschlleßend nach einem bestimmten schlüssel umzuvertellen, Pließt das MWSt-Aufkommen zunächst in einen gemeinsamen Topf und wird dann zwischen den Mitglledstaaten aufgetellt. Belde VerPahren können, bel der Verwendung entsprechender Vertellungsschlussel, zu genau demselben Ergebnis hinfuhren. Trotzdem dürte der Ubergang zu elnem Verbund-System aus leicht elnsehbaren Gründen als Polltikum erster Ordnung einzustufen sein. 


\section{Der willensblldungsprozeß}

\subsection{Zur Abschaffung der Steuergrenzen pür nicht-steuerpflichtige Letztverbraucher}

\subsubsection{Rückblick auf eine erfolgreiche $\mathrm{Zwischenlösung:}$ die Relseverkehrs-Richtlinien}

\section{Vlelversprechende Anfänge}

An dem Abbau der Steuergrenzen für (nicht-steuerpflichtige) Letztverbraucher versuchte sich die EG schon recht Prüh.1 Es war insbesondere dle Bundesrepubllk und hr Finanzminister Strauß, die bereits vor der endgültigen Beseitigung der EG-Binnenzölle - erfolgt am 1.Jull 1968 - dazu aufriefen, ohne eine weitere USt-Harmonisierung aup die Steuergrenzen im privaten Reiseverkehr sofort und soweit als möglich zu verzichten. ${ }^{2}$ Dem europäischen Bürger sollten, so der politische Hintergedanke der Forderung, die Erfolge der Gemeinschaft deutlich vor Augen gefuhrt werden. Mit nlederländischer und belgischer Unterstützung gelang es, am 28.Mai 1969 eine erste Reiseverkehrsrichtlinie $\mathrm{zu}$ verabschleden. ${ }^{3}$ Darin einigte man sich, die im innergemeinschaftlichen Reiseverkehr mitgeführten Güter bis zu einem Höchstbetrag von 75 Rechnungseinheiten - Pür die spezlellen Verbrauchsteuern unterliegenden Güter wurden mengenmäßige Obergrenzen, z.B. 200 Zigaretten, 2 Liter Weln, etc. Pestgelegt - von der Einfuhrbesteuerung zu befreien. Die im folgenden kurz als Freimengen bezelchneten steuerbefreiungen erhöhten sich zum 1.Juli 1972, also zu einem Zeltpunkt, als man auf die baldige Verwirklichung der WWU-Pläne noch hoffen durfte, aup 125 Rechnungseinheiten bzw. 300 Zigaretten, 3 Liter Wein, etc. ${ }^{4}$ Demgegenüber wurden die Freimengen im Reiseverkehr mit Drittländern, um dle EG nach

1 Ein überblick über die vielpältigen Aktivitäten, die unter das genannte Stichwort subsumiert werden können, findet sich bel Guleu (1983b).

2 Vgl. z.B. Le Monde 28.5.68. Vgl. a. Dally Telegraph 14.1.69, New York Times 14.1.69 u. NZZ 15.1.69.

3 Vgl. AB 1969/L 133, S.6Pf.

4 Vgl. AB 1972/L 139, S.28PP. 
außen hin abzugrenzen und damit ihre politische Identität zu stärken, deutlich niedriger festgesetzt. ${ }^{5}$

Die Kommission hielt zunächst von den Plänen zur Einfuhrung begrenzter Freimengen nicht viel. Sie befürchtete, daß die Diskussion über einzelne Vereinfachungen im privaten Reiseverkehr von der als wichtiger erachteten Fortführung der USt-Harmonisierung ablenken könnte. So falsch lag die Kommission mit ihren Angsten nicht. Die Deutschen und einige andere wollten begrenzte Frelmengen, verkauften die Sache in der Opfentlichkeit aber als Abschaffung der Steuergrenzen.

Alles in allem aber dürfte es kaum den beiden ersten Reiseverkehrsrichtlinien zuzuschreiben sein, daß die Bemühungen um eine weitere USt-Harmonislerung nach 1973 merkllch erlahmten. Ob die anfängliche Zurückhaltung der Kommission gerechtfertigt war, soll daher dahingestellt bleiben. Tatsache ist jedenfalls, daß Brüssel sich erst dann für eine Vereinfachung der Grenzkontrollen im privaten Relseverkehr erwärmen konnte, nachdem die Sache 1969 ins Rollen gekommen war. Und erst als die Errelchung des Endzieles - Wegfall der Grenzkontrollen nach erfolgter Angleichung der Steuersätze - ab 1973 in immer weltere Ferne rückte, widmete Brüssel der ungellebten Zwischenlösung - Vereinfachung der Grenzkontrollen im privaten Reiseverkehr - eine langsam ansteigende Aufmerksamkeit. ${ }^{6}$

\section{Schleppende Weiterentwicklung}

Nun war es der Rat, der in dem Glauben, mit den belden Richtlinien von 1969 und 1972 seine Pplicht und Schuldigkeit getan zu haben, in Untätigkeit verharrte. Die fortdauernden Rufe der Kommission und des EP nach weiteren Erleichterungen im privaten Reiseverkehr Panden bei den Politikern der Mitglledstaaten erst wieder Gehör, als 1979 die ersten Direktwahlen zum EP ins Haus standen. Um die europäischen Bürger zu den Wahlurnen zu locken, mußten die Regierungen ihrer Bevölkerung beweisen, daß die Gemeinschaft nlcht nur für die Bauern und Bürokraten, sondern auch für den Mann auf der Straße etwas zu bieten hat. Als ein entsprechendes Demonstrationsinstrument bot sich u.a. elne Erhöhung der im Reiseverkehr gewăhrten Frelmengen an: Die USt-BePreiungen wurden zum

- Zusätzlich zu den Steuerbefrelungen im privaten Reiseverkehr wurden später auch Kleinsendungen in einem gewissen Rahmen vom steuerlichen Grenzausgleich bepreit. Eine erste entsprechende Richtlinie Pindet sich in: $A B$ 1974/L 354, S.57f.

- Die von Brüssel später verbreitete Behauptung, die Kommission habe "..den Steuerbefreiungen der Einfuhr durch Privatpersonen im innergemeinschaftlichen Reiseverkehr IMMER beträchtliche Bedeutung beigemessen", entspricht, wie der Autor in zahlreichen Gesprächen Peststellen mußte, nicht der historischen Wahrheit. Zitat entnommen aus: KOM(83) 47 v. 4.2.83, Zlff.1, Hervorhebung durch d.Verf. 
1.Januar 1979 von bis dato 125 Rechnungseinheiten auf nunmehr 180 ECU angehoben.?

Kaum waren die Wahlen vorüber, zelgte sich wieder das alte Bild. Die Kommission und das EP forderten weitere Verbesserungen im innergemeinschaftlichen Reiseverkehr, der Rat stellte sich taub. Wăhrenddessen schmolz unter der allgemeinen Inflation die reale Kaufkraft der in Werteinheiten flxierten Obergrenze fur die USt-Befreiung dahin. Erst die fur 1984 angesetzten zwelten Direktwahlen zum EP waren wieder in der Lage, den Rat für eine neuerliche Entscheidung zu motivieren. ${ }^{8}$ Zum 1 .Jull 1984 wurde die innergemeinschaftllche USt-Befreiung auf 280 ECU angehoben. ${ }^{9}$ Der 1984 in Schwung gekommenen Bewegung hin zu einem Europa der Bürger in Verbindung mit der erfolgrelchen Binnenmarktinitiative der Kommision ist es zu verdanken, daß der Rat sich im Sommer 1985 nochmals aufraffte und elne weitere Erhöhung der Freimengen auf nunmehr 350 ECU beschlo $\beta .{ }^{11}$ Zugleich verpflichteten sich die Mitgliedstaaten, die USt-Befreiung im 2Jahres-Rythmus entsprechend der durchschnittlichen Inflationsrate der Gemeinschaft nach oben anzupassen.

\section{Zur aktuellen Situation}

Blicken wir auf die bisherige Entwicklung zurück, so läßt sich positiv vermerken, daß ein Freibetrag von zur Zeit 350 ECU - er entsprach zum 1.Januar 1986 ca.780 DM - zumindest in der Lage ist, einen Großteil des privaten Relseverkehrs von dem mit einem steuerlichen Grenzausglelch verbundenen Papierkrieg zu entlasten. Zugleich eröffnet er die Möglichkeit, die Kontrollen an den EG-Binnengrenzen aup eine geringe Zahl von Stichproben zu reduzleren. Bedauerlich ist demgegenüber, daß seit 1972 eine substantielle Erhöhung der Freimengen nicht mehr zu beobachten war. Die reale Kaufkraft der 350 ECU in 1986 entspricht mehr oder weniger dem Wert der

7 Vgl. $\mathrm{AB}$ 1978/L 366, S.28f . Vgl. a. Burke (1981), S.11.

B Vl. z.B. AE 11.3.83 u. AE 20.2.84. Eine bereits zum 1.1.83 erfolgte Anhebung der USt-Befrelung auf 210 ECU kann wegen ihrer GeringPügigkeit - sie relchte noch nicht einmal aus, um den seit 1979 aufgetretenen Kaufkraftverlust auszugleichen - außer Acht bleiben. Vgl. AB 1982/L 206, S.35f. Vgl. a. Tugendhat (1983), S.9P.

- Vgl. AB 1984/L 117, S.42f.

10 Auch wenn die Erklärungen der Europäischen Gipfel nicht zu wörtlich genommen werden sollten, so ist doch die folgende Forderung des Treffens von Fontalnebleau im Juli 1984 immerhin beachtenswert: Die Staats- und Reglerungschels ersuchten "..den Rat und die Mitgliedstaaten, sehr rasch Maßnahmen zu prufen, durch die innerhalb kurzer Zelt erreicht werden kann, daß...alle Pollzel- und Zollformalitäten an den innergemelnschaftlichen Grenzen entfallen.."; zitlert in: Kommission (1985), S.3.

11 Vgl. AB $1985 / \mathrm{L} 183$, S.24ff. Der neue Freibetrag ist anzuwenden ab 1.10.85, in den neuen Mitgliedstaaten Spanien und Portugal ab 1.4.86. 
bereits in 1972 gewăhrten 125 Rechnungseinheiten - damals ca.460 DM im Jahr lhrer Einfuhrung.

Als ein negativer Punkt kommt hinzu, daß nach und nach insgesamt drei neuen Mitgliedstaaten das Recht eingerăumt werden mußte, von der gemeinschaftlich festgelegten USt-Befrelung nach unten abzuweichen. Die Dänen waren die ersten, dle schon in ihren Beitrittsverträgen zur EG elne entsprechende Ausnahmegenehmigung erhielten. Zwar wurden auch die in Dänemark zugelassenen Freimengen von Zeit zu Zeit erhöht, das für die anderen Mitgliedstaaten vorgeschriebene Niveau haben sie aber bis heute nicht erreicht. Uber eine zweite Ausnahmeregelung verfügt selt 1979 Irland. Den beiden genannten Staaten ist gemeinsam, daß dle Sätze der von ihnen erhobenen Verbrauchsteuern wesentlich höher sind als in den unmittelbar angrenzenden Nachbarländern Deutschland bzw. Großbritannien. Da belde Staaten darüberhinaus vergleichsweise klein sind, liegen für eine Mehrzahl ihrer Bürger die Transaktionskosten, die mit einer Einkaufsfahrt ins Ausland verbunden sind, relativ niedrig. Um das von den indirekten Steuern erbrachte Aufkommen abzusichern, bestanden daher Dänemark und Irland auch bei der jüngsten Erhöhung der Frelmengen wieder darauf, im privaten Relseverkehr restriktivere Bestimmungen anzuwenden als sle von den anderen Mitgliedstaaten für notwendig gehalten wurden. Den Griechen wurde ein ähnliches Zugeständnis gemacht. Zwar grenzt Griechenland an keinen EG-Staat unmittelbar an. Da aber zahlrelche Griechen Im Ausland arbeiten und von dort der Heimat regelmaßige Besuche abstatten, sieht auch die Athener Reglerung durch hohe Steuerbefrelungen die öffentlichen Kassen bedroht.

In Anbetracht der Tatsache, daß die in 1985 beschlossene Erhöhung der Frelmengen nur mit "Hăngen und Würgen"12 zustandekam, scheint es so, als könne elne substantielle Erhöhung der Freimengen mit dem Zlel, die Beschränkungen im privaten Relseverkehr eines Tages ganz aufzuheben, nur mit einer Verringerung der heute zwischen den Mitgliedstaaten noch bestehenden Steuersatzdifferenzen einhergehen. Im folgenden Abschnitt soll daher untersucht werden, bis $\mathrm{zu}$ welchem Grade eine Annăherung der Steuersätze notwendig ist, und wie die Aussichten dafür beurtellt werden können.

\subsubsection{Ausblick auf das Endziel: die Angleichung der Steuersätze}

\section{Eine Satzangleichung auf 5 Prozentpunkte ist hinreichend}

In den 60er Jahren war man noch mehrheitlich davon ausgegangen, daß die Beseitigung aller Grenzkontrollen eine nahezu vollständige Vereinheit-

12 Persönliches Interview. 
Ilchung der in den Mitgliedstaaten erhobenen Steuersätze zur Voraussetzung haben würde. Während der 70er Jahre setzte sich langsam die AufPassung durch, das gleiche Zlel könne auch schon erreicht werden, wenn die nationalen MWSt-Sătze noch um 2 bis 3 Prozentpunkte voneinander abwichen.13 In ihrem Weißbuch von 1985 wirbt die Kommission nun mit Hinweis au US-amerikanische Erfahrungen ${ }^{14}$ Pür dle These, daß Satzdifferenzen bis zu 5 Prozentpunkten elner Abschafpung der Steuergrenzen nicht entgegenstehen würden. ${ }^{15}$

Ob eine Satzdifferenz von 2 oder 5 oder gar 7 Prozentpunkten hingenommen werden kann, ist, da einigermaßen exakte Wirkungsanalysen vor einer Beseitigung der Grenzkontrollen nicht erhältlich sind, letztendlich eine Glaubensfrage. Gehen wir von einem Konzept strenger Wettbewerbsneutralität aus, so dürfte es nach Abschaffung der Steuergrenzen natürllch überhaupt keine Satzdifferenzen mehr geben. Das sich bel den Gegnern einer Abschaffung der Steuergrenzen großer Bellebtheit erfreuende wettbewerbspolitische Argument sollte man aber nicht überstrapazieren:

- Die Wettbewerbssituation des gesamten Dienstleistungsbereiches wird, da der Grenzubertritt einer Dienstleistung de facto einer physischen Kontrolle ohnehin nicht zugänglich ist ${ }^{16}$, durch die Abschapfung der Steuergrenzen, wie hoch auch immer die Satzdifferenzen sind, überhaupt nicht berührt. Schon heute wird daher bei einer Vielzahl der von Privaten in Anspruch genommenen Dienste - z.B. im Hotel- und Gaststättenbereich - auf einen Grenzausgleich verzichtet. Bei anderen Dienstleistungen ist ein Grenzausgleich vorgesehen, eine Kontrolle kann jedoch nur uber die Buchhaltung des Lieferanten erfolgen. Sind die Satzdifferenzen zum Zeitpunkt der Abschaffung der Steuergrenzen erheblich, so kann die letztere Methode ohne weiteres für eine Ubbergangszelt beibehalten werden. Grenzkontrollen aber sind bel Dienstleistungen weder praktikabel noch nötig.

- Auch die Wettbewerbsbedingungen bei einer Vielzahl von teuren und leicht transportierbaren Gütern werden sich durch einen Verzicht aup die Grenzkontrollen kaum verändern. Theoretisch ist $z$ war bei Textilien, Pelzen, Schmuck, Armbanduhren, Edelmetallen, etc., sofern die Freimengen überschritten werden, ein Grenzausgleich durchzuführen. Faktisch aber überqueren die genannten Güter - der Volksmund spricht

13 Vgl. z.B. Kommission (1980), Zlef.68.

14 In den USA gibt es zwar keine MWSt, dafür aber von Staat zu Staat in unterschiedlicher Höhe erhobene EinzelhandelsuStn.

Vgl. Kommission (1985), Ziff.185.

Wollte man beispielsweise einen Friseurbesuch im Ausland an der Grenze feststellen, so müßte man bel allen Personen die Haarlänge zum Zeitpunkt der Ausreise mit der zum Zeitpunkt der Einreise vergleichen. Ein Kommentar erübrigt sich. 
hier auch von schmuggeln - die EG-Binnengrenzen schon heute oft ohne jeden Grenzausgleich: Man zleht die Sachen einfach an und steckt die Goldmünze in den Schuh. Demgegenüber lassen sich bei all denjenigen Gütern, die im Importland elner Registrierungspflicht unterliegen z.B. Kraftfahrzeugen, Motoryachten, etc. - die zur Vornahme eines Grenzausgleichs notwendigen Kontrollen ubergangsweise, d.h. solange noch größere Satzunterschiede bestehen, ohne weiteres von der Grenze ins Inland verlagern. ${ }^{17}$

- Bei allen Gutern des tägllchen Bedarfs und bel allen kundendienstintensiven Produkten werden sich die Wettbewerbsbedingungen, unterstellen wir eine Satzdifferenz von bis zu 5 Prozentpunkten, allenfalls in den an ein EG-Nachbarland unmittelbar angrenzenden Regionen in nennenswertem Umfang verändern. Einzelne Einkăufe werden von dem hoch- in den nledrigbesteuernden Staat verlagert werden. Reagieren, wie zu erwarten ist, die Händler beiderseits der Grenze mit elner Annäherung threr Verkaupspreise, so kommt es auch zu einer Verschlebung der Gewinne. Da aber hohe MWSt-Sătze in aller Regel mit einer niedrigen Einkommensteuer einhergehen und vice versa, wird das Gefalle bei den Bruttogewinnen auf dem Weg der direkten Besteuerung zumindest tellweise wieder nivelliert werden.

Insgesamt sollte man also denjenigen, die eine weltgehende Angleichung der Steuersätze als Voraussetzung für dle Abschaffung der Steuergrenzen fordern ${ }^{18}$, mit einer gewissen Skepsis gegenübertreten. Das gilt umso mehr, als die Mitglledstaaten bisher, sowelt es um ihre elgenen internen Belange ging, das Ziel Wettbewerbsneutralität auch nicht als sakrosankt angesehen haben. Man denke nur an die Butterschiffe der Deutschen, die z.T. extreme Satzdifferenzierung zwischen Gütern, die um die gleiche Kaufkraft konkurrieren, die zahlrelchen Steuerbefrelungen und Pragwürdigen Sonderregelungen im Rahmen der MwSt u.v.m.

Weit wichtiger als die Wettbewerbsneutralităt ist den nationalen Regierungen melst die Sicherung ihres Steueraufkommens. Wie das aber durch die Abschapfung der Steuergrenzen für Letztverbraucher beeinflußt wird, hängt nicht nur von den Steuersatzdifferenzen, sondern auch von den Wechselkursen und den Wettbewerbsverhältnissen innerhalb der einzelnen Länder ab. Da z.B. die Deutsche Mark relativ stark ist, schöpfen nur wenige Franzosen die mit den Freimengen gegebene Möglichkeit aus, im Nachbarland zu einem um 4,6 Prozentpunkte niedrigeren MWSt-Satz einzukaufen. Umgekehrt

17 Bei allen registrierungspplichtigen Gutern bietet sich darüberhinaus noch eine zweite Lösung an: Der MWSt-Satz wird in allen EG-Ländern vereinheitlicht, jedes Land erhebt jedoch zusätzlich, wie heute schon bel PKWs in Dänemark der Fall, eine Registrlerungsabgabe in beliebiger Höhe.

18 Zu ihnen gehört z.B. das Bonner Finanzministerium; vgl. Bonner Rundschau 24.1.86. 
Pahren viele Deutsche zu elnem Einkaufsbummel in die Niederlande, die, obwohl der MwSt-Satz fur die meisten Güter um 5 Prozentpunkte über dem deutschen liegt, oft billiger anbleten kann. Spürbare Aufkommensverluste dürften, wenn uberhaupt, nur in klelnen Ländern mit sehr hohen Steuersätzen - z.B. Dänemark und Irland - drohen. Das Problem ist, sofern nötig, durch Ausgleichszahlungen an die wenigen betroffenen Staaten durchaus in den Gripf zu bekommen.

Angesichts der zahlrelchen Unwägbarkelten, durch dle die Handelsströme in der EG beeinflußt werden, erscheint es vertretbar und sinnvoll, die Steuergrenzen zunächst bel einer Satzdifferenz von bis zu 5 Prozentpunkten zwischen benachbarten Ländern abzuschalfen und anschlleßend zu sehen, ob gegebenenfalls hier und da eine weitere Angleichung der Sătze um 1 oder 2\% erforderlich 1st. Llegen die Länder, wie z.B. die Bundesrepublik und Spanien oder Großbritannien und Italien, sehr weit auseinander, so kann die Differenz von 5 Prozentpunkten auch ohne welteres uberschritten werden. Gehen wir von diesen Prämissen aus und stellen wir sle der augenblicklichen Höhe der in der EG erhobenen MWSt-Sătze gegenüber, so wird deutlich, daß die Beseitigung der Steuergrenzen im privaten Reiseverkehr zumindest in der Mehrzahl der Mitgliedstaaten keine unüberwindlichen Probleme aufwerfen dürte:

Tabelle E-1

MWSt-Sätze in den Mitgliedstaaten der EG - Stand März 1985 - in \%

\begin{tabular}{lccl}
\hline & reduzierte Sätze & Standardsätze & erhöhte Sätze \\
\hline Luxemburg & 3 u. 6 & 12 & - \\
Belgien & 6 & 17 u. 19 & 25 u. 33 \\
Niederlande & 5 & 19 & (Zusatzst. f. KFZ) $^{2)}$ \\
Deutschland & 7 & 14 & - \\
Frankreich & 5,5 u. & 18,6 & 33,3 \\
Italien & 2 u. 9 & 18 & 38 \\
Spanien & 6 & 12 & 33 \\
Portugal & 8 & 18 & 30 \\
V. Königreich & 0 & 15 & (Zusatzst. f. KFZ) $^{2)}$ \\
Irland & 0 u. 10 & 23 & - \\
Dänemark & - & 22 & (Zusatzsteuern) $^{2)}$ \\
\hline
\end{tabular}

Quelle: Kommission (1985), Ziff. 198.

Anm.: 1. Neben den hier angegebenen Sätzen verwenden viele Mitgliedstaaten noch Sondersätze für eine jeweils sehr beschränkte Zahl von Produkte. Sie werden hier wegen ihrer geringen fiskalischen Bedeutung außer Acht gelassen.

2. Es handelt sich um einphasig erhobene Abgaben, die in ihrer Wirkung einem erhöhten MWSt-Satz gleichzusetzen sind. 
Eine Vergemeinschaftung der nationalen Finanzpolitlk ist nicht erforderlich

Bevor wir auf die in den verschiedenen Mitgliedstaaten notwendigen Anpassungsmaßnahmen zu sprechen kommen, muß noch kurz auf ein Argument grundsätzlicher Art elngegangen werden, das gerne gegen die Abschaffung der Steuergrenzen vorgebracht wird. Gemeint ist die Behauptung, da $\beta$ dle Mitgliedstaaten ihrer Handlungsfreiheit bel den MWSt-Sătzen erst dann beraubt werden dürften, wenn vorher die Entscheidungsbefugnis uber die mit Hilfe der MWSt verfolgten Politiken von der nationalen auf die europälsche Ebene verlagert worden sel. Dem genannten Einwand ist entgegenzuhalten, da $\beta$

- erstens die MWSt für konjunkturelle Zwecke bisher fast nle eingesetzt worden ist und sich auch in Zukunft daran nichts ändern durfte. Der Grund für diese in manchen Ohren wohl uberraschend klingende These Ist einfach einzusehen: Eine in Boom-Zeiten vorgenommene MWSt-Erhöhung schöppt zwar inländische Kaufkraft ab, heizt aber zugleich, wegen der unvermeldllchen Uberwallzung der Steuererhöhung ${ }^{18}$, die in aller Regel ohnehin schon hohe Inflation welter an. Angesichts des beschriebenen Zlelkonfliktes wird es verständlich, warum in den wenigen Fällen, wo die MWSt als konjunkturpolitisches Instrument einmal zum Einsatz kam, die Jewelligen Reglerungen ganz unterschiedliche und sich widersprechende Verhaltensweisen an den Tag legten: wahrend belsplelsweise die Niederländer $1971^{20}$ und die Itallener $1975^{21}$ die Inflation mit elner MWSt-Erhöhung zu bekämpfen versuchten, reaglerten die Briten $1974^{22}$ und die Franzosen $1973^{23}$ und $1977^{24}$ auf dieselbe wirtschaftspolitische Situation mit einer MWSt-Senkung.

- zweltens die MWSt fur die Errelchung vertellungspolitischer Zielsetzungen nur bedingt geeignet ist. Eindeutig abgrenzbare Luxusgüter, die insbesondere von einkommensstarken Bevölkerungsschichten verbraucht werden und daher mit einem erhöhten Steuersatz belastet werden könnten, glbt es in den hochentwickelten Lăndern Westeuropas heute last keine mehr. Die Konsumstrukturen von Haushalten unterschiedlicher

Die MWSt-Erhöhung zieht, da sie mit einer Anhebung des steuerlichen Grenzausgleichs einhergeht, in aller Regel eine entsprechende Erhöhung des Preisniveaus nach sich. Der inflationäre EPfekt kann nur verhindert werden, wenn die Anhebung des Grenzausgleichs durch eine gleichzeitige Abwertung der nationalen währung kompensiert wird. Konjunkturpolitisch motivierte Wechselkursveränderungen jedoch passen spätestens selt Gründung des EWS nicht mehr in die geldpolitische Landschaft Europas.

20 Vgl. z.B. Blick durch die Wirtschaft 25.1.71.

21 Vgl. z.B. FAZ 8.7.74 u. 9.7.74.

22 Vgl. z.B. Times 23.7.74.

23 Vgl. z.B. Le Monde 9.12.72.

24 Vgl. z.B. Le Monde 14.12.76. 
Leistungsfähigkeit divergieren weniger in der Art als vielmehr in der Qualität der verbrauchten Guter und Dienstleistungen. Da das Kriterium Qualität im Rahmen eines Steuergesetzes nicht hinreichend exakt definierbar ist, bleibt der Versuch, Produkte unterschiedlicher Einkommenselastizität mit differenzlerten MWSt-Sătzen zu belasten, zwangsläufig mit zahlreichen Unzulänglichkeiten behaftet. ${ }^{29}$ In mehreren EG-Staaten durchgefuhrte Inzidenzanalysen zeigen denn auch, daß von einer Politik der Satzdifferenzierung nur relativ geringe Progressionswirkungen ausgehen. ${ }^{26}$ Wird also, wie beabsichtigt, die Freiheit der Mitgliedstaaten zur Festlegung differenzierter Steuersatze geringfügig eingeschränkt, so sind die daraus erwachsenden verteilungspolitischen Konsequenzen durchaus tragbar und können sogar bel Bedarf durch kleinere Modiflkationen im Bereich der direkten Abgaben ohne weiteres kompensiert werden..

- drittens die MWSt fur allokationspolitisch motivierte Eingriffe nicht gedacht, sondern als neutrale steuer konzipiert worden ist und in diesem Sinne auch von den Mitgliedstaaten in der uberwlegenden Zahl der Fälle benutzt wird. Ausnahmeregelungen wie beispielsweise die umsatzsteuerliche Berlin-Förderung oder kulturpolitisch motivierte Entlastungen können ganz unabhängig von der Abschaffung der Steuergrenzen beibehalten werden.

- viertens, da die Abschaffung der Steuergrenzen keine Vereinheitlichung der Steuersătze voraussetzt, den Mitgliedstaaten für die Errelchung des fiskalischen Zieles ein hinreichend großer Handlungsspielraum bleibt. Eine Begrenzung der Satzhöhen nach oben ist, sind die Grenzkontrollen erst einmal beseitigt, vollkommen uberflüssig. Jeder EG-Staat sollte auch in Zukunft seine MWSt-Sătze eigenmächtig heraufsetzen können, muß er doch die daraus gegebenenfalls resultierenden Nachteile Abwanderung von Kaufkraft in Nachbarländer - selbst tragen.

Das Polgende zitat bezleht sich zwar aup die Pranzösische TVA Ende der 60er Jahre, vermittelt aber einen guten Eindruck von den mannigfaltigen Inkonsistenzen, mit denen jede mit dipferenzierten Steuersätzen arbeltende MWSt auch heute noch zu kämpfen hat: "Ce poulet qui change de taux selon qu'il est cru ou cuit, ce poivre qui en change suivant qu'il est en grain ou moulu,..., ces harengs Pumés quil sont à $7 \%$ ou à $15 \%$ selon que la Pumée était Prolde ou chaude." Entnommen aus dem Bericht elner vom Pranzösischen Finanzministerium eingesetzten Arbeitsgruppe, zitiert in: Cozian (1971), S.87.

26 Vgl. z.B. KOM(82)855. Zur Situation in Frankreich vgl. a. Les Echos 28.12.82 u. Le Monde 31.12.82, zu der in den Niederlanden Cnossen (1982), S.207Pf. 


\section{Angleichung von Zahl und Anwendungsbereich der Steuersätze}

Nach den Erörterungen grundlegender Natur können wir nun auf die in den einzelnen Mitgliedstaaten notwendigen Anpassungsmaßnahmen $\mathrm{zu}$ sprechen kommen. Ein erstes Problem liegt in der anzustrebenden Zahl der Steuersătze und in deren jeweiligen Anwendungsbereichen begrüdet. Insbesondere stellt sich die Frage, ob die in einer Mehrzahl von EG-Staaten üblichen erhöhten Steuersätze beibehalten werden sollen oder nicht. ${ }^{27}$ Ein Nebeneinander von Ländern mit und ohne erhöhte sătze erscheint, da zwischen der Höhe der sogenannten Luxussteuersătze einerseits und der der Standardsätze andererseits eine erhebliche Lücke klafft, nicht möglich.

Schauen wir uns das Problem ein wenig näher an, dann stellt sich schnell heraus, daß sich ein Kompromiß durchaus finden läßt. Der weitaus bedeutendste Tell des von den erhöhten Steuersätzen erbrachten Aufkommens geht auf die Belastung von Kraftfahrzeugen zurück.20 Es bletet sich daher an, die unterschiedlichen Steuersätze für KFZ, wie oben schon vorgeschlagen, aus fiskalischen Gründen vorübergehend belzubehalten und mit Hilfe der Registrierungspflicht einen Grenzausgleich vorzunehmen. Ein sehr geringer Tell des Steueraufkommens wird durch die Höherbelastung von Pelzen, Schmuck, Kaviar, pornographischen Filmen, etc. erzlelt. Geht man die Sache mit ein wenig Reallsmus an, dann lassen sich nennenswerte Probleme selbst bei Beibehaltung erheblicher Satzdifferenzen nicht festellen. Kaviar kann heute schon im Rahmen der zugelassenen Frelbeträge sogar in großen Mengen importiert werden, Pelze und Schmuck werden, auch wenn es Grenzkontrollen gibt, ohnehin oft geschmuggelt, und der Kinoeintritt unterliegt, wle viele andere Dienstleistungen auch, bereits jetzt keinem Grenzausgleich mehr.

Erhebliche Probleme werfen Luxussteuersătze daher nur bel einer Gruppe von Gütern auf: elektronische Geräte. Eigentlich ist es ein schlechter Witz, daß elektronische Artikel in einer ganzen Relhe von Mitgliedstaaten der hochindustrialisierten EG erhöhten Verbrauchsteuersätzen unterworfen werden. Verteilungspolitisch jedenfalls läßt sich das nicht rechtfertigen. Der Chef der MWSt-Abteilung im Pariser Finanzministerium glbt denn auch gerne zu:

\footnotetext{
"Enfin, à mon sens, le taux majoré ne doit pas consideré comme le taux applicable aux produits de luxe, mais dolt plutôt être celui à appliquer aux bien d'un coût élevé et d'un achat peu fréquent." 29
}

Es erscheint daher, auch im Hinblick auf dle Schaffung elnes aufnahmefähigen Binnenmarktes für die europäischen Zukunftsindustrien, angebracht.

Vgl. z.B. Handelsblatt 17.1.86 u. Suddeutsche Zeltung 31.1.86.

28 In Frankreich z.B. liegt der entsprechende Antell bel ca.60\%.

29 Lebrun (1979), S.115. 
elektronisches Gerät mit dem normalen MWSt-Satz zu besteuern und als Kompensation fur das verlorengegangene Aupkommen den Standardsatz geringfügig anzuheben. Aber zu einer Prinzlplenfrage sollte dieses nicht hochstllisiert werden. Genauso gut wäre natürlich umgekehrt denkbar, daß die wenigen Staaten ohne Luxussätze ihren sudlichen Nachbarn und den Dänen ein wenig Entgegenkommen zelgen und ebenfalls elektronische Artikel höher besteuern. Der dadurch verursachte Anstieg der Verwaltungskosten halt sich durchaus im Rahmen, wenn, wie z.B. in Dänemark schon der Fall, die Sonderbelastung als elnphasige Punktsteuer zusatzlich zur MWSt auf der Produktions- oder der Großhandelsstufe erhoben wird. Festzuhalten blelbt damit: wahrend der Brüsseler Verhandlungen über die Beseltigung der Steuergrenzen werden nur diejenigen in den Luxussteuersätzen eln zentrales Problem sehen, die weiterhin mit allen Mitteln an ihren Grenzkontrollen Pesthalten wollen.

\section{Angleichung der Höhe der Steuersätze in den Gründerstaaten der EG}

Wenden wir uns nun der Hohe der normalen und der reduzierten steuersätze zu und betrachten zunächst die Situation in der ursprünglichen EG der Sechs. In der Mehrzahl der betreffenden Länder llegt der Standardsatz der MWSt zwischen 14\% auf der elnen und 19\% auf der anderen selte. Allein Luxemburg fallt mit elnem Satz von nur $12 \%$ aus dieser Spanne heraus. Dle nledrigen Sătze der Luxemburger Verbrauchsteuern - Luxemburg verdankt einen beträchtlichen Tell seines Aufkommens an indirekten Steuern den Elnkäufen von Ausländern - sind den Nachbarstaaten schon lange eln Dorn Im Auge. Da die Luxemburger an der Spitze derer stehen, die sich mit den Zielen der europäischen Integration identifizieren, und da zugleich sie es sind, dle von einem Wegfall der Grenzkontrollen den größten Vorteil - Luxemburg ist als elnziges Land an allen Seiten von EG-Staaten umgeben - zu erwarten hätten, sollte es für die füf Partnerstaaten aus der Gründerzeit der EG und die Kommission keine große Schwierlgkeit sein, das kleine Fürstentum durch sanften Druck zu einer Anhebung der MWSt aup $14 \%$ oder $15 \%$ zu bewegen.

Eine Anhebung des deutschen MWSt-Satzes von zur Zeit $14 \%$ ist, da die Deutsche Mark auch in năchster Zukunft ihre Stärke innerhalb des EWS belbehalten dürte, nicht zwingend erforderlich. Eine Erhöhung um 1 oder 2 Prozentpunkte wurde aber mit Sicherheit den EG-Nachbarstaaten das Leben leichter machen. Es scheint, als ob Bundesfinanzminister Stoltenberg aus innenpolitischen Gründen - er hofft dabel ganz offensichtlich auf politische Ruckendeckung aus Brüssel - mit einer solchen Maßnahme llebăugelte. ${ }^{30}$ Schon selt Anbeginn der EG erwog Bonn in regelmäßigen Abständen, die allokativ eindeutig verzerrend wirkende Gewerbesteuer eines Tages

30 Vgl. FAZ 15.11.85, Handelsblatt 15.11 .85 u. Welt 15.11.85. 
durch eine MwSt-Erhöhung um ca.4 Prozentpunkte uberflussig zu machen. ${ }^{31}$ Immer wieder wurde die Reform verschoben mit dem Argument, Deutschland solle für eine kunftige Satzangleichung in der EG keine einseltigen Vorleistungen erbringen. Jetzt ist der Tag gekommen, an dem den Worten Taten Polgen müssen. Selbstverstăndlich dürfte von seiten der städte und Gemeinden ein erheblicher widerstand gegen die Abschaffung der Gewerbesteuer zu erwarten sein. Aber ein erster Schritt in die richtige Richtung kann schon getan werden, ohne dle Finanzautonomle der Kommunen überhaupt anzutasten: Die Länder verzichten auf die Gewerbesteuer-Umlage und werden dafür mit elner MWSt-Erhöhung entschädigt; die Hebesätze der Kommunen können entsprechend gesenkt werden.

Für eine Abschaffung der Steuergrenzen ist elne Reduktion des Pranzösischen Standardsatzes von derzelt $18,6 \%$ weder nötig noch, da u.U. eln bel der Senkung des erhöhten Steuersatzes entstehender Aufkommensverlust aufgefangen werden muß, in năchster Zukunft möglich. Mittelfristig aber sollte sich Paris trotzdem auf die guten Vorsätze zurückbesinnen, mit denen Giscard d'Estaing Anfang der 60er Jahre sein Amt als Finanzminister angetreten hat und die er später des öfteren $z u$ bekräftigen pflegte. Gemeint ist die Absicht, Im Rahmen der Umgestaltung des Pranzösischen Steuersystems in eine fiscallté moderne das relative Gewicht der indirekten Besteuerung zu verringern. ${ }^{32}$ Zugegebenermaßen gelang es den Franzosen, die MWSt-Last im Laufe der 70 er Jahre spürbar zu reduzieren. ${ }^{33}$ Welteren Schritten in diese Richtung steht vor allem die in Frankreich weit verbreitete Gleichsetzung von staatlicher Finanzverwaltung mit organisiertem Straßenraub entgegen. Die Hinterzlehung direkter Abgaben ist an der Tagesordnung und stellt in den Augen vieler bestenfalls eln Kavaliersdelikt dar. Eine baldige und durchgrelfende Verbesserung der Steuerkontrolle ist nicht nur aus europälscher Sicht wünschenswert, sondern liegt auch, da sie die Steuergerechtigkelt erhöht, im ureigensten Interesse der Franzosen

31 Vgl. z.B. FAZ 3.4.71 u. Handelsblatt 24.5.71. Vgl. a. Albers (1968), S.143P.

32 Vgl. z.B. NZZ 5.9.70, Le Monde 12.2.72, Figaro 18.2.72, Süddeutsche Zeltung 12.8.72, Le Monde 3.2.76, Times 3.2.76 u. La Vie Francalse 8.11.76.

33 Der Standardsatz wurde in zwel publikumswirksamen Aktionen - jeweils kurz vor Neuwahlen - von 23\% aup 17,6\% gesenkt. Zudem kamen einige Gütergruppen, die bis dato dem Standardsatz unterlagen, in den Genuß des reduzlerten Satzes; vgl. z.B. Handelsblatt 7.9.70. Bel der in 1982 von den Sozlalisten beschlossenen Anhebung des Standardsatzes um 1\% handelte es sich nur um elnen kleinen Rückschritt, da die Maßnahme, bedingt durch die glelchzeltige Verminderung des reduzlerten Satzes, lediglich eln Mehraufkommen von ca.3 Milliarden Franc erbrachte; vgl. z.B. Handelsblatt 5.3.82 u. Figaro 12.5.82. 
selbst.34 Das für Frankreich Gesagte gilt, das sel ergänzt, in ähnlichem Maße auch für Italien und Belgien.

\section{Angleichung der Höhe der Steuersätze in der erweiterten EG}

Die beiden zuletzt zur EG gestoßenen Länder Spanien und Portugal passen sich in die steuerpolitische Struktur der alten Sechsergemeinschaft bestens ein. Alleine der spanische Standardsatz von $12 \%$ liegt im Vergleich zu den beiden Nachbarländern - $18 \%$ in Portugal und 18,6\% in Frankreich - zu niedrig. Das spanische Problem dürfte sich aber in kurzer zeit von selbst beheben. Die Regierung mußte sich bel der Einführung der MWSt, wle andere Lånder in derglelchen situation auch, mit relativ niedrigen steuersätzen begnügen, um den durch die Steuerreform ausgelösten Preisanstieg in Grenzen zu halten. Haben sich die Spanier erst einmal an die MWSt gewöhnt, dann wird es Madrid bel der nächsten im Budget auftretenden Finanzlücke sicherlich nicht versăumen, aup das durch die MWSt geschaffene Aufkommenspotential zurückzugreifen und die Sätze schrittweíse zu erhöhen.

Es verbleiben die drei Staaten der ersten EG-Erweiterung. Allesamt handelt es sich, sofern es um die MWSt-Sătze geht, um Problemkandidaten. Großbritannien verwendet $z$ war elnen für die Gemeinschaft akzeptablen Standardsatz von $15 \%$, aber mit $0 \%$ einen viel zu geringen reduzierten Satz. Elne Steuersatzdifferenz von $6 \%$ gegenüber Belgien und $7 \%$ gegenüber Frankreich dürfte, da die Transaktionskosten für die Uberquerung des Kanals relativ hoch sind, zumindest in einer Ubergangszeit hingenommen werden können. Mittelfristig aber und spätestens, wenn aus den Tunnelplänen elnmal Realltăt werden sollte, muß für die Null-Sătze eine Lösung gefunden werden. Da die Belgler und Franzosen beim reduzierten Satz kaum mehr Spielraum nach unten haben und auch in den Niederlanden alle Zeichen auf eine weitere Erhöhung des derzeit bel $5 \%$ liegenden Satzes hindeuten, kann elne gemeinschaftskonforme Lösung nur heißen: die schrittweise vorgenommene Beseitlgung der Null-Satze. Das liegt auch im Interesse Großbritanniens. Denn ohne eine Anderung bel den Null-Sätzen ist das Aufkommenspotential der britischen VAT ausgeschöpft, da eine isollerte Erhöhung des Standardsatzes die an der Schnittstelle zwischen normalem und reduziertem Steuersatz auftretenden Abgrenzungs- und Wettbewerbsprobleme weiter verschärfen wurde. ${ }^{35}$ Die konservative Regierung Thatcher hat denn auch im Rahmen

34 Wie in Frankreich - vgl. z.B. Splegel 24.9.73 - so gehört auch in Italien - vgl. z.B. Handelsblatt 3.4.84 u. Welt 29.6.84 - die Kamplansage an die Steuerhinterzlehung zum standardrepertoire jeder neuen Regierung. An Taten hat es bisher aber, nicht zuletzt wegen des Widerstandes mächtiger Interessengruppen, gemangelt. Ein beständiger Druck aus Brüssel könnte hler also durchaus helfen.

35 Mit einer Satzdifferenz von 15 Prozentpunkten ist, wie die niederlandische Erfahrung deutlich gezeigt hat, eine kritische Grenze erreicht. Die Niederlande begannen in $1969 \mathrm{mit}$ MWSt-Sătzen von 4\% und 12\%. Da der Widerstand der Gewerkschaften lange Zeit eine Anderung des reduzierten Satzes nicht zuließ - vgl. z.B. Nachrichten für 
ihrer Bemuhungen zur Umstrukturierung des Steuersystems von direkten zu indirekten Abgaben wiederholt versucht, den Anwendungsbereich des 15prozentigen Standardsatzes zu Lasten des Null-Satzes auszudehnen. Die von einer plötzlichen Mehrbelastung von $15 \%$ bedrohten Produzenten und Händler waren, da es sich 1.d.R. um überschaubare und homogene Gruppen handelte, regelmäßig in der Lage, in der Bevölkerung whe auch Im Parlament einen erheblichen Widerstand gegen die Regierungspläne zu mobilisieren. ${ }^{36}$ Manche der Vorhaben, wie zum Beispiel die vor dem Budget 1985 diskutlerte Mehrwertbesteuerung von Büchern und Zeitschriften, mußten daher von London wieder ganz Pallengelassen werden. ${ }^{37}$ Hat die britische Regierung, worauf jüngste Bemerkungen lhres Schatzkanzlers Lawson hindeuten ${ }^{38}$, wirklich die Absicht, die Null-Sätze langfristig zu beseltigen, so sollte sie sich daher lieber eine neue Strategie überlegen: die Herausnahme größerer Gütergruppen aus dem Anwendungsbereich des Null-Satzes und ihre Belastung mit einem neu einzuführenden reduzlerten Satz, der in einem ersten Schritt durchaus sehr niedrig liegen kann. Bel der großen Mehrheit der britischen Wirtschaft würde eine solche Maßnahme auf Sympathle stoßen. Zwar mußten sich bisher Verbände wie der CBI mit Rücksicht aup die von der MWSt-Last befreiten Unternehmen für eine Aufrechterhaltung des Status quo aussprechen. Ergreift die Reglerung aber erst einmal die Initiative, dann wird sich der CBI, nunmehr in Ubereinstimmung mit den Interessen der mehrheltlich mit $15 \%$ belasteten Unternehmen, einer $\mathrm{Ab}-$

den Außenhandel 7.2.73 -, wurde lediglich der Standardsatz nach und nach auf 19\% erhöht. Gleichzeltig stieg die Zahl der Erlasse und Gerichtsurtelle, die die Abgrenzung zwischen den mit unterschiedlichen Steuersätzen belasteten Gütergruppen zum Gegenstand haben, sprunghaft an. Eine merkliche Linderung der Probleme ist, das stellten zwel 1981 angefertigte Berichte deutlich heraus, nur von einer Verminderung der $z w i s c h e n$ den beiden Sätzen bestehenden Differenz zu erwarten. Vgl. z.B. Cnossen (1982), S.2061.

36 Ein instruktives Beisplel liefert die im Budget 1984 vorgesehene Mehrwertbesteuerung von warmem "take-away food". Die im Parlament und in der Presse wochenlang gefuhrte, erhitzte Debatte drängte dem außenstehenden Beobachter den Schluß aup, dle MWSt aup "fish and chips" würde die britische Nation in den Hungertod treiben; vgl. z.B. FT 11.4.84 u. 27.4.84, Times 1.5.84. Dabel wurde gänzlich vergessen, daß der Aufschwung des "take-away" nicht zuletzt durch die in 1973 eingefuhrte MWSt für Restaurants ausgelöst wurde; vgl. z.B. Times 29.6.74.

37 Vgl. z.B. FAZ 14.11.84, Guardian 18.1.85 u. Newsweek 25.2.85. Bel dem Widerstand gegen die Regierungspläne wurde wohlweislich nicht erwăhnt, daß zur Zeit nicht nur die Werke Sheakespears in den Genuß eines Null-Satzes kommen, sondern, da kulturpolitisch förderungswürdige Veröffentlichungen im MWSt-Gesetz nicht elndeutig definierbar sind, auch der Playboy.

39 Anfang 1984 machte Lawson, zuerst in einem Intervlew und dann Im Parlament, die vielbeachtete Bemerkung, daß, im Gegensatz zur früheren Regierung Heath, die derzeitige Regierung sich nicht verpplichtet habe, Lebensmittel von der MWSt auszunehmen; vgl. FT 21.3.84 u. 6.4.84. 
schaffung der Null-Sătze nicht entgegenstellen. Heftiger widerstand ist alleine in der Bevolkerung und von seiten der Gewerkschaften zu erwarten: "..it would be a bold government indeed which flew in the face of a tradition of 'free food' going back to over a hundred years,.."39 Aber auch sie müssen eines Tages begreifen, daß sich die Konsumstrukturen selt dem 19.Jahrhundert grundlegend verăndert haben und daß daher die undifferenzlert gewăhrten Null-Sätze an vertellungspolitlschem Wert stark eingebü $\mathrm{t}$ haben.

Das Problem der Null-Sätze stellt sich in vergleichbarem Maße in der Republik Irland. Auf den ersten Blick könnte man hler auf dle Idee kommen, die belden reduzlerten satze von $0 \%$ und $10 \%$ in einer aufkommensneutralen Reform zu elnem Steuersatz mittlerer Höhe zusammenzulegen. Dann aber würde die Differenz zwischen dem einheitlichen, reduzlerten Satz auf der einen und dem Standardsatz von $23 \%$ auf der anderen Selte erschreckend groß werden. Sowohl im Hinblick auf die reduzierten sätze als auch mit Rücksicht auf den vom Nachbarn Großbritannien erhobenen normalen Steuersatz erschiene es also wünschenswert, den Irländischen Standardsatz zu senken. Das aber dürfte in nächster Zukunft kaum mögllch seln. Für das bel der MWSt verlorengegangene Aufkommen kann Irland auf absehbare Zeit weder bei den direkten Steuern - wegen der großen Bedeutung der Landwirtschaft und der steuerlichen Förderung ausiändischer Direktinvestitionen - noch bel den Akzisen - ihre Sătze llegen im EG-Vergleich ohnehin schon an der Spltze - einen Ausgleich finden.

Auch im Falle Dänemarks ist eine EG-konforme Anpassung der MWSt-Sătze mit ganz erheblichen Problemen verbunden. Zwar könnte elne Beibehaltung des dänischen Standardsatzes von $22 \%$, Palls die Deutschen den thren aup 16-17\% anheben, unter Umstănden toleriert werden. Die Dänen kennen bisher jedoch noch keinen reduzierten Steuersatz. Eine Senkung des MWStSatzes Pur Grundbedarisgater kann, da die dänischen Akzlsen zusammen mit den irischen innerhalb der EG schon zu den höchsten zählen, nur über eine Erhöhung der direkten Steuern Pinanzlert werde.40 Eine derartige Maßnahme aber stellt, wegen der Verminderung des steuerlichen Grenzausgleichs bel konstantem Belastungsniveau, eine zusätzliche Bedrohung fur die unter chronischer Schwäche leldende dänische Handelsbilanz dar. Sie müßte daher,

39 Prest (1980), S.43.

40 Die extrem hohen Sătze der dänischen Verbrauchsteuern können weder, wie in Sudeuropa, mit elner laxen Steuermoral noch, wie in Irland, mit elnem geringen pro-Kopp Einkommen erklärt werden. Ihre Ursache ist denn auch vielmehr in der chronisch defizitären Handelsbilanz Dänemarks zu sehen. Mit Rủcksicht auf die desöfteren unter Abwertungsdruck stehende dänische Krone wurde seit Ende der 60er Jahre, Immer wenn eln Budgetdefizit zu decken war, die Erhöhung der indirekten Steuern tendenzlell gegenüber einer Anhebung der direkten Abgaben preferiert; vgl. z.B. FAZ 10.5.74, Handelsblatt 10.5.74 u. 1.8.77, Stuttgarter Zeitung 2.9.77 u. NZZ 8.5.80. 
eine politisch äußerst brisante Entscheldung, notwendigerweise von einer erheblichen Abwertung der dänischen Krone begleitet werden.

\section{Zur Harmonisierung der spezlellen Verbrauchsteuern}

Bevor wir den vorliegenden Abschnitt abschließen, soll noch kurz auf die bel den speziellen Verbrauchsteuern sich stellenden Probleme eingegangen werden. Auch ihre Sätze mùssen, bevor aup die Grenzkontrollen im privaten Relseverkehr ganz verzichtet werden kann, einander angeglichen werden. Oft ist die Behauptung zu hören, daß, Im Gegensatz zur MWSt, die bel den Akzisen erhobenen Steuersătze sogar nahezu vollstăndig vereinheitlicht werden müßten. Dabei wird wie folgt argumentlert: Wăhrend bel der MWSt alle Produktions- und Vertellerstufen der Steuerpflicht unterliegen, werden die speziellen Verbrauchsteuern als einphasige Abgaben in aller Regel belm Hersteller erhoben; der gesamte Handel pallt damit unter die Kategorie der Nicht-Steuerpflichtigen; da, wegen des größeren Umsatzvolumens, die Im Handel anfallenden Transaktionskosten wesentlich geringer sind als die der privaten Haushalte, kommt es schon bel marginalen Steuersatzdifferenzen $\mathrm{zu}$ wettbewerbs- und aufkommensverzerrenden Verlagerungen von Elnkăufen in andere EG-Länder. ${ }^{41}$

Der hier skizzlerte Effekt läßt sich durch ein sehr elnfaches Verfahren vermelden: Das in einigen EG-Staaten tellweise schon gebräuchliche Bandarolen-System wird auf alle Güter ausgedehnt, die speziellen Verbrauchsteuern unterliegen; ein Wiederverkaup der betreffenden Guter 1st, sobald die Waren den Bereich des Zollagers verlassen haben, alleine in dem Land gestattet, dessen Bandarolen aup den Gütern angebracht sind; die Aupdeckung eines Verstoßes gegen diese Beschränkung sollte, da die Bandarolen leicht erkenntlich sind, unschwer möglich seln; lediglich den als Letztverbrauchern auftretenden privaten Haushalten bleibt damit, wie schon bel der MWSt, die Mögllchkeit, eln zwischen den EG-Staaten existlerendes Steuersatzgefălle durch Einkäufe im Ausland auszunutzen. ${ }^{42}$

Wie bel der MWSt, so können also auch bel den Akzisen die Steuersătze zwischen benachbarten Staaten ohne welteres um mehrere Prozentpunkte

41 Vgl. z.B. Kommission (1985), Ziff.182.

42 Zu dem gleichen Ergebnis wie ein Bandarolen-System fuhrt die Polgende Verfahrensweise: Dle bel den Herstellern erhobenen Verbrauchsteuersätze werden in allen EG-Staaten vereinheltlicht; die Mitgliedstaaten haben aber dle Freihelt, für verbrauchsteuerpflichtige Waren auf der Einzelhandelsstufe eine Zusatzsteuer zu erheben, deren Sătze von Land zu Land innerhalb gewisser Grenzen varileren können; vgl. ahnl. Prest (1983), S.82. Dle Einführung einer Zusatzsteuer ist mit einem eindeutig höheren Verwaltungsaupwand verbunden als das Anbringen von Bandarolen. Sle sollte daher nur dort erwogen werden, wo, wie im Fall von Mineralölprodukten, Bandarolen nicht verwandt werden konnen oder wo, wle z.B. in Großbritannien, der Verkaup bestimmter verbrauchsteuerpflichtiger Waren ohnehin nur von lizensierten Geschäften vorgenommen werden darf. 
voneinander abweichen, ohne daß merkliche Kaufkraftverlagerungen $z u$ befürchten wären. Bei Mineralölprodukten sind, da Transport und Lagerung relativ aufwendig ist, größere Satzdifferenzen akzeptabel als etwa bei Tabak oder Spirituosen. Dle Annäherung der Verbrauchsteuersătze in der EG bringt, abgesehen von den schon erwähnten Ausnahmefällen Irland und Dänemark, keine unüberwindlichen budgetären Schwlerigkeiten mit sich. Im Gegentell könnten in elner ganzen Reihe von Ländern - z.B. In Großbritannien, Frankreich und Itallen - wünschenswerte Erhöhungen bzw. Verminderungen des MWSt-Aufkommens mit einer entgegengerichteten Veränderung der Akzisensätze Pinanziell aufgefangen werden. ${ }^{43}$

Die bei der Harmonisierung der Akzisen auptretenden Probleme liegen, wenn wir von den beiden Sonderfăllen Irland und Dänemark einmal absehen, denn auch weniger in der durchschnittlichen Höhe der Steuersätze als vielmehr in deren von Land zu Land unterschiedlichen Struktur begründet. Im Laufe einer langen Entwicklungsgeschichte haben sich in den verschiedenen Mitgliedstaaten die Verbrauchsteuerstrukturen einerseits und die Produktionsund Konsumstrukturen andererseits elnander angepaßt mit dem Ergebnis, daß heute im Inland hergestellte Waren tendenziell gegenüber den importierten Konkurrenzprodukten steuerlich begünstigt werden. In einer Serie langwleriger Gerichtsverfahren ist es der Kommission berelts gelungen, einige der steuerlichen Diskriminierungen aus dem Weg zu räumen.44 Gegen eine weitere Angleichung der Steuerstrukturen bringen die Mitgliedstaaten insbesondere den Einwand vor, die Importwaren hatten in ihren jewelligen Ländern den Charakter eines Luxusgutes und sollten daher aus verteilungspolitischen Gründen einer erhöhten Abgabe unterworfen werden. ${ }^{49}$ Das genannte Argument verliert, da sich die Verbrauchsgewohnheiten der europäischen Bürger elnander zunehmend angleichen, von Tag zu Tag an Relevanz. Auch die Unternehmer in der EG haben die Zelchen der Zelt erkannt und passen ihr Verhalten, soweit ihnen dies aufgrund der natürlichen Produktionsbedingungen möglich ist, den sich verändernden Verbraucherwünschen an. So investieren beispielsweise die britischen Bierbrauer in den Import und Vertrieb des Konkurrenzproduktes Wein, wăhrend umgekehrt die Spirituosenproduzenten und -händler Südeuropas versuchen, an den anstelgenden Whiskyimporten in ihre Länder mitzuverdienen. Es ist nun an den nationalen Reglerungen, die Konsequenzen aus der beschrlebenen Entwicklung zu ziehen und den Weg hin zu einem Gemeinsamen Markt für Tabakerzeugnisse und alkoholische Getränke nicht länger durch unterschiedliche Verbrauchsteuerstrukturen $\mathrm{zu}$ hemmen.

43 Ein Uberblick uber die Sătze der wichtigsten in der EG erhobenen Akzisen - Stand März 1985 - Pindet sich in Kommission (1985), Ziff.201. Vgl. z.B. Easson (1981a) u. Easson (1984).

45 Neben dem verteilungspolitischen Argument spielen auch administrative, gesundheits- und agrarpolitische Einwände elne Rolle; vgl. z.B. Kommission (1980), ZifP.72ff. 


\subsection{Zur Abschaffung der Steuergrenzen für steuerpplichtige Unternehmer}

Während die Abschaffung der Steuergrenzen für (nicht-steuerpflichtige) Letztverbraucher eine gewisse Annäherung der in den einzelnen Ländern erhobenen Steuersätze voraussetzt, erfordert die Abschaffung der Steuergrenzen für (steuerpflichtige) Unternehmer elne Vernetzung der nationalen Finanzverwaltungen. Wie das erste so kann auch das zweite Teilziel in mehreren, aufeinander aupbauenden Schritten einer Verwirklichung nähergebracht werden: Dle im gewerblichen Handel durchgeführten Grenzkontrollen werden zunehmend reduzlert mit dem Ziel, auf die Innergemeinschaftlichen Schlagbăume elnes Tages ganz zu verzichten. Als erster Schritt in diese Richtung war die im Juli 1982 von der Kommission vorgeschlagene 14.UStRichtlinie konziplert.46 Der Vorschlag muß, da der Ministerrat trotz wiederholter Beratungen die zahlreichen Meinungsverschiedenheiten nicht auszuräumen vermochte, ${ }^{47}$ als vorläuflg gescheitert betrachtet werden. Auch die Kommission scheint mittlerweile das Interesse an einer Zwischenlösung der Vorschlag für elne 14.USt-Richtllnie wird im Weißbuch von 1985 nur noch kurz erwähnt ${ }^{48}$ - weitgehend verloren zu haben. Brüssel möchte das Endzlel - Beseltigung aller Grenzkontrollen durch, wie das Weißbuch vorschlägt, Einführung eines clearing's - möglichst bald und in möglichst einem Schritt erreichen.

Obwohl es sich also bel dem Entwurf für eine 14.USt-Richtlinie nurmehr um elnen "cadavre"so handelt, Ist es aus zwel Gründen notwendig, sich näher mit ihm auseinanderzusetzen. Erstens läßt sich heute noch nicht absehen, ob die Finanzminister der Gemeinschaft den direkten Ubergang zu einem clearing und den damit verbundenen Sprung ins kalte Wasser wagen. Bleibt die erhopfte Einigung aus, dann wird die 14.USt-Richtlinie, wenn auch gegebenenfalls in modifizierter Form, wieder an Aktualltăt gewinnen. Zweitens erlaubt die wechselvolle Geschichte der 14.USt-Richtlinie einen nahezu einmaligen Einblick in die selbst für Insider oft undurchsichtigen Strukturen europäischer willensbildungsprozesse. Am Beispiel der Ablehnung der 14.USt-Richtlinie soll verdeutlicht werden, woran der Fortgang der europäischen Integration im allgemeinen und die Entwicklung des gemeinsamen Binnenmarktes im besonderen so oft scheitern: Fragwürdige Partialinteressen, institutionelle Zufälligkeiten und mangelnder Sachverstand gehen eine fatale Koaltion ein, die jeden Fortschritt blockiert.

\footnotetext{
46 Eine Kommentlerung und Kritik des Richtlinienentwurfs findet sich bei Simons (1981) u. Simons (1986).

47 Vgl. z.B. AE 2.2.83, 2.3.83, 18.3.83, 11.4.83, 28.5.83, 8.3.84 u. 10.3.84.

48 Vgl. Kommission (1985), Ziff.171.

4 Vgl. Kommission (1985), Ziff.172.

so Persönliches Interview.
} 


\subsubsection{Der Rückblick auf eine gescheiterte $\mathrm{Zwischenlösung:}$ der Vorschlag für eine 14.USt-Richtlinie}

\section{Argumente pro und contra}

Bevor wir auf die Geschichte des Vorschlages für eine 14.USt-Richtlinie im einzelnen zu sprechen kommen, sollen zunächst die drel wichtigsten Einwände analysiert werden, die dem Kommissionsentwurf von seiten verschiedener Mitgliedstaaten entgegengehalten wurden. Stichhaltig ist, wie im folgenden nachgewiesen werden soll, keines der Argumente.

1. Ein wesentliches Element des Entwurfs einer 14.USt-Richtlinie - ihr Inhalt wurde bereits weiter oben dargestellt51 - ist der Vorschlag, im innergemelnschaftlichen Handel zwlschen steuerpflichtigen Unternehmern auf die Erhebung der EinfuhruSt zu verzichten. Großer Bellebtheit erfreut sich die Behauptung, eine solche Maßnahme würde inländisch produzierte Waren gegenuber Importprodukten steuerlich benachteiligen. Die gängige Argumentation lautet dabel wie folgt: Bezieht ein Händler seine Waren von elnem inländischen Hersteller, dann wird er mit der darauf zu entrichtenden MWSt - sie wird in der Rechnung dem Nettopreis zugeschlagen - unmittelbar belastet; die gezahlte MWSt erhält er erst im Anschluß an seine nächste UStErklärung und damit 1.d.R. einige Wochen später vom Fiskus zurückerstattet. Bezieht der Händler demgegenüber die gleichen Waren aus dem EGAusland, dann braucht er, sofern eine ElnfuhruSt nicht erhoben wird, keinerlei MWSt vorzustrecken; Importe sind also im Vergleich zum inländischen Bezug der Waren mit einem geldwerten cash-flow Vorteil verbunden.

Das skizzlerte Argument wurde von seiten der Wirtschaft und insbesondere von den Unternehmen vorgebracht, die sich einer harten Konkurrenz aus anderen EG-Lăndern ausgesetzt Pühlten. Es ist bestechend einfach und daher in der Lage, Politiker von seiner Richtigkeit $\mathrm{zu}$ überzeugen. Es hat nur einen Haken: Die Argumentation stellt die Tatsachen auf den Kopf.

Um das zu bewelsen, müssen wir uns das aup inländische Geschäfte angewandte Besteuerungsverfahren ein wenlg genauer ansehen. Es ist richtig, daß eln Käufer inländischer Produkte vorübergehend, d.h. bis er den VSA geltend machen kann, mit MWSt belastet wird. Er erleidet dadurch einen Finanzlerungsnachtell. Gleichzeitig aber erhält der Lieferant, da er die vom Kunden gezahlte MWSt bis im Anschluß an selne năchste USt-Erklärung behalten darf, elnen Finanzierungsvorteil. Belde Effekte heben sich, da alle Unternehmen eines Landes thre USt-Erklärungen an genau demgleichen Tag abgeben und abrechnen müssen ${ }^{02}$, gegenseitig exakt auf. Der Fiskus kommt,

31 Vgl. dle Darstellung in Kap.E.1., insbesondere Schaubild E-5.

02 Davon abweichende Sonderregelungen gibt es 1.d.R. Pür Kleinunternehmen. Das ändert jedoch nichts an der Allgemeingultigkelt der oben gemachten Aussagen, da die Kleinunternehmen, falls sie sich durch die 
solange die gehandelten Guter in der Sphäre der steuerpflichtigen Unternehmer verbleiben, nie und auch nicht vorubergehend in den Genuß elner MwSt-Einnahme: Der MWSt-Abfuhrung des Lleferanten steht immer der in gleicher Höhe und am gleichen Tag vorgenommene VSA des Kunden gegenüber. Geschäfte $z$ wischen steuerpplichtigen Unternehmern werden von der MWSt nur insolern berührt, als die Besteuerungstechnik einen zeitweiligen cash-flow Transfer vom Kunden an den Lieferanten erzwingt. Den aber können die beiden jewelligen Geschäftspartner bel der Aushandlung ihres Kaufvertrages berücksichtigen und damit neutralisieren. So steht ihnen beisplelsweise frel, für den die MWSt betreffenden Teil der Rechnungssumme als Zahlungsziel den Tag festzulegen, an dem der Lieferant die MWSt abführen muß bzw. der Kunde seinen VSA geltend machen kann. Oft dürfte es jedoch elnfacher sein, den vom Staat erzwungenen cash-flow-Transfer in die Gestaltung einer anderen Vertragsvariablen - z.B. Preis, Zahlungsziel für den Gesamtbetrag, Menge, Qualität, etc. - einfließen zu lassen. Welches Verfahren gewählt wird, ist die alleinige Entscheidung der beiden $\mathrm{Ge}-$ schäptspartner und hängt letztendlich von deren Präferenzen ab. Für uns Ist nur eines wichtig: Die zwischen inländischen Unternehmern gehandelten Güter sind zu keinem Zeitpunkt mit an den Fiskus abgeführter MWSt belastet.

Wollen wir eine wettbewerbsneutrale Besteuerung sicherstellen, dann muß dieselbe Bedingung auch für importierte Waren gelten. Dle geforderte Gleichbehandlung wird von der 14.USt-Richtlinie sichergestellt: Das Exportland erhebt von vornherein keine MWSt; Im Importland wird dle Zahlung der MWSt bis zu dem Tag aufgeschoben, an dem der Importeur den VSA geltend machen kann; auf die Zahlung der EinfuhruSt wird also de facto verzichtet mit dem Ergebnis, daß das Importgut zu keinem Zeitpunkt mit MWSt belastet ist. Alleine das in der 14.USt-Richtlinie vorgesehene Verfahren kann daher als wettbewerbsneutral bezeichnt werden.

Demgegenüber führt die derzeit in der Mehrhelt der Mitglledstaaten angewandte Methode der Importbesteuerung - die EinfuhrUSt wird zunächst erhoben und erst später, d.h. nach der năchsten USt-Erklärung des Importeurs, als Vorsteuer zurückerstattet - zu elner vorübergehenden steuerllchen Belastung der Importwaren. Die dem Importeur abverlangte EinfuhruSt läßt sich als ein zinsloses Darlehen an den nationalen Fiskus interpretieren. Die damit verbundenen Finanzlerungskosten diskriminieren Importwaren gegenüber glelchartigen Inlandsprodukten und stellen daher einen eindeutigen Verstoß gegen Art.95 des EWG-Vertrages dar. ${ }^{53}$

Sonderregelung finanziell benachtelligt fühlen, für das normale $\mathrm{Be}-$ steuerungsverfahren optleren können.

Am Rande sel daraup hingewiesen, daß der EuGH bereits in einem ahnlich gelagerten Fall - es ging um die Einfuhr von Spirituosen nach Irland, Urtell v. 27.2 .80 in der RS 55/79 - ausdrulcklich festgelegt hat, daß sich die effektive Belastung elner Importware nicht nur aus dem nominalen Steuersatz ergebe, sondern daß darüberhinaus auch der 
2. Während also der wettbewerbspolitische Einwand gegen den Vorschlag einer 14.USt-Rlchtlinie als ökonomisch falsch zurückgewiesen werden muß, läßt sich einem zweiten und insbesondere bei den Finanzministern der Gemeinschaft bellebten Argument eine gewisse Berechtigung nicht absprechen. Den Finanzministern geht es, wie meist, wenn sie sich zu Wort melden, um die Sicherung ihres Steueraupkommens. Alle diejenigen Staaten, die die EinfuhruSt zunächst erheben und sle erst später wleder zurückerstatten (bzw. sie zur Anrechnung auf die MWSt-Schuld zulassen), würden durch die Annahme der 14.USt-Richtlinie des oben bereits erwähnten zinslosen Darlehens beraubt. Die daraus für dle Staatskasse erwachsenden budgetären Konsequenzen bleiben jedoch in einem engen Rahmen, und zwar aus zwei Grunden. Zum einen führt die Implementierung der 14.USt-Richtlinie nicht $\mathrm{zu}$ einer dauernden Verminderung des Steueraupkommens, sondern nur zu einem einmaligen Steuerausfall in dem Jahr, in dem der Fiskus besagtes zinsloses Darlehen an die Gläubiger, d.h. die Importeure, zurückzahlen muß. Zum anderen kann der Steuerausfall, Palls er in einem Haushaltsjahr nicht zu verkraften sein sollte, über einen beliebig langen Zeitraum verteilt werden. Als technisches Hilfsmittel kommen hierfür beisplelsweise von den Importeuren beim Staat zinslos zu hinterlegende Sicherheitsleistungen ${ }^{34}$ in Betracht: Ihre Höhe bemißt sich am Volumen der im Vorjahr oder Vormonat getätigten Importe; sle werden von Jahr zu Jahr pauschal herabgesetzt, bis sie eines Tages ganz verschwinden. ${ }^{55}$

3. Die zwel bisher diskutierten Einwände beziehen sich belde aup die im Vorschlag einer 14.USt-Richtlinie enthaltene Anderung der Zahlungsströme. Aber der Kommissionsentwurf bringt noch eine weitere Neuerung mit sich: Ein Großteil der bel der Besteuerung von Importwaren anfallenden Verwaltungsarbeit soll von den Grenzstationen ins Inland verlagert werden. Hier setzt ein dritter Einwand an, der insbesondere von den Verwaltungsexperten der betroffenen Bürokratien vorgebracht wird. Die Implementierung der 14.USt-Richtlinie würde, so die Argumentation der Beamten, entweder die Verwaltungskosten sprunghaft in die Höhe treiben oder aber, bel gleichblelbendem Personalbestand, die Gefahr der Steuerhinterziehung erheblich vergrößern. ${ }^{36}$

Zeitpunkt der Abführung der Steuer bzw. die damit verbundenen Finanzierungskosten in die Analyse miteinbezogen werden müßten.

o4 Der gewăhlte Name ist letztendlich unwichtig, da er ohnehin nur zur Verschleierung der Tatsache dient, daß es sich hierbei um ein Zwangsdarlehen handelt.

so Die Kommission hat elnen entsprechenden Anderungsvorschlag zur 14.USt-Richtlinie bereits vorgelegt; das Papler sieht vor, die budgetären Ausfälle uber einen Zeitraum von 5 Jahren zu strecken; vgl. z.B. AE 11.7.84. Es sei bemerkt, daß der Vorschlag, aus den unter Pkt.1 angefuhrten Grunden, Im Widerspruch zu Art.95 steht!

s6 Die Franzosen sprechen in diesem Zusammenhang von einem "bouleversement administrative considerable" - Persönliches Interview - und 
Die von den Verwaltungsapparaten selbst gemachten Angaben sind für einen Außenstehenden nur schwer überprüfbar. Sle müßten also unwidersprochen hingenommen werden, gäbe es da nicht gewisse Widersprüche, die Zweifel an der Richtigkeit der obigen Behauptung aufkommen lassen. Die Behörden der Länder nämlich, die, wie die Niederlande und Großbritannien, das in der 14.USt-Richtlinie anvisierte Verfahren schon jahrelang in der Praxis erprobt haben, sind damit vollauf zufrieden. Ja, sie behaupten sogar, das von der Kommission vorgeschlagene Verfahren sei wesentlich besser und kostengünstiger als das herkömmliche.97 Wie kommt es, so müssen wir uns fragen, daß die Kostenschätzungen der deutschen, Pranzösischen oder italienischen Beamten sich derart gravierend von denen ihrer niederländischen und britischen Kollegen unterscheiden?

Objektive Gründe, die das weite Auseinanderklaffen der in den einzelnen Ländern entstehenden Verwaltungskosten hinreichend erklären könnten, gibt es kelne. Dafür aber gibt es allen Anlaß fur die Vermutung, daß die Beamten einiger Mitgliedstaaten aus einem subjektiven Eigeninteresse heraus, ob bewußt oder unbewußt, sei dahingestellt, die mit der 14.USt-Richtlinie verbundenen Verwaltungskosten systematisch überschätzen. Greifen wir uns das deutsche Beisplel heraus. Die Verwaltung der deutschen MwSt liegt in den Handen zweler Organisationen, die strikt voneinander getrennt sind. wahrend die Zollverwaltung (eine Bundesbehörde) die EinfuhruSt erhebt, fallen alle anderen administrativen Aufgaben, die im Zusammenhang mit der MwSt zu erledigen sind, in den Zuständigkeitsberelch der Finanzverwaltung (sie untersteht den Ländern). Die Zollverwaltung lehnte den Vorschlag elner 14.USt-Richtlinie $a b$, bedroht doch der Verzicht aup die Erhebung der EinfuhruSt ihre derzeit wichtigste Einnahmequelle. Die Abgabe eines Telles der Verwaltungsaufgaben an die Finanzbehörden würde nicht nur thre jetzige Bedeutung und ihren Personalbestand in Frage stellen, sondern würde auch, was fast noch schlimmer ist, die Zollbeamten zu Handlangern der Finanzbeamten degradieren. Umgekehrt hat auch die Finanzverwaltung kein Interesse an der 14.USt-Richtlinie. Da sie mit einer merklichen Aupstockung ihres Personals nicht rechnen kann, scheut sie das Mehr an Verwaltungsarbeit.

Ganz anders liegen die Dinge in Großbritannien. Im Gegensatz zu Deutschland wird hier die gesamte MWSt von Customs and Excise erhoben. Die durch den Entwurf einer 14.USt-Richtlinie bewirkte Verlagerung von Verwaltungsarbeiten und Einnahmen von der Grenze ins Inland bedroht nicht die Stellung der Organisation als Ganzes, da sle durch Restrukturierungen innerhalb des Hauses aufgefangen werden können. Alle für den öffentlichen Sektor relevanten administrativen Vor- und Nachteile der 14.USt-Richtlinie

die Deutschen von einem "Kompetenzwirrwarr" - Arnim (1983), S.292 -

57 Zur Position der Briten vgl. z.B. HM Customs and Excise, Memorandum on VAT, in: Papers of the House of Lords, 1981/82: H.L.204. 
sind somit innerhalb elner Behörde internalisiert. Das von Customs and Exclse zur 14.USt-RIchtlinle abgegebene Urtell dürfte daher den tatsăchlichen Verhältnissen wesentlich mehr entsprechen als das der deutschen Behörden, deren Erwägungen - diese Vermutung erscheint zumindest plausibel - von den Eigeninteressen der Beamten dominiert werden.

Dehnen wir unsere Untersuchung auf andere Mitglledstaaten der EG aus, dann wird das blsher gewonnene Bild bestätigt. Neben dem Vereinigten Königreich haben auch Irland, Dänemark und die Niederlande keine administrativen Einwände gegen den Entwurf elner 14.USt-Richtlinie. In allen vier Ländern ist die Verwaltung der MWSt in elner elnzigen Behörde integriert. ${ }^{38}$ Neben den Deutschen halten auch die Franzosen ${ }^{58}$ den verwaltungstechnischen Aufwand der 14.USt-Richtlinie für viel zu hoch. In beiden Ländern Ist die Verwaltung der MWSt auf zwei unterschledliche Organisationen aufgetellt. Die institutionelle Trennung zwischen Zoll- und Finanzverwaltung ist zwar Im zentralistischen Frankreich weniger ausgeprägt als in der Bundesrepublik; belde Behörden unterstehen dem Parlser Finanzministerium. Zoll- und Finanzverwaltung blicken aber jede für sich auf eine lange Geschichte zurück und legen auf ihre Elgenständigkeit außerordentlichen Wert. So wäre es belsplelswelse für einen französischen Zollbeamten ganz und gar undenkbar, sich wegen der 14.USt-Richtlinie in die Finanzverwaltung versetzen $\mathrm{zu}$ lassen, um dort sein restliches Berufsleben $\mathrm{zu}$ fristen.

Wir können damit festhalten: Der verwaltungstechnische Einwand gegen den Vorschlag einer 14.USt-Richtlinie erscheint nicht haltbar; er wurde nur von solchen Behörden vorgebracht, die ein erkennbares Eigeninteresse am Scheitern der 14.USt-Richtlinie haben.

\section{Dle Vorreiterrolle der Benelux-Staaten}

Nachdem wir die Hintergründe der Diskussion um die 14.USt-Richtlinie eingehend beleuchtet haben, kommen wir nun en détall auf ihre Geschichte zu sprechen. Sle läßt sich zurückverfolgen bls in die fruhen 60er Jahre. Das damals von den Nlederlanden vorgeschlagene System-Tuk wurde aus Gründen, die oben berelts hinlänglich analysiert wurden ${ }^{60}$, von der Kommission und den anderen Mitgliedstaaten nicht aufgegriffen. Man widmete sich stattdessen der Ausarbeitung der ersten beiden USt-Richtlinien. Als eln Element des in 1967 vorgelegten Richtlinienentwurfs fur die Anwendung der

* Das gllt für die Niederlande nur eingeschränkt, da hler die Inländische MWSt, wle in Deutschland, von der Finanzverwaltung erhoben wird. Finanz- und Zollverwaltung sind aber belde dem Haager Finanzministerium unterstellt und eng miteinander verzahnt. 
MWSt auf die Landwirtschaft'i1 kam das System Tuk vorübergehend aus der Versenkung empor, in der es aber schon zwel Jahre später, zusammen mit besagter Richtlinie, wieder verschwand. Trotzdem gaben die Niederländer nicht auf. Sie griffen zur Selbsthilfe und versuchten, nachdem die EG sich desinteressiert gezeigt hatte, ihre Partner in der Benelux-Union für die Tuksche Idee von einem raschen Abbau der Grenzformalitäten zu begeistern.

Die Belgier reagierten zunächst mit Zurückhaltung. Man befürchtete budgetäre Einbußen, und es gab auch einigen Widerstand in der belgischen Verwaltung. ${ }^{62}$ Die wichtigste Ursache für den anfänglichen Widerstand Belgiens gegen das System Tuk durfte allerdings in der Tatsache begründet liegen, daß die belgische USt inklusive der EinfuhruSt damals noch als Stempelsteuer erhoben wurde: Die für die Implementlerung des System Tuk unumgängliche umsatzsteuerliche Kontrolle der Unternehmensbuchhaltung gab es in Belgien daher noch nicht. Erst als Ende der 60er Jahre die Einführung der MWSt und damit auch der Verzicht auf die Stempeltechnik năher ruckte, gewann das System Tuk für die Belgler an Attraktivität. Hinzu kam, daß sich die EG zur gleichen Zeit anschickte, die Gemeinschaft zu einer WWU weiterzuentwickeln. Da die Benelux-Union, um die eigene politische Identităt $\mathrm{zu}$ wahren, der EG immer elnen Schritt voraus $z u$ sein bemuht war, entschloß sie sich 1969 zu einem ganzen Paket von Integrativen Maßnahmen. Die Regierungen Belglens, Luxemburgs und der Niederlande einigten sich unter anderem auf die Einführung eines Systems der Einfuhrbesteuerung, das der später vorgelegten 14.USt-Richtlinie zum Vorblld wurde.63

Nach diesem Erfolg hätten es die Niederländer gerne gesehen, wenn das Benelux-System Im Rahmen der 6.USt-RIchtlinie auf die gesamte EG ausgedehnt worden wăre. Da DenHaag aber, um dle elgene Verhandlungsposition bel anderen Punkten nicht $\mathrm{zu}$ schwächen, die Sache nicht forcierte, blieb eine ernsthafte Diskussion darüber aus.64 Sle wurde erst möglich, als die

61 Vgl. die Darstellung in Kap.D.1.1.

62 Die belgische USt-Verwaltung ist wie die Pranzösische zwelgetellt. Das Verhältnis $z$ wischen belgischer Finanz- und Zollverwaltung ist aber wesentlich entspannter als Im Nachbarland.

63 Vgl. Décisions de la Conférence Intergouvernementale du Benelux tenue à LaHaye les 28 et 29 Avril 1969, abgedr. In: Bulletin Benelux, 1969, Heft 4. Der Übergang zu dem neuen Verfahren der Einfuhrbesteuerung erfolgte in den 3 Staaten jewells zeitgleich mit der Einfuhrung der MWSt. Es sei darauf hingewlesen, daß dle Entscheldung von 1969 nicht aus heiterem Himmel kam, sondern daß die Benelux-Staaten auch schon vorher - Belgien z.B. mit dem Erlaß v. 18.5.67, Moniteur Belge 25.8.67 - erste vorsichtige Schritte unternommen hatten, um die umsatzsteuerlichen Grenzkontrollen $\mathrm{zwischen}$ ihren Ländern zu vereinPachen.

64 In Art.23 der 6.USt-Richtlinie machte man den Benelux-Staaten lediglich das Zugeständnis, Ihr System der Einfuhrbesteuerung auch in $\mathrm{Zu}-$ kunft beibehalten zu dürfen. 
Kommission im Jahre 1982, nunmehr als gesonderter Richtlinienvorschlag und eingebettet in die Binnenmarktpolitik der Gemeinschaft, den Mitgliedstaaten der EG die Ubernahme des Benelux-Modells emprahl. Da die Niederlande und Luxemburg den in der 14.USt-Richtlinie gemachten Vorschlägen schon entsprachen, traf der Richtlinienentwurf bel thnen erwartungsgemä $\beta$ auf ungetellte Zustimmung. Durchaus gemischte Gefühle kamen demgegenuber bei den Belgiern auf. Eine Ausdehnung des von ihnen bislang nur im intra-Benelux Handel verwandten Verfahrens der Importbesteuerung aup den gesamten EG-Handel bereitete lhnen budgetäre Kopfschmerzen.65 Auf der anderen Selte konnten sie zur 14.USt-Richtlinle - man hatte das System in der Benelux-Union ja schon für gut und richtig befunden - aus politischen Gründen auch nicht Nein sagen. Man wartete also erst elnmal ab.

\section{Der Widerstand der Franzosen, Italiener, Dänen und Griechen}

Opfener Widerstand gegen den Vorschlag einer 14.USt-Richtlinie kam demgegenüber aus Frankreich, Italien, Dänemark und Grlechenland. Die Regierungen der genannten Staaten machten administrative Probleme geltend und sprachen der 14.USt-Richtlinie schlicht die Fähigkeit ab, die Formalitäten an den Binnengrenzen der Gemeinschaft durchgreifend vereinfachen zu können. Im Hintergrund ihrer Ablehnungshaltung standen jedoch in allen Fällen budgetăre Erwägungen. Hinzu kam, daß sich die Jeweiligen Finanz- und Zollverwaltungen nicht auf eine Neuordnung ihrer Zuständigkeiten elnlassen wollten.66 Für eine Aufrechterhaltung des Status quo sprachen sich auch, wie so oft, die Spitzenverbände der Wirtschaft aus. Zwar hatten die in den vier Mitgliedstaaten ansässigen Importeure und Exporteure durchaus ein Interesse an der Annahme der 14.USt-Richtlinie. Sie konnten sich aber gegen die Lobby der Unternehmen, die eine Verbilligung der Importe aus anderen EG-Ländern befürchteten, nicht durchsetzen.

\section{Die Unentschlossenheit der Deutschen}

Angesichts des skizzierten Interessengegensatzes zwischen den BeneluxStaaten auf der einen und Frankreich, Itallen, Dänemark und Griechenland auf der anderen Selte kam der Haltung der Deutschen zum Entwurf einer 14.USt-Richtlinie eine zentrale Bedeutung zu. Bonn aber konnte sich nicht entscheiden. Budgetare Probleme hatten die Deutschen mit der 14.UStRichtlinie nicht: $\mathrm{Da}$ das deutsche Zollrecht Pür die AbPührung der Einfuhr-

65 Belgien verzichtete bel Importen von außerhalb der Benelux-Union nur dann auf die Erhebung der ElnfuhrUSt, wenn die Importeure einen Betrag in Höhe ihrer durchschnittlichen monatlichen EinfuhruSt-Schuld zinslos beim Fiskus hinterlegten. Dlese Beträge hătten im Falle einer Annahme der 14.USt-Richtlinle an die betroffenen Unternehmen $\mathrm{zu}-$ rückgezahlt werden müssen.

66 Nur die dänische Bürokratie sah in der 14.USt-Richtlinie kelne unüberwindlichen administrativen Schwierigkeiten. Das ist insofern keine Uberraschung, als die Dänen, wie oben schon vermerkt, die Verwaltung ihrer MWSt alleine in die Hände ihrer Zollverwaltung gelegt hatten. 
USt einen relativ langen Zahlungsaufschub gewahrt, hätte der Verzicht auf die Erhebung der EinfuhrUSt keinen vorübergehenden Steuerausfall zur Folge gehabt.67 Aus genau demgleichen Grund wurde auch die Wettbewerbsposition der mit Importgütern konkurrierenden deutschen Industrien von der 14.USt-Richtlinie nicht berührt. Warum also, so drängt sich die Frage aup, sagten die Deutschen nicht Ja zur 14.USt-Richtlinie?

Dle Ursache des deutschen Zögerns lag in dem schon erwähnten widerstand der Zoll- und Finanzverwaltung begründet. Die Implementierung der 14.UStRichtlinie würde, so rechneten die Beamten vor, Verwaltungsmehrkosten in Höhe von DM 100 Millionen jährlich verursachen.60 Das konnten die für die 14.USt-Richtlinie eintretenden Spitzenverbände der deutschen Wirtschaft nicht aup sich sitzen lassen. Sie gaben ihrerseits elne Studie in Auftrag, die zu dem Ergebnis kam, daß die Unternehmen durch die Annahme der 14.USt-Richtlinie Verwaltungskosten in Hohe von DM 100 Millionen Jährlich einsparen würden. ${ }^{69} \mathrm{Zu}$ ernst sollte man das Zahlenspiel nicht nehmen. Es war für die Presse gedacht und Pur dle in DM-Betrăgen denkenden Bonner Polltiker. Unter der Hand gaben die Wirtschaftsverbănde zu, daß die deutschen Importformalitäten schon sehr weitgehend vereinfacht worden seien und daher von der 14.USt-Richtlinie kaum noch Verbesserungen erwartet werden könnten. Trotzdem befurworteten sie die Annahme der 14.UStRichtlinie mit dem Ziel, Im Interesse der deutschen Exportwirtschaft die anderen EG-Länder zu ähnlichen Schritten $z u$ bewegen. Das letztere Argument aber war wlederum nicht in der Lage, die deutschen Verwaltungsbeamten zum Einlenken zu bewegen.

Der Konflikt zwischen der deutschen Wirtschapt aup der einen und der Administration auf der anderen Seite wurde im Laufe der Zeit auf immer höheren Ebenen ausgetragen. Zunăchst kam es zur Gründung einer eher informellen und aus Vertretern beider Konfllktparteien zusammengesetzten Arbeitsgruppe beim Deutschen Industrie- und Handelstag. Der im Februar 1983 vorgelegte Bericht äußerte sich zur 14.USt-Richtlinie, wie kaum

67 Der in Deutschland gewährte zollrechtliche Zahlungsaupschub für die EinfuhrUSt Pührt dazu, daß die Abführung der EinfuhruSt an die Zollverwaltung und ihre Rückerstattung von der Finanzverwaltung zeitgleich erfolgt.

68 Das Zustandekommen dieser Zahl ist bezelchnend für die den Verwaltungsangaben innewohnende Tendenz, die mit der 14.USt-Richtlinie verbundenen Probleme zu überzelchnen: Erstens wurden von den Mehrkosten der Flnanzverwaltung die belm Zoll möglichen Personaleinsparungen nicht abgezogen; zweitens wurde bei der Kalkulation unterstellt, daß die Finanzverwaltung, während sle sich bel Inlandsgeschäften auf Stichprobenkontrollen beschränkt, die Importvorgänge lückenlos überprüft. Vgl. Arbeltsgemeinschaft für Wirtschaftliche Verwaltung, Erhebung der Einfuhrumsatzsteuer, Eschborn, Juni 1984, S.2.

69 Vgl. Arbeitsgemeinschaft für Wirtschaftliche Verwaltung, Erhebung der Einfuhrumsatzsteuer, Eschborn, Juni 1984. 
anders zu erwarten, mit einem Jein.70 Anschließend gingen die Landespolitíker zu Werke. Wăhrend sich die Länderfinanzminister mit den ihnen unterstellten Finanzverwaltungen solidarisierten, nahmen sich die Wirtschaftsministerien der Länder den Unternehmerinteressen an. Den Dissens versteckte der Bundesrat in seiner Entschlleßung zur 14.USt-Richtlinie hinter schwammigen Formullerungen, die ebenfalls auf eln Jein hinausliefen. ${ }^{71}$ Nun waren die Bundespolitiker an der Relhe. Auch in Bonn machte sich das Wirtschaftsministerium für die 14.USt-Richtlinie stark, wăhrend der Bundesfinanzminister, als oberster Dienstherr der Zollverwaltung, dagegen Einspruch erhob.

Damit war der Willensbildungsproze $\beta$ vorläufig festgefahren. Wieder in Gang kommen konnte er nur, wenn eine der belden Partelen von dritter Selte Unterstutzung erhielte. Dem Finanzausschuß des Bundestages war diese Rolle zu gefăhrlich. Er wollte sich in die Auselnandersetzung zwischen den beiden mächtigen Ministerien nicht einmischen und stellte daher - ein außerst ungewöhnliches Vorgehen - nur lapidar fest, daß er, solange das Kabinett sich nicht einigen könne, zur 14.USt-Richtlinie keine Stellungnahme abzugeben gedenke. Die Bundesreglerung aber ließ sich Zeit. ${ }^{72}$ Erst ab Mitte 1984, so scheint es, wurde die Position des Wirtschaftsministeriums von den Europåern Im Kanzleramt und im Außenministerium nachhaltig gestärkt. Selther jedenfalls glaubten die Brüsseler Verhandlungspartner der Deutschen feststellen zu können, daß Bonn ein sehr vorsichtiges Vielleicht Ja zur 14.USt-Richtllnie signallsierte. Aber die deutsche Zustimmung zum Kommissionsentwurf war zu schwach und kam, da die Briten und Iren nach threr anfänglichen Unterstutzung der 14.USt-Richtlinle inzwischen zum geordneten Rückzug geblasen hatten, entschieden zu spät.

\section{Der Meinungswandel der Briten und Iren}

Vor der Einfuhrung ihrer MwSt hatten sich dle Briten und Iren gründlich uber die in anderen EG-Ländern schon gemachten Erfahrungen informiert. Da ihnen, sowelt es um die Methode der Einfuhrbesteuerung ging, das in der Benelux-Union verwandte Verfahren als die Optimallösung erschien, ubernahmen sie es von Anfang an in thre MwSt. Sowohl die Administration als auch die Wirtschaftsverbănde waren äußerst zufrieden damit. Dle Kommission konnte Polglich, als sie in der 14.USt-Richtlinie die Ubernahme des Benelux-Modells durch alle anderen EG-Staaten vorschlug, aup die britische und irische Zustimmung bauen. Aber dann geschah etwas, womit viele in

70 Vgl. Deutscher Industrie- und Handelstag, Erhebung der Einfuhrumsatzsteuer, Bonn, Februar 1983.

71 Vgl. Entschließung des Bundesrates v. 20.5.83, Bundesrats-Drs. 189/83. Vgl. a. Handelsblatt 30.5.83.

72

Im Mal 1984 stand die 14.USt-Richtlinie aup der Tagesordnung einer Kabinettsitzung, wurde aber, da sich Finanzminister Stoltenberg vorab in elnem kompromißlosen Brief direkt an den Kanzler gewandt hatte, dann doch nicht behandelt. 
Brüssel nlcht gerechnet hatten: Die Iren wandten sich mit Wirkung vom 1.September 1982 von dem in der 14.USt-Richtlinie emplohlenen Verfahren $a b$ und gingen, dem französischen, itallenischen und dänischen Beispiel folgend, zu einer Erhebung der EinfuhrUSt uber. Und es kam noch schllmmer: Für dle Partner in der EG vollkommen uberraschend gab der britlsche Schatzkanzler im März 1984 bekannt, daß sich Großbritannien mit Wirkung vom 1.Oktober 1984 der Irischen Entscheidung anschlleßen würde. Damit hatten die Briten, auch wenn sle das öffentlich natürlich nicht eingestehen konnten, das Schicksal der 14.USt-Richtlinie endgulltig besiegelt. Zwischen der Verkündung und der Verwirklichung der britischen Entscheldung versuchte die Kommission in elnem letzten Anlauf, Im Ministerrat eine Einigung herbelzupuhren. ${ }^{73}$ Aber auch dieser schelterte. Das Bonner Ja zur 14.USt-Richtlinie war viel zu schwach, als daß es London zu elner Umkehr hătte bewegen können.

Doch wie hatte es zu den überraschenden Entscheldung der Irischen und britischen Regierung von 1982 bzw. 1984 kommen können? Da in beiden Ländern sehr ähnliche Motive - nämlich rein budgetăre - elne ausschlaggebende Rolle spielten, wollen wir uns im folgenden aup die Darstellung des britischen Meinungsbildungsprozesses beschränken. Die große Mehrheit der britischen Industrie, insbesondere die Importhändler und die auf Importprodukte angewlesene, verarbeltende Industrie, waren mit dem als Postponed Accounting System - kurz PAS genannt - bezelchneten Verfahren der Importbesteuerung sehr zufrieden. Lediglich vereinzelte Branchen, besonders aus der Konsumgüterindustrie, versprachen sich von der Abschaffung des PAS eine Verbesserung ihrer Wettbewerbsposition gegenuber der ausländschen Konkurrenz. Von Anfang an opponlerten sie gegen das PAS, konnten sich damit aber zunächst nicht durchsetzen: Eine unnötige Belastung der in den Prühen 70er Jahren noch als "lifeblood of British industry"74 empfundenen Importe kam nicht in Frage. Aber die wirtschaftliche Situation anderte sich. Immer mehr verwandelte sich Großbritannien von elnem Exporteur zu einem Importeur von Fertigprodukten.70 Dle Stimmen derer, die die Importunternehmer als "the bad guys who trade Japanese TV for British Jobs"76 und das PAS als "subsidy for imports" 7 verdammten, wurden lauter.

Anfang der 80er Jahre unternahm daraufhin die britlsche Schuhindustrie einen Vorsto $\beta$ gegen das PAS innerhalb des CBI. Das Thema PAS wurde in den Gremien des CBI beraten und, da kelne Elnstimmigkeit hergestellt werden konnte, wleder von der Tagesordnung verbannt: Dle Verteldigung des PAS und damit des Status quo blleb die offizielle Politik des Verban-

73 Vgl. z.B. FT 15.3.84, 9.7.84 u. 10.7.84, Economist 14.7.84.

74 Persönliches Intervlew.

Vgl. z.B. FT 1.3.84.

76 Persönliches Interview.

7 Personliches Interview. 
des.78 Aber die Opponenten gaben nicht auf. Sie suchten sich einen anderen Kanal, durch den sie ihr Anllegen dem Schatzkanzler vortragen konnten, und fanden ihn Im National Economic Development Council. Innerhalb des branchenmaßig gegliederten NEDC war es der Rat der Knitting Industry ${ }^{79}$, der, da nur Hersteller, aber keine Händler in ihm vertreten waren ${ }^{* 0}$, dle Beseitigung des PAS zuerst auf seine Fahnen schreiben konnte. Hinzu kam der für die Knitting Industry glückliche Umstand, daß der Vorsitzende ihres Ausschusses - er kam aus einer anderen Branche - sich selbst dem Kampf gegen das PAS verschrieben hatte. Er war Manager in einer Unternehmung, die die britische Lizens fur ein weltbekanntes amerikanisches Getränk besaß. Besagtes Unternehmen ärgerte sich immens darüber, daß eine bedeutende britische Supermarktkette dasselbe Getrănk in großen Mengen vom Kontinent importierte. Diesem Mann - er wird als außerst dynamisch beschrieben - sollte es gelingen, die britische Regierung zu einer Abschaffung des PAS zu bewegen.

Der erste Anlauf scheiterte noch: Ein im Januar 1983 an den Schatzkanzler gerichtetes Schreiben wurde mit den Standardargumenten, die Customs and Exclse gewöhnlich für das PAS ins Feld führte, abgeschmettert. Beim zweiten Mal klappte es dann: Der neue Schatzkanzler Lawson wollte sich mit seinem ersten Budget profilieren, ihm fehlte im Dezember 1983 fur die Verwirklichung seiner Pläne aber noch ein Betrag von ca.1,5 Milliarden Pfund. Der Zufall wollte es, daß die Knitting Industry just im Januar 1984 die ungefahr alle 4 Jahre wiederkehrende Gelegenheit hatte, ihre wirtschaftliche Situation in der Generalversammlung des NEDC darzustellen. Die Knitting Industry kam aup das PAS zu sprechen und nannte Lawson die Zahl, die er hören wollte: Der Schatzkanzler würde, so wurde lhm vorgerechnet, durch die Abschaffung des PAS seln Budget um 1,6 Milliarden Pfund aupbessern. Allen war klar: "Lawson liked this number"81.

Eine ebenso erhitzte wie konfuse Debatte war vom Zaun gebrochen. ${ }^{82}$ Die Knitting Industry stellte selbstbewußt fest: "The PAS is in effect a subsidy on imports and, like all subsidies, it produces distortions."83 Obwohl diese

78 Vgl. z.B. Confederation of British Industry, Supplementary Memorandum on VAT in: Papers of the House of Lords, 1981/82: H.L.204 v. 13.7.82.

79 Hersteller von Strickwaren.

- Die Händler verkaufen neben einheimischen Produkten auch Importwaren. Da sie ein Interesse an der Belbehaltung des PAS haben, blockierten sie in anderen Gremlen des NEDC, die sich ebenfalls mit diesem Thema beschäftigten, regelmäßig eine Entscheidung gegen das PAS.

a1 Persönliches Interview.

82 Vgl. z.B. FT 16.1 .84 u. 1.3.84.

83 Vgl. National Economic Development Council, A Memorandum by the Chairman of the Knitting EDC, London 22.12.83. Vgl. ähnl. lautende Leserbriefe in der FT 23.2.84 u. 25.2.84. 
Aussage, wie oben gezelgt wurde, dle Tatsachen auf den Kopf stellt, präsentierte die Knitting Industry ihre Argumente mit einer solchen Uberzeugungskraft, daß selbst die Befürworter des PAS in Customs and Excise und innerhalb des $\mathrm{CBI}^{84}$ dem Nichts entgegenzusetzen wußten. Unterdessen beschlo $\beta$ Lawson "..in a rush and for purely political reasons.."85 - gemeint sind budgetäre Gründe - die Abschaffung des PAS. Am Budget Day verkündete er seine Entscheidung mit den Worten: "I must tell the House that I am not longer prepared to put British industry at a competitive disadvantage in the home market any longer."86 Damit hatte der von der Knitting Industry verbreitete ökonomische Unfug endgültig den Segen der Regierung, und der Schatzkanzler hatte sein Geld.

\section{Die Rolle der Kommission}

Bisher sind wir auf die Haltung der Kommission zur 14.USt-Richtlinie noch nicht eingegangen. Eigentlich sollte das auch überflüssig sein, müßten wir doch annehmen können, daß die Kommission mit all ihren Kräften auf die Annahme des Richtlinienentwurfes hingewirkt hat. Das aber war, erstaunlicherweise, nicht der Fall. Verschiedene Begebenheiten lassen vielmehr Zweifel an dem Willen der Kommission aufkommen, alle die ihr zur Verfügung stehenden Mittel auszuschöpfen, um das in der 14.USt-Richtlinie vorgesehene Verfahren in der EG einzuführen:

Verwunderlich ist zum einen, daß der Vorschlag für eine 14.USt-Richtlinie erst im Sommer 1982 vorgelegt wurde. Schon selt 1977 hatte das EP die Kommission wiederholt aufgefordert, einen entsprechenden Richtlinienvorschlag auszuarbeiten. ${ }^{87}$ Aber Brüssel stellte sich taub, auf Jahre hinaus. Erstaunlich ist zum zweiten, daß die Kommission nicht in der Lage war, das gegen die 14.USt-Richtlinie völlig zu Unrecht eingewandte wettbewerbspolltische Argument mit einer sauberen ökonomischen Analyse zu widerlegen. ${ }^{80}$

84 Da die Mitglieder des CBI in der Frage des PAS zerstritten waren, war der Verband Anfang 1984 kramplhapt bemüht, sich aus der Auseinandersetzung herauszuhalten. Ende Februar startete er deshalb eine UmPrageaktion zur Beurteilung des PAS. Es war von vornherein abzusehen, daß deren Ergebnis erst nach dem Budget Day und damit nach der de facto unwiderruflichen Entscheidung der Regierung vorliegen würde. Vgl. CBI, Economic Directorate, The Payment of VAT on Imports, London 2.3.84. Vgl. a. FT 20.2.84.

8s Persönliches Interview.

Bo Budget-Rede Lawsons, gehalten im House of Commons am 13.3.84, abgedr. in: FT 14.3.84.

87 Vgl. z.B. EP Dok.557/77.

8 Die Kommission behauptete: "Je nachdem, welche Beispiele man für die Länge der Zahlungsziele wählt, die der Verkäufer dem Käufer im Inland zugesteht, läßt sich leicht nachweisen, daß ein bestimmter Zahlungsmodus für die Einfuhrumsatzsteuer Einfuhren gegenüber Lieferungen von Gegenständen im Inland begünstigen kann oder umgekehrt." - KOM(82)402 v. 5.7.82, Pkt.12. Das in einem Kaufvertrag ver- 
Der Verdacht drängt sich auf, daß es der Kommission an dem Interesse gemangelt hat, das nun einmal notwendig ist, um den Arbeltselfer eines Okonomen zu beflügeln und seinen analytischen Blick zu schärfen. Erkenntnis und Interesse liegen, wie auch der gleichlautende Buchtitel eines bekannten deutschen Soziologen zum Ausdruck bringt, sehr dicht beleinander.

Wăhrend sich für die ersten beiden Punkte vielleicht noch Entschuldigungen finden ließen, ist das Verhalten der Kommission in einer dritten Angelegenheit ganz und gar unverständlich. Gemeint ist die vor dem EuGH verhandelte Rechtssache 42/83. In dem Verfahren warf die niederländische Firma Denkavit dem dänischen Staat vor, daß die dänische Methode der Importbesteuerung - die EinfuhruSt wird zunächst erhoben und erst 7 Wochen später wieder zurückerstattet bzw. verrechnet - Importe gegenüber gleichartigen inländischen Waren diskriminlere und damit einen Versto $\beta$ gegen Art.95 darstelle. Da der Vorwurf, wle oben schon gezeigt, vollkommen korrekt 1st, hătte das Verfahren mit einer Verurtellung Dănemarks enden müssen. Analoge Klagen gegen Frankreich und Italien wären möglich geworden.99 Sowohl den wettbewerbspolitischen als auch den budgetären Einwänden gegen die 14.USt-Richtlinie wäre damit der wind aus den Segeln genommen worden mit der Folge, daß dle Annahme der Richtlinie im Rat, da nur noch dle administrativen Einwände weiterbestanden hătten, wesentlich erleichtert worden wäre. Das Verfahren Denkavit gegen Dänemark bot also eine geradezu einmalige Chance und das zu einer Zeit, als die Verhandlungen im Rat bereits auf erhebliche Widerstände gestoßen waren.

Was aber tat die Kommission? Sie stellte sich mit ökonomisch unhaltbaren und juristisch Pragwürdigen 90 Argumenten hinter den dänischen Staat. Da die Richter des EuGH - sie waren durch die große finanzielle Bedeutung, die das Verfahren für mehrere Mitgliedstaaten hatte, verunsichert - nicht in das politische Fettnäpfchen der Gemeinschaft treten wollten, folgten sie in ihrem Urtell der Stellungnahme der Kommission und wiesen die Klage ab.91 $\mathrm{Zu}$ dem damaligen Verhalten der Kommission kommentierte eine bestens informierte Brüsseler Quelle: "Es war elne polltische Entscheidung, Denkavit vor dem EuGH nicht zu unterstützen; das Verfahren hătte ohne weiteres auch gewonnen werden können."92

elnbarte Zahlungszlel ist, wle die Variablen Preis, Menge und Quălităt auch, alleine abhängig von den Präferenzen der beiden jeweiligen Geschäftspartner. KEINE der genannten Größen hat, wie zu Beginn des Kapitels unter Pkt.1 heraugearbeitet wurde, auf die Inzidenz der Einfuhrbesteuerung einen Einfluß.

99 Das gilt ebenfalls für Irland ab 1982, Großbritannien ab 1984 und Belgien, soweit die Besteuerung des nicht-Benelux Handels betroffen ist.

90 Eine juristische Würdigung bzw. Kritik des Verfahrens und des Urtells findet sich z.B. bel Vaulont (1985).

91 Urtell v. 10.7 .84 in der RS $42 / 83$.

92 Persönliches Interview. 
Viele Anzeichen sprechen also dafür, daß sich die Kommission, um es vorsichtig auszudrücken, bei der Durchsetzung der 14.USt-Richtlinie nicht aller ihr zur Verfügung stehenden Möglichkeiten bedient hat. Aber warum? Eindeutlge Antworten auf diese Frage kann man aus Brüssel verständlicherweise nicht erwarten. Aber es gibt Indizien: Dänemark, Frankreich und Itallen sind die Staaten, die, aus budgetären und anderen Gründen, von einer Annahme der 14.USt-Richtlinie die, subjektiv zumindest, weitaus größten Nachtelle zu erwarten gehabt hätten; der damals für Steuersachen zuständige Generaldirektor der Kommission war Däne; der Leiter der Brüsseler MwSt-Abteilung war Franzose; der Leiter der für steuerliche Gerichtsverfahren zuständigen Abtellung der Kommission war Itallener.

\subsubsection{Ausblick auf das Endzlel: die Vernetzung der Finanzverwaltungen}

Der Ausflug in die Vergangenheit war eher ernüchternd. Sollte sich an dem Widerstand des Rates gegen den Vorschlag einer 14.USt-Richtlinie in nächster Zukunft nichts ăndern - es gibt keinen Anlaß, auf das Gegenteil zu hoffen -, dann muß das Endzlel, nämlich die Abschaffung der Grenzkontrollen im gewerblichen Warenverkehr, notgedrungen auf direktem Wege angesteuert werden. Erforderlich hierfur ist, wie schon mehrfach betont, eine Vernetzung der nationalen Finanzverwaltungen. In der Praxis heißt das, daß elne Kontaktaufnahme zwischen den Finanzämtern Flensburg und Sevilla genauso schnell und problemlos möglich sein muß wle zwischen Flensburg und Hannover. Um das zu gewährlelsten, sind zunächst eine ganze Reihe unterschiedlichster Voraussetzungen zu schaffen. Es stellt sich zum einen die Frage, in welcher Sprache die Kontaktaupnahme erfolgen soll. Auch muß geklärt werden, wer im jewells anderen Finanzamt als Ansprechpartner dienen soll. Selbst wenn der Kontakt zustandegekommen ist, bedeutet das noch nicht, daß die benötigten Informationen auch innerhalb einer vertretbaren Frist beschafft werden können. Kompllkationen könnten sich beispielsweise daraus ergeben, daß der Termin, zu dem die Unternehmer ihre regelmäßige USt-Erklärung einreichen müssen, von Land $z u$ Land verschieden ist. Unterschiedlich sind auch die rechtlichen und organisatorischen Voraussetzungen, die die jewelligen Finanzverwaltungen in die Lage versetzen, kurziristig elne Außenprüfung zu veranlassen.

Die Liste möglicher Probleme ließe sich weiter fortführen. OPfenkundig ist, daß sle nicht von heute auf morgen gelöst werden können. Die Schaffung relbungsloser Verwaltungsabläufe sowle das Entstehen einer vertrauensvollen Zusammenarbeit bedarf einer längeren Anlaufphase und verlangt daher nach einem step-by-step approach. Erste, wenn auch sehr vorsichtige Schritte in diese Richtung sind bereits getan: 
- Zu nennen sind hier insbesondere die in 1977 bzw. 1979 verabschiedeten Amtshilfe-Richtlinien, die es den Finanzverwaltungen der Mitgliedstaaten gestatten, sich zur Verhinderung der Hinterziehung direkter Abgaben und der MWSt gegenseitig Beistand zu leisten.93 Die mit den Amtshilfeabkommen geschaffenen Möglichkeiten sind bisher bedauerlicherweise erst wenig ausgeschöpft worden ${ }^{94}$, was wohl nicht zuletzt darauf zurückzuführen ist, daß die in den Richtlinien vorgesehenen Verwaltungsablăufe zu schwerfällig sind.

- Positiv zu bewerten ist auch die für den 1.Januar 1988 beschlossene Einführung eines Einheitsdokumentes im innergemeinschaftlichen Warenverkehr.95 Es Puhrt noch nicht unmittelbar zu einer Kooperation zwischen den nationalen Administrationen, erleichtert aber mittelfristig den Ubergang zu EG-einheitlichen, EDV-gestützten Verwaltungsabläufen und schafft damit die Voraussetzung für einen schnellen Informationsaustausch. 96

Positive Ansätze sind also durchaus vorhanden. Sle müssen weiter ausgebaut werden, um $z u$ verhindern, daß es nicht eines Tages rein administrative Probleme sind, die einen möglichen Verzicht auf die Grenzkontrollen blockieren. Zu ergänzen bleibt, daß die EG, was den Abbau der steuerlichen Grenzformalitäten anbelangt, bei den speziellen Verbrauchsteuern schon sehr viel weiter ist als bei der MWSt. Güter, die einer Akzise unterliegen, werden 1.d.R. beim Transport vom Zollager eines EG-Staates in das eines anderen EG-Staates nur symbolisch mit der Steuer belastet: Exporteur und Importeur haften zwar für die Steuer, aber sowohl im Export- als auch im Importland wird von der Erhebung der Abgabe und anschließenden Rückerstattungen abgesehen. Das bei den speziellen Verbrauchsteuern angewandte Verfahren entspricht also im Ergebnis genau dem, das die Kommission in ihrem Vorschlag für eine 14.USt-Richtlinie auch für die MwSt vorgesehen hatte. Zwar werden auch bei den mit Akzisen belasteten Gütern noch Grenzkontrollen durchgefuhrt. Die Kontrollen dienen aber alleine dem Zweck, für den Fall, daß die betreffenden Güter aup dem Transport abhanden kommen (bzw. gestohlen werden), eindeutig feststellen zu können, aup dem Schwarzmarkt welchen Landes die Ware verkauft wurde: Dasjenige Land, auf dessen Territorium die Ware verlorengegangen ist, hat Anspruch auf die vom Exporteur oder vom Importeur dann $\mathrm{zu}$ entrichtende Steuer. Angesichts der Tatsache, daß der Großteil der Güter seinen Bestimmungsort unbeschadet erreicht, sollte es keine Schwierigkeiten bereiten, sich für die

Vgl. AB 1977/L 336, S.15ff. u. AB 1979/L 331, S.8f. Vgl. a. Burke (1981), S.101. u. Guleu (1983a), S.18f.

94 Vgl. z.B. Dle Gemeinschaftsaktion gegen die internationale Steuerhinterziehung, KOM(84)603 v. 28.11.84. Vgl. a. Blick durch die Wirtschaft 24.1.85.

Vgl. Moltke (1985), S.148. 
wenigen gestohlenen Güter auf eine Regel zu einigen, die das Steueraupkommen zwischen den jeweils betroffenen Staaten nach pauschalen Sätzen aufteilt. Dle Grenzkontrollen könnten dann ganz wegfallen. Sie müßten, wie das innerhalb eines jeden Staates bereits üblich ist, durch eine Meldung des Zollagers des Exporteurs an das des Importeurs ersetzt werden.

\subsection{Zukunftsperspektiven: ein Europa der vier Geschwindigkeiten?}

In Anbetracht der unübersehbaren Vielfalt der Probleme, die vor einer endgültigen Abschaffung der Steuergrenzen gelöst werden müssen, erscheint ein "step-by-step approach"97 sowohl rein technisch als auch politisch unvermeidbar. Step-by-step kann dabel zweierlei heißen. Es kann zum einen bedeuten, daß sich alle EG-Staaten zusammen dem Endziel Abschaffung der Steuergrenzen in aufeinanderfolgenden Teilschritten langsam annähern. Eine solche Vorgehensweise ist, wie in den vorangehenden Abschnitten gezeigt wurde, ohne weiteres möglich und auch sinnvoll. Step-by-step kann aber auch dahingehend interpretiert werden, daß diejenigen Mitgliedstaaten, die eine rasche Integration wünschen und dafür auch entsprechende Voraussetzungen mitbringen, auf dem Weg hin zu einer Abschaffung der Steuergrenzen voranschreiten, während die anderen Staaten erst später nachfolgen. Damit kommen wir auf ein politisch äußerst brisantes Thema zu sprechen: das, wie es in der Opfentlichkeit auch gern genannt wird, Europa der zwei Geschwindigkeiten. Ohne auf die ebenso zahlreichen wie umstrittenen Vorund Nachtelle eines solchen Integrationskonzeptes näher eingehen zu wollen, sei lediglich darauf hingewiesen, daß das Europa der zwel Geschwindigkeiten schon heute Realität ist. Man denke nur an das Europäische Währungssystem, an dem sich bislang einige Mitgliedstaaten der EG noch nicht beteiligen. Und es sei darauf aufmerksam gemacht, daß die Gemelnschaft, was den Abbau der Grenzformalitäten betrifft, bereits jetzt mit insgesamt vier verschiedenen Geschwindigkeiten fährt:

- Das höchste Tempo legt die Benelux-Union vor. Die im intra-Benelux Verkehr den privaten Reisenden gewährten Freimengen sind größer als im Rest der EG, die Rechtsvorschriften hinsichtlich der Normen, Sicherheits - und Gesundheitsstandards, etc. sind weitgehend vereinheitlicht, die Kontrollen an den Binnengrenzen der Union sind aup ein Minimum reduziert und betreffen Privatpersonen nur sehr selten.

- Der Benelux-Union folgen in einigem Abstand dle Deutschen und Franzosen. Bonn und Paris haben sich, zunächst alleine und kurze zeit später unter Einschluß der Benelux-Staaten, im Sommer 1984 verpplichtet, die an den gemeinsamen Grenzen durchgeführten Kontrollen zu

97 Persönliches Interview. 
vereinfachen.98 Auch wenn die dem Wählervolk mit viel Werbeaufwand verkaufte Grüne Europa-Plakette weniger halten konnte als sie zunächst versprach, so wurde doch immerhin der politische wille bekundet, die Grenzen notfalls auch im Alleingang durchlässiger zu machen.

- In der dritten Gruppe Pindet sich die große Mehrzahl der EG-Mitgliedstaaten wieder. Es handelt sich um alle diejenigen Länder, die den bisher in Brüssel verabschiedeten Richtlinien in vollem Umfang entsprechen.

- Das Schlußlicht bilden die Dänen, Iren und Griechen. Sie haben, wie bereits vermerkt99, im Rahmen der gemeinschaftlich erlassenen Reiseverkehrs-Richtlinien eine Ausnahmeregelung zugestanden bekommen.

In Zukunft wird es sich als unabdingbar erweisen, auf dem Weg des stepby-step weiter voranzuschreiten. Im Augenblick aber deuten die Zeichen zunächst in eine andere Richtung. Die im Januar 1986 von den EG-Finanzund Wirtschaftsministern auf hoher Beamtenebene eingesetzte ad hoc Arbeltsgruppe ${ }^{100}$ hat ihre Untersuchungen inzwischen beendet. Die Experten brauchten nicht lange, um die mit der Abschaffung der Steuergrenzen verbundenen zentralen Probleme herauszuarbeiten:

- Ein clearing für jede einzelne Transaktion ist verwaltungsaufwendig und führt, da der Grad der Steuerhinterziehung in den Mitgliedstaaten unterschiedlich ist, unter Umständen zu Ungerechtigkeiten bel der Aufkommensvertellung. Vorzuziehen wäre daher gegebenenfalls ein auf statistischen Angaben aufbauendes makroökonomisches clearing. Dafür aber fehlt, bislang jedenfalls, das nötige Zahlenmaterial.

- Soll die MwSt in Zukunft zwei oder drel Sätze haben, und wie hoch sollen sie liegen? Ein Tell der Mitgliedstaaten scheint daraup zu bestehen, daß die MWSt-Sätze, bevor auf die Grenzkontrollen verzichtet werden kann, auf 1 oder höchstens 2 Prozentpunkte einander angenähert werden müssen.

- Wie soll die Zusammenarbeit zwischen den Finanzverwaltungen in der Praxis aussehen?

In der Arbeitsgruppe wurden viele Fragen aufgeworfen, Antworten aber gab es keine. In dem am 16.Juni 1986 dem Rat zugeleiteten Bericht kommen die Beamten zu der Schlußfolgerung, daß, bevor die Mitgliedstaaten sich zu dem

\footnotetext{
9 "Ubereinkommen zwischen den Regierungen der Bundesrepublik Deutschland und der Französischen Republik betreffend den schrittweisen Abbau der Kontrollen an den Gemeinsamen Grenzen", abgedr. in: Bundesgesetzblatt Teil II, 1984, S.767ff.

$99 \quad$ Vgl. Kap.E.2.1.1.

100 Vgl. a. Kap.D.2.3.
} 
Ziel Abschaffung der Steuergrenzen abschließend äußern könnten, Brüssel zunächst detailllerte Vorschläge unterbreiten müsse.101

Damit liegt der Schwarze Peter also wieder bei der Kommission. Was wird sie tun? Die Kommssion wird, wie sie inzwischen dem Ministerrat ankündigte, den Mitglledstaaten in nächster Zeit ein ganzes Paket von Richtlinienvorschlägen präsentieren. Ein erster Richtlinienentwurf liegt bereits vor. Er beinhaltet ein Stillhalteabkommen für die Zahl und die Höhe der Verbrauchsteuersätze in der Gemeinschaft. ${ }^{102}$ Andere Vorschlăge, betreffend die Steuersätze, die Zusammenarbeit zwischen den Finanzverwaltungen und das clearing, werden folgen. Jeder einzelne Artikel der Richtlinienentwürfe wird, das läßt sich nicht vermeiden, mindestens einem Mitgliedstaat der EG erhebliche Schwierigkeiten bereiten. Alle Probleme zusammengenommen werden sich auftürmen zu einem Berg von Widerständen, an dem das ganze Projekt zu scheitern droht. Die Finanzminister und ihre Beamten werden daraufhin, um eine Beschlußfassung hinauszuzögern, immer neue Vorschläge, Voruntersuchungen und Studien anfordern, bis die mit dem Weißbuch von 1985 in Gang gekommene Diskussion langsam unter einem riesigen Haufen von Papier erstickt.

Das hier skizzlerte Szenario kann nur verhindert werden, wenn man die Entscheidung über das Wie und Wann der Abschaffung der Steuergrenzen nicht alleine den Finanzpolitkern überläßt, sondern sie von außen her ganz massiv unter Druck setzt. Aber woher soll der so dringend benötigte politische Druck kommen? Anlaß zur Hopfnung könnte nur eine erfolgreiche Weiterführung der EG-Binnenmarktpolitk geben. Erst wenn in den nichtPiskalischen Bereichen des Gemeinsamen Marktes weitere Fortschritte erzielt worden sind, erst wenn die nicht-fiskalisch bedingten Grenzkontrollen nach und nach abgebaut werden, erst dann werden dle Außen- und Wirtschaptsminister der Gemeinschaft mit dem Finger auf ihre Kollegen von den Finanzen zelgen und sie dafur verantwortlich machen, daß der Durchbruch zu einer EG ohne Binnengrenzen noch immer nicht erreicht werden konnte. Aber auch dann ist noch nicht sichergestellt, daß im Rat der Finanzminister auch wirklich eine Einigung zustandekommt. Zur Erleichterung eines Kompromisses, und das lehrt schon die mit der 6.USt-Richtlinie gemachte Erfahrung, dürpte es sich als unabdingbar erweisen, die Harmonisierungssubstanz der Richtlinienvorschläge im Laufe der Verhandlungen zu vermin-

101 Vgl. z.B. FAZ 18.6.86.

102 "Vorschlag einer Richtlinie des Rates zur Einführung einer Stillhaltevereinbarung im Bereich der Mehrwertsteuer und der Verbrauchsteuern", KOM(85)606 v. 18.11.85. Der Richtlinienentwurf sieht u.a. vor, daß die Mitgliedstaaten (a) die Zahl der MwSt-Sătze nicht verändern, es sel denn, sie gingen zu einem System mit 2 oder 3 Sätzen über, daß sle (b) die Höhe der Steuersätze nicht verändern, es sel denn, sle bewegten sich zum EG-Durchschnitt hin, und daß sie (c) keine neuen Akzisen einführen, es sel denn, die Akzisen bedürften kelnes steuerlichen Grenzausgleichs. 
dern. Für eine Reduktion des Harmonisierungsbedarfes bieten sich zwei unterschiedliche Konzepte an: Entweder man entschließt sich dazu, das Endziel Abschaffung der Steuergrenzen nicht in einem, sondern in vielen kleinen Teilschritten zu erreichen - step-by-step in sachlicher Hinsicht -, und/oder man gewährt einzelnen Mitgliedstaaten großzügige Ausnahmeregelungen von und lange Anpassungsfristen an die gemeinsam erlassenen Richtlinien - step-by-step in regionaler Hinsicht - . 


\section{F. Abschließende Bemerkungen}

Auch wenn, wie im letzten Kapitel deutlich wurde, bei der USt-Harmonisierung noch viel zu tun bleibt, so kann die EG auf das in der Vergangenheit berelts Erreichte durchaus mit elnlgem Stolz zurückblícken. Der bislang größte Erfolg der europäischen Steuerharmonisierung überhaupt bestand zweifelsohne in der Verabschiedung der beiden ersten USt-Richtlinien im Februar 1967. Zugegebenermaßen wăre dieser Beschluß niemals zustandegekommen, hätte es in den damaligen Mitgliedstaaten nicht einen politischen Druck gegeben, der unabhängig von den Harmonisierungserfordernissen auf eine Reform der althergebrachten USt-Systeme hinwirkte. Aber es war die EG, die den einzelnen Ländern zu einer ebenso raschen wie durchgreifenden Steuerreform verhalf und die entscheidend dazu beitrug, die vergleichsweise neutrale MWSt während der labilen Einführungsphase vor Durchlöcherungsversuchen zu bewahren.

Im Verlauf der 70er Jahre stand die Harmonislerung der MWSt-Bemessungsgrundlage im Vordergrund des Interesses. Der erneute Harmonisierungsschritt wurde politisch ermöglicht durch die im Ministerrat leichten Herzens getroffene Entscheidung, einen Teil der Elgenen Einnahmen der Gemeinschaft auf der Basis einer gemeinschaftlich festzulegenden, steuerpflichtigen MWSt-Bemessungsgrundlage $z u$ erheben. Die Finanzminister und deren Beamte setzten sich jahrelang erfolgreich gegen die Verabschiedung der 6.USt-Richtlinie zur Wehr. Es verging eine geraume Zeit, bis die für die nationale Finanzpolitik Verantwortlichen sich klargemacht hatten, daß einem europäischen MWSt-Gesetz auch durchaus Vorteile abzugewinnen waren: Die um die einzelstaatlichen Rechtsvorschriften errichtete und von Brüssel scharf bewachte Mauer erleichterte es den nationalen Entscheidungsträgern, das jeweilige MWSt-Gesetz gegen die von den verschiedensten Interessengruppen vorgetragenen Angriffe zu verteidigen.

Während der 80er Jahre hat sich, zumindest wenn man auf Zahl und Inhalt der vom Rat verabschiedeten Richtlinien abstellt, im Bereich der USt-Harmonisierung bislang nicht viel getan. Trotzdem ist Europa, auch in der Steuerpolitk, zunehmend enger belsammengerückt. Die in den Finanzministe- 
rien der EG-Staaten für die USt zuständigen Beamten kennen sich alle persönlich, sie sehen sich regelmäßig in Brüssel und pflegen bilaterale Kontakte, sie lernen vonelnander und stimmen sich ab. All das, was vor 15 oder 20 Jahren noch unvorstellbar war, ist inzwischen zu einer Selbstverständlichkeit geworden. Und das im Junl 1985 vorgelegte Binnenmarktprogramm der Kommission gab den politischen Anstoß, sich über die baldige Abschaffung der Innergemeinschaftlichen Grenzkontrollen intensive Gedanken zu machen.

Ungewi ist, wie und mit welcher Geschwindigkeit die USt-Harmonisierung in nächster Zeit welter voranschrelten wird. $\mathrm{Zu}$ oft noch hört man von seiten der nationalen Finanzpolitiker das Argument, daß die jewelligen Steuergesetze auf dle wirtschaftlichen Notwendigkeiten und sozialen Gegebenheiten in den einzelnen Staaten bestens abgestimmt seien und da $\beta$ daher Anderungen, sofern sie lediglich integrationspolitisch motiviert sind, nur mit Bedacht und sehr langsam vorgenommen werden dürften. Der genannten Behauptung sollte man, wie schon der in 1963 abgefaßte DeringerBericht feststellte, mit einem gewissen Maß an Skepsis gegenübertreten:

\begin{abstract}
"Jedes Steuersystem ist im Laufe der Geschichte gewachsen und weist viele nur historisch erklärbare Irrationalitäten auf, die manchmal mehr den Witz des Humoristen als die Ehrfurcht des geplagten Steuerzahlers hervorzurufen geelgnet sind. Man sollte also prinzipiell nicht das so oft gehörte Argument uberstrapazieren, da $\beta$ jedes Land auf Grund seiner Eigenheiten ein ihm entsprechendes Steuersystem gefunden habe, das auf seiner Sozialordnung beruhe und unmöglich geändert werden könne. Hinter solchen Argumenten verbirgt sich häufig sterile Immobilităt oder eln massives Interesse an der Erhaltung eines bestehenden Vortells. Häuplg sind es auch die historisch gewachsenen Steuersysteme, die gewisse soziale Verhältnisse geschaffen oder mit begünstigt haben, mit denen sie oberflächlich gesehen so gut übereinstimmen, und nicht umgekehrt."1
\end{abstract}

Deringers Auffassung wurde durch die blslang mit der USt-Harmonislerung gemachten Erfahrungen in vollem Umfang bestätigt. Das gestehen auch diejenigen Finanzbeamten ein, die inzwischen, wegen Pensionierung oder da sle in eine andere Position gewechselt sind, das USt-politische Tagesgeschäpt verlassen haben. Sie bedauern im Nachhinein, bei der Beratung der 6.UStRIchtlinie nicht mehr Zugeständnisse gemacht und damt eine weitergehende USt-Harmonisierung verhindert $\mathrm{zu}$ haben.

1 Deringer-Bericht (1963), Ziff.114. 
Ihre Kollegen aber, die zur Zeit für die USt-Politik der Mitgliedstaaten verantwortlich zeichnen, sehen das anders. Es bleibt zu hoffen, daß auch sie, vielleicht wăhrend eines Aufenthaltes in Brüssel und mit dem nötigen Abstand zum heimatlichen Tagesgeschehen, einmal in der Lage sein werden, sich den Einsichten der älteren Generation anzuschlleßen. Denn es sind die Finanzminister gemeinsam mit den jeweillgen Beamten, die über die Zukunft der europäischen USt-Harmonisierung entscheiden. Die nationalen Parlamente haben, mehr noch als die Spitzenverbände der Wirtschaft, seit Gründung der EG an steuerpolitischem Einfluß merklich eingebußt, da ihnen der direkte Zugang zu den Brüsseler Entscheidungszentren versperrt ist.

Alles in allem kann sich die EG mit dem bei der USt-Harmonisierung bislang Erreichten durchaus sehen lassen. Das gilt umso mehr, wenn man bedenkt, daß der Deutsche Zollverein und anschließend das Deutsche Reich für die Harmonisierung der fiskalisch vergleichsweise unbedeutenden Biersteuer uber 80 Jahre benötigt haben. ${ }^{2}$ 


\section{Anlage I: \\ Verzeichnis der wichtigsten Abkürzungen}

\begin{tabular}{|c|c|}
\hline $\mathrm{AB}$ & Amtsblatt der Europäischen Gemeinschaften \\
\hline $\mathrm{AE}$ & Agence Europe \\
\hline$A G$ & Arbeitsgruppe \\
\hline ALNV & $\begin{array}{l}\text { Ausschuß der Leiter der nationalen Steuer- } \\
\text { verwaltungen }\end{array}$ \\
\hline BLP & Bestimmungslandprinzip \\
\hline CBI & Confederation of British Industry \\
\hline COREPER & Comité des Représentations Permanentes \\
\hline EAG & Europäische Atomgemeinschapt \\
\hline EG & Europäische Gemeinschaft \\
\hline EGKS & Europäische Gemeinschaft für Kohle und Stahl \\
\hline EP & Europäisches Parlament \\
\hline EWG & Europäische Wirtschaftsgemeinschaft \\
\hline EWS & Europäisches Währungssystem \\
\hline FAZ & Frankfurter Allgemeine Zeitung \\
\hline FT & Financial Times \\
\hline MWSt & Mehrwertsteuer \\
\hline NEDO & National Economic Development Opfice \\
\hline NZZ & Neue Züricher Zeitung \\
\hline
\end{tabular}


PAS

RS

SET

TVA

UG

ULP

UNICE

USt

VAT

VSA

VUA

WSA

WWU
Postponed Accounting System

Rechtssache

Selective Employment Tax

Taxe sur la Valeur Ajoutée

Untergruppe

Ursprungslandprinzip

Union des Industries de la Communauté Européenne

Umsatzsteuer

Value Added Tax

Vorsteuerabzug

Vorumsatzabzug

Wirtschafts - und Sozlalausschuß

Wirtschafts- und Wăhrungsunion 


\section{Anlage II: \\ Verzeichnis der vom Verfasser geführten Interviews}

\section{Europäische Institutionen}

M. Bonafons

Mr. Bott

Dr. von der Groeben

M. Guieu

Mme. Hick

Herr Krämer
Kommission der EG, USt-Abt.

Gespräch, Brüssel am 11.12.1984.

Kommission der EG, Juristische Abt. der Steuerdirektion.

Gespräch, Brüssel am 12.11.1985.

vormals: Kommissar der EG.

davor: Bundesministerium für Wirtschaft, Leiter der EGKS-Abt.

Gespräch, Rheinbach bei Bonn am 10.12.1984 u. 17.5.1985.

Kommission der EG, Leiter der UStAbt.

Gespräch, Brüssel am 11.12.1984.

Sekretariat der Benelux-Union, Steuer-Abt.

Gespräch, Brüssel am 14.12.1984.

Kommission der EG, Abt. Spezielle

Verbrauchsteuern

Gespräch, Brüssel am 11.12.1984 u. 12.12.1984.

\footnotetext{
Anm.: Das Verzeichnis der Interviews ist insofern unvollständig, als einige der Geprächspartner darum gebeten haben, in einer Veröffentlichung nicht namentlich genannt zu werden.
} 
Dr. Lang

M. Lefevre

Prof. Dr. Relschl

Herr Vaulont

H. VerLoren van Themaat

Herr Vogelaar

Prof. Dr. Wăgenbaur vormals: Kommission der EG, USt-Abt. Gespräch, Preetz/Holstein am 19.8.1985.

Kommission der EG, Abt. Spezielle Verbrauchsteuern.

vormals: Kommission der EG, USt-Abt. Gespräch, Brüssel am 12.11.1985 u. 13.11.1985.

vormals: Europäischer Gerichtshof, Generalstaatsanwalt.

Gespräch, Bonn am 8.11.1985.

Kommission der EG, Dienst der Zollunion, Assistent des Generaldirektors.

Gesprăch, Brüssel am 12.12.1984.

Europăischer Gerichtshof, Generalstaatsanwalt.

vormals: Kommission der EG, Generaldirektor Wettbewerbspolitik.

Gesprăch, Luxemburg am 24.10.1985.

vormals: Kommission der EG, Generaldirektor Wettbewerbspolitik.

Briefwechsel, Wassenaar bel DenHaag am 10.9.1985.

Kommission der EG, Juristischer Dienst.

Gespräch, Brüssel am 13.12.1984.

Europäsche Unternehmen und Unternehmensverbände

Herr Buys

Herr Kröger

Herr Simons
Fa. Denkavit International, SteuerAbt.

Gespräch (telefonisch), Voorthuizen bei Utrecht am 18.12.1984.

Union des Industries de la Communauté Européenne (UNICE), Leiter der Finanz-Abt.

Gesprăch, Brüssel am 11.12.1984.

Fa. Shell International, Steuer-Abt. vormals: Finanzministerium der Nlederlande, USt-Abt.

Gespräch, DenHaag am 12.3.1986. 


\section{Belglen}

Herr Breugelmans

Herr Cappelleman

Herr Haber

M. Scailteur

\section{Bundesrepublik Deutschland}

Dr. von Arnim

Dr. Christiansen

Herr Dittrich

Herr Kohler

Herr Müller

Dr. Rau

Herr Schultze vormals: Finanzministerium, USt-Abt. Gespräch, Brüssel am 13.11.1985.

vormals: Finanzministerium, USt-Abt. Gespräch, Brüssel am 13.11.1985.

Ständige Vertretung Belgiens bei der EG.

Gespräch, Brüssel am 13.11.1985.

vormals: Finanzministerium, Generaldirektor Steuern.

Briefwechsel, Brüssel am 25.1.1985.

vormals: Finanzministerium, Abt. Spezielle Verbrauchsteuern.

Gespräch, Saarbrücken am 24.10.1985.

Finanzministerium, Leiter der Abt. Spezielle Verbrauchsteuern. Gesprăch, Bonn am 15.5.1985.

Finanzministerium, Abt. Spezielle Verbrauchsteuern.

Gespräch, Bonn am 15.5.1985.

Finanzministerium, Leiter des Grundsatzreferates USt.

Gespräch, Bonn am 20.9.1984 u. 9.6.86.

vormals: Finanzministerium, Leiter der USt-Abt.

Gespräch, Königswinter bei Bonn am 17.5.1985.

Deutscher Industrie und Handelstag, Steuer-Abt.

Gesprăch, Bonn am 28.9.1984.

Wirtschaftsministerium, Zoll-Abt.

Gespräch, Bonn am 26.9.1984. 
Dänemark

Herr Heine

Finanzminlsterium/Zölle, Abt. Steuerharmonisierung.

Gespräch, Kopenhagen am 22.8.1985.

Prof. Moller

Handelshochschule Kopenhagen.

Gespräch, Kopenhagen am 22.8.1985.

\section{Frankrelch}

M. Egret

M. Hutchings

M. Laxan

M. Lebrun

M. Mespouhlès

vormals: Finanzministerium, USt-Abt. Briefwechsel, Les Moutils bel Orléans am 8.12.1985.

Prof. Philippe

vormals: Finanzministerium, USt-Abt. Gespräch, Paris am 9.9.1985.

M. Timbart

Patronat Français, Steuer-Abt. Gespräch, Paris am 19.9.1985.

Italien

Dott. Bopfi

Finanzministerium, Abt. Internationale Bezlehungen-USt.

Gespräch, Rom am 29.5.1986. 
Dott. Formica

Prof. Forte

Dott. del Guidice

Sig. Pletropaolo

Sig. Silvestri

Nlederlande

Herr Bek

Herr van der Bljl

Dr. Duisenberg

Herr Millenaar

Prop. Reugebrink

Prof. Zijlstra

\section{Vereinigtes Könlgreich}

Mr. Arrow-Smith

Mr. Glynn vormals: Finanzministerium, Abt.

Internationale Bezlehungen-USt. Gespräch, Rom am 30.5.1986.

Universität Turin.

Gespräch, Rom am 30.5.1986.

Finanzministerium, Generaldirektor Internationale Beziehungen. Gespräch, Rom am 29.5.1986.

Finanzministerium, Abt. Steuern-USt. Gespräch, Rom am 28.5.1986.

Finanzministerium, Generaldirektor Steuern.

Gespräch, Rom am 28.5.1986.

Finanzministerium, Leiter der Abt. USt-Gesetzgebung.

Gespräch, DenHaag am 18.12.1984.

Verbond van de Nederlandse Ondernemingen, Steuer-Abt.

davor: Finanzministerium, USt-Abt. Gespräch, DenHaag am 20.12.1984.

vormals: Finanzminister.

Gesprăch, Amsterdam am 12.3.1986.

vormals: Finanzministerlum, USt-Abt. Gespräch, DenHaag am 21.12.1984.

vormals: Finanzministerium, USt-Abt. Gespräch, DenHaag am 21.12.1984.

vormals: Premier und Finanzminister. Gespräch, Amsterdam am 9.12.1985.

vormals: National Economic Development office.

Gespräch, London am 6.7.1984.

vormals: Confederation of British

Industry.

Gespräch, London am 28.6.1984. 
Rt.Hon. Higgins

Lord Kaldor

Miss MacNess

Mr. Packman

Mr. Trevett

Rt.Hon. Sheldon

Prof. Stout

Mr. Wilson vormals: Staatssekretär im Treasury. Gespräch, London am 3.7.1984.

vormals: Okonomischer ChePberater der Labour-Party.

Gespräch, Cambridge am 9.3.1985.

Außenministerium, Europa-Abt. Gespräch, London am 13.3.1985.

Customs and Excise.

Gespräch, London am 25.5.1984 u. 13.3.1985.

Customs and Exclse, USt-Abt.

Gespräch, London am 25.5.1984 u. 13.3.1985.

vormals: Staatssekretär im Treasury. Gespräch (telefonisch), London am 3.7.1984.

vormals: National Economic Development office.

Gespräch, London am 28.6.1984 u. 4.3.1985.

Confederation of British Industry, Steuer-Abt.

Gespräch (telefonisch), London am 25.5.1984. 


\title{
Anlage III: Verzeichnis der USt-Richtlinien der EG
}

1.USt-Richtlinie Elnführung einer MwSt

\author{
Vorschlag: Bulletin der EWG, 5.1962, Beilage zu \\ EP: \\ WSA: \\ Heft 12. KOM(62)217 v. 31.10 .62 . \\ AB 1963/157, S.2631. E.P.Dok.56/ \\ $1963-64$. \\ Abg.Vorschlag: \\ AB 1964/158, S.2512. \\ EP: \\ Bulletin der EWG, 7.1964, Bellage zu \\ Rat: \\ Heft 7. KOM(64)190 v. 29.5.64. \\ Behandelt in: \\ AB 1966/53, S.761. E.P.Dok.17/66. \\ AB $1967 / 71$, S.1301. \\ Kap.C, Insbes. Kap.C.2.1.4.1. u. \\ C.2.1.4.2.
}

2.USt-Richtl.

$\begin{aligned} & \text { Struktur und Anwendungsmodalltäten der gemeinsamen } \\ & \text { MWSt }\end{aligned}$
$\begin{array}{ll}\text { Stellungnahme der Kommission: Bulletin der EWG, 7.1964, } \\ \text { Beilage zu Heft 7. } \\ \text { Vorschlag: } & \text { Bulletin der EWG, 8.1965, Beilage zu } \\ & \text { Heft 5. KOM(65)144 v. 13.4.65. } \\ \text { EP: } & \text { AB } 1966 / 53, \text { S.751. E.P.Dok.1/1966-67. } \\ \text { WSA: } & \text { AB } 1966 / 41, \text { S.569. } \\ \text { Rat: } & \text { AB } 1967 / 71, \text { S.1303. } \\ \text { Behandelt in: } & \text { Kap.C., insbes. Kap.C.2.1.4.3. }\end{array}$

Anm.: Stand Januar 1986. In dem Verzeichnis sind nur solche Richtlinien und Richtlinienvorschläge aufgeführt, die von der Kommission und/oder dem Rat in eine durchgehende Nummerierung aufgenommen worden sind. Alle anderen USt-relevanten Richtlinien werden an den entsprechenden Stellen im Text erwähnt. 
3.USt-Richtl.

1.Aufschub der MWSt-Einführung für Belgien und Italien

Vorschlag:

EP:

WSA:

Rat:

Behandelt in:

AB 1969/C 129, S.4. KOM(69)862 v. 1.10 .69 .

AB 1969/C 139, S.32.

$\mathrm{AB} 1969 / \mathrm{C} 144, \mathrm{~S} 13$.

AB 1969/L 320, S.34.

Kap.C.2.1.5.

4.USt-Richtl.

2.Aufschub der MWSt-Einführung für Italien

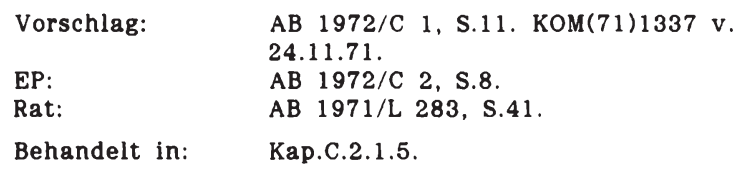

EP:

$\mathrm{AB} 1972 / \mathrm{C} 2, \mathrm{~S} .8$.

Rat:

AB $1971 / \mathrm{L} 283$, S. 41 .

Behandelt in: Kap.C.2.1.5.

5.USt-Richtl. 3.Aufschub der MWSt-Einführung für Italien

$\begin{array}{ll}\text { Vorschlag: } & \mathrm{AB} 1972 / \mathrm{C} 44, \text { S.7. } \mathrm{KOM}(72) 344 \mathrm{v} . \\ & 29.3 .72 . \\ \text { EP: } & \mathrm{AB} 1972 / \mathrm{C} 46, \text { S.43. E.P.Dok.18/72. } \\ \text { Rat: } & \mathrm{AB} 1972 / \mathrm{L} 1962, \text { S.18. }\end{array}$

Behandelt in: Kap.C.2.1.5.

6.USt-Richtl. Harmonisierung der MWSt-Bemessungsgrundlage

\begin{tabular}{|c|c|}
\hline Vorschlag: & $\begin{array}{l}\text { AB } 1973 / \mathrm{C} 80, \text { S.1. KOM(73)950 v. } \\
29.6 .73 \text {. Bulletin der EG, } 6.1973 \text {, } \\
\text { Bellage zu Heft } 11 \text {. }\end{array}$ \\
\hline EP: & AB $1974 / C$ 40, S.31. E.P.Dok. $360 / 73$. \\
\hline WSA: & AB $1974 / C 139$, S. 15. \\
\hline Abg.Vorschlag: & $\begin{array}{l}\text { АВ } 1974 / \text { C } 121, \text { S.34. КОМ(74)795 v. } \\
26.7 .74 \text {. }\end{array}$ \\
\hline EP: & $\begin{array}{l}\text { AB } 1975 / \text { C } 157, \text { S.85. AB } 1976 / \text { C } 178 \text {, } \\
\text { S.27. AB } 1977 / \text { C } 118, \text { S.40. E.P.Dok. } \\
118 / 77 \text {. }\end{array}$ \\
\hline Rat: & $\begin{array}{l}\text { AB } 1977 / \text { L } 145, \text { S.1. AB } 1977 / \text { L } 149 \\
\text { S.26. }\end{array}$ \\
\hline & ? \\
\hline
\end{tabular}

7.USt-Richtl. Vervollständigung der 6.USt-Richtlinie: Besteuerung von Gebrauchtwaren

Vorschlag:

EP:

WSA:

Abg.Vorschlag:

Rat:

Behandelt in:
AB $1978 / C 26$, S.2. AB $1978 / C 92$. S.11. KOM(77)735 v. 6.1.78. $A B 1979 / C$ 93, S.9. E.P.Dok.647/78. AB $1978 / C 269$, S. 21 . AB 1979/C 136, S.8. KOM(79)249 v. 4.5.79. Verabschiedung steht noch aus. Kap.D.2.2.2. 
8.USt-Richtl. Vervollständigung der 6.USt-Richtlinie: Verfahren zur Erstattung der MWSt an ausländische Steuerpflichtige

Vorschlag:

EP:

WSA:

Rat:

Behandelt in:

AB 1978/C 26, S.5. КОМ(77)721 v.

11.1 .78 .

AB 1979/C 39, S.14. E.P.Dok.543/78.

AB 1978/C 269, S.51.

AB 1979/L 331, S.11.

Kap.D.2.2.2.

9.USt-Richtl.

10.USt-Richtl.

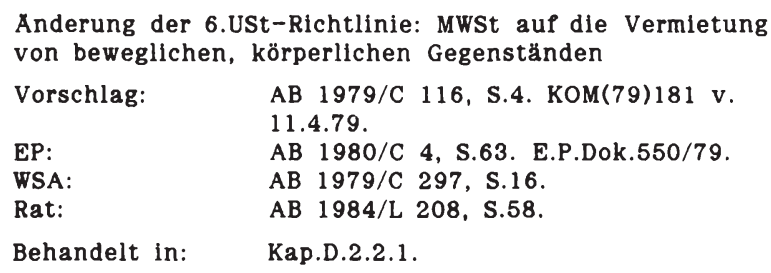

WSA:

$A B 1980 / C$ 4, S.63. E.P.Dok.550/79.

Rat:

AB 1979/C 297, S.16.

AB 1984/L 208, S.58.

Behandelt in:

11.USt-Richtl. Anderung der 6.USt-Richtlinie: Ausschluß der Pranzösischen Uberseedepartements vom Anwendungsbereich der 6.USt-Richtlinie

Vorschlag: $\quad$ KOM(79)695 v. 6.12.79.

Rat: AB 1980/L 90, S.41.

Behandelt in: Kap.D.2.2.1.

12.USt-Richtl. Vervollständigung der 6.USt-Richtlinie: Ausschluß des Rechts aup VSA bei bestimmten Ausgaben

$\begin{array}{ll}\text { Vorschlag: } & \mathrm{AB} 1983 / \mathrm{C} 37, \mathrm{~S} .8 . \mathrm{KOM}(82) 870 \mathrm{v} . \\ & 25.1 .83 . \\ \text { EP: } & \mathrm{AB} 1983 / \mathrm{C} 342, \mathrm{~S} .81 \text {. E.P.Dok. } \\ & 1-777 / 83 . \\ \text { WSA: } & \mathrm{AB} 1984 / \mathrm{C} 206, \mathrm{~S} .21 . \\ \text { Abg.Vorschlag } & \mathrm{AB} 1984 / \mathrm{C} 56, \mathrm{~S} .7 . \\ \text { Rat: } & \text { Verabschiedung steht noch aus. } \\ \text { Behandelt in: } & \text { Kap.D.2.2.2. }\end{array}$


13.USt-Richtl. Vervollständigung der 6.USt-Richtlinie: Verfahren zur Erstattung der MWSt an Steuerpflichtige außerhalb der EG

Vorschlag: $\quad A B 1982 / C 223$, S.5. $\mathrm{KOM}(82) 443 \mathrm{v}$.

EP: $\quad$ AB $1983 / \mathrm{C} 161$, S.110. E.P.Dok.

$1-88 / 83$.

WSA: $\quad A B 1983 / C 176$, S.22.

Abg. Vorschlag: AB 1983/C 196, S.6. KOM(83)413 v.

Rat: $\quad 24.6 .83$. $\quad$ Verabschiedung steht noch aus.

Behandelt in: Kap.D.2.2.2.

14.USt-Richtl. Vereinfachung der Grenzformalitäten: Zahlungsaufschub Pür die EinfuhrUSt

Vorschlag: $\quad$ AB $1982 / C 201$, S.5. KOM(82)402 v.

5.7.82.

EP: $\quad$ AB $1983 / C$ 42, S.69. E.P.Dok.1-976/82.

TSA:- AB $1984 / \mathrm{C} 274$, S.41.

Rat: Verabschiedung steht noch aus.

Behandelt in: Kap.E.2.2.1. sowle in Kap.D.2.2.3. u. Kap.E.1.

15.USt-Richtl. 1.Aufschub der MWSt-Einfuhrung für Griechenland

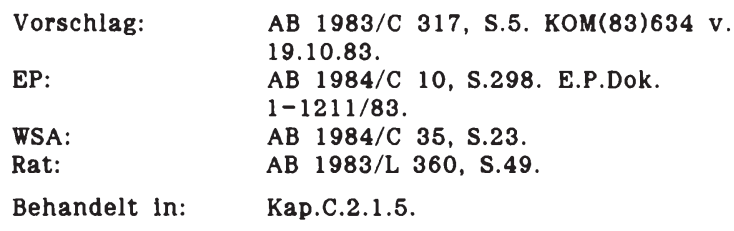

16.USt-Richtl. Vervollstăndigung der 6.USt-Richtlinie: Einfuhr von Gebrauchtwaren durch Privatpersonen

Vorschlag:

EP:

WSA:

Rat:

Behandelt in:
AB $1984 / C 226$, S.2. KOM(84)318 v. 28.8.84.

Stellungnahme steht noch aus. AB 1985/C 78, S.19. Verabschledung steht noch aus.

Kap.D.2.2.2. 
17.USt-Richtl. Vereinfachung der Grenzformalitäten: MWSt-Befreiung bei der vorübergehenden Einfuhr anderer Gegenstände als Verkehrsmittel

Vorschlag:

EP:

WSA:

Abg.Vorschlag:

Rat:

Behandelt in:
AB 1984/C 244, S.4. KOM(84)412 v. 10.8 .84 .

AB 1985/C 12, S.111.

AB 1985/C 25, S.8.

$\mathrm{AB} 1985 / \mathrm{C} 68, \mathrm{~S} .6 . \mathrm{KOM}(85) 58$ v. 20.2.85.

AB 1985/L 192, S.20.

Kap.D.2.2.3.

18.USt-Richtl. Vervollständigung der 6.USt-Richtlinie: Beseltigung von bestimmten in Art.28 vorgesehenen Abwelchungen

Vorschlag:

EP:

WSA:

Behandelt in:
AB $1984 /$ C347, s.3. KOM(84)649 v. 30.11 .84 .

Stellungnahme steht noch aus. AB 1985/C218, S.11.

Kap.D.2.2.2.

19.USt-Richtl. Vervollständigung der 6.USt-Richtlinie: Klarstellung verschiedener Ungenauigkeiten

Vorschlag: $A B 1984 / C 347$, S.5. KOM(84)648 v. 22.11 .84

EP:

WSA:

Behandelt in: Kap.D.2.2.1. u. v. 6.12 .84 .

Stellungnahme steht noch aus. AB 1985/C 218, S.12.

20.USt-Richtl. Anderung der 6.USt-Richtlinie: Ausnahmeregelung für Sonderbeihilfen an die deutschen Landwirte

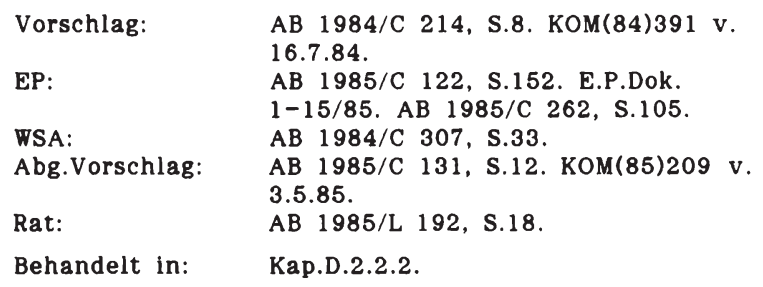

21.USt-Richtl. 2.Aufschub der MWSt-Einführung für Griechenland Vorschlag: $\quad$ KOM(85)821 v. 7.1.86.

Behandelt in: Kap.C.2.1.5. 


\section{Anlage IV: Literaturverzeichnis}

Aaron, H.J. (1981), The Value Added Tax: Lessons Prom Europe, Washington D.C.: Brookings Institution 1981.

Adams, T.S. (1917), The Taxation of Business, in: Proceedings of the National Tax Association, 1917, S.185P.

Albers, $\nabla$. (1963), Steuerprobleme in der Monatanunion, in: Die Weltwirtschaft, 4.1953, S.162ff.

Albers, W. (1968), Dle Harmonislerung der Steuern im Gemeinsamen Markt, in: Wirtschaftsdienst, 48.1968, S.141ff.

Albers, W. (1973), Steuerharmonisierung in der EWG, Wunsch und Wirklichkelt, in: Wirtschaftsdienst, 53.1973, S.593Pf.

Andel, N. (1983a), Direction of Tax Harmonisation in the EEC, in: Cnossen, S. (Hrsg.), Comparative Tax Studies, Amstderdam: NorthHolland 1983, S.295f.

Andel, N. (1988b), Europäische Gemeinschaften, in: Andel, N., Haller, H. u. Neumark, F. (Hrsg.), Handbuch der Finanzwissenschaft, 3.Aufl., Bd.4, Tübingen: Mohr (Slebeck) 1983, S.312ff.

Andel, N. (1988c), Vorbemerkungen und Kommentar zu Artikel 95-99 EWGVertrag (Steuerliche Vorschriften), in: Groeben, $H$. von der , Beackh, H. von u. Thlesing, J. (Hrsg.), Handbuch Pür Europäische Wirtschaft, Baden-Baden: Nomos, 195. Lleferung v. Februar 1983, Kap.I/A/51, S.19f.

Andel, N., Grasmann, G., Rehm, H. u. Schnolder, K. (1976), Bericht der Fachgruppe Steuerharmonisierung, in: Groeben, $H$. von der u. Möller, H. (Hrsg.), Möglichkeiten und Grenzen einer Europäischen Union, Bd.3, Baden-Baden: Nomos 1976 , S.69fP.

Antal, K.V. (1963), Harmonisation of Turnover Taxes in the Common Market, in: Common Market Law Revlew, 1.1963/64, S.41 pf.

Arnim, H. von (1983), Zum Vorschlag der EG-Kommission, die Erhebung der Einfuhrumsatzsteuer von der Zollverwaltung auf die Finanzverwaltung der Länder zu ubertragen, in: Zeitschrift für Zölle und Verbrauchsteuern, 59.1983, S.290ff.

Anm.:Von sehr wenigen Ausnahmepallen abgesehen werden diejenigen Veröffentlichungen, bel denen ein Verfasser nicht genannt ist, im Literaturverzeichnis nicht aufgeführt. Sle werden stattdessen in voller Länge im Text zitiert. 
Aron, R. (1957), A propos l'Unité de l'Europe: La Dialectique du Politique et de l'Economie, in: Mitteilungen der List-Gesellschaft, 1.1957, S.266PP.

Barents, R. (1978), Charges of Equivalent Effect to Customs Duties, in: Common Market Law Review, 15.1978, S.415fP.

Barents, R. (1983), Artikel 95 en de gemeenschappelijke markt, in: Tijdschrift voor Europees en economisch recht, 31.1983, S.438PP.

Baur, U. (1976), Uberlegungen zum Vorschlag der Kommission der Europäischen Gemeinschaft fur eine 6.Richtlinie zur Harmonisierung der Umsatzsteuer, in: Umsatzsteuer-Rundschau, 25.1976, S.133Pf.

Bebr, G. (1970), Direct Applicabllity Provisions of Community Law, in: International and Comparative Law Quaterly, 1970. S.257fP.

Beck, E. (1962), Aktuelle Probleme der Mehrwertsteuer (Netto-Umsatzsteuer), in: Umsatzsteuer-Rundschau, 11.1962, S.177ff. u. S.185ff.

Berlin, D. (1080), Portée des Dispositions Fiscales du Traité de Rome et Harmonisation des Fiscalités Indirectes, in: Revue de Droit Européen, 16.1980, S.460pf. u. S. 635 Pf.

Berglas, ש. (1981), Harmonisation of Commodity Taxes: Destination, Origin and Restricted Origin Principle, in: Journal of Public Economics, 16.1981, S.377ff.

Biehl, D. (1969), Ausfuhrland-Prinzlp, Einfuhrland-Prinzip und Gemeinsamer Markt-Prinzip - Ein Beitrag zur Theorie der Steuerharmonisierung, Annales Universitatis Saraviensis, Heft 30. Saarbrücken: C. Heymanns 1969.

Bohley, P. (1970), Die Probleme der schwelzerischen Einphasensteuer: elne Chance Pur die Mehrwertsteuer?, in: Finanzarchiv, N.F. 29.1970, S.420Pf.

Bonafons, J. (1974), La Taxation des Prestations de Service dans la Proposition de la Sixième Directive, In: Revue du Marché Commun, 17.1974, S.467Pf.

Bracerell-Milnes, J.B. (1969), Value Added Tax in the United Kingdom, in: Journal of Business Finance, 1.1969, S.17ff.

Braunthal, G. (1965), The Federation of German Industry in Politics, Ithaca N.Y.: Cornell University Press 1965.

Brittan, 8. (1964), The Treasury under the Tories: 1951-1964, Harmondsworth: Penguin 1964.

Brockerhoff, E. (1963), Die Harmonislerung der Ausgabesteuern im Deutschen Zollverein mit elnem Ausblick auf die Probleme der Ausgabesteuerharmonislerung in der EWG, Mainz: Dissertation 1963.

Burke, R. (1979), Harmonization of Taxation in Europe, in: Intertax, 1979, S.46P. 
Burke, R. (1981), Tax Harmonization in the European Community, in: Intertax, 1981, S.7ff.

Butler, E.B. (1968), Britian and the Continental Value Added Tax, in: The Bankers' Magazine, 205.1968, S.274ff. u. S.348f., 206.1968, S.39Pf.

Carbonelle, C. (1963), Quelques Eléments de Base pour une Réforme de la Taxe de Transmission en Belgique, in: Cahiers Economiques de Bruxelles, 6.1963, S.15Pf.

Coulemans, J. (1964), La Belgique et la T.V.A., in: Bulletin de Documentation, Bruxelles: Ministère des Finances, 1964, Heft 5 , S.5Pf.

Cnossen, 8. (1977), Excise Taxation: A Global Study of the Selective Taxation of Goods and Services, Baltimore/London: John Hopkins University Press 1977.

Cnossen, s. (1981), Dutch Experience with the Value-Added Tax, in: Finanzarchiv, N.F.39.1981, S.223Pf.

Cnossen, s. (1982), what Rate Structure for a Value-Added Tax?, in: National Tax Journal, 35.1982, S.205pl.

Cnossen, 8. (1983), Harmonisation of Indirect Taxes in the EEC, in: British Tax Review, 1983, S.232ff.

Coffey, P. (1984), The European Monetary System - Past, Present and Future, Dordrecht: Nijhopf 1984.

Cosciani, C. (1961), Aspects de la Fiscallté dans la C.E.E., in: Revue de Sclence Financière, 53.1961, S.550 f.

Cosciani, C. (1970), Conjectures à propos de l'Introduction du Réglme de la T.V.A. en Italle, in: Reflets et Perspectives de la Vle Economique, 9.1970, S.459Pf.

Couche, J.-P. (1960), Les Principes du G.A.T.T., l'Intégration Européenne et la Réglementation Française des Echanges, Straßbourg: Thèse S.E. 1960.

Cozien, M. (1971), Les Dessous de la T.V.A., Paris: Armand Colln 1971.

Dahlgran, R. (1964), Die Steuergrenzen müssen fallen, in: Aussenhandelsdienst der Industrie- und Handelskammern und Wirtschaftsverbande, 18.1964, S.1104f.

Dagby (1939), L'Impôt sur le Chiffre d'Afpaires et la Taxe à la Production, in: Journal des Contributions Indirects, 78.1939, Heft 1 , S.3fP.

Dachwood, A. (1977), The Principle of Direct Effect in the European Community Law, in: Journal of Common Market Studies, 16.1977/78, S.229Pf.

Dachwood, A. (1983), Hastening Slowly: The Community's Path Towards Harmonization, in: Wallace, H., Wallace, W. u. Webb, C. (Hrsg.), Pollcy-Making in the European Communities, 2.Aufl., Chichester u.a.: John Wiley 1983.

Davies, A.G. (1962), Britian into Europe: The Prospect of Tax Reform, in: British Tax Review, 1962, S.81fl. 
Dequae (1964), La Réforme des Impôts Indirects dans le Cadre de la CEE, in: Bulletin de Documentation, Bruxelles: Ministère des Finances, 1964, Heft 10, S.5ff.

Deringer-Bericht (1963), Bericht im Namen des Binnenmarktausschusses uber den Vorschlag der EWG-Kommission an den Rat uber eine Richtlinie zur Harmonisierung der Rechtsvorschriften der Mitgliedstaaten betreffend die Umsatzsteuer, Berichterstaater: A. Deringer, E.P.Dok.1963-64/56.

Derouln, P. (1977), La Taxe sur la Valeur Ajoutée dans la C.E.E., Paris: Ed. Jupiter 1977.

D'Heeze, М. (1960), L'Impôt sur Transactions et Transmissions en Belgique, in: Masoln, M. u. Marselli, M. (Hrsg.), Impôts sur Transactions, Transmissions et Chiffre d'Affaires - Problèmes du Marché Commun et de l'Inegration Internationale, Padova: Cedam 1959, S.83fP.

Dlchgans, H. (1963), Die polltischen Aspekte der Umsatzsteuerreform, in: Deutsche Steuer Zeitung, 61.1963, S.194ff.

Dodeworth, J. (1976), European Community Financing: An Analyses of the Dublin Amendment, in: Journal of Common Market Studies, $14.1975 / 76$, S.129re.

Dosser.D. (1967), Economic Analysis of Tax Harmonization, in: Shoup, C.S. (Hrsg.), Fiscal Harmonization in Common Markets, Bd.1, New York/London: Colombla University Press 1967, S.1Pf.

Dosser, D. (1978), British Taxation and the Common Market, London: Knight 1973.

Dosser, D. (1981), The Value Added Tax in the UK and the EEC, in: Peacock, A. u. Forte, F. (Hrsg.), The Political Economy of Taxation, Oxford: Basil Blackwell 1981, S.118ff.

Dubouls, L. (1964), La Taxe Locale, in: Revue de Sclence Financlère, 56.1964, S.793fP.

Due, J.F. (1967), Sales Taxation, London: Routledge and Kegan Paul 1957.

Dussart, J. (1976), La T.V.A. Belge: Cing Ans après..., in: Reflets et Perspectives de la Vie Economique, 15.1976, S.81ff.

Easson, A.J. (1971), The British Tax Reforms - a Step towards Harmonization, in: Common Market Law Review, 8.1971, S.325pr.

Easson, A.J. (1980a), The Spirits, Wine and Beer Judgements: A Legal Mickey Finn?, in: European Law Review, 5.1980, S.318fP.

Easson, A.J. (1980b), Tax Law and Policy in the EEC, London: Sweet \& Maxwell 1980.

Easson, A.J. (1981a), Fiscal Discrimination: New Perspectlves on Article 95 of the EEC Treaty, in: Common Market Law Review, 18.1981 , S.521Pf.

Easson, A.J. (1981b), Tax Harmonization in the EEC: The Commission's Programme, in: British Tax Review, 1981, S.329f.

Easson, A.J. (1984), Cheaper Wine or Dearer Beer? - Article 95 again, in: European Law Review, 9.1984, S.57 ff. 
Eckhardt, W. (1967), Grenzen und Zulässigkeit der Hersteller-Zusatzsteuer, Köln/Berlin 1957.

Eckhardt, W. (1960), Das Schicksal der Umsatzsteuer, in: UmsatzsteuerRundschau, 9.1960, S.1ff.

Eckhardt, W. (1963), Bundesfinanzhof und Mehrwertsteuer, in: Umsatzsteuer-Rundschau, 12.1963, S.77f.

Egret, M.G. (1967), La T.V.A. Française, in: Chambre de Commerce de Bruxelles (Hrsg.), T.V.A. - La Réforme des nos Impôts Indirects et la Taxe sur la Valeur Ajoutée, Brüssel 1967. S.31Pf.

Pmerson, M.R. u. Scott, T.W.K. (1977), The Financial Mechanism in the Budget of the European Community: The Hard Core of the British "Renegotiations" of 1974-1975, in: Common Market Law Revlew, 14.1977, S.209fP.

Fischer, J. (1961), Dle Geschichte der Umsatzsteuerreform selt dem zwelten Weltkrleg, Köln: Dissertation 1961.

Fischer, H. (1968), Das Steuerharmonisierungsproblem der EWG Im Spannungsfeld der deutschen Wirtschafts- und Finanzpolitik, in: Deutsche Gesellschaft Pur Betrlebswirtschaft (Hrsg.), Die EWG auf dem Weg zur Wirtschaftsunion, Berlin 1968, S.69f?.

Fisher, N. (1973), Macleod, Ialn, London: André Deutsch 1973.

Flick, H. (1963), Zweimaliger Systemwechsel bel einer Umsatzsteuer-Reform?, in: Umsatzsteuer-Rundschau, 12.1963, S.161f.

Flockermann, P.G. (1966), Die Pranzösische Mehrwertsteuer-Reform, in: Umsatzsteuer-Rundschau, 15.1966, S.145f1.

Flume, ซ. u. schmidt, K. (1962), Dle steuerliche Behandlung des grenzüberschreltenden Verkehrs nach Montanunion- und EWG-Vertrag, Schriftenrelhe der Wirtschaftsvereinigung Eisenund Stahlindustrie zur Wirtschafts- und Industriepolitik, Heft 3, Düsseldorf: Verlag Stahleisen 1962.

Folkers, C. (1986), Wandlungen der Verbrauchsbesteuerung, Referat für die 28. Arbeltstagung des Ausschusses fur Finanzwissenschaft der Gesellschaft Pur Wirtschafts - und Sozlalwissenschaften (Verein Pur Sozialpolitik) vom 29.-31.5.85 in Augsburg.

Formica, R. (1983), Armonizzazione della legislazioni degll Stati membri relative alla imposte sulla cifra d'affari, in: Annali Instituto di studi europel A. de Gasperi, 5.1983, S.133ff

Forte, F. (1956), A quel Stade du Cercle Economique Dolt-on Percevolr l'Impôt sur le Chiffre d'Affalres?, in: Revue de Science et de Legislation Financières, 48.1956, S.387ff.

Forte, F. (1966), On the Feasibility of a Truly General Value Added Tax: Some Reflections on the French Experience, in: National Tax Journal, 19.1966, S.337ff.

Forte, F. (1973), Il Consumo e la sua Tassozione, 2 Bde., Torino: Einaudi 1973. 
Fraenkel-Haeberle, G. (1968), Die Neuordnung des itallenischen Steuersystems, in: Wirtschaftsdienst, 19.1968, S.148ff.

Frapenuce, Y. (1963), Die Mehrwertsteuer in Frankreich, Grundzlige des Pranzösischen Umsatzsteuersystems, Bonn: Wilhelm StollPuss 1963.

Frapance, M. (1964), La Taxe sur la Valeur Ajoutée, in: Bulletín des Documentation, Bruxelles: Ministère des Finance, 1964, Heft 2, S.5PP.

Fratianni, C. u. Christie, H. (1981), Abolishing Fiscal Frontiers within the EEC, In: Public Finance, 36.1981, S.4119P.

Fredersdorf-Bericht (1978), Tax Harmonization in the Community, Information Report of the Section for Economic and Fiscal Questions of the Economic and Social Committee on Tax Harmonization, CES $846 / 78$ v. 12.7.78, abgedr. In: Intertax, 1978, S.384fP. u. S.445Pf.

Frenkel, A. (1976), La Genèse de la T.V.A., Parls: Thèse de Doctorat, Paris II, 1978.

Fuchs, H.O. (1966), Mehrwertsteuer in Dänemark ab 1.1.1966?, in: Umsatzsteuer-Rundschau, 14.1965, S.217Pf.

Gallavielle, J.-P. (1972), La TVA Européenne, Mythe ou Réalité?, in: Les Cahlers Fiscaux Européens, 3.1972, S.11ff.

Gantner, E. (1967), Die Problematik der Umsatzsteuer Im Gemeinsamen Markt, Mannheim: Dissertation 1957.

Genot, A.E. (1978), Fiscal Harmonisation and European Integration: A 1978 Appraisal, in: European Law Review, 3.1978, S.355ff.

Gerckens, P. (1970), EWG ohne Grenzkontrollen - Unterschledliche allgemeine Verbrauchsbesteuerung in Einzelstaaten einer Gemelnschaft, dargestellt am Beisplel der USA, Düsseldorf: Verlag Handelsblatt 1970.

Glersch, H. (1962), Zur Frage der Anwendung des Ursprungs- und des Bestimmungslandprinzips bel der Umsatzsteuer im Gemeinsamen Markt, Schriftenreihe der Wirtschaftsvereinigung Eisen- und Stahlindustrie zur Wirtschafts- und Industriepolitlk, Heft 1, Düsseldorf: Verlag Stahleisen 1962.

Glover, G.N. u. Lóvy, C. (1974), The New Draft Directive for the Harmonisation of Value Added Tax, in: Britlsh Tax Review, 1974 , S.206ff.

Goergen, R. (1977). The Decisions of the Council of Ministers of the Community on the Proposal for a Sixth Directive on VAT, in: European Taxation, 17.1977, S.48fP.

Gozard, G. (1963), L'Harmonisation des Fiscalités Indirectes dans la CEE, in: Revue des Contributions Indirectes, 1963, S.377ff.

Grabower, R., Herting, D. u. schwarz, G. (1962), Die Umsatzsteuer - Ihre Geschichte und gegenwärtige Ausgestaltung Im In- und Ausland, Köln u.a.: Heymann 1962. 
Grant, W.P. (1972), British Employers' Association and the Enlarged Community, in: Journal of Common Market Studies, $11.1972 / 73$, S.276ff.

Groeben, H. von der (1962), Natlonale Steuersysteme und Gemeinsamer Markt, in: Europälsche Steuer-Zeitung, 1962, Heft 1, S.6PP.

Groeben, H. von der (1963), Harmonisierung der Umsatzsteuer im Gemeinsamen Markt, Auszug aus einer Rede gehalten vor dem Europälschen Parlament am 17.10.63, in: Bulletin der EWG, 6.1963, Heft 12, S.5ff.

Groeben, H. von der (1969), Steuerharmonisierung und Gemeinsamer Markt, Referat gehalten vor dem Europälschen Parlament am 2.7.69, in: Bulletin der EG, 2.1969, Heft 9-10, S.11ff.

Groeben, H. von der (1970), Zur weiteren Harmonislerung der Umsatzsteuer, in: Umsatzsteuer-Rundschau, 19.1970, S.93ff.

Groeben, H. von der (1982), Aufbaujahre der Europalschen Gemeinschaft Das Ringen um den Gemeinsamen Markt und die Politische Union (1958-1966), Baden-Baden: Nomos 1982.

Gulou, P. (1977), The Sixth Council Diective on Value Added Tax, Deventer: Kluwer 1977.

Guiou, P. (1979), Le Système Européen de Taxe sur la Valeur Ajoutée, in: Collection Jupiter, Drolt des Affaires dans les Pays du Marché Commun, Tome VII - Commerce Extérieur Douanes, Mise d Jour No 67, Paris: Editions Jupiter 1979.

Guleu, P. (1989a), Le Système Commun de Taxe sur la Valeur Ajoutée: Directives et Proposition Récentes, in: Fiscalité Européenne, 1.1983, Heft 3, S.3pP.

Guleu, P. (1983b), Les Franchises Fiscales Accordés aux Particuliers à l'Intérieur de la Communauté: Directives et Propositions Récentes, In: Fiscalité Européenne, 1.1983, Heft 5, S.3ff.

Gulllaume, Y. u. Waelbroeck, J. (1972), Impact of the Added Value Tax on an Economy: The Case of Belgium, in: European Economic Review, 3.1972, S.91Pf.

Guyot-8ionnest, J. (1969), Le Marché Commun et la Fiscalité, in: Revue des Contributions Indirectes, 1959, S.329Pf.

Healey, D. (1976), Taxation Policy in Britian: The Government's Objectives, in: European Taxation, 15.1975, S.363ff.

Hellmann, y. (1976), Die Umsatzsteuerreform in der Bundesrepublik Deutschland - Die Entstehung des Umsatzsteuergesetzes von 1967, Europäische Hochschulschriften, Reihe 5: Volks- und Betriebswirtschaft, Bd.94, Bern u. Frankfurt/M.: Lang 1975.

Holnze, B. (1963), Die Umsatzsteuer-Anderungsgesetze des Jahres 1963, in: Umsatzsteuer-Rundschau, 12.1963, S.221ff. 
Hijazeler, 8. (1963), The Sales-Tax in the Netherlands, in: Association International de Drolt Financler et Fiscal, Rapports pour le Septième Congrès à Paris, Sept. 1953, Cahlers de Drolt Fiscal International, Bd.24., Amsterdam: Sweets \& Zeitlinger 1970, S.87ff.

Hintzen, T. (1960), Umsatzsteuer in der Diskussion - Das Saarland: Beispiel oder Warnung?, Dusseldorf 1959.

Hoppner, H.-D. (1977), Dle EG-Steuerharmonisierung, in: Europarecht, 12.1977, S.122fl.

Habschmann, W. (1966), Vier Jahrzehnte Umsatzbesteuerung in Deutschland, In: Umsatzsteuer-Rundschau, 5.1956, S.146Pf.

Jahrmarkt, M. (1909), Die umsatzsteuerliche Behandlung der Einfuhr im EWG-Raum in historischer, wirtschaftlicher und rechtsvergleichender Sicht, Mannheim: Dissertation 1969.

Jansen, J.C. (1981), Die steuerliche Harmonislerung im europälschen Raum, In: Deutsche Gesellschaft Pur Betriebswirtschaft (Hrsg.), Betriebswirtschaftliche Erfordernisse für dle Harmonisierung im europälschen Raum, Berlln 1961, S.107ff.

Jansen, J.C. (1967), L'Harmonisation des Systèmes de Taxes sur le Chifre d'Alfalres par l'Introduction d'une T.V.A. de Type Communautaire, in: Chambre de Commerce de Bruxelles (Hrsg.), T.V.A. - La Réforme de nos Impôts Indirects et la Taxe sur la Valeur Ajoutée, Bruxelles 1967, S.79ff.

Johnson, H.L. u. Kraus, Y. (1970), Border Taxes, Border Tax Adjustments, Comparative Advantage and the Balance of Payments, in: Canadian Journal of Economics, 3.1970, S.595P.

Johnstone, D. (1976), A Tax Shall Be Charged, Clvil Service Studies No.1, London: HMSO 1975.

Juretzek, w. (1962), Die Umsatzsteuer in der Europäischen Wirtschaftsgemeinschaft, in: Deutsche Steuer-Zeitung, 50.1962, S.109fP.

Juretzok, W. (1964a), Der Stand der Umsatzsteuer-Harmonisierung, in: Deutsche Steuer-Zeltung, 52.1964, S.241 fP.

Juretzek, W. (1964b), Die Vorstellung der EWG-Kommission von dem gemeinsamen Mehrwertsteuersystem, in: Deutsche Steuer-Zeitung, 14.1964, S.337ff

Juretzek, W. (1967a), Bllanz zum Jahresanfang, in: Umsatzsteuer-Rundschau, 16.1967 , S.1Pf.

Juretzek, . (1967b), Die Verabschiedung der belden EWG-Richtlinien zur Harmonislerung der Umsatzsteuern, in: Deutsche SteuerZeltung, 65.1967, S.105ff.

Jusgen, H. (1969), Ist die Umsatzbesteuerung der einstufigen Betriebe mit dem Gleichheltsgrundsatz des Art.3 Abs.1 GG vereinbar?, In: Deutsche Steuer-Zeitung, 47.1959, S.184fP.

Kaldor., N. (1964), A Memorandum on the Value-Added Tax, In: Kaldor, N. (Hrsg.), Essays on Economic Planning, Bd.1, London: G. Duckworth 1964, S.266fl. 
Kaummann, J. (1962), Die Steuergesetzgebung des Großherzogtums Luxemburg in der Sicht der Harmonisierungsbestrebungen in der EWG, in: Europäische Steuer-Zeitung, 1962, Heft 3, S.59fP.

Kohmann, H. (1956), Niederländische Umsatzsteuer-Reformen und ihre volks- und finanzwirtschaftlichen Auswirkungen, in: Finanzarchiv, N.F.17.1956/57, S.276PP.

Kommission der EG (1980), Bericht der Kommission an den Rat uber die Aussichten fur eine Angleichung der Steuersysteme in der Gemeinschaft, KOM(80)139 v. 27.3.80, abgedr. in: Bulletin der EG, 13.1980, Bellage 1 .

Kommission der EG (1986), Vollendung des Binnenmarktes, Weißbuch der Kommission an den Europälschen Rat, Luxemburg 1985.

Kramer, H. (1986), Ein Kompromiß des Fortschritts, in: EG-Magazin, 1985, Heft $9-10$, S.3Pf.

Krautwald, H. (1982), Ungelöste Probleme im Rahmen der Umsatzbesteuerung - Eine Bestandsaupnahme, Europälsche Hochschulschriften, Reihe 5: Volks- und Betriebswirtschaft Bd.350, Bern u. Frankfurt/M.: Lang 1982.

Kasters, H.J. (1982), Die Gründung der Europäischen Wirtschaftsgemeinschaft, Baden-Baden: Nomos 1982.

Kurlbaum, G. (1968), Dle Umsatzsteuer duldet keinen Aufschub, in: Aktionsgemeinschaft Soziale Marktwirtschaft (Hrsg.), Neuordnung der Finanzpolltik, Ludwigsburg 1958, S.60ff.

Lang, H. (1963), Dle deutsche Umsatzsteuerreform Im Hinblick auf die Harmonisierung der Umsatzsteuern im Gemeinsamen Markt, in: Deutsche Steuer-Zeitung, 51.1963, S.200Pf.

Leufenburger, H. (1948), Unions Economiques et Alignement des Fiscalités, in: Revue de Sclence et de Legislation Financières, 40.1948 , S.265PP.

Laufenburger, H. (1960), L'Impossible "Réforme Fiscal", In: Revue de Science Financtère, 52.1960, S.5pf.

Løurb, జ. (1952), La Taxe sur la Valeur AJoutée, Parls: Recuell Serey 1952.

Laure, M. (1967), Au Secours de la T.V.A., Paris: Presses Universitaires de France 1957.

Laur6, Y. u. Campet, C. (1970), Les Conséquences de l'Application de la T.V.A., in: Public Finance, 25.1970, S.174fP.

Lewton, P. (1971), Value Added Tax, in: British Tax Review, 1971, S.171ff.

Laxan, M.E. (1966), The Recent Evolution of the French Tax System, In: European Taxation, 5.1965, S.264PP.

Lebrun, M. (1979), Taxe sur la Valeur Ajoutée, in: La Revue du Trésor, 60.1979, S.110p?

Lindholm, R.T. (1970), The Value Added Tax: A Short Review of the Literature, in: Journal of Economic Literature, 8.1970, S.1178Pf. 
Lutzke, H.-H. (1967), Der Weg zur Mehrwertsteuer, In: Umsatzsteuer-Rundschau, 16.1967, S.109ff.

MacCormac, M.J. (1967), Turnover Taxes - The Irish Experience, in: Lloyds Bank Revlew, 1967, Heft 84, S.1ff.

Malnprice, H.H. (1976), Value Added Tax after Three Years, In: British Tax Revlew, 1976, S.2301P.

Mattern, G. (1963), Soll man bel der Umsatzbesteuerung in der Bundesrepublik zum Mehrwertsteuersystem ubergehen?, In: Der Betrieb, 16.1963, S.1513PP.

Matthofer, H. (1979), Steuerharmonisierung in Europa - Chancen fur mehr Steuergerechtigkeit und Steuervereinfachung oder neuer Zlelkonflikt?, in: Deutsche Steuer-Zeltung, 67.1979, S.203Pf.

McLure, C.E. Jr. (1980), State and Federal Relations in the Taxation of Value Added Tax, in: The Journal of Corporartion Law, 6.1980, S.127ff.

Meade, J.E., Llesner, H.H. u. Wells, S.J. (1962), Case Studles in European Economic Union: The Mechanics of Integration, London u.a.: Oxford University Press 1962.

Mercler, A. (1967), Die Neuregelung der französischen Mehrwertsteuer, in: Europäische Steuer-Zeitung, 1967, Heft 25, S.603Pf.

Morigot, J.G. (1954), Une Première Etape dans la Vole de la Réforme Fiscale: la Loi du 10 Avril 1954, In: Revue de Science et de Legislation Financières, 46.1954, S.954fP.

Meramann, . (1969a), Die deutsche Steuergesetzgebung an der Jahreswende 1958/9, in: Deutsche Steuer-Zeitung, 47.1959, S.2pf.

Mersmann, . (1969b), Steuerprobleme in der Europäischen Wirtschaftsgemeinschaft, in: Deutsche Steuer-Zeitung, 47.1959, S.369ff.

Mormann, W. (1963a), Das küftige EWG-Steuerrecht, in: Deutsche SteuerZeitung, 51.1963, S.293PP.

Meramann, ॠ. (1963b), Stand der Diskussion um die Umsatzsteuerreform in der Bundesrepublik und der EWG, in: Deutsche SteuerZeitung, 51.1963, S.2fP.

Mersmann, . (1964a), Gedanken zum Programm der Steuerharmonisierung im Gemeinsamen Markt aup dem Geblet der indirekten Steuern, In: Europalsche Steuer-Zeitung, 1964, Heft 8, S.179Pf.

Moremann, . (1964b), Die Tătigkeit des beratenden Ausschusses zur Umsatzsteuerreform (Hartmann-Ausschuß) in den Jahren 1959-1960, In: Deutsche Steuer-Zeitung, 52.1964, S.273Pf.

Mesenberg, H. (1960), Die umsatzsteuerliche Behandlung der Ein- und Ausfuhr in den Staaten der Europäischen Wirtschaftsgemeinschaft, DIHT Schriftenreihe, Heft 63, Bonn: DIHT 1960. 
Mesenberg, H. (1965), Harmonisierung der Umsatzsteuern in der Europalschen Wirtschaftsgemeinschaft, in: Außenwirtschaftsdienst des Betriebsberaters, 11.1965, S.341ff.

Mespoulhes, J. (1966), L'Harmonisation des Taxes sur le Chiffre d'Affaires et des Droits d'Accise dans le Marché Commun, in: Revue du Marché Commun, 8.1965, S.432ff.

Messere, K. (1970), A Defense of Present Border Tax Adjustment Practices, in: National Tax Journal, 32.1979, S.481ff.

Metze, I. (1969), Steuerharmonisierung in einer Wirtschaftsgemeinschaft, Hamburg: Verlag Weltarchiv 1969.

Millonaar, K. (1969), Die neue Umsatzsteuer in den Niederlanden, in: Europälsche Steuer-Zeitung, 1969, Heft 37, S.127ff.

Millenaar, K. (1970), Die Grundzüge der niederländischen Mehrwertsteuer und die anlaßlich ihrer Einfuhrung gemachten Erfahrungen, Wien: Institut Pür Flnanzwissenschapt und Steuerrecht 1970.

Millenear, K. (1973), L'Harmonisation Fiscale dans le Bénélux, in: CEE Drolt et Affaires, 1973, Heft 246, S.29ff.

Moller, M.E. (1967), On the Value-Added Tax in Denmark and the EEC and the Renaissance of Tax Neutrality, in: Bulletin for International Fiscal Documentation, 21.1967, S.431 fP.

Moltke, H. von (1984), Binnenmarktpolltik, in: Weldenfeld, W. u. Wessels, W. (Hrsg.), Jahrbuch der Europäischen Integration 1983, Bonn: Europa Union Verlag 1984, S.1419f.

Moltke, H. von (1986), Binnenmarktpolitik, in: Weldenfeld, W. u. Wessels, W. (Hrsg.), Jahrbuch der Europäischen Integration 1984, Bonn: Europa Union Verlag 1985, S.143ff.

Maller, F. (1903), Grundsätze Pür die Gestaltung der Mehrwertsteuer, in: Deutsche Steuer-Zeltung, 51.1963, S.207ff.

Muller, F. (1966), Der Vorschlag der EWG-Kommlssion Pur eine zwelte Richtlinie zur Harmonisierung der Umsatzsteuern, in: Deutsche Steuer-Zeitung, 53.1965, S.225fP.

yaller, F. (1966), Die Geschichte und der derzeitige Stand der Umsatzsteuerreform, in: Deutsche Steuer-Zeitung, 54.1966, S.290pP.

Muller, A. (1965), L'Assiette de la Taxe sur la Valeur Ajoutée, Paris: Dalloz 1965.

Mundell, R.A. (1961), A Theory of Optimum Currency Areas, in: American Economic Review, 51.1961, S.657 Pf.

Musgrave, P.B. (1967), Harmonization of Direct Business Taxes, in: Shoup, C.S. (Hrsg.), Fiscal Harmonization in Common Markets, New York u. London: Colombla University Press 1967, Bd.2, S.207ff.

Muggrave, R.A. (1969), Fiscal Systems, New Haven: Yale University Press 1969. 
Nasini, P. (1973a), The Efforts of the E.E.C. Commission to Achieve a Better Balance among the National V.A.T. Systems, in: Wheatcroft, G.S.A. (Hrsg.), Value Added Tax in the Enlarged Common Market, London: Associated Business Programmes 1973, S.111Pf.

Nagini, P. (1973b), Harmonization of National Systems of V.A.T., in: European Taxation, 13.1973, S.39Pf.

Neumark-Bericht (1962), Bericht des Steuer- und Finanzausschusses, 0.0.: 1962.

OCDE (1968), Aménagements Fiscaux aux Frontièrs et Structures Fiscales des Pays Membres de l'OCDE, Paris: OCDE 1968.

Pagano, U.B.M. (1966), Vergleich der Umsatzsteuern Itallens und Frankreichs unter Berücksichtigung der Pinanzpolitischen Postulate der Europälschen Wirtschaftsgemeinschaft, Basel: Stehlin 1966.

Papke, J.A. (1960), Michigan's Value Added Tax apter Seven Years, in: National Tax Journal, 13.1960, S.350ff.

Peffokoven, R. (1983), Probleme der internationalen Finanzordnung, in: Andel, N., Haller, H. u. Neumark, F. (Hrsg.), Handbuch der Finanzwissenschaft, 3.Aufl., Bd.4, Tubingen: Mohr (Slebeck) 1983, S.219ff.

Pelkmans, J. (1984), Market Integration in the European Community, Dordrecht: Kluwer Academic Publishers 1984.

Phllippe, J.-J. (1973), La Taxe sur la Valeur Ajoutée, Paris: BergerLevrault 1973.

Phillppe, J.-J. (1980), La VIe Dírective du Consell des Communautés Européennes, in: Annales de l'Université des Sciences Sociales de Toulouse, 28.1980 , S.23ff.

Phillppe, J.-J. (1983), L'Harmonisation Européenne de la T.V.A., in: Revue Française des Finances Publiques, 1.1983, S.149ff.

Plackebsum, K. u. Molltzky, H. (1966), Kommentar zum UStG, 9.Aufl., Bd.2, Köln u.a. 1966.

Pohner, D. (1960), Dle Neuordnung der Umsatzbesteuerung - Grundlagen der bisherigen Diskussion und Grundsätze elner Reform, Bonn 1960.

Pohmer, D. (1980), Allgemeine Umsatzsteuern, in: Andel. N., Haller, H. u. Neumark, F. (Hrsg.), Handbuch der Finanzwissenschaft, 3.Aufl., Bd.2, Tübingen: Mohr (Siebeck) 1980, S.650ff.

Pohmer, D. (1983), Value-Added Tax after Ten Years: The European Experience, in: Cnossen, S. (Hrsg.), Comparative Tax Studies, Amsterdam: North-Holland 1983, S.243fP.

Popltz, J. (1928), Kommentar zum Umsatzsteuergesetz in der Fassung vom 8.Mal 1926, 3.Aufl., Berlin: Otto Liebermann 1928.

Popitz, J. (1930), Kommentar zum Umsatzsteuergesetz in der Fassung vom 8.Mal 1926, 3.Aufl., Ergänzungsband, Berlin: Otto Liebermann 1930. 
Prest, A.R. (1963), A Value Added Tax Coupled with a Reduction in Taxes on Business Profits, in: British Tax Review, 1963, S.336ff.

Prest, A.R. (1964), Reform for Purchase Tax, in: Harris, R. u.a. (Hrsg.), Anclent or Modern? - Essays in Economic Efficiency and Growth, 2.Aufl., London: Institute of Economic Affaires 1964, S.13PP.

Prest, A.R. (1967), The E.E.C. Value Added Tax and the U.K., in: District Bank Review, 1967, Heft 164, S.3ff.

Prest, A.R. (1980), Value Added Taxation - The Experience of the United Kingdom, Washington D.C. u. London: American Enterprise Institute 1980 .

Prest, A.R. (1988), Fiscal Policy, in: Copfey, P. (Hrsg.), Main Economic Policy Areas of the EEC, DenHaag: NLhoff 1983, S.59fP.

Pretl, L. (1968), Reforms in the Italian Tax System and their Social and Economic Effects, in: European Taxation, 8.1968, S.76Pf.

Puchala, D.J. (1980), European Fiscal Harmonization: Politics During the Dutch Interlude, in: Hurwitz, L. (Hrsg.), Contemporary Perspectives on European Integration, Westport: Greenwood Press 1980, S.209Pf.

Puchala, D.J. (1983), Worm Cans and Worth Taxes: Fiscal Harmonization and the European Pollcy Process, in: Wallace, H., Wallace, W. u. Webb, c. (Hrsg.), Pollcy-Making in the European Communities, 2.Aufl., Clichester u.a.: John Wlley 1983 , S.237ff.

Puchala, D.J. (1984), Fiscal Harmonization in the European Communities National Politics and International Cooperation, London u. Dover N.H.: Pinter 1984.

Puchala, D.J. u. Lankovak1, C.F. (1977), The Polltics of Fiscal Harmonization in the European Communities, in: Journal of Common Market Studies, 15.1977, S.155fP.

Rau, G. (1969), Erläuterung zum BFH-Urtell von 1962, in: UmsatzsteuerRundschau, 12.1963, S.29ff.

Rau, G. (1966), Die Mehrwertsteuer nach den Hearings, in: UmsatzsteuerRundschau, 15.1966, S.169P.

Rau, G. (1979), Umsatzsteuergesetz 1980 - Einführungs-Kommentar, Köln: Otto Schmidt 1979.

Regul, R. (1966), Wirtschaftsintegration und Steuersysteme - der gegenwärtige Stand der Untersuchungen uber das Steuerproblem In der Europalischen Gemeinschapt für Kohle und Stahl, in: Finanzarchiv, N.F.16.1955, S.313ff.

Regul, R. (1966), Internationale Finanzprobleme der Europaischen Gemeinschaft fur Kohle und Stahl, in: Gerloff, w. u. Neumark, F. (Hrsg.), Handbuch der Finanzwissenschaft, 2.Aupl., Bd.4, Tübingen: Mohr (Siebeck) 1965, S.288fP.

Regul, R. u. Renner, $\mathbf{W}$. (1966), Finances and Taxes in European Integration, Amsterdam: International Bureau of Fiscal Documentation 1966. 
Relschl, H. (1963), Die Große Steuerreform, Hamburg 1953.

Renfort, C. (1964), Zur Reform der Pranzösischen Umsatzbesteuerung, in: Außenwirtschaftsdienst des Betriebsberaters, 10.1964, S.48Pf.

Reugebrink, J. (1973), Omzetbelasting, Deventer: Kluwer 1973.

Reugebrink, J. (1978), The Sixth Directive for the Harmonisation of Value Added Tax, in: Common Market Law Review, 15.1978, S.309Pf.

Richter, J.-U. (1968), Dle Diskussion um die Einführung der Nettoumsatzsteuer in Großbritannien, Hannover: Verlag Literatur und Zeitgeschehen 1968.

Rimlet, R. (1969), After The Hague, in: Journal of Common Market Studies, 8.1969, S.281Pf.

Robinson, A. u. Sandford, C. (1983), Tax Policy-making in the United Kingdom, London: Helnemann 1983.

Rogalle-Berlcht (1983), Bericht im Namen des Ausschusses für Wirtschaft und Währung über die Steuerharmonislerung in der Gemeinschaft, Berichterstatter: D. Rogalla, E.P.Dok.1903/83.

Rothsteln, J. (1968), Die Mehrwertsteuer in Frankreich, In: UmsatzsteuerRundschau, 17.1968, S.145fl. u. S.161ff.

8acchetto, C. (1983), L'Article 95 du Traité de Rome: Certudes et Doutes d'Interpretation et Applications en Egard à l'Expérience et aux Perspectives de l'Ordre Juridique Italien, in: Revue Françalse des Finances Publiques, 1.1983, S.51pf.

Sarrazin. V. (1973), Vorschlag elner sechsten EWG-Richtlinte zur Umsatzsteuerharmonisierung, in: Umsatzsteuer-Rundschau, 22.1973 , S.209fP.

8arrazin, V. (1974), Stand der Beratungen des Vorschlags einer 6.Umsatzsteuer-Richtlinie der EG-Kommission, in: UmsatzsteuerRundschau, 23.1974, S.281fP.

Scallteur, C. (1967), Distortions Economiques et la Taxe sur la Valeur Ajoutée, in: Bulletin de Documentation, Bruxelles: Ministère des Finances, 1957, Heft 11-12, S.24ff.

Scallteur, C. (1962), Das belgische Steuersystem und der EWG-Vertrag, in: Europälsche Steuer-Zeitung, 1962, Heft 2, S.48f.

Scallteur, C. (1967), La Belgique devant les Perspectives d'Instauration d'une Taxe sur la Valeur Ajoutée, in: Chambre de Commerce de Bruxelles (Hrsg.), T.V.A. - La Réforme des nos Impôts Indirects et la Taxe sur la Valeur Ajoutée, Brüssel 1967, S.131ff.

Scallteur, C. (1974), L'Influence de l'Intégration et de la Coopération Economlques Internationales dans la Domaine de la Taxation, In: Chronlque de Politique Etrangère, 27.1974, S.455Pf. 
Schendstock, B. (1964), Das niederländische Steuersystem und der EWGVertrag, in: Europåische Steuer-Zeitung, 1964, Heft 9, S.208ff.

Schiff, E. (1973), Value Added Taxation in Europe, Washington D.C.: American Enterprise Institute 1973.

Schindler, J.H.K. (1970), Die Praxis der großzügigen Behandlung ausländischer Unternehmer in der niederländischen Mehrwertsteuer, in: Umsatzsteuer-Rundschau, 19.1970, S.371 ff.

Schllenkamp, A. (1977a), Auswirkungen der Sechsten Mehrwertsteuer-Richtlinle der EG auf das deutsche Umsatzsteuerrecht, in: Betriebs-Berater, 32.1977, Bellage 5 zu Heft 31, S.1ff.

8chllenkamp, A. (1977b), Die Ratsentscheidungen vom 21.10. und 16.12.1976 uber die 6.Richtlinie zur Harmonisierung der Umsatzsteuern, in: Umsatzsteuer-Rundschau, 26.1977, S.1pf.

Schllenkamp, A. (1078), Der Regierungsentwurf elnes neuen Umsatzsteuergesetzes (UStG 1979), In: Umsatzsteuer-Rundschau, 27.1978 , S.101Pf. u. S.121ff.

Schlienkamp, A. (1984), Erster Berlcht der EG-Kommission über das Funktionieren des gemeinsamen Mehrwertsteuersystems, in: Umsatzsteuer-Rundschau, 33.1984, S.6ff., S.51ff. u. S.99P.

Schmidt, G. (1984), Dle Durchpuhrung des Europäischen Gemeinschaftsrechts in der Bundesrepublik Deutschland und anderen EG-Mitgliedstaaten, in: Integration, 1984, S.217ff.

8chmidt, 0. (1963), Die politischen Aspekte der Mehrwertsteuer, SteuerKongress-Report, München u. Berlin 1963, S.48Pf.

8chmolders, G. (1949), Das Pranzösische Umsatzsteuersystem - Erkenntnisse und Lehren zur modernen Umsatzbesteuerung, in: Steuer und Wirtschaft, 26.1949, Sp.203ff.

8chmolders, G. (1053a), Organlsche Steuerreform - Grundlagen, Vorarbeiten, Gesetzentwürfe, Berlin u. Frankfurt/M. 1953.

Schmolders, G. (1953b), Der Steuerstreit in der Montanunion, in: Archiv des öfentlichen Rechts, 79.1953, S.91ff.

Schmolders, G. (1968), Die ungesetzliche Zusatzsteuer - Durchbruch zur "wirtschaftlichen Betrachtungswelse" im Verfassungsrecht?, in: Steuer und Wirtschaft, 35.1958 , Sp.395Pf.

8chmolders, G. (1969), Die Besteuerung der Verbrauchsabgaben - Eine dänische Gedenkschrift zur Steuerreform, in: Finanzarchiv, N.F.19.1959, S.313fP.

Schmolders, G. (1960), Umsatzsteuerreform - Prüfstein der Demokratie, in: Aktionsgemeinschaft Soziale Marktwirtschaft (Hrsg.), Heiße Eisen im Wahlkampp, Ludwigsburg 1960, S.77ff.

schmolders, G. (1962), Zur Frage der steuerlichen Wettbewerbsverzerrungen im grenzüberschreitenden Warenverkehr innerhalb der Europaischen Gemeinschaft, Schriftenreihe der wirtschaftsvereinigung Eisen- und Stahlindustrle zur Wirtschafts- und Industriepolitlk, Heft 2, Düsseldorf: Verlag Stahleisen 1962. 
Schneider, K. (1970), Eigene Einahmen für die Europäische Gemeinschaft, in: Europälsche Steuer-Zeitung, 1970, Heft 41, S.79ff.

Schule, F. (1964e), EWG-Kommission legt Grundzüge des gemeinsamen europäischen Mehrwertsteuersystems vor, in: UmsatzsteuerRundschau, 13.1964, S.249f.

8chale, F. (1964b), Soll die Bundesrepublik ihr kumulatives Umsatzsteuersystem beibehalten?, in: Deutsche Steuer-Zeitung, 52.1964, S.250fP.

Schulze-Brachmann, A. (1969), Die Entwicklung des Steuerwesens in der Europäischen Wirtschaftsgemeinschaft, in: Europäische Steuer-Zeitung, 1969, Heft 34, S.51 ff., Heft 36, S.117ff., Heft 37, S.141Pf.

Shibata, н. (1967), The Theory of Economic Unions: A Comparative Analysis of Customs Unions, Free Trade Area, and Tax Unions, in: Shoup, C.S. (Hrsg.), Fiscal Harmonization in Common Markets, Bd.2, New York u. London: Colombia University Press 1967, S.145Pf.

8houp, C.S. (1961), Tax Tension and the British Fiscal System, in: National Tax Journal, 14.1961, S.1ff.

Shoup, C.S. (1969a), Experience with the Value Added Tax in Denmark, and Prospects in Sweden, in: Finanzarchiv, N.F.28.1969, S.236 Pf.

Shoup, C.8. (1969b), Public Finance, London: Weidenfeld and Nicolson 1969.

Slemens, W. von (1910), Veredelte Umsatzsteuer, Slemensstadt 1919. Nach dem Tode des Verfassers wurde die Schrift in einer zweiten und erweiterten Auplage von C.F. von Siemens Siemensstadt 1921 - herausgegeben.

8levert, O. (1964), Aussenwirtschaftliche Probleme steuerlicher Ausgleichsmaßnahmen für den internationalen Handel, Annales Universitatis Saraviensis, Heft 9, Saarbrücken: C. Heymanns 1964.

simonet, H. (1975), Tax Harmonisation and the Economic and Monetary Union, in: Intertax, 1975, S.40pf.

Simons, A.L.C. (1981), Simplification of VAT Procedures in Intra-Community Trade, in: Intertax, 1981, S.375fP.

8imons, A.L.C. (1983), Artikel 95 en de belastingsharmonisatie, in: Tijdschrift voor Europees en economisch recht, 31.1983, S.483Pr.

8imons, A.L.C. (1986), Inter-member State Clearing of VAT or the 14th VAT Directive, paper presented to a seminar at the European Institute of Public Administration, Maastricht, 13-14 Pebr. 1986.

88hn, H. (1976a), Die Harmonisierung der USt in der EG, in: Steuer und Wirtschaft, 53.1976, S.1ff.

86hn, Н. (1976b), Steuersystematische Aspekte der Umsatzsteuerharmonisierung, In: Umsatzsteuer-Rundschau, 25.1976, S.69f1. 
Spaak-Bericht (1966), Regierungsausschuss, eingesetzt von der Konferenz von Messina, Bericht der Delegationsleiter an die Aussenminister, Brüssel 21.April 1956.

Stephenson, P. (1970), Problems and Political Implications for the United Kingdom of Introducing the EEC Value Added Tax, in: Journal of Common Market Studies, 8.1970, S.305ff.

Steuernegel, W. (1967), Die Angletchung der Besteuerung in der EWG als Problem der Pinanzpolitischen Willensbildung, Köln: Dissertation 1967.

8tout, D.K. (1963), Value Added Tax, Exporting and Growth, In: British Tax Review, 1963, S.314fP.

Strauß, F.J. (1967), Theorie und Praxis der Steuerharmonisierung, in: Deutsche Steuer-Zeitung, 55.1967, S.137ff.

Sullivan, C.K. (1967a), Indirect Taxation and Goals of the European Community, in: Shoup, C.S. (Hrsg.), Fiscal Harmonization in Common Markets, Bd.2, New York u. London: Colombia University Press 1967, S.1pf.

Sullivan, C.K. (1967b), Indirect Tax System in the European Community and the United Kingdom, in: Shoup, C.S. (Hrsg.), Fiscal Harmonization in Common Markets, Bd.2, New York u. London: Colombia University Press 1967, S.103eP.

Sullivan, C.K. (1967c), Potential Rates of Value-Added Tax in the European Community, in: Shoup, C.S. (Hrsg.), Fiscal Harmonization in Common Markets, Bd.2, New York u. London: Colombla University Press 1967, S.173fP.

Tall, A. U. Due, J.F. (1966), Sales Taxation in Eire, Denmark and Finland, In: National Tax Journal, 18.1965, S.286ff.

Tausalg, A.J. (1971), The Impact of the European Community Upon German Ministries, Doctoral Thesis, Harvard University 1971.

Terra, B.J.M. (1984), Omzetbelasting bif grenzoverschrijdend verkeer, Leiden: Dissertation 1984.

Timmermans, C.w.A. (1979), Directives: Their Effect within the National Legal Systems, In: Common Market Law Review, 16.1979, S.533P.

TImmermans, J.-P. u. Joseph, G.T.J. (1980), Value Added Tax (V.A.T.) National Modifications to Comply with the Sixth Directive of the Council of the European Communities, in: European Taxation, 20.1980, S.37ff.

Tinbergen-Berlcht (1963), Europälsche Gemeinschaft für Kohle und Stahl, Hohe Behörde, Bericht über die durch die Umsatzsteuer aufgeworfenen Probleme aup dem Gemeinsamen Markt, verfaßt von dem gemäß Beschluß der Hohen Behörde Nr.1/53 v. 5.März 1953 gebildeten Sachverständigenrat, o.O. u. o.J.

Tsoukalis, L. (1977). The Politics and Economics of European Monetary Integration, London: Allen \& Unwin 1977.

Tugendhat, C. (1983), The State of Tax Harmonization in the European Community, in: Intertax, 1983, S.6pp. 
Tugendhat. C. (1986), Current State of Tax Harmonization in the European Community, in: Intertax, 1985, S.6Pf.

Tuk, C.P. (1969), La Taxe de Transmission aux Pays-Bas, in: Masoin, M. u. Marselli, M. (Hrsg.), Impôts sur Transactions, Transmissions et Chiffre d'Affaires - Problèmes du Marché Commun et de l'Integration Internationale, Padova: Cedam 1959, S.287 Pि.

Tuk, C.P. (1961), Verleden, heden en toekomst van de omzetbelasting, in: Weekblad voor fiscaal recht, 90.1961 , Heft 4636, S.30ff.

Tuk, C.P. (1968), Wet op de omzetbelasting, Deventer: Kluwer 1968.

Uckmar, V. (1963), Das italienische Steuersystem und der EWG-Vertrag, in: Europalsche Steuer-Zeitung, 1963, Heft 4, S.83ff.

Uelner, A. (1977), Entwicklungstendenzen der Steuergesetzgebung in der Europäischen Gemeinschaft und in Europa, in: Deutsches Steuerrecht, 15.1977, S.459ff.

Untergruppen-Bericht (1962), Kommission der EWG, Direktion für SteuerPragen, Gesamtbericht der Untergruppen A, B und C, eingesetzt zur Prüfung verschledener Möglichkeiten einer Harmonisierung der Umsatzsteuern, o.O.: 1962.

Vandammo, R. (1967). Nécessité d'une Harmonisation des Accises au Sein de la Communauté Economique Europénne et Etat des Travaux, in: Revue du Marché Commun, 10.1967, S.624ff.

Vandencasteele, A. (1984), L'Article 95 du Traité CEE - Un Examen de la Jurisprudence Récente de la Cour de Justice, in: Cahiers de Droit Européen, 20.1984, S.543fP.

Vaulont, N. (1977), Abbau der Zoll- und Steuergrenzen im Warenverkehr innerhalb der Benelux-Union, in: Recht der internationalen Wirtschaft, 23.1977 , S.687fP.

Vaulont, N. (1986), Abrechnungszeitrăume und Zahlungsfristen bei der EinPuhrumsatzsteuer (Kommentar zu Rechtssache 42/83), in: Recht der internationalen Wirtschaft, 31.1985, S.229ff.

Vernholes, A. (1968), La T.V.A. Précipite la Transformation de la Distribution en France, in: Transmondia, 1968, Heft 162, S.28Pf.

Vogelaar. T.W. (1970), Tax Harmonization in the European Community, in: Common Market Law Review, 7.1970, S.223ff.

Wachweger, D. (1965a), Der Stand der Umsatzsteuerharmonisierung nach der Tagung des Rates der EWG am 29.3.65, in: UmsatzsteuerRundschau, 14.1965, S.109ff.

Wachweger, D. (1965b), Struktur und Anwendungsmodalitäten des gemeinsamen Mehrwertsteuersystems nach dem Vorschlag der EWG-Kommission, in: Umsatzsteuer-Rundschau, 14.1965, S.183Pf.

Wachweger, D. (1966), Der Stand der Umsatzsteuerharmonislerung im FruhJahr 1966, in: Umsatzsteuer-Rundschau, 15.1966, S.135f. 
Wachweger, D. (1974), Der Vorschlag der Kommission der Europäischen Gemeinschaften Pur eine 6.Richtlinie zur Harmonisierung der Umsatzsteuern, in: Deutsche Steuer-Zeitung, 62.1974, S.115ff.

Wachweger, D. (1975), Stand der Beratungen uber eine 6.Richtlinie zur Harmonisierung der Umsatzsteuern, in: Deutsche Steuer-Zeltung, 63.1975, S.195Pf.

Wachweger, D. (1976), Die Ratstagung vom 24.11.1975 über Fragen der Umsatzsteuer-Harmonisierung aup der Grundlage einer 6.Richtlinie, in: Umsatzsteuer-Rundschau, 25.1976, S.21ff.

Wachweger, D. (1978), Die Auswirkungen der 6.USt-Richtlinle des Rates der EG auf das deutsche USt-Recht, in: Deutsche SteuerZeltung, 66.1978, S.11fP. u. S.43fP.

Wachweger, D., Schllenkamp, A. u. Schutz, M. (1977), Die 6.EG-Richtlinie zur Harmonisierung der Umsatzsteuer, in: UmsatzsteuerRundschau, 26.1977, S.121ff., S.141ff., S.165ff. u. S.185ff.

Wagenbaur, R. (1969), Das Verbot steuerlicher Diskriminierung nach dem EWG-Vertrag im Lichte der Rechtssprechung des $\mathrm{Ge}-$ richtshofes, in: Europarecht, 4.1969, S.20ff.

VAgenbaur, R. (1976), Les Fondements Juridiques d'une Politique Fiscale des Communautés Européennes, in: Revue de Science Financlère, 67.1975, S.5PP.

THgenbeur, R. (1980), Die Beseltigung steuerlicher Diskriminierungen im innergemeinschaftlichen Warenverkehr - Der Beitrag des Gerichtshofs der Europäischen Gemeinschaft zur Auslegung der Artikel 95 bis 97 EWGV, in: Recht der internationalen Wirtschaft, 26.1980, S.121ff.

Tagne r. K.D. (1967), Der nlederländische Regierungsentwurf eines Mehrwertsteuergesetzes, in: Umatzsteuer-Rundschau, 16.1967, S.307ff.

Wallis, H. von (1960), Dle Studie zu einer Mehrwertsteuer mit Vorsteuerabzug, in: Umsatzsteuer-Rundschau, 9.1960, S.169ff.

Whalley, J. (1979), Uniform Domestic Tax Rates, Trade Distortions and Economic Integration, In: Journal of Public Economics, 11.1979, S.213ff.

Wheatcroft, G.S.A. (1963), Some Administrative Problems of an Added Value Tax, in: British Tax Review, 1963, S.348fP.

Wilhelmi, H. (1960), Die Durchfuhrbarkeit der Umsatzsteuer-Reformvorschläge, In: Umsatzsteuer-Rundschau, 9.1960, S.9pf.

Fissenschaftllcher Belrat beim Bundesministerium der Finanzen (1963), Organische Steuerreform, Bonn: BMF 1953.

Wissenschaftlicher Belrat belm Bundesministerium der Finanzen (1962), Probleme einer Netto-Umsatzbesteuerung, Bonn: BMF 1962.

Zacharopoulos, K. (1980), The Design of Value Added Tax in Greece in the Light of the United Kingdom Experience, London: Doctoral Thesis, LSE 1980. 
Zeltler, F.-C. (1977), Die Betelligung der Länder an Rechtsetzungsmaßnahmen der EG, insbesondere der steuerharmonisierung, in: Deutsche Steuer-Zeitung, 65.1977, S.379ff.

Zlerold-Pritsch, B. (1954), Die optimale Umsatzsteuer, Köln 1954.

Zlerold-Pritsch, B. (1964), Anmerkungen zu dem Regierungsentwurf eines Umsatzsteuergesetzes nach dem System der Mehrwertsteuer, in: Umsatzsteuer-Rundschau, 13.1964, S.73P. 


\section{FINANZWISSENSCHAFTLICHE SCHRIFTEN}

Band 1 Werner Steden: Finanzpolitik und Einkommensverteilung. Ein Wachstums- und Konjunkturmodell der Bundesrepublik Deutschland. 1979.

Band 2 Rainer Hagemann: Kommunale Finanzplanung im fóderativen Staat. 1976.

Band 3 Klaus Scherer: Maßstäbe zur Beurteilung von konjunkturellen Wirkungen des offentlichen Haushalts. 1977.

Band 4 Brita Steinbach: "Formula Flexibility" - Kritische Analyse und Vergleich mit diskretionarer Konjunkturpolitik. 1977.

Band 5 Hans-Georg Petersen: Personelle Einkommensbesteuerung und Inflation. Eine theoretisch-empirische Analyse der Lohn- und veranlagten Einkommensteuer in der Bundesrepublik Deutschland. 1977.

Band 6 Friedemann Tetsch: Raumwirkungen des Finanzsystems der Bundesrepublik Deutschland. Eine Untersuchung der Auswirkungen der Finanzreform von 1969 auf die Einnahmenposition der untergeordneten Gebietskorperschaften und ihrer regionalpolitischen Zieladăquanz. 1978.

Band 7 Wilhelm Pfahler: Normative Theorie der fiskalischen Besteuerung. Ein methodologischer und theoretischer Beitrag zur Integration der normativen Besteuerungstheorie in der Wohlfahrtstheorie. 1978.

Band 8 Wolfgang Wiegard: Optimale Schattenpreise und Produktionsprogramme für offentliche Unternehmen. Second-Best Modelle im finanzwirtschaftlichen Staatsbereich. 1978.

Band 9 Hans P. Fischer: Die Finanzierung des Umweltschutzes im Rahmen einer rationalen Umweltpolitik. 1978.

Band 10 Rainer Paulenz: Der Einsatz finanzpolitischer Instrumente in der Forschungs- und Entwicklungspolitik. 1978.

Band 11 Hans-Joachim Hauser: Verteilungswirkungen der Staatsverschuldung. Eine kreislauftheoretische Inzidenzbetrachtung. 1979.

Band 12 Gunnar Schwarting: Kommunale Investitionen. Theoretische und empirische Untersuchungen der Bestimmungsgründe kommunaler Investitionstătigkeit in NordrheinWestfalen 1965-1972. 1979.

Band 13 Hans-Joachim Conrad: Stadt-Umland-Wanderung und Finanzwirtschaft der Kernstadte. Amerikanische Erfahrungen, grundsătzliche Zusammenhănge und eine Fallstudie für das Ballungsgebiet Frankfurt am Main. 1980.

Band 14 Cay Folkers: Vermogensverteilung und staatliche Aktivitat. Zur Theorie distributiver Prozesse im Interventionsstaat. 1981.

Band 15 Helmut Fischer: US-amerikanische Exportforderung durch die DISC-Gesetzgebung. 1981.

Band 16 Günter Ott: Einkommensumverteilungen in der gesetzlichen Krankenversicherung. Eine quantitative Analyse. 1981.

Band 17 Johann Hermann von Oehsen: Optimale Besteuerung. (Optimal Taxation). 1982.

Band 18 Richard Kössler: Sozialversicherungsprinzip und Staatszuschüsse in der gesetzlichen Rentenversicherung. 1982.

Band 19 Hinrich Steffen: Zum Handlungs- und Entscheidungsspielraum der kommunalen Investitionspolitik in der Bundesrepublik Deutschland. 1983.

Band 20 Mantred Scheuer: Wirkungen einer Auslandsverschuldung des Staates bei flexiblen Wechselkursen. 1983.

Band 21 Christian Schiller: Staatsausgaben und crowding-out-Effekte. Zur Effizienz einer Finanzpolitik keynesianischer Provenienz. 1983. 
Band 22 Hannelore Weck: Schattenwirtschaft: Eine Möglichkeit zur Einschrânkung der offentlichen Verwaltung? Eine Okonomische Analyse. 1983.

Band 23 Wolfgang Schmitt: Steuern als Mittel der Einkommenspolitik. Eine Ergănzung der Stabilitătspolitik? 1984.

Band 24 Wolfgang Laux: Erhöhung staatswirtschaftlicher Effizienz durch budgetäre Selbstbeschrănkung? Zur ldee einer verfassungsmäßig verankerten Ausgabengrenze. 1984.

Band 25 Brita Steinbach-van der Veen: Steuerinzidenz. Methodologische Grundlagen und empirisch-statistische Probleme von Länderstudien. 1985.

Band 26 Albert Peters: Okonomische Kriterien tür eine Aufgabenverteilung in der Marktwirtschatt. Eine deskriptive und normative Betrachtung für den Allokationsbereich. 1985.

Band 27 Achim Zeidler: Moglichkeiten zur Fortsetzung der Gemeindefinanzreform. Eine theoretische und empirische Analyse. 1985.

Band 28 Peter Bartsch: Zur Theorie der langertristigen Wirkungen 'expansiver' Fiskalpolitik. Eine dynamische Analyse unter besonderer Berücksichtigung der staatlichen Budgetbeschrănkung und ausgewăhlter Möglichkeiten der offentlichen Defizitfinanzierung. 1986.

Band 29 Konrad Beiwinkel: Wehrgerechtigkeit als finanzpolitisches Verteilungsproblem. Möglichkeiten einer Kompensation von Wehrungerechtigkeit durch monetäre Transfers. 1986.

Band 30 Wolfgang Kitterer: Eftizienz- und Verteilungswirkungen des Steuersystems. 1986.

Band 31 Heinz Dieter Hessler: Theorie und Politik der Personalstevern. Eine Kritik ihrer Einkommens- und Vermógensbegrifte. 1987.

Band 32 Wolfgang Scherf: Die beschättigungspolitische und fiskalische Problematik der Arbeitgeberbeitrăge zur Rentenversicherung. Eine Auseinandersetzung mit der Kritik an der lohnbezogenen Beitragsbemessung. 1987.

Band 33 Andreas Măstle: Die Steuerunion. Probleme der Harmonisierung spezifischer Güterstevern. 1987.

Band 34 Günter Ott: Internationale Verteilungswirkungen im Finanzausgleich der Europăischen Gemeinschaften. 1987.

Band 35 Heinz Haller: Zur Frage der zweckmäßigen Gestalt gemeindlicher Steuern. Ein Diskussionsbeitrag zur Gemeindesteuerreform. 1987.

Band 36 Thomas Kuhn: Schlüsselzuweisungen und fiskalische Ungleichheit. Eine theoretische Analyse der Verteilung von Schlüsselzuweisungen an Kommunen. 1988.

Band 37 Walter Hahn: Steverpolitische Willensbildungsprozesse in der Europáischen Gemeinschaft. Das Beispiel der Umsatzssteuer-Harmonisienung. 1988. 
Walter Hahn - 978-3-631-75235-7 Downloaded from PubFactory at 01/11/2019 06:49:14AM via free access 
Walter Hahn - 978-3-631-75235-7 Downloaded from PubFactory at 01/11/2019 06:49:14AM via free access 